
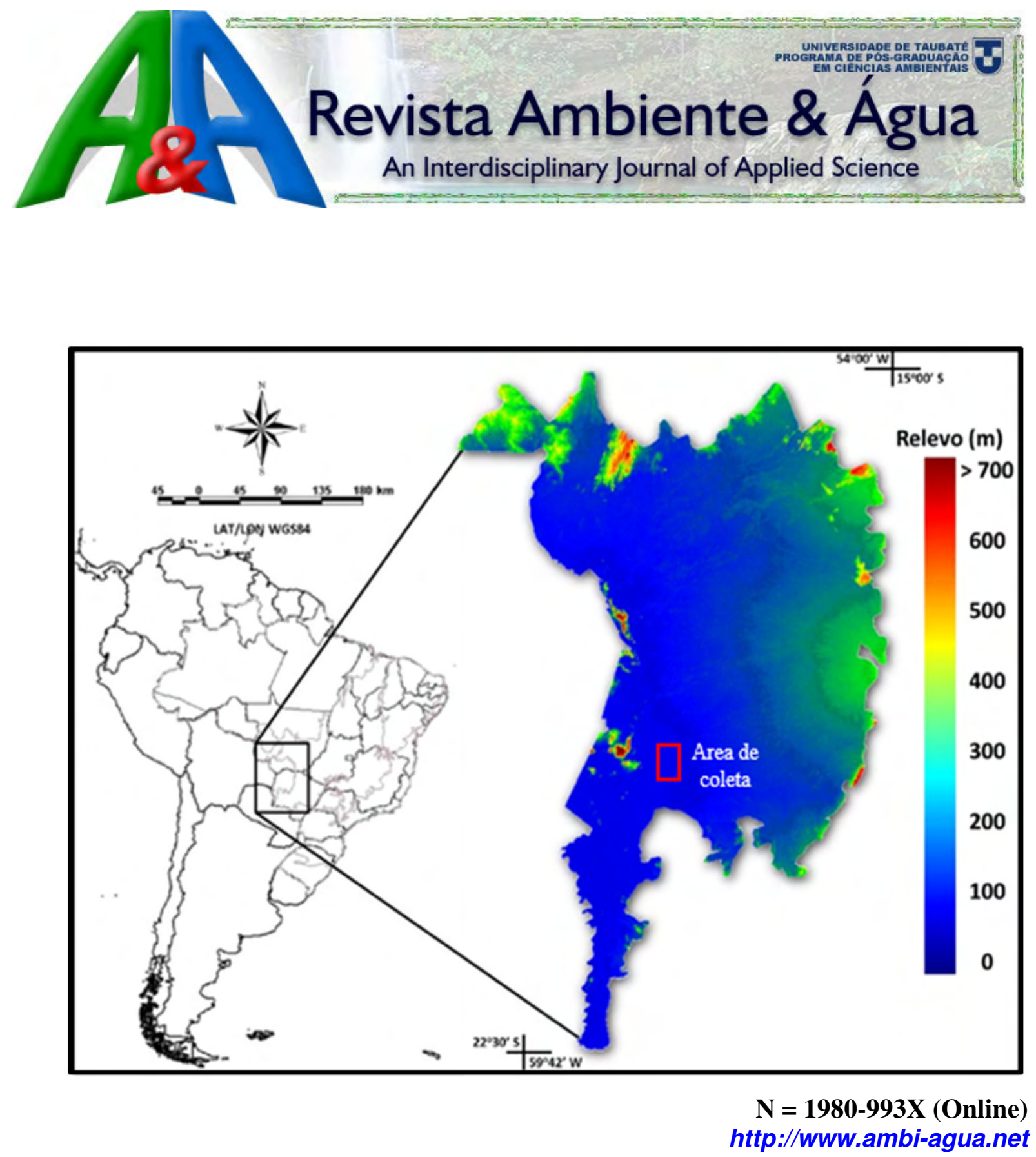

$33^{\text {rd }}$ Edition of Revista Ambiente \& Água - An Interdisciplinary Journal of Applied Science,Taubaté, V. 11, N. 2, p. 239-485 Apr./June 2016. (doi:10.4136/ambi-agua.v11.n2) 


\section{EDITORIAL BOARD}

\section{Editor}

\section{Getulio Teixeira Batista}

Instituto de Pesquisas Ambientais em Bacias Hidrográficas (IPABHi), SP, BR

Amaury Paulo de Souza

Ana Aparecida da Silva Almeida

Andrea Giuseppe Capodaglio

Antonio Evaldo Klar

Antonio Teixeira de Matos

Carlos Eduardo de M. Bicudo

Cláudia S. de C. M. dos S. Cordovil

Dar Roberts

Delly Oliveira Filho

Ehsan Noroozinejad Farsangi

Gabriel Constantino Blain

Giordano Urbini

Gustaf Olsson

Hélio Nobile Diniz

János Fehér

João Vianei Soares

José Carlos Mierzwa

Julio Cesar Pascale Palhares

Luis Antonio Merino

Marcelo dos Santos Targa

Massimo Raboni

Nelson Wellausen Dias

Petr Hlavínek

Richarde Marques da Silva

Sergio Francisco de Aquino

Silvio Jorge Coelho Simões

Stefan Stanko

Teresa Maria Reyna

Yosio Edemir Shimabukuro

Zhongliang Liu Beijing

\section{Editorial Section}

Text Editors

Reference Editor

Layout Editors

Technical Support

Secretaria e Comunicação

\section{Associate Editors}

Universidade Federal de Viçosa (UFV), BR

Universidade de Taubaté (UNITAU), BR

University of Pavia, ITALY

Universidade Est. Paulista Júlio de Mesquita Filho (UNESP), BR

Universidade Federal de Viçosa (UFV), BR

Instituto de Botânica, IBT, BR

Centro de estudos de Engenharia Rural (CEER), Lisboa, Portugal

University of California, Santa Barbara, United States

Universidade Federal de Viçosa (UFV), BR

International Institute of Earthquake Engineering and Seismology(IIEES), Farmanieh, Tehran, Iran

Instituto Agronômico de Campinas, IAC, Brasil.

University of Insubria, Varese, Italy

Lund University, Lund, Sweden

Inst. Geológico, Sec. do Meio Amb. do Est. de SP (IG/SMA),BR

Debrecen University, Hungary

Instituto Nacional de Pesquisas Espaciais (INPE), BR

Universidade de São Paulo, USP, BR

Embrapa Pecuária Sudeste, CPPSE, São Carlos, SP, BR

Institute of Regional Medicine, National University of the Northeast,

Corrientes, Argentina

Universidade de Taubaté, (UNITAU), BR

Polytechnic University of Milan, Milan, Italy

Inst. Bras. de Geogr. e Estatística (IBGE). Aracaju, SE, BR

Brno University of Technology República Tcheca

Universidade Federal da Paraíba, UFPB, BR

Universidade Federal de Ouro Preto, UFOP, BR

Univ. Est. Paulista Júlio de Mesquita Filho, UNESP, BR

Slovak Technical University in Bratislava Slovak, Eslováquia

Universidad Nacional de Córdoba, Argentina

Instituto Nacional de Pesquisas Espaciais (INPE), BR

University of Technology, China

\section{Nelson Wellausen Dias, PPGCA, UNITAU, IBGE, BR}

Theodore D`Alessio, FL, USA, Maria Cristina Bean, FL, USA

Getulio T. Batista, UNITAU, BR

Liliane Castro, Bibliotecária - CRB/8-6748, Taubaté, BR

Vera L. F. Batista, IPABHi \& Getulio T. Batista, UNITAU, BR

Tiago dos Santos Agostinho, LAGEO, UNITAU, BR

Luciana Gomes de Oliveira, UNITAU, BR

Library catalog entry by Liliane Castro CRB/8-6748

Revista Ambiente \& Água - An Interdisciplinary Journal of Applied Science / Instituto de Pesquisas Ambientais em Bacias Hidrográficas. Taubaté. v. 11, n. 2 (2006)-

Taubaté: IPABHi, 2016.

Trimestral

ISSN 1980-993X

1. Ciências ambientais. 2. Recursos hídricos. I. Instituto de Pesquisas Ambientais em Bacias Hidrográficas. 


\section{TABLE OF CONTENTS}

\section{COVER:}

\section{Topographic gradient of the Brazilian Pantanal}

Source: SILVA, M. G. et al. Análise da influência de parâmetros ambientais no fluxo de metano em áreas alagáveis e lagoas permanentes na região do Rio Abobral, no Pantanal, Brasil. Rev. Ambient. Água, Taubaté, vol. 11 n. 2, p. 327-338, 2016. doi:10.4136/ambi-agua.1775

\begin{tabular}{|c|c|c|}
\hline 01 & $\begin{array}{l}\text { Technologies for rational water use in Brazilian agriculture } \\
\text { doi:10.4136/ambi-agua.1808 } \\
\text { Christian Luiz da Silva; Nádia Solange Schmidt Bassi; Weimar Freire da Rocha Junior }\end{array}$ & 239-249 \\
\hline 02 & $\begin{array}{l}\text { Advances in wastewater nitrogen removal by biological processes: state of the art review } \\
\text { doi:10.4136/ambi-agua.1772 } \\
\text { Andrea G. Capodaglio; Petr Hlavínek; Massimo Raboni }\end{array}$ & $250-267$ \\
\hline 03 & $\begin{array}{l}\text { Life cycle assessment of four potable water treatment plants in northeastern Colombia } \\
\text { doi:10.4136/ambi-agua.1759 } \\
\text { Oscar Orlando Ortiz Rodriguez; Raquel Amanda Villamizar-Gallardo; Rafael Guillermo García }\end{array}$ & $268-278$ \\
\hline 04 & $\begin{array}{l}\text { El agua en las industrias alimenticias de Mendoza (Argentina): estimación de los requerimientos } \\
\text { hídricos y la potencialidad de reúso agrícola } \\
\text { doi:10.4136/ambi-agua.1771 } \\
\text { Alicia Elena Duek }\end{array}$ & $279-290$ \\
\hline 05 & $\begin{array}{l}\text { Regulação das águas doces superficiais e subterrâneas na integração regional do MERCOSUL } \\
\text { doi:10.4136/ambi-agua.1666 } \\
\text { Celso Maran de Oliveira; Ozelito Possidônio de Amarante Junio; Celso Antonio Pacheco Fiorillo; Pedro } \\
\text { Luciano Colenci }\end{array}$ & $291-303$ \\
\hline
\end{tabular}

Remoção de matéria orgânica e nitrogênio em biorreator com membranas submersas operando em condição de nitrificação e desnitrificação simultânea

doi:10.4136/ambi-agua.1684

Izabela Major Barbosa; José Carlos Mierzwa; Ivanildo Hespanhol; Eduardo Lucas Subtil

Redução da toxicidade aguda de lixiviado de aterro sanitário em co tratamento com esgoto doméstico pelo processo integrado de lodo ativado com biofilme em leito móvel

07 doi:10.4136/ambi-agua.1835

Fábio Campos; Roque Passos Piveli

Análise da influência de parâmetros ambientais no fluxo de metano em áreas alagáveis e lagoas permanentes na região do Rio Abobral, no Pantanal, Brasil

08 doi:10.4136/ambi-agua.1775

Marcelo Gomes da Silva; Plínio Carlos Alvalá; Luciano Marani; Willian José Ferreira

Estoque de carbono no solo e agregados em Cambissolo sob diferentes manejos no sul do Amazonas

Milton César Costa Campos; Marcelo Dayron Rodrigues Soares; Mailson Ferreira Nascimento; Douglas Marcelo Pinheiro Silva 
10 Marcos Alves Fausto; Lucas Peres Angelini; Heloisa Oliveira Marques; Armando Silva Filho; Nadja

Gomes Machado; Marcelo Sacardi Biudes

Gestão dos serviços públicos de água e esgoto operados por municípios em Goiás, GO, Brasil

11 doi:10.4136/ambi-agua.1739

Poliana Nascimento Arruda; Aline Souza Carvalho Lima; Paulo Sérgio Scalize

A Dinâmica entre as águas e terras na Amazônia e seus efeitos sobre as várzeas
12 doi:10.4136/ambi-agua.1805
Sandra Helena Silva; Sandra Nascimento Noda

Processos oxidativos avançados: uma revisão de fundamentos e aplicações no tratamento de águas residuais urbanas e efluentes industriais

13 doi:10.4136/ambi-agua.1862

Karla Santos de Araújo; Raissa Antonelli; Beatriz Gaydeczka; Ana Claudia Granato; Geoffroy Roger Pointer Malpass

\footnotetext{
Vulnerabilidade à contaminação das águas subterrâneas no município de Humaitá, Amazonas, Brasil
}

14 doi:10.4136/ambi-agua.1797

$402-413$

Miqueias Lima Duarte; Fabrício Berton Zanchi; Juliana Rocha Duarte Neves; Heron Salazar Costa; Walleson Higor Corrêa Jordão

\section{Contaminação da água de reservatórios do semiárido potiguar por bactérias de importância médica}

15 doi:10.4136/ambi-agua.1801

Ermeton Duarte do Nascimento; Claudio Marcio de Medeiros Maia; Magnólia Fernandes Florêncio de Araújo

\begin{tabular}{|c|c|c|}
\hline 16 & $\begin{array}{l}\text { Análise bacteriológica das águas de irrigação de horticulturas } \\
\text { doi:10.4136/ambi-agua.1798 } \\
\text { Ákylla Fernanda Souza Silva; Camila Ananias de Lima; José Jeyvson Florencio Queiroz; Paula Regina } \\
\text { Luna de Araújo Jácome; Agenor Tavares Jácome Júnior }\end{array}$ & $428-438$ \\
\hline 17 & $\begin{array}{l}\text { Eficácia de velas filtrantes na retenção de cistos de Giardia duodenalis em água } \\
\text { experimentalmente contaminada } \\
\text { doi:10.4136/ambi-agua.1821 } \\
\text { Larissa Imaculada da Costa Sobrinho; Francine Alves da Silva Coelho; Matheus Diniz Gonçalves } \\
\text { Coelho }\end{array}$ & $439-447$ \\
\hline
\end{tabular}

Eleição de áreas prioritárias para pagamento por serviços ambientais: uma análise em nível de microbacia

18 doi:10.4136/ambi-agua.1809

Fernando Salles Rosa; Kelly Cristina Tonello; Roberto Wagner Lourenço

Crescimento inicial e tolerância de cultivares de meloeiro à salinidade da água doi:10.4136/ambi-agua.1726

19 Erbia Bressia Gonçalves Araujo; Francisco Vanies da Silva Sá; Fernanda Andrade de Oliveira; Lauter Silva Souto; Emanoela Pereira de Paiva; Maria Kaline do Nascimento Silva; Evandro Franklin de Mesquita; Marcos Eric Barbosa Brito

Uso da terra e degradação na qualidade da água na bacia hidrográfica do rio Peixe-Boi, PA, Brasil doi:10.4136/ambi-agua.1802

20 Bruno Wendell de Freitas Pereira; Maria de Nazaré Martins Maciel; Francisco de Assis Oliveira; Marcelo Augusto Moreno da Silva Alves; Adriana Melo Ribeiro; Bruno Monteiro Ferreira; Ellen Gabriele Pinto Ribeiro 


Ambiente \& Água - An Interdisciplinary Journal of Applied Science
ISSN 1980-993X - doi:10.4136/1980-993X
www.ambi-agua.net
E-mail: ambi.agua@gmail.com

\title{
Technologies for rational water use in Brazilian agriculture
}

\author{
doi:10.4136/ambi-agua.1808 \\ Received: 24 Nov. 2015; Accepted: 01 Mar. 2016 \\ Christian Luiz da Silva ${ }^{1^{*}}$; Nádia Solange Schmidt Bassi ${ }^{2}$; \\ Weimar Freire da Rocha Junior ${ }^{3}$ \\ ${ }^{1}$ Universidade Tecnológica Federal do Paraná (UTFPR), Curitiba, PR, Brasil \\ Programa de Pós Graduação em Tecnologia \\ ${ }^{2}$ Empresa Brasileira de Pesquisa Agropecuária Suinos e Aves (Embrapa), Concordia, SC, Brasil \\ Departamento de Transferência de Tecnologia \\ ${ }^{3}$ Universidade Estadual do Oeste do Paraná (UNIOESTE), Toledo, PR, Brasil \\ Programa de Pós-graduação em Desenvolvimento Regional e Agronegócios \\ *Autor correspondente: e-mail: christiansilva@utfpr.edu.br, \\ nadia.bassi@embrapa.br,wrochajr2000@gmail.com
}

\begin{abstract}
Brazil has the highest water availability of any country in the world. Nearly $20 \%$ of all the world's rivers flow on Brazilian soil. Brazil's herds of cattle, pigs and poultry are among the largest in the world, and the country uses irrigated agriculture extensively, which accounts for most water consumption (approximately $70 \%$ of the water consumed in the world). The Brazilian Agricultural Research Corporation (Embrapa), the largest and most important public institution of Brazilian agricultural research, has attempted to develop environmental technologies in order to minimize the impact caused by the scarcity and pollution of water resources. This paper describes the technologies this institution offers to different regions. For this purpose, a descriptive and exploratory study was conducted in various Embrapa research units. The results showed that research on the rational use of water in agriculture has intensified since the early 2000s. However, the pace of growth in agricultural activities and their impact is much greater than that of the generated technologies, demonstrating the difficulty in striking a balance in this relationship. Furthermore, it is clear that that water scarcity and the increasing pollution of shallow and deep waters are complex issues with no short-term solution.
\end{abstract}

Keywords: Brazilian agriculture, Embrapa, rational use of water.

\section{Tecnologias para o uso racional da água na agricultura brasileira}

\section{RESUMO}

O Brasil é o país com a maior disponibilidade hídrica do mundo, quase $20 \%$ das vazões de todos os rios do planeta, fluem em solo brasileiro. Possui um dos maiores rebanhos mundiais de suínos, aves e gado e utiliza largamente a agricultura irrigada, principal consumidora dos recursos hídricos (cerca de $70 \%$ da água consumida no mundo). A Empresa Brasileira de Pesquisa Agropecuária - Embrapa, como a maior e mais importante instituição pública de pesquisa agropecuária brasileira, tem envidado esforços na tentativa de buscar 
soluções para, minimizar os impactos causados pela escassez e poluição dos recursos hídricos, por meio do desenvolvimento tecnologias ambientais. Esse trabalho descreve as tecnologias disponibilizadas por esta instituição para as diferentes regiões brasileiras. Para isso, foi desenvolvida uma pesquisa descritiva e exploratória junto às diversas unidades de pesquisa da Embrapa. Os resultados demonstram que houve uma intensificação das pesquisas voltadas para o uso racional da água na agricultura, a partir da década de 2000. Todavia, o ritmo de crescimento das atividades agropecuárias e seus impactos é bem maior do que o das tecnologias geradas, o que dificulta se encontrar um equilíbrio nesta relação. Além disso, deve-se considerar que o problema da escassez da água assim como da crescente poluição das águas rasas e profundas, é complexo e não existe uma solução a curto prazo.

Palavras-chave: agricultura brasileira, Embrapa, uso racional da água.

\section{INTRODUCTION}

Brazilian society is embroiled in a number of conflicts regarding the use of water, especially in regions where this resource is historically scarce. Conflict over the use of water tends to intensify due to increasing demand, the pollution of water resources and the instability of the climate. Therefore, seeking solutions for the adequate monitoring and use of these resources is considered a priority by public research institutions and management agencies.

The supply of food is a huge priority in countries that are essentially agricultural, such as Brazil. One of the major challenges is the development and application of rational methods and techniques concerning the use of water in agriculture and raising livestock.

In the agriculture sector, it took a long time for farmers and the government to realize that exploitation of the ecosystem could cripple agriculture in the long term, depending on the methods employed. This occurs through the exhaustion of natural resources like water and soil, which are directly involved in the process. When this connection was made, it inspired a drive to seek new farming methods and technologies that would lead to environmental and economic sustainability. Without this sustainability, any changes that might be made would not endure (WWF, 2002). In this respect, Conceição et al. (2013) emphasize that agriculture is growing at a much faster pace than are efforts to achieve sustainable management of water resources.

According to the Sebrae (2014), agriculture is responsible for the consumption of almost $70 \%$ of the water in rivers, lakes and aquifers. However, much of the water is wasted, especially in distribution. Only $15 \%$ to $50 \%$ of the water intended for irrigation reaches its destination. This means that it is very important to search for new technologies and knowledge that will not only help to preserve natural resources but also result in greater efficiency of distribution.

In this context, Embrapa, as a public agriculture research institution, has a mission to develop technologies and rational methods for the use of water in agriculture and livestock. Thus, the aim of this study is to describe the technologies developed by this institution for the rational use of water in different regions of Brazil. It should be highlighted that the concept of technology used in this work is broad, encompassing knowledge, tools and techniques derived from science and practical experience that are used in the development, production and application of products, processes, systems and services.

The methodology employed is descriptive and exploratory, using secondary data such as websites and articles published in digital and print media. We also reviewed documents maintained by Embrapa, where research on this theme is conducted.

This work is divided into five sections. Following this introduction, the methodology is described. The third section addresses the availability of water in Brazil and agriculture 
activities. The fourth section presents the technologies developed by Embrapa for the rational use of water in Brazilian agriculture. Finally, we discuss conclusions suggested by our research.

\section{METHODOLOGY}

This study is descriptive and exploratory. The Embrapa website was consulted in order to obtain data. The site has clusters of information from 46 decentralized research units. Data and reports from these units were also accessed using corporate internal access programs. To complement the data obtained, each unit was sent a list of the technologies they had developed and asked to confirm the information and provide any other data that was considered relevant. The data were collected and confirmed between 30 April and 2 June 2015.

\section{AVAILABILITY OF WATER IN BRAZIL AND FARMING ACTIVITIES}

Brazil can be said to have an ample supply of water resources, although there is some imbalance between availability and need. According to Senra (2001), Brazil has $12 \%$ of the planet's water reserves but only $2.8 \%$ of the population. In comparison, China has $25 \%$ of the population but only $10 \%$ of water reserves. According to Tucci et al. (2000), the average surface water production in Brazilian territory is $168,790 \mathrm{~m} 3 / \mathrm{s}$. The surface water resources produced in Brazil account for $50 \%$ of the total resources of South America and $11 \%$ of the resources worldwide. However, the distribution of these resources is uneven, with an excess of water in some regions, such as the Amazon Rainforest, and a shortage in other regions, such as the Northeast (Tucci et al., 2000).

To Gomes and Barbieri (2004), there is considerable disparity between water production and demographic concentration. Less than $20 \%$ of national water discharge supplies approximately $95 \%$ of the population, while $80 \%$ of this production originates from regions occupied by only $5 \%$ of the population (Gomes and Barbieri, 2004).

According to Christofidis (2002), of the total water used in the world, around $70 \%$ is destined for irrigated agriculture, which is far higher than the demands of the industrial sector $(21 \%)$ and of the urban sector $(9 \%)$. In Brazil, the irrigated area corresponds to approximately $18 \%$ of total cultivated area, with $42 \%$ of total production (Christofidis, 2002). The author points out that, with the incorporation of more efficient technologies and processes for managing the treatment and use of water, this consumption should fall over the years. Even so, it is estimated that by 2025 three billion people will be affected by water shortages and availability will be lower than $1,700 \mathrm{~m}^{3} /$ ha/year (Christofidis, 2002).

Due to the high consumption of water in irrigated agriculture, most of the technologies and knowledge generated for the rational use of water are focused on this type of farming. According to the Sebrae (2014), almost every method concentrates on the use of climate information to help calculate the irrigation needs of crops and methods for monitoring parameters, such as soil humidity, that enable a significant reduction in the use of water and energy (Sebrae, 2014).

To Garcia and Vieira Filho (2014), Brazilian agriculture and livestock is a modern and highly dynamic activity. It has been highlighted as a source of development and economic stability, providing jobs and income and playing a central role in ensuring food safety and bridging poverty and inequality gaps. Nevertheless, the sector faces considerable challenges in terms of sustainable development. In addition to meeting the new ecological requirements, it must satisfy the growing demand worldwide for farming products. Therefore, preparing the 
Brazilian economy to meet these goals and challenges is a strategy for future growth, which may result in an increase in exports of farming and livestock products (Garcia and Vieira Filho, 2014).

Zamberlan et al. (2014) highlight the need to rethink the use of natural resources in farming and livestock systems. Technologies should be developed with a view to a more rational use of these resources. In the opinion of these authors, the environmental variable should be incorporated into production in order to adopt new technologies that minimize environmental impact.

\subsection{Regional farming activities}

According to Oliveira and Souza-Lima (2003, p. 33), the "development of a region can be explained as the result of the interaction of three forces: allocation of resources, economic policy and social activation". The more intensive farming becomes, and the less concern there is over the availability of resources, the harder it will be for that region to develop. This approach makes it easier to understand the Brazilian agriculture and livestock context, as highlighted by Garcia and Vieira Filho (2014).

When it comes to regional development, it is noted that water shortages due to intensive farming can lead to restrictions on freedom and other issues for the population, as mentioned by Azevêdo et al. (2013). To these authors, "water shortages condemn millions of people to a life of poverty, with precarious living conditions and health issues and limited opportunities. This serves to perpetuate serious inequalities not only between countries but within them" (Azevêdo et al., 2013: p. 5).

Brazil is one of the major producers of sugarcane, cocoa, corn and oranges. Other important crops are soy, tobacco, potatoes, cotton, rice, wheat, cassava and bananas. Annual grain production is approximately eighty million tons. Beef cattle are raised in almost every region, especially Mato Grosso do Sul, São Paulo and the southern states, where there are also dairy cows, pigs, poultry, sheep, goats, donkeys, mules and oxen. Brazil is divided into five major regions: The South, Southeast, Midwest, Northeast and North. These regions each have their own characteristics and diversity in farming and livestock.

Most of the swine and poultry industries are concentrated in the South. This type of farming has a high potential for the pollution of water resources, soil and air (Tucci et al., 2000).

In the Southeast, sugarcane, soy and oranges are grown. The region also has the second largest herd of cattle in the country.

In the Midwest, the major crops are rice, corn, coffee, cotton and soy. The raising of beef cattle is the region's most important economic activity. The Pantanal is located here, which suffers from the effects of economic development and requires soil conservation measures as well as controls on mining and management of the potential impacts of sailing on the Paraguay River. The Cerrado ecoregion has the greatest farming potential in the country, but requires care to avoid disastrous impacts.

In the Northeast, sugarcane, soy, cotton, tobacco, cocoa and fruit are grown. Agriculture is a great challenge, especially in the semiarid region, given limitations such as low precipitation, high temperatures, evaporation, subsoil with little capacity for storing water, low levels of education of the local rural population and a system of land ownership that concentrates income in the hands of a few people (Tucci et al., 2000).

In the North, there has been a rise in the planting of crops such as soy, rice, guarana, cassava, cocoa, coconut, passion fruit and cupuassu. The Amazon Rainforest is located in this region, with a great forest reserve. Despite the capacity for regeneration, the constant deforestation and expansion of the occupied areas, especially close to the Cerrado, has considerable potential for environmental impact. 
Due to the economic and social importance of agriculture and livestock and the intensive use of natural resources, especially water, it is essential that technologies be developed to minimize the negative impacts or to enable the rational use of these resources.

Tundisi (2003) claims that it is technically possible to achieve greater efficiency in the use of water in agriculture. Investing in the use of new technologies can reduce water consumption by $30 \%$ to $70 \%$. Therefore, it is important to assess techniques for more efficient water use together with optimized farming in order to enable gains in crop productivity, avoid impacts on soil and plant systems and to avoid wasting water.

In the next section, we present the main technologies developed by Embrapa for the rational use of water in farming and livestock in the different regions of Brazil.

\section{TECHNOLOGIES DEVELOPED BY EMBRAPA FOR RATIONAL WATER USE IN DIFFERENT REGIONS OF BRAZIL}

The Brazilian Agricultural Research Corporation (Embrapa) is the largest and most important Brazilian institution for agricultural research. It operates through a network of 46 decentralized research units and has formed partnerships with a number of public and private institutions.

As a public research institution, it has been charged by the government and society with fostering the sustainability of water use by farming production chains. The institution also defines priorities for water use in basins and closely monitors those that are facing water shortages. While water use is not currently threatened in most of the country, it is important not to lose sight of the issue of efficient water use in diverse economic sectors and activities (Rodrigues, 2015).

According to Embrapa (2015), the scientific knowledge generated in recent years proves that it is possible to use water in agriculture rationally and without waste. With the water crisis in important regions of Brazil, it is fundamental that this knowledge be made available to society. Many of these technologies are already being adopted in the field, while others are beginning to attract the attention of farmers (Embrapa, 2015).

It would be opportune to define the word "technology", as it will be used in this work. There are several definitions of the word "technology". According to Kruglianskas (1996) "technology is the set of knowledge necessary for conceiving, producing and distributing goods and services competitively". This encompasses all the knowledge related to a company's activities.

The concept of technology has a broader or narrower scope depending on the focus of analysis. However, it includes not only products, but also knowledge that can be translated into processes and services. Therefore, the concept of technology used in this work is provided by Abetti (1989), who defines technology as "a body of knowledge, tools and techniques derived from both science and practical experience that is used in the development, design, production and application of products, processes, systems and services".

Due to the geographic and climatic diversity of the Brazilian regions, some of the technologies developed by Embrapa are developed for a specific region. Others may be used in any region of the country. These technologies are made known to farmers in several ways, such as field trips, lectures, courses, fairs and demonstrations. Furthermore, Embrapa is supported by rural extension institutions that help transfer these technologies.

Tables 1 to 4 contain summaries of the main technologies developed by Embrapa for the rational use of water in agriculture for the different regions of Brazil. 
Table 1. Technologies developed by Embrapa for the rational use of water in agriculture in the South and Midwest regions of Brazil.

\begin{tabular}{|c|c|c|c|c|c|}
\hline Technology & Type & Objective/description & Region & Year & Unit \\
\hline $\begin{array}{l}\text { Use of controlled water } \\
\text { stress to standardize the } \\
\text { quality of irrigated coffee } \\
\text { crops }\end{array}$ & Practical & $\begin{array}{l}\text { To enable irrigated coffee } \\
\text { plantations in the Cerrado } \\
\text { region, reducing the amount } \\
\text { of water and the cost of } \\
\text { energy }\end{array}$ & Midwest & 2005 & $\begin{array}{l}\text { Cerrados } \\
\text { (DF) }\end{array}$ \\
\hline $\begin{array}{l}\text { Software for the efficient } \\
\text { use of water and savings in } \\
\text { irrigation costs for crops in } \\
\text { the Cerrado }\end{array}$ & $\begin{array}{l}\text { Online } \\
\text { service }\end{array}$ & $\begin{array}{l}\text { To enable decision-making } \\
\text { regarding the time for } \\
\text { irrigation and water depth for } \\
\text { irrigated crops in the Cerrado }\end{array}$ & Midwest & 2014 & $\begin{array}{l}\text { Cerrados } \\
\text { (DF) }\end{array}$ \\
\hline $\begin{array}{l}\text { Efficient water use in } \\
\text { irrigated rice farming }\end{array}$ & Practical & $\begin{array}{l}\text { To reduce waste and increase } \\
\text { efficiency in the irrigation of } \\
\text { rice crops }\end{array}$ & South & 2006 & $\begin{array}{l}\text { Temperate } \\
\text { Climate } \\
\text { (RS) }\end{array}$ \\
\hline
\end{tabular}

Source: Research data

The technologies developed for the Midwest and the South are for use in irrigated crops (coffee, crops in the Cerrado Region and rice). As mentioned above, these are the crops with the highest water consumption.

Table 2. Technologies developed by Embrapa for the rational use of water in agriculture in the northern region of Brazil.

\begin{tabular}{|c|c|c|c|c|c|}
\hline Technology & Type & Objective/description & Region & Year & Unit \\
\hline $\begin{array}{l}\text { Irrigation and water } \\
\text { management for } \\
\text { watermelon crops in } \\
\text { Roraima State }\end{array}$ & Methodology & $\begin{array}{l}\text { To reduce water } \\
\text { consumption and production } \\
\text { costs without affecting } \\
\text { productivity }\end{array}$ & North & 2010 & $\begin{array}{c}\text { Embrapa } \\
\text { Roraima (RO) }\end{array}$ \\
\hline $\begin{array}{l}\text { Irrigacaju (Irrigation } \\
\text { for Cashews) }\end{array}$ & Methodology & $\begin{array}{l}\text { To calculate the volume of } \\
\text { water necessary for } \\
\text { irrigating dwarf cashew } \\
\text { trees }\end{array}$ & North & 2005 & $\begin{array}{l}\text { Tropical } \\
\text { Agribusiness } \\
\quad \text { (CE) }\end{array}$ \\
\hline $\begin{array}{l}\text { Cowpea crop with } \\
\text { fish farm effluents }\end{array}$ & Practical & $\begin{array}{l}\text { To optimize the use of water } \\
\text { resources and agriculture } \\
\text { with the shared use of water }\end{array}$ & North & 2010 & $\begin{array}{l}\text { Meio Norte } \\
\text { ("Mid North") } \\
\text { (PI) }\end{array}$ \\
\hline
\end{tabular}

For the North, characterized by a warm and damp climate, Embrapa developed two methods for use in irrigated watermelon and cashew crops and a practice for the shared use of water, i.e., fish farms and crops.

Of the ten technologies developed for the northeast, seven focus on irrigated agriculture and three on rainwater harvesting, as the region has low levels of rainfall. Therefore, like the other regions, the types of technologies that are developed are practical and users are shown how to use them and improve results. 
Table 3. Technologies developed by Embrapa for the rational use of water in agriculture in the Northeast of Brazil.

\begin{tabular}{|c|c|c|c|c|c|}
\hline Technology & Type & Objective/description & Region & Year & Unit \\
\hline $\begin{array}{l}\text { Small dam for irrigating } \\
\text { subsistence crops }\end{array}$ & Practical & To increase water storage & Northeast & 1981 & $\begin{array}{l}\text { Semiarid } \\
\quad(\mathrm{PE})\end{array}$ \\
\hline $\begin{array}{l}\text { In situ rainwater } \\
\text { collection for food } \\
\text { production }\end{array}$ & Practical & $\begin{array}{l}\text { To make water available } \\
\text { for crops and conserving } \\
\text { the soil and its nutrients }\end{array}$ & Northeast & 1983 & $\begin{array}{l}\text { Semiarid } \\
\quad(\mathrm{PE})\end{array}$ \\
\hline $\begin{array}{l}\text { Ridge-furrow rainwater } \\
\text { harvesting }\end{array}$ & Practical & To increase water storage & Northeast & 1989 & $\begin{array}{l}\text { Semiarid } \\
\quad(\mathrm{PE})\end{array}$ \\
\hline Underground dam & Practical & $\begin{array}{l}\text { To retain rainwater that } \\
\text { oozes into the soil }\end{array}$ & Northeast & 2005 & $\begin{array}{l}\text { Semiarid } \\
\quad(\mathrm{PE})\end{array}$ \\
\hline $\begin{array}{l}\text { Management of } \\
\text { irrigation for dwarf } \\
\text { coconut trees }\end{array}$ & Practical & $\begin{array}{l}\text { To increase the } \\
\text { productivity and } \\
\text { efficiency of water usage } \\
\text { in the irrigation of dwarf } \\
\text { coconut trees }\end{array}$ & Northeast & 2006 & $\begin{array}{l}\text { Tropical } \\
\text { Agribusiness } \\
\quad(\mathrm{CE})\end{array}$ \\
\hline $\begin{array}{l}\text { Drip irrigation in the } \\
\text { semiarid region of the } \\
\text { Northeast }\end{array}$ & Practical & Drip irrigation methods & Northeast & 2007 & $\begin{array}{l}\text { Cassava and } \\
\text { Fruit (BA) }\end{array}$ \\
\hline $\begin{array}{l}\text { Management of } \\
\text { irrigation for tabasco } \\
\text { pepper crops }\end{array}$ & Practical & $\begin{array}{l}\text { To determine the needs } \\
\text { for irrigation considering } \\
\text { the climate and soil, } \\
\text { maximizing productivity } \\
\text { and water use }\end{array}$ & Northeast & 2008 & $\begin{array}{l}\text { Tropical } \\
\text { Agribusiness } \\
\text { (CE) }\end{array}$ \\
\hline $\begin{array}{l}\text { Optimization of } \\
\text { modular systems for } \\
\text { irrigated crop } \\
\text { production with } \\
\text { brackish water }\end{array}$ & Practical & $\begin{array}{l}\text { Use of desalination } \\
\text { rejects, brackish water } \\
\text { from low production } \\
\text { wells for small rural } \\
\text { properties }\end{array}$ & Northeast & 2011 & $\begin{array}{l}\text { Environment } \\
\quad(\mathrm{SP})\end{array}$ \\
\hline $\begin{array}{l}\text { Evapotranspiration and } \\
\text { coefficient of } \\
\text { watermelon crop } \\
\text { irrigated by drip } \\
\text { irrigation in Piauí State }\end{array}$ & Practical & $\begin{array}{l}\text { To estimate water } \\
\text { consumption for the } \\
\text { watermelon crop in its } \\
\text { different phases of } \\
\text { development }\end{array}$ & Northeast & 2012 & $\begin{array}{l}\text { Meio Norte } \\
\text { ("Mid North") } \\
\text { (PI) }\end{array}$ \\
\hline $\begin{array}{l}\text { Projected water demand } \\
\text { for irrigation of } \\
\text { muskmelon in the } \\
\text { semiarid region in times } \\
\text { of climate change }\end{array}$ & Zoning & $\begin{array}{l}\text { To evaluate the impact of } \\
\text { climate change on water } \\
\text { requirements for } \\
\text { muskmelon irrigation in } \\
\text { the Brazilian Semiarid } \\
\text { region. }\end{array}$ & Northeast & 2013 & $\begin{array}{l}\text { Tropical } \\
\text { Agribusiness } \\
\quad(\mathrm{CE})\end{array}$ \\
\hline
\end{tabular}


Table 4. Technologies developed by Embrapa for the rational use of water in agriculture in all regions of Brazil.

\begin{tabular}{|c|c|c|c|c|c|}
\hline Technology & Type & Objective/description & Region & Year & Unit \\
\hline $\begin{array}{l}\text { Collecting rainwater: } \\
\text { plowing and strip farming }\end{array}$ & Practical & $\begin{array}{l}\text { To increase water storage in the } \\
\text { soil }\end{array}$ & All & 1989 & Semiarid (PE) \\
\hline $\begin{array}{l}\text { Rainwater collection: } \\
\text { plowing before and after } \\
\text { planting }\end{array}$ & Practical & $\begin{array}{l}\text { To increase water storage in the } \\
\text { soil }\end{array}$ & All & 1989 & Semiarid (PE) \\
\hline Multiple-use lake & Practical & $\begin{array}{l}\text { Waterproofing for environmental } \\
\text { protection }\end{array}$ & All & 1991 & $\begin{array}{c}\text { Corn and } \\
\text { Sorghum (MG) }\end{array}$ \\
\hline $\begin{array}{l}\text { Upgrading soil and water } \\
\text { management }\end{array}$ & Training & $\begin{array}{l}\text { To train people for the sustainable } \\
\text { management of the soil and water } \\
\text { in agriculture }\end{array}$ & All & 2000 & $\begin{array}{l}\text { Meio Norte } \\
\text { ("Mid North") } \\
\text { (PI) }\end{array}$ \\
\hline Irrigas & Equipment & $\begin{array}{l}\text { Systems and accessories for } \\
\text { management of agricultural and } \\
\text { domestic irrigation }\end{array}$ & All & 2000 & Vegetables (DF) \\
\hline $\begin{array}{l}\text { Diagnosis and planning to } \\
\text { recover ecosystems }\end{array}$ & Practical & $\begin{array}{l}\text { To teach techniques for recovering } \\
\text { polluted ecosystems }\end{array}$ & All & 2000 & Soil (RJ) \\
\hline $\begin{array}{l}\text { Course on irrigation and } \\
\text { management }\end{array}$ & Training & $\begin{array}{l}\text { To provide training on irrigation } \\
\text { and management of equipment for } \\
\text { monitoring water in the soil }\end{array}$ & All & 2002 & Semiarid (PE) \\
\hline $\begin{array}{l}\text { EPS method for managing } \\
\text { irrigation in pastures }\end{array}$ & Practical & $\begin{array}{l}\text { EPS (evaporation-precipitation- } \\
\text { soil) method for low-cost } \\
\text { irrigation }\end{array}$ & All & 2002 & $\begin{array}{c}\text { Livestock } \\
\text { Southeast (SP) }\end{array}$ \\
\hline $\begin{array}{l}\text { Collecting rainwater: } \\
\text { cistern }\end{array}$ & Consultancy & $\begin{array}{l}\text { To provide instructions for } \\
\text { building cisterns to capture } \\
\text { rainwater }\end{array}$ & All & 2005 & $\begin{array}{c}\text { Swine and } \\
\text { Poultry (SC) }\end{array}$ \\
\hline $\begin{array}{l}\text { Irriga fácil (Easy } \\
\text { Irrigation) }\end{array}$ & Software & $\begin{array}{l}\text { To estimate the time for irrigation } \\
\text { and the required water depth }\end{array}$ & All & 2006 & $\begin{array}{c}\text { Corn and } \\
\text { Sorghum (MG) }\end{array}$ \\
\hline Small dams & Practical & $\begin{array}{l}\text { To collect rainwater and contain } \\
\text { the erosive force of flashfloods }\end{array}$ & All & 2006 & $\begin{array}{c}\text { Corn and } \\
\text { Sorghum (MG) }\end{array}$ \\
\hline $\begin{array}{l}\text { Analysis of water for } \\
\text { irrigation purposes }\end{array}$ & Analysis & $\begin{array}{l}\text { To determine the potential of } \\
\text { water for irrigation purposes }\end{array}$ & All & 2008 & Semiarid (PE) \\
\hline $\begin{array}{l}\text { Consultancy regarding } \\
\text { water on dairy farms }\end{array}$ & Consultancy & $\begin{array}{l}\text { Management of water sources and } \\
\text { use of technologies for treating } \\
\text { water on the farm }\end{array}$ & All & 2010 & $\begin{array}{l}\text { Dairy Cattle } \\
\text { (MG) }\end{array}$ \\
\hline $\begin{array}{l}\text { SiBCTI (Brazilian system } \\
\text { for the Classification of } \\
\text { Land for Irrigation) }\end{array}$ & Software & $\begin{array}{l}\text { To evaluate land that is fit for } \\
\text { irrigation, minimizing } \\
\text { environmental impacts }\end{array}$ & All & 2011 & Soil (RJ) \\
\hline $\begin{array}{l}\text { Optimization of modular } \\
\text { system for irrigated crop } \\
\text { production with brackish } \\
\text { water. }\end{array}$ & Practical & $\begin{array}{l}\text { Enables the use of desalination } \\
\text { rejects, brackish water from low } \\
\text { production wells }\end{array}$ & All & 2011 & $\begin{array}{l}\text { Environment } \\
\text { (SP) }\end{array}$ \\
\hline $\begin{array}{l}\text { Environmental risk } \\
\text { assessment in water } \\
\text { resources }\end{array}$ & Methodology & $\begin{array}{l}\text { Providing instructions on the use } \\
\text { of the ARAquáGeo software for } \\
\text { spatial analysis of the } \\
\text { environmental risk of water } \\
\text { contamination }\end{array}$ & All & 2013 & $\begin{array}{l}\text { Territorial } \\
\text { Management } \\
\text { (DF) }\end{array}$ \\
\hline $\begin{array}{l}\text { ARAquá (Evaluation of } \\
\text { Pesticide Risk) }\end{array}$ & Software & $\begin{array}{l}\text { To assess the environmental risks } \\
\text { of pesticides in surface and } \\
\text { underground water }\end{array}$ & All & 2014 & Cerrados (DF) \\
\hline $\begin{array}{l}\text { Monitoring the quality of } \\
\text { rural water resources }\end{array}$ & Training & $\begin{array}{l}\text { To monitor the quality of water } \\
\text { and recognize the effects of the } \\
\text { use of land on the hydro } \\
\text { geochemistry of waterways }\end{array}$ & All & 2015 & $\begin{array}{l}\text { Environment } \\
\text { (SP) }\end{array}$ \\
\hline Igstat Sensor & Equipment & $\begin{array}{l}\text { Water tension sensor in the soil to } \\
\text { manage and monitor irrigation. }\end{array}$ & All & 2015 & $\begin{array}{l}\text { Instrumentation } \\
\quad(\mathrm{RJ})\end{array}$ \\
\hline Dihedral Sensor & Equipment & $\begin{array}{l}\text { Sensor to evaluate tension, } \\
\text { potential and activity of water in } \\
\text { soil and crops }\end{array}$ & All & 2015 & $\begin{array}{l}\text { Instrumentation } \\
\qquad(\mathrm{RJ})\end{array}$ \\
\hline
\end{tabular}


Embrapa has concentrated its efforts on the development of technologies that can be used in all regions of Brazil. Given the diversity of the regions, the technologies are less specific than those that are developed for a particular region. The types of technologies are more varied. In addition to practical technologies and training, they include equipment, software and water analyses.

Since 2000, Embrapa has intensified its research efforts in a drive for technologies that reduce or maximize the use of water in agriculture and livestock. Of the thirty-seven technologies mentioned, twenty-five were developed in the last fifteen years. This is an example of the growing concern over rational water use, which is concomitant with the diminishing availability of this natural resource.

Figure 1 shows that the Embrapa research units located in the northeast and southeast were the ones that developed the most technologies for the rational use of water.

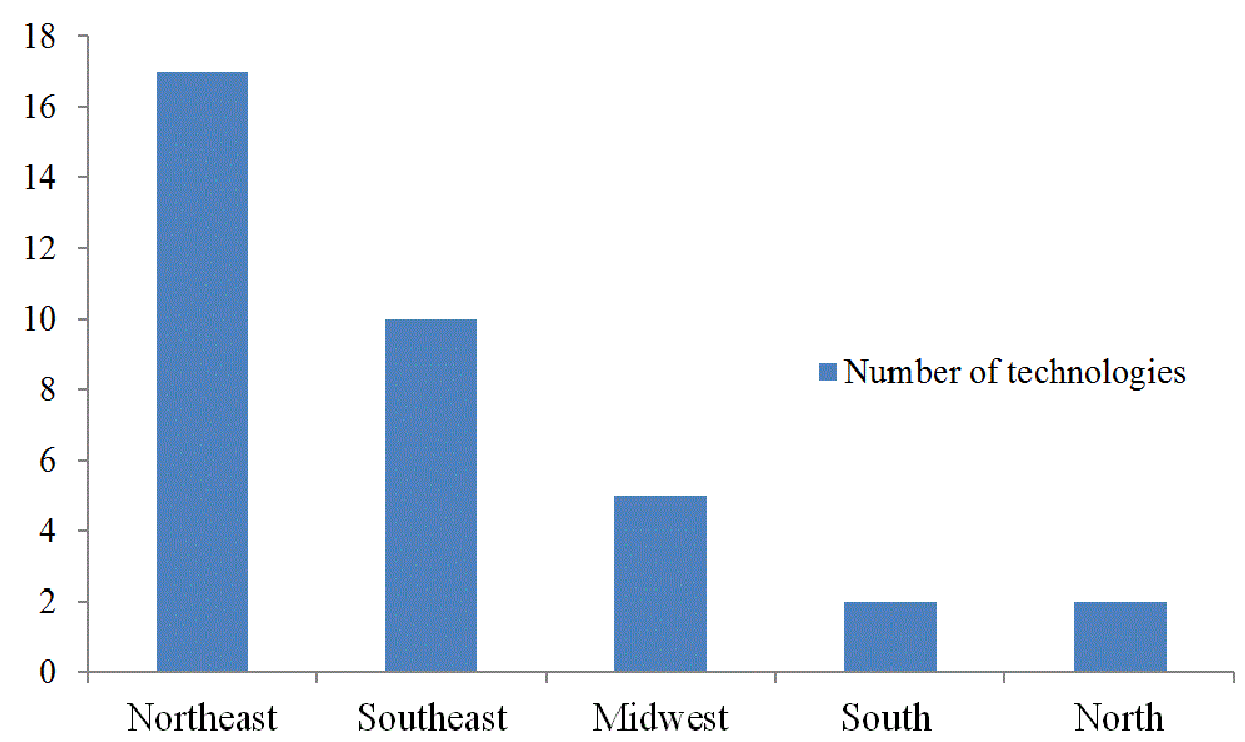

Figure 1. Number of technologies developed by the Embrapa units by region.

This fact can be explained by the water shortages in the northeast of Brazil and the existence of large areas of irrigated crops in the southeast. This means that the need for solutions for the rational use of water is more pressing and important.

Most of the technologies developed are practical methods and training courses aimed at irrigated agriculture.

It should be highlighted that knowledge and techniques are also considered "technologies" and can have a considerable effect on the water cycle, with greater groundwater recharging and better regulation of water flow throughout the year. The ability of farmers is essential, for instance, to the increased adoption of soil, plant and irrigation management. This will help make the use of water in agriculture sustainable, especially when irrigation is employed. In addition to greater economic profitability, better quality of farming can be achieved, as excess water can in many cases be harmful (Embrapa, 2015).

\section{CONCLUSION}

Despite the efforts by Embrapa in recent years to provide technologies focusing on the rational use of water in agriculture and livestock, this problem cannot be solved in the short term, especially in a country like Brazil that is essentially agricultural.

The results show that in spite of increased research by Embrapa, problems of water 
shortages and growing pollution in both shallow waters and deep wells are complex, as stated by Conceição et al. (2013), and tend to intensify more rapidly than solutions emerge. The growth rate of agribusiness and its consequent impacts are much greater than the technologies being developed, demonstrating how difficult it is to strike a balance in this relationship. In this sense, there is a greater need to incorporate environmental variables, such as water, into the rationalization of productive systems, as pointed out by Zamberlan et al. (2014). In this respect, Embrapa has introduced new technologies to improve these processes and to include the water variable in production systems.

The technologies developed by Embrapa are focused on application to specific crops or small rural properties, which shows the need to increase research efforts for the development of wider-ranging technologies that can be applied to agriculture and livestock on a large scale, as big farmers are the largest consumers of water. However, it should be noted that more technologies have been developed since the year 2000. Twenty-five of the thirty-seven technologies that have emerged were developed in the last fifteen years. This shows an alignment between the problem of water shortages in the production system and the growing importance and complexity of the issue in the agriculture and livestock sector.

The research tends to be concentrated in the Northeast and Southeast, the regions most affected by the climate. However, it should be emphasized that the intense farming practices in other regions, such as the South, have not aroused interest in the importance and urgency of the work of this research institution. There should be greater concern over the problem of water shortages in the medium and long term, especially in the South. Alternatives for production systems and the water supply in the region should be proposed and monitored.

Finally, it should be noted that this study set out only to describe the technologies developed by Embrapa as a public research institution for the rational use of water in agriculture. Consequently, the feasibility, adoption and efficiency of these technologies do not fall within the scope of the present study.

\section{ACKNOWLEDGEMENTS}

This research was supported by the Coordination for the Improvement of Higher Education Personnel (CAPES) under Project 189/13 - CAPES/MES Cuba Project Program and the Brazilian National Council for Scientific and Technological Development (CNPq) under the Universal Call- MCTI/CNPq No 14/2014, process number 442782/2014-4 and process number 308634/2013-6.

\section{REFERENCES}

ABETTI, P. A. Technology: a key strategic resource. Management Review, v. 78, n. 2, p. 37-41, 1989.

AZEVÊDO, A. C.; SOUSA, C. M. de; CASEMIRO, R.; MOTTA, R. M. C. Água, tecnologia e desenvolvimento: o caso do programa Água Doce no semiárido paraibano. Revista Tecnologia e Sociedade, v. 8, n. 18, p. 01-12, 2013.

CHRISTOFIDIS, D. Irrigação, a fronteira hídrica na produção de alimentos. Irrigação \& Tecnologia Moderna, n. 54, p. 46- 55, 2002.

CONCEIÇÃO, G.; VIANNA, L. F. N.; BACIC, I. L.; KOBIYAMA, M.; BELLI FILHO, P. Análise espacial do balanço hídrico no meio rural de Santa Catarina. RBRH - Revista Brasileira de Recursos Hídricos, v. 18, n. 4, p. 89-100, 2013. 
EMPRESA BRASILEIRA DE PESQUISA AGROPECUÁRIA - EMBRAPA. Água na agricultura. 2015. Disponível em: http://www.embrapa.br/agua-na-agricultura. Acesso em: 29 maio 2015.

GARCIA, R. J.; VIEIRA FILHO, J. E. R. Política agrícola brasileira: produtividade, inclusão e sustentabilidade. Revista de Política Agrícola, v. 23, n. 1, p. 91-104, 2014.

GOMES, J. L.; BARBIERI, J. C. Gerenciamento de recursos hídricos no Brasil e no Estado de São Paulo: um novo modelo de política pública. Cadernos EBAPE.BR, v. 2, n. 3, 2004. http://dx.doi.org/10.1590/S1679-39512004000300002

KRUGLIANSKAS, I. Tornando a pequena e média empresa competitiva. São Paulo: Instituto de Estudos Gerenciais e Editora, 1996. 137p.

OLIVEIRA, G. B.; SOUZA LIMA, J. E. Elementos endógenos do desenvolvimento regional: considerações sobre o papel da sociedade local no processo de desenvolvimento sustentável. Revista da FAE, v. 6, n. 2, p. 29-37, 2003.

RODRIGUES, L. N. Água na agricultura: com planejamento e gestão não há crise hídrica. 2015. Disponível em: https://www.embrapa.br/busca-de-noticias//noticia/2798136/artigo---agua-na-agricultura-com-planejamento-e-gestao-nao-ha-crisehidrica. Acesso em: 3 mar. 2016.

SERVIÇO BRASILEIRO DE APOIO A MICROS E PEQUENAS EMPRESAS - SEBRAE. Irrigação e uso racional da água no campo. 2014. Disponível em: http://www.sebraemercados.com.br/irrigacao-e-uso-racional-da-agua-no-campo/. Acesso em: 18 fev. 2016.

SENRA, J. B. Água, o desafio do terceiro milênio. In: VIANA, G.; SILVA, M.; DINIZ, N. (Eds.). O Desafio da sustentabilidade- um debate socioambiental do Brasil. São Paulo: Fundação Perseu Abramo, 2001. 364p.

TUCCI, C. E. M.; HESPANHOL, I.; CORDEIRO NETTO, O. A gestão da água no Brasil: uma primeira avaliação da situação atual e das perspectivas para 2025. Brasília: ANA, 2000. 145 p.

TUNDISI, J. G. Água no século XXI: enfrentando a escassez. São Carlos: RiMa, 2003. 247p.

WORLD WIDE FUND FOR NATURE - WWF. Análise dos impactos ambientais da atividade agropecuária no cerrado e suas inter-relações com os recursos hídricos na região do Pantanal. Consultoria Andréa Aguiar Azevedo; colaboração Jorge Luiz Gomes Monteiro. Disponível em: http://d3nehc6yl9qzo4.cloudfront.net/downloads /wwf_brasil_impactos_atividade_agropecuaria_cerrado_pantanal.pdf. Acesso em: 18 fev. 2016.

ZAMBERLAN, J. F.; ZAMBERLAN, C. O.; SCHUCH JR., V. F.; GOMES, C. M.; KNEIPP, J. M. Produção e manejo agrícola: impactos e desafios para sustentabilidade ambiental. Engenharia Sanitária e Ambiental, v. 19, n. spe, p. 95-100, 2014. http://dx.doi.org/10.1590/S1413-41522014019010000680 


Ambiente \& Água - An Interdisciplinary Journal of Applied Science
ISSN 1980-993X - doi:10.4136/1980-993X
www.ambi-agua.net
E-mail: ambi.agua@gmail.com

\title{
Advances in wastewater nitrogen removal by biological processes: state of the art review
}

\author{
doi:10.4136/ambi-agua.1772
}

Received: 06 Oct. 2015; Accepted: 28 Mar. 2016

\author{
Andrea G. Capodaglio ${ }^{1}$; Petr Hlavínek ${ }^{2}$; Massimo Raboni ${ }^{3 *}$ \\ ${ }^{1}$ University of Pavia (UNIPV), Pavia, PV, Italy \\ Department of Civil Engineering and Architecture \\ ${ }^{2}$ University of Technology, Brno, Czech Republic \\ ${ }^{3}$ University LIUC, Castellanza (VA), Italy \\ *Corresponding author: e-mail: mraboni@liuc.it, \\ capo@unipv.it, hlavinek.p@fce.vutbr.cz
}

\begin{abstract}
The paper summarizes the state-of-the-art of the most recent advances in biological nitrogen removal, including process design criteria and technological innovations. With reference to the Modified Ludzck Ettinger (MLE) process (pre-denitrification and nitrification in the activated sludge process), the most common nitrogen removal process used nowadays, a new design equation for the denitrification reactor based on specific denitrification rate (SDNR) has been proposed. In addition, factors influencing SDNR (DO in the anoxic reactor; hydrodynamic behavior) are analyzed, and technological solutions are proposed. Concerning technological advances, the paper presents a summary of various "deammonification" processes, better known by their patent names like ANAMMOX ${ }^{\circledR}$, DEMON $^{\circledR}$, CANON $^{\circledR}$, ANITA $^{\circledR}$ and others. These processes have already found applications in the treatment of high-strength wastewater such as digested sludge liquor and landfill leachate. Among other emerging denitrification technologies, consideration is given to the Membrane Biofilm Reactors (MBfRs) that can be operated both in oxidation and reduction mode.
\end{abstract}

Keywords: biological processes, deammonification, denitrification, nitrogen removal.

\section{Avanços na remoção biológica de nitrogênio das águas residuais: uma revisão}

\section{RESUMO}

$\mathrm{O}$ artigo resume o estado da arte dos mais recentes avanços na remoção biológica de nitrogênio, incluindo os critérios para o cálculo do processo e as inovações tecnológicas. Em relação ao processo Ludzck Ettinger modificado (pré-desnitrificação, nitrificação, no sistema de lodo activados), o qual é amplamente utilizado na remoção biológica de nitrogênio, foi proposta uma nova equação para calcular o reactor de desnitrificação, com base na taxa de desnitrificação (SDNR-Specific Denitrification Rate). Além disso, foram analisados os fatores que influenciam o SDNR (oxigênio dissolvido no reator; comportamento hidrodinâmico do reator) e foram propostas as soluções tecnológicas. Quanto à evolução tecnológica, o artigo apresenta um resumo dos vários processos de remoção biológica de amônia, que são mais 
conhecidos com os nomes patenteados, tais como: ANAMMOX ${ }^{\circledR}$, DEMON $^{\circledR}, \mathrm{CANON}^{\circledR}$, ANITA $^{\circledR}$ e outros. Estes processos já encontraram aplicações industriais no tratamento de águas residuais de alta concentração, tais como o licor de lodo digerido e o percolado de aterro sanitário. Entre as tecnologias emergentes de desnitrificação foram considerados os bioreatores com membranas (MBfR), os quais podem ser operados tanto na fase aeróbia quanto na fase anóxica.

Palavras-chave: desnitrificação, remoção biológica de amônia, remoção de nitrogênio.

\section{INTRODUCTION}

Nitrogen removal from wastewater can be achieved by means of physico-chemical or biological processes. As far as the former are concerned, many technologies are available, as discussed elsewhere (Raboni et al., 2013b; Capodaglio et al., 2015).

Biological processes for nitrogen removal are generally applied to the denitrification of municipal wastewaters, and often to food and beverage processing industries, tanneries, fertilizer and petrochemical plants, as well as extensive livestock farm wastewaters. At present, the dominant technology is pre-denitrification in activated sludge systems, where an anoxic stage (DEN) is located upstream of an aerobic oxidation-nitrification (OX-NIT) stage.

Research in this field is mainly focused on evaluating optimal sizing criteria for the denitrification reactor. One of the key factors is represented by dissolved oxygen (DO) inhibition on the denitrification rate; thus, technological improvements that can reduce DO presence in the anoxic stage are among the most relevant (Raboni et al., 2014a; Torretta et al., 2014; Urbini et al., 2015). Recent studies have highlighted the limits of denitrification efficiency in small communities' plants due to strong fluctuations of incoming loads (Raboni et al., 2013b). Equally important is the effect of the denitrification reactor hydrodynamic behavior on process performance (Raboni et al., 2015).

Among the most recent developments in biological denitrification, the "deammonification" process (better known by its patented versions ANAMMOX®, DEMON®, CANON®, ANITA® and others) carried out by aerobic ammonia-oxidizing bacteria capable of degrading ammonia to nitrogen, has already found widespread application in the treatment of high-strength wastewaters such as digested sludge liquor and landfill leachate (US-EPA, 2009; 2010).

\section{ADVANCES IN DESIGN OF DENITRIFICATION REACTORS IN ACTIVATED SLUDGE PLANTS}

\subsection{SDNR (Specific denitrification rate) for pre-denitrification design}

Design of biological pre-denitrification has been usually carried out on the basis of the denitrification rate $r_{D E N}$, represented by a zero-order kinetics (for both $\mathrm{NO}_{3}-\mathrm{N}$ and organic substrate) corrected for the effects of process temperature according to Arrhenius (Equation 1; Ekama, 2011):

$$
\left(r_{D E N}\right)_{T}=\left(r_{D E N}\right)_{20^{\circ} \mathrm{C}} \cdot \theta^{T-20}
$$

where:

$\left(r_{D E N}\right)_{20^{\circ} \mathrm{C}}$ is the denitrification rate at $20^{\circ} \mathrm{C}$ in denitrification tank (DEN), usually equal to $2.9 \div 3.0 \mathrm{gNO}_{3}-\mathrm{N} \mathrm{h}^{-1} \mathrm{kgMLVSS}^{-1}$ (Raboni et al., 2014b). This approach is still widely used nowadays; however, since it was observed that denitrification rates can be significantly reduced by the presence of DO, its inhibitory effect was taken into account by including an 
inhibition term $K^{\prime}{ }_{O} /\left(K^{\prime}{ }_{O^{+}}+D O\right)$ in $r_{D E N}$ expression (US-EPA, 2009; 2010) (Equation 2).

$$
r_{D E N}=\left(\frac{1-1.42 Y}{2.86}\right) \cdot\left(\frac{K \cdot S \cdot X}{K_{S}+S}\right) \cdot\left(\frac{N O_{3}-N}{K_{N}+N O_{3}-N}\right) \cdot\left(\frac{K_{O}^{\prime}}{K_{O}^{\prime}+D O}\right) \cdot \eta
$$

where:

$r_{D E N}$ is the denitrification rate $\left(\mathrm{NO}_{3}-\mathrm{N}\right.$ removal by dissimilation; $\left.\mathrm{mgNO}_{3}-\mathrm{N} \mathrm{L}^{-1} \mathrm{~h}^{-1}\right)$;

$Y$ is the heterotrophic bacteria synthesis yield ( $\mathrm{mgVSS} \mathrm{mg}^{-1}$ substrate consumed);

$K$ is the maximum specific rate of substrate utilization $\left(\mathrm{h}^{-1}\right)$;

$X$ is the biomass concentration (mgMLVSS $\left.\mathrm{L}^{-1}\right)$;

$S$ is the soluble degradable substrate concentration $\left(\mathrm{mg} \mathrm{L}^{-1}\right)$;

$K_{S}$ is the substrate utilization half-velocity coefficient $\left(\mathrm{mg} \mathrm{L}^{-1}\right)$;

$\mathrm{NO}_{3}-\mathrm{N}$ is the nitrate concentration, as $\mathrm{N}\left(\mathrm{mgNO}_{3}-\mathrm{N} \mathrm{L}^{-1}\right)$;

$K_{N}$ is the nitrate half-velocity coefficient $\left(\mathrm{mgNO}_{3}-\mathrm{N} \mathrm{L}^{-1}\right)$;

$K_{O}^{\prime}$ is the $D O$ inhibition constant for nitrate reduction $\left(\mathrm{mgO}_{2} \mathrm{~L}^{-1}\right)$; and

$\eta$ is the fraction of heterotrophic bacteria that use nitrate in lieu of oxygen (dimensionless).

Tchobanoglous et al. (2003) proposed a similar equation, adding an assimilative (cell synthesis) term to the dissimilative one as Equation 3.

$$
r_{D E N}{ }^{\prime}=r_{D E N}+\left(\frac{N O_{3}-N}{K_{N}+N O_{3}-N}\right) \cdot\left(\frac{K_{O}^{\prime}}{K_{O}^{\prime}+D O}\right) \cdot\left(\frac{1.42}{2.86}\right) \cdot K_{d} \cdot X \cdot \eta
$$

where:

$K_{d}$ is the endogenous decay coefficient $\left(\mathrm{h}^{-1}\right)$.

$K^{\prime}{ }_{O}$ varies in a wide value range $\left(0.02-0.2 \mathrm{mg} \mathrm{L}^{-1}\right)$ depending on floc size and sludge structure (Tchobanoglous et al., 2003). In any case, the mere presence of $0.2 \mathrm{mgDO} \mathrm{L}^{-1}$ could theoretically induce a $40 \%$ decrease in denitrification, compared to uninhibited conditions (Tchobanoglous et al., 2003). Other studies showed the effects of inhibition (Oh and Silverstein, 1999; Plòsz et al., 2003); in particular, significant effects of DO inhibition at concentrations as low as $0.09 \mathrm{mg} \mathrm{L}^{-1}$, with up to $35 \%$ denitrification reduction, were observed (Oh and Silverstein, 1999).

For the practical calculation of the denitrification reactor volume a semi-empirical relationship (Equation 4; Tchobanoglous et al., 2003) was proposed, which correlates SDNR (Specific DeNitrification Rate) with the sludge load in DEN ( $F: M_{D E N} ; \mathrm{gBOD}_{5}$ applied $\left.\mathrm{d}^{1} \mathrm{gMLVSS}^{-1}\right)$ :

$$
\operatorname{SDNR}_{20^{\circ} \mathrm{C}}=0.029+0.03 \cdot F: M_{D E N}\left(\text { at about } 20^{\circ} \mathrm{C}\right)
$$

where:

$$
\begin{aligned}
& S D N R=Q \cdot \triangle N O_{3}-N V_{D E N}^{-1} X_{D E N}^{-1}\left(\mathrm{gNO}_{3}-\mathrm{N} \mathrm{gMLVSS}^{-1} \mathrm{~d}^{-1}\right) ; \\
& V_{D E N} \text { is the DEN volume }\left(\mathrm{m}^{3}\right) ; \text { and } \\
& X_{D E N} \text { is the biomass concentration in DEN }\left(\mathrm{gMLVSS} \mathrm{m}^{-3}\right) \text {. }
\end{aligned}
$$


US-EPA (2010) proposes the same formula applying a correction factor to the F:M ratio in order to take into account the deviation of the active fraction of biomass in the mixed-liquor from the reference value (30\%). Values of SDNR observed in pre-anoxic reactors at full-scale installation range from 0.04 to $0.42 \mathrm{gNO}_{3}-\mathrm{N}$ gMLVSS$^{-1} \mathrm{~d}^{-1}$ (Tchobanoglous et al., 2003), while US-EPA (2010) reports a more narrow range, 0.05 to $0.15 \mathrm{gNO}_{3}-\mathrm{N}_{\mathrm{gMLVSS}} \mathrm{d}^{-1}$ at $20^{\circ} \mathrm{C}$.

Recently, the strong dependence of $S D N R$ in DEN on DO and F: $\mathrm{M}_{\mathrm{DEN}}$ has been highlighted (Raboni et al., 2014b; Torretta et al., 2014). Experimental results, supported by theoretical evaluations, allowed the representation of $S D N R_{20^{\circ} \mathrm{C}}$ (Equation 5).

$$
S D N R_{20^{\circ} \mathrm{C}}=0.0864\left(\frac{K_{O}^{\prime}}{K_{O}^{\prime}+D O}\right)+0.05 F \cdot M_{D E N} \cdot \eta_{B O D} \cdot\left(\frac{D O}{0.2+D O}\right)
$$

where:

$$
\begin{gathered}
K_{O}^{\prime}=0.18 \mathrm{mg} \mathrm{L} \mathrm{L}^{-1} ; \eta_{B O D}=0.90-0.95 \text { depending on } F: M_{D E N} \text { in the range } \\
0.4-0.2 \mathrm{kgBOD}_{5} \mathrm{~d}^{-1} \mathrm{kgMLVSS}^{-1} \text {. }
\end{gathered}
$$

\subsection{Limiting DO concentration in denitrification processes}

As mentioned, small levels of DO are constantly present in biological pre-denitrification reactors, inducing adverse effects on the kinetics of nitrogen removal, and consequently on denitrification performance.

Normally, a great part of the oxygen supplied to the anoxic reactor can be attributed to the mixed-liquor recycle, while a small contribution is given by raw sewage, and that of sludge recycle can be considered negligible. In addition, surface dissolution exchanges from the atmosphere should also be considered. As a result, daily average concentrations measured in real scale facilities are mostly in the range $0.2-0.4 \mathrm{mg} \mathrm{L}^{-1}$, with higher peaks during the day, especially in small plants, characterized by strong fluctuations of flow rate and quality (Raboni et al., 2013a).

Minimizing DO in the mixed-liquor recycle stream seems relevant for limiting DO additions to denitrification. Addition of a post-anoxic reactor (after the pre-denitrification and oxidation-nitrification steps) has been proposed (Urbini et al., 2015) as a possible means of increasing denitrification performance.

A further strategy for DO control is based on the addition of reducing agents that can react with it. A recent study evidentiated that the most suitable reagent for this purpose is a salt of ferrous iron $\left(\mathrm{Fe}^{2+}\right)$, that proved to be very efficient in controlling DO while rapidly oxidizing to ferric ion (Viotti et al., 2015). At the same time ferric ion reacts with phosphorous, precipitating as ferric orthophosphate. Tests proved that a dosage of $6 \mathrm{mgFe}^{2+} \mathrm{L}^{-1}$ can lower the mean DO concentration from $0.45 \mathrm{mg} \mathrm{L}^{-1}$ to $0.28 \mathrm{mg} \mathrm{L}^{-1}$, increasing denitrification efficiency from $64.8 \%$ to $77 \%$. This efficiency was progressively increased to $89 \%$ dosing ferrous ion at $9 \mathrm{mg} \mathrm{L}^{-1}$ (50\% over stoichiometric for $\mathrm{P}$ removal), achieving average DO of $0.1 \mathrm{mg} \mathrm{L}^{-1}$. This also confirmed the strong influence of DO on SDNR suggesting that maintaining DO values lower than $0.2 \mathrm{mg} \mathrm{L}^{-1}$ may achieve high denitrification efficiency.

\subsection{Influence of denitrification reactor hydrodynamics}

Pilot plant studies highlighted the influence of hydrodynamics of DEN on denitrification efficiency (Raboni et al., 2015). In particular, Retention Time Distribution (RTD) influences the concentrations of the denitrification reactants $\left(\mathrm{NO}_{3}-\mathrm{N}\right.$ and $\left.\mathrm{BOD}\right)$, but has also an influence on residual DO, and consequently on denitrification efficiency. A denitrification reactor 
composed of 4 reactors in series has an oxygen consumption capacity greater than a single complete mixing reactor (which allows, at equal conditions, a residual DO of $0.18-0.30 \mathrm{mg} \mathrm{L}^{-1}$ ). The study showed a noticeable difference in SDNR values between the two reactor models. In fact, the model with four reactors in series has demonstrated a higher efficiency of $16.6 \%$ (compared to the complete mixing model) at $\mathrm{F}: \mathrm{M}_{\mathrm{DEN}}=0.2 \mathrm{kgBOD}_{5} \mathrm{~d}^{1} \mathrm{kgMLVSS}^{-1}$; this percentage has increased to $25 \%$ at $\mathrm{F}: \mathrm{M}_{\mathrm{DEN}}=0.4 \mathrm{kgBOD}_{5} \mathrm{~d}^{-1} \mathrm{kgMLVSS}^{-1}$. Hence, hydrodynamic configuration plays an important role in the efficiency of the anoxic reactor, conditioning residual DO concentration and, consequently, denitrification performance. For the same reasons, the right selection of the operating F:M ratio in denitrification is of great importance.

\subsection{Denitrification efficiency in small treatment plants}

Large variations in quantity and quality of sewage, typical of small communities, make it hard to achieve high biological denitrification efficiencies (i.e. $\eta \geq 90 \%$ ). In a specific study of a pre-denitrification plant, fed by sewage of a community of 15,000 inhabitants, an average efficiency of only $60.2 \%$ was achieved, with isolated peaks of $75 \%$ (Raboni et al., 2013a). Two factors affected this result:

- Great variability of the $\mathrm{BOD}_{5} / \mathrm{NO}_{3}-\mathrm{N}$ ratio in denitrification, implying a shortage of carbon $\left(\mathrm{BOD}_{5}\right)$ for denitrification at different times of the day;

- Accumulation of DO in DEN, in the periods of lower $\mathrm{BOD}_{5}$ inflow at night time and early in the day, reaching peak values of $1.2 \mathrm{mgO}_{2} \mathrm{~L}^{-1}$, enough to determine inhibitory effects on the denitrification rate.

It was shown that, by adding supplemental carbon, it was possible to overcome the difficulties encountered and achieve denitrification efficiencies greater than $90 \%$. A practical solution could likely consist of the introduction of an equalization tank before the treatment. The choice of a simultaneous denitrification process (achieving complete mixing conditions), also appears of interest.

\section{ADVANCES IN DENITRIFICATION PROCESSES AND TECHNOLOGIES}

\subsection{Deammonification}

\subsubsection{Deammonification cycle vs. conventional processes}

Deammonification is a biological treatment process used to convert ammonia to nitrogen gas. It includes both nitritation and the anaerobic ammonia-oxidizing (anammox) processes. Nitritation, aerobic oxidation of ammonia- $\mathrm{N}\left(\mathrm{NH}_{4}-\mathrm{N}\right)$ to nitrite-nitrogen $\left(\mathrm{NO}_{2}-\mathrm{N}\right)$ is carried out by autotrophic, Aerobic Ammonia-Oxidizing Bacteria (AerAOB): a well-known process in wastewater treatment which forms the initial step of biological nitrification of $\mathrm{NH}_{4}-\mathrm{N}$ to nitrates $\left(\mathrm{NO}_{3}-\mathrm{N}\right)$.

The anammox reaction is carried out by Planctomycetales, autotrophic, Anaerobic Ammonia-Oxidizing Bacteria (AnAOB) which use $\mathrm{NO}_{2}-\mathrm{N}$ as electron acceptor to anaerobically oxidize $\mathrm{NH}_{4}-\mathrm{N}$ to $\mathrm{N}_{2}$ (Strous et al., 1999). In the overall process, about $89 \%$ of the inorganic nitrogen $\left(\mathrm{NH}_{4}-\mathrm{N}+\mathrm{NO}_{2}-\mathrm{N}\right)$ ends up as $\mathrm{N}_{2}$ gas and about $11 \%$ as $\mathrm{NO}_{3}-\mathrm{N}$. Deammonification and the complete denitrification reaction are illustrated in Figure 1. 


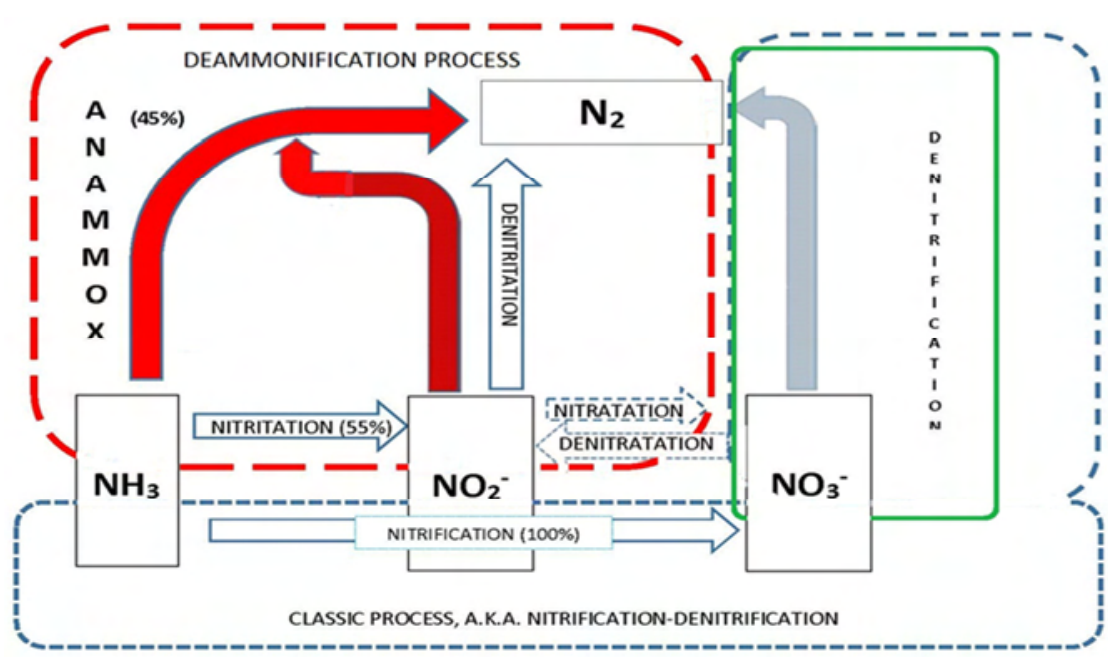

Figure 1. Simplified scheme of the Deammonification and nitrification/denitrification processes.

In order to facilitate the understanding throughout the paper, we introduce Table 1 with the major acronyms and units used in the discussion.

Table 1. Nomenclature of terms and symbols.

\begin{tabular}{lll}
\hline \multicolumn{1}{c}{ Symbol } & \multicolumn{1}{c}{ Unit of measurement } & \multicolumn{1}{c}{ Description } \\
\hline$D O$ & $\mathrm{mgO}_{2} \mathrm{~L}^{-1}$ & Dissolved oxygen concentration \\
$\triangle N O_{3}-N$ & $\mathrm{mgNO}_{3}-\mathrm{N} \mathrm{L}^{-1}$ & Nitrate concentration removed, as $\mathrm{N}$ \\
$\eta$ & - & Fraction of heterotrophic bacteria that use nitrate in \\
$\eta_{B O D}$ & - & lieu of oxygen \\
$K$ & $\mathrm{~h}^{-1}$ & BOD removal efficiency \\
$K_{D}$ & $\mathrm{~h}^{-1}$ & Maximum specific substrate utilization rate \\
$K_{N}$ & $\mathrm{mgNO}_{3}-\mathrm{N} \mathrm{L}^{-1}$ & Endogenous decay coefficient \\
$K_{S}$ & $\mathrm{mg} \mathrm{L}^{-1}$ & Nitrate utilization half-velocity coefficient \\
$K^{\prime}$ & $\mathrm{mgO}_{2} \mathrm{~L}^{-1}$ & Substrate utilization half-velocity coefficient \\
$F: M$ & $\mathrm{gBOD}_{5} \mathrm{~d}^{-1} \mathrm{gMLVSS}^{-1}$ & Oxygen inhibition constant \\
$M L V S S$ & - & Sludge load \\
$N O_{3}-N$ & $\mathrm{mgNO}_{3}-\mathrm{N} \mathrm{L}^{-1}$ & Mixed-Liquor Volatile Suspended Solids \\
$Q$ & $\mathrm{~m}^{3} \mathrm{~d}^{-1}$ & Nitrate concentration, as N \\
$r_{D E N}$ & $\mathrm{gNO}_{3}-\mathrm{N} \mathrm{h}^{-1} \mathrm{kgMLVSS}^{-1}$ & Flow rate \\
$r_{D E N}$, & $\mathrm{gNO}_{3}-\mathrm{N} \mathrm{h}^{-1} \mathrm{kgMLVSS}^{-1}$ & Denitrification rate \\
$S$ & $\mathrm{mg} \mathrm{L}^{-1}$ & Denitrification rate proposed by Tchobanoglous et \\
$S D N R$ & $\mathrm{gNO}_{3}-\mathrm{N} \mathrm{gMLVSS}^{-1} \mathrm{~d}^{-1}$ & al. (2003) \\
$T$ & ${ }^{\circ} \mathrm{C}^{3}$ & Soluble degradable substrate concentration \\
$V_{D E N}$ & $\mathrm{~m}^{3}$ & Specific DeNitrification Rate \\
$\theta$ & - & Temperature \\
$Y$ & $\mathrm{mgVSS} \mathrm{mg}^{-1}$ substrate consumed & Denitrification reactor volume \\
$X$ & $\mathrm{mgMLVSS} \mathrm{L}^{-1}$ & Coefficient of the Arrhenius equation \\
& & Heterotrophic bacteria synthesis yield \\
& & Biomass concentration in the activated sludge \\
\hline $\mathrm{T}$ & ${ }^{\circ} \mathrm{C}^{\circ} \mathrm{Subscripts}$ and superscripts \\
\hline & - & Temperature \\
\hline & & At 20 ${ }^{\circ} \mathrm{C}$ \\
\hline
\end{tabular}

\section{IPABH}


In the conventional denitrification process, $\mathrm{NH}_{4}-\mathrm{N}$ is oxidized first to $\mathrm{NO}_{2}-\mathrm{N}$ and then to $\mathrm{NO}_{3}-\mathrm{N}$ by autotrophic bacteria. The $\mathrm{NO}_{3}-\mathrm{N}$ is then biologically reduced to $\mathrm{N}_{2}$ by heterotrophic bacteria (denitrification) with the consumption of organic substrate in anoxic conditions (blue process path in Figure 1). Aerobic biological nitrification is well known and is accomplished by Nitroso-bacteria (Nitrosomonas) for $\mathrm{NH}_{4}-\mathrm{N}$ oxidation to $\mathrm{NO}_{2}-\mathrm{N}$ and by Nitro-bacteria (Nitrobacter) for $\mathrm{NO}_{2}-\mathrm{N}$ oxidation to $\mathrm{NO}_{3}-\mathrm{N}$.

In the nitritation/denitritation process, $\mathrm{NH}_{4}-\mathrm{N}$ is oxidized to $\mathrm{NO}_{2}-\mathrm{N}$, and then biologically reduced to $\mathrm{N}_{2}$ by heterotrophic bacteria with the consumption of organic substrate in anoxic conditions (red process path in Figure 1). In the deammonification process, aerobic nitritation of $\mathrm{NH}_{4}-\mathrm{N}$ to $\mathrm{NO}_{2}-\mathrm{N}$, accounts for the transformation of about 55\% of the $\mathrm{NH}_{4}-\mathrm{N}$ fed. The remaining $\mathrm{NH}_{4}-\mathrm{N}$ is anaerobically oxidized with $\mathrm{NO}_{2}-\mathrm{N}$ to $\mathrm{N}_{2}$ gas in the anammox process. In practice, the process skips the need for complete $\mathrm{NO}_{2}-\mathrm{NO}_{3}$ oxidation, and subsequent $\mathrm{NO}_{3}$ denitrification to nitrogen gas (green path in Figure 1). Compared to conventional nitrification and denitrification, the aeration and the carbon-source demand is reduced by over $50 \%$ and $100 \%$, respectively. It should be noted that specific biomass production is higher in the conventional process than in the deammonification process ( $20 \mathrm{~g} \mathrm{COD}$ biomass vs. $3 \mathrm{~g} \mathrm{COD}$ biomass per mole of $\mathrm{NH}_{4}{ }^{+}$degraded).

In the absence of dissolved oxygen, heterotrophic bacteria can oxidize organic substrate with $\mathrm{NO}_{2}-\mathrm{N}$ or $\mathrm{NO}_{3}-\mathrm{N}$ as electron acceptor to reduce oxidized nitrogen to $\mathrm{N}_{2}$ gas. These reactions for $\mathrm{NO}_{2}-\mathrm{N}$ and $\mathrm{NO}_{3}-\mathrm{N}$ reduction are termed denitritation and denitratation, respectively. The stoichiometry of biological denitritation and denitratation reactions with acetate consumption and heterotrophic biomass growth are:

Denitritation (nitrite reduction by heterotrophic bacteria) (Equation 6).

$$
\begin{aligned}
& 1.0 \mathrm{NO}_{2}^{-}+1.0 \mathrm{H}^{+}+0.24 \mathrm{NH}_{4}^{+}+0.975 \mathrm{CH}_{3} \mathrm{COO}^{-} \rightarrow 0.5 \mathrm{~N}_{2}+0.24 \mathrm{C}_{5} \mathrm{H}_{7} \mathrm{O}_{2} \mathrm{~N}+0.015 \\
& \mathrm{CO}_{2}+0.735 \mathrm{HCO}_{3}^{-}+1.235 \mathrm{H}_{2} \mathrm{O}
\end{aligned}
$$

Denitratation (nitrate reduction by heterotrophic bacteria) (Equation 7).

$$
\begin{aligned}
& 1.0 \mathrm{NO}_{3}^{-}+1.0 \mathrm{H}^{+}+0.33 \mathrm{NH}_{4}^{+}+1.45 \mathrm{CH}_{3} \mathrm{COO}^{-} \rightarrow 0.5 \mathrm{~N}_{2}+0.33 \mathrm{C}_{5} \mathrm{H}_{7} \mathrm{O}_{2} \mathrm{~N}+0.13 \mathrm{CO}_{2} \\
& +1.12 \mathrm{HCO}_{3}^{-}+1.62 \mathrm{H}_{2} \mathrm{O}
\end{aligned}
$$

Therefore, $6.6 \mathrm{~g}$ of acetate $\mathrm{COD}$ are needed per $\mathrm{g}$ of $\mathrm{NO}_{3}-\mathrm{N}$ denitrified (Equation 7). For denitritation of $\mathrm{NO}_{2}-\mathrm{N}$, about $30 \%$ less is needed, at $4.5 \mathrm{~g}$ acetate COD per $\mathrm{g}$ of $\mathrm{NO}_{2}-\mathrm{N}$ denitrified (Equation 6).

Anammox involves the exoenergetic reaction of $\mathrm{NH}_{4}-\mathrm{N}$ oxidation by $\mathrm{NO}_{2}-\mathrm{N}$, and uptake of $\mathrm{CO}_{2}$ and nutrients by autotrophic anammox bacteria for biomass growth. The overall reaction, accounting for cell synthesis, was described in Equation 8 by Strous et al. (1998).

$$
\begin{aligned}
& 1.0 \mathrm{NH}_{4}^{+}+1.32 \mathrm{NO}_{2}^{-}+0.066 \mathrm{HCO}_{3}^{-}+0.13 \mathrm{H}^{+} \rightarrow 1.02 \mathrm{~N}_{2}+0.26 \mathrm{NO}_{3}^{-}+0.066 \\
& \mathrm{CH}_{2} \mathrm{O}_{0.5} \mathrm{~N}_{0.15}+2.03 \mathrm{H}_{2} \mathrm{O}
\end{aligned}
$$

During anaerobic oxidation of ammonia (Equation 8), some nitrates are formed from nitrites, which may provide reducing power for fixation of carbon dioxide (Schmidt et al., 2002). Eq. (8) also indicates that removal of 1.0 mole of $\mathrm{NH}_{4}-\mathrm{N}$ requires 1.32 moles of $\mathrm{NO}_{2}-\mathrm{N}$ and produces 0.26 moles of $\mathrm{NO}_{3}-\mathrm{N}$. Combination of nitritation and deammonification reactions gives the overall deammonification reaction (Equation 9).

$$
\begin{aligned}
& 1.0 \mathrm{NH}_{4}{ }^{+}+0.804 \mathrm{O}_{2}+0.071 \mathrm{HCO}_{3}^{-} \rightarrow 0.436 \mathrm{~N}_{2}+0.111 \mathrm{NO}_{3}{ }^{-}+0.009 \mathrm{C}_{5} \mathrm{H}_{7} \mathrm{O}_{2} \mathrm{~N}+0.028 \\
& \mathrm{CH}_{2} \mathrm{O}_{0.5} \mathrm{~N}_{0.15}+1.038 \mathrm{H}^{+}+1.46 \mathrm{H}_{2} \mathrm{O}
\end{aligned}
$$


The stoichiometric ratio of nitrate production to ammonium consumption for the anammox bacteria is 1:0.382. In real applications, deammonification has demonstrated ammonia reductions of $90-95 \%$ and total nitrogen reductions of $80-85 \%$ (WERF, 2014).

Table 2 summarizes the benefits of the deammonification process in comparison to the conventional denitrification process.

Table 2. Comparison between deammonification process and conventional denitrification process (WERF, 2014).

\begin{tabular}{|c|c|c|c|}
\hline Parameter & Deammonification & $\begin{array}{c}\text { Nitritation/Denitritation } \\
\qquad(\eta=89 \%)\end{array}$ & $\begin{array}{c}\text { Nitrification/Denitrification } \\
\qquad(\eta=89 \%)\end{array}$ \\
\hline $\mathrm{O}_{2}$ demand & $\begin{array}{l}1.84 \mathrm{gO}_{2} \mathrm{gNH}_{4}-\mathrm{N}^{-1} \\
\text { removed }\end{array}$ & $\begin{array}{l}2.65 \mathrm{gO}_{2} \mathrm{gNH}_{4}-\mathrm{N}^{-1} \\
\text { removed }\end{array}$ & $\begin{array}{c}3.3 \mathrm{gO}_{2} \mathrm{gNH}_{4}-\mathrm{N}^{-1} \\
\text { removed }\end{array}$ \\
\hline $\begin{array}{l}\text { Acetate-COD } \\
\text { demand }\end{array}$ & 0 & $\begin{array}{l}4.5 \mathrm{~g} \text { acetate } \mathrm{COD} \mathrm{gNO}_{2^{-}} \\
\mathrm{N}^{-1} \text { removed }\end{array}$ & $\begin{array}{c}6.6 \mathrm{~g} \text { acetate } \mathrm{COD} \mathrm{gNO}_{3^{-}} \\
\mathrm{N}^{-1} \text { removed }\end{array}$ \\
\hline $\begin{array}{l}\text { Biomass } \\
\text { production }\end{array}$ & $\begin{array}{c}0.12 \underset{1}{\mathrm{gVSS} \mathrm{gNH}_{4}-\mathrm{N}^{-}} \text {removed } \\
\mathrm{gln}^{-}\end{array}$ & $\begin{array}{c}1.5 \mathrm{gVSS} \mathrm{gNH}_{4}-\mathrm{N}^{-1} \\
\text { removed }\end{array}$ & $\begin{array}{l}1.93 \mathrm{gVSS} \mathrm{gNH}_{4}-\mathrm{N}^{-1} \\
\text { removed }\end{array}$ \\
\hline
\end{tabular}

\subsubsection{Deammonification technologies}

Several technical solutions have been developed for the deammonification process. Table 3 shows the reported number of installations (as of 2014's end) under various technical proprietary solutions commercially available. These differ in terms of the method to grow and retain anammox bacteria, number of stages, configuration, control strategies, and include granular sludge blanket reactors (GSBRs), suspended growth sequencing batch reactors (SBRs), moving bed biofilm reactors (MBBRs), and rotating biological contactors (RBCs).

The first full-scale facility was built in 2001, and their number has rapidly increased since 2007, operating on side stream dewatering flows and some industrial applications. The DEMON $^{\circledR}$ process has the most installations. The largest facilities are two $12,000 \mathrm{kgN} \mathrm{d}^{-1}$ ANAMMOX $^{\circledR}$ plants in China. A larger $13,500 \mathrm{kgN} \mathrm{d}^{-1} \mathrm{DEMON}^{\circledR}$ installation is under construction in the USA (WERF, 2014).

Table 3. Active deammonification facilities worldwide.

\begin{tabular}{|c|c|c|c|c|}
\hline \multirow{2}{*}{$\begin{array}{l}\text { Technology } \\
\text { Trade Name }\end{array}$} & \multirow{2}{*}{ Number* } & \multicolumn{2}{|c|}{ Size $\left[\mathrm{kgN} \mathrm{d}^{-1}\right]$} & \multirow{2}{*}{$\begin{array}{c}\text { First installation } \\
\text { (year) }\end{array}$} \\
\hline & & Smallest & Largest & \\
\hline ANAMMOX $^{\circledR}$ & 22 & 50 & 12,100 & 2002 \\
\hline ANITA $^{\mathrm{TM} M o x}$ & 6 & 110 & 350 & 2010 \\
\hline $\operatorname{DeAmmon}^{\circledR}$ & 3 & 130 & 2,455 & 2001 \\
\hline DEMON $^{\circledR}$ & 37 & 50 & 13,500 & 2004 \\
\hline Terra-N ${ }^{\circledR}$ & 5 & 90 & 750 & 2008 \\
\hline
\end{tabular}

*In operation or construction as of Oct. 2014 (WERF, 2014).

\subsubsection{ANAMMOX ${ }^{\circledR}$ Granulated Sludge Blanket Reactor (GSBR)}

Anammox bacteria can grow in granules readily settling by gravity. GSBRs take advantage of this by employing a high rate clarifier that captures and retains anammox granules, while flushing out competing bacterial flocs. Two arrangements are used: two-step and single-step. 


\section{Two-Step ANAMMOX ${ }^{\circledR}$ Process:}

Developed by the Paques company, it uses the SHARON process (Single reactor system for High Activity Ammonium Removal Over Nitrite), a stable, partial nitrification to nitrite instead of nitrate (Hellinga et al., 1998), to convert ammonia to nitrite, followed by the anammox process (Figure $2 \mathrm{~A}$ ).
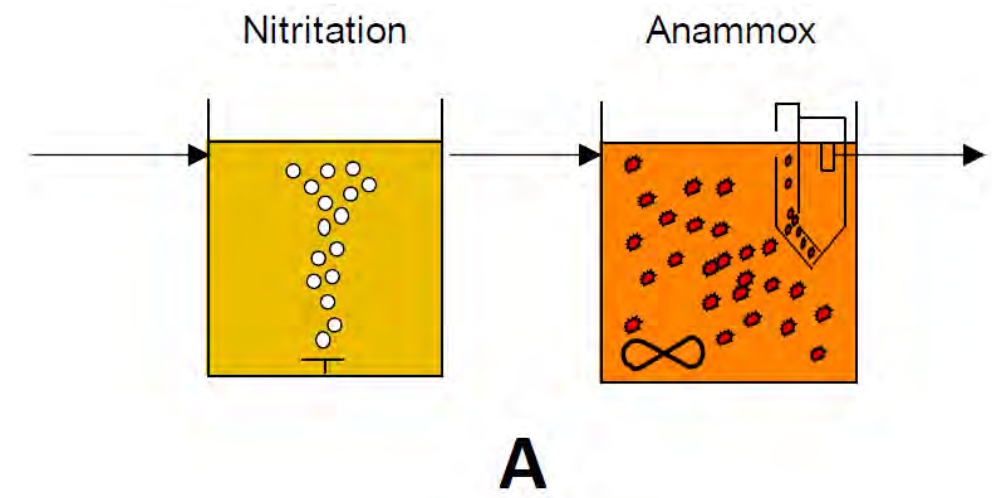

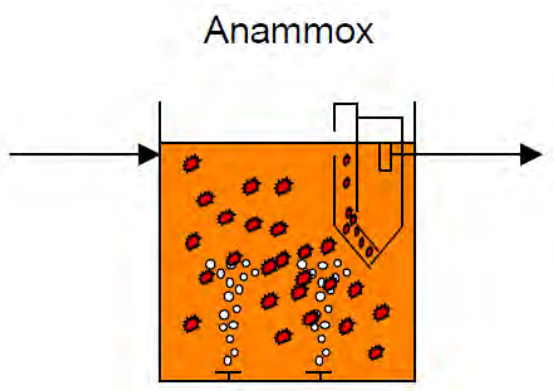

B

Figure 2. Two-step (A) and Single-step (B) anammox process.

This is optimized by controlling $\mathrm{pH}, \mathrm{DO}$, and by taking advantage of the higher growth rate of ammonia-oxidizing bacteria at higher temperatures (Van Loosdrecht and Jetten, 1998). Granular anammox bacteria are retained in the second reactor using up flow clarification. Their conversion capacity is high, up to $4.8 \mathrm{kgTN} \mathrm{m}^{-3} \mathrm{~d}^{-1}$. This system was introduced in the Netherlands at several treatment plants, achieving $80 \%$ ammonia conversion to nitrogen gas at loading rate of $1.2 \mathrm{kgN} \mathrm{m}^{-3} \mathrm{~d}^{-1}$ (van Dongen et al., 2001). A system receiving 1,000-1,300 $\mathrm{mgNH}_{4}-\mathrm{N} \mathrm{L}^{-1}$ could produce an effluent with 5-10 $\mathrm{mg} \mathrm{NO}_{2}-\mathrm{N} \mathrm{L}^{-1}, 60-130 \mathrm{mg}$ $\mathrm{NH}_{4}-\mathrm{N} \mathrm{L}^{-1}$, and about $130 \mathrm{mg} \mathrm{NO}_{3}-\mathrm{N} \mathrm{L}^{-1}$ (Abma et al., 2007).

The advantage of this arrangement is that the two main reactions (nitritation and deammonification) occur in separate reactors, allowing better control of each process. Its disadvantage is that reactor volumes are significantly larger due to the large nitritation reactor needed.

\section{Single-Step ANAMMOX ${ }^{\circledR}$ Process:}

In this process, nitritation and deammonification (anammox) occur in the same reactor (Figure 2B), making process control ( $\mathrm{pH}, \mathrm{DO}$, and Oxidation-Reduction Potential - ORP) essential to prevent bacterial competition for nitrite (heterotrophic denitritation, and in particular autotrophic Nitrite Oxidizing Bacteria - NOBs), while maintaining a long solid retention time (SRT) for anammox bacteria. Ammonia reduction of $95 \%$, with over $80 \%$ total nitrogen reduction, have been reported (Abma et al., 2010).

The advantage of this process is that single reactors are very compact due to high-granule concentration. Granular sludge growth protects the process against high nitrite levels. A disadvantage consists of requiring online control to achieve stable nitritation and deammonification in one reactor. Operational experience with this system has been quite positive in reported cases; therefore, single step ANAMMOX ${ }^{\circledR}$ is the most commonly used.

\section{Incorporation of Anammox in mainstream processes}

Incorporating anammox in mainstream processes is still an emerging technology. Figure 3 illustrates a possible process flowsheet including anammox return sludge treatment in a conventional WWTP (Wett et al., 2010). 


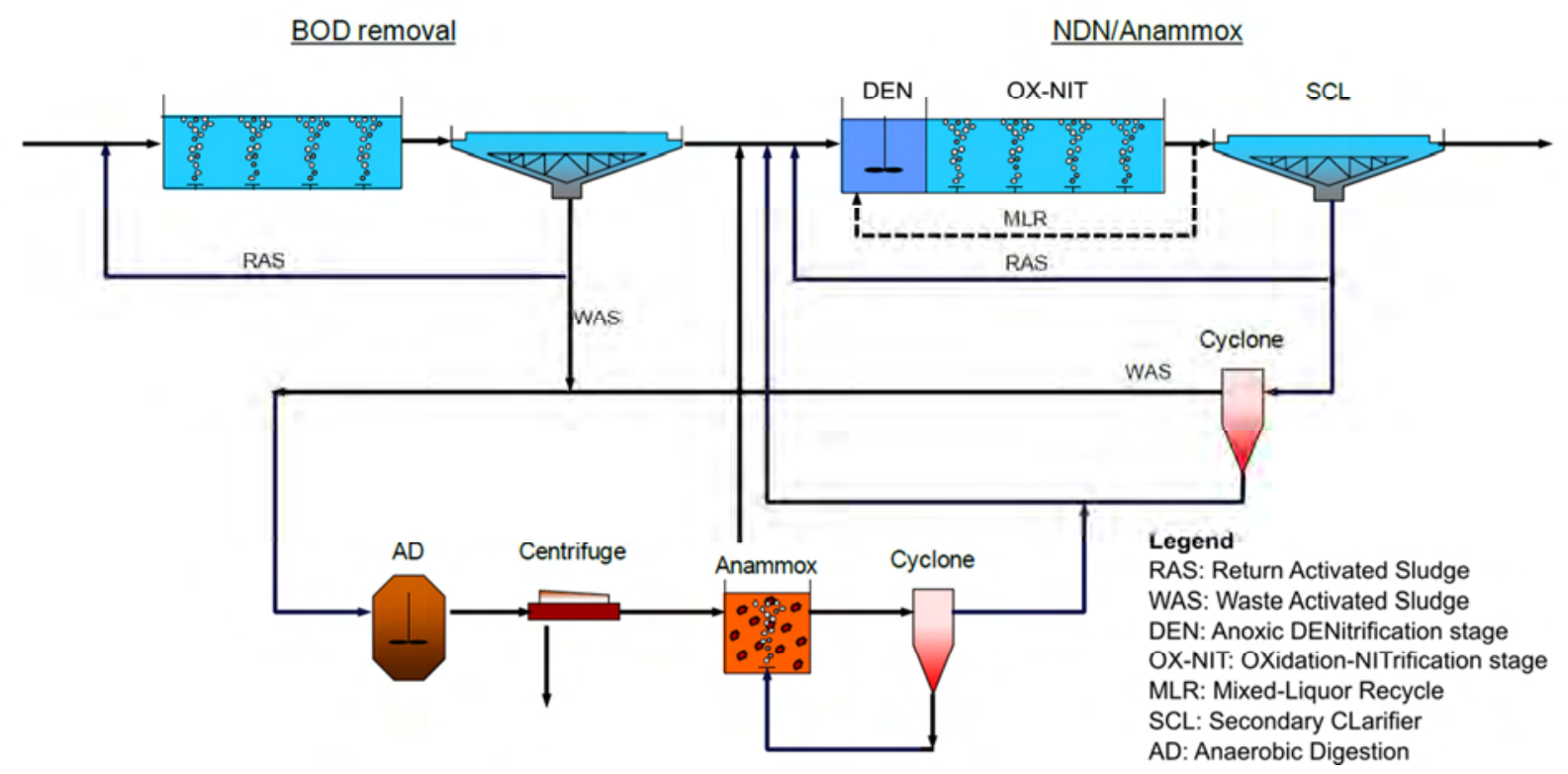

Figure 3. Integration of Anammox process in conventional processes (Wett et al., 2010).

\subsubsection{DEMON ${ }^{\circledR}$ Sequencing Batch Reactor (SBR)}

The DEMON ${ }^{\circledR}$ process (DE-amMONnification) employs aerobic nitrification to nitrite and anaerobic ammonia oxidation under controlled DO and $\mathrm{pH}$ conditions (Wett et al., 2010). The process uses a hydrocyclone to separate heavier granular anammox bacteria from floc-forming bacteria, allowing accumulation of NOBs, and performance stabilization.

Process control addresses three parameters: (1) time of filling and drawing the SBR (feed rate), (2) DO, and (3) $\mathrm{pH}$, to balance the nitritation and anammox reactions (O'Shaughnessy et al., 2008). DO is set to a low value (around $0.3 \mathrm{mg} \mathrm{L}^{-1}$ ) to prevent rapid nitrite production by $\mathrm{AOB}$, and repress NOBs. Aeration cycles control also regulates $\mathrm{pH}$ : nitritation depresses the $\mathrm{pH}$ during aeration, while the anammox reaction increases $\mathrm{pH}$ in its absence. Aeration is initiated at the upper $\mathrm{pH}$ and stopped at the lower $\mathrm{pH}$ set points to maintain $\mathrm{pH}$ within 0.01 units (Wett et al., 2010). The nitritation step may suffer inhibition, leading to process instability.

\subsubsection{Moving-Bed Biofilm Reactor (MBBR)}

MBBR configurations using different types of support media are used for deammonification of high-strength, ammonium-rich recycle streams (Seyfried et al., 2001). AOB and anammox bacteria are established within the biofilm (Figure 4). The main

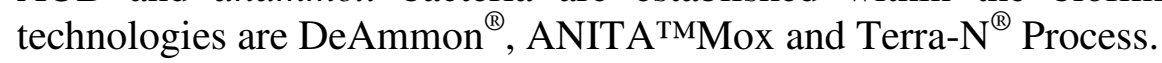

\section{DeAmmon $^{\circledR}$}

Developed by Purac/Läckeby AB (Sweden) in collaboration with the University of Hannover and Ruhrverband (the Ruhr River Association), consists of a single- or dual-train system with three stages per reactor, normally operated in series, with built-in flexibility to allow also parallel operation. For biofilm growth support, Kaldnes K1 filter media (AnoxKaldnes/Veolia) with active area of $500 \mathrm{~m}^{2} \mathrm{~m}^{-3}$ is typically added to fill up to $40 \%$ of the reactor volume. To retain media within each stage, separating screens are placed between stages. Internal recirculation from the third to the first stage may be required for very high-strength streams, to limit ammonia concentration in the first stage. Intermittent aeration supporting partial nitritation and anammox reactions is provided by coarse bubble diffusers. Alternance of aeration/anoxic periods limits nitrite accumulation and restrict the growth of aerobic nitrite-oxidizing bacteria (Plaza et al., 2011; Thöle, 2007). DO concentration of 
$3 \mathrm{mg} \mathrm{L}^{-1}$ during aeration is considered appropriate for design and operation, but higher concentrations are avoided to prevent potential for NOB growth, and limit anammox inhibition. Mechanical mixers ensure well mixed conditions during non-aerated periods. Reactor $\mathrm{pH}$ is usually in the 7.3-7.7 range and not controlled. On-line conductivity measurements are a low-cost tool for performance monitoring and control (e.g. duration of aeration cycles).

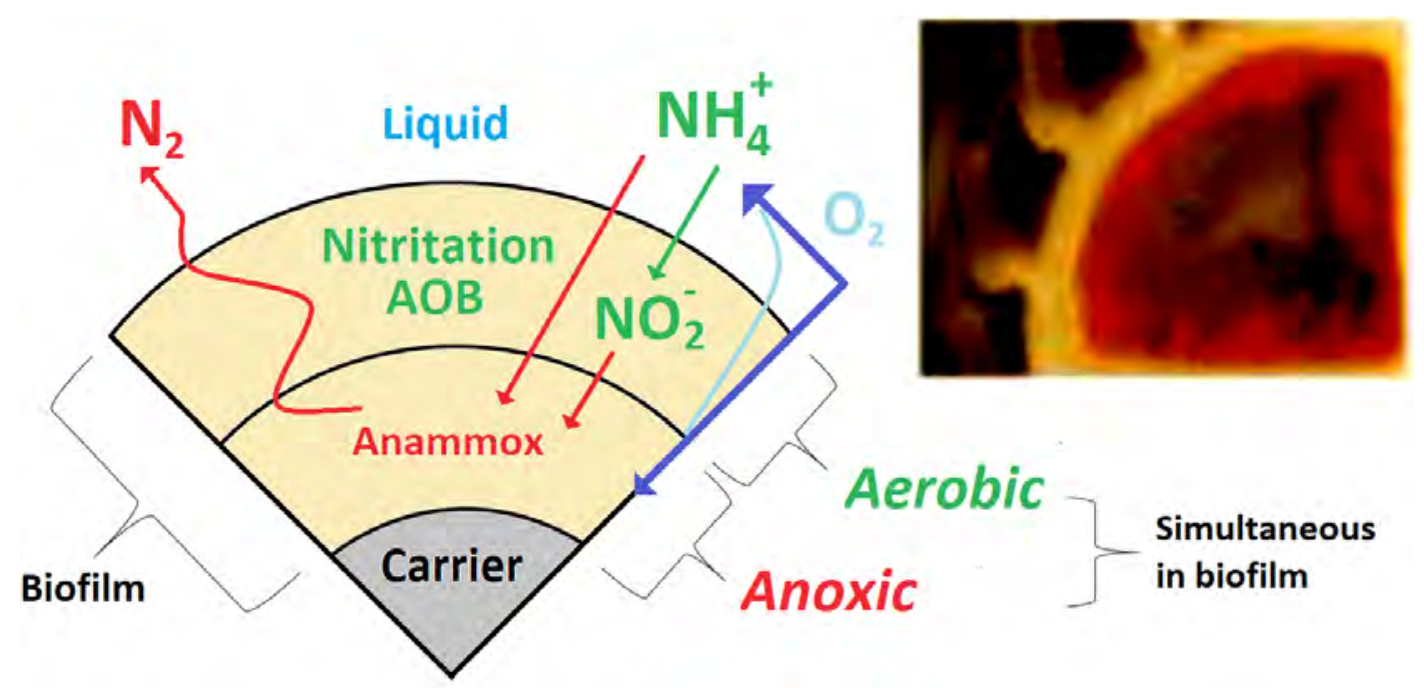

Figure 4. Anammox bacteria in biofilm (Source: Seyfried et al., 2001).

Inorganic nitrogen removal efficiency is usually in the range $70-85 \%$ and in the temperature range $25-30^{\circ} \mathrm{C}$ (Plaza et al., 2011). Minimum process operating temperature is $20^{\circ} \mathrm{C}$, after which substantial performance deterioration occurs (Thöle, 2007). With Kaldnes $\mathrm{K} 1$ media, a design load of $0.6 \mathrm{~kg}-\mathrm{N} \mathrm{m}^{-3} \mathrm{~d}^{-1}$ can be assumed.

\section{ANITA ${ }^{\mathrm{TM}}$ Mox}

ANITA $^{\text {TMMOx }}$ is a single-stage deammonification MBBR system developed by AnoxKaldnes/Veolia. It uses BiofilmChip ${ }^{\mathrm{TM}} M$, a support medium with high specific surface area which allows achieving a volumetric ammonium-N removal rate of up to $1.2 \mathrm{~kg}-\mathrm{N} \mathrm{m}^{-3} \mathrm{~d}^{-1}$ with $40 \%$ media-filled volume in a temperature range of $27-30^{\circ} \mathrm{C}$ (Christensson et al., 2011). The specific ammonium removal rate is approximately $3 \mathrm{~g}-\mathrm{N} \mathrm{m}^{-2} \mathrm{~d}^{-1}$, with ammonium-N and total inorganic nitrogen removal efficiencies of approximately $90 \%$ and $80 \%$, respectively, at $\mathrm{pH}$ in the range 6.7-7.5. The MBBR is continuously aerated with DO concentration controlled in the range $0.5-1.5 \mathrm{mg} \mathrm{L}^{-1}$. The reported energy consumption for the single-stage MBBR is 1.6-1.9 $\mathrm{kWh} \mathrm{kgN}^{-1}$ removed (Christensson et al., 2011).

\section{Terra- $N^{\circledR}$ Process}

Terra- $\mathrm{N}^{\circledR}$ Process, developed by Clariant/SÜD-Chemie AG (Munich, Germany), uses bentonite instead of plastic as support medium for biofilm growth. The process is designed as single-stage SBR, or as two-stages in series, with gravity clarification. The bentonite product contains a wide range of particle sizes, with mean $25-45 \mu \mathrm{m}$, and mean surface area of $60 \mathrm{~m}^{2} \mathrm{~g}^{-1}$, with lower active surface area for biofilm growth.

Bentonite is added at $10-12 \mathrm{~g} \mathrm{~L}^{-1}$ to the nitritation stage of the two-stage process, or in the single-stage SBR, resulting in a TSS concentration of $15-20 \mathrm{~g} \mathrm{~L}^{-1}$, at full loading. Granulation of anammox bacteria in the second stage of the two-stage system eliminates the need for a support media in that stage. Second-stage biomass concentrations of 5-7 $\mathrm{g} \mathrm{L}^{-1}$ have been reported. 
The bentonite induces a high solids settling rate, and compact settled solids, resulting in insignificant losses of bentonite in the effluent. Biomass lost with the effluent by washout is sufficient to control the reactor solids concentration, so no additional solids wastage is normally necessary.

In SBR systems, aeration is intermittent and the aerobic/anoxic pattern is adjusted based on ammonium loading and reactor performance. Mechanical mixing is required to maintain solids in suspension during the SBR anoxic phases, and in the anammox stage of a two-stage system.

Many Terra- $\mathrm{N}^{\circledR}$ systems are retrofits of existing tanks, and operate at loading rates from 0.4 to $1.0 \mathrm{~kg}-\mathrm{N} \mathrm{m}^{-3} \mathrm{~d}^{-1}$ (WERF, 2014); however, with the SBR variant, higher loading rates up to $1.5 \mathrm{~kg}_{-} \mathrm{N} \mathrm{m}^{-3} \mathrm{~d}^{-1}$ are possible. Inorganic nitrogen removal efficiencies are reported in the range $80-90 \%$. Startup time for the SBR or the anammox stage (two-stage process) can be reduced to $60-90 \mathrm{~d}$ by seeding the reactors with anammox-enriched sludge from existing full-scale systems.

\subsubsection{Benefits of deammonification}

The benefits of deammonification can be summarized as:

- Energy savings: aeration energy needed for the process is about 55-60\% of that needed for a conventional nitrification/denitrification process;

- No extra carbon is needed for nitrogen removal. Even if carbon is added to remove the nitrates produced from anammox, total carbon demand is still about $90 \%$ less than that used in the conventional nitrification/denitrification process;

- Greenhouse effects: the process is a net consumer of $\mathrm{CO}_{2}$, compared to that released by heterotrophic bacteria in the conventional nitro/denitro process;

- Alkalinity demand for nitrogen removal is reduced by about $45 \%$;

- The process sludge production is much less than in a conventional nitrification/denitrification plant.

\subsection{Technologies for conventional denitrification with attached biological culture}

\subsubsection{Denitrification in submerged bio filters}

Denitrifying filters have been utilized for wastewater treatment for a number of years. The combination of denitrification and solids removal was first patented in the 1970s. Since then, several companies have developed their own denitrifying filters. There are two main configurations for denitrification filters commercially available: down flow and up flow continuous backwash filters. Down flow denitrification filters operate in a conventional filtration mode and consist of media and support gravel laying on an underdrain. Manufacturers include Severn Trent Services (TETRA Denite ${ }^{\circledR}$ ), F.B. Leopold Co. Inc. (elimi.NITE $^{\circledR}$ ), and Siemens Water Technology (Davco®). In up flow continuous-backwash filters, wastewater flows upward through the filter, countercurrent to the movement of the sand bed. Manufacturers include Parkson Corp. (DynaSand ${ }^{\circledR}$ ), and Paques bv. (Astrasand ${ }^{\circledR}$ ) (US-EPA 2007). Other configurations include Biologically Active Filter (BAF) with floating media, continuous backwashing moving bed filters, and nonbackwashing, and submerged filters. BAF with floating media includes systems with polystyrene, polypropylene, or polyethylene media, such as Kruger Biostyr ${ }^{\circledR}$. These are backwashed using intermittent countercurrent flow, and are typically designed to also remove suspended solids to secondary levels. Continuous backwashing moving bed filters operate in up flow mode and consist of media heavier than water continuously moving countercurrent to the wastewater. Media is directed to a central air lift where it is scoured, rinsed, and returned to the top of the media bed. Well-known filters are DynaSand ${ }^{\circledR}$, AstraSand ${ }^{\circledR}$, and Centraflo ${ }^{\circledR}$, typically designed to 
produce filter-quality effluent $(<5 \mathrm{NTU})$. Nonbackwashing, submerged filters consist of submerged, static media and are often referred to as submerged aerated filters (SAF), although recent work applied this technology in anoxic conditions for denitrification. Solids are carried through the reactor and removed by a separate, dedicated solid-separation process (WERF, 2010).

Leopold elimi-NITE ${ }^{\circledR} 2.0$ denitrification system reduces nitrate-nitrogen in wastewater effluent by converting it to nitrogen gas. The biological conversion is done in an attached growth, down flow, deep bed, mono-media filter. Oxygen is removed to create an anoxic environment for denitrification, and particulate matter as well as insoluble $\mathrm{P}$ is removed. The system adds a supplemental carbon source or microbiological food needed to metabolize nitrogen (Leopold, 2003).

BIOSTYR ${ }^{\circledR}$ is a process based on the biological filter principle to fix biomass in a biofilm combination. The bed is formed by special polystyrene balls with a diameter of $4.5 \mathrm{~mm}$, kept inside the filter thanks to the filter-jets ceiling. Biomass development starts in the filter-bed, while removing nitrogen from sewage water. Periodical cleaning of the filter is made by purified wastewater stored over the filter ceiling. Dosing of an external substrate (methanol) is necessary for nitrate-nitrogen denitrification. Installation of a separation stage is not necessary, and the fixed biomass enables rather high volumetric loading. This technology is used for post denitrification, when a low concentration of $\mathrm{TN}$ is achieved and specific consumption of external substrate can be minimized.

Airlift reactors with biofilm attached on fixed supports exploit the different DO concentrations within the biofilm for nitrogen removal. In such systems, a Simultaneous Nitrification and Denitrification (SND) process occurs in the outer and inner part of the biofilm, respectively. The advantages of these reactors are the small volumes, a low-odor sludge due to high DO concentration, and low suspended solids content in the effluent (Luciano et al., 2012; Viotti et al., 2014).

\subsubsection{Moving bed biofilm and fluidized bed biofilm reactors}

A moving bed biofilm reactor (MBBR) is a process utilizing a basin filled with a carrier medium that promotes attachment and growth of biofilm carrying out biological treatment. MBBRs have been extensively used for BOD/COD removal, as well as for nitrification and denitrification in municipal and industrial wastewater treatment. Nitrification rates as high as $1.2 \mathrm{gNH}_{4}-\mathrm{N} \mathrm{m}^{-2} \mathrm{~d}$ were demonstrated in practical operation at low temperatures $\left(11^{\circ} \mathrm{C}\right)$, while denitrification rates as high as $3.5 \mathrm{gNO}_{3}-\mathrm{N}_{\text {equiv. }} \mathrm{m}^{-2} \mathrm{~d}^{-1}$ have been reported. Depending on pretreatment needs, total hydraulic retention time (HRT) of a MBBR for N-removal will be in the range of 3-5 h (Ødegaard, 2006).

The carrier media is either in fixed form as sheets/rope or made by buoyant, loose plastic media requiring energy in the form of either aeration or mixing for buoyancy, showing at the same time durability by not so far requiring replacement as in first generation MBBRs built over 15 years ago (Rusten et al., 1996). The primary difference between BAFs and MBBRs is that an MBBR does not provide any filtration or require any backwash. Rather, a separation process downstream of the unit removes solids from the stream. Downstream separation technologies used include sedimentation, flotation, filtration, high-rate clarifiers, and membranes (WERF, 2010).

Fluidized Bed Biofilm Reactor (FBBR) is a treatment process that utilizes carrier media to promote attached growth like BAFs and MBBRs; similarly to MBBRs, FBBRs do not filter solids and require downstream solids separation. Carrier media selection governs process sizing: historically, carrier medium of choice has been either silica sand or granular activated carbon (GAC). (Coahelso et al., 1992). A FBBR operates in up flow mode with the media fluidized within the reactor as the drag force associated with the feed up flow exceeds the 
gravity force pulling down particles, and lifts the carrier media. This configuration (i) maximizes media exposure between attached biomass and the feed stream, (ii) avoids plugging, and (iii) provides scour to maintain a thin biofilm improving mass transfer. Despite small footprints, FBBRs suffer from scale-up issues and lack of commercial systems (Sutton and Mishra, 1994).

\subsubsection{Membrane Biofilm Reactors (MBfR)}

MBfR is an emerging technology for water and wastewater treatment, based on pressurized membranes that supply a gaseous substrate to a biofilm formed on the membrane's exterior. MBfR biofilms behave differently from conventional biofilms due to their counter-diffusion of substrates, and are suited for numerous treatment applications, including removal of carbon and nitrogen when oxygen is supplied, and reduction of oxidized contaminants (such as nitrate) when hydrogen is supplied. Major benefits include high gas utilization efficiency, low energy consumption, and small reactor footprints. MBfRs development still faces challenges, including biofilm management, design of scalable reactor configurations, and identification of cost-effective membranes (Martin and Nerenberg, 2012).

\section{CONCLUSIONS}

The paper presents some of the most recent advances in biological nitrogen removal. Both design criteria of conventional denitrification processes and technological innovations have been considered.

With reference to former, a new equation for SDNR applicable to reactor sizing was proposed, highlighting the influence of both Dissolved Oxygen (DO) and the F:M ratio in the denitrification reactor on process design. The adverse effect of DO in a conventional denitrification anoxic reactor is quite relevant, and its minimization, mainly by reduction in the mixed-liquor recycle, or by addition of a post-anoxic reactor (after pre-denitrification and oxidation-nitrification) should be pursued. An alternative for controlling DO in the denitrification phase is based on the addition of chemical reducing agents that can react with DO. Specifically, the most suitable reagent has proved to be a salt of ferrous iron, evidencing that such dosages can be very efficient in controlling DO, as it rapidly oxidizes ferrous to ferric ion, subsequently reacting with phosphorous and precipitating as orthophosphate.

Of great importance are also recent studies highlighting the limits of denitrification efficiency in small community plants, due to the strong load fluctuations. Effects of the hydrodynamic behavior of the denitrification reactor (complete-mixing or plug-flow) on the denitrification performance have been proven equally important.

The greatest technological innovation to date regards the increasing diffusion of "deammonification" processes, often better known by their patent names (ANAMMOX ${ }^{\circledR}$, $\mathrm{DEMON}^{\circledR}, \mathrm{CANON}^{\circledR}, \mathrm{ANITA}^{\circledR}$ and others). Deammonification is achieved by bacteria capable of using nitrous ions as electron acceptors to degrade ammonia to nitrogen. The process reduces aeration and carbon-source demands by over $50 \%$ and $100 \%$, respectively, compared with traditional nitrification-denitrification and has already found industrial applications in the treatment of high-strength wastewater such as digested sludge liquor and landfill leachate.

A promising new technology MBfRs is based on pressurized membranes supplying a gaseous substrate to a biofilm formed on the membrane's exterior. These can be used in both oxidizing (COD removal) and reducing (nitrate removal) processes depending on the substrate provided. 


\section{ACKNOWLEDGEMENT}

Part of the work that led to this paper has been performed under the project No. LO1408 "AdMaS UP - Advanced Materials, Structures and Technologies" supported by the Czech Ministry of Education, Youth and Sports under the "National Sustainability Programme I".

\section{REFERENCES}

ABMA, W. R.; SCHULTZ, C. E.; MULDER, J. W.; VAN DER STAR, W. R. L.; STROUS, M.; TOKUTOMI, T. et al. Full-scale granular sludge Anammox process. Water Science and Technology, v. 55, n. 8-9, p. 27-33, 2007.

http://dx.doi.org/10.2166/wst.2007.238

ABMA, W. R.; DRIESSEN, W.; HAARHUIS, R.; VAN LOOSDRECHT, M. C. M. Upgrading of sewage treatment plant by sustainable and cost-effective separate treatment of industrial wastewater. Water Science and Technology, v. 61 n. 7, p. 17151722, 2010. http://dx.doi.org/10.2166/wst.2010.977

CHRISTENSSON, M.; EKSTRÖM, S.; LEMAIRE, R.; LE VAILLANT, E.; BUNDGGAARD, E.; CHAUZY, J. et al. ANITA ${ }^{\mathrm{TM} M o x}$ - A Biofarm Solution for Fast Start-Up of Deammonifying MBBRs. In: WATER ENVIRONMENT FEDERATION, 84., 15-19 October 2011, Los Angeles, CA. Proceedings.... Sacramento: ACWA, 2011.

CAPODAGLiO, G. A.; HLAVÍNEK, P.; RABONI, M. Physico-chemical technologies for nitrogen removal from wastewaters: a review. Revista Ambiente \& Agua, v. 10, n. 3, p. 481-498, 2015. http://dx.doi.org/10.4136/ambi-agua.1618

COAHELSO, I.; BOAVENTURA, R.; RODRIGUES, A. Biofilm reactors - An experimental and modeling study of wastewater denitrification in fluidized-bed reactors of activated carbon particles. Biotechnology and Bioengineering., v. 40, n. 5, p. 625-633, 1992. http://dx.doi.org/10.1002/bit.260400510

EKAMA, G.A. Biological Nutrient Removal. In: Reference Module in Earth Systems and Environmental Sciences - Volume 4: Treatise on Water Science. Amsterdam: Elsevier, 2011. p. 409-526. doi: http://dx.doi.org/10.1016/B978-0-444-53199-5.00094-4

HELlinGA, C.; SCHELlEN, A. A. J. C.; MULDER, J. W.; VAN LOOSDRECHT, M. C. M.; HEIJNEN, J. J. The SHARON process: an innovative method for nitrogen removal from ammonium-rich waste water. Water Science and Technol., v. 37, n. 9, p. 135142, 1998. http://dx.doi.org/10.1016/S0273-1223(98)00281-9

LEOPOLD COMPANY, INC. Leopold elimi-NITE Denitrification System. 2003. Available in: http://www.xylemwatersolutions.com. Access in: September 2015.

LUCIANO, A.; VIOTTI, P.; MANCINI, G.; TORRETTA, V. An integrated wastewater treatment system using a BAS reactor with biomass attached to tubular supports. Journal of Environmental Management, v. 113, p. 51-60, 2012.

MARTIN, K. J.; NERENBERG, R. The membrane biofilm reactor (MBfR) for water and wastewater treatment: principles, applications, and recent developments. Bioresource Technology, v. 122, p. 83-94, 2012. http://dx.doi.org/10.1016/j.biortech.2012.02.110 
ØDEGAARD, H. Innovations in wastewater treatment: the moving bed biofilm process. Water Science and Technology, v. 53, n. 9, p. 17-33, 2006. http://dx.doi.org/10.2166/wst.2006.284

OH, J.; SILVERSTEIN, J. Oxygen inhibition of activated sludge denitrification. Water Research, v. 33, n. 8, p. 1925-1937, 1999. http://dx.doi.org/10.1016/S00431354(98)00365-0

O'SHAUGHNESSY, M.; SIZEMORE, J.; MUSABYIMANA, M.; SANJINES, P.; MURTHY, S.; WETT, B. et al. Operations and process control of the deammonification (DEMON) process as a sidestream option for nutrient removal. In: WATER ENVIRONMENT FEDERATION, WEFTEC 2008, 18-22 Oct., Chicago. Proceedings... Chicago: WEF, 2008. p. 6333-6348. http://dx.doi.org/10.2175/193864708788809743

PLAZA, E.; STRIDH, S.; ÖRNMARK, J.; KANDERS, L.; TRELA, J. Swedish experience of the deammonification process in a biofilm system. In: WATER ENVIRONMENT FEDERATION, NUTRIENT RECOVERY AND MANAGEMENT, 9-12 Jan. 2011, Miami. Proceedings... Miami: WEF, 2011. p. 1067-1079. http://dx.doi.org/10.2175/193864711802867397

PLÓSZ, B. G.; JOBBÁGY, A.; LESLIE GRADY JR., C. P. Factors influencing deterioration of denitrification by oxygen entering an anoxic reactor through the surface. Water Research, v. 37, n. 4, p. 853-863, 2003. http://dx.doi.org/10.1016/S00431354(02)00445-1

RABONI, M.; TORRETTA, V.; URBINI G. Influence of strong diurnal variations in sewage quality on the performance of biological denitrification in small community wastewater treatment plants (WWTPs). Sustainability, v. 5, n. 9, p. 3679-3689, $2013 \mathrm{a}$. http://dx.doi.org/10.3390/su5093679

RABONI, M.; TORRETTA, V.; VIOTTI, P.; URBINI, G. Experimental plant for the physical-chemical treatment of groundwater polluted by municipal solid waste (MSW) leachate, with ammonia recovery. Revista Ambiente \& Agua, v. 8, n. 3, p. 22-32, 2013b. http://dx.doi.org/10.4136/ambi-agua.1250

RABONI, M.; TORRETTA, V.; VIOTTI, P.; URBINI, G. Pilot experimentation with complete mixing anoxic reactors to improve the performance of sewage denitrification in small communities treatment plants. Sustainability, v. 6, n.1, p.112-122, 2014a. http://dx.doi.org/10.3390/su6010112

RABONI, M.; TORRETTA, V.; VIOTTI, P.; URBINI, G. Calculating specific denitrification rates in pre-denitrification by assessing the influence of dissolved oxygen, sludge loading and the mixed-liquor recycle. Environmental Technology, v. 35, n. 20, p. 2582-2588, 2014b. http://dx.doi.org/10.1080/09593330.2014.913690

RABONI, M.; GAVASCI, R.; VIOTTI, P. Influence of denitrification reactor retention time distribution (RTD) on dissolved oxygen control and nitrogen removal efficiency. Water Science and Technology, v. 72, n. 1, p. 45-51, 2015. http://dx.doi.org/10.2166/wst.2015.188 
RUSTEN, B.; WIEN, A.; SKJEFSTAD, J. Spent aircraft deicing fluid as external carbon source for denitrification of municipal wastewater, from waste problem to beneficial Use. In: PURDUE INDUSTRIAL WASTE CONFERENCE, May 6-8 1996, Purdue. Proceedings... Purdue: Purdue University, 1996. p. 359-369.

SEYFRIED, C. F.; HIPPEN, A.; HELMER, C.; KUNST, S.; ROSENWINKEL, K. H. Onestage deammonification: nitrogen elimination at low costs. Water Science and Technology: Water Supply. v. 1, n. 1, p. 71-80, 2001.

SCHMIDT, I.; HERMELINK, C.; VAN DE PAS-SCHOONEN, K.; STROUS, M.; OP DEN CAMP, H. J.; KUENEN, J. G.; JETTEN, M. S. M. Anaerobic ammonia oxidation in the presence of nitrogen oxides (NOx) by two different lithotrophs. Applied and Environmental Microbiology, v. 68, n. 11, p. 5351-5357, 2002.

STROUS, M.; HEIJNEN, J. J.; KUENEN J. G.; JETTEN M. S. M. The sequencing batch reactor as a powerful tool for the study of slowly growing anaerobic ammoniumoxidizing microorganisms. Applied Microbiology and Biotechnology, v. 50, n. 5, p. 589-596, 1998.

STROUS, M.; FUERST, J. A.; KRAMER, E. H. M.; LOGEMANN, S.; MUYZERT, G.; VAN DE PAS-SCHOONEN, K. T. et al. Missing lithotroph identified as new planctomycete. Nature, v. 400, p. 446-449, 1999. http://dx.doi.org/10.1038/22749

SUTTON, P. M.; MISHRA, P. N. Activated carbon-based biological fluidized-beds for contaminated water and wastewater treatment: A state-of-the-art review. Water Science and Technology, v. 29, n. 10-11, p. 309-317, 1994.

THÖLE, D. Presentation on MBBR system startup and performance. Ruhrverband: Department of Technical Management and Waste Management, 2007.

TORRETTA, V.; RAGAZZI, M.; TRULLI, E.; DE FEO, G.; URBINI, G.; RABONI, M.; RADA, E. C. Assessment of biological kinetics in a conventional municipal WWTP by means of oxygen uptake rate method. Sustainability, v. 6, n. 4, p. 1833-1847, 2014. http://dx.doi.org/10.3390/su6041833.

TCHOBANOGOLOUS, G.; BURTON, F. L.; STENSEL, H. D. Wastewater engineering: treatment and reuse. 4th ed. New York: McGraw Hill, 2003.

URBINI, G.; GAVASCI, R.; VIOTTI, P. Oxygen control and improved denitrification efficiency by means of a post-anoxic reactor. Sustainability, v. 7, n. 2, p. 1201-1212, 2015. http://dx.doi.org/10.3390/su7021201.

UNITED STATES. Enviromental Protect Agency - US-EPA. Wastewater management fact sheet -denitrifying filters. EPA 832-F-07-014. Whashington, 2007.

UNITED STATES. Enviromental Protect Agency - US-EPA. nutrient control design manual: state of technology, review report. EPA/600/R-09/012. Washington, 2009. $104 \mathrm{p}$.

UNITED STATES. Enviromental Protect Agency - US-EPA. Nutrient control design manual. EPA/600/R-10/100. Washington, 2010. 369 p.

VAN DONGEN, U.; JETTEN, M. S. M.; VAN LOOSDRECHT, M. C. M. The SHARON ${ }^{\circledR}-$ Anammox ${ }^{\circledR}$ process for treatment of ammonium rich wastewater. Water Science and Technology, v. 44, n. 1, p 153-160, 2001. 
VAN LOOSDRECHT, M. C. M.; JETTEN M.S.M. Microbiological conversions in nitrogen removal. Water Science and Technology, v. 38, n. 1, p. 1-7, 1998. http://dx.doi.org/10.1016/S0273-1223(98)00383-7

VIOTTI, P.; LUCIANO, A.; MANCINI, G.; TORRETTA, V. A wastewater treatment using a biofilm airlift suspension reactor with biomass attached to supports: a numerical model, International Journal of Environmental Science and Te, v. 11, n. 3, p. 571-588, 2014. http://dx.doi.org/10.1007/s13762-013-0256-6.

VIOTTI, P.; COLlivignARELli, M. C.; MARTORELli, E.; RABONI, M. Oxygen control and improved denitrification efficiency by dosing ferrous ions in the anoxic reactor. Desalination and water treatment, 2015.

http://dx.doi.org/10.1080/19443994.2015.1089200.

WETT, B.; NYHUIS, G.; TAKÁCS, I.; MURTHY S. Development of enhanced deammonification selector. In: WATER ENVIRONMENT FEDERATION, WEFTEC, 2-6 Oct. 2010, New Orleans. Proceedings... New Orleans, 2010. p. 5917-5926. http://dx.doi.org/10.2175/193864710798194139

WATER ENVIRONMENT RESEARCH FOUNDATION - WERF. Deammonification. Alexandria, 2014. 22 p.

WATER ENVIRONMENT RESEARCH FOUNDATION - WERF. Tertiary denitrification processes for low nitrogen and phosphorus. Alexandria, 2010. $26 \mathrm{p}$. 


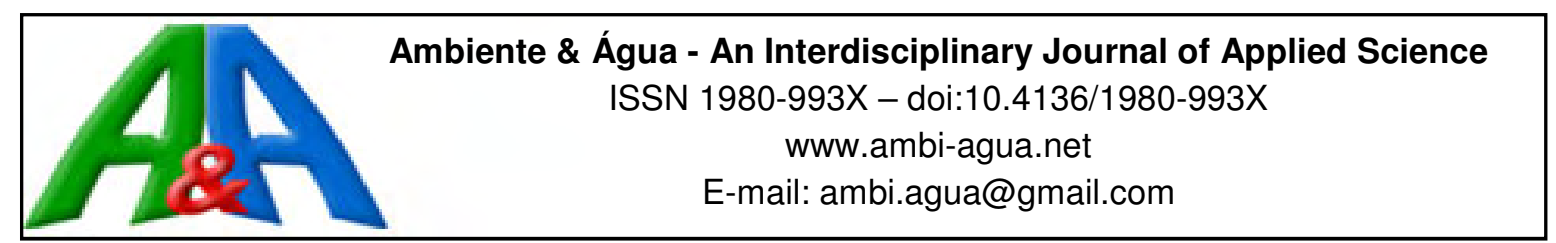

\title{
Life cycle assessment of four potable water treatment plants in northeastern Colombia
}

\author{
doi:10.4136/ambi-agua.1759
}

Received: 18 Sep. 2015; Accepted: 29 Mar. 2016

\section{Oscar Orlando Ortiz Rodriguez ${ }^{1^{*}}$; Raquel Amanda Villamizar-Gallardo ${ }^{2}$; Rafael Guillermo García ${ }^{3}$}

\author{
${ }^{1}$ Universidad de Pamplona, Facultad de Ingenierías y Arquitectura, \\ Pamplona, Norte de Santander, Colombia \\ Departamento de Ingeniería Industrial \\ ${ }^{2}$ Universidad de Pamplona, Facultad de Ciencias Básicas, \\ Pamplona, Norte de Santander, Colombia \\ Departamento de Microbiología \\ ${ }^{3}$ Universitaria Agustiniana (Uniagustiniana), Bogotá, D.C, Colombia \\ Departamento de Vicerectoría de investigaciones \\ *Corresponding author: e-mail: oscarortiz@unipamplona.edu.co, \\ raquel.villamizar@gmail.com,rafael.garcia@uniagustiniana.edu.co
}

\begin{abstract}
There is currently great concern about the processes that directly or indirectly contribute to the potential for global warming, such as stratospheric ozone depletion or acidification. In this context, and provided that treated water is a basic public utility in urban centers around the world as well as in some rural areas, its impact on the environment is of great interest. Therefore, this study applied the environmental methodology of Life Cycle Assessment (LCA) to evaluate the environmental loads of four potable water treatment plants (PWTPs) located in northeastern Colombia following the international guidelines delineated in ISO 14040. The different stages of the drinking water process were thoroughly assessed, from the catchment point through pumping to the distribution network. The functional unit was defined as $1 \mathrm{~m}^{3}$ of drinking water produced at the plant. The data were analyzed through the database Ecoinvent v.3.01, and modeled and processed in the software LCA-Data Manager. The results showed that in plants PLA-CA and PLA-PO, the flocculation process has the highest environmental load, which is mostly attributable to the coagulant agent, with a range between $47-73 \%$ of the total impact. In plants PLA-TON and PLA-BOS, electricity consumption was identified as the greatest impact source, with percentages ranging from 67 to $85 \%$. Treatment processes and techniques, bioclimatic conditions and culturally driven consumption behavior varied from region to region. Furthermore, changes in treatment processes and techniques are likely to affect the environment during all stages of a plant's operational cycle.
\end{abstract}

Keywords: climate change, environmental impact, treated water. 


\section{Avaliação do ciclo de vida de quatro estações de tratamento de água potável localizado no nordeste da Colômbia}

\section{RESUMO}

Atualmente, existe uma grande preocupação com os processos que direta ou indiretamente contribuem para as alterações climáticas, destruição da camada de ozônio ou acidificação, entre outros impactos ambientais. Neste contexto, e desde que a água tratada constitui um serviço público básico em centros urbanos de todo o mundo e em algumas áreas rurais, o impacto de suas emissões no meio ambiente tem sido considerado de grande interesse. Assim, na pesquisa atual foi aplicada a metodologia ambiental de avaliação do ciclo da vida (LCA) para avaliar os impactos ambientais de quatro estações de tratamento de água potável (PWTPs), localizadas no nordeste da Colômbia seguindo diretrizes internacionais da ISO 14040. As diferentes etapas do processo de purificação a partir do ponto de captação por meio de bombeamento para a rede de distribuição foram completamente avaliadas. A unidade funcional foi definida como $1 \mathrm{~m}^{3}$ de água potável produzida na fábrica. Os dados foram analisados com base no banco de dados Ecoinvent v.3.01 e processados no software LCAData Manager. Os resultados possibilitaram determinar que em plantas PLA-CA e PLA POR, o processo de floculação tem a maior carga ambiental, o que é principalmente atribuível ao agente coagulante, com uma percentagem entre 47 e $73 \%$ do impacto total. Em plantas PLA-TON e PLA-BOS, o consumo de energia eléctrica foi identificado como sendo a maior fonte de impacto, com percentagens que variam de 67 a $85 \%$. Os processos e técnicas de tratamento, condições bioclimáticas e comportamento de consumo culturalmente impulsionado variam de região para região. Além disso, mudanças nos processos e técnicas de tratamento podem afetar o meio ambiente durante todos os estágios do ciclo de operação de uma planta.

Palavras-chave: água tratada, impacto ambiental, mudança climática.

\section{INTRODUCTION}

Beyond 2015, in order to fulfill the $7^{\text {th }}$ objective of the Millennium Development Goals (MDGs) it will be necessary to both incorporate sustainable development principles into national policies and programs and to reduce the loss of environmental resources (United Nations, 2012).

For this purpose, it has been estimated that Colombia needs to invest approximately 4 billion dollars in order to improve unsatisfied basic needs in guaranteeing good drinking water service, which is vital to public health and human life (UNICEF, 2006). The same study revealed that, of 1027 Columbian municipalities, 70\% had Potable Water Treatment Plants (PWTPs) in urban areas and $20 \%$ in rural areas.

These PWTPs are typically supplied by surface waters (mainly rivers) and utilize gravity, pumping and/or mixed systems to move the water from the catchment point, where the first stage of the drinking water process occurs. Subsequently, a series of conventional methods are applied, consisting of a more or less standardized sequence of physicochemical and, sometimes, biological treatment processes which vary depending on the quality of the water that enters the plant (Stackelberg et al., 2007). These processes require energy and chemical supplies in order to guarantee an adequate product for human consumption (Friedrich 2002).

However, excessive power consumption or use of chemical agents such as coagulants, flocculants, $\mathrm{pH}$ stabilizers and disinfectants not only impact consumer health, but generate environmental loads as well (Khan et al., 2013; Mery et al., 2013; Ribera et al., 2014). This has generated significant social and industrial interest in developing new strategies aimed at 
improving environmental indicators throughout the entire water management life cycle (Vince et al., 2008; Amores et al., 2013), and at obtaining cleaner and more sustainable processes in order to provide a better quality of life for the consumer of the final product (El-Sayed Mohamed et al., 2010).

Environmental methodologies such as Life Cycle Assessment (LCA), which follows ISO 14040 guidelines (ISO, 2006), allow assessing the environmental loads generated by a process and/or product during its life cycle, with the aim of reducing environmental loads, thereby improving sustainability indicators.

The scientific literature on water science and technology includes important international studies which have applied LCA during the last five years. These studies have increasingly gained more attention as they have been applied to the processes of potable water treatment plants in developed and developing countries (Kulay et al., 2015; Ahmadi and Tiruta-Barna 2015; Bonton et. al., 2012; Hyunju et al., 2015; Igos et al., 2013; Meneses et al., 2010; Pasqualino et al., 2011; Ribera et al., 2014).

During this decade in Latin America, countries such as Argentina, Brazil, Colombia and Mexico have been making progress in the application and capacity building of LCA in different economic sectors. Although this application has included both private companies and governments, it must still develop specifically targeted programs as well as financial support and technical assistance, in order that it may become a fundamental policy and, as such, the cornerstone of any industrial process (Güereca et al., 2015; Swarr et al., 2015).

The current research therefore constitutes one of the first applications of LCA to PWTPs in Colombia. As such, it represents a significant contribution to the domain of water science and technology in fostering the use of LCA in developing countries, using a combination of promotion among both natural science and engineering experts. In this context, the main objective of the present research was to apply LCA to four PWTPs located in northeastern Colombia and, based upon the results, propose strategies that allow mitigating the environmental impact of the potable water processes currently used in these PWTPs.

\section{METHODOLOGY}

The LCA methodology consists of four stages (Ortiz-R et al., 2014):

\subsection{Objective definition and scope}

This stage defines the limits of the system and the level of detail of the study. The four studied PWTPs are located in northeastern Colombia and deliver potable water to approximately 4 million inhabitants. These plants were selected from the municipal development plans. They are located in different cities and each one draws water from different catchment points. Due to confidentiality concerns, the PWTPs are labeled hereafter as plant PLA-CA, PLA-POR, PLA-TON and PLA-BOS, respectively. Each plant was analyzed in terms of the different stages of the drinking water process, (e.g. catchment point, de-sanding, coagulation, flocculation, sedimentation, filtration, disinfection, storage before the distribution network). A general scheme of the four PWTPs is shown in Figure 1.

For example, PLA-CA (i) has a pretreatment process meanwhile PLA-POR (ii), PLA-TON (iii) and PLA-BOS (iv) complete the flocculation process by using hydraulic and mechanical systems. For all cases, the water source was surface water with levels of turbidity equal to 6.58 NTU (Nephelometric Turbidity Unit), Dissolved Oxygen (DO) $4.8 \mathrm{mg} \mathrm{L}^{-1}$, pH 7.67, BOD $52.38 \mathrm{mg} \mathrm{L}^{-1}$, COD 4,34 $\mathrm{mg} \mathrm{L}^{-1}$, uncountable bacteriological pollution. All values were considered according to the Colombian national standard (Colombia, 2000).

In this context, the data collected were quantitatively related to one quantitative output of the product. In this research, the functional unit is defined as " $1 \mathrm{~m}^{3}$ of drinking water 
produced at the plant".

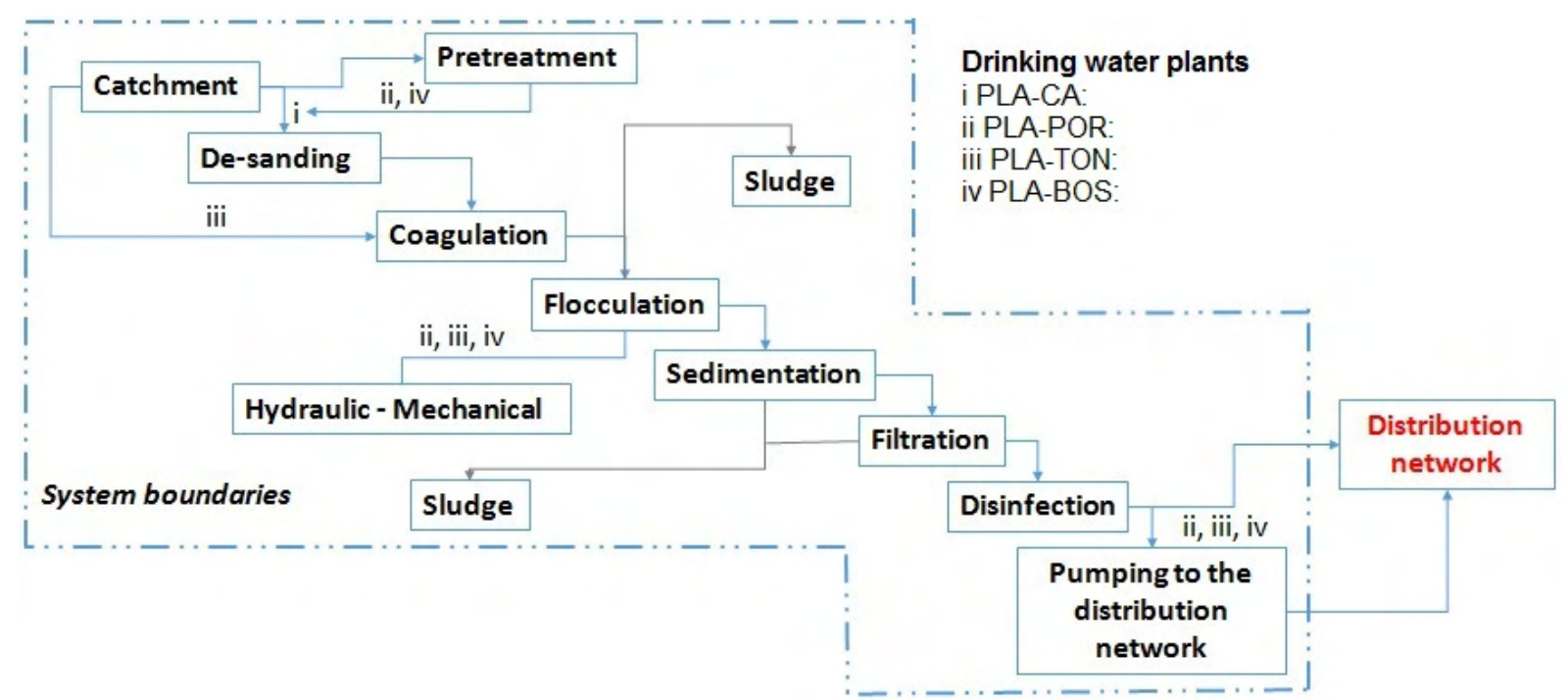

Figure 1. System boundaries of the process at the PWTPs studied.

The following assumptions were considered:

- Electric power generation corresponds to an energetic mix of $78 \%$ hydro-electrical plants, $7 \%$ carbon, $12 \%$ gas and 3\% other sources, adapted from Ortiz-R and García-Cáceres (2013).

- Environmental loads due to the maintenance of the sedimentation zone have been calculated using sodium hypochlorite and tap water.

- The infrastructure was assumed to last 50 years.

Transportation of coagulants and other reagents was not considered. It was assumed that these raw materials are disposed of at the plant. Also, the distribution network has not been included in this research. The transportation and distribution phases will be included and discussed in future studies.

\subsection{Inventory analysis}

This stage developed an inventory of inputs and outputs of the water treatment system based not only on information regarding power consumption and chemical supplies required in the drinking water process, but on the equivalent contaminating factor as well. Both primary and secondary information sources were employed for this inventory.

The primary source corresponded to data provided by the technical personnel of the studied plants, who collected information about the plants' processes during an operational period of twelve (12) months, from January to December of 2014. The secondary source corresponded to the database Ecoinvent v3.01(Ecoinvent, 2013), which was intended to provide background generic data about the products and processes employed in the PWTPs. Table 1 shows the inventory of chemical supplies and energy flow at each of the studied plants.

\subsection{Impact assessment}

This stage provided the environmental indicators which supported the assessment of the Life Cycle Inventory (LCI) results. The CML 2001 method was chosen in the present research because it provides operational guidelines for conducting an LCA study step by step according to the ISO standards according to Guinée (2002). This method is a midpoint approach which covers all emissions and resource-related impacts (e.g. carbon dioxide, 
methane, $\mathrm{N}_{2} \mathrm{O}$ and other greenhouse gas emissions were aggregated into $\mathrm{CO}_{2}$ equivalent emissions in accordance with their respective global warming potential).

Table 1. Inventory of the four PWTPs expressed in the functional unit (FU) " $1 \mathrm{~m}^{3}$ of drinking water produced at the plant.

\begin{tabular}{|c|c|c|c|c|c|}
\hline & & Plant 1 & Plant 2 & Plant 3 & Plant 4 \\
\hline Process & Input & \multicolumn{4}{|c|}{ Amount per FU } \\
\hline $\begin{array}{l}\text { Disinfection with } \\
\text { Chlorine }\end{array}$ & $\begin{array}{l}\text { Chlorine gas } \\
\left(\mathrm{kg} \mathrm{m}^{-3}\right)\end{array}$ & $1.64 \mathrm{E}-03$ & $1.84 \mathrm{E}-03$ & $1.41 \mathrm{E}-03$ & $2.61 \mathrm{E}-03$ \\
\hline \multirow{3}{*}{ Coagulation } & $\begin{array}{l}\text { Clarifloc (Coagulant: } \\
\mathrm{kg} \mathrm{m}^{-3} \text { ) }\end{array}$ & $1.65 \mathrm{E}-02$ & - & - & - \\
\hline & $\begin{array}{l}\text { Aluminum sulfate } \\
\left(\mathrm{kg} \mathrm{m}^{-3}\right)\end{array}$ & - & - & - & 4.45E-02 \\
\hline & $\begin{array}{l}\text { Coagulant AK } 23 \\
\left(\mathrm{~kg} \mathrm{~m}^{-3}\right)\end{array}$ & - & $6.83 \mathrm{E}-03$ & 4.09E-03 & - \\
\hline $\begin{array}{l}\text { Coagulation } \\
\text { Flocculation }\end{array}$ & $\begin{array}{l}\text { Super Floc (Polymer: } \\
\mathrm{kg} \mathrm{m}^{-3} \text { ) }\end{array}$ & - & $9.00 \mathrm{E}-05$ & $9.80 \mathrm{E}-05$ & $1.79 \mathrm{E}-04$ \\
\hline $\begin{array}{l}\mathrm{pH} \text { Stabilization and } \\
\text { Pretreatment }\end{array}$ & $\begin{array}{l}\text { Hydrated lime } \\
\left(\mathrm{kg} \mathrm{m}^{-3}\right)\end{array}$ & & - & - & $8.49 \mathrm{E}-05$ \\
\hline $\begin{array}{l}\text { Flocculation and } \\
\text { distribution network }\end{array}$ & $\begin{array}{l}\text { Mechanical } \\
\text { Flocculators and drive } \\
\left.\text { pumps_(kWh m }{ }^{-3}\right)\end{array}$ & - & $1.37 \mathrm{E}-02$ & $6.20 \mathrm{E}-01$ & $1.31 \mathrm{E}+00$ \\
\hline $\begin{array}{l}\text { Maintenance in the } \\
\text { filtration }\end{array}$ & $\begin{array}{l}\text { Energy Consumption } \\
\left(\mathrm{kWh} \mathrm{m}^{-3}\right)\end{array}$ & $2.57 \mathrm{E}-03$ & - & - & - \\
\hline
\end{tabular}

In the present research, Global Warming Potential (GWP) $\left(\mathrm{kg} \mathrm{CO}_{2}-\mathrm{Eq}\right)$ was chosen as the main environmental impact because of its worldwide effect, which makes it the greatest environmental challenge presently facing the sustainable water management of the world (Russo et al., 2014). Some other environmental impacts corresponded to acidification (kg $\mathrm{SO}_{2}$-Eq), and stratospheric ozone depletion (SOD/kgCFC-11-Eq). Finally, the software LCAData Manager ${ }^{\circledR}$ (an environmental management tool developed by SIMPPLE S.L.) was used to create and modify the scenarios under study as well as to develop the material balances and the inventory (SIMPPLE SL, 2013).

\subsection{Interpretation of results}

The last stage is the interpretation of the results, not only in terms of environmental load assessment, but also through the generation of alternative proposals for mitigating the environmental impacts associated with the process (Ortiz-R et al., 2010).

\section{RESULTS AND DISCUSSION}

Table 2 presents the overall results obtained by applying the environmental impact indicators to the four studied plants. The results show a similar order of magnitude to those reported by Amores et al., (2013) and Ribera et al. (2014) in terms of the application of aluminum sulfate and chlorine gas to the drinking water process. It can also be observed that PLA-BOS has the highest impact of all of the environmental impacts studied. With respect to GWP, this plant emitted indirect emissions of $3.83 \mathrm{E}-01 \mathrm{~kg} \mathrm{CO}_{2}-\mathrm{Eq}$, of which $86 \%$ corresponded to extended power consumption during the pumping process, mainly due to the topographic conditions of the plant's location. This was also the case for the elevated water 
volumes forced by the use of the chemical agents required for the flocculation and disinfection processes. Contrastingly, the plant that emitted the least emissions was PLA-TON, with $1.39 \mathrm{E}-02 \mathrm{~kg} \mathrm{CO}$-Eq, resulting from low energy consumption and from the particular nature of the treated hydric source. In effect, water in this case only needs to travel a short distance from its source to the catchment point, thus accounting for the low potable water chemical agent requirements of this plant.

Table 2. Results of the environmental impact assessments of the four potable water treatment plants.

\begin{tabular}{lcccc}
\hline \multicolumn{1}{c}{ Environmental Indicator } & PLA-CA & PLA-TON & PLA-POR & PLA-BOS \\
\hline Abiotic resource depletion (kg Antimony eq) & $1.39 \mathrm{E}-04$ & $8.06 \mathrm{E}-05$ & $6.11 \mathrm{E}-04$ & $1.46 \mathrm{E}-03$ \\
Acidification potential $\left(\mathrm{kg} \mathrm{SO}_{2}\right.$ eq) & $2.28 \mathrm{E}-04$ & $1.12 \mathrm{E}-04$ & $5.90 \mathrm{E}-04$ & $1.48 \mathrm{E}-03$ \\
Eutrophication $\left(\mathrm{kg} \mathrm{PO}_{4} \mathrm{eq}\right)$ & $5.03 \mathrm{E}-05$ & $3.16 \mathrm{E}-05$ & $1.93 \mathrm{E}-04$ & $5.05 \mathrm{E}-04$ \\
Global warming potential $\left(\mathrm{kg} \mathrm{CO}_{2}\right.$ eq) & $2.21 \mathrm{E}-02$ & $1.39 \mathrm{E}-02$ & $1.73 \mathrm{E}-01$ & $3.83 \mathrm{E}-01$ \\
Stratospheric ozone depletion $(\mathrm{kg} \mathrm{CFC}-11 \mathrm{eq})$ & $4.14 \mathrm{E}-09$ & $3.22 \mathrm{E}-09$ & $9.56 \mathrm{E}-09$ & $2.23 \mathrm{E}-08$ \\
Human Toxicity $(\mathrm{kg} 1,4-\mathrm{DCB}$ eq) & $8.04 \mathrm{E}-03$ & $4.72 \mathrm{E}-03$ & $4.31 \mathrm{E}-02$ & $9.81 \mathrm{E}-02$ \\
\hline
\end{tabular}

Previous results show that in PLA-CA and PLA-TON the highest impact was due to the use of the coagulant agent, respectively accounting for $82 \%$ and $46 \%$ of the total impact of each of these plants. The second greatest impact in these plants was caused by chlorine gas, which is employed in the disinfection process, with total emission percentages of $13 \%$ and $21 \%$ for PLA-CA and PLA-POR, respectively. Energy consumption contributed 4\% in PLA$\mathrm{CA}$, resulting from processes like pumping, flocculation and filter re-washing (locally named retrolavado). In PLA-POR, power consumption accounted for $30 \%$ of total emissions, while $3 \%$ was attributed to a polymer employed as coagulation coadjutant. Regarding PLA-TON, the greatest impact was due to energy consumption, since the plant uses a water suction supply system. This was also the case with PLA-BOS, where the use of monitoring systems, flocculation, engines (moto-redactors), compressors for the pneumatic gates system, and electric drive pumps was found to emit 2.83E-01 $\mathrm{kg} \mathrm{CO}_{2}$ eq., all of which makes up $92 \%$ of the total emissions relating to GWP. Such an elevated percentage results from the need to move large volumes of water and the unfavorable location of the plant with respect to the population it services. The emissions of both PLA-TON and PLA-BOS are less intense due to the application of coagulant substances such as AK23 and aluminum sulfate, which respectively accounted for $1 \%$ and $7 \%$ of total emissions (Figure 2).

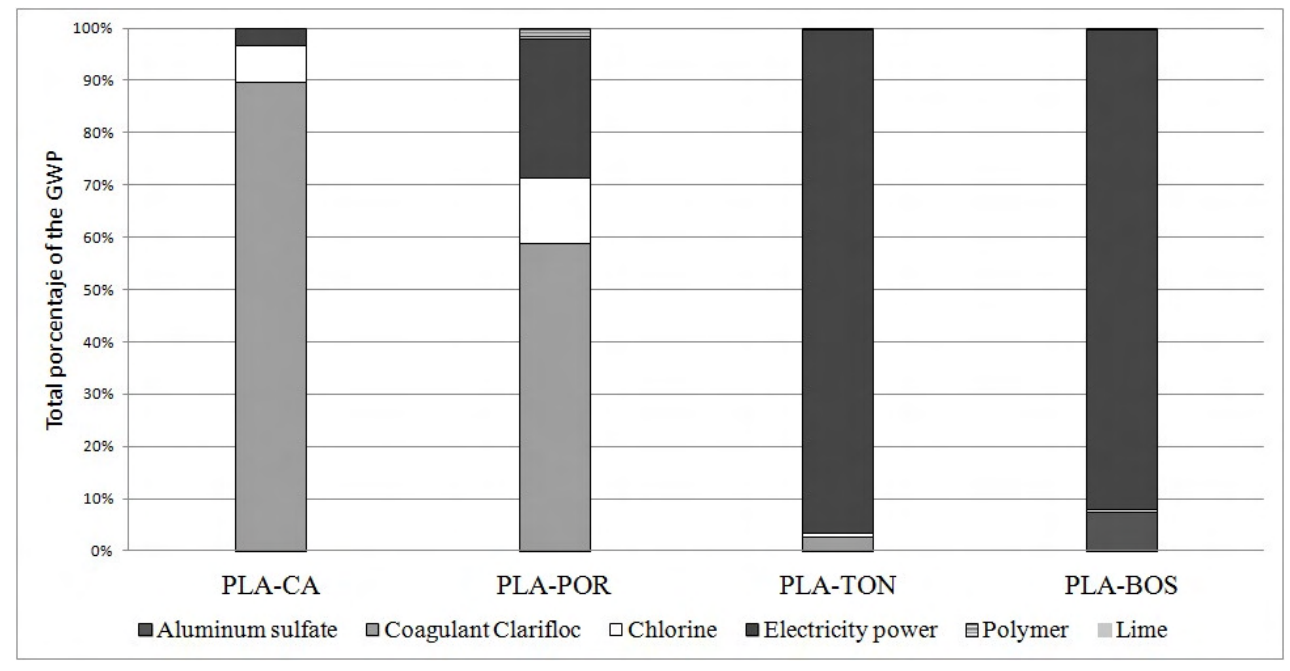

Figure 2. Percentages affecting Global Warming based on $1 \mathrm{~m}^{3}$ of drinking water produced at the plant. 
Regarding the environmental impact of GWP, $\mathrm{CO}_{2}$ emissions resulting from fossil fuel combustion cause the greatest impact on the atmosphere. Ethane (HFC) accounted for 3 to $18 \%$ of total GEGs (Greenhouse Effect Gases) (Figure 3).

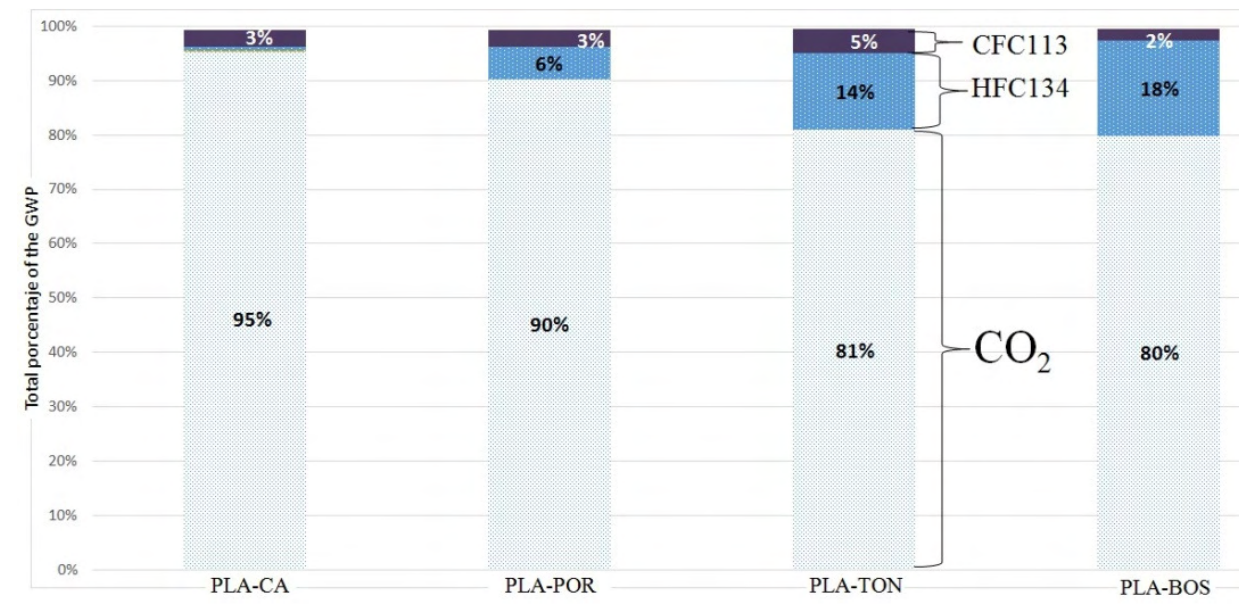

Figure 3. Total of GEG percentages based on $1 \mathrm{~m}^{3}$ of drinking water produced at the plant.

The compared effects of the studied plants across environmental impacts shows a basic trend, according to which PLA-BOS has the greatest impact, followed by PLA-CA and PLATON, while the smallest impact corresponds to PLA-POR. However, in the case of ozone layer depletion, the latter three plants exhibit close values.

The largest environmental impact due to contaminant additives corresponded to the use of chlorine gas in PLA-CA and PLA-POR, with $79 \%$ and $89 \%$ of the overall impact, respectively. The second largest impact was caused by the coagulant agent Clarifloc, which was applied in PLA-CA and accounted for $21 \%$ of the overall impact, and by the coagulant agent AK23, used in PLA-POR, where it generated 9\% of said impact.

In PLA-CA, the largest impact was caused by Clarifloc (82\%), followed by chlorine gas $(13 \%)$ and energy consumption (4\%). In PLA-POR, the largest impact corresponded to AK23 $(46 \%)$, followed by electricity consumption $(30 \%)$, chlorine gas $(21 \%)$ and polymer addition (3\%). Contrastingly, the most outstanding impact in PLA-BOS was electricity consumption, with $92 \%$, followed by aluminum sulfate $(7 \%)$ and chorine gas $(0.18 \%)$. Finally, energy consumption also dominated in PLA-TON, with 74\%, contrasting with the low counts registered by the other environmental impacts.

These indicators reveal that there are processes and energy flows in each of these plants that have indirectly adverse environmental effects. For this reason, the companies involved in the sustainability of the drinking water service should ideally reduce these environmental loads during the entire process.

For example, the use of Clarifloc can be reduced by applying coadjutants or other coagulant agents. Also, the preservation of the hydric source that supplies the treatment plant is an important factor, since its deterioration contaminates the water that is to be treated. This contamination involves color, turbidity and suspended material, all of which directly affect the amounts of coagulant that are needed to purify the water. The best scenario might be reached by analyzing the viability of a pretreatment process intended to improve the physicochemical characteristics of the water that enters the plant, thus reducing the need for coagulant.

As to the application of chlorine gas, there are alternatives such as inverse osmosis (Vingerhoeds et al., 2016), nanofiltration (Shon et al., 2013), UV disinfection, per acetic acid and advanced oxidative processes such as the PAA/UV (De Souza et al., 2015) which 
eliminate all pathogens. This is likely to reduce the application of chlorine to the residual dose stipulated by the corresponding Colombian normative system through Resolution 2115 of 2007. Yet this alternative also has disadvantages, since it requires higher investments and power consumption during the process of membrane filtration (Villamizar et al., 2015).

In those PWTPs producing unfavorable impacts due to the use of the coagulant agent, environmental loads can be reduced by $5-20 \%$ by analyzing the necessary dose. For example, pilot tests can be conducted to assess the efficiency of the coagulant as compared to that of other substances with weaker environmental impact. It is also possible to reduce the use of coagulant by introducing flocculation coadjutants with better performance than the polymers currently employed. The effect of increasing the polymer dose in order to reduce the necessary amount of coagulant may also be studied.

Finally, regarding elevated power consumption due either to water transport over long distances (from the catchment point to the plant, from the plant to the distribution network, or from any point to altitudes above $200 \mathrm{~m}$ from where the plant is located) or processes such as flocculation, more efficient energy alternatives must be considered.

\section{CONCLUSIONS}

In this study, we applied LCA to four PWTPs located in northeastern Colombia. In conclusion, it can be said that the use of Clarifloc can be reduced by applying coadjutants or other coagulant agents. Also, the preservation of the hydric source that supplies the treatment plant is an important factor, since its deterioration contaminates the water that is to be treated. Treatment processes and techniques, bioclimatic conditions and culturally driven consumption behavior vary from region to region. Furthermore, changes in treatment processes and techniques are likely to affect the environment during all stages of a plant's operational cycle. Therefore, any improvement is generally oriented to raw materials and energy use, always keeping in mind that a treatment plant must be both environmentally and socio-economically feasible. The different types of treatment techniques vary substantially depending on the geographic location of the plant.

Climate, technological, cultural and socio-economical differences clearly define a plant's standards in any context and region. However, the function is always the same: providing good water quality for the people it serves. To a great extent, variations in results are due to the different conditions under which the process is conducted. One of the most important variables is the hydric source that supplies the plant, depending on the particular supply types and amounts may be used in the potable water process.

\section{ACKNOWLEDGMENTS}

To the Colombian Administrative Department of Science, Technology and Innovation COLCIENCIAS reference project \#112156934429. The first author would also like to thank the partial financial support from the internal open call 2015 of the Universidad de Pamplona.

\section{REFERENCES}

AHMADI, A.; TIRUTA-BARNA, L. A Process Modelling-Life Cycle Assessment MultiObjective Optimization tool for the eco-design of conventional treatment processes of potable water. Journal of Cleaner Production, v. 100, p. 116-125, 2015. http://dx.doi.org/10.1016/j.jclepro.2015.03.045 
AMORES, M. J.; MENESES, M.; PASQUALINO, J.; ANTÓN, A.; CASTELlS, F. Environmental assessment of urban water cycle on Mediterranean conditions by LCA approach. Journal of Cleaner Production, v. 43, p. 84-92, 2013. http://dx.doi.org/10.1016/j.jclepro.2012.12.033

BONTON, A.; BOUCHARD, C.; BARBEAU, B.; JEDRZEJAK, S. Comparative life cycle assessment of water treatment plants. Desalination, v. 284, p. 42-54. 2012. http://dx.doi.org/10.1016/j.desal.2011.08.035

COLOMBIA. Ministerio de Vivienda. Reglamento técnico del sector de agua potable y saneamiento básico: título $\mathrm{C}$ sistemas de potabilización. Bogotá, 2000. Available in: http://www.minvivienda.gov.co/Documents/ViceministerioAgua/Titulo\%20C\%20\%20Dic\%204\%202013.pdf. Access: mar. 2016.

DE SOUZA, J. B.; QUEIROZ, F.; JERANOSKI, R.; DE SOUSA, C.; SOARES G. Water and wastewater disinfection with peracetic acid and uv radiation and using advanced oxidative process PAA/UV. International Journal of Photoenergy, v. 2015, 2015. http://dx.doi.org/10.1155/2015/860845

ECOINVENT CENTRE. Ecoinvent Data v 3.01. St. Gallen: Swiss Centre for Life Cycle Inventories, 2013.

EL-SAYED MOHAMED, M.; VAN DER STEEN N. P.; ABU-ZEID, K.; VAIRAVAMOORTHY, K. Towards sustainability in urban water: a life cycle analysis of the urban water system of Alexandria City, Egypt. Journal of Cleaner Production, v. 18, n. 10-11, p. 1100-1106, 2010. http://dx.doi.org/10.1016/j.jclepro.2010.02.009

FRIEDRICH, E. Life-cycle assessment as an environmental management tool in the production of potable water. Water Science Technology, v. 46, n. 9, p. 29-36, 2012.

GUINÉE, J. B. E. Handbook on life cycle assessment: operational guide to the ISO Standards. Dordrecht: Kluwer Academic Publishers, 2002.

GÜERECA, L. P.; OCHOA, R.; GILBERT, H. E.; SUPPEN, N. Life cycle assessment in Mexico: overview of development and implementation. The International Journal of Life Cycle Assessment, v. 20, n. 3, p. 311-317, 2015. http://dx.doi.org/10.1007/s11367014-0844-9

HYUNJU, J.; ELIZABETH, M.; JOHN, C. C. Life cycle assessment of the City of Atlanta, Georgia's centralized water system. International Journal of Life Cycle Assessment, v. 20, n. 6, p. 880-891, 2015. http://dx.doi.org/10.1007/s11367-015-0874-y

IGOS, E.; BENETTO, E.; BAUDIN, I.; TIRUTA-BARNA, L.; MERY, Y.; ARBAULT, D. Cost-performance indicator for comparative environmental assessment of water treatment plants. Science of the Total Environment, v. 443, p. 367-374, 2013. http://dx.doi.org/10.1016/j.scitotenv.2012.11.010

INTERNATIONAL ORGANIZATION FOR STANDARDIZATION - ISO. ISO 14040: environmental management - life cycle assessment principles and framework. Geneva, 2006.

KHAN, S.; SHAHNAZ, M.; JEHAN, N.; REHMAN, S.; SHAH, M. T.; DIN, I. Drinking water quality and human health risk in Charsadda district, Pakistan. Journal of Cleaner Production, v. 60, p. 93-101, 2013. http://dx.doi.org/10.1016/j.jclepro.2012.02.016

KULAY, L. A.; VIÑAS, R. S.; HESPANHOL, I. Avaliação de desempenho ambiental de 
sistemas para fornecimento de água quente para uso doméstico. Revista Ambiente \& Água, v. 10, n. 2, p. 386-401, 2015. http://dx.doi.org/10.4136/ambi-agua.1364

MENESES, M.; PASQUALINO, J. C.; CASTELLS, F. Environmental assessment of urban wastewater reuse: Treatment alternatives and applications. Chemosphere, v. 81, n. 2, p. 266-272, 2010. http://dx.doi.org/10.1016/j.chemosphere.2010.05.053

MERY, Y.; TIRUTA-BARNA, L.; BENETTO, E.; BAUDIN I. An integrated "process modelling-life cycle assessment" tool for the assessment and design of water treatment processes. International Journal of Life Cycle Assessment, v. 18, n. 5, p. 1062-1070, 2013. http://dx.doi.org/10. 1007/s11367-012-0541-5

ORTIZ-R, O. O.; CASTELLS, F.; SONNEMANN, G. Sustainability assessment within the residential building sector: a practical life cycle method applied in a developed and a developing country. Saarbrücken: VDM Publishing, 2010.

ORTIZ-R, O. O.; GARCÍA-CÁCERES, R. G. Assessing sustainability within the construction industry by means of a composite indicator. Dyna, v. 80, n. 182, p. 15-24, 2013.

ORTIZ-R, O. O.; VILLAMIZAR, R.A.; RANGEL, J.M. Applying life cycle management of colombian cocoa production. Food Science and Technology, v. 34, n. 1, p. 62-68, 2014. http://dx.doi.org/10.1590/S0101-20612014005000006

PASQUALINO, J. C.; MENESES, M.; CASTELLS, F. Life cycle assessment of urban wastewater reclamation and reuse alternatives. Journal of Industrial Ecology, v. 15, n. 1, p. 49-63, 2011. http://dx.doi.org/10.1111/j.1530-9290.2010.00293.x

RIBERA, G.; CLARENS, F.; MARTÍNEZ-LLADÓ, X.; JUBANY, I.; MARTÍ, V.; ROVIRA, M. Life cycle and human health risk assessments as tools for decision making in the design and implementation of nanofiltration in drinking water treatment plants. Science of the Total Environment, v. 466-467, p. 377-386, 2014. http://dx.doi.org/10.1016/j.scitotenv.2013.06.085

RIBERA G.; CLARENS F.; MARTÍNEZ-LLADÓ X.; JUBANY I.; MARTÍ, V.; ROVIRA M. Life cycle and human health risk assessments as tools for decision making in the design and implementation of nanofiltration in drinking water treatment plants. Science $\begin{array}{llllll}\text { of the Total Environment, v. 466, p. 377-386, } 2014 . & \end{array}$ http://dx.doi.org/10.1016/j.scitotenv.2013.06.085

RUSSO, T.; ALFREDO, K.; FISHE, J. Sustainable water management in urban, agricultural, and natural systems. Water, v. 6, n. 12, p. 3934-3956, 2014. http://dx.doi.org/10.3390/w6123934

SHON, H. K.; PHUNTSHO, S.; CHAUDHARY D. S.; VIGNESWARAN, S.; CHO, J. Nanofiltration for water and wastewater treatment - a mini review. Drinking Water Engineering Science, v. 6, p. 47-53, 2013. http://dx.doi.org/10.5194/dwes-6-47-2013

STACKELBERG, P. E.; GIBS, J.; FURLONG, E. T.; MEYER, M. T.; ZAUGG, S. D.; LIPPINCOTT, R. L. Efficiency of conventional drinking-water-treatment processes in removal of pharmaceuticals and other organic compounds. Science of the Total $\begin{array}{llllll}\text { Environment, } & \text { v. } & 377, & \text { p. } & 255-272, & \end{array}$ http://dx.doi.org/10.1016/j.scitotenv.2007.01.095 
SWARR, T. E.; ASSELIN A. C.; MILÀ, I.; CANALS, L.; DATTA, A.; FISHER, A. et al. Building organizational capability for life cycle management. In: KLÖPFFER, W.; CURRAN, N. A. (Eds.). LCA compendium - the complete world of Life Cycle Assessment. Chapter 17. Cham: Springer, 2015. p. 239-256. http://dx.doi.org/10.1007/s11367-016-1041-9

UNITED NATIONS. Millennium development goals (Mdgs). New York, 2012.

UNITED NATIONS CHILDREN'S FUND - UNICEF. La infancia, el agua y el saneamiento básico en los planes de desarrollo departamentales y municipales: la planeación local, una oportunidad para que los niños, las niñas y los adolescentes del país tengan un medio ambiente adecuado para su desarrollo. Bogotá, 2006. 162 p.

VILLAMIZAR, R. A.; ORTÍZ, O. O.; AQUILES-DARGHAN, E. Quick and easy methodology to determine somatic coliphages as indicators of fecal contamination in a water treatment plant located in northeastern Colombia. Universidad y Salud, v. 17, n. 1, p. 57-68. 2015.

VINCE, F.; AOUSTIN, E.; BRÉANT, P.; MARECHAL, F. LCA tool for the environmental evaluation of potable water production. Desalination, v. 220, n. 1-3, p. 37-56, 2008. http://dx.doi.org/10.1016/j.desal.2007.01.021

VINGERHOEDS, M. H.; NIJENHUIS-DE VRIES, M. A.; RUEPERT, N.; VAN DER LAAN, H.; BREDIE, W.; KREMER, S. Sensory quality of drinking water produced by reverse osmosis membrane filtration followed by remineralisation. Water Research, v. 94, p. 42-51, 2016. http://dx.doi.org/10.1016/j.watres.2016.02.043. 


Ambiente \& Água - An Interdisciplinary Journal of Applied Science
ISSN 1980-993X - doi:10.4136/1980-993X
www.ambi-agua.net
E-mail: ambi.agua@gmail.com

\title{
El agua en las industrias alimenticias de Mendoza (Argentina): estimación de los requerimientos hídricos y la potencialidad de reúso agrícola
}

doi:10.4136/ambi-agua.1771

Received: 05 Oct. 2015; Accepted: 01 Feb. 2016

\author{
Alicia Elena Duek \\ Instituto Nacional del Agua (INA), Mendoza, Argentina \\ Centro de Economía, Legislación y Administración del Agua (CELA) \\ e-mail: aliciaduek@yahoo.com.ar
}

\section{RESUMEN}

El objetivo de este trabajo es estimar el volumen de agua utilizada por las industrias alimenticias de Mendoza, atendiendo a diferentes escenarios de eficiencia en la utilización del recurso hídrico. Complementariamente se estudia la potencialidad del aprovechamiento para riego de los efluentes generados por tales industrias. La metodología de trabajo se sustenta en información recolectada de entrevistas realizadas a informantes calificados de diversos organismos de Mendoza, como también a personal idóneo de diversos establecimientos industriales alimenticios, seleccionados mediante una muestra dirigida. Para la construcción de escenarios se recurre a diversas fuentes de información secundaria, tanto locales como internacionales. Se estima que las industrias alimenticias de Mendoza utilizan un volumen de $19,65 \mathrm{hm}^{3}$ de agua por año; un manejo eficiente del recurso hídrico permitiría reducir el consumo en un $64 \%$, es decir, a $7,11 \mathrm{hm}^{3}$. Actualmente, el $70 \%$ del agua total consumida corresponde a las industrias elaboradoras de conservas de frutas y hortalizas, el $16 \%$ a bodegas, el $8 \%$ a embotelladoras de agua mineral y el $6 \%$ restante abarca los consumos de las industrias olivícola, cervecera y de gaseosas. Asimismo, se calcula que las industrias alimenticias de Mendoza generan un volumen de efluente de $16,27 \mathrm{hm}^{3}$ anuales. Debido a la estacionalidad de estos efluentes, a las altas concentraciones de sodio y elevada conductividad eléctrica de alguno de ellos, el aprovechamiento de estas aguas para riego es posible, pero debe estar diseñado como un sistema de tratamiento en tierra, teniendo en cuenta estas variables y sus impactos en el ambiente.

Palabras claves: industrias alimenticias, Mendoza, reúso agrícola, usos del agua.

\section{A água nas indústrias de alimentos de Mendoza (Argentina): estimação dos requerimentos hídricos e a potencialidade de reúso na agricultura}

\section{RESUMO}

O objetivo deste trabalho é estimar o volume de água utilizado pela indústria de alimentos de Mendoza, de acordo com diferentes cenários de uso eficiente dos recursos hídricos. Além disso, é estudada a potencialidade da utilização para irrigação dos efluentes 
gerados por tais indústrias. A metodologia é baseada na informação recolhida a partir de entrevistas com informantes qualificados de diferentes entidades de Mendoza, bem como com pessoal idôneo de vários estabelecimentos industriais de alimentos, selecionados por meio de uma amostragem direcionada. Para a construção de cenários são utilizadas várias fontes secundárias, tanto locais como internacionais. Estima-se que as indústrias de alimentos de Mendoza utilizam um volume de água de $19,65 \mathrm{hm}^{3}$ por ano; uma gestão eficiente dos recursos hídricos permitiria reduzir o consumo em $64 \%$, ou seja, $7,11 \mathrm{hm}^{3}$. Atualmente, $70 \%$ da água consumida correspondem às indústrias de processamento de frutas e hortaliças em conserva, 16\% a adegas, $8 \%$ para engarrafamento de água mineral e o $6 \%$ restante abrange o consumo dos produtores de azeite, azeitonas em conserva, indústrias cervejeiras e de refrigerantes. Também se estima que as indústrias de alimentos de Mendoza geram um volume de efluentes de $16,27 \mathrm{hm}^{3}$ anuais. Devido à sazonalidade destes efluentes, às altas concentrações de sódio e à alta condutividade eléctrica de alguns deles, o aproveitamento destas águas para irrigação é possível, mas tem de passar por um sistema de tratamento em terra, considerando estas variáveis e seus impactos sobre o meio ambiente.

Palavras-chave: indústrias de alimentos, Mendoza, reúso agrícola, usos da água.

\title{
Water in the Mendoza, Argentina, food processing industry: water requirements and reuse potential of industrial effluents in agriculture
}

\begin{abstract}
This paper estimates the volume of water used by the Mendoza food processing industry considering different water efficiency scenarios. The potential for using food processing industry effluents for irrigation is also assessed. The methodology relies upon information collected from interviews with qualified informants from different organizations and foodprocessing plants in Mendoza selected from a targeted sample. Scenarios were developed using local and international secondary information sources. The results show that food-processing plants in Mendoza use $19.65 \mathrm{hm}^{3}$ of water per year; efficient water management practices would make it possible to reduce water use by $64 \%$, i.e., to $7.11 \mathrm{hm}^{3}$. At present, $70 \%$ of the water is used by the fruit and vegetable processing industry, $16 \%$ by wineries, $8 \%$ by mineral water bottling plants, and the remaining $6 \%$ by olive oil, beer and soft drink plants. The volume of effluents from the food processing plants in Mendoza has been estimated at $16.27 \mathrm{hm}^{3}$ per year. Despite the seasonal variations of these effluents, and the high sodium concentration and electrical conductivity of some of them, it is possible to use them for irrigation purposes. However, because of these variables and their environmental impact, land treatment is required.
\end{abstract}

Keywords: agricultural reuse, food processing industry, Mendoza, water uses.

\section{INTRODUCCIÓN}

Todo el conocimiento relacionado con los usos del agua actuales y futuros forma parte de la información clave para la toma de decisiones en cuanto a la asignación del agua y a su distribución geográfica. La demanda de agua de uso industrial es insumo en los modelos de decisión, los cuales permiten evaluar distintas políticas públicas aplicables a la gestión integrada de los recursos hídricos.

Algunos organismos de la Provincia de Mendoza vinculados a los recursos hídricos, vienen realizando estimaciones para el balance hídrico provincial, las que figuran en diversas publicaciones (Llop et al., 2013). 
Sin embargo, no se han llevado a cabo estimaciones del consumo de agua por parte del sector industrial en Mendoza a partir de una metodología objetiva y que tengan un nivel de precisión aceptable para los fines específicos de la gestión hídrica. Existen algunos estudios efectuados por el Centro de Economía, Legislación y Administración del Agua dependiente del Instituto Nacional del Agua, pero que han sido enfocados en la contaminación generada y no consideran el uso consuntivo. Dichos estudios han estimado volúmenes de efluentes industriales basándose en información de censos industriales y de coeficientes de vuelco (Zoia y Fasciolo, 1995).

Otaki et al. (2008) han propuesto metodologías para estimaciones globales del uso industrial del agua que se basan en efectuar análisis de regresión con diferentes variables: área urbana, número de empresas, número de empleados y tasas de envíos. La mejor correlación encontrada fue con la variable área urbana, con la cual se construyó un mapa global, ya que de tal variable es posible encontrar bases de datos georreferenciadas para todos los países. Otros estudios establecen primero los consumos de agua para determinados países a través de coeficientes y luego extrapolan los datos a nivel mundial, como una función de las luces nocturnas urbanas. Estos últimos modelos no presentan altas eficiencias pero arrojan estimaciones aceptables para países y regiones que no cuentan con coeficientes de consumo ni con datos de materia prima procesada y/o productos terminados (Vassolo y Döll, 2005). Por su parte, la Organización de las Naciones Unidas para la Alimentación y la Agricultura ha desarrollado modelos que permiten estimar el uso industrial del agua a partir de dos variables principales: la población y la energía eléctrica consumida por una determinada región, agregando luego los datos por continentes y calculando el consumo de agua global por parte del sector industrial (FAO, 2011).

Diversos autores han presentado coeficientes de consumo industrial de agua para diferentes ramas de actividad (Martín-Ortega et al., 2008). Específicamente para la industria alimenticia, Stave (2006) exhibió coeficientes de consumo de tales establecimientos de Noruega, en función de los volúmenes de facturación, o bien, del número de trabajadores. También se calcularon otros en función de la materia prima procesada y del producto terminado (NCDENR, 1998; Duek y Fasciolo, 2014a). Para industrias conserveras, se pueden hallar algunos coeficientes en relación a los volúmenes de agua volcada (Bonino y Rearte, 1974; De Tullio et al., 1984). Asimismo existen coeficientes de consumo para diferentes industrias de bebidas, tales como elaboradoras de gaseosas, embotelladoras de aguas minerales, cervecerías, productoras de bebidas destiladas y elaboradoras y fraccionadoras de vino. Concretamente en este último caso, hay buenas estimaciones de coeficientes de consumo como las propuestas por Storm (1997) y por Nazrala et al. (2003).

A partir de los coeficientes existentes de bibliografía local e internacional y de información primaria obtenida mediante entrevistas, algunas investigaciones precedentes han presentado estimaciones sobre consumos de agua en bodegas (Duek y Fasciolo, 2012) y para las industrias de elaboración de conserveras de tomate y de durazno (Duek y Fasciolo, 2014b); en ambos casos, valores para la Provincia de Mendoza y desagregados a nivel cuenca hidrogeológica de la provincia. Se considera que conocer la demanda de agua para uso industrial y su proyección en el mediano plazo requiere de estudios específicos con metodologías rigurosas.

Con respecto al volumen de agua proveniente del uso industrial que retorna al sistema - o sea al ciclo de aprovechamiento - si bien no existen coeficientes que ponderen la relación uso consuntivo con uso total, existen para la Provincia de Mendoza datos sobre el uso de efluentes industriales para riego, informados por el Departamento General de Irrigación. Sin embargo, no se ha cuantificado su volumen potencial como una fuente alternativa de agua para las diferentes cuencas. 


\section{MATERIAL Y MÉTODOS}

Se realizaron dos bloques de entrevistas; uno dirigido a informantes calificados y otro a personal idóneo de diversos establecimientos industriales alimenticios, los cuales fueron visitados.

Las entrevistas en profundidad efectuadas a informantes calificados de diversos organismos de la Provincia de Mendoza (universidades, centros de investigación y organismos de gestión relacionados a la temática), apuntaron a indagar sobre: el panorama industrial de Mendoza, las fuentes de información disponibles vinculadas a esta temática, la existencia de aforos de agua en las industrias de la provincia, el origen del agua utilizada por estas industrias, la eficiencia en relación al uso del agua por parte de este sector y las principales variables a partir de las cuales podría estimarse el volumen de agua utilizado por las industrias alimenticias de Mendoza.

Por su parte, para el segundo bloque de entrevistas destinadas a personal idóneo de los establecimientos industriales alimenticios, se planteó una muestra dirigida (no probabilística) por tamaño y por rama de actividad; se concertaron 19 entrevistas. Los objetivos de las mismas fueron: i) conocer los procesos productivos e identificar las etapas de éstos donde se producen los mayores usos y consumos; ii) recabar información que permita construir coeficientes insumo/producto (litros de agua consumida por producto terminado o bien, litros de agua consumida por materia prima procesada); iii) indagar sobre las actitudes empresariales con relación a la sustentabilidad ambiental de los procesos industriales; iv) identificar las etapas generadoras de efluentes en cada proceso productivo; v) analizar las principales características fisicoquímicas de los efluentes; vi) estimar los volúmenes de efluentes generados y vii) conocer los tipos de tratamientos efectuados y la disposición final en tierra de los mismos.

Los establecimientos visitados pertenecen a los siguientes rubros: bodegas, conserveras de frutas y hortalizas, cerveceras, embotelladoras de agua mineral, elaboradoras de bebidas gaseosas, elaboradoras de sidras y productores de aceite de oliva y aceitunas en conserva.

Las dificultades para concertar las entrevistas son propias del sector abordado. Éstas se deben a los temores de las empresas para brindar información, así como también a las dificultades para disponer del tiempo necesario para las mismas. La entrevista, si bien respeta el cuestionario base, es abierta por lo que permite la incorporación de otras variables no incluidas en el mismo y que surgen espontáneamente. No toda la información cuantitativa de estas variables pre seleccionadas es posible de obtener, pero se logran aproximaciones valiosas a los fines de la investigación.

Se obtienen coeficientes de consumo de agua por rama de actividad. Para conocer el uso actual del agua en las industrias alimenticias de Mendoza, a nivel de cuenca, se utiliza la información obtenida en las entrevistas y se aplica a datos estadísticos provenientes de diversas fuentes de información secundarias. En relación a la composición industrial de Mendoza: el Censo Industrial Provincial del 2003, luego corregido y actualizado en el año 2005 por el Instituto de Desarrollo Industrial, Tecnológico y de Servicios (IDITS) del Gobierno de Mendoza. Respecto al origen y uso industrial del agua en Mendoza, se utilizan: la base de datos de pozos de agua subterránea y la base de datos del Registro Único de Establecimientos (RUE), ambas del Departamento General de Irrigación (DGI) del Gobierno de Mendoza. Las fuentes de información utilizadas para obtener datos de producción o de materia prima procesada son el Instituto Nacional de Vitivinicultura (INV), el Instituto Nacional de Tecnología Agropecuaria (INTA), el Instituto de Desarrollo Rural (IDR) y el Registro Permanente del Uso de la Tierra (RUT) de la Dirección de Agricultura y Contingencias Climáticas (DACC). Estos dos últimos organismos dependientes del Gobierno de Mendoza. 
Los coeficientes obtenidos en las entrevistas permiten generar escenarios de consumo actual de agua por parte de las industrias alimenticias de Mendoza, para cada rama de actividad. También se emplean coeficientes internacionales, nacionales y locales para construir escenarios de consumo sostenible (NCDENR, 1998; Khdair, 2007; Vassolo y Döll, 2005; Storm, 1997; BIER, 2011). Estos últimos coeficientes se presentan en intervalos en la bibliografía citada y para la construcción de los escenarios sostenibles se adopta el límite inferior de cada uno de ellos (Tabla 1).

Tabla 1. Coeficientes de consumo de agua en industrias alimenticias. Por tipo de industria.

\begin{tabular}{lll}
\hline \multicolumn{1}{c}{ Tipo de industria } & $\begin{array}{c}\text { Coeficientes obtenidos de } \\
\text { entrevistas }\end{array}$ & $\begin{array}{c}\text { Coeficientes provenientes de } \\
\text { bibliografía }\end{array}$ \\
\hline Bodegas & $\begin{array}{l}3 \text { litros de agua por litros de } \\
\text { vino producido }\end{array}$ & $\begin{array}{l}1,5 \text { litros de agua por litros de } \\
\text { vino producido }\end{array}$ \\
Conserveras de hortalizas & $\begin{array}{l}25 \text { litros de agua por kilo de } \\
\text { materia prima procesada }\end{array}$ & $\begin{array}{l}5 \text { litros de agua por kilo de } \\
\text { materia prima procesada }\end{array}$ \\
Conserveras de frutas & $\begin{array}{l}18 \text { litros de agua por kilo de } \\
\text { materia prima procesada }\end{array}$ & $\begin{array}{l}5,3 \text { litros de agua por kilo de } \\
\text { materia prima procesada }\end{array}$ \\
Industria olivícola & $\begin{array}{l}2,7 \text { litros de agua por kilo de } \\
\text { aceituna procesada }\end{array}$ & $\begin{array}{l}0,25 \text { litros de agua por kilo de } \\
\text { aceituna procesada }\end{array}$ \\
Industria cervecera & $\begin{array}{l}4,15 \text { litros de agua por litro de } \\
\text { cerveza elaborada }\end{array}$ & $\begin{array}{l}3,4 \text { litros de agua por litro de } \\
\text { cerveza elaborada }\end{array}$ \\
$\begin{array}{l}\text { Embotelladoras de agua } \\
\text { mineral }\end{array}$ & $\begin{array}{l}1,73 \text { litros de agua por litro de } \\
\text { agua embotellada }\end{array}$ & $\begin{array}{l}1,22 \text { litros de agua por litro de } \\
\text { agua embotellada }\end{array}$ \\
Industria de gaseosas & $\begin{array}{l}2,5 \text { litros de agua por litro de } \\
\text { gaseosa producida }\end{array}$ & $\begin{array}{l}1,56 \text { litros de agua por litro de } \\
\text { gaseosa producida }\end{array}$ \\
\hline
\end{tabular}

Fuente: Elaboración propia sobre la base de datos de Khdair (2007), Vassolo y Döll (2005), Storm (1997), NCDENR (1998), BIER (2011) y de información recolectada en entrevistas.

Finalmente, para estimar la potencialidad del reúso agrícola vinculada a los efluentes generados por cada tipo de industria alimenticia, se recurrió a información recabada en el segundo bloque de entrevistas. Con dicha información resultó posible construir rangos de volumen de efluente generado en función del volumen total de agua utilizada. De este modo, se calcularon los volúmenes de efluentes provenientes de cada industria alimenticia de Mendoza y se analizó la potencialidad de reúso agrícola.

\section{RESULTADOS Y DISCUSIÓN}

El consumo actual de agua por parte de cada uno de los principales rubros de la industria alimenticia de Mendoza se estima tal como se explicitó en el apartado metodológico, es decir, los coeficientes de consumo obtenidos de las entrevistas son afectados por los volúmenes de producción o de materia prima procesada, provenientes de fuentes de información secundaria. La Tabla 2 sintetiza el consumo actual agregado por cuenca y por tipo de industria, como también el total provincial.

El consumo actual de agua por parte de las industrias alimenticias de Mendoza se estima en $19,65 \mathrm{hm}^{3}$ por año, de los cuales el $51 \%\left(9,94 \mathrm{hm}^{3}\right)$ se concentra en la cuenca de los ríos Mendoza y Tunuyán Inferior, el $33 \%\left(6,50 \mathrm{hm}^{3}\right)$ ocurre en la cuenca de los ríos Atuel y Diamante y el $16 \%\left(3,21 \mathrm{hm}^{3}\right)$ restante en la cuenca del río Tunuyán Superior. 
Tabla 2. Consumo actual de agua en industrias alimenticias de Mendoza según cuenca. Por tipo de industria. En $\mathrm{hm}^{3}$ año ${ }^{-1}$ y $\%$.

\begin{tabular}{|c|c|c|c|c|c|}
\hline \multirow{4}{*}{ Tipo de industria } & \multicolumn{5}{|c|}{ Consumo de agua } \\
\hline & \multirow{3}{*}{$\begin{array}{c}\text { Ríos Mendoza y } \\
\text { Tunuyán Inferior } \\
\mathrm{hm}^{3} \text { año }\end{array}$} & \multicolumn{2}{|l|}{ Cuenca } & \multirow{2}{*}{\multicolumn{2}{|c|}{ Total Mendoza }} \\
\hline & & \multirow{2}{*}{$\begin{array}{l}\begin{array}{l}\text { Río Tunuyán } \\
\text { Superior }\end{array} \\
\mathrm{hm}^{3} \text { año }^{-1}\end{array}$} & \multirow{2}{*}{$\begin{array}{c}\text { Río Diamante } \\
\text { y Atuel } \\
\mathrm{hm}^{3} \text { año }^{-1}\end{array}$} & & \\
\hline & & & & $\mathrm{hm}^{3}$ año $^{-1}$ & $\%$ \\
\hline Bodegas & 2,717 & 0,208 & 0,274 & 3,199 & 16,28 \\
\hline Conserveras de hortalizas & 2,408 & 1,025 & 0,293 & 3,725 & 18,95 \\
\hline Conserveras de frutas & 2,433 & 1,809 & 5,858 & 10,100 & 51,39 \\
\hline Industria olivícola & 0,129 & 0,000 & 0,078 & 0,207 & 1,05 \\
\hline Industria cervecera & 0,670 & 0,000 & 0,000 & 0,670 & 3,41 \\
\hline Embotelladoras de agua mineral & 1,400 & 0,168 & 0,000 & 1,567 & 7,97 \\
\hline Industria de gaseosas & 0,186 & 0,000 & 0,000 & 0,186 & 0,94 \\
\hline \multirow{2}{*}{$\begin{array}{c}\text { Total } \\
h^{\prime 3} \mathbf{a n ̃ o}^{-1}\end{array}$} & 9,942 & 3,209 & 6,503 & 19,654 & - \\
\hline & 51 & 16 & 33 & - & 100 \\
\hline
\end{tabular}

Fuente: Elaboración propia sobre la base de datos del RUT, del INTA, del IDR y de información recolectada en entrevistas.

Asimismo, en la Tabla 2, puede observarse que el 51,39\% del consumo de agua corresponde a las industrias elaboradoras de conservas de frutas, el 18,95\% a las elaboradoras de conservas de hortalizas, el 16,28\% a bodegas, el 7,97\% a embotelladoras de agua mineral y el 5,41\% restante incluye los consumos de las industrias olivícola, cervecera y de gaseosas.

Por su parte, el escenario de uso sostenible de recurso hídrico para cada una de las ramas de la industria alimenticia de Mendoza se resume en la Tabla 3. En este caso, el consumo total de agua alcanza los $7,11 \mathrm{hm}^{3}$ anuales, lo que implica que si se hiciera un uso racional del recurso hídrico, el consumo actual disminuiría un $64 \%$.

Tabla 3. Consumo sostenible de agua en industrias alimenticias de Mendoza según cuenca. Por tipo de industria. En hm${ }^{3}$ año $^{-1}$ y $\%$.

\begin{tabular}{|c|c|c|c|c|c|}
\hline \multirow{4}{*}{ Tipo de industria } & \multicolumn{5}{|c|}{ Consumo de agua } \\
\hline & \multicolumn{3}{|c|}{ Cuenca } & \multirow{2}{*}{\multicolumn{2}{|c|}{ Total Mendoza }} \\
\hline & \multirow{2}{*}{$\begin{array}{l}\text { Ríos Mendoza y } \\
\text { Tunuyán Inferior } \\
\mathrm{hm}^{3} \text { año }\end{array}$} & \multirow{2}{*}{$\begin{array}{c}\text { Río Tunuyán } \\
\text { Superior } \\
\mathrm{hm}^{3} \mathrm{añono}^{-1}\end{array}$} & \multirow{2}{*}{$\begin{array}{c}\text { Río Diamante } \\
\text { y Atuel } \\
\mathrm{hm}^{3} \mathrm{año}^{-1}\end{array}$} & & \\
\hline & & & & $\mathrm{hm}^{3}$ año ${ }^{-1}$ & $\%$ \\
\hline Bodegas & 1,358 & 0,104 & 0,137 & 1,599 & 22,50 \\
\hline Conserveras de hortalizas & 0,482 & 0,205 & 0,059 & 0,745 & 10,48 \\
\hline Conserveras de frutas & 0,717 & 0,533 & 1,725 & 2,974 & 41,84 \\
\hline Industria olivícola & 0,012 & 0,000 & 0,007 & 0,019 & 0,27 \\
\hline Industria cervecera & 0,549 & 0,000 & 0,000 & 0,549 & 7,72 \\
\hline Embotelladoras de agua mineral & 0,987 & 0,118 & 0,000 & 1,105 & 15,55 \\
\hline Industria de gaseosas & 0,116 & 0,000 & 0,000 & 0,116 & 1,63 \\
\hline \multirow{2}{*}{ Total } & 4,220 & 0,960 & 1,928 & 7,108 & - \\
\hline & 59,5 & 13,5 & 27 & - & 100 \\
\hline
\end{tabular}

Fuente: Elaboración propia sobre la base de datos del RUT, del INTA, del IDR y de información recolectada en entrevistas. 
Bajo este escenario, el $59,5 \%\left(4,22 \mathrm{hm}^{3}\right)$ del consumo se concentra en la cuenca de los ríos Mendoza y Tunuyán Inferior, el $27 \%\left(1,93 \mathrm{hm}^{3}\right)$ corresponde a la cuenca de los ríos Atuel y Diamante y el $13,5 \%$ restante $\left(0,96 \mathrm{hm}^{3}\right)$ a la cuenca del río Tunuyán Superior.

Los valores porcentuales de los consumos arrojados por el escenario de uso sostenible para cada una de las industrias alimenticias estudiadas pueden observarse en la última columna de la Tabla 3. El 41,84\% del volumen de agua estimado corresponde a las industrias conserveras de frutas, el $22,50 \%$ a bodegas, el $15,55 \%$ a los establecimientos embotelladores de agua mineral, el 10,48\% a las industrias conserveras de hortalizas y el 9,62\% restante agrupa a las industrias cerveceras, de gaseosas y olivícolas.

Al comparar los valores porcentuales de los consumos para el escenario de consumo actual y para el escenario de consumo sostenible, se observan diferencias significativas para un mismo tipo de industria. Por ejemplo, las industrias conserveras de frutas son responsables del $51 \%$ del consumo actual de agua en las industrias alimenticias de Mendoza; mientras que para el escenario sostenible se estima un consumo que representa el $42 \%$ del total. Resulta necesario fundamentar las causas de tales diferencias, de modo que se diseña un indicador denominado Indicador de Convergencia Relativa (ICR). Éste se calcula como indica la Ecuación 1.

$$
I C R=\frac{C A_{i-} C S_{i}}{C A_{i}}
$$

en que:

$C A_{i}$ : Consumo actual de agua, en $\mathrm{hm}^{3} \mathrm{año}^{-1}$.

$C S_{i}$ : Consumo sostenible de agua, en $\mathrm{hm}^{3} / \mathrm{añono}^{-1}$.

$i$ : Tipo de industria. "i" varía: (bodegas; conserveras de hortalizas; conserveras de frutas; industria olivícola; industria cervecera; embotelladoras de agua mineral; industria de gaseosas)

El ICR es un indicador que mide el esfuerzo relativo que cada tipo de industria debe realizar para alcanzar los valores de consumo estimados en los escenarios de uso sostenible del recurso hídrico. Cuando éste toma valor cero, el sector industrial se encuentra en una situación de óptima, es decir no debe realizar esfuerzo alguno. A medida que el indicador aumenta su valor, mayor es el esfuerzo que tendrá que efectuar el sector.

En la Tabla 4 se presentan los valores que toma el Indicador de Convergencia Relativa en Mendoza, para los sectores industriales analizados en la presente investigación.

Tabla 4. Indicador de Convergencia Relativa. Por tipo de industria. En Mendoza.

\begin{tabular}{lc}
\hline Tipo de industria & $\begin{array}{c}\text { Indicador de } \\
\text { Convergencia Relativa }\end{array}$ \\
\hline Bodegas & 0,500 \\
Conserveras de hortalizas & 0,800 \\
Conserveras de frutas & 0,706 \\
Industria olivícola & 0,907 \\
Industria cervecera & 0,181 \\
Embotelladoras de agua mineral & 0,295 \\
Industria de gaseosas & 0,376 \\
\hline
\end{tabular}

Fuente: Elaboración propia sobre información recolectada en entrevistas. 
Las industrias que presentan valores cercanos a cero deben realizar un esfuerzo relativo menor para que sus consumos de agua alcancen los valores óptimos estimados en los escenarios de uso sostenible del recurso hídrico. En la medida que el ICR de tales industrias aumenta, mayor será el esfuerzo requerido.

En este sentido, se concluye que las industrias olivícolas y las elaboradoras de conservas de frutas y hortalizas deberían realizar esfuerzos mayores si quisieran alcanzar consumos óptimos; mientras que el menor esfuerzo requerido corresponde a la industria cervecera. Las industrias de bebidas (de gaseosas, de agua mineral y bodegas) adoptan valores intermedios del ICR.

Por su parte, en la Tabla 5 se exhiben los rangos de las relaciones volumen volcado respecto del volumen consumido para cada tipo de industria de Mendoza. Los volúmenes de efluentes se estiman calculando los puntos medios de cada rango y aplicando éstos a los consumos actuales de agua para cada tipo de industria alimenticia de la provincia. En la Tabla 5 también se observa que el volumen total de efluente estimado es de $16,27 \mathrm{hm}^{3}$ por año.

Tabla 5. Efluente generado por las industrias alimenticias de Mendoza. Por tipo de industria. En $\mathrm{hm}^{3}$ año ${ }^{-1}$.

\begin{tabular}{lccc}
\hline Tipo de industria & $\begin{array}{c}\text { Consumo de } \\
\text { agua }\left(\mathrm{hm}^{3}\right)\end{array}$ & $\begin{array}{c}\text { Relación volumen } \\
\text { volcado / volumen } \\
\text { consumido - } \\
\text { (rango) }\end{array}$ & $\begin{array}{c}\text { Efluente }\left(\mathrm{hm}^{3}\right) \\
* /\end{array}$ \\
\hline Bodegas & 3,199 & $0,90-0,95$ & 2,96 \\
Conserveras de hortalizas & 3,725 & $0,90-0,95$ & 3,45 \\
Conserveras de frutas & 10,100 & $0,80-0,95$ & 8,84 \\
Industria olivícola & 0,207 & $0,80-0,95$ & 0,18 \\
Industria cervecera & 0,670 & $0,50-0,70$ & 0,40 \\
Embotelladoras de agua mineral & 1,567 & $0,20-0,30$ & 0,39 \\
Industria de gaseosas & 0,186 & $0,20-0,40$ & 0,06 \\
\hline Total & $\mathbf{1 9 , 6 5 4}$ & - & $\mathbf{1 6 , 2 7}$ \\
\hline
\end{tabular}

*/ Calculado con el punto medio de cada rango.

Fuente: Elaboración propia sobre información recolectada en entrevistas.

Cabe destacar que el $54,3 \%\left(8,84 \mathrm{hm}^{3}\right)$ de dicho efluente es generado por las industrias elaboradoras de conservas de frutas, el $21,2 \%\left(3,45 \mathrm{hm}^{3}\right)$ proviene de los establecimientos elaboradores de hortalizas, el 18,2\% $\left(2,96 \mathrm{hm}^{3}\right)$ corresponde al efluente de las bodegas y el $6,3 \%$ restante concentra a los efluentes de las industrias olivícolas, cerveceras, embotelladoras de agua mineral y elaboradoras de gaseosas.

Resulta importante resaltar que no podrá emplearse la totalidad de este volumen de efluente para reúso agrícola. Esto se debe a varias razones, por un lado, como ya se ha explicado, las industrias alimenticias bajo estudio presentan una alta estacionalidad. En zonas de climas templados como Mendoza, con cuatro estaciones bien definidas, la principal demanda de agua por parte de la mayoría de los cultivos que aportan a la industria alimenticia, ocurre en el período de inicio de primavera y durante el verano. No obstante, los efluentes que generan estas industrias están disponibles a fines del verano y durante el otoño. Respecto de este inconveniente, podría impulsarse la construcción de reservorios que permitan almacenar 
el efluente tratado o, alternativamente aprovechar el efluente para riego de jardines y árboles de hoja perenne o de hortalizas de otoño e invierno.

Por otra parte, los efluentes provenientes de los establecimientos industriales alimenticios de Mendoza en general presentan altas concentraciones de sodio debido al uso de la soda caustica en diferentes etapas de los procesos productivos, como así también valores moderados a altos de conductividad eléctrica. La legislación de Mendoza para reúso agrícola de efluentes industriales considera que los mismos deben cumplir con valores de

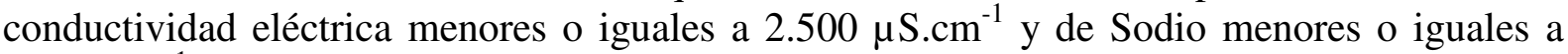
$500 \mathrm{mg} . \mathrm{L}^{-1}$ (Mendoza, 2003). Efluentes de industrias de aceitunas en conserva y de duraznos en almíbar sobrepasan los valores de sodio, debido al desamarizado con hidróxido de sodio, en caso de las aceitunas y al pelado químico, en el caso de las conservas de duraznos. En industrias de bebidas, con líneas de fraccionamiento para botellas de vidrio, la soda cáustica es utilizada para el lavado de los envases, razón por la cual también se producen residuos líquidos con altos contenidos de sodio.

Asimismo, las soluciones salinas o con concentraciones de sodio y/o cloruros que no cumplen con la normativa para riego con efluentes, pueden adecuarse a la misma mediante dilución con el resto de los efluentes o, mejor aún, mediante una gestión integrada de los residuos líquidos que abarque, entre otras, alternativas de tratamientos y disposición de lotes salinos. Además, cabe destacar que en Argentina la soda agotada debe tratarse como un residuo peligroso de acuerdo a la normativa del país (Rauek, 2015).

Por lo expuesto, una porción del volumen de efluente no puede ser utilizada para riego. Al presente no es posible determinar dicha porción, razón por la cual surge la necesidad de realizar nuevas entrevistas que profundicen en la temática del reúso agrícola.

Cabe enfatizar que cualquier uso de efluentes industriales para riego, debe encararse mediante un proyecto técnico (también llamado diseño del sistema) que contemple: el estudio de la calidad del agua del efluente para riego, el balance hídrico y el balance de nutrimentos, especialmente del Nitrógeno y del Fósforo; esto último para evitar que las formas solubles de estos elementos alcancen los acuíferos (WEF, 1990).

\section{CONCLUSIONES}

La industria alimenticia emplea el agua en diversas etapas del proceso: como elemento de transferencia de calor, como elemento de transporte, para el lavado de las materias primas, como componente del propio producto y para limpieza en general. Se estima que tales industrias de Mendoza utilizan un volumen de $19,65 \mathrm{hm}^{3}$ de agua por año.

Un manejo eficiente del agua por parte de las industrias alimenticias de Mendoza permitiría reducir el consumo de agua hasta valores de $7,11 \mathrm{hm}^{3}$ anuales, lo que implica una disminución del $64 \%$ del consumo actual estimado.

El mayor consumo de agua en las industrias alimenticias de Mendoza se produce en la cuenca de los ríos Mendoza y Tunuyán Inferior (51\%), seguido por el consumo correspondiente a la cuenca de los ríos Atuel y Diamante (33\%) y el menor en la cuenca del río Tunuyán Superior (16\%).

Actualmente, el $70 \%$ del agua total consumida corresponde a las industrias elaboradoras de conservas de frutas y hortalizas, el 16\% a bodegas, el $8 \%$ a embotelladoras de agua mineral y el $6 \%$ restante abarca los consumos de las industrias olivícola, cervecera y de gaseosas.

Se diseñó un indicador que mide el esfuerzo relativo que cada sector industrial debe realizar para alcanzar los valores de consumo estimados en los escenarios de uso sostenible del recurso hídrico. Dicho indicador permite concluir que las industrias olivícolas, de conservas de frutas y de hortalizas deberán realizar esfuerzos mayores si pretenden alcanzar consumos óptimos, mientras que la industria cervecera es la que requerirá el menor esfuerzo. 
En relación a las industrias vitivinícola, de gaseosas y de agua mineral, éstas se encuentran en situaciones intermedias.

Las industrias alimenticias de Mendoza presentan una alta estacionalidad en sus procesos productivos, esto se debe a la disponibilidad de frutas u hortalizas y, en el caso de las industrias de bebidas, al incremento de la demanda en los meses de primavera y verano. Consecuentemente sus efluentes también exhiben una fuerte estacionalidad. Estos se caracterizan por contener una gran cantidad de sólidos, tanto solubles como en suspensión, altos contenidos de materia orgánica y de nutrimentos y variable conductividad eléctrica. En la mayoría de los casos, los efluentes presentan altas concentraciones de sodio debido al uso de la soda cáustica en diferentes etapas de los procesos productivos. Asimismo, eventualmente se observa la presencia de mercurio y plomo, ocasionada por impurezas del hidróxido de sodio.

Se estima que las industrias olivícolas y las elaboradoras de conservas de frutas y hortalizas de Mendoza generan un volumen de efluente de $12,46 \mathrm{hm}^{3}$ anuales; mientras que el volumen correspondiente a las industrias de bebidas es de $3,81 \mathrm{hm}^{3}$ por año. Esto implica un volumen total de efluente de $16,27 \mathrm{hm}^{3}$, donde el $54,3 \%$ corresponde a las industrias elaboradoras de conservas de frutas, el $21,2 \%$ es generado por los establecimientos elaboradores de conservas de frutas, el 18,2\% proviene de las bodegas y el restante 6,3\% agrupa a los efluentes de las industrias olivícolas, cerveceras, embotelladoras de agua mineral y elaboradoras de gaseosas.

Por último, cabe destacar que el volumen de efluente estimado por las industrias alimenticias de Mendoza sólo podrá utilizarse parcialmente para reúso agrícola, debido a la estacionalidad de los mismos, a las altas concentraciones de sodio y elevada conductividad eléctrica. Se recomienda encarar el aprovechamiento de estos efluentes para riego mediante un diseño técnico del sistema de reúso.

\section{AGRADECIMIENTOS}

Quiero agradecer de manera muy especial a Graciela Fasciolo, quien desinteresadamente aceptó dirigir mi tesis de maestría resumida en este artículo. Asimismo manifiesto mi gratitud con cada uno de los directivos y demás personal entrevistado de los establecimientos industriales de la Provincia de Mendoza, por habernos abierto las puertas, por la buena predisposición y por los datos aportados.

\section{REFERENCIAS}

BEVERAGE INDUSTRY ENVIRONMENTAL ROUNDTABLE - BIER. Water use benchmarking in the beverage industry. Trends and observations, 2010. 2011. BIER Reports. Disponible en: http://bieroundtable.com/files/BIER\%20Benchmarking\% 20Publication\%202011.pdf. Acceso en: 20 Oct. 2014.

BONINO, A. F.; REARTE, A. E. Efluentes de la industria conservera. En: CONGRESO ARGENTINO DE SANEAMIENTO, 4., Mayo 1974, San Miguel de Tucumán, Argentina. Actas... San Miguel de Tucumán: OPS/OMS, 1974. p. 277-294.

DE TUllio, L. A.; MAGLIOTTO, R.; CITTA, C. A.; MONOPOLI, V. F. Los efluentes líquidos de la elaboración de la industria del tomate pelado. En: CONGRESO INTERAMERICANO DE INGENIERÍA SANITARIA Y AMBIENTAL, 19., Noviembre 1984, Santiago de Chile, Chile. Actas... Santiago de Chile: ABES, 1984. p. $5-48$. 
DUEK, A. E.; FASCIOLO, G. E. Uso de agua en las bodegas de Mendoza. Revista de la Facultad de Ciencias Agrarias, v. 46, n. 1, p. 59-72, 2012.

DUEK, A. E.; FASCIOLO, G. E. Uso industrial del agua en Mendoza, Argentina: coeficientes para la industria alimenticia. Revista Tecnología y Ciencias del Agua, v. 5 , n. 3, p. 51-62, 2014a.

DUEK, A. E.; FASCIOLO, G. E. Uso de agua en industrias de elaboración de conservas de tomate y de durazno de Mendoza, Argentina. Revista de la Facultad de Ciencias Agrarias, v. 44, n. 2, p. 263-268, 2014 b.

FOOD AND AGRICULTURE ORGANIZATION - FAO. Municipal and industrial water withdrawal modelling for the years 2000 and 2005 using statistical methods. 2011. AQUASTAT Reports. Disponible en: http://www.fao.org/nr/water/aquastat/ catalogues/Mun_Ind_Model_20110210.pdf. Acceso en: 10 marzo 2015.

KHDAIR, A. Cleaner Production (CP) in Olive Oil in Jordan. En: ARAB CLEANER PRODUCTION WORKSHOP, 2., Agosto 2007, Amman, Jordania. Proceedings... Amman: Royal Scientific Society, 2007. Disponible en: http://www.cp.org.jo/ docs/2nd\%20Arab\%20CP\%20workshop\%20materials/Lect\%2022\%20CP\%20in\%20O1 ive\%20Oil\%20Industry\%20in\%20Jordan.pdf. Acceso en: 11 Feb. 2015.

LLOP, A.; FASCIOLO, G. E.; DUEK, A. E.; COMELLAS, E.; BUCCHERI, M. El balance hídrico en las cuencas de Mendoza: aportes para su medición. Revista Proyección, v. 7, n. 14, p. 48-67, 2013.

MARTÍN-ORTEGA, J.; GUTIÉRREZ MARTÍN, C.; BERBEL VECINO, J. Caracterización de los usos del agua en la Demarcación del Guadalquivir en aplicación de la Directiva Marco de Aguas. Revista de Estudios Regionales, n. 81, p. 45-76, 2008.

MENDOZA (Provincia). Resolución $n^{\circ} 400$, de 04 de julio de 2003. Boletín Oficial de la Provincia de Mendoza, Poder Ejecutivo, Mendoza, 15 jul. 2003. p. 5888-5892.

NAZRALA, J.; VILA, H.; GARCÍA, R.; JAIT, R.; DESPOUS, G. Gestión de efluentes y consumo de agua en bodega. Revista de la Facultad de Ciencias Agrarias, v. 35, n. 1, p. 35-42, 2003.

NORTH CAROLINA. Department of Environment and Natural Resources - NCDENR. Water efficiency. Manual for commercial, industrial and institutional facilities. 1998. Disponible http://documents.northgeorgiawater.org/P2AD_WATER_EFFICIENCY_MANUAL.pd f. Acceso en: 20 Jun. 2015.

OTAKI, Y.; OTAKI, M.; YAMADA, T. Attempt to establish an industrial water consumption distribution model. Journal of Water and Environment Technology, v. 6, n. 2, p. 8591, 2008.

RAUEK, T. Gestión integrada para la disposición final de efluentes agroindustriales salinos. JORNADA DÍA MUNDIAL DEL AGUA: Agua y Desarrollo Sostenible, 2015, Mendoza. Actas... Mendoza: RIGA, FCE-UNCu, 2015. p. 1-7.

STAVE, S. E. Water consumption in food processing and service industries in Norway. Oslo: Statistics Norway, Division for Environmental Statistics, 2006. Disponible en: http://www.ssb.no/a/english/publikasjoner/pdf/doc_200612_en/doc_200612_en.pdf. Acceso en: 8 Jul. 2015. 
STORM, D. R. Winery utilities: planning, design and operation. New York: Chapman \& Hall, 1997. 438p.

VASSOLO, S.; DÖLL, P. Global-scale gridded estimates of thermoelectric power and manufacturing water use. Water Resources Research, v. 41, n. 4, p. 1-11, 2005.

WATER ENVIRONMENT FEDERATION - WEF. Sistemas naturales para el tratamiento de aguas residuales. 1. Edición. Alexandria, 1990. p. 75-80.

ZOIA, O.; FASCIOLO, G. Contaminación hídrica industrial en Mendoza. En: MARTÍNEZ CARRETERO, E.; DAlMASSO, A. (Eds.). Mendoza Ambiental. Mendoza: Ministerio de Medio Ambiente y Urbanismo y Vivienda, 1995. p. 99-105. 


Ambiente \& Água - An Interdisciplinary Journal of Applied Science
ISSN 1980-993X - doi:10.4136/1980-993X
www.ambi-agua.net
E-mail: ambi.agua@gmail.com

\title{
Regulação das águas doces superficiais e subterrâneas na integração regional do MERCOSUL
}

\author{
doi:10.4136/ambi-agua.1666 \\ Received: 20 May 2015; Accepted: 02 Feb. 2016 \\ Celso Maran de Oliveira ${ }^{1^{*}}$; Ozelito Possidônio de Amarante Junior²; \\ Celso Antonio Pacheco Fiorillo ${ }^{3}$; Pedro Luciano Colenci ${ }^{1}$ \\ ${ }^{1}$ Universidade Federal de São Carlos (UFSCar), São Carlos, SP, Brasil \\ Departamento de Ciências Ambientais \\ ${ }^{2}$ Instituto Federal do Maranhão (IFMA), São Luis, MA, Brasil \\ Departamento de Química \\ ${ }^{3}$ Centro Universitário das Faculdades Metropolitanas Unidas (FMU), São Paulo, SP, Brasil \\ Programa de Mestrado em Direito da Sociedade da Informação \\ *Autor correspondente: e-mail: celmaran@ufscar.br, \\ ozelito@ifma.edu.br, celsofiorillo@gmail.com, colencilu@yahoo.com.br
}

\section{RESUMO}

Este trabalho aborda a normatização existente entre os Países Partes do MERCOSUL, que formam o arcabouço jurídico e institucional para as diversas relações mercosulistas em relação aos recursos hídricos - um recurso importante e estratégico, que merece um tratamento normativo para sua preservação e proteção para futuras gerações. Diante da inexistência de uma normativa geral a respeito dos recursos hídricos no MERCOSUL, foi necessário trabalhar os principais acordos multilaterais nesse domínio e que envolvem os países do MERCOSUL, como o Tratado de Cooperação Amazônica e o Tratado da Bacia do Prata, em relação às águas superficiais; e também do arcabouço jurídico da Declaração Conjunta dos Presidentes dos Estados do MERCOSUL sobre o Aquífero Guarani, importante riqueza para as gerações atuais e futuras mercosulistas. A pesquisa foi desenvolvida a partir do método hermenêutico, por meio do levantamento e análise das normas jurídicas internacionais envolvendo os Estados partes do MERCOSUL, em tratados multilaterais sobre águas transfronteiriças superficiais e subterrâneas. Realizou-se a coleta de informações, por meio de materiais bibliográficos, livros, periódicos, mapas temáticos, informações e documentos disponíveis em páginas eletrônicas da rede mundial de computadores. A combinação das normas jurídicas esparsas acaba por regular boa parte das relações jurídicas hídricas entre os Estados Partes do MERCOSUL, uma vez que sua conjugação abrangem todos os Estados integrantes do MERCOSUL.

Palavras-chave: recursos hídricos, direito da integração, América do Sul.

\section{Regulation of surface and subterranean fresh water in the MERCOSUR regional integration}

\begin{abstract}
This work discusses the regulatory standardization among countries that are party to
\end{abstract}


MERCOSUR. This standardization forms the legal and institutional framework for maintaining important and strategic water resources, which require such regulation in order to be preserved and protected for present and future generations. Due to the lack of general legislation relating to MERCOSUR's water resources, it was necessary to study the main multilateral agreements among the MERCOSUR countries, such as the Amazon Cooperation Treaty and the River Plate Basin Treaty relating to surface water, and also the legal points included in a recent joint statement of the presidents of the Mercosur States regarding the Guarani Aquifer, which is an important resource for current and future generations of the MERCOSUR. The survey was developed using the hermeneutical method, based upon surveys and analysis of international legislation involving MERCOSUR member states, multilateral treaties relating to transboundary waters and groundwater zones and also included a search of bibliographic materials, books, journals, thematic maps, information and documents available on the Internet. The combination of the sparse legal rules covers most legal relationships between MERCOSUR member states relating to water.

Keywords: hydric resources, right of integration, South America.

\section{INTRODUÇÃO}

Os esforços dos países da sociedade internacional no sentido de conseguir um tratamento jurídico internacional dos recursos hídricos vêm ganhando força, principalmente pelos diversos tratados internacionais já alcançados. Neles vemos que a água é tratada como um recurso natural limitado e essencial à sadia qualidade de vida, um direito fundamental; que sua gestão deve ser democrática, contando com a participação de todos os interessados, principalmente as minorias; que os Estados têm o dever de oferecer água de boa qualidade para sua população; que os instrumentos econômicos são uma forma de conseguir um uso racional e adequado, principalmente através da cobrança pelo uso da água, dentre muitos outros objetivos. Nota-se um avanço nesse campo, na esfera internacional, em virtude, diretamente, da grave crise hídrica enfrentada por alguns países na atualidade e projetada para muitos outros em um futuro próximo (Oliveira e Amarante Junior, 2009). Essa nova visão dos recursos hídricos, com princípios e normas jurídicas próprias, deve abranger todas as águas doces (superficiais e subterrâneas).

No caso específico dos países sul-americanos, nomeadamente os integrantes do processo de integração do Mercado Comum do Sul - MERCOSUL (formado por Argentina, Brasil, Paraguai, Uruguai, e Venezuela), estes têm incorporado as normas oriundas dos tratados internacionais em seus ordenamentos jurídicos internos, inclusive em suas Constituições. Um exemplo foi o reconhecimento do princípio da soberania estatal. De um lado, é benéfico aos Estados pelo fato de garantir a independência dos mesmos na adoção do modelo de gestão, porém, pode apresentar problemas, porque não se podem dissociar os recursos hídricos de seu caráter transfronteiriço: uma vez afetado em um Estado pode gerar malefícios em outros Estados.

Assim, torna-se muito importante que, além de uma regulação universal, tenha, também, normas jurídicas regionalizadas, como dentro de um processo de integração regional em que respeite as identidades próprias daquela região e povo.

Os países do MERCOSUL têm especial interesse em desenvolver uma gestão adequada e eficiente dos recursos hídricos, principalmente porque detêm uma quantidade significativa da água doce disponível ${ }^{1}$.

\footnotetext{
${ }^{1}$ Segundo dados da Organização das Nações Unidas para a Agricultura e Alimentação - FAO (2014), os recursos hídricos totais per capita nos países do MERCOSUL, metros cúbicos/habitante/ano, são: Argentina (20.960K), Brasil (42.800K), Paraguai (56.057K), Uruguai (50.366K), Venezuela (42.948K).
} 
No MERCOSUL diversos são os usos dados aos recursos hídricos pelos seus Estados Partes, como abastecimento de água potável, navegação, irrigação, secagem de grãos, lazer e geração de energia. Porém, os interesses podem ser conflitantes, e para tanto diversas medidas protetoras dos sistemas dos recursos hídricos devem ser tomadas, para assegurar seu uso para as presentes e vindouras gerações (Vianna, 2002).

O MERCOSUL é desprovido de uma política mercosulista no domínio das águas (Oliveira, 2013). Somente é dotado de alguns textos legais internacionais ambientais, sem, contudo, ter influência imperativa sobre os Estados partes, além de alguns acordos internacionais que trata os cursos d'água transnacionais como da Bacia Amazônica e da Bacia do Prata, que em muitas vezes norteiam as relações entre os Estados abrangidos e serve de fonte jurídica para o MERCOSUL. Há necessidade iminente de superar essa deficiência normativa sobre um recurso natural tão importante como a água, principalmente levando-se em conta a grande riqueza hídrica sul-americana e as interações proporcionadas pelos inúmeros rios que atravessam os países, bem como pelas águas subterrâneas, como é o caso do Aquífero Guarani.

Tendo em conta essa grande riqueza natural dos Estados Partes do MERCOSUL, imprescindível para todos, que é realizado o presente estudo. Primeiramente foram identificadas as principais bacias hidrográficas onde se concentra boa parte das águas superficiais (que poderá servir como unidade de gestão), bem como das águas subterrâneas (podendo representar um fator estratégico desses países para o futuro em que o quadro de escassez hídrica tende a aumentar). Além da simples identificação das grandes bacias hidrográficas e das águas subterrâneas, buscou-se, também, abordar as normas jurídicas que envolvem esses recursos naturais, em específico. Isso porque a conjugação desses diplomas legais deve constituir o tratamento legal específico sobre águas doces para o processo de integração regional do MERCOSUL.

Essas informações servem para esclarecer a toda população dos países do MERCOSUL, principalmente seus governantes, sobre a importância dessa grande riqueza natural para que possa influenciar nos trabalhos dos Estados Partes no sentido de harmonizarem suas legislações no domínio dos recursos hídricos, ou mesmo na adoção de normas mercosulistas específicas, que propiciem uma gestão racional e adequada dos recursos hídricos.

\section{MATERIAIS E MÉTODOS}

A pesquisa é desenvolvida a partir do método hermenêutico, por meio do levantamento e análise das normas jurídicas internacionais envolvendo os Estados partes do MERCOSUL, em tratados multilaterais sobre águas transfronteiriças superficiais e subterrâneas. Nesse sentido, realizou-se uma coleta de informações, por meio de materiais bibliográficos, livros, periódicos, mapas temáticos, informações e documentos disponíveis em páginas eletrônicas da rede mundial de computadores.

Em seguida à coleta dos dados utilizando-se a bibliografia e rede Internet, fez-se a organização dos dados utilizados e analisados. Foi empregada a matriz teórica hermenêutica, porque, fundamentalmente, esta se analisando a legislação existente buscando, à luz da linguagem, a compreensão, a interpretação e a aplicação mais satisfatória.

\section{RESULTADOS}

Na América Latina há duas grandes e importantes bacias hidrográficas transfronteiriças, a Bacia do Prata e a Bacia Amazônica, que somadas ocupam aproximadamente $9.540 .000 \mathrm{~km}^{2}$ de extensão.

Ambas as bacias hidrográficas encontram regulação jurídica, em forma de tratado 
internacional, que regulam o uso e gestão desses recursos entre os Estados soberanos abrangidos, muitos deles Estados partes do MERCOSUL.

Em relação às águas subterrâneas, foi firmado em 2010 a Declaração Conjunta dos Presidentes dos Estados do sobre o Aquífero Guarani, uma norma jurídica inovadora que determina o respeito à soberania dos Estados, e há o compromisso destes em conservar e proteger esse importante recurso natural, de maneira a assegurar seu uso múltiplo, racional, sustentável e equitativo.

\subsection{Bacia do Prata}

Segundo Steinke e Saito (2010) a bacia hidrográfica localiza-se praticamente $80 \%$ no Brasil e na Argentina. Tem sua distribuição espacial da seguinte forma: Brasil (39,49\%), Argentina (39,25\%), Paraguai (11,21\%), Bolívia (6,97\%), Uruguai (3,08\%). O Paraguai, o Paraná, e o Uruguai são as três grandes unidades hidrográficas do sistema. O Paraguai termina no Oceano Atlântico, Paraná e Uruguai formam o rio do Prata (Villela, 1984).

Os países abrangidos pela Bacia do Prata (Argentina, Brasil, Bolívia, Paraguai e Uruguai) celebraram o Tratado da Bacia do Prata na cidade de Brasília, em 23 de abril de 1969, complementado pelo Tratado Sobre o Rio da Prata e Seus Limites marítimos, em 1973. Considerado por Villela (1984, p. 154) um "[...]tratado-marco, que vai sendo complementado na sua regulamentação pelos órgãos institucionais, que estabeleceu, embora nenhum deles seja dotado de supranacionalidade".

O Tratado da Bacia do Prata prevê a convergência de esforços com o escopo de promover o desenvolvimento harmônico e a integração física da Bacia do Prata e de suas áreas de influência direta e ponderável, sendo que o parágrafo único do artigo $1^{\circ}$ do tratado prevê como alcançar esses objetivos os Estados promoverão a identificação de áreas de interesse comum e a realização de estudos, programa e obras, bem como a formulação de entendimentos operativos ou instrumentos jurídicos que visem: a) facilitar a navegação; utilizar racionalmente os recursos, principalmente a água, pela regularização dos cursos d'água e seu aproveitamento múltiplo e equitativo; preservar e desenvolver a fauna e a flora; aperfeiçoas as interconexões rodoviárias, ferroviárias, fluviais, aéreas, elétricas e de telecomunicações; favorecer a complementação econômica regional; cooperar mutuamente em matéria educação, saúde e luta contra as enfermidades; melhorar o conhecimento e utilização dos recursos naturais da área; e estudar a Bacia do Prata.

Diante desses objetivos, Soares (2001), destaca o Tratado da Bacia do Prata como sendo o primeiro tratado multilateral na América Latina e no Caribe a se referir ao conceito de preservação dos recursos naturais, com vistas às futuras gerações.

O Tratado adota o princípio da gestão compartilhada como base para as atividades que provoquem impacto sobre a Bacia do Prata (Meirelles, 2005).

Em novembro de 2005 ocorreu o Fórum Internacional denominado de "Diálogos da Bacia do Prata", que contou com representantes da Argentina, Bolívia, Brasil, Paraguai e Uruguai. Esse encontro teve por objetivo tratar da gestão dos recursos hídricos disponíveis na região, tendo como temáticas: água para o desenvolvimento sustentável; água e saneamento para todos; outras dimensões da água: ancestralidade, equidade e espiritualidade; a juventude e a água; hidroeletricidade, múltiplo uso da água e sustentabilidade; agricultura e ambiente; e aquíferos da Bacia do Prata. Nesse encontro chegaram a conclusão que a água é um bem social e cultural antes de econômico e, como tal, um direito universal inalienável sobre o qual cada país é soberano.

\subsection{Bacia Amazônica}

A bacia hidrográfica ocupa uma área total da ordem de $6.110 .000 \mathrm{~km}^{2}$, desde suas nascentes nos Andes Peruanos até sua foz no oceano Atlântico (na região norte do Brasil). 
Esta bacia continental se estende sobre vários países da América do Sul: Brasil (63,5\%), Peru $(15,8 \%)$, Bolívia $(11,6 \%)$, Colômbia $(6,2 \%)$, Equador $(2,0 \%)$, Venezuela $(0,7 \%)$ Guiana $(0,2 \%)$, Suriname $(0,07 \%)$, Guiana Francesa $(0,03 \%)$ (Steinke e Saito, 2010$)$.

Por diversos motivos a bacia Amazônica é alvo de pressões antrópicas, e que acabam por conduzir em processos de fragmentação de seu ambiente por meio da substituição da vegetação original pela ocupação humana, nomeadamente, por meio de atividade agropastoril e de mineração. Acrescidos dos processos de urbanização e logística de transportes rodoviários e ferroviários (Steinke e Saito, 2010).

Em 3 de julho de 1978 foi concluído o Tratado de Cooperação Amazônica (TCA), entre Bolívia, Brasil ${ }^{2}$, Colômbia, Equador, Guiana, Peru, Suriname e Venezuela ${ }^{3}$. Soares (2001, p. 245) define a área de abrangência do Tratado como um "espaço complexo, mas suficientemente individualizado, exatamente por fatores relacionados ao meio ambiente." Dentre seus Estados membros dois são Estados Partes do MERCOSUL - Brasil e Venezuela, e a Bolívia encontra-se em processo de adesão.

O tratado foi fruto da convergência de esforços dos Estados amazônicos objetivando a promoção do desenvolvimento harmônico de seus respectivos territórios amazônicos, para que essas ações conjuntas produzam resultados equitativos e mutuamente proveitosos, bem como para a preservação do meio ambiente e a conservação e utilização racional de seus recursos naturais. Esses objetivos traduzem o desejo dos Estados participantes desse tratado no sentido de afastar a ameaça da internacionalização, na forma de reafirmarem suas soberanias. Esse é o entendimento, inclusive, de Caubet (1984) onde a conclusão do TCA se explica pela vontade comum dos oito Estados interessados em reafirmar sua soberania contra as cobiças exteriores.

No mesmo sentido Amayo Zevallos (1993) aponta que o Tratado reside no reconhecimento da soberania de cada um dos países signatários sobre a parte que lhe corresponde da Amazônia, chamando de regionalização.

Pode, inclusive, ser encontrado no texto do artigo $4^{\circ}$ do Tratado o respeito à soberania de cada Estado: "As Partes Contratantes proclamam que o uso e aproveitamento exclusivo dos recursos naturais em seus respectivos territórios é direito inerente à soberania do Estado e seu exercício não terá outras restrições senão as que resultem do Direito Internacional". Mesmo respeitando o poder soberano de cada Estado membro do Tratado, comprometeram-se a envidar esforços no sentido de utilizarem de forma racional os recursos hídricos (artigo $5^{\circ}$ ).

Com o objetivo de manter o equilíbrio ecológico de toda a região amazônica, bem como preservar as espécies da fauna e flora, decidiram no artigo $7^{0}$.

a) promover a pesquisa cientifica e o intercâmbio de informações e de pessoal técnico entre as entidades competentes dos respectivos países, a fim de ampliar os conhecimentos sobre os recursos da flora e da fauna de seus territórios amazônicos e prevenir e controlar as enfermidades nesses territórios;

b) estabelecer um sistema regular de troca adequada de informações sobre as medidas conservacionistas que cada Estado tenha adotado ou adote em seus territórios amazônicos, as quais serão matérias de um relatório anual apresentado por cada país (Brasil, 1980).

\footnotetext{
${ }^{2}$ Promulgado no Brasil pelo Decreto no ${ }^{8}$ 85.050, de 18/08/1990.

${ }^{3}$ Neste tratado não participa a Guiana Francesa.
} 
O Tratado prevê a colaboração entre os países membros para promover: a pesquisa científica e tecnológica e o intercâmbio de informações; a utilização racional dos recursos naturais; a liberdade de navegação nos rios amazônicos; a proteção da navegação e do comércio; a preservação do patrimônio cultural; os cuidados com a saúde; a criação e a operação de centros de pesquisa; o estabelecimento de adequada infraestrutura de transportes e comunicações; o incremento do turismo; e o comércio fronteiriço. Todas essas medidas devem ser adotadas mediante ações bilaterais ou de grupos de países, com o objetivo de promover o desenvolvimento harmonioso dos respectivos territórios.

\subsection{Aquíferos}

Os limites geológicos e hidrogeológicos não são os mesmos dos limites políticos. Assim sendo, os aquíferos, de uma forma geral, transpõem as fronteiras dos países vizinhos.

Os aquíferos transfronteiriços podem ser divididos em dois tipos: os de extensões locais e os regionais.

Em geral, os aquíferos de rochas cristalinas são de expressão local, pois apresentam grande descontinuidade, e não são importantes para a abordagem de legislações internacionais. Os aquíferos sedimentares, geralmente são extensos e contínuos, podendo ser partilhado por países diferentes. Neste aspecto, alguns sofrem descontinuidades por interdigitações de sedimentos com maior ou menor permeabilidade. Este último tipo de aquífero sedimentar também tem expressão local e não é importante nas legislações internacionais. Como exemplo pode-se citar o Aquífero Bauru da Formação Bauru, da Bacia do Paraná, correlacionável com a Formação Mariano Boedo, na Bacia do Chaco- Paraná.

Deve-se citar que a Bacia do Paraná, é uma bacia sedimentar transfronteiriça, e cujos sedimentos estão interdigitados com a Bacia do Chaco-Paraná. Possui aquíferos transfronteiriços de expressão local, como o acima citado Aquífero Bauru, os aquíferos cristalinos, com sistema fraturado, da Formação Serra Geral, o Grupo Tubarão e Formação Ordoñes, e o Aquífero Guarani, com extensão regional, formado por sedimentos eólicos da Formação Botucatú, na Bacia Sedimentar do Paraná, e pelos sedimentos da Formação Tacuarembó, na Bacia Sedimentar do Chaco-Paraná.

Para Lima (2004) a principal diferença entre as bacias do Paraná e do Chaco-Paraná reside em suas histórias geológicas. Para este autor:

A Bacia do Chaco-Paraná foi influenciada por um intenso processo de
subsidência como reflexo da formação da Cordilheira dos Andes, durante o
Terciário, o que não se observa na Bacia do Paraná. A cobertura arenosa
depositada nesta época, na Bacia do Chaco-Paraná, chega a alcançar dois mil
metros de espessura. Por outro lado, a Bacia do Paraná foi deveras afetada
pela abertura do Oceano Atlântico Sul, quando sofreu intensos processos
erosivos, intrusões e derrames basálticos eocretácicos da Formação Serra
Geral, os quais apresentaram menor expressão na Bacia do Chaco-Paraná
(Lima, 2004, p. 8)

O Aquífero Guarani está inserido na Bacia Geológica Sedimentar do Paraná, estendendose desde essa Bacia até a do Chaco-Paraná, abrangendo: Argentina (com 18,9\% de sua área), Brasil (com 70,2\% de sua área), Paraguai (com 6\% de sua área) e Uruguai (com 4,9\% de sua área), em uma área aproximada de 1,2 milhão de $\mathrm{km}^{2}$. (Brasil, 2015). Todo esse volume de água de boa qualidade pode ser utilizado para diversos fins, principalmente para consumo humano, considerados usos prioritários.

\footnotetext{
${ }^{4}$ Sobre o assunto conhecimento estratigráfico, recomenda-se: Milani (1997); Cordani et al. (2000); Daemon e Quadros (1970); Quintas (2002); Playford e Dino (2002); Souza e Marques-Toigo (2001).
} 
Segundo Borghetti et al. (2004), entende-se por água subterrânea:

[...]toda água que ocorre abaixo da superfície da Terra, preenchendo os poros ou vazios intergranulares das rochas sedimentares, ou as fraturas, falhas e fissuras das rochas compactas, e que sendo submetida a duas forças (de adesão e de gravidade) desempenha papel essencial na manutenção da umidade do solo, do fluxo dos rios, lagos e brejos. As águas subterrâneas cumprem uma fase do ciclo hidrológico, uma vez que constituem uma parcela da água precipitada.

As águas subterrâneas ocorrem em duas zonas: saturada e insaturada. De acordo com Tundisi (2005, p. 12), a zona insaturada recebe esse nome por conter água e ar: "A zona superior se estende da superfície até profundidades que vão de menos de um metro a algumas centenas de metros em regiões semiáridas". Já a zona saturada contém somente água e está localizada logo abaixo da insaturada.

O conceito de aquífero é fornecido por Borghetti et al. (2004) como "uma formação geológica do subsolo, constituída por rochas permeáveis, que armazena água em seus poros ou fraturas".

Segundo Rocha (1997, apud Ribeiro, 2008, p. 229) o Sistema Aquífero Guarani é resultado de diversas formações geológicas situadas no Triássico e no Jurássico: "Tiveram origem no Triássico as Formações Pirambóia e Rosário do Sul, no Brasil, e a Formação Buena Vista, no Uruguai. Remontam ao Jurássico as Formações Botucatu, no Brasil, Misiones, no Paraguai, e Tacuarembó, que ocorre na Argentina e no Uruguai”.

Diante do quadro alarmante de escassez hídrica mundial, com tendência a se ampliar, os aquíferos podem representar uma alternativa estratégica para os países sobrejacentes a fim de garantir água de boa qualidade para sua população, e provavelmente mais uma fonte de riqueza para estes.

O Aquífero Guarani ${ }^{5}$, por sua localização geográfica, abrangendo quatro dos atuais cinco Estados Partes do MERCOSUL, pode ser considerado como naturalmente integrador dos Estados nesse processo de integração regional, que inicialmente objetiva aspectos comerciais e econômicos, mas que são indissociáveis dos aspectos ambientais, principalmente os recursos hídricos.

Quanto às águas subterrâneas, foi criado o Grupo Ad Hoc de Alto Nível Aquífero Guarani, pela Decisão do CMC n⿳0 25/2004, com a missão de elaborar um projeto de Acordo dos Estados Partes relativo ao Aquífero Guarani, consagrando os princípios e critérios que melhor garantam seus direitos sobre esse recurso natural.

Vianna (2002) apresenta diversas sugestões para o melhor gerenciamento das águas subterrâneas do MERCOSUL, com o objetivo de dar manutenção ao grande volume de água e

\footnotetext{
5 Para Machado (2006) o Aquífero Guarani foi o nome que, no ano de 1996, o geólogo uruguaio Danilo Anton sugeriu para denominar uma imensa camada aquífera que abrange partes dos quatro Estados que constituíram o MERCOSUL (Argentina, Paraguai, Uruguai, e principalmente o Brasil). Na ocasião, ele chegou a ser considerado o maior do mundo. Atualmente é considerado o segundo maior, capaz de abastecer a população brasileira durante 2500 anos. A maior reserva atualmente conhecida é o Aquífero Alter do Chão, com o dobro do volume do Aquifero Guarani. Para este autor "Ainda não existem estudos detalhados sobre toda a área de ocorrência do Aquífero Guarani no Brasil e nos outros países do Mercosul. Entretanto, teria sido melhor denominá-lo "Sistema Aqüífero Guarani", já que se trata de um conjunto heterogêneo de "unidades hidroestratigráficas" que podem conter muita, pouca ou nenhuma água. Sinteticamente, essas unidades poderiam ser descritas como formações geológicas portadoras de água, em maior ou menor quantidade. Algumas delas, exploradas há mais de cem anos, já foram estudadas por pesquisadores dos países do Mercosul" (Machado, 2006).
} 
sua qualidade para que desempenhe uma função sustentável para a presente e futuras gerações.

Nesse trabalho o autor aponta três soluções: a) Inicialmente é apontado o "zoneamento, proteção individual dos poços e das fontes naturais e a proposição de áreas de proteção" - a exemplo do sistema austríaco, que cria três tipos de áreas concêntricas em torno do poço ou fonte, com o estabelecimento de restrições por áreas, que vão diminuindo à medida que se afasta do poço ou fonte (quanto mais perto do poço, mais restritivas as atividades possíveis de serem desempenhadas com o objetivo de proteger a fonte). O mesmo autor considera a necessidade de adaptação para o Sistema Aquífero Guarani, principalmente pelo seu tamanho, e de controlar a perfuração dos poços, conjuntamente com o estabelecimento de normas que obriguem o que chama de "tamponamento" dos poços não utilizados, para que se evite assim a contaminação; b) "Políticas compensatórias na gestão do SAG" - é a utilização de instrumentos econômicos, a exemplo do ocorrido no Estado do Paraná (Brasil), que criou o ICMS-Ecológico, isto é, compensações financeiras aos municípios que pratiquem uma política de uso do solo e de preservação de mananciais para que se consiga uma água de boa qualidade natural; c) "Adequação do sistema de gestão por bacia às águas subterrâneas e ao SAG" - estabelecimento de um sistema de gestão integrada dos recursos hídricos (superficiais e subterrâneos) tendo a bacia hidrográfica como unidade territorial.

Em relação a essa última sugestão, deve-se mencionar que nem todos os países do MERCOSUL adotam esse modelo de gestão. Mesmo no caso brasileiro, que com sua Lei 9433/97 estabelece esse tipo de gestão, observa-se que não se alcançaram ainda todos os objetivos almejados pela norma. Um ponto positivo dessa sugestão é o da participação de todos na gestão integrada dos recursos hídricos existentes na bacia hidrográfica, ou seja, além dos particulares (sociedade civil organizada e usuários), também o Poder Público, principalmente os municípios, uma vez que legislam sobre uso e ocupação do solo. Com essa gestão democrática se terá uma concentração de interesses com benefícios para os recursos hídricos, especialmente os localizados no subsolo.

Um movimento conservacionista ocorreu com o Projeto de Proteção Ambiental e Gerenciamento Sustentável Integrado do Sistema Aquífero Guarani (Projeto SAG), cujo principal objetivo é: "contribuir para a superação da situação atual por meio da formulação de um modelo técnico, legal e institucional para a gestão dos recursos do Aquífero de forma coordenada pelo conjunto dos países e organismos envolvidos" (Meio Ambiente News, 2014). Acresce, ainda, com os seguintes objetivos: o fornecimento de água para os Estados subjacentes para o abastecimento sustentável de água potável para a população; água de alta qualidade para a indústria; abastecimento sustentável de água termal para turismo, indústria e municípios; e menores possibilidades de conflitos em virtude do uso das águas do Sistema Aquífero Guarani nas zonas transfronteiriças.

Quando se fala em recursos naturais, logo os Estados soberanos buscam o respeito ao princípio da soberania, porém, quando se trata de recursos naturais transfronteiriços, como no caso do Aquífero Guarani, não se pode pretender que cada país o utilize soberanamente sem ter em conta os efeitos que esse uso ocasionará em outros países. A esse respeito Segovia (2009, p. 15):

Por eso, al hablar del acuífero y de la soberanía se debe entender no que cada país utilice el agua a su antojo, o que el agua en él disponible sea exclusivamente de los países suprayacentes, sino que cada pueblo (cambiemos la palabra país por pueblo ya que ilustra mejor una colectividad social y no una institución impersonal) sea soberano para satisfacer sus necesidades cotidianas de un modo cultural y ambientalmente adecuado, sin depender de los intereses económicos que operan en el entorno (es decir de los intereses de empresas transnacionales de aprovechar el recurso en sus multimillonarios negocios). El respeto al medio ambiente y a los demás 
pueblos que comparten y no el territorio del acuífero, son imperativos inherentes a la soberanía sobre este recurso.

A grande reserva de água doce representada pelo Aquífero Guarani deve ser explorada com um plano de gestão, que seja construído de forma conjunta entre todos os interessados, ou seja, dentro do campo de abrangência do Aquífero Guarani.

Em 2 de agosto de 2010, na cidade de San Juan, foi firmada a Declaração Conjunta dos Presidentes dos Estados do sobre o Aquífero Guarani. Neste acordo ficou estabelecido que cada Estado exerce o domínio territorial soberano sobre suas respectivas porções do Sistema Aquífero Guarani, de acordo com suas disposições constitucionais e legais e de conformidade com as normas de direito internacional aplicáveis.

Cada Estado exerce em seu respectivo território o direito soberano de promover a gestão, o monitoramento e o aproveitamento sustentável dos recursos hídricos do Sistema Aquífero Guarani, e utilizará esses recursos com base em critérios de uso racional e sustentável e respeitando a obrigação de não causar prejuízo sensível aos Estados abrangidos pelo Aquífero, nem ao meio ambiente.

O Aquífero deve ser conservado e protegido ambientalmente de maneira a assegurar o uso múltiplo, racional, sustentável e equitativo de seus recursos hídricos. E quando um Estado abrangido se propuser a empreender estudos, atividades ou obras relacionadas com as partes do sistema Aquífero Guarani que se encontrem localizadas em seus respectivos territórios e que possam ter efeitos além de suas respectivas fronteiras, deverá atuar de conformidade com os princípios e normas de direito internacional aplicáveis.

Nas atuações ou obras de aproveitamento e exploração do recurso hídrico do Sistema Aquífero Guarani, os Estados comprometeram-se em adotar todas as medidas necessárias para evitar que se causem prejuízos sensíveis às outras Partes ou ao meio ambiente. Em caso de ocorrência de prejuízo sensível a outro Estado abrangido pelo Aquífero ou ao meio ambiente, o Estado causador deverá adotar todas as medidas necessárias para eliminá-lo ou reduzi-lo.

O intercâmbio de informação técnica sobre estudos, atividades e obras que contemplem o aproveitamento sustentável dos recursos hídricos do Sistema Aquífero foi adotado pelos Estados signatários. Ficando acordado que cada Estado deverá informar aos outros Estados sobre todas as atividades e obras que se proponha a executar ou autorizar em seu território e que possam ter efeitos no Sistema Aquífero Guarani além de suas fronteiras. A informação seguirá acompanhada de dados técnicos disponíveis, incluídos os resultados de uma avaliação dos efeitos ambientais, para que os Estados que receberem a informação possam avaliar os possíveis efeitos de tais atividades e obras. Em relação a essa situação, os artigos 10 a 11 estabeleceram como procedimento:

\section{Artigo 10}

1. A Parte que considerar que uma atividade ou obra, a que se refere o Artigo 8, que se proponha autorizar ou executar outra Parte, possa, a seu juízo, ocasionar-lhe um prejuízo sensível, poderá solicitar a essa Parte que lhe transmita os dados técnicos disponíveis, incluídos os resultados de uma avaliação dos efeitos ambientais.

2. Cada Parte facilitará os dados e a informação adequada requeridos por outra ou outras Partes a respeito de atividades e obras projetadas em seu respectivo território e que possam ter efeitos além de suas fronteiras.

Artigo 11

1. Se a Parte que recebe a informação prestada nos termos do parágrafo 1 do Artigo 10 chegar à conclusão de que a execução das atividades ou obras projetadas pode causar-lhe prejuízo sensível, indicará suas conclusões à outra Parte com uma exposição documentada das razões em que elas se fundamentam. 
2. Neste caso, as duas Partes analisarão a questão para chegar, de comum acordo e no prazo mais breve possível, compatível com a natureza do prejuízo sensível e sua análise, a uma solução equitativa com base no princípio de boa fé, e tendo cada Parte em conta os direitos e os legítimos interesses da outra Parte.

3. A Parte que proporciona a informação não executará nem permitirá a execução de medidas projetadas, sempre que a Parte receptora lhe demonstre prima facie que estas atividades ou obras projetadas lhe causariam um prejuízo sensível em seu espaço territorial ou em seu meio ambiente. Neste caso, a Parte que pretende realizar as atividades e as obras se absterá de inicia-las ou de continuá-las enquanto durem as consultas e as negociações, que deverão ser concluídas no prazo máximo de seis meses (Argentina et al., 2010).

A cooperação está presente neste Acordo, através do estabelecimento de programas com o propósito de ampliar o conhecimento técnico e científico sobre o Sistema Aquífero Guarani, a promoção de intercâmbio de informações sobre práticas de gestão, assim como o desenvolvimento de projetos comuns. Essa cooperação internacional não prejudicará os projetos e empreendimentos que cada Estado decidir executar em seu território, de conformidade com o direito internacional. A cooperação está presente também na identificação de áreas críticas, especialmente em zonas fronteiriças que demandem medidas de tratamento específico.

Os conflitos em decorrência da interpretação ou aplicação deste Acordo serão resolvidos através das negociações diretas. As negociações diretas são formas das próprias partes chegarem à resolução de suas controvérsias, sem a intervenção de um tribunal internacional. Não se chegando a uma solução, o procedimento arbitral do MERCOSUL deverá ser acionado.

O uso dessa fonte de água pelos Estados deve ser monitorada, uma vez que a exploração do recurso sem controle pode levar a um quadro de escassez de água mesmo que seja apenas no aspecto da qualidade. Sanches et al. (2010) realizaram estudo da qualidade de águas provenientes de poços em Ribeirão Preto, SP, Brasil, sugerindo que, embora as amostras analisadas atendam às exigências do Ministério da Saúde do Brasil, para potabilidade, na maioria dos parâmetros analisados, deve-se manter atenção e realizar monitoramentos constantes, uma vez que concentrações de nitrato (um indicador da presença de fertilizantes ou efluentes domésticos) e crômio (metal que na forma hexavalente pode induzir vários tipos de câncer) já se apresentam como parâmetros de destaque. Os nitratos são sais extremamente solúveis e, por isso, estão amplamente distribuídos na natureza. Além deste parâmetro, para que se possa relacionar os dados dos autores à contaminação de origem antrópica outros constituintes de efluentes e fertilizantes deveriam ser analisados, como nitrito, nitrogênio amoniacal e fósforo (na forma de fosfato ou ortofosfato). A presença de metais traço, que também não ultrapassaram os limites legais no estudo citado, podem não ser preocupantes atualmente, mas uma quantidade maior de metais tem aportado o ambiente constantemente na forma de resíduos sólidos ou diluídos em efluentes industriais. Isso demonstra que o uso das águas do aquífero guarani interessa não apenas ao país onde a retirada é efetuada, mas também aos outros membros do MERCOSUL, especialmente com estudos que avaliem a pluma de dispersão desses contaminantes e outros poluentes que podem depreciar a qualidade dos recursos hídricos compartilhados. 


\section{CONCLUSÃO}

As águas doces serviram para os países da América do Sul como meios de controlar os grandes espaços e riquezas do interior, sendo também apontado como fonte de tensões e conflitos, inclusive armados. Essa grande disponibilidade de água, diante do alarmante quadro de escassez hídrica mundial, representa enorme riqueza hídrica sul-americana, principalmente pela existência do Aquífero Guarani e suas grandes bacias hidrográficas (Bacia do Prata e Bacia Amazônica). É incontestável que os países do MERCOSUL detêm uma riqueza que precisa ser gerenciada de forma adequada e sustentável, levando-se em conta todos os potenciais usos.

Até o presente momento, não existe uma política mercosulista no domínio das águas, sendo de crucial importância a adoção de um modelo de gestão dos os recursos hídricos existentes em seus Estados Partes.

Diante da inexistência de uma norma mercosulista específica no domínio dos recursos hídricos, acredita-se necessário um profundo estudo do direito interno de seus Estados Partes do MERCOSUL, para que possam comparar os diversos regimes jurídicos, verificando similaridades ou disparidades de tratamento. Em sendo constatada a similaridade, isso será um fator favorável à aproximação ou harmonização do direito dos Estados através de uma norma geral e única no MERCOSUL. Caso se observe disparidade normativa entre os países Estados Partes do MERCOSUL, uns protegendo menos que outros os recursos hídricos, poderá haver, além de distorções no comércio intrabloco, sérios danos aos recursos hídricos existentes nesse espaço territorial alargado, e com prejuízo para todos.

Até que se chegue a um marco legal geral no domínio das águas doces no processo do MERCOSUL, todos os esforços normativos alcançados por seus Estados partes, por meio de tratados internacionais, devem ser aproveitados e aplicados como importantes fontes originárias do direito do MERCOSUL. Porém, esses acordos internacionais são regionalizados, abrangendo trechos dos Estados somente; mesmo no caso do aquífero Guarani. Por isso, é imperioso que os Estados partes do MERCOSUL iniciam uma ampla discussão pública para a construção de um marco legal para os recursos hídricos em toda extensão do território mercosulino, com o fim de proteger esse importante e estratégico recurso natural.

\section{AGRADECIMENTOS}

Ao Grupo de Pesquisa CNPq/UFSCar Novos Direitos.

\section{REFERÊNCIAS}

AMAYO ZEVAllos, E. A. Da Amazônia ao Pacífico cruzando os Andes. Estudos Avançados, v. 7, n. 17, p. 117-169, 1993. http://dx.doi.org/10.1590/S010340141993000100006

ARGENTINA; BRASIL; PARAGUAI; URUGUAI. Acordo sobre o Aquífero Guarani. San Ruan, 2010. Disponível em: http://www.internationalwaterlaw.org/documents/ regionaldocs/Guarani_Aquifer_Agreement-Portuguese.pdf. Acesso em: jan. 2016.

BORGHETTI, N. R. B.; BORGHETTI, J. R.; ROSA FILHO, E. F. Aquífero Guarani: a verdadeira integração dos países do MERCOSUL. Curitiba: Imprensa Oficial, 2004. 
BRASIL. Ministério do Meio Ambiente. Aquífero Guarani: gestão do Sistema Aquífero Guarani. Disponível em: http://www.mma.gov.br/legislacao/item/8617-aqu\%C3\%A Dfero-guarani. Acesso em: 13 maio 2015.

BRASIL. Senado Federal. Secretaria de Informação Legislativa. Decreto $n^{\circ} 85.050$, de 18 de agosto de 1980. Promulga o Tratado de Cooperação Amazônica, concluído entre os Governos República da Bolívia, da República Federativa do Brasil, da República da Colômbia, da República do Equador, da República Cooperativa da Guiana, da República do Peru, da República do Suriname e da República da Venezuela. Diário Oficial [da] União, Brasília, 20 ago. 1980, Seção 1, p. 6.

CAUBET, C. G. Le Traité de Coopération Amazonienne: regionalisation et développement de l’Amazonie. Annuaire Français de Droit International, v. 30, n. 1, p. 803-818, 1984.

CORDANI, U. G.; MILANI, E. J.; THOMAZ FILHO, A.; CAMPOS, D. A. (Eds.) Tectonic evolution of South America. Revista Geológica de Chile, v. 27, n. 2, p. 255, 2000. http://dx.doi.org/10.4067/S0716-02082000000200006

DAEMON, R. F.; QUADROS, L. P. Bioestratigrafia do Neopaleozóico da Bacia do Paraná. CONGRESSO BRASILEIRO DE GEOLOGIA, 14., 1970, Brasília. Anais... São Paulo: SBGO, 1970. p. 359-412.

LIMA, R. A. Caracterização geoquímica e avaliação do potencial petrolífero do PermoCarbonífero da Bacia do Chaco- Paraná. 2004. 53f. Projeto de final de curso (Graduação em Geologia) - Universidade do Estado do Rio de Janeiro, Rio de Janeiro, 2004.

MACHADO, J. L. F. A redescoberta do Aquífero Guarani. Scientific American Brasil, n. 47, p. 32-39, 2006.

MEIO AMBIENTE NEWS. Descrição do Aquífero Guarani. Disponível em: http://www.meioambientenews.com.br/conteudo.ler.php?q\%5B1\%7Cconteudo.idcatego ria\%5D=27\&id=1893. Acesso em: jan. 2014.

MEIRELLES, E. A. O Aquífero Guarani: uma proposta de regulamentação jurídica internacional. 2005. Tese (Doutorado) - Faculdade de Direito, Universidade de São Paulo, São Paulo, 2005.

MILANI, E. J. Evolução Tectono-Estratigráfica da Bacia do Paraná e seu relacionamento com Geodinâmica Fanerozóica do Gondwana Sul Ocidental. 1997. 225f. Tese (Doutorado em Geociências) - Instituto de Geociências, Universidade Federal do Rio Grande do Sul, Porto Alegre, 1997.

OLIVEIRA, C. M. Mercosul Ambiental. Revista Brasileira de Direito Ambiental, v. 36, p. 37-63, 2013.

OLIVEIRA, C. M.; AMARANTE JUNIOR, O. P. Direito internacional das águas doces. São Carlos: RiMa, 2009.

ORGANIZAÇÃO DAS NAÇÕES UNIDAS PARA A AGRICULTURA E ALIMENTAÇÃO - FAO. Aquastat. 2014. Disponível em: http://www.fao.org/nr/water/ aquastat/data/ query/results.html. Acesso em: 23 dez. 2015. 
PLAYFORD, G.; DINO, R. Permian Palynofloral Assemblages of the Chaco-Paraná Basin, Argentina: systematics and stratigraphic significance. Revista Española de Micropaleontología, v. 34, n. 3, p. 235-288, 2002.

QUINTAS, M. Geoquímica orgânica do devoniano da Bacia do Chaco-Paraná, Nordeste da Argentina. 2002. 43f. Monografia (Graduação em Geologia) - Universidade do Estado do Rio de Janeiro, Rio de Janeiro, 2002.

RIBEIRO, W. C. Aquífero Guarani: gestão compartilhada e soberania. Estudos Avançados, v. 22, n. 64, p. 227-238, 2008. http://dx.doi.org/10.1590/S0103-40142008000300014

SANCHES, S. M.; VIEIRA, E. M.; PRADO, E. L.; TAKAYANAGUI, A. M. M. Qualidade da água de abastecimento público de Ribeirão Preto em área de abrangência do aquífero Guarani: determinação de metais e nitrato. Revista Ambiente \& Água, v. 5, p. $202-$ 216, 2010. http://dx.doi.org/10.4136/ambi-agua.148

SEGOVIA, D. Situación de la gestión, la disponibilidad y el acceso al agua en Paraguay desde una perspectiva de derechos humanos. Disponível em: http://www.infoandina.org/sites/default/files/publication/files/agua_py.pdf. Acesso em: 14 jan. 2015.

SOARES, G. F. S. Direito internacional do meio ambiente: emergência, obrigações e responsabilidades. São Paulo: Atlas, 2001.

SOUZA, P. A.; MARQUES-TOIGO, M. Zona Vittatina: Marco Palinobioestratigráfico do Permiano Inferior da Bacia do Paraná. Ciência-Técnica-Petróleo, Seção Exploração de Petróleo, v. 20, p. 153-159, 2001.

STEINKE, V. A.; SAITO, C. H. Avaliação geoambiental do territorio brasileiro nas bacias hidrográficas transfronteiriças. Revista Brasileira de gestão e desenvolvimento regional, v. 6, n. 1, p. 189-222, 2010.

TUNDISI, J. G. Água no século XXI: enfrentando a escassez. 2 ed. São Carlos: RiMA, 2005.

VIANNA, P. C. G. Gestão internacional dos recursos hídricos no Mercosul: o caso do Aquífero Guarani. 2002. 125f. Tese (Doutorado) - Departamento de Geografia, Universidade de São Paulo, São Paulo, 2002.

VILLELA, A. M. O tratado da bacia do Prata. Revista de Informação Legislativa, n. 81, p. 147-176, 1984. 


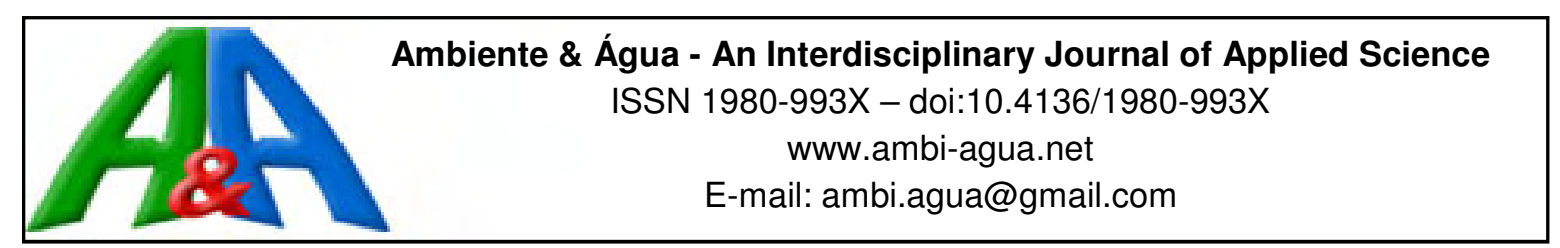

\title{
Remoção de matéria orgânica e nitrogênio em biorreator com membranas submersas operando em condição de nitrificação e desnitrificação simultânea
}

\author{
doi:10.4136/ambi-agua.1684 \\ Received: 17 Jun. 2015; Accepted: 28 Mar. 2016

\begin{abstract}
Izabela Major Barbosa $^{1^{*}}$; José Carlos Mierzwa ${ }^{1}$; Ivanildo Hespanhol ${ }^{1}$; Eduardo Lucas Subtil ${ }^{2}$
\end{abstract} \\ ${ }^{1}$ Universidade de São Paulo (USP), São Paulo, SP, Brasil \\ Escola Politécnica \\ ${ }^{2}$ Universidade Federal do ABC (UFABC), Santo André, SP, Brasil \\ Centro de Engenharia, Modelagem e Ciências Sociais Aplicadas. \\ *Autor correspondente: e-mail: izamajor@usp.br, \\ mierzwa@usp.br, ivanhesp@usp.br, eduardosubtil@gmail.com
}

\section{RESUMO}

Neste estudo se avaliou a remoção de nitrogênio e matéria orgânica em biorreatores com membranas submersas operado em condição de nitrificação e desnitrificação simultânea controlada por aeração intermitente. Foi utilizado um sistema de biorreator com membranas submersas, em escala piloto, para tratamento de esgoto doméstico. A concentração de oxigênio dissolvido foi mantida entre 0,5 e $0,8 \mathrm{mg} \mathrm{L}^{-1}$. A concentração dos sólidos suspensos voláteis no liquor misto (SSVLM) do sistema variou de 1 a $6 \mathrm{~g} \mathrm{~L}^{-1}$. A eficiência do sistema foi avaliada por meio da remoção de matéria orgânica quantificada pela Demanda Química de Oxigênio (DQO), Demanda Bioquímica de Oxigênio $\left(\mathrm{DBO}_{5}\right)$ e Carbono Orgânico Total (COT). A remoção de nitrogênio foi avaliada por meio da quantificação de Nitrogênio Total Kjeldahl (NTK) e nitrogênio amoniacal. Durante o período de partida do sistema, as eficiências de remoção de DQO e NTK foram próximas de $90 \%$ e $80 \%$, respectivamente. Após serem estabelecidas as condições de nitrificação e desnitrificação simultânea (NDS), a eficiência de remoção de DQO e NTK tiveram valores médios de $70 \%$ e 99\%, respectivamente. Os resultados obtidos mostraram que o sistema de Biorreatores com Membranas (BRM), operando com nitrificação e desnitrificação simultâneas, foi capaz de remover matéria orgânica e nitrogênio em um único reator, produzindo um permeado de alta qualidade.

Palavras-chave: aeração intermitente; biorreator de membranas; remoção de nitrogênio; remoção de matéria orgânica.

\section{Removal of nitrogen and organic matter in a submerged-membrane bioreactor operating in a condition of simultaneous nitrification and denitrification}

\section{ABSTRACT}

This study evaluated the removal of nitrogen and organic matter in a membrane bioreactor system operating in a condition of simultaneous nitrification and denitrification 
controlled by intermittent aeration. A submerged-membrane system in a bioreactor was used in a pilot scale to treat domestic wastewater. The dissolved oxygen concentration was maintained between 0.5 and $0.8 \mathrm{mg} \mathrm{L}^{-1}$. The concentration of the mixed liquor suspended solids (MLSS) in the system ranged from 1 to $6 \mathrm{~g} \mathrm{~L}^{-1}$. The system efficiency was evaluated by the removal efficiency of organic matter, quantified by Chemical Oxygen Demand (COD), Biochemical Oxygen Demand $\left(\mathrm{BOD}_{5}\right)$ and Total Organic Carbon (TOC). Nitrogen removal was assessed by quantifying Total Kjeldahl Nitrogen (TKN) and ammonia nitrogen. During the system start-up, the removal efficiencies of COD and NTK were around $90 \%$ and $80 \%$, respectively. After the simultaneous nitrification and denitrification (SND) conditions were established, the removal efficiencies of COD and NTK were $70 \%$ and $99 \%$, respectively. These results showed that sewage treatment with the membrane bioreactor (MBR) system, operating with simultaneous nitrification and denitrification conditions, was able to remove organic matter and promote nitrification and denitrification in a single reactor, producing a high-quality permeate.

Keywords: intermittent aeration; membrane bioreactor; nitrogen removal; organic matter removal.

\section{INTRODUÇÃO}

O uso de tratamentos biológicos em conjunto com processos de separação por membranas, Biorreatores com Membranas (BRM), aplicados ao tratamento de esgoto doméstico é uma alternativa eficiente e economicamente viável para fornecer efluentes de excelente qualidade (Hoinkis et al., 2012; Subtil et al., 2013; 2014).

Os sistemas BRM apresentam diversas vantagens em relação aos sistemas convencionais de tratamento de esgoto doméstico, pois: são sistemas compactos; podem operar com maior concentração de biomassa; há menor produção de lodo excedente; operação em baixa pressão de trabalho e o efluente gerado é de alta qualidade (Judd, 2011, 2015; Wen et al., 2010; Roest et al., 2006; Schneider e Tsutiya, 2001).

Nos sistemas BRM, o tempo de detenção hidráulico independe do tempo de retenção celular ou idade do lodo e a biomassa pode ser selecionada de modo a aumentar a eficiência de biodegradação (Wen et al., 2010). A possibilidade de operação de sistemas biológicos com maior idade de lodo promove maior retenção de microrganismos com taxa de crescimento relativamente lenta, (como bactérias nitrificantes) o que aumenta a possibilidade de nitrificação. Por essa característica, observa-se a expansão da publicação de estudos recentes em tratamento de águas residuárias utilizando BRM com foco direcionado para remoção de nutrientes, como nitrogênio (Rodríguez-Hernández et al., 2014; Ding et al., 2013; Khan et al., 2013; Lin et al., 2013; Yao et al., 2013).

As formas mais comuns de nitrogênio no decorrer do tratamento de esgotos são: amônia $\left(\mathrm{NH}_{3}\right)$, íon amônio $\left(\mathrm{NH}_{4}^{+}\right)$, nitrogênio gás $\left(\mathrm{N}_{2}\right)$, nitrito $\left(\mathrm{NO}_{2}^{-}\right)$, nitrato $\left(\mathrm{NO}_{3}^{-}\right)$e nitrogênio orgânico. No esgoto doméstico o nitrogênio encontra-se, principalmente, na forma amoniacal e na forma de nitrogênio orgânico, a qual consiste em uma mistura complexa de amino $\left(\mathrm{NH}_{2}^{-}\right)$ compostos, incluindo proteínas e aminoácidos presentes em resíduos humanos. $\mathrm{O}$ nitrogênio orgânico é facilmente convertido em amoniacal por via bacteriana de decomposição por processo de amonificação. O nitrato e nitrito são formas oriundas da decomposição biológica da matéria orgânica nitrogenada. O lançamento de despejos contendo elevadas concentrações de compostos nitrogenados nos corpos d'água, causa diversos efeitos adversos, como eutrofização, toxicidade à biota e consumo de oxigênio dissolvido das águas naturais na etapa de oxidação biológica, desse modo alternativas de tratamento eficientes na remoção de nutrientes têm recebido crescente atenção (Metcalf e Eddy, 2014).

Devido às diferentes condições ambientais requeridas por bactérias nitrificantes e 
desnitrificantes, a remoção total de nitrogênio em estações de tratamento de esgoto convencionais é comumente atingida em sistemas com dois estágios ou em reatores sequenciais em batelada, nos quais a nitrificação e desnitrificação são atingidas por separação temporal. No entanto, estudos recentes demonstram que estas duas importantes etapas podem ocorrer em um mesmo reator em sistemas de BRM. Esse processo é denominado Nitrificação e Desnitrificação Simultânea (NDS) (Capodici et al., 2015; Vijayalayan et al., 2014; Lin et al., 2013).

De modo geral, a NDS é baseada na formação de um núcleo anóxico no interior do floco biológico e uma região aeróbia na parte externa do floco. Para que essa estrutura de floco seja atingida em sistemas BMR, utiliza-se aeração intermitente (Lin et al., 2013). Existem vários fatores que influenciam a NDS em BRM tais como estrutura, tamanho, densidade e concentração dos flocos de lodo, tempo de detenção hidráulico, concentrações da mistura de sólidos suspensos, concentração de $\mathrm{OD}$, relação Alimento/Microrganismo (A/M), relação Carbono/Nitrogênio $(\mathrm{C} / \mathrm{N})$ e $\mathrm{pH}$. Esses parâmetros têm forte impacto na produção das substâncias poliméricas extracelulares (EPS) e produtos microbiológicos solúveis (SMP), os quais são reconhecidos por estimular a formação de depósito na superfície das membranas (Guadie et al., 2014).

Estudos prévios mostraram o grande sucesso obtido na aplicação de sistemas BMR para remoção de nitrogênio de esgoto doméstico ou sintético, em escalas de laboratório, piloto e real. Contudo, informações sobre as comunidades nitrificantes em sistemas BMR e sua relação com a eficiência de nitrificação e as condições de operação ainda são escassas (Reboleiro-Rivas et al., 2015; Guadie et al., 2014; Yao et al., 2013; Villain e Marrot, 2013; Zuthi et al., 2012). Desse modo, o entendimento dos mecanismos envolvidos no processo de nitrificação e desnitrificação simultânea precisam ser melhor compreendidos para que os sistemas de tratamentos por BMR operando em condição de NDS sejam otimizados. Nesse sentido, o presente estudo objetivou avaliar a remoção de matéria orgânica e nitrogênio por NDS de esgoto doméstico por sistema de BRM.

\section{MATERIAIS E MÉTODOS}

O sistema aeróbio de BRM em escala piloto, com volume total de $120 \mathrm{~L}$, tratando esgoto doméstico, foi investigado por 60 dias. O sistema de BRM era composto por dois tanques, sendo a recirculação do lodo do tanque de membrana feita por air lift. O módulo de membranas de ultrafiltração utilizado foi do tipo placa plana (Martin System AG) com 6,25 m² de área útil e membranas com tamanho de poro menor que $0,1 \mu \mathrm{m}$. O cassete de membranas possuía aeradores acoplados a sua estrutura, vazão máxima de permeado de $130 \mathrm{~L} \mathrm{~h}^{-1} \mathrm{e}$ dimensões de 42,3 x $28,9 \times 80,5 \mathrm{~cm}$. A razão entre os períodos de filtração e de relaxamento foi de $9: 1 \mathrm{~min} / \mathrm{min}$.

A unidade piloto operou com concentração de oxigênio dissolvido e medição de $\mathrm{pH}$ controlados. A entrada de ar no reator foi controlada por uma válvula solenóide, mantendo a concentração de OD no reator entre 0,5 e $0,8 \mathrm{mg}$ de $\mathrm{O}_{2} \cdot \mathrm{L}^{-1}$. A concentração de oxigênio dissolvido no reator foi monitorada por sensor de luminescência (Thermo Scientific OD). O $\mathrm{pH}$ foi mantido em torno de 7,0 com dosagem de solução de hidróxido de sódio por bomba dosadora acoplada a um controlador (ECO-PH, Etatron). Um esquema da unidade piloto pode ser observado na Figura 1.

O monitoramento do potencial de óxido-redução (POR) foi realizado por sensor (Aqua Sensor Datastic ORP Measurement System, Thermo Scientific). Para este sensor, valores positivos indicam reações de oxidação e valores negativos indicam reações de redução. $\mathrm{O}$ POR foi utilizado para identificar se a atividade biológica encontrava-se em condição aeróbia, anaeróbia ou anóxica. Todos os experimentos foram conduzidos em temperatura ambiente. 
Foram utilizados também sensores para medir temperatura, pressão (Marca Gulton) e vazão (Marca Burkert, Modelo 8611). Todos esses sensores foram conectados a um data logger (Marca Novus) para armazenar os parâmetros monitorados.
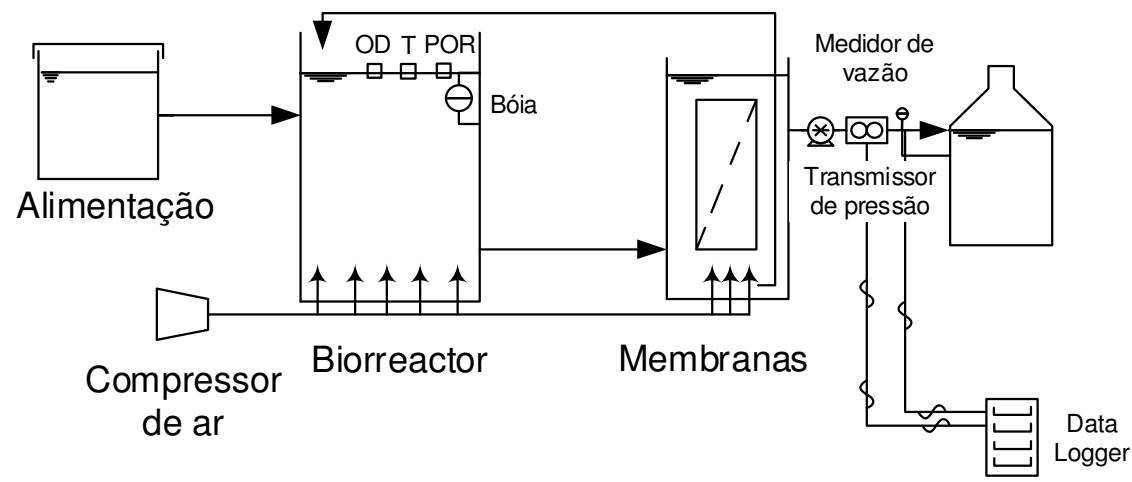

Figura 1. Esquema da unidade piloto de BMR.

Durante a operação, o controle de depósito foi feito de modo contínuo, com cisalhamento causado por passagem de ar, relaxamento de sucção das membranas e limpeza química a cada 20 dias com solução de hipoclorito de sódio $\left(500 \mathrm{mg} \mathrm{L}^{-1}\right)$. Para avaliar partículas presentes no permeado, a turbidez foi monitorada com uso de turbidímetro (Marca Hach, modelo 2100Q). O monitoramento da qualidade do permeado foi feito por meio de coleta semanal de amostras e análise para avaliar parâmetros como demanda química de oxigênio (DQO), demanda bioquímica de oxigênio $\left(\mathrm{DBO}_{5}\right)$ (Analisador Aqualytic - Oxi Direct) e carbono orgânico total (Analisador de Carbono Orgânico da SHIMADZU), nitrogênio total Kjeldahl, nitrogênio amoniacal e fósforo total.

As análises de demanda química de oxigênio, nitrogênio amoniacal, nitrogênio total Kjeldahl, fósforo total, sólidos suspensos totais no liquor misto (SSTLM) e sólidos suspensos voláteis no liquor misto (SSVLM) seguiram metodologia preconizada no Standard Methods for the Examination of Water and Wastewater (APHAet al., 1995).

A quantificação de substâncias poliméricas extracelulares (SPE) e das substâncias poliméricas solúveis (SPS), presentes no liquor misto do reator, foram quantificadas de acordo com métodologia apresentada por Judd ( 2011).

A idade do lodo $(\Theta)$ foi determinada por meio da Equação 1, isolando-se o valor de $\Theta$ (Grady et al., 1999).

$$
\mathrm{V}=\frac{\mathrm{Y}_{\mathrm{H}} \cdot \theta \cdot \mathrm{Q} \cdot\left(\mathrm{S}_{\mathrm{S} 0}-\mathrm{S}_{\mathrm{S}}\right)}{\mathrm{X}_{\mathrm{BH}} \cdot\left(1+\theta \cdot \mathrm{b}_{\mathrm{L}, \mathrm{H}}\right)}
$$

em que:

V é o volume do reator $(\mathrm{L})$;

$\mathrm{Y}_{\mathrm{H}}$ é a produção de biomassa em função da DQO consumida (mg DQOformada.mg DQOremov $^{-1}$ ) sendo adotado o valor de 0,6 (Van Haandel e Marais, 1999); $\Theta$ é a idade do lodo (h);

Q é a vazão $\left(\mathrm{m}^{3} \mathrm{~h}^{-1}\right)$;

$\mathrm{S}_{\mathrm{S} 0}$ é a DQO afluente $\left(\mathrm{mg} \mathrm{L}^{-1}\right) \mathrm{e}$

$\mathrm{S}_{\mathrm{S}}$ é a DQO efluente $\left(\mathrm{mg} \mathrm{L}^{-1}\right)$;

$\mathrm{X}_{\mathrm{BH}}$ é a biomassa heterotrófica ativa (mg DQO.L $\left.\mathrm{L}^{-1}\right)$ e 
$\mathrm{b}_{\mathrm{L}, \mathrm{H}}$ é a constante de decaimento endógeno para bactérias heterotróficas $\left(\mathrm{h}^{-1}\right)$, sendo o valor de $b_{L, H}$ utilizado igual a $0,0028 \mathrm{~h}^{-1}$ (corrigido para $23{ }^{\circ} \mathrm{C}$ ). Segundo Van Haandel e Marais (1999), existe uma relação entre DQO e massa de sólidos em suspensão voláteis (SSV) igual a 1,5 mg DQO.mg.SSV ${ }^{-1}$, pela qual $\mathrm{X}_{\mathrm{BH}}$ foi determinada.

Esse estudo foi dividido em duas etapas: partida do sistema e operação em condição de nitrificação e desnitrificação simultânea. A partida do sistema durou cerca de 35 dias. O lodo utilizado como inóculo foi obtido a partir do descarte de lodo de outra planta piloto de lodos ativados tratando o mesmo esgoto doméstico. O tempo de detenção hidráulico foi de 6,5 horas.

A produção de permeado e desempenho das membranas foram avaliados por meio do fluxo, da permeabilidade e da pressão transmembrana. O fluxo das membranas, J, foi calculado de acordo com a Equação 2.

$$
J=\frac{Q_{p}}{A_{m}}
$$

em que:

J é o fluxo de permeado através das membranas $\left(\mathrm{L} \mathrm{m}^{-2} \mathrm{~h}^{-1}\right)$,

$\mathrm{Q}_{\mathrm{p}}$ representa a vazão de permeado $\left(\mathrm{L} \mathrm{h}^{-1}\right) \mathrm{e}$

$\mathrm{A}_{\mathrm{m}}$ a área útil das membranas $\left(\mathrm{m}^{2}\right)$. A permeabilidade das membranas, $\mathrm{J}_{\mathrm{p}}$, foi calculada de acordo com a Equação 3.

$$
J_{p}=\frac{J}{\Delta P_{t}}
$$

em que:

J é o fluxo de permeado $\left(\mathrm{L} \mathrm{m}^{-2} \mathrm{~h}^{-1}\right)$ e

$\Delta \mathrm{P}_{\mathrm{t}}$ a pressão transmembrana (bar) (Judd, 2011).

\section{RESULTADOS E DISCUSSÃO}

\subsection{Desempenho hidráulico do sistema}

O fluxo médio de permeado através das membranas (Equação 2) foi em torno de 4,5 $\mathrm{L} \mathrm{m}^{2} \mathrm{~h}^{-1}$. A permeabilidade (Equação 3), na etapa de partida esteve em torno de $49 \mathrm{~L} \mathrm{~m}^{2} \mathrm{~h}^{-1}$ bar $^{-1}$ (Figura 2, lado esquerdo) e, na etapa sob condição de NDS (Figura 2, lado direito), a permeabilidade foi cerca de $30 \mathrm{~L} \mathrm{~m}^{-2} \mathrm{~h}^{-1}$ bar $^{-1}$.

A pressão transmembrana do sistema (Figura 2) variou de 0,04 bar a 0,3 bar. A causa do aumento de pressão transmembrana pode ser atribuída à formação de depósito, por isso, sempre que foi registrado pressão superior a 0,3 bar realizou-se limpeza química das membranas com solução de hipoclorito de sódio. Sistemas BRM possuem como característica baixas pressões de operação (Judd, 2015).

A relação Alimento/Microrganismo manteve-se em 0,4 kg DBO $5 . \mathrm{kg} \mathrm{SSVML}^{-1} \mathrm{dia}^{-1}$. Para essa mesma relação Alimento/Microrganismo, os autores He et al. (2009) já haviam relatado remoção de NTK superiores a 90\% em sistemas BRM, operando em condição de NDS.

Na Figura 3 estão os dados de permeabilidade em relação à concetração de sólidos em suspensão totais no liquor misto (SSTLM) verificados durante o período de operação do sistema. 


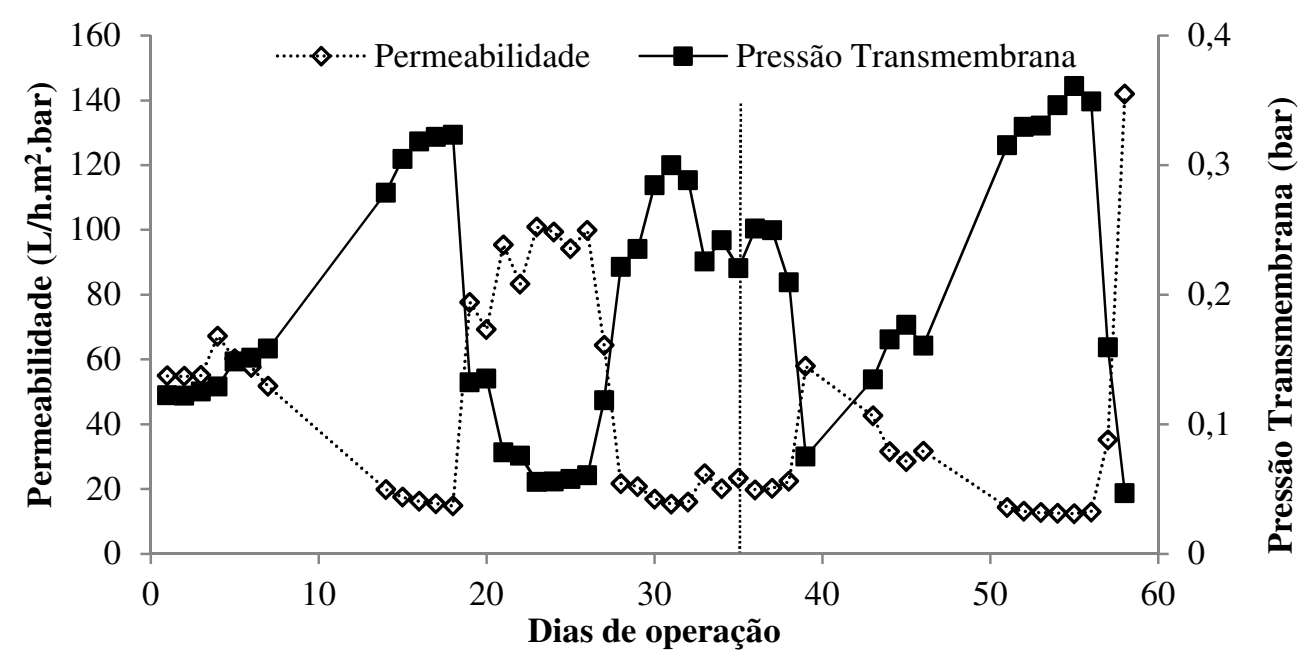

Figura 2. Variação da permeabilidade em relação à pressão transmembrana.

A concentração média de SSTLM e SSVLM durante todo o período de operação foi de $3058 \mathrm{mg} \mathrm{L}^{-1}$ e $2768 \mathrm{mg} \mathrm{L}^{-1}$, respectivamente. Ao observar o comportamento da permeabilidade em relação à concentração de SSTLM (Figura 3), verificou-se que houve aumento da permeabilidade de 20 para valores em torno de $100 \mathrm{~L} \mathrm{~m}^{-2} \mathrm{~h}^{-1}$ bar $^{-1}$ quando a concentração de SSTLM esteve próxima de $6000 \mathrm{mg} \mathrm{L}^{-1}$. Judd (2011) já havia relatado que o desempenho hidráulico de sistemas BRM é melhor quando a operação se dá com maiores concentrações de SSTLM.

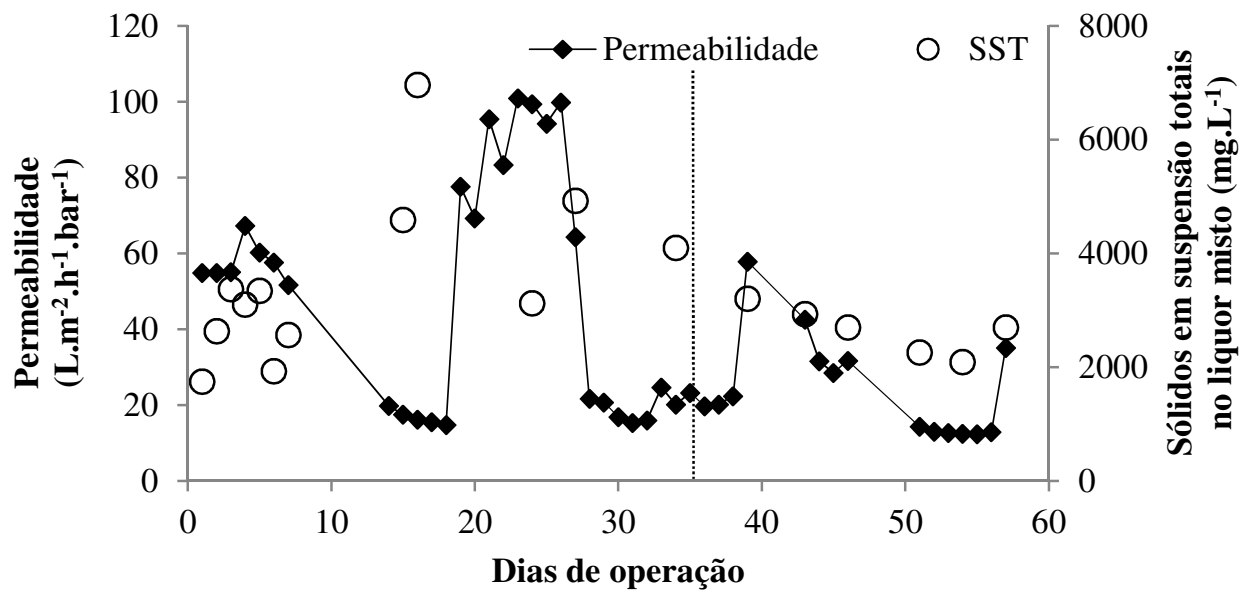

Figura 3. Variação da permeabilidade em relação à concentração de SSTLM.

As concentrações médias de SSTLM e SSVLM na etapa de partida foram: 3532 e $3190 \mathrm{mg} \mathrm{L}^{-1}$, respectivamente (Figura 4, lado esquerdo). As concentrações médias de SSTLM e SSVLM na etapa com NDS foram: 2855 e $2528 \mathrm{mg} \mathrm{L}^{-1}$, respectivamente (Figura 4, lado direito). A razão SSVLM/SSTLM variou entre 0,7 e 0,9, indicando que 70 a $90 \%$ dos sólidos presentes no liquor misto atuou como biomassa ativa para degradação (Figura 4). Os autores Phan et al. (2014) verificaram razão SSVLM/SSTLM em torno de 0,8 em reator operando em condição de nitrificação e desnitrificação simultânea, corroborando com dados aqui verificados.

A idade do lodo foi estimada em 3 dias (Equação 1). Embora a literatura clássica relate que a desnitrificação ocorra com idades de lodo superior a 12 dias (Metcalf e Eddy, 2014), alguns autores como Capodici et al. (2015) atingiram condições de NDS em sistemas de BRM 
com lodo de idade de 5 dias. Isto indica que os mecanismos envolvidos no processo de nitrificação e desnitrificação simultâneas, por meio da variação da concentração de oxigênio no reator, podem ser diferentes daqueles observados em sistemas nos quais estes processos ocorrem em reatores independentes.

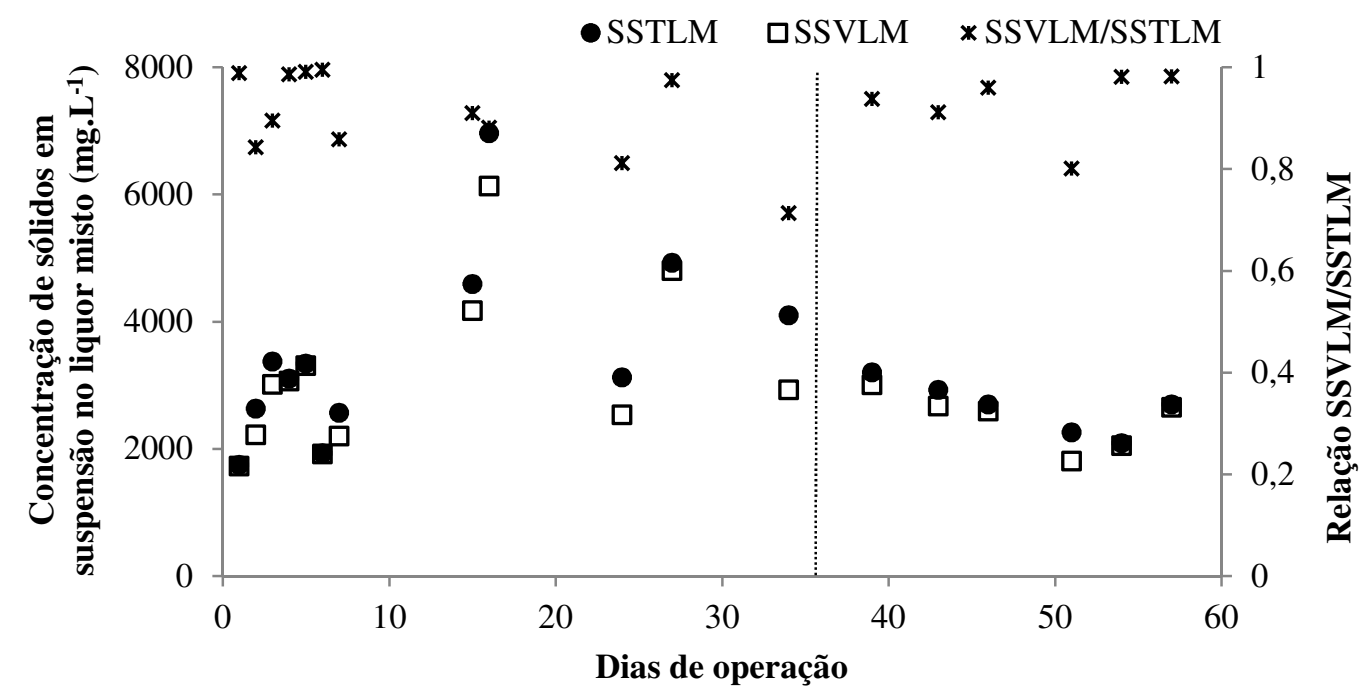

Figura 4. Variações das concentrações de SSTLM e SSVLM e razão SSVLM/SSTLM no reator BRM.

\subsection{Qualidade do permeado produzido}

Na Figura 5 é possível observar que a eficiência de remoção de turbidez pelo sistema BRM, foi sempre superior a $99 \%$. Verifica-se que a turbidez do afluente não interfere na eficiência de remoção de turbidez no permeado, com turbidez média de 0,4 UNT.

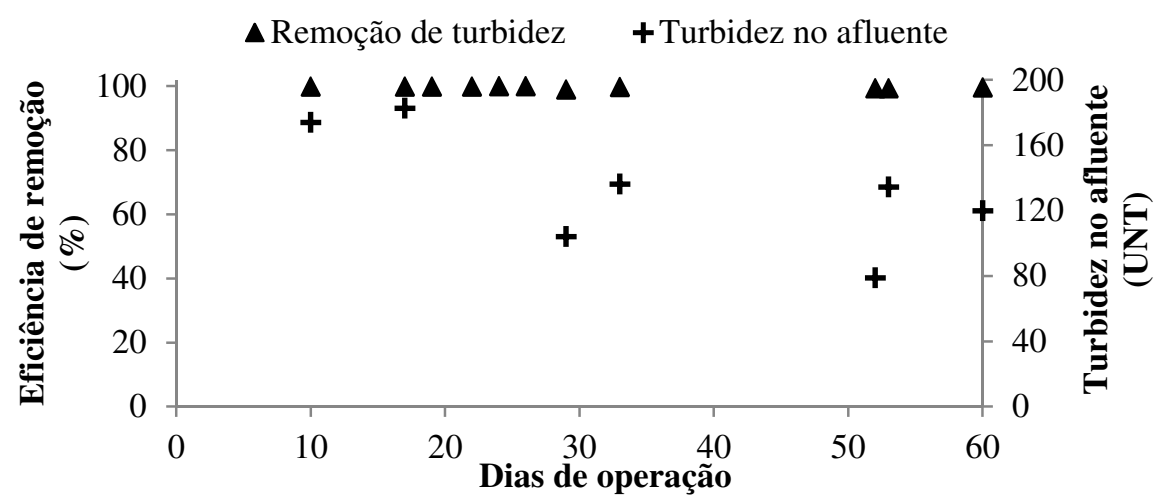

Figura 5. Eficiência de remoção de turbidez e turbidez afluente no sistema BRM.

Na Tabela 1 são apresentados os parâmetros médios para caracterizar a qualidade da alimentação e do permeado, bem como as eficiências médias de remoção.

A boa qualidade do permeado produzido é retratada pelas elevadas eficiências de remoção obtidas para DQO, nitrogênio amoniacal e total, sempre superiores a $80 \%$ (Tabela 1). Autores como Capodici et al. (2015) obtiveram eficiência de remoção de DQO em torno de $95 \%$ e de nitrogênio total em torno de $75 \%$, no entanto as concentrações iniciais de nitrogênio não foram relatadas. Os autores Phan et al. (2014) também relataram eficiência de remoção de nitrogênio total superior a $80 \%$ por sistema MBR com operação sob condição de nitrificação e desnitrificação simultânea. 
Tabela 1. Caracterização do efluente durante a etapa de partida do sistema.

\begin{tabular}{ccccc}
\hline Parâmetros & Alimentação & Permeado & Unidade & $\begin{array}{c}\text { Eficiência de } \\
\text { remoção (\%) }\end{array}$ \\
\hline DQO $^{*}$ & $625 \pm 26$ & $30 \pm 21$ & $\mathrm{mg} \mathrm{O} / \mathrm{L}$ & 95 \\
$\mathrm{DBO}_{5}^{*}$ & $260 \pm 47$ & $13 \pm 7$ & $\mathrm{mg} \mathrm{O}_{2} / \mathrm{L}$ & 94 \\
$\mathrm{NH}_{3}-\mathrm{N}^{*}$ & $54 \pm 7,3$ & $5 \pm 5,4$ & $\mathrm{mg} \mathrm{N} / \mathrm{L}$ & 90 \\
$\mathrm{NTK}^{*}$ & $85 \pm 24,1$ & $16 \pm 11,1$ & $\mathrm{mg} \mathrm{N} / \mathrm{L}$ & 81 \\
P-total $^{*}$ & $6 \pm 0,6$ & $4 \pm 1,1$ & $\mathrm{mg} \mathrm{P} / \mathrm{L}$ & 33 \\
\hline
\end{tabular}

* DQO - Demanda química de oxigênio.

$\mathrm{DBO}_{5}$ - Demanda bioquímica de oxigênio.

$\mathrm{NH}_{3}-\mathrm{N}$ - Nitrogênio amoniacal.

NTK - Nitrogênio total Kjeldahl.

P-total - fósforo total.

A eficiência de remoção de fósforo de $33 \%$ representa valores típicos para sistemas de lodos ativados sem adição de produtos químicos.

As análises de carbono orgânico total (COT) revelaram concentração média de $61 \mathrm{mg} \mathrm{L}^{-1}$ de COT no afluente e de $15 \mathrm{mg} \mathrm{L}^{-1}$ no permeado. Na Figura 6 pode ser observado o comportamento da eficência de remoção de COT pelo sistema de BRM durante o período de monitoramento.

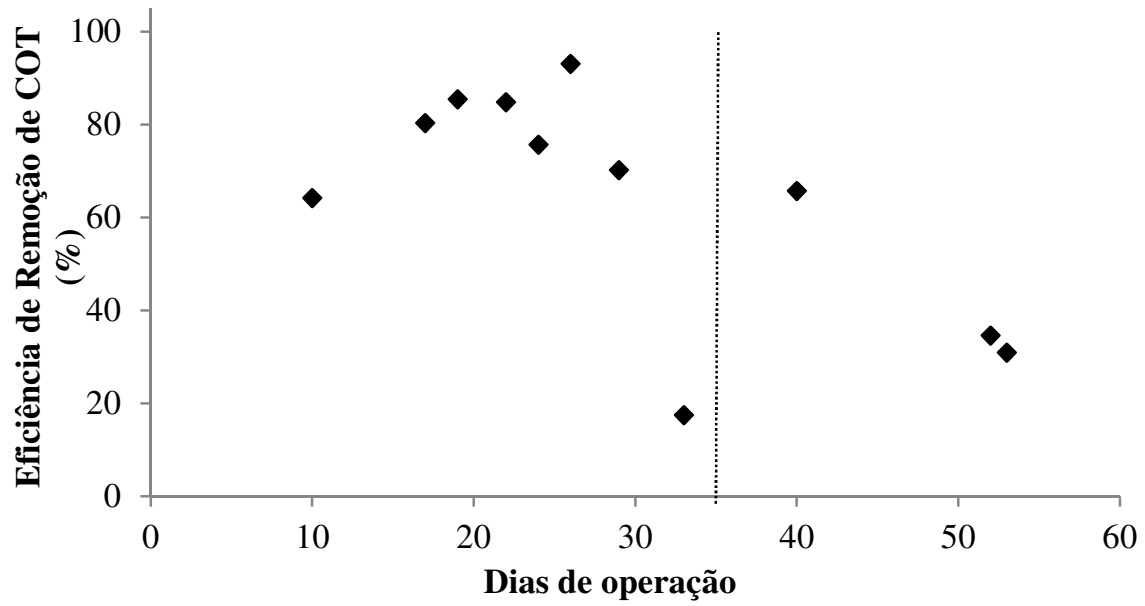

Figura 6. Eficiência de Remoção de COT.

Houve redução na eficiência de remoção de COT após 35 dias de operação (Figura 5, lado direito). O aumento do COT no permeado sugere o acúmulo de substâncias microbiológicas solúveis de baixa degradabilidade, ou seja, a parcela solúvel das substâncias poliméricas extracelulares.

Para o sistema de BRM avaliado, a concentração média de substância polimérica extracelular (SPE) no liquor misto foi de $104 \mathrm{mg} \mathrm{COT.g} \mathrm{SSV}{ }^{-1}$ e de substâncias poliméricas solúveis (SPS) foi de $31 \mathrm{mg}$ COT.g SSV${ }^{-1}$, o que pode estar relacionado à menor eficiência de remoção de COT. Capodici et al. (2015) verificaram valores de SPE entre 100 e $200 \mathrm{mg}$ COT.g SSV ${ }^{-1}$ e para SPS, valores entre 40 e $50 \mathrm{mg} \mathrm{COT.g} \mathrm{SSV}{ }^{-1}$. Assim, os valores verificados para a unidade piloto avaliada estão em acordo com o relatado na literatura.Alguns autores, como Judd (2011), acreditam que a formação de depósito nas 
membranas esteja associada ao material polimérico excretado por biomassa jovem.

\subsection{Remoção de nitrogênio por nitrificação e desnitrificação simultânea}

Para que houvesse condições aeróbias e anóxicas no reator, houve controle da concentração de OD. Após 35 dias de operação, o sistema passou a operar em condição de NDS, pois a biomassa mostrou-se estável e a concentração máxima de oxigênio dissolvido foi mantida em $0,8 \mathrm{mg} \mathrm{L}^{-1}$. Na Figura 7 podem ser observados os dados de eficiência de remoção de nitrogênio total em função da concentração de oxigênio dissolvido OD na etapa de partida (Figura 7, lado esquerdo) e de operação em NDS do sistema (Figura 7, lado direito).

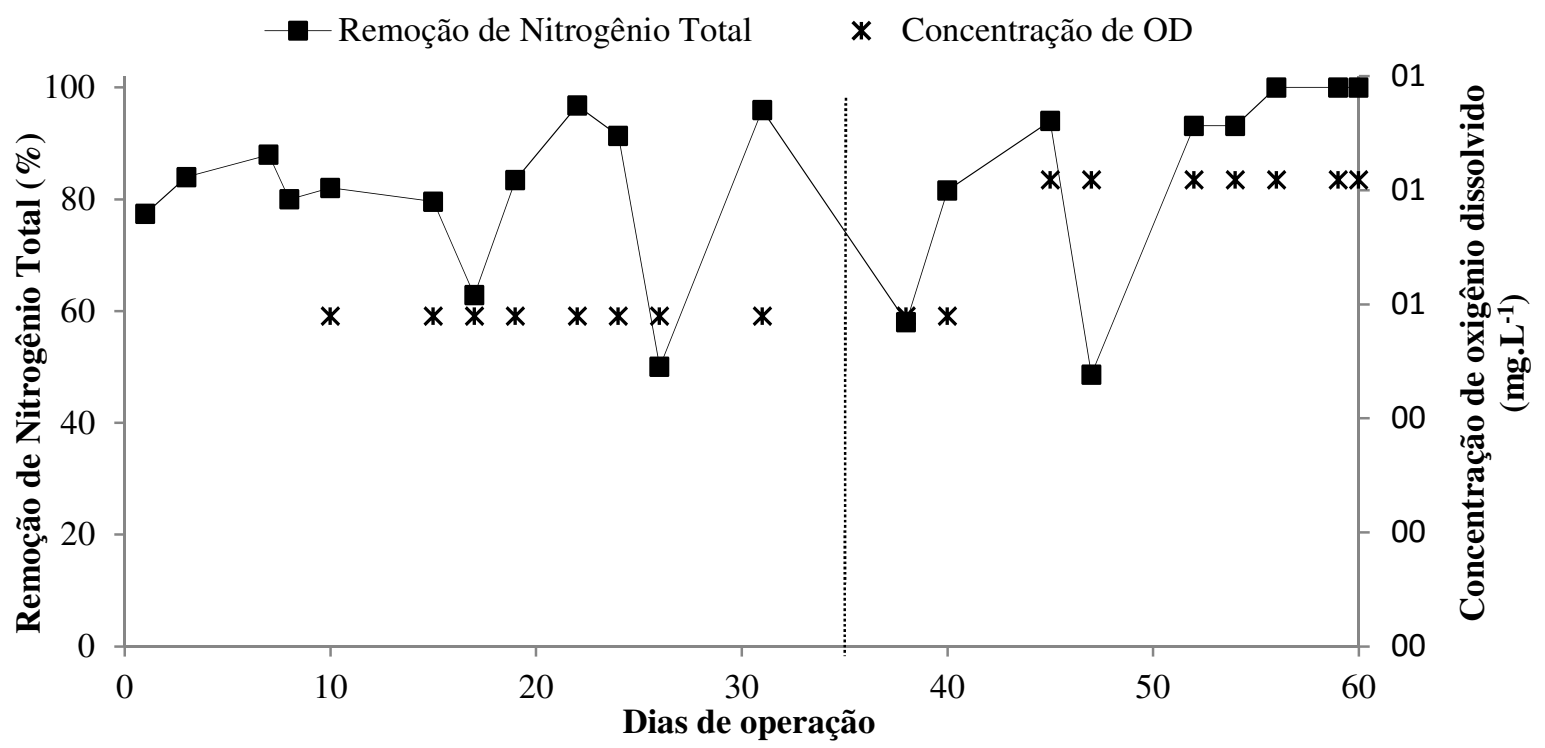

Figura 7. Remoção de nitrogênio total e variação da concentração de OD.

Tais condições tornaram possível a ocorrência de nitrificação e desnitrificação simultânea, resultando em elevada eficiência de remoção de nitrogênio total, pois a faixa de OD selecionada é um fator decisivo no balanço entre os microrganismos que atuam em conjunto para que ocorra a NDS no sistema (Capodici et al., 2015; Chen et al., 2012).

Para avaliar as condições anóxicas no reator, o potencial de óxido-redução (POR) foi monitorado. A remoção de nitrogênio total e as variações do POR podem ser observados na Figura 8.

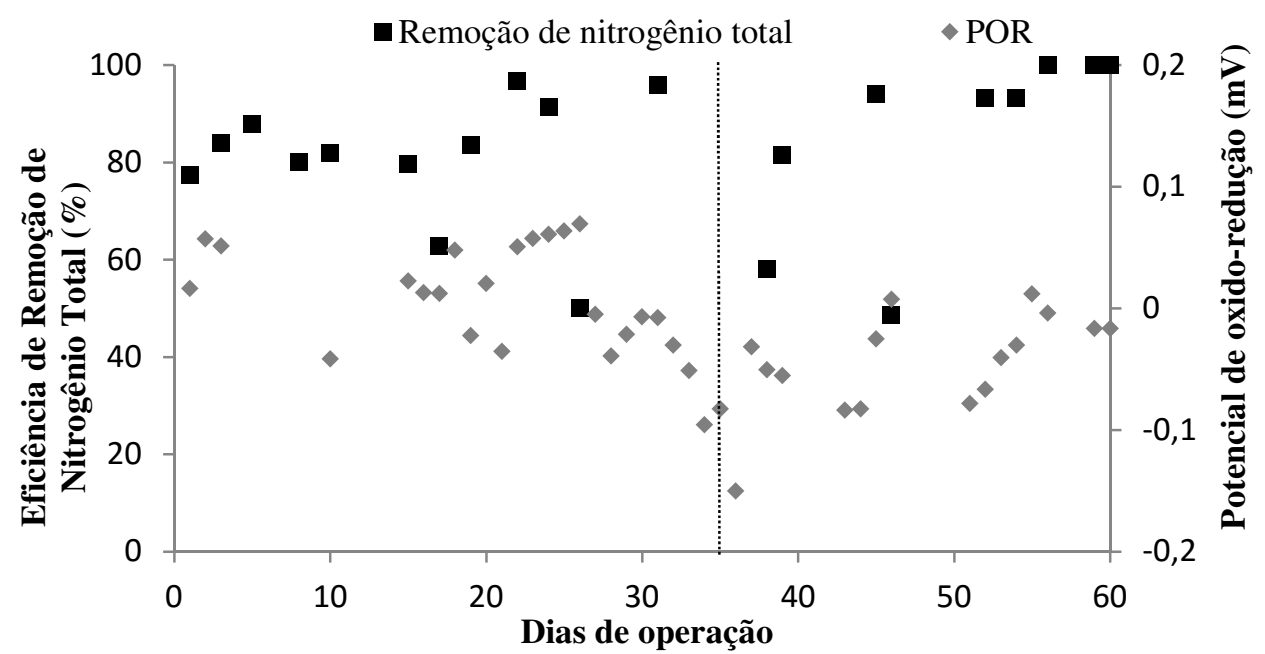

Figura 8. Eficiência de Remoção de Nitrogênio Total em relação ao POR. 
Ao observar a Figura 8, verifica-se que após cerca de 35 dias de operação (Figura 8, lado direito), quando a condição de NDS teve início, os dados de POR mantiveram-se entre $-0,1$ e 0 , indicando que as condições de oxidação e redução estavam se alternando e possibilitando a NDS. A ocorrência de NDS foi confirmada quando se constatou a elevada eficiência de remoção de nitrogênio total, após 35 dias de operação (Figuras 7 e 8, lado direito).

\section{CONCLUSÕES}

Os resultados obtidos nesse estudo demonstram que a operação de sistemas de BRM é viável sob condições de NDS, pois a unidade piloto pôde operar com elevada eficiência para remoção de matéria orgânica. Durante o estudo, a eficiência de remoção de DQO e nitrogênio total foi maior que $90 \%$, sob condições de NDS.

Embora essa configuração de operação seja bastante eficiente, desafios operacionais como garantia de elevada produção de permeado pelas membranas ainda existem, pois em decorrência das condições de operação pode haver aumento da ocorrência de depósitos nas membranas. Desse modo, faz-se necessário mais estudos voltados para NDS em BRM para completo entendimento do precesso.

\section{AGRADECIMENTOS}

Os autores gostariam de expressar sua gratidão à Fundação de Amparo à Pesquisa do Estado de São Paulo - FAPESP (2013/06821-6) e FINEP pelo suporte financeiro e ao CIRRA - Escola Politécnica da Universidade de São Paulo pela estrutura fornecida.

\section{REFERÊNCIAS}

AMERICAN PUBLIC HEALTH ASSOCIATION - APHA; AMERICAN WATER WORKS ASSOCIATION - AWWA; WATER ENVIROMENT FEDERATION - WEF. Standard methods for the examination of water and wastewater. $20^{\text {th }}$ ed. Washington, D.C., 1995.

CAPODICI, M.; DI BELLA, G.; DI TRAPANI, D.; TORREGROSSA, M. Case study: pilot scale experiment with MBR operated in intermittent aeration condition: analysis of biological performance. Bioresource Technology, v. 177, p. 398-405, 2015. http://dx.doi.org/10.1016\%2Fj.biortech.2014.11.075

CHEN, W.; LIU, J.; XIE, F. Identification of the moderate SRT for reliable operation in MBR. Desalination, v. 286, p. 263 - 267, 2012. http://dx.doi.org/10.1016\%2Fj.desal.2011.11.033

DING, A.; QU, F.; LIANG, H.; MA, J.; HAN, Z.; YU, H.; GUO, S.; LI, G. A novel integrated vertical membrane bioreactor (IVMBR) for removal of nitrogen from synthetic wastewater/domestic sewage. Chemical Engineering Journal, v. 223, p. 908-914, 2013. http://dx.doi.org/10.1016\%2Fj.cej.2013.01.096

GRADY, C. P. L.; DIGGER, G. T.; LIM, H. C. Biological wastewater treatment. 2. ed. New York: IWA; CRC Press, 1999.

GUADIE, A.; XIA, S.; ZHANG, Z.; ZELEKE, J.; GUO, W.; NGO, H. H. et al. Effect of intermittent aeration cycle on nutrient removal and microbial community in a fluidized bed reactor-membrane bioreactor combo system. Bioresource Technology, v. 156, p. 195-205, 2014. http://dx.doi.org/10.1016\%2Fj.biortech.2014.01.008 
HE, S.; XUE, G.; WANG, B. Factors affecting simultaneous nitrification and de-nitrification (SND) and its kinetics model in membrane bioreactor. Journal of hazardous materials, v. 168, n. 2-3, p. 704-10, 2009.

http://dx.doi.org/10.1016\%2Fj.jhazmat.2009.02.099

HOINKS, J.; DEOWAN, S. A.; PANTEN, V.; FIGOLI, A.; HUANG, R. R.; DRIOLI, E. Membrane Bioreactor (MBR) Technology - a promising approach for industrial water reuse. Procedia Engineering, v. 33, p. 234-241, 2012. http://dx.doi.org/10.1016\%2Fj.proeng.2012.01.1199

JUDD, S. The MBR book. 2. ed. Oxford: Elsevier, 2011. 526 p.

JUDD, S. The status of industrial and municipal effluent treatment with membrane bioreactor technology. Chemical Engineering Journal, 2015. In press. http://dx.doi.org/10.1016/j.cej.2015.08.141

KHAN, S. J.; PARVEEN, F.; AHMAD, A.; HASHMI, I.; HANKINS, N. Performance evaluation and bacterial characterization of membrane bioreactors. Bioresource Technology, v. 141, p. 2-7, 2013. http://dx.doi.org/10.1016\%2Fj.biortech.2013.01.140

LIN, J.; GUO, H.; CHEN, J.; LI, Y. Removal characteristics of pollutants in airlift intermittent circulation membrane bioreactor. Procedia Environmental Sciences, v. 18, p. 592 - 596, 2013. http://dx.doi.org/10.1016\%2Fj.proenv.2013.04.080

METCALF, E.; EDDY, M. Wastewater engineering: treatment and Resource recovery. 5. ed. New York: McGraw Hill, 2014.

PHAN, H. V.; HAI, F. I.; KANG, J.; DAMD, H. K.; ZHANG, R.; PRICE, W. E. et al. Simultaneous nitrification/denitrification and trace organic contaminant (TrOC) removal by an anoxic-aerobic membrane bioreactor (MBR). Bioresource Technology, v. 165, p. 96-104, 2014. http://dx.doi.org/10.1016\%2Fj.biortech.2014.03.094

REBOLEIRO-RIVAS, R.; MARTÍN-PASCUAL, J.; JUÁREZ-JIMÉNEZ, B.; POYATOS, J. M.; VÍLCHEZ-VARGAS, R.; VLAEMINCK, S. E. et al. Nitrogen removal in a moving bed membrane bioreactor for municipal sewage treatment: Community differentiation in attached biofilm and suspended biomass. Chemical Engineering Journal, v. 277, p. 209-218, 2015. http://dx.doi.org/10.1016\%2Fj.cej.2015.04.141

RODRÍGUEZ-HERNÁNDEZ, L.; ESTEBAN-GARCÍA, A. L.; TEJERO, I. Comparison between a fixed bed hybrid membrane bioreactor and a conventional membrane bioreactor for municipal wastewater treatment: a pilot-scale study. Bioresource Technology, v. 152, p. 212-219, 2014.

http://dx.doi.org/10.1016\%2Fj.biortech.2013.10.081

ROEST, H. F.; LAWRENCE, D. P.; BENTEM, A. G. N. Membrane bioreactors for municipal wastewater treatment. London: IWA Publishing, 2006. 141 p.

SCHNEIDER, R. P.; TSUTIYA, M. T. Membranas filtrantes para o tratamento de água, esgoto e água de reúso. São Paulo: ABES, 2001.

SUBTIL, E. L.; MIERZWA, J. C.; HESPANHOL, I. Comparison between a conventional membrane bioreactor (C-MBR) and a biofilm membrane bioreactor (BF-MBR) for domestic wastewater treatment. Brazilian Journal of Chemical Engineering, v. 31, n. 3, 2014. http://dx.doi.org/10.1590/0104-6632.20140313s00002890 
SUBTIL, E. L.; HESPANHOL, I.; MIERZWA, J. C. Biorreatores com membranas submersas (BRMs): alternativa promissora para o tratamento de esgotos sanitários para reúso. Revista Ambiente \& Água, v. 8, n. 3, 2013. http://dx.doi.org/10.4136/ambi-agua.1230

VAN HAANDEL, A.; MARAIS, G. O comportamento do sistema de lodo ativado. Campina Grande: Epgraf, 1999.

VIJAYALAYAN, P.; THANH, B. X.; VISVANATHAN, C. Simultaneous nitrification denitrification in a batch granulation membrane airlift bioreactor. International Biodeterioration \& Biodegradation, v. 95, p. 139-143, 2014. http://dx.doi.org/10.1016\%2Fj.ibiod.2014.05.020

VILLAIN, M.; MARROT, B. Influence of sludge retention time at constant food to microorganisms ratio on membrane bioreactor performances under stable and unstable state conditions. Bioresource Technology, v. 128, p. 134-144, 2013. http://dx.doi.org/10.1016\%2Fj.biortech.2012.10.108

WEN, G.; MA, J.; ZHANG, L. Membrane bioreactor in water treatment. p. 195-209, 2010 .

YAO, Y. C.; ZHANG, Q. L.; LIU, Z. P. Simultaneous removal of organic matter and nitrogen by a heterotrophic nitrifying-aerobic denitrifying bacterial strain in a membrane bioreactor. Bioresource Technology, v. 143, p. 83-87, 2013.

http://dx.doi.org/10.1016\%2Fj.biortech.2013.05.120

ZUTHI, M. F. R.; NGO, H. H.; GUO, W. S. Modelling bioprocesses and membrane fouling in membrane bioreactor (MBR): a review towards finding an integrated model framework. Bioresource Technology, v. 122, p. 119-129, 2012.

http://dx.doi.org/10.1016\%2Fj.biortech.2012.04.090 


Ambiente \& Água - An Interdisciplinary Journal of Applied Science
ISSN 1980-993X - doi:10.4136/1980-993X
www.ambi-agua.net
E-mail: ambi.agua@gmail.com

\title{
Redução da toxicidade aguda de lixiviado de aterro sanitário em co-tratamento com esgoto doméstico pelo processo integrado de lodo ativado com biofilme em leito móvel
}

\author{
doi:10.4136/ambi-agua.1835 \\ Received: 08 Jan. 2016; Accepted: 15 Mar. 2016 \\ Fábio Campos*; Roque Passos Piveli \\ Escola Politécnica da Universidade de São Paulo (EPUSP), São Paulo, SP, Brasil \\ Departamento de Engenharia Hidráulica e Ambiental da Escola Politécnica da USP \\ *Autor correspondente: e-mail: fcampos@usp.br, \\ rppiveli@usp.br
}

\section{RESUMO}

Neste estudo objetivou-se avaliar a redução da toxicidade aguda no efluente gerado pelo processo híbrido IFAS (Integrated Fixed-Film Activated Sludge) tratando lixiviado de aterro sanitário com esgoto doméstico, por meio de ensaios de toxicidade aguda sobre bactérias marinhas Allivibrio fischeri e microcrustáceo Daphnia similis. Com o intuito de avaliar a capacidade do tratamento no abrandamento da toxicidade do afluente, foram desenvolvidas três etapas experimentais com contribuições de lixiviado na composição do afluente de: $5 \%, 10 \%$ e $20 \%$ da carga total de DBO. De uma forma geral, os resultados demonstram que mesmo na maior contribuição de lixiviado não ocorreram alterações significativas no comportamento e eficiência do processo biológico; contudo, em relação ao grau de toxicidade aguda observado no afluente, foi possível se obter apenas alteração na sua classificação de Muito Tóxico para Tóxico nos efluentes nas três fases de operação, mesmo chegando a níveis de redução em torno de $70 \%$ como o obtido na última etapa do estudo; o que evidencia a necessidade de um maior controle e avaliação dessa variável. A metodologia empregando a técnica de Microtox ${ }^{\circledR}$ mostrou-se mais sensível aos compostos presente nas amostras quando comparada com a técnica utilizando os microcrustáceos D. similis.

Palavras-chave: ecotoxicologia, processos biológicos, tratabilidade.

\section{Reduction of acute toxicity of landfill leachate in co-treatement with domestic sewage by integrated fixed-film activated sludge reactor}

\begin{abstract}
This study used acute toxicity tests on the marine bacteria Allivibrio fischeri and on microcrustaceans Daphnia similis to evaluate the reduction of acute toxicity in effluent generated by the IFAS (Integrated Fixed Film Activated Sludge) hybrid process, treating landfill leachate with domestic sewage. In order to evaluate the treatment's ability to lessen the toxicity of the effluent, three experimental stages were developed with leachate contributions of 5,10 and $20 \%$ of the total load of BOD in the effluent composition. In general, the results show that, even with the greatest contribution of leachate, no significant
\end{abstract}


alterations were observed in the behavior and efficiency of the biological process; however, with regard to the degree of acute toxicity observed in the affluent, the classification of the effluents changed from Very Toxic to Toxic in three phases of operation, even reaching the reduction levels around $70 \%$ in the last stage of the study, highlighting the need for greater control and evaluation of this variable. The methodology of using the Microtox ${ }^{\circledR}$ technique proved to be more sensitive to compounds present in the samples when compared to the technique using the microcrustaceans $D$. similis.

Keywords: biological processes, ecotoxicology, treatability.

\section{INTRODUÇÃO}

Lixiviados de aterro sanitário são formados por líquidos que percolam a célula do aterro incorporando a si compostos dissolvidos advindos dos processos metabólicos de decomposição e estabilização do resíduo sólido presente, sendo que muitos desses elementos são potencialmente tóxicos (Ferreira, 2010; Qasim e Chiang, 1994).

Isidori et al. (2003) comentam sobre a dificuldade de identificar os contaminantes responsáveis pela toxicidade em virtude da complexidade e da incerteza em torno da biodisponibilidade de seus componentes. Seu grupo realizou um trabalho a fim de avaliar e identificar os compostos tóxicos presentes nos lixiviados, chegando à conclusão de que a toxicidade era em maior parte devido à presença de metais catiônicos bivalentes e amônia, sendo que esta em sua forma não ionizada $\left(\mathrm{NH}_{3}-\mathrm{N}\right)$ eleva o nível de toxidez, fato confirmado por outros autores (Forgier, 1988 apud Welander et al., 1997).

A alta concentração de alcalinidade é também citada como contribuintes da toxicidade do lixiviado por Kjeldsen et al. (2002), assim como a presença de compostos orgânicos recalcitrantes mesmo em pequenas concentrações (Thomas et al., 2009).

De acordo com Gotvajn et al. (2009), mesmo os modernos sistemas de tratamento de efluente não são capazes de eliminar por completo a ação de determinadas substâncias xenobióticas, inibidoras ou genotóxicas, as quais podem permanecer causando impactos sobre a biota aquática.

Mediante a necessidade de aprimoramento do controle da poluição, visando à proteção e preservação dos recursos hídricos no Brasil, o uso de novas ferramentas tem demonstrado ser necessário. Neste sentido, a Resolução CONAMA 357/2005, em Artigo 34, dispõe sobre a obrigatoriedade do controle ecotoxicológico em efluentes sobre espécies representativas de corpos d'água naturais.

Assim, admitindo-se que o envio do lixiviado de aterro sanitário às estações de tratamento de esgoto poderá continuar sendo a alternativa mais viável praticada em nosso sistema de saneamento, faz-se necessário uma avaliação pormenorizada e atualizada das cargas admissíveis e seus efeitos tóxicos sobre as unidades de tratamento, bem como na qualidade do efluente final.

O presente estudo teve por objetivo avaliar a capacidade de redução da toxicidade aguda de lixiviados de aterro sanitário tratado conjuntamente com esgoto doméstico em um processo integrado de lodo ativado com biomídia móvel, por meio de ensaios de toxicidade aguda sobre bactérias marinhas Allivibrio fischeri e microcrustáceo Daphnia similis.

\section{MATERIAL E MÉTODOS}

A pesquisa foi desenvolvida por meio de experimento em escala piloto, sendo colocado em operação um processo híbrido baseado na tecnologia IFAS, por meio de um Reator Integrado de Lodo Ativado com Biofilme em Leito Móvel. 
O processo promove o incremento de biomassa ativa no tanque de aeração de um sistema de lodo ativado mediante a introdução de biomídias móveis, com o propósito de aumentar sua capacidade de retenção de biomassa e melhorar seu desempenho (WEF MOP ${ }^{\circ} 35,2010$ ).

$\mathrm{O}$ reator biológico da unidade piloto (Figura 1) foi construído em chapas de acrílico e dividido em dois compartimentos, sendo que o primeiro, com $270 \mathrm{~L}$ de volume útil e provido de um misturador, operou como câmara anóxica de pré-desnitrificação. $O$ segundo compartimento, com 800 L de volume útil, trabalhou como câmara aerada, contando com 4 difusores de bolhas finas de membrana, instalados em seu fundo para a distribuição do ar fornecido por compressor, a fim de manter a concentração de OD no intervalo de 3,0 a 4,0 $\mathrm{mg} \mathrm{L}^{-1}$.

A unidade piloto possuía um decantador secundário de seção circular, com raspadores de parede e de fundo, contando com uma área superficial de $0,785 \mathrm{~m}^{2}$, e volume útil de $1,47 \mathrm{~m}^{3}$. Fora prevista também elevatória de recirculação do lodo do compartimento aerado para o compartimento anóxico (reciclo interno).

Ambas as câmaras do reator biológico receberam adição de biomídias. Foi utilizado o produto K1 fabricado pela empresa Anox Kaldnes ${ }^{\circledR}$, atualmente pertencente ao grupo Veolia Water, com área superficial específica (protegida) de $300 \mathrm{~m}^{2} \mathrm{~m}^{-3}$ de material suporte. A fração de enchimento de cada câmara, anóxico e aeróbio, foram de 0,3 e 0,5 , respectivamente.

$\mathrm{O}$ esgoto sanitário que alimentou o reator biológico era recalcado para a área da unidade piloto por meio de uma elevatória, recebendo previamente tratamentos primários como: gradeaemento, desarenação, remoção de gordura e decantação primária.

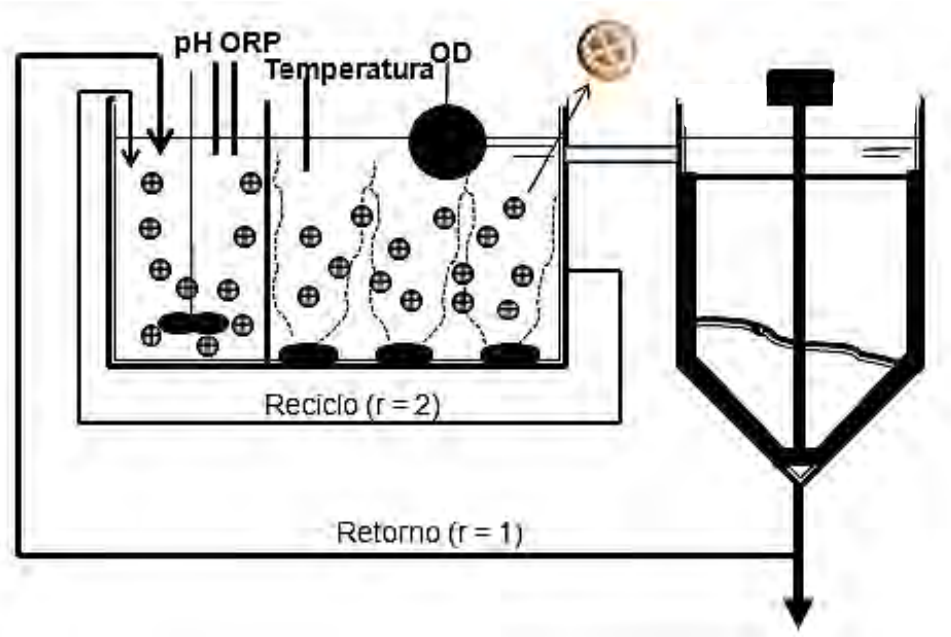

Figura 1. Perfil do sistema em escala piloto.

Com o intuito de atender ao escopo desse projeto, foi utilizado durante toda a pesquisa, lixiviado proveniente do Aterro Sanitário Caieiras (CTR-Caieiras). O referido aterro localiza-se no município de Caieiras, no Estado de São Paulo, situado próximo à Rodovia dos Bandeirantes, km 33, sendo gerido pela empresa Essencis Soluções Ambientais S.A.

Semanalmente eram coletados em uma Estação Elevatória, cerca de 800 L de lixiviado e acondicionados num reservatório para equalização e alimentação da unidade piloto. Sua caracterização era feita periodicamente em conjunto com as demais análises envolvendo todo o controle operacional.

A vazão de alimentação do lixiviado era introduzida na câmara anóxica mediante o uso de uma bomba peristáltica que permitia os eventuais ajustes necessários para controle da contribuição de carga.

O esgoto decantado, o lixiviado de aterro sanitário e o efluente produzido pela unidade piloto, foram caracterizados duas vezes por semana, por meio da determinação das variáveis 
Nitrogênio Total Kjeldahl, Nitrogênio Amoniacal, Alcalinidade, DBO e DQO e Sólidos em Suspensão (Fixos e Voláteis). Todas as metodologias analíticas utilizadas seguiram à $21^{\text {a }}$ edição do Standard Methods for Examination of Water and Wastewater, da APHA et al. (2005). Foi realizado, também, o monitoramento da biomassa aderida e em suspensão.

A fim de avaliar a capacidade de redução da toxicidade aguda do afluente pelo processo, a unidade piloto operou em três fases, variando-se a contribuição do lixiviado na composição percentual da carga de DBO total afluente aplicada, em 5, 10 e 20\%, mantendo-se as demais condições constantes.

Operou-se a unidade piloto descartando-se lodo ativado em excesso de forma a resultar em idade do lodo de 9 dias com base apenas na concentração de biomassa em suspensão (SSV). A partir da caracterização inicial, estabeleceu-se a vazão de alimentação de $1,6 \mathrm{~m}^{3} \mathrm{~d}^{-1}$ para esgoto decantado e de 0,$01 ; 0,03$ e $0,07 \mathrm{~m}^{3} \mathrm{~d}^{-1}$ de lixiviado para cada fase do estudo; correspondendo à razão alimento/microrganismos de $0,2 \mathrm{kgDBO}_{\mathrm{kgSSV}} \mathrm{d}^{-1}$ e a um TDH de $0,48 \mathrm{~d}$.

A avaliação da redução da toxicidade aguda promovida pelo processo frente às diferentes cargas de lixiviado foi realizada por meio de ensaios de toxicidade aguda sobre bactérias marinhas Allivibrio fischeri, utilizando o Sistema Analisador de Toxicidade Microtox ${ }^{\circledR}$, e microcrustáceos Daphnia similis.

O sistema Microtox ${ }^{\circledR}$ consiste em um fotômetro de precisão, que permite medir a luminescência emitida pela colônia de bactérias antes e após a adição da substância tóxica. $\mathrm{O}$ teste é realizado a partir de uma cultura de bactérias liofilizadas, contendo $10^{8}$ células por ampola, que é rehidratada no momento do ensaio; dessa forma, procede-se a introdução de diferentes alíquotas da amostra em cubetas contendo suspensão bacteriana com concentração de $10^{6}$ células ampola ${ }^{-1}$, e, em seguida, feitas as leituras no fotômetro (CETESB, 1997; Borrely, 2001).

A Tabela 1, descrita por Bulich (1982) e modificada por Coleman e Quereshi (1985), estabelece faixas de toxicidade, permitindo comparar amostras avaliadas com o sistema Microtox®.

Tabela 1. Faixas de toxicidade para o sistema Microtox ${ }^{\circledR}$ proposta por Bulich (1982).

\begin{tabular}{ll}
\hline & Grau de Toxicidade \\
\hline $\mathrm{CE}_{50}-\% \mathrm{v} / \mathrm{v}$ & Classificação \\
$<25$ & Muito Tóxica \\
$25-50$ & Tóxica \\
$51-75$ & Moderadamente Tóxica \\
$>75$ & Levemente Tóxica \\
\hline
\end{tabular}

Nota: Adaptado de: Bulich (1982).

Em que $\mathrm{CE}_{50}$, corresponde à concentração efetiva mediana a $50 \%$ da população exposta, quando o efeito for à imobilidade dos organismos expostos (CETESB, 1997), podendo ser expresso em termos de Unidade de Toxicidade (UT), o qual é obtido pela Equação (1).

$$
U T=\frac{100}{C E_{50}}
$$

O teste empregando os microcrustáceos Daphnia similis tem como princípio a exposição de jovens Daphnias (tempo de vida variando de 6 a 24 horas) a diferentes concentrações da substância a ser avaliada, dentro das condições estabelecidas na padronização do teste 
(Borrely, 2001; Damato, 1997).

O efeito observado, no final de um período de 24 ou 48 horas de exposição, é a imobilidade ou a letalidade dos organismos (CETESB, 1987).

Com os dados de imobilidade ou mortalidade dos organismos no teste determina-se, estatisticamente, a $\mathrm{CE}_{50}$.

\section{RESULTADOS E DISCUSSÃO}

A fim de avaliar o comportamento da toxicidade aguda medida no efluente gerado pela unidade piloto ao longo do estudo e sua relação com o nível de eficiência obtido pelo tratamento, todo o processo foi devidamente monitorado. A seguir serão detalhados os resultados medidos das principais variáveis.

\subsection{Condições operacionais}

No tocante às variáveis de entrada impostas ao processo em cada fase da pesquisa, foi possível manter uma normalidade dos valores, sobretudo, devido à estabilidade do afluente composto (esgoto decantado+lixiviado).

A composição média tanto do esgoto decantado quanto do lixiviado que compuseram o afluente do processo biológico ao longo do estudo mantiveram-se relativamente constantes; dessa forma, com a variação da contribuição de lixiviado em cada fase da pesquisa na obtenção da vazão aplicada às pilotos, a composição média do afluente é apresentada na Tabela 2.

Tabela 2. Caracterização do afluente (esgoto+lixiviado) aplicado ao processo.

\begin{tabular}{|c|c|c|c|c|c|c|c|c|c|c|c|c|}
\hline \multirow{3}{*}{ Variável } & \multicolumn{4}{|c|}{$\begin{array}{c}1^{\mathrm{a}} \text { Fase } \mathrm{N}=19 \\
(5 \% \text { de lixiviado) }\end{array}$} & \multicolumn{4}{|c|}{$\begin{array}{c}2^{\mathrm{a}} \text { Fase } \mathrm{N}=8 \\
\text { (10\% de lixiviado) }\end{array}$} & \multicolumn{4}{|c|}{$\begin{array}{c}3^{\mathrm{a}} \text { Fase } \mathrm{N}=20 \\
\text { (20\% de lixiviado) }\end{array}$} \\
\hline & \multicolumn{2}{|c|}{ Afluente } & \multicolumn{2}{|c|}{ Efluente } & \multicolumn{2}{|c|}{ Afluente } & \multicolumn{2}{|c|}{ Efluente } & \multicolumn{2}{|c|}{ Afluente } & \multicolumn{2}{|c|}{ Efluente } \\
\hline & Média & $\mathrm{DP}$ & Média & DP & Média & DP & Média & DP & Média & $\mathrm{DP}$ & Média & DP \\
\hline $\begin{array}{l}\mathrm{DQO} \text { total } \\
\left(\mathrm{mgO}_{2} \mathrm{~L}^{-1}\right)\end{array}$ & 522 & 93 & 55 & 17 & 531 & 51 & 66 & 15 & 614 & 95 & 108 & 26 \\
\hline $\begin{array}{l}\mathrm{DBO}_{5,20} \text { total } \\
\left(\mathrm{mgO}_{2} \mathrm{~L}^{-1}\right)\end{array}$ & 220 & 22 & 26 & 10 & 216 & 6 & 28 & 6 & 286 & 51 & 57 & 19 \\
\hline $\begin{array}{l}\text { NTK } \\
\left(\mathrm{mgN} \mathrm{L}^{-1}\right)\end{array}$ & 107 & 18 & 13 & 7 & 157 & 17 & 13 & 7 & 214 & 48 & 33 & 14 \\
\hline $\begin{array}{l}\mathrm{N}-\mathrm{NH}_{4}{ }^{+} \\
\left(\mathrm{mgN} \mathrm{L}^{-1}\right)\end{array}$ & 82 & 5 & 6 & 4 & 108 & 11 & 7 & 6 & 125 & 28 & 25 & 12 \\
\hline $\begin{array}{l}\text { Alcalinidade } \\
\left(\mathrm{mgCaCO}_{3} \mathrm{~L}^{-1}\right)\end{array}$ & 228 & 50 & 47 & 27 & 369 & 26 & 59 & 45 & 568 & 154 & 268 & 157 \\
\hline $\mathrm{pH}$ & & & 7,2 & 0,1 & & & 7,4 & 0,4 & & & 7,1 & 0,5 \\
\hline Temp. ${ }^{\circ} \mathrm{C}$ & & & 18 & 2,6 & & & 17 & 0,7 & & & 18 & 2,1 \\
\hline
\end{tabular}

Levando-se em conta as condições operacionais impostas ao processo e as características do afluente (Tabela 2), foi possível trabalhar dentro de valores típicos tanto para aplicação de carga orgânica volumétrica como para carga nitrogenada, variando de $0,4 \mathrm{a} 0,9 \mathrm{kgDBO} \mathrm{\textrm {m } ^ { 3 }} \mathrm{d}^{-1}$ e de 0,32 a $0,7 \mathrm{kgN} \mathrm{m}^{3} \mathrm{~d}^{-1}$.

Observando-se a composição média obtida para cada fase da pesquisa, constata-se que as concentrações de nitrogênio total (NTK), de nitrogênio Amoniacal $\left(\mathrm{NH}_{4}{ }^{+}-\mathrm{N}\right)$ e de 
alcalinidade, são superiores ao comumente encontrado no esgoto doméstico, evidenciando a contribuição oriunda da carga de lixiviado.

\subsection{Caracterização da Biomassa em Suspensão e Biomassa Aderida}

Foi possível trabalhar com valores de sólidos em suspensão voláteis (SSV) no lodo do tanque de aeração dentro do desejável para as condições operacionais impostas ao processo na maior parte do estudo (2.000 a $5.000 \mathrm{mg} \mathrm{L}^{-1}$, de acordo com Van Haandel e Marais, 1999), observando-se valores médios de $2.319 ; 2.225$ e $3.099 \mathrm{mg} \mathrm{L}^{-1}$ de $\mathrm{SSV}$ nas $1^{\mathrm{a}}, 2^{\mathrm{a}}$ e $3^{\mathrm{a}}$ fases, respectivamente. Em relação ao lodo da linha de retorno, obteve-se valores na faixa de 3.000 a $6.000 \mathrm{mg} \mathrm{L}^{-1}$. Tal fato demonstra que a carga introduzida de lixiviado não comprometeu a formação da biomassa em suspensão em todas as fases experimentais.

Com relação à biomassa aderida, considerando-se a área superficial específica dos suportes Kaldnes ${ }^{\circledR}$ do tipo $\mathrm{K} 1 \mathrm{de} 300 \mathrm{~m}^{2} \mathrm{~m}^{-3}$, obtiveram-se ao longo do estudo, valores de SSV de 7,7; 8,9 e 7,2 $\mathrm{gSSV} \mathrm{m}^{-2}$ de biofilme, respectivamente às três fases experimentais. Estes valores encontram-se abaixo aos apresentados na literatura, sendo que a NBR 12.209 da ABNT (1989) considera o limite máximo de $12 \mathrm{gSSV} \mathrm{m}^{-2}$.

\subsection{Eficiência Global do Processo: Remoção de Matéria Orgânica e Nitrogenada}

No que tange à remoção de matéria orgânica e nitrogenada, pode-se afirmar que o sistema foi mantido sob operação estável nas três etapas da pesquisa.

Em termos de eficiência do processo, foi possível obter números da ordem de $85 \%$ de remoção de $\mathrm{DBO}$ e de $90 \%$ para DQO nas três fases de operação; enquanto que para os compostos nitrogenados, os valores situaram-se em torno de $90 \%$ de conversão de NTK e $\mathrm{NH}_{4}{ }^{+}$nas duas primeiras fases, e de aproximadamente $80 \%$ na $3^{\mathrm{a}}$ fase. NTK.

A Figura 2 apresenta as eficiências de remoção alcançadas para as variáveis DBO e

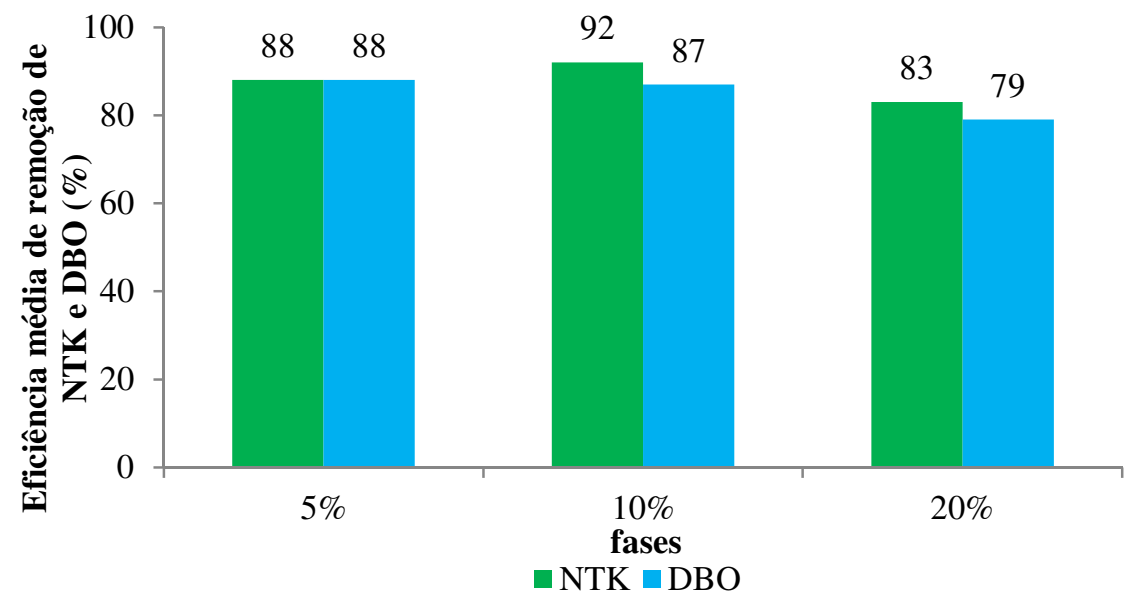

Figura 2. Eficiência de remoção de DBO e NTK em cada fase da pesquisa.

Avaliando-se os resultados apresentados na Figura 3, bem como da quantificação da biomassa ao longo do estudo, pode-se inferir que a introdução de lixiviado de aterro sanitário em conjunto ao esgoto doméstico, mesmo em sua máxima contribuição (20\%), não resultou na redução da eficiência global do processo.

Comparando-se a eficiência do processo em termos de remoção de carga orgânica e nitrogenada, com dados obtidos na literatura em pesquisas envolvendo o co-tratamento de lixiviado com esgoto doméstico por meios biológicos, constata-se que o mesmo obteve resultados semelhantes (Silva et al., 2012; Klimiuk e Kulikowska, 2006; Facchin et al., 2000; Diamadopoulos et al., 1997). 


\subsection{Monitoramento da Toxicidade Aguda}

Pode-se afirmar que um dos principais objetivos de uma estação de tratamento de esgoto seja a diminuição do potencial poluidor da água residuária, o que se traduz por remover, sobretudo, cargas de matéria orgânica e nutrientes (nitrogênio e fósforo) em sua máxima eficiência.

Dessa forma, ao se propor a redução de tais compostos é de se supor que, por conseguinte, seja observada uma diminuição no nível de toxicidade.

Ambos os ensaios de toxicidade aguda empregados nesse estudo, foram realizados simultaneamente e com as mesmas amostras coletadas: Afluente (esgoto doméstico+lixiviado) e Efluente.

A seguir serão discutidos separadamente os resultados obtidos em cada ensaio.

\subsubsection{Toxicidade Aguda - Allivibrio fischeri}

A Tabela 3 apresenta os valores médios de toxicidade aguda medidas pela técnica do Microtox $^{\circledR}$.

Tabela 3. Valores de Toxicidade Aguda ao organismo Allivibrio fischeri.

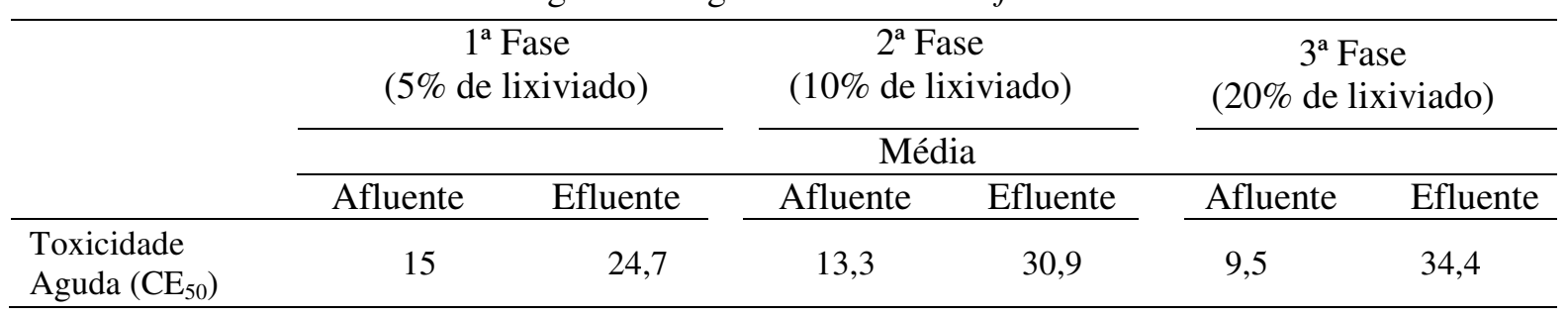

Os resultados medidos por meio dessa técnica evidenciam o aumento da toxicidade do afluente em cerca de $10 \%$ da primeira para a segunda fase, e de $29 \%$ da segunda para a terceira. Esse incremento se deve ao aumento progressivo da carga de lixiviado na composição da vazão afluente ao processo.

A resposta obtida nos ensaios demonstra uma diminuição considerável do nível de toxicidade aguda, como pode ser visualizado na Figura 3, entretanto, levando-se em consideração a classificação do grau de toxicidade apresentada na Tabela 1 , o processo permitiu apenas a mudança do nível Muito Tóxico do afluente para Tóxico, no efluente.

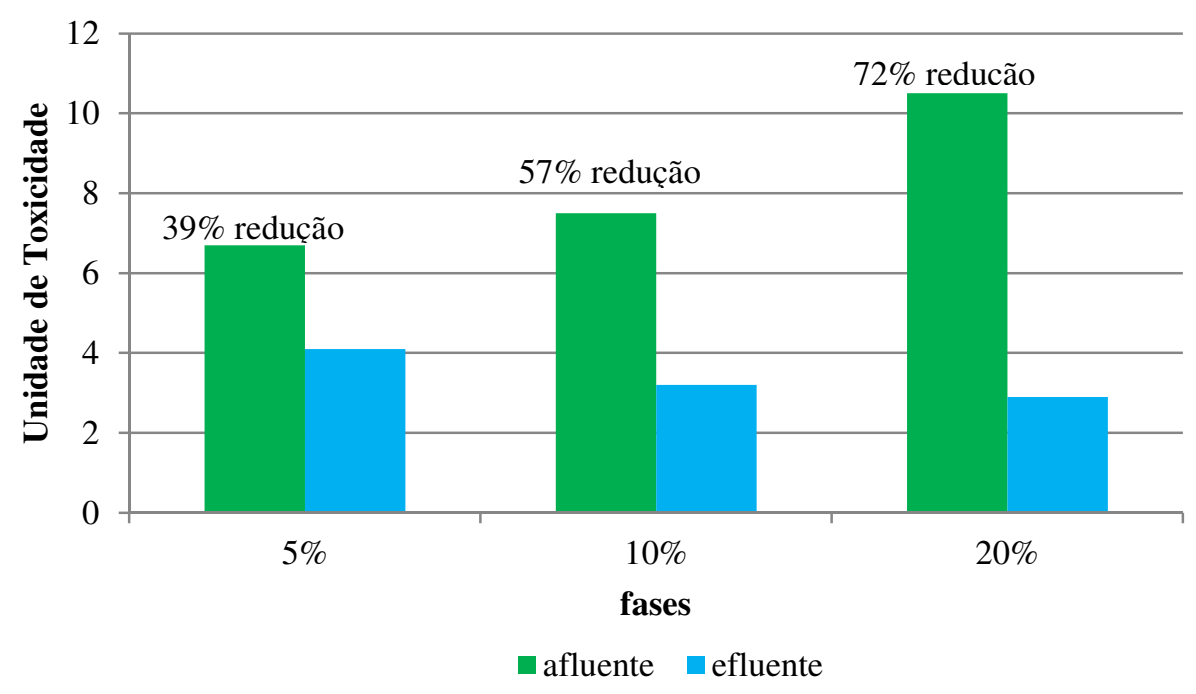

Figura 3. Resultados do monitoramento da toxicidade aguda empregando Allivíbrio fischeri. 
A Figura 4 ilustra o comportamento das principais variáveis monitoradas no efluente da unidade piloto ao longo do estudo e que se correlacionam com a toxicidade aguda.

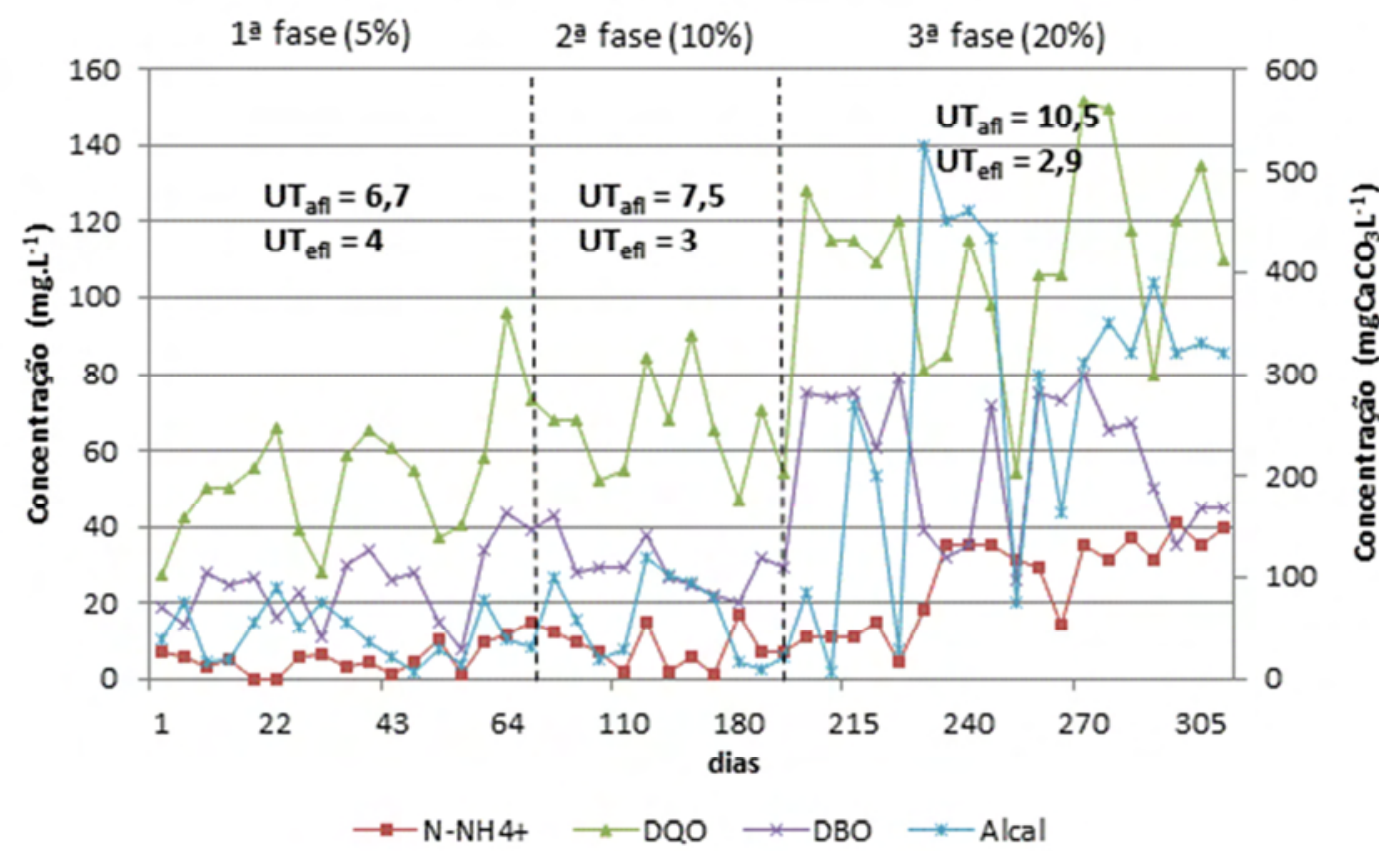

Figura 4. Série Histórica das variáveis: nitrogênio amoniacal, DQO, DBO e alcalinidade, monitoradas no efluente.

\subsubsection{Toxicidade Aguda - Daphnia similis}

Os ensaios realizados com o microcrustáceo $D$. similis não demonstraram muita sensibilidade às substâncias presentes nas amostras, como pode ser visualizado na Tabela 4.

Tabela 4. Valores de Toxicidade Aguda ao organismo D. similis.

\begin{tabular}{ccccccc}
\hline & \multicolumn{2}{c}{ Afluente } & & \multicolumn{2}{c}{ Efluente } \\
\cline { 2 - 3 } \cline { 6 - 6 } \cline { 5 - 6 } & CE 50 $(\%)$ & UT & & CE 50 $(\%)$ & UT \\
\hline $1^{\text {a }}$ Fase & 17,2 & 5,8 & & NT & NT \\
$2^{\text {a }}$ Fase & 19,3 & 5,2 & & NT & NT \\
$3^{\text {a }}$ Fase & 25,5 & 3,9 & & NT & NT \\
\hline
\end{tabular}

NT = Não Tóxico.

Como se observa nos dados dispostos na Tabela 4, os testes acusaram ausência de toxicidade (NT) no efluente do processo em todas as fases do estudo, além de, ao contrário do esperado, apontar uma ligeira queda nos valores de toxicidade para o afluente à medida que a contribuição de lixiviado aumentou.

Thomas (2010), em seus estudos, também aponta para uma menor sensibilidade desses organismos na avaliação de toxicidade de lixiviado.

\subsubsection{Considerações à cerca dos resultados obtidos nos ensaios de toxicidade}

De fato, a remoção de matéria orgânica e nitrogenada proporcionada pelo processo de tratamento abranda a toxicidade inicial na medida em que os poluentes são reduzidos a níveis 
mais tolerados pelos organismos-testes utilizados nos ensaios, entretanto, a persistência dos compostos orgânicos recalcitrantes oriundos do lixiviado que não são afetados pelo tratamento bem como o residual de amônia, somados pelos altos valores medidos para alcalinidade, devem ser os principais contribuintes para a manutenção de um nível ainda alto de toxicidade aguda no efluente (Thomas, 2010, Kjeldsen et al., 2002).

Comparando-se os resultados obtidos em ambos os ensaios, pode-se inferir que a técnica empregando Allivibrio fischeri mostrou-se mais coerente e consistente, demonstrando maior sensibilidade às substâncias presentes.

Hamada et al. (2011) analisando os ensaios de toxicidade no efluente gerado pela ETE Suzano, a qual recebe lixiviado de aterro sanitário, utilizando os mesmos organismos testes, concluíram, igualmente, que a técnica com Allivibrio fischeri fora ligeiramente mais sensível quando comparada com $D$. similis.

Entretanto, deve-se considerar que Isidori et al. (2003) reportam para o uso desse teste, em amostras de lixiviado, apenas como ferramenta de seleção por conta de influências físico-químicas interferirem no processo.

Tais situações reforçam a necessidade do uso de mais de um organismo-teste para se avaliar e mapear o efeito tóxico (Borrely, 2001), sobretudo, quando se trata de uma matriz tão complexa como o lixiviado de aterro sanitário.

Boccheglieri (2010) conclui, em sua pesquisa com quatro ETE's de São Paulo, que ainda são necessários estudos para a compreensão integral das implicações advindas do tratamento em conjunto de lixiviado e esgoto doméstico, em relação a diversos aspectos tais como os efeitos tóxicos aos processos biológicos, qualidade do lodo e do efluente do tratamento.

\section{CONCLUSÃO}

Em linhas gerais, os resultados obtidos a partir da investigação experimental permitiram concluir que o co-tratamento de lixiviado de aterro sanitário com esgoto doméstico é uma alternativa viável para a correta estabilização desse tipo de água residuária, e que o controle operacional da planta de tratamento é fundamental para o desempenho do processo.

Foi possível receber contribuições de lixiviado de até $20 \%$ da carga orgânica, em termos de DBO, sem prejuízo para a remoção de matéria orgânica e nitrogenada, contudo, os resultados obtidos para o efluente de toxicidade aguda permitem ainda classificá-lo como Tóxico, mesmo frente a uma redução da ordem de $70 \%$ da toxicidade inicial.

A metodologia empregando a técnica de Microtox ${ }^{\circledR}$, mediante o uso da bactéria Allivibrio fischeri, mostrou-se mais sensível aos compostos presente nas amostras quando comparada com a técnica utilizando os microcrustáceos $D$. similis.

É recomendável que sejam realizados ensaios de toxicidade crônica a fím de avaliar os impactos do co-tratamento lixiviado e esgoto, ao longo do tempo, tanto para o processo, como para o corpo receptor, assim como o estudo da influência da concentração de metais no lixiviado na composição de sua toxicidade.

\section{REFERÊNCIAS}

ASSOCIAÇÃO BRASILEIRA DE NORMAS TÉCNICAS - ABNT. Nbr 12209: projeto de estações de tratamento de esgoto sanitário. Rio de Janeiro, 1989.

AMERICAN PUBLIC HEALTH ASSOCIATION - APHA; AMERICAN WATER WORKS ASSOCIATION - AWWA, WATER ENVIRONMENT FEDERATION - WEF. Standard methods for the examination of water and wastewater, 21 . ed. Washington DC, 2005. 
BORRELY, S. I. Redução da toxicidade aguda de efluentes industriais e domésticos tratados por irradiação com feixes de elétrons, avaliada com espécies Vibrio fischeri, Daphnia similis e Poecilia reticulata. 2001. Tese (Doutorado em Tecnologia Nuclear-Aplicações) - Instituo de Pesquisas Energéticas e Nucleares, São Paulo, 2001.

BULICH, A. A. A pratical and reliable method for monitoring the toxicity of aquatic samples. Process Biochemistry, p. 45-47, 1982.

BOCCHIGLIERI, M. M. A influência do recebimento de chorume dos aterros sanitários da região metropolitana de São Paulo nas estações de tratamento de esgotos do sistema integrado. 2005. Dissertação (Mestrado em Saúde Pública) - Faculdade de Saúde Pública, Universidade de São Paulo, São Paulo, 2005.

COLEMAN, R. N.; QURESHI, A. A. Microtox® and Spirillum volutans tests for assessing toxicity of environmental samples. Bulletin of Environmental Contamination and Toxicology, v. 35, n. 1, p. 443-451, 1985. http://dx.doi.org/10.1007/BF01636536

COMPANHIA DE TECNOLOGIA DE SANEAMENTO AMBIENTAL - CETESB. Métodos de avaliação da toxicidade de poluentes e organismos aquáticos. Volume 1. São Paulo, 1997.

DAMATO, M. Estudo da influência do nível de tratamento de efluentes de refinarias de petróleo na sua toxicidade, empregando diferentes espécies indicadoras. 1997. Tese (Doutorado em Engenharia Hidráulica e Sanitária) - Escola Politécnica, Universidade de São Paulo, São Paulo, 1997.

DIAMADOPOULOS, E. et al. Combined treatment of landfill leachate and domestic sewage in a sequencing batch reactor. Water Science \& Technology, v. 36, p. 61-68, 1997. http://dx.doi.org/10.1016/S0273-1223(97)00370-3

FACCHIN, J. M. J.; COLOMBO, M. C.; COTRIM, S. L. S.; REICHERT, G. A. Avaliação do Tratamento Combinado de Esgoto e Lixiviado de Aterro Sanitário na ETE Lami (Porto Alegre) Após o Primeiro Ano de Operação. In: CONGRESSO INTERAMERICANO DE ENGENHARIA SANITÁRIA E AMBIENTAL, 27., 2000, Porto Alegre. Anais... Rio de Janeiro: ABES, 2000.

FERREIRA, A. G. Estudo dos lixiviados das frações do aterro sanitário de São Carlos/SP por meio da caracterização físico-química. 2010. Dissertação (Mestrado) - Escola de Engenharia, Universidade de São Paulo, São Carlos, 2010.

GOTVAJN, A. Z.; TISLER, T.; ZAGORC-KONCAN, J. Comparison of different treatment strategies for industrial landfill leachate. Journal for Hazardous Materials, v. 162, n. 2-3, p. 1446-1456, 2009. http://dx.doi.org/10.1016/j.jhazmat.2008.06.037

HAMADA, N.; MESQUITA, L. C. A.; PEREIRA, I. W.; NAKANO, E.; BORRELY, S. I.; TALLARICO, L. F. Avaliação ecotoxicológica da estação de tratamento de esgoto Suzano (São Paulo) utilizando Daphnia similis e Vibrio Fischeri. JBSE - Journal of the Brazilian Society of Ecotoxicology, v. 6, n 1, p. 31-35, 2011.

ISIDORI, M.; LAVORGNA, M.; NARDELLI, A.; PARRELLA, A. Toxicity identification evaluation of leachates from municipal solid waste landifills: a multispecies approach. Chemosphere, v. 52, p. 85-94, 2003. http://dx.doi.org/10.1016/S0045-6535(03)00298-4 
KJELDESEN, P.; BARLAZ, M. A.; ROOKER, A. P.; BAUN, A.; LEDIN, A.; CHRISTENSEN, T. H. Present and long-term composition of msw landfill leachate: a review. Critical Reviews in Environmental Science and Technology, v. 32, n. 4, p. 297-336, 2002.

KLIMIUK, E.; KULIKOWSKA, D. Organics removal from landfill leachate and activated sludge product on in SBR reactors. Waste Management, v. 26, n. 10, p. 1140-1147, 2006. http://dx.doi.org/10.1016\%2Fj.wasman.2005.09.011

QASIM, S. R.; CHIANG, W. Sanitary landfill leachate: generation, control and treatment. Boca Raton: CRC Press, 1994.

SILVA, J. D.; COSTA, R. H. R. da; MATIAS, W. G.; CASTILHO JR., A. B. Avaliação da Toxicidade de Lixiviado de Aterro Sanitário em Sistema de Lagoas de Estabilização com Testes de Toxicidade Aguda (Daphnia magna). Revista DAE, n.189, p. 40-49, 2012.

THOMAS, D. J. L. Understanding the causes of toxicity in treated landfill leachate through whole effluent testing. Tese (PhD) - School of Applied Sciences, Cranfield University, 2010.

THOMAS, D. J. L.; TYRREL, S. F.; SMITH, R.; FARROW, S.; Bioassay for the evaluation of landfill leachate toxicity. Journal of Toxicology and Environmental Health, v. 2, p. 83-105, 2009. http://dx.doi.org/10.1080/10937400802545292

VAN HAANDEL, A. C.; MARAIS, G. V. R. O comportamento do sistema de lodo ativado: teoria e aplicações para projetos e operações. Campina Grande: Epgraf, 1999. $472 \mathrm{p}$.

WATER ENVIRONMENT FEDERATION - WEF. Biofilm Reactors: manual of practice no. 35. New York: McGraw Hill, 2010.

WELANDER, U.; HENRYSSON, T.; WELANDER, T. Nitrification of landfill leachate using suspended-carrier biofilm technology. Water Research, v. 31, p. 2351-2355, 1997. http://dx.doi.org/10.1016/S0043-1354(97)00080-8 


Ambiente \& Água - An Interdisciplinary Journal of Applied Science
ISSN 1980-993X - doi:10.4136/1980-993X
www.ambi-agua.net
E-mail: ambi.agua@gmail.com

\title{
Análise da influência de parâmetros ambientais no fluxo de metano em áreas alagáveis e lagoas permanentes na região do Rio Abobral, no Pantanal, Brasil
}

\author{
doi:10.4136/ambi-agua.1775
}

Received: 05 Oct. 2015; Accepted: 20 Jan. 2016

Marcelo Gomes da Silva ${ }^{1 *}$; Plínio Carlos Alvalá Luciano Marani²; Willian José Ferreira²

\author{
Instituto Nacional de Pesquisas Espaciais (INPE), São José dos Campos, SP, Brasil \\ ${ }^{1}$ Departamento de Geofísica Espacial (DGE) \\ ${ }^{2}$ Centro de Ciência do Sistema Terrestre (CCST) \\ *Autor correspondente: e-mail: engmarcgomes@gmail.com, \\ carlos.alvala@gmail.com, lmarani@gmail.com,will.ferreira@hotmail.com
}

\section{RESUMO}

Neste estudo foi analisada a influência de características físico-químicas da coluna d'água nos processos que resultam na emissão de metano no Pantanal. Foram realizadas duas campanhas intensivas de coleta de dados durante os anos de 2009 e 2010, correspondendo aos períodos de seca e cheia. O fluxo de metano foi determinado usando a técnica de câmara estática. Em cada ponto de coleta foi medida a profundidade, temperatura da água, $\mathrm{pH}$, potencial de oxirredução, oxigênio dissolvido e total de sólidos dissolvidos. Os fluxos foram classificados em difusivos e ebulitivos, com média de $11,1 \pm 13,5 \mathrm{mg} \mathrm{CH}_{4} \mathrm{~m}^{-2} \mathrm{~d}^{-1}$ e $275,9 \pm$ $348,5 \mathrm{mg} \mathrm{CH}_{4} \mathrm{~m}^{-2} \mathrm{~d}^{-1}$, respectivamente, que é um valor próximo ao observado em outras regiões alagadas tropicais. A aplicação de teste $t$ mostrou diferença estatística significativa $(p \leq 0,05)$ entre os dois períodos, com os maiores valores médios ocorrendo na estação de cheia. Durante o período de seca houve um predomínio de fluxos difusivos (83\%) em relação aos ebulitivos. Na cheia ocorreram mais casos de fluxo ebulitivo (77\%). As análises estatísticas de correlação e Análise de Componentes Principais demostraram que as interações entre características físico-químicas da água podem influenciar o fluxo de metano. Os fluxos difusivos apresentaram correlação principalmente com $\mathrm{pH}$, potencial de oxirredução e oxigênio dissolvido, que estão de acordo com o aumento de matéria orgânica durante o alagamento do Pantanal. Fluxos ebulitivos no período da seca tiveram influência da profundidade, temperatura da água, $\mathrm{pH}$ e potencial de oxirredução que indicam que o ambiente foi propício para a formação de bolhas ou para sua liberação do sedimento.

Palavras-chave: ciências ambientais, indicadores ambientais, mudanças globais, química ambiental.

\section{Analysis of the influence of environmental parameters on methane flux from floodplains and lakes in the Abobral River, Pantanal, Brazil}

\section{ABSTRACT}

This study evaluates the influence of physical and chemical characteristics of the water column in the processes that result in methane emissions in the Pantanal. Two surveys were 
conducted in 2009 and 2010, corresponding to the drought and flood seasons, respectively. The $\mathrm{CH}_{4}$ fluxes were determined using the static chamber technique. Environmental variables, such as depth, water temperature, $\mathrm{pH}$, redox potential, dissolved oxygen and total dissolved solids were also measured. Diffusive and bubble flux presented an average value of $11.1 \pm$ $13.5 \mathrm{mg} \mathrm{CH}_{4} \mathrm{~m}^{-2} \mathrm{~d}^{-1}$ e $275.9 \pm 348.5 \mathrm{mg} \mathrm{CH}_{4} \mathrm{~m}^{-2} \mathrm{~d}^{-1}$, which is a value near those observed in other tropical flooded regions. Statistical t-tests have shown significant differences between drought and flood seasons $(p \leq 0.05$ ). Diffusive fluxes represented about $87 \%$ of the total fluxes measured in drought. During the flood season there were more instances of bubble fluxes (77\%). Statistical analysis (correlation and Principal Components Analysis) indicate that physical and chemical characteristics could affect methane fluxes. Diffusive fluxes correlated mainly with $\mathrm{pH}$, redox potential and dissolved oxygen, which is in accordance with the increase of organic matter during flooding. Bubble fluxes measured during the drought season correlated mainly with water depth and temperature, $\mathrm{pH}$ and redox potential, which is an indication of an environment to suitable to the formation and liberation of the bubbles from sediment.

Keywords: environmental chemistry, environmental indicators, environmental sciences, global changes.

\section{INTRODUÇÃO}

O metano $\left(\mathrm{CH}_{4}\right)$ é o hidrocarboneto mais abundante na atmosfera terrestre, com razão de mistura em torno de $1800 \mathrm{pbbv}$ (partes por bilhão por volume) (NOAA, 2014), e um dos principais gases indutores do efeito estufa, responsável por cerca de $20 \%$ do aquecimento global (Dalal e Allen, 2008; IPCC, 2007). A emissão de metano para a atmosfera está relacionada a diversas fontes, naturais e antropogênicas, sendo as principais a queima de carvão e combustíveis fósseis, aterros sanitários, cultivo de arroz, cupins e ruminantes (Wuebbles e Hayhoe, 2002). Destas, a maior fonte individual de metano para a atmosfera são as áreas alagadas (rios, lagos e pântanos), com contribuição de 100 a $231 \mathrm{Tg}$ ano $^{-1}$, correspondendo a 20-30\% das emissões naturais biogênicas do gás (IPCC, 2007; Wuebbles e Hayhoe, 2002).

Em ambientes aquáticos, a produção de metano ocorre no substrato, por ação de microrganismos que degradam macromoléculas da matéria orgânica existente no meio em compostos menores (ácido acético, dióxido de carbono e hidrogênio). Estes compostos são processados por microrganismos metanogênicos (Domínio Archaea) dando origem ao metano, que com baixa solubilidade em água, tende a ser liberado para a atmosfera (Thauer et al., 2008; Conrad, 1999).

Quando o gás contido no substrato é transportado para a superfície por meio de bolhas, o fluxo é classificado como ebulitivo. Porém, parte do metano produzido se dissolve e é transportado através da coluna d'água via difusão (fluxos difusivos) (Belger et al., 2011; Dalal e Allen, 2008; Abril et al., 2006). Diversos estudos consideram que características físico-químicas do meio possam influenciar a produção e o consumo do metano na coluna d'água, afetando a emissão do gás para a atmosfera, independente do sistema de transporte (Dalal e Allen, 2008; Bastviken et al., 2004; Yang e Chang, 1998; Wang et al., 1993; Bartlett et al., 1988).

Com grande interesse mundial devido às suas potenciais emissões de metano, Bacia Amazônica e Pantanal são destacadas como principais áreas naturalmente alagáveis do Brasil. Enquanto estudos realizados a partir da década de 1980 estimam a produção amazônica em $30 \mathrm{Tg} \mathrm{CH}_{4}$ ano $^{-1}$ (Melack et al., 2004; Devol et al., 1988; Bartlett et al., 1988), poucos foram os estudos que investigaram o processo de emissão do gás na planície pantaneira (Marani e 
Alvalá, 2007; Alvalá e Kirchhoff, 2000).

O Pantanal é uma planície sedimentar aluvial parcialmente alagável, localizada na bacia do rio Paraguai, predominantemente na região Centro-Oeste do Brasil e com áreas menores na Bolívia e Paraguai. Sua área total é de aproximadamente $138 \mathrm{mil} \mathrm{km}^{2}$, dos quais a área máxima sob possibilidade de alagamento é de quase $131 \mathrm{mil} \mathrm{km}^{2}$, com média anual da área inundada sazonalmente de aproximadamente $35 \mathrm{mil} \mathrm{km}^{2}$ (Hamilton, 2002).

A baixa declividade da planície, que varia entre 80 e $120 \mathrm{~m}$ acima do nível do mar, associada com a falta de gradiente hidráulico, são responsáveis pelo lento escoamento das águas na bacia, o que faz com que considerável parte da bacia permaneça alagada na maior parte do ano. O pico da inundação ocorre em março, no final do período chuvoso (Hamilton et al., 2002; Calheiros e Ferreira, 1996; Rao et al., 1996), mas, durante o período de cheia, vegetação e restos animais são submersos, podendo constituir-se como principal fonte de nutrientes para a produção de metano.

Aliada a entrada de matéria orgânica no sistema, a temperatura da água é apontada como um fator que influencia diretamente a atividade dos microrganismos e, consequentemente, a produção do metano no substrato, numa faixa ótima entre 15 e $37^{\circ} \mathrm{C}$ (Agostinetto et al., 2002; Yang e Chang, 1998). Outros parâmetros, no entanto, podem ter importância no desempenho dos microrganismos metanogênicos e metanotróficos.

$\mathrm{O}$ pH ideal para a produção do metano encontra-se próximo à neutralidade mas pode haver inibição quando os valores são inferiores à 3,2 (meio ácido) ou superior à 9,3 (meio básico) (Yang e Chang, 1988; Wang et al., 1993). O processo de inibição também pode estar associado à concentração de oxigênio dissolvido na água (Agostinetto et al., 2002). A presença de $\mathrm{O}_{2}$ provoca a suspensão da metanogênese por parte das arqueas, além de aumentar a probabilidade de oxidação do $\mathrm{CH}_{4}$ que é transportado por processo de difusão na água. De forma análoga, o potencial de oxirredução é uma medida que indica o grau de redução ou oxidação do meio. Assim, estes parâmetros ambientais se inter-relacionam.

O total de sólidos dissolvidos é uma medida da concentração de substâncias iônicas em meio aquoso e tem relação com a turbidez da água, com efeitos na taxa de fotossíntese, que afeta a concentração de dióxido de carbono na água (Parron et al., 2011; Thauer et al., 2008; Conrad, 1999). De forma análoga, o potencial de oxirredução é uma medida que indica o grau de redução ou oxidação do meio. Solos extremamente oxidados tem potencial de redução na faixa de +400 a $+700 \mathrm{mV}$ enquanto solos inundados podem ter caráter redutor, com valores menores que $-300 \mathrm{mV}$ devido à ausência de oxigênio. Tanto microrganismos metanogênicos quanto metanotróficos dependem da disponibilidade de compostos químicos doadores/receptores de elétrons para realizar as reações de obtenção de carbono e energia que resultam na produção ou consumo do metano na água (Agostinetto et al., 2002).

Neste trabalho são apresentados a avaliação da influência de algumas características físico-químicas da água nos fluxos de metano durante os períodos de seca e cheia no Pantanal Sul Mato-grossense, importante na avaliação do potencial de emissão de gases do efeito estufa de áreas alagáveis.

\section{MATERIAL E MÉTODOS}

As medidas de fluxo de metano foram feitas em áreas alagáveis e lagoas permanentes na sub-região do Abobral, próximo à localidade do Passo do Lontra, entre as cidades de Miranda e Corumbá, no estado do Mato Grosso do Sul. A área de coleta está sob influência das bacias do Rio Miranda e do Rio Negro (Figura 1). Dos locais de amostragem, uma lagoa permanente e uma área alagável ficam sob influência do Rio Miranda durante o período da cheia. Os demais, são localizados na bacia do Rio Negro. A Base de Estudos do Pantanal - BEP (19³ 'S, 5701'O), da Universidade Federal do Mato Grosso do Sul (UFMS) foi utilizada 
para logística e acomodações durante as duas campanhas intensivas de coleta de dados, sendo a primeira realizada em setembro de 2009 e a segunda em março de 2010, correspondendo ao período de seca e cheia, respectivamente, no sul do Pantanal.

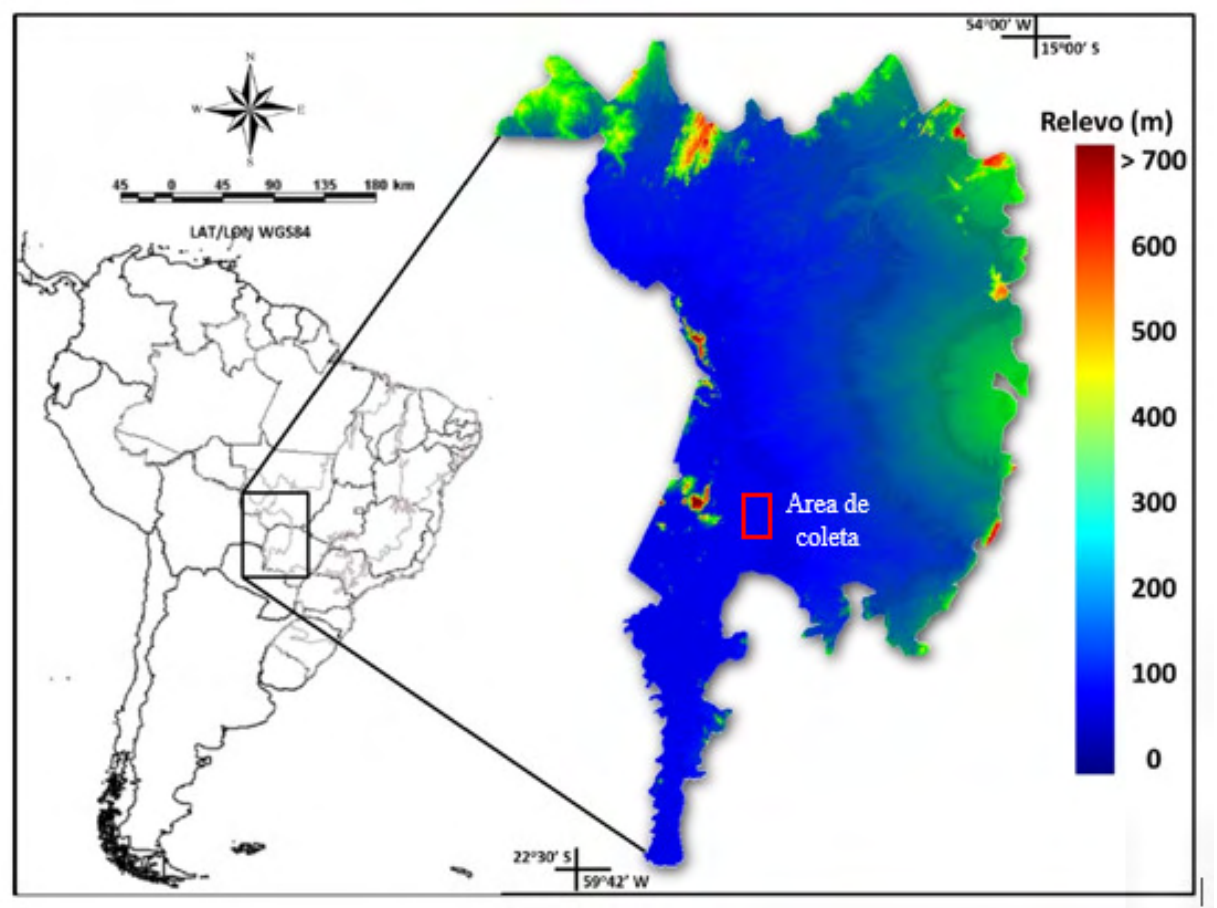

Figura 1. Localização e gradiente topográfico do Pantanal. A área de coleta, na sub-região do Abobral está destacada na figura.

Fonte: Adaptado de Pereira et al. (2012).

O fluxo de metano foi determinado através da técnica de câmara estática descrita por Khalil et al. (1998) e Marani e Alvalá (2007). Neste estudo foram utilizadas câmaras cilíndricas de policloreto de polivinila (PVC), com volume de 26 litros, área de 0,066 $\mathrm{m}^{2}$, recoberta com manta térmica para evitar variações de temperatura no interior e equipada com flutuadores externos acoplados na base para sustentação na água. A medição do fluxo consiste em retirar amostras de ar do interior da câmara em intervalos constantes. A coleta do ar era realizada através de um tubo de teflon instalado à meia altura da câmara com o auxílio de uma seringa de poliuretano de $60 \mathrm{ml}$, equipada com torneira de três vias e trava do tipo "luerlock". O tempo de coleta em que a câmara permanecia na água era de 15 minutos. Neste intervalo eram coletadas 4 amostras de ar, sendo a primeira no minuto inicial e as posteriores em 5, 10 e 15minutos, com o intuito de obter a variação da razão de mistura do metano no interior da câmara em função do tempo e numa área de dimensão conhecida. Trabalhos mais recentes utilizam adaptações na câmara estática para a obtenção dos fluxos difusivos (Bastviken et al., 2010), que consistem na instalação de um escudo plástico sob a superfície da água (a uma profundidade entre 50 e $70 \mathrm{~cm}$ ) que defletem as bolhas provenientes dos sedimentos.

As amostras de ar foram transportadas para o Laboratório de Biogeoquímica Ambiental do Instituto Nacional de Pesquisas Espaciais (INPE), São José dos Campos-SP. A análise foi realizada em um cromatógrafo a gás (Shimadzu, GC-14A) equipado com detector de ionização de chama (DIC), equipado com um loop de amostragem de 2,5 $\mathrm{ml}$ e duas colunas de aço inoxidável, com 1/8 polegada de diâmetro. A primeira coluna, com comprimento de 2,5 metros, é preenchida com gel de sílica e tem a finalidade de reter vapor d'água, dióxido de carbono $\left(\mathrm{CO}_{2}\right)$ e compostos de carbono mais pesado que o metano. A segunda é uma coluna empacotada com peneira molecular de zeolite de $5 \AA$ (Ângstrons), com 3 metros de 
comprimento, e responsável pela separação cromatográfica dos gases da amostra. Para cada seringa foram analisadas 3 alíquotas com precisão de 0,7\% ou melhor (Alvalá et al., 2004).

A validação dos fluxos e a determinação quanto ao tipo de transporte na coluna d'água foram realizados utilizando dois critérios. O primeiro considerou que o fluxo difusivo é caracterizado pela correlação linear entre a variação da razão de mistura e o tempo de coleta, expresso matematicamente pelo quadrado do coeficiente de correlação $\left(\mathrm{R}^{2}\right)$ igual ou superior a 0,9 . O segundo critério utilizado para validar o fluxo define que a razão de mistura do ar ambiente e no minuto inicial de coleta deve ter valores próximos significando que não houve perturbação da superfície da água durante a deposição da câmara estática. Os fluxos que não cumpriram o primeiro critério, mas tiveram a primeira amostra de ar com razão de mistura próxima à do ar ambiente foram considerados fluxos ebulitivos (Marani e Alvalá, 2007; Sass et al., 1992). Neste método, pode-se separar entre os dois meios de transporte e estimar um valor médio para o fluxo ebulitivo. Bastviken et al. (2010) sugere que esta forma de obtenção de fluxos ebulitivos podem subestimar a emissão de metano por bolhas, logo, os resultados aqui apresentados representam uma estimativa para o limite inferior de emissões ebulitivas.

Nos pontos de amostragem também foram realizadas medições de características físico-químicas da coluna da água: profundidade, temperatura da água, $\mathrm{pH}$, potencial de oxirredução (ORP), oxigênio dissolvido (OD) e total de sólidos dissolvidos (TSD). A profundidade foi medida com o auxílio de uma régua graduada enquanto que os demais parâmetros foram medidos com uma sonda multiparâmetros de qualidade de água da marca Horiba, modelo U-51.

A influência das variáveis ambientais na emissão de metano foi avaliada por Teste de Correlação e por Análise de Componentes Principais (ACP), conforme método descrito por Wilks (2006). Nesta etapa procurou-se reduzir as interdependências entre as variáveis por combinações lineares das variáveis originais e obter sua importância no processo de emissão de metano. As matrizes de correlação criadas para cada grupo permitiram a obtenção de $90 \%$ da informação significativa com apenas dois ou três fatores.

\section{RESULTADOS E DISCUSSÃO}

As duas campanhas de coleta de dados resultaram em 712 amostras de ar que foram utilizadas para obter 165 fluxos, dos quais 147 foram validados. Destes, 76 fluxos foram classificados como puramente difusivos, com valores de 1,3 a $71,5 \mathrm{mg} \mathrm{CH}_{4} \mathrm{~m}^{-2} \mathrm{~d}^{-1}$ e valor médio de $11,1 \pm 13,5 \mathrm{mg} \mathrm{CH}_{4} \mathrm{~m}^{-2} \mathrm{~d}^{-1}$ (mediana de $6,3 \mathrm{mg} \mathrm{CH}_{4} \mathrm{~m}^{-2} \mathrm{~d}^{-1}$ ). Os demais 71 fluxos apresentaram a ocorrência de bolhas sendo classificados como ebulitivos, com valores de 31,2 a 2.098,7 mg CH $\mathrm{CH}_{4} \mathrm{~m}^{-2} \mathrm{~d}^{-1}$ e valor médio de 275,9 $\pm 348,5 \mathrm{mg} \mathrm{CH}_{4} \mathrm{~m}^{-2} \mathrm{~d}^{-1}$ (mediana de $\left.149,8 \mathrm{mg} \mathrm{CH}_{4} \mathrm{~m}^{-2} \mathrm{~d}^{-1}\right)$. A comparação entre as médias dos fluxos obtidos na Bacia do Rio Miranda (difusivo: 17,3 $\pm 36,2 \mathrm{mg} \mathrm{CH}_{4} \mathrm{~m}^{-2} \mathrm{~d}^{-1}$; ebulitivo: $219,5 \pm 202,5 \mathrm{mg} \mathrm{CH}_{4} \mathrm{~m}^{-2} \mathrm{~d}^{-1}$ ) com os obtidos na bacia Rio Negro (difusivo: $15,2 \pm 23,2 \mathrm{mg} \mathrm{CH}_{4} \mathrm{~m}^{-2} \mathrm{~d}^{-1}$; ebulitivo: $292,7 \pm$ $398,1 \mathrm{mg} \mathrm{CH}_{4} \mathrm{~m}^{-2} \mathrm{~d}^{-1}$ ) não apresentaram diferença significativa.

Os fluxos apresentaram comportamento diferente entre as estações e estão de acordo com os resultados obtidos por outros pesquisadores, os quais observaram que as quantidades liberadas de metano por fluxos ebulitivos são maiores do que no fluxo difusivo (Marani e Alvalá, 2007; Bastviken et al., 2004; Alvalá e Kirchhoff, 2000).

Durante o período de seca (campanha de setembro de 2009), aproximadamente $83 \%$ dos fluxos $(\mathrm{n}=58)$ foram classificados como difusivos, variando de 1,3 e $31,6 \mathrm{mg} \mathrm{CH}_{4} \mathrm{~m}^{-2} \mathrm{~d}^{-1} \mathrm{e}$ média de 7,2 $\pm 5,7 \mathrm{mg} \mathrm{CH}_{4} \mathrm{~m}^{-2} \mathrm{~d}^{-1}$ (mediana $=5,5 \mathrm{mg} \mathrm{CH}_{4} \mathrm{~m}^{-2} \mathrm{~d}^{-1}$ ). No período da cheia (campanha realizada em março de 2010), houve um número menor de fluxos difusivos $\left(\mathrm{n}=18\right.$ ), porém a média foi maior, $23,7 \pm 21,8 \mathrm{mg} \mathrm{CH}_{4} \mathrm{~m}^{-2} \mathrm{~d}^{-1}$ (mediana $=12,4 \mathrm{mg} \mathrm{CH}_{4} \mathrm{~m}^{-2}$ $\mathrm{d}^{-1}$ ), com variação de 1,8 a $71,5 \mathrm{mg} \mathrm{CH}_{4} \mathrm{~m}^{-2} \mathrm{~d}^{-1}$. 
A ocorrência de fluxos ebulitivos no período de seca foi de $17 \%(\mathrm{n}=12)$, com variação entre 31,2 e $246,0 \mathrm{mg} \mathrm{CH} \mathrm{m}^{-2} \mathrm{~d}^{-1}$, média de $112,2 \pm 75,7 \mathrm{mg} \mathrm{CH}_{4} \mathrm{~m}^{-2} \mathrm{~d}^{-1}$ (mediana $=101,8 \mathrm{mg} \mathrm{CH}_{4} \mathrm{~m}^{-2} \mathrm{~d}^{-1}$ ). No período da cheia houve um aumento expressivo do número de casos de ebulitivos $(\mathrm{n}=59)$, aproximadamente $77 \%$ do total de fluxos, assim como do valor médio em relação à seca, 309,2 $\pm 372,6 \mathrm{mg} \mathrm{CH}_{4} \mathrm{~m}^{-2} \mathrm{~d}^{-1}$ (mediana $=172,2 \mathrm{mg} \mathrm{CH}$ $\mathrm{m}^{-2} \mathrm{~d}^{-1}$ ), com variação de 38,8 a $2.098,76 \mathrm{mg} \mathrm{CH}_{4} \mathrm{~m}^{-2} \mathrm{~d}^{-1}$. A aplicação do teste $\mathrm{t}$ para comparação das médias mostrou que houve diferença estatística significativa entre as duas estações, assumindo-se um nível de confiança de $95 \%(p \leq 0,05)$.

Com a diferença observada entre as estações de seca e cheia, optou-se por analisar os parâmetros ambientais em cada estação. Os boxplots para profundidade, temperatura da água, pH, ORP, OD e TSD são mostrados na Figura 2.
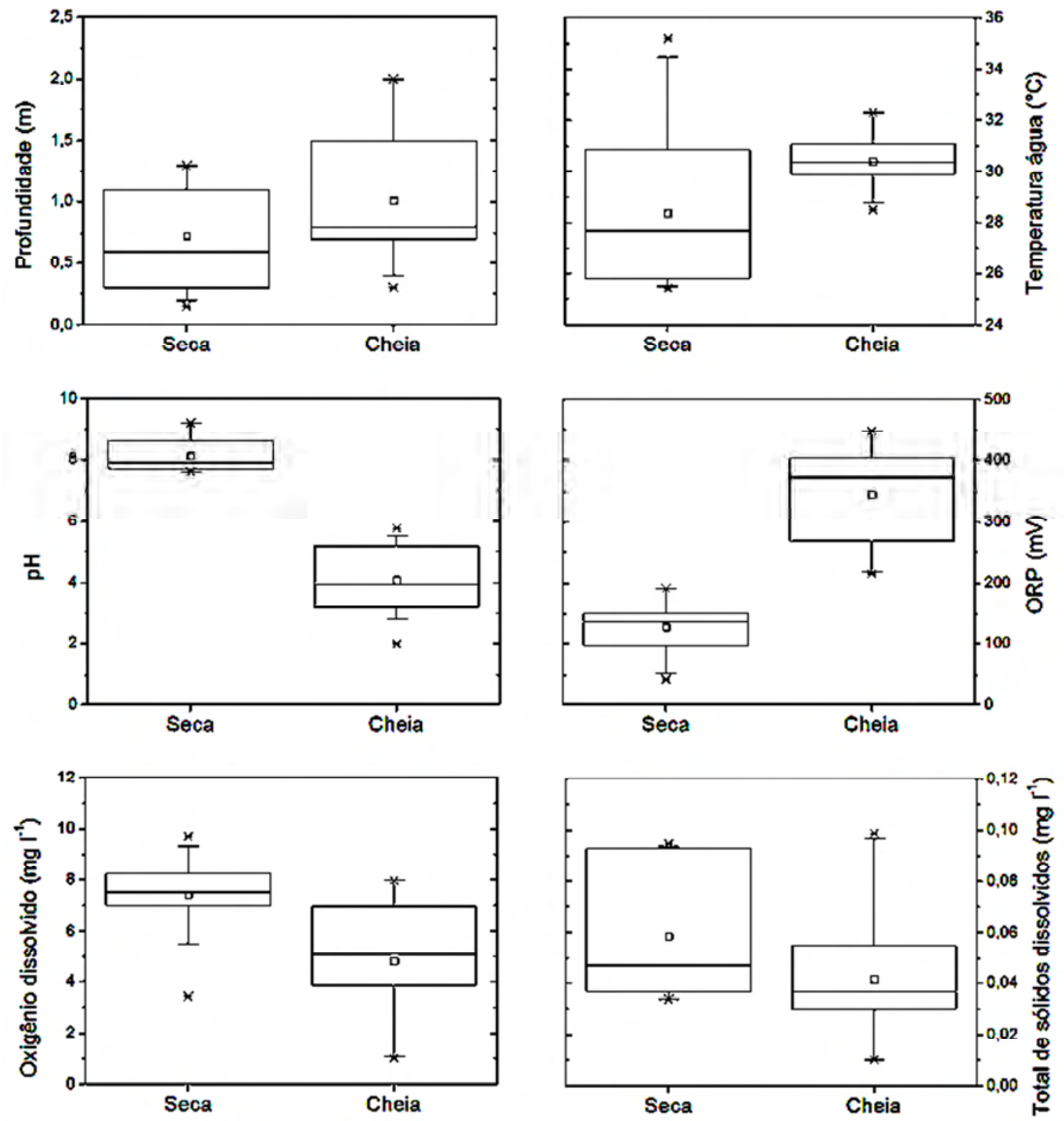

Figura 2. Variação dos parâmetros ambientais no período de seca e cheia no Pantanal, na sub-região do Abobral, Corumbá, Mato Grosso do Sul.

A aplicação do teste $t$ de Student mostrou que houve diferença estatística significativa 
$(p \leq 0,05)$ entre os dois períodos para todos os parâmetros medidos.

\subsection{Análise da influência dos parâmetros ambientais no fluxo}

Para estudar a influência das variáveis ambientais medidas neste estudo no fluxo de metano, o primeiro passo foi a realização de testes de correlação entre cada variável e os fluxos medidos em cada ponto de coleta (Tabela 1).

Tabela 1. Valores do teste de correlação entre parâmetros ambientais e os fluxos e para cada estação (seca e cheia) no Pantanal, na sub-região do Abobral, Corumbá, Mato Grosso do Sul. Os valores que apresentaram $p \leq 0,05$ foram marcados em negrito.

\begin{tabular}{|c|c|c|c|c|c|c|}
\hline \multirow{2}{*}{ Parâmetros } & \multirow{2}{*}{$\begin{array}{c}\text { Difusivo } \\
\text { (seca+cheia) }\end{array}$} & \multirow{2}{*}{$\begin{array}{c}\text { Ebulitivo } \\
\text { (seca+cheia) }\end{array}$} & \multicolumn{2}{|c|}{ Difusivo } & \multicolumn{2}{|c|}{ Ebulitivo } \\
\hline & & & Seca & Cheia & Seca & Cheia \\
\hline Profundidade & $-0,01$ & $-0,07$ & 0,19 & $-0,38$ & $-0,48$ & $-0,15$ \\
\hline Temp Água & 0,18 & 0,21 & $-0,22$ & $-0,07$ & 0,63 & 0,36 \\
\hline $\mathrm{pH}$ & $-0,53$ & $-0,18$ & $-0,16$ & $-0,10$ & 0,66 & $-0,01$ \\
\hline ORP & $\mathbf{0 , 5 9}$ & 0,17 & $\mathbf{0 , 3 1}$ & 0,33 & $-0,67$ & 0,03 \\
\hline OD & $-0,42$ & $-0,08$ & $-0,24$ & $-0,02$ & 0,20 & $-0,01$ \\
\hline TSD & $-0,27$ & $-0,19$ & $-0,17$ & $-0,27$ & 0,48 & $-0,20$ \\
\hline
\end{tabular}

A correlação direta mostrou que a maioria dos parâmetros ambientais medidos não apresentou significância estatística $(p \leq 0,05)$ com os fluxos. Algumas exceções foram observadas, como no caso de fluxos difusivos (considerando todos os casos tanto na seca quanto na cheia) que tiveram correlação moderada com $\mathrm{pH}$, ORP e OD, e para ebulitivos na seca que apresentaram correlação moderada com a temperatura da água, $\mathrm{pH}$ e ORP.

A dificuldade em estudar um sistema complexo como o Pantanal deve-se ao fato que cada parâmetro pode causar alterações na relação de produção e consumo do gás metano na coluna d'água.

\subsection{Análise de Componentes Principais (ACP)}

Os parâmetros medidos neste trabalho podem ser utilizados como indicadores de fatores que influenciam tanto a produção quanto o consumo de metano no ambiente. Além disso, estes fatores se inter-relacionam. Com a utilização da ACP pretendeu-se reduzir a variância do sistema com intuito de destacar o conjunto de parâmetros ambientais com maior influência no fluxo de metano. A Figura 3 apresenta a projeção das variáveis ambientais em relação às componentes principais para fluxos difusivos e ebulitivos nos períodos de seca e cheia.

Os resultados da ACP (Figura 3) mostraram que a variação dos fluxos difusivos (considerando tanto os obtidos na seca quanto na cheia) teve alta correlação com a Componente $1(r=0,70 ; p=0,00)$. Apesar de todas as variáveis ambientais apresentarem algum grau de influência, os parâmetros com maior peso foram o $\mathrm{pH}(0,97)$, OD $(0,77)$ e ORP $(-0,94)$. A dominância destas variáveis ambientais indica que a variação do fluxo difusivo pode estar associada ao incremento e espalhamento de matéria orgânica e nutrientes durante a época da cheia. $\mathrm{O}$ alagamento da região resulta na decomposição de restos animais e de espécies vegetais crescidas durante a seca (Calheiros e Ferreira, 1996; Agostinho et al., 1995). Quando inserida num meio aquoso, a matéria orgânica age como um agente redutor do meio consumindo o oxigênio dissolvido. Esta reação também é responsável pela liberação de íons na água que resultam na alteração do valor de pH. Segundo Langmuir (1997), o declínio do pH em solos alcalinos está associado ao aumento da pressão parcial de $\mathrm{CO}_{2}$. Esta relação está 
coerente com os dados obtidos neste trabalho onde foi observado que durante a cheia houve um aumento no valor de ORP, diminuição da concentração de OD e acidificação do meio, em relação à seca. A influência destes parâmetros entre as duas estações resultou num aumento da média do fluxo difusivo de $7.2 \pm 5.7 \mathrm{mg} \mathrm{CH}_{4} \mathrm{~m}^{-2} \mathrm{dia}^{-1}$ (seca) para $23.7 \pm 21.8 \mathrm{mg} \mathrm{CH}_{4} \mathrm{~m}^{-2}$ $\mathrm{dia}^{-1}$ (cheia). Para fluxos ebulitivos, a análise da ACP não evidenciou correlação significativa com as componentes que explicasse a variação do fluxo.
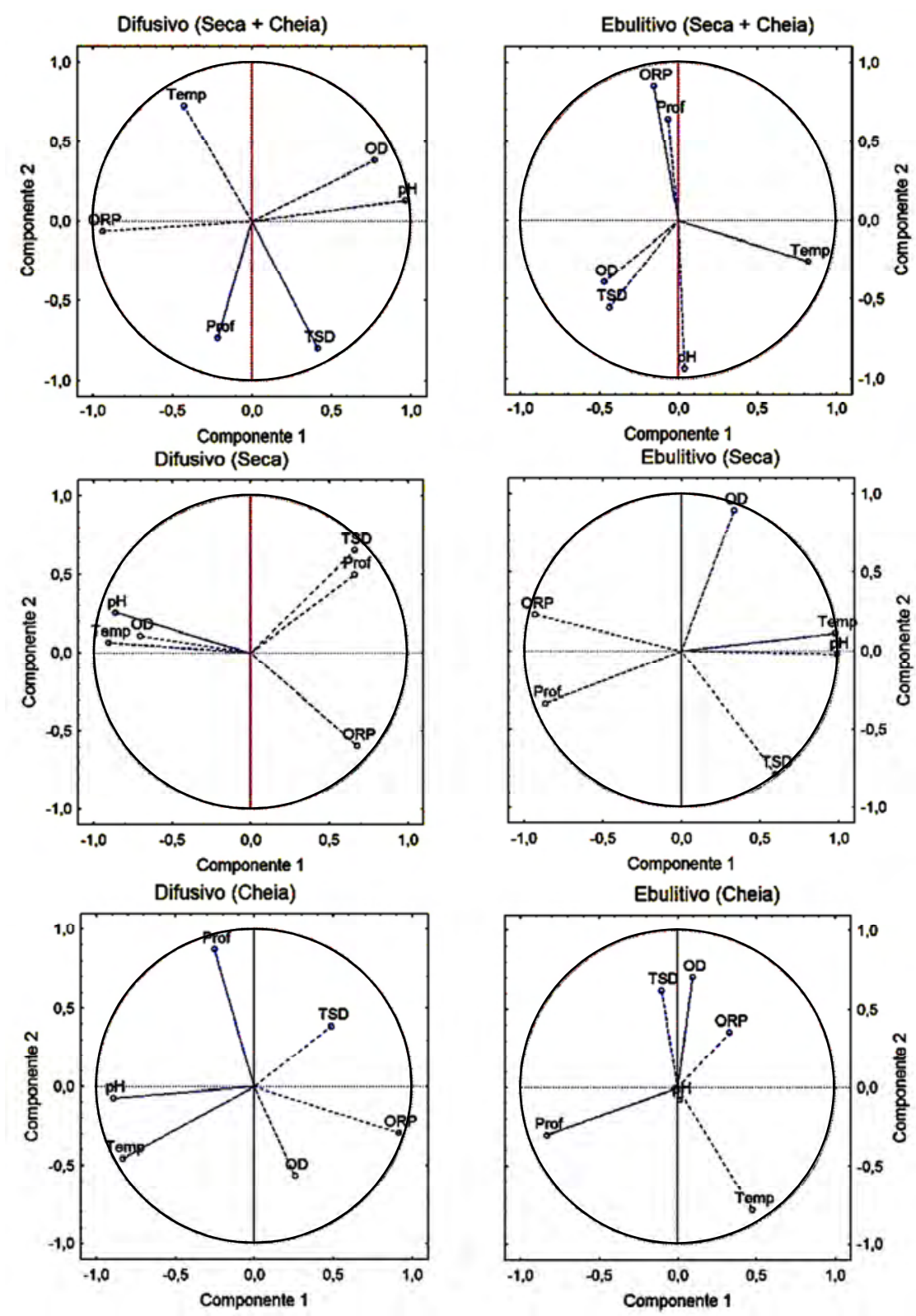

Figura 3. Projeção das variáveis ambientais na primeira e segunda componente principal para fluxos difusivos e ebulitivos nos períodos de seca e cheia do Pantanal, na sub-região do Abobral, Corumbá, Mato Grosso do Sul.

A ACP também foi aplicada para analisar o comportamento dos fluxos difusivos e ebulitivos em cada estação. Quando a ACP foi aplicada para as medidas realizadas durante a estação seca, verificou-se que nenhum grupo de parâmetros ambientais apresentou correlação significativa com os fluxos difusivos. O mesmo resultado foi obtido tanto para os fluxos difusivos quando os fluxos ebulitivos na estação da cheia. Apenas no conjunto de medidas de 
fluxos ebulitivos na estação seca verificou-se a ocorrência de correlação entre os fluxos e a componente $1(r=0,66 ; p=0,02)$. Os parâmetros com maior peso na Componente 1 , como destacado na Figura 3, foram a profundidade $(-0,87)$, temperatura da água $(0,98), \mathrm{pH}(0,99)$ e ORP (-0,93). A ocorrência de profundidades menores implica numa diminuição da pressão hidrostática que resulta numa maior probabilidade da bolha se desprender do sedimento (Dalal e Allen, 2008). O aumento da temperatura da água pode aumentar a produção de metano, além de poder induzir turbulência na água, fazendo com que as bolhas sejam liberadas (Abril et al., 2006; Devol et al., 1988). Este fato está coerente com a diminuição da temperatura da água no decorrer da campanha de coleta de dados na seca devido à entrada de uma frente fria que resultou em chuvas na região. $\mathrm{O}$ valor médio da temperatura da água nos primeiros dias de campanha foi de aproximadamente $30^{\circ} \mathrm{C}$ e passou para $26^{\circ} \mathrm{C}$ após as chuvas. Com relação ao pH e ORP, foi observado que os maiores valores de fluxo ocorreram em locais onde o $\mathrm{pH}$ era básico, próximo do valor 9 na escala, enquanto que o ORP apresentava valores positivos, mas próximos de zero, que indicavam que o ambiente estava pouco oxidado. O fluxo ebulitivo, diferente de difusivos, não está sujeito à oxidação no transporte devido à rápida passagem pela coluna d'água. Entretanto, o metano presente nas bolhas que estão presas ao sedimento pode ser consumido por reações de oxidação na interface de contato com a água. Desta forma, a diminuição de agentes oxidantes na água tende a diminuir a probabilidade do consumo de $\mathrm{CH}_{4}$ retido na forma de bolha até que ele se desprenda e seja transportado para a superfície da coluna d'água.

Os conjuntos de parâmetros ambientais que apresentaram valores estatisticamente significativos de correlação com o fluxo de metano foram os mesmos em ambas as análises. Assim, as características físico-químicas que podem influenciar o balanço entre os processos de produção e consumo de metano, ao se considerar o transporte difusivo em ambientes aquosos, foram principalmente o $\mathrm{pH}$, ORP e OD, que são indicativos do aumento da disponibilidade de matéria orgânica entre as estações de seca e cheia em decorrência do alagamento do Pantanal e, portanto, favorecem a produção.

A influência dos parâmetros ambientais também pôde ser verificada nos valores de fluxo ebulitivo no período da seca onde os maiores valores de fluxo foram observados em locais com temperatura da água maior, $\mathrm{pH}$ básico, menor índice de oxidantes na água e profundidades menores. A relação destes parâmetros sugere que as bolhas que são formadas encontram menor resistência para se desprender do substrato antes que ocorra o consumo na interface de contato entre a bolha e a água.

\section{CONCLUSÃO}

A medição do fluxo de metano na sub-região do Abobral nos anos de 2009 e 2010 mostrou que o transporte difusivo através da coluna d'água ocorreu com mais frequência no período da seca (83\%), enquanto que na cheia houve um predomínio de fluxos ebulitivos (77\%). O valor médio de fluxo para ambas as formas de transporte foi significativamente maior no período da cheia. No desenho experimental utilizado não é possível a coleta separada de fluxos difusivos e ebulitivos e assim, destaca-se que os valores obtidos para o fluxo ebulitivo podem ser subestimados. Mesmo assim, estes resultados são importantes ao destacar os parâmetros ambientais que podem estar relacionados à emissão de metano em corpos d'água.

As análises estatísticas mostraram que é possível obter um conjunto de parâmetros ambientais relacionados com os processos de produção e consumo de metano na água. Estes parâmetros se mostraram dependentes do ciclo de alagamento anual da área de amostragem, devido à distribuição e decomposição de matéria orgânica, e podem ser diferentes quando 
considerado o mecanismo de transporte e a estação do ano.

\section{AGRADECIMENTOS}

Agradecimento ao CNPq pelo apoio financeiro (Proc. $\mathrm{N}^{\circ} 475976 / 2008-8$ ), ao Instituto Nacional de Pesquisas Espaciais (INPE) e à Universidade Federal de Mato Grosso do Sul pela utilização logística da Base de Estudos do Pantanal (BEP).

\section{REFERENCIAS}

ABRIL, G.; RICHARD, S.; GUÉRIN, F. In situ measurements of dissolved gases $\left(\mathrm{CO}_{2}\right.$ and $\mathrm{CH}_{4}$ ) in a wide range of concentrations in a tropical reservoir using an equilibrator. Science of the Total Environment, v. 354, p. 246-251, 2006. http://dx.doi.org/10.1016/j.scitotenv.2004.12.051

AGOSTINETTO, D.; FLECK, N. G.; RIZZARDI, M. A.; BALBINOT JR., A. A. Potencial de emissão de metano em lavouras de arroz irrigado. Ciência Rural, v. 32, n. 6, p. 1073-1081, 2002. http://dx.doi.org/10.1590/S0103-84782002000600026

AGostinho, A. A.; VAZOLlER, A. E. A. M.; THOMAZ, S. M. The high Paraná river basin: limnological and ichthyological aspects. In: TUNDISI, J. G.; BICUDO, C. M.;MATSUMURA-TUNDISI, T. (Eds.). Limnology in Brazil. Rio de Janeiro: ABC/SBL, 1995. p. 59-104.

ALVALÁ, P. C.; KIRCHHOFF, W. V. J. H. Methane fluxes from the Pantanal floodplain in Brazil: seasonal variation. In: VAN HAM, J. et al. (Eds.) Non- $\mathrm{CO}_{2}$ Greenhouse gases: scientific understanding, control and implementation. Dordrecht: Kluwer Academic Publishers, 2000. p. 95-99. http://dx.doi.org/10.1007/978-94-015-9343-4_6

ALVALÁ, P. C.; BOIAN, C.; KIRCHHOFF, V. W. J. H. Measurements of $\mathrm{CH}_{4}$ and $\mathrm{CO}_{2}$ during ship cruises in the South Atlantic. Atmospheric Environment, v. 38, p. 45834588, 2004. http://dx.doi.org/10.1016/j.atmosenv.2004.03.042

BARTLETT, K. B.; CRILL, P. M.; SEBACHER, D. I.; HARRIS, R. C.; WILSON, J. O.; MELACK, J. M. Methane flux from the central Amazonian floodplain. Journal of Geophysical Research, v. 93, p. 1571-1582, 1988.

http://dx.doi.org/10.1029/JD093iD02p01571

BASTVIKEN, D.; COLE, J.; PACE, M.; TRANVIK, L. Methane emissions from lakes: Dependence of lake characteristics, two regional assessments, and global estimate. Global Biogeochemical Cycles, v. 18, p. 1-12, 2004.

http://dx.doi.org/10.1029/2004GB002238

BASTVIKEN, D.; SANTORO, A. L.; MAROTTA, H.; PINHO, L. Q.; CALHEIROS, D. F.; CRILL, P. et al. Methane emissions from Pantanal, South America, during the low water season: toward more comprehensive sampling. Environmental Science and Technology, v. 44, n. 14, p. 5450-5455, 2010. http://dx.doi.org/10.1021/es 1005048

BELGER, L.; FORSBERG, B. R.; MELACK, J. M. Carbon dioxide and methane emissions from interfluvial wetlands in the upper Negro River basin, Brazil. Biogeochemistry, v. 105, p. 171-183, 2011. http://dx.doi.org/10.1007/s10533-010-9536-0 
CALHEIROS, D. F.; FERREIRA, C. J. A. Alterações limnológicas no rio Paraguai (“dequada") e o fenômeno natural de mortandade de peixes no Pantanal MatoGrossense - MS. Corumbá: EMBRAPA-CPAP, 1996. p. 51. (Boletim de Pesquisa, 7).

CONRAD, R. Contribution of hydrogen to methane production and control of hydrogen concentrations in methanogenic soils and sediments. FEMS Microbiology Ecology, v. 28, p. 193-202, 1999. http://dx.doi.org/10.1111/j.1574-6941.1999.tb00575.x

DALAL, R. C.; ALLEN, D. E. Greenhouse gas fluxes from natural ecosystems. Australian Journal of Botany, v. 56, p. 369-407, 2008. http://dx.doi.org/10.1071/BT07128

DEVOL, A. H.; RICHEY, J. E.; CLARK, W. A.; KING, S. L.; MARTINELLI, L. A. Methane emissions to the troposphere from the Amazon floodplain. Journal Of Geophysical Research, v. 93, n. D2, p. 1583-1592, 1988.

http://dx.doi.org/10.1029/JD093iD02p01583

HAMILTON, S. K.; SIPPEL, S. J.; MELACK, J. M. Comparison of inundation patterns among major South American floodplains. Journal of Geophysical Research, v. 107, n. D20, p. 1-14, 2002. http://dx.doi.org/10.1029/2000JD000306

INTERGOVERNMENTAL PANEL ON CLIMATE CHANGE - IPCC. Climate Change 2007: the physical basis. Cambridge, 2007.

KHALIL, M. A. K.; RASMUSSEN, R. A.; SHEARER, M.; DALlUGE, R.; REN, L.; DUAN, C. L. Factors affecting methane emissions from rice fields. Journal of Geophysical Research, v. 103, n. D19, p. 25219-25231, 1998.

http://dx.doi.org/10.1029/98JD01115

LANGMUIR, D., Aqueous environmental geochemistry. Upper Saddle River: PrenticeHall, 1997.

MARANI, L.; ALVALÁ, P. C. Methane emissions from lakes and floodplains in Pantanal, Brazil. Atmospheric Environment, v. 41, n. 8, p. 1627-1633, 2007. http://dx.doi.org/10.1016/j.atmosenv.2006.10.046

MELACK, J. M.; HESS, L. L.; GASTIL, M.; FORSBERG, B. R.; HAMILTON, S. K.; LIMA, I. B. T.; NOVO, E. M. L. M. Regionalization of methane emissions in the Amazon basin with microwave remote sensing. Global Change Biology, v. 10, p. 530544, 2004. http://dx.doi.org/10.1111/j.1365-2486.2004.00763.x

NATIONAL OCEANIC AND ATMOSPHERIC - NOAA. The NOAA Annual Greenhouse Gas Index (AGGI). Broadway, 2014.

Disponível em: http://www.esrl.noaa.gov/gmd/aggi/aggi.html. Acesso em: ago. 2015.

PARRON, L. M.; MUNIZ, D. H. F.; PEREIRA, C. M. Manual de procedimentos de amostragem e análise físico-química da água. Colombo: EMBRAPA Florestas, 2011. (Documentos, 232). Disponível em: http://www.infoteca.cnptia.embrapa.br/ bitstream/doc/921050/1/Doc232ultimaversao.pdf. Acesso em: 16 ago. 2015.

PEREIRA, G.; CHÁVEZ, E.S.; SILVA, M.E.S. O estudo das unidades de paisagem do bioma Pantanal. Revista Ambiente \& Água, Taubaté, v.7, n. 1, p. 89-103, 2012. http://dx.doi.org/10.4136/ambi-agua.826 
RAO, V. B.; CAVALCANTI, I. F. A.; HADA, K. Annual variation of rainfall over Brazil and water vapor characteristics over South America. Jounal of Geophysical Research, v. 101, n. D21, p. 26539-26551, 1996. http://dx.doi.org/10.1029/96JD01936

SASS, R. L.; FISHER, F. M.; WANG, Y. B.; TURNER, F. T.; JUND, M. F. Methane emissions from rice fields: the effect of floodwater management. Global Biogeochem. Cycles, v. 6, n. 3, p. 249-262, 1992. http://dx.doi.org/10.1029/92GB01674

THAUER, R. K.; KASTER, A. K.; SEEDORF, H.; BUCKEL, W.; HEDDERICH, R. Methanogenic archaea: ecologically relevant differences in energy conservation. Microbiology, v. 6, p. 579-591, 2008. http://dx.doi.org/10.1038/nrmicro1931

WANG, Z. P.; DELAUNE, R. D.; MASSCHELEYN, P. H. et al. Soil redox and pH effects on methane production in a flooded rice. Soil Science Society of America Journal, v. 57, n. 2, p. 382-385, 1993. http://dx.doi.org/10.2136/sssaj1993.03615995005700020016x

WILKS, D. S. Statistical methods in the atmospheric sciences. San Diego: Academic Press, 2006. 627p.

WUEBBLES, D. J.; HAYHOE, K. Atmospheric methane and global change. Earth-Science Reviews, v. 57, p. 177-210, 2002. http://dx.doi.org/10.1016/S0012-8252(01)00062-9

YANG, S. S.; CHANG, H. L. Effect of environmental conditions on methane production and emission from paddy soil. Agriculture Ecosystems \& Environment, v. 69, n. 1, p. 6980, 1998. http://dx.doi.org/10.1016/S0167-8809(98)00098-X 


Ambiente \& Água - An Interdisciplinary Journal of Applied Science
ISSN 1980-993X - doi:10.4136/1980-993X
www.ambi-agua.net
E-mail: ambi.agua@gmail.com

\title{
Estoque de carbono no solo e agregados em Cambissolo sob diferentes manejos no sul do Amazonas
}

\author{
doi:10.4136/ambi-agua.1819
}

Received: 03 Dec. 2015; Accepted: 23 Feb. 2016

\author{
Milton César Costa Campos*; Marcelo Dayron Rodrigues Soares; \\ Mailson Ferreira Nascimento; Douglas Marcelo Pinheiro Silva \\ Universidade Federal do Amazonas (UFAM), Humaitá, AM, Brasil \\ Instituto de Educação, Agricultura e Ambiente \\ *Autor correspondente: e-mail: mcesarsolos@gmail.com, \\ marcelo.dayron@gmail.com, mailsonnf@gmail.com,dougllasmarcelo@gmail.com
}

\section{RESUMO}

Os sistemas de uso e manejo dos solos são fatores que podem influenciar nos estoques de carbono e na estabilidade de agregados. Neste trabalho os estoques de carbono e estabilidade de agregados de um Cambissolo Háplico Alítico plíntico sob diferentes usos e manejos foram avaliados. O estudo foi realizado em cinco propriedades, localizadas na região sul do Estado do Amazonas, foram selecionadas cinco áreas com diferentes sistemas de usos tradicionais nesta região da Amazônia (agroflorestal, mandioca, cana-de-açúcar, pastagem e floresta nativa). Nestes locais foram feitas malhas de $50 \mathrm{~m}$ x $50 \mathrm{~m}$, com espaçamentos regulares de 10 em 10 metros, perfazendo um total de 36 pontos amostrais em cada malha na profundidade de 0-0,10 m. Foram determinadas a densidade do solo, estabilidade de agregado, carbono orgânico total e estoque de carbono. Os dados foram submetidos à análise de variância (teste F) e as médias foram comparadas pelo teste de Tukey, a 5\% de probabilidade. Nota-se que os maiores valores de estoque de carbono foram observados nas áreas sob cana-de-açúcar e pastagem, seguidos pelas áreas sob mandioca, agrofloresta e floresta nativa. Os estoques de carbono e estabilidade de agregados foram alterados significativamente pelos sistemas de manejo.

Palavras-chave: agroecossistemas, bioma amazônico, manejo do solo, matéria orgânica.

\section{Carbon storage in soil and aggregates of Inceptisols under different land use management systems in southern Amazonas}

\begin{abstract}
Land use and management systems are factors that can influence carbon stock and its aggregate stability. This study assessed the carbon stock and aggregate stability of Inceptisols under different land use and management systems. The study was conducted on five properties located in the southern region of Amazonas state. Five areas were selected with different traditional land use systems (agroforestry, cassava, sugarcane, pasture and native forest). On each site, grids of $50 \mathrm{~m}$ x $50 \mathrm{~m}$, with regular spacing of 10 by 10 meters were outlined for a sampling of 36 points in each mesh at a depth $0.00-0.10 \mathrm{~m}$. We determined the bulk density, aggregate stability, total organic carbon and carbon stock. Data were subjected
\end{abstract}


to analysis of variance ( $\mathrm{F}$ test) and means were compared by Tukey test at $5 \%$ probability. We found that the highest values of carbon stocks were found in areas under sugar cane and pasture, followed by the areas under cassava, agroforestry and native forest. Carbon stocks and aggregate stability were significantly altered by land use management systems.

Keywords: agroecosystems, environment amazon, management, soil organic matter.

\section{INTRODUÇÃO}

A conversão dos ecossistemas naturais em ambientes de cultivo vem alterando a dinâmica de carbono no solo, essas modificações frequentemente, provocam o declínio no teor de carbono (C) orgânico do solo, em função da redução do aporte, perdas por erosão e por decomposição da matéria orgânica (Hickmann e Costa, 2012). Por outro lado, o manejo e tipo de agroecossistema utilizado podem minimizar o aporte de $\mathrm{C}$ orgânico do solo, pois há baixa produção primária de $\mathrm{C}$ em subsuperfície e a maior remoção da produção de $\mathrm{C}$ da superfície pelas atividades de colheita, queima ou até pela alimentação animal (Lavelle et al., 1994).

Os mecanismos de formação dos agregados do solo são influenciados pelos teores e formas do $\mathrm{C}$ orgânico do solo que irá permitir maior ou menor agregação do solo (Castro Filho e Logan, 1991). Em contrapartida o estado de agregação do solo interfere no comportamento de outras variáveis, tais como aeração do solo, desenvolvimento radicular, suprimento de nutrientes, resistência mecânica do solo à penetração, retenção e armazenamento de água (Heid et al., 2009). Portanto entender as relações entre o estoque de $\mathrm{C}$ e estado de agregação do solo são fundamentais para se manejar adequadamente um agroecossistema e assim intervir previamente no meio de cultivo de modo a reduzir impactos negativos ao ambiente (Chaves e Farias, 2008).

$\mathrm{Na}$ região amazônica alguns trabalhos têm centrado esforços no sentido de avaliar as transformações ocorridas no solo após a substituição de ecossistemas de floresta em agroecossistemas (sistemas agrícolas) (Aquino et al., 2014). De acordo com Salimon et al. (2007), a introdução de ecossistemas de pastagens resulta decréscimo nos estoques de C no solo na implantação, e tendem a aumentar nos anos seguintes, podendo atingir valores próximos ou superiores aos existentes antes da conversão. Apesar disso, Makewitz et al. (2004), destacam que conversão de ambientes naturais alteram os atributos físicos e químicos do solo.

Por outro lado, se o agroecossistema for para fins agrícolas propriamente, é necessário considerar alguns aspectos, tais como espécie a ser cultivada, pois o tipo de sistema radicular, arquitetura da copa, aporte de resíduos vegetais e ciclo da planta, assim como aspectos ligados ao manejo, como, por exemplo, se é plantio convencional, plantio direto, rotação de culturas e cultivo mínimo interferem nos conteúdos de carbono orgânico (Zinn et al., 2005). Alguns trabalhos, tais como o desenvolvido por D'Andréa et al. (2004) constataram decréscimo no conteúdo de matéria orgânica do solo com o tempo de conversão floresta-agricultura.

Assim, o presente trabalho tem como objetivo avaliar os estoques de carbono no solo e agregados de um Cambissolo Háplico Alítico plíntico sob agrofloresta, pastagem, cana-de-açúcar, mandioca e floresta nativa na região Sul do Amazonas de modo a fornecer subsídios ao manejo mais sustentável desses agroecossistemas na região.

\section{MATERIAIS E MÉTODOS}

O estudo foi realizado em cinco propriedades rurais, localizadas na região de Humaitá e Manicoré, sul do Estado do Amazonas, situada nas coordenadas geográficas: $7^{\circ} 30^{\prime 2} 24^{\prime \prime} \mathrm{S}$ e 
6304'56" W, numa altitude média de $59 \mathrm{~m}$. O clima da região, segundo a classificação de Köppen, é do tipo tropical chuvoso, apresentando um período seco de pequena duração (Am), temperaturas variando entre 25 e $27^{\circ} \mathrm{C}$ e precipitação média anual de $2.500 \mathrm{~mm}$, com período chuvoso iniciando em outubro e prolongando-se até junho e umidade relativa do ar entre 85 e $90 \%$.

Geologicamente as áreas situam-se sobre os sedimentos da Formação Solimões, do Plioceno Médio - Pleistoceno Superior, com materiais provenientes de deposições de ambientes continentais, fluviais e lacustres (Brasil, 1978). O solo foi classificado como Cambissolo Háplico Alítico plíntico, A moderado, textura média (CXalf) (Campos et al., 2012).

Foram selecionadas cinco áreas com diferentes sistemas de usos tradicionais nesta região da Amazônia (Figura 1), a saber:

a) Agrofloresta: área com uso agroflorestal, com aproximadamente 17 anos cultivada com espécies frutíferas amazônicas (cupuaçu, cacau, açaí, bacaba, manga e etc.), neste sistema foram realizadas roçagem manual a cada ano;

b) Pastagem (Brachiaria decumbens): área sob uso de pastagem com 10 anos de uso contínuo;

c) Cana-de-açúcar: área cultivada com cana-de-açúcar há mais de 8 anos, com colheita manual sem queima, sendo realizada a correção e adubação no primeiro ano de cultivo;

d) Mandioca: área cultivada há 15 anos, com queima, correção e adubação apenas no primeiro ano e com aproximadamente 120 dias após o plantio e e) Floresta: fragmento florestal de mata ombrófila densa contiguo as áreas. Os solos foram amostrados entre maio e julho de 2011.

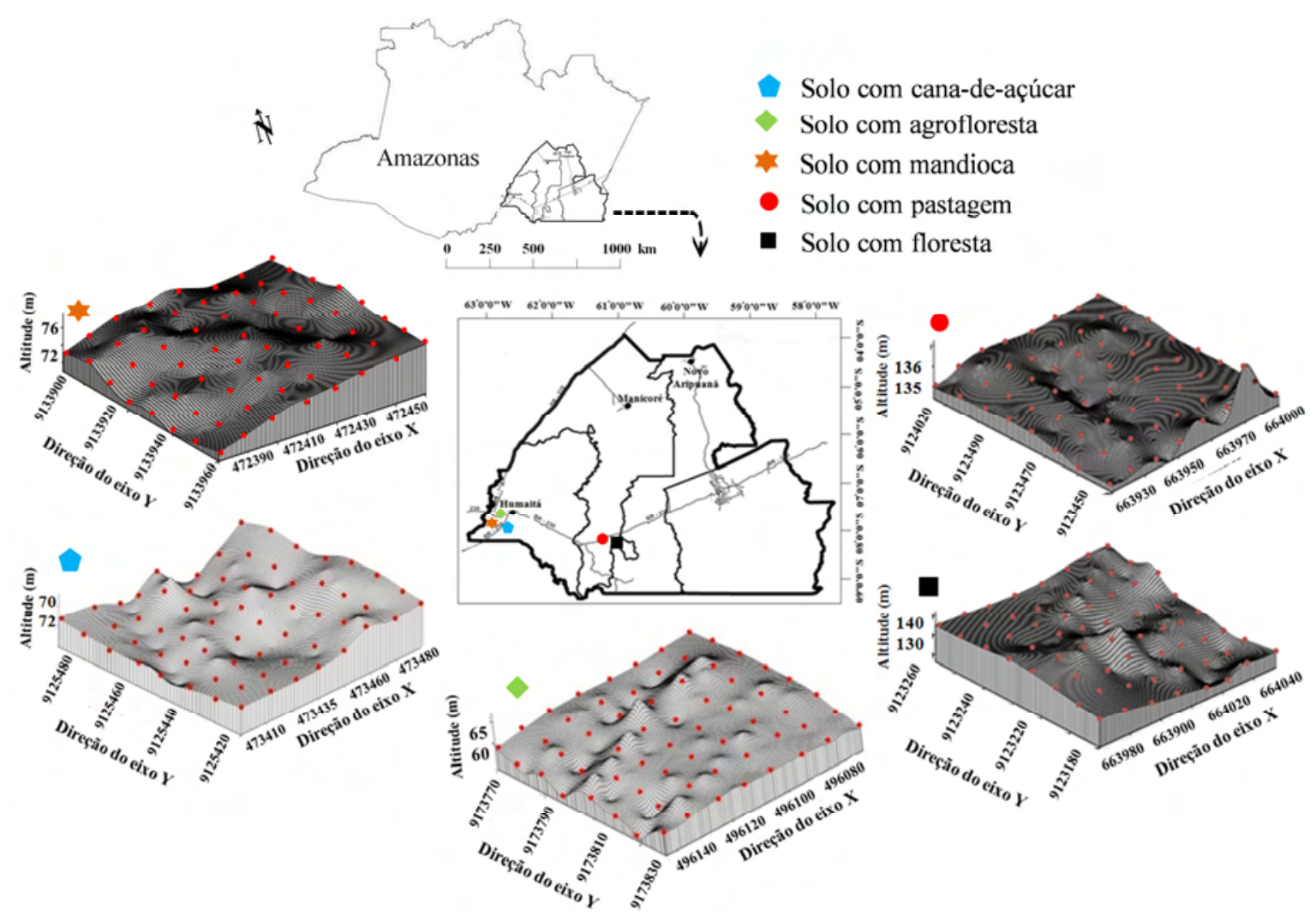

Figura 1. Localização e modelo de elevação digital dos diferentes ambientes na região Sul do Amazonas. 
Nestas áreas foram estabelecidas malhas de $50 \mathrm{~m}$ x $50 \mathrm{~m}$ e o solo foi amostrado nos pontos de cruzamento da malha, com espaçamentos regulares de $10 \mathrm{em} 10$ metros, perfazendo um total de 36 pontos amostrais em cada malha. Em seguida foram coletadas amostras de solos, na profundidade $0,00-0,10 \mathrm{~m}$ da superfície, totalizando 180 amostras de solo nas cinco malhas.

Foram realizadas caracterização física e química foram realizadas de acordo com Embrapa (1997). A textura foi determinada pelo método da pipeta, utilizando uma solução de $\mathrm{NaOH}$ 0,1 $\mathrm{N}$ como dispersante químico e agitação mecânica em aparato de alta rotação por 10 min. A fração argila foi separada por sedimentação; as areias, grossa e fina, por tamisação; e o silte, calculado por diferença. Ainda foram determinados os teores de $\mathrm{Ca}, \mathrm{Mg}$ e $\mathrm{K}$ trocáveis e P disponível.

Para determinação da densidade do solo foram coletadas amostras de solos com estrutura preservada, utilizando um anel volumétrico com 0,045 $\mathrm{m}$ de altura e 0,0405 $\mathrm{m}$ de diâmetro, na profundidade $0,0-0,10 \mathrm{~m}$. Em seguida foi calculada pela relação entre a massa seca a $105^{\circ} \mathrm{C}$ durante $24 \mathrm{~h}$ da amostra de solo do cilindro volumétrico e o volume do mesmo cilindro (Embrapa, 1997).

Em cada ponto amostral, foram coletadas amostras com estrutura preservada (bloco de aproximadamente dois quilogramas) na profundidade $0,00-0,10 \mathrm{~m}$ para determinação da estabilidade dos agregados do solo. As amostras foram levemente destorroadas, de forma manual e passadas em peneira de $9,51 \mathrm{~mm}$ de diâmetro de malha e retidos na peneira de $4,76 \mathrm{~mm}$, secadas à sombra, para as análises relativas à estabilidade de agregados. A separação e estabilidade dos agregados foram determinadas segundo Kemper e Chepil (1965), com modificações, nas seguintes classes de diâmetro: $>2,0 ; 2,0-1,0$ e $<1,00 \mathrm{~mm}$. Os agregados foram colocados em contato com a água sobre a peneira de 2,0 $\mathrm{mm}$ por quinze minutos, a massa do material retido em cada peneira, foi colocada em estufa a $105^{\circ} \mathrm{C}$. Os resultados foram expressos em percentual dos agregados retidos nas peneiras 4-2,0; 2,0-1,0 e $<1,0 \mathrm{~mm}$.

A determinação do carbono orgânico total (COT) no solo foi efetuada segundo Yeomans e Bremner (1988) utilizando-se, como agente oxidante, o dicromato de potássio em meio ácido e uma fonte externa de calor (chapa aquecedora) e titulação com sulfato ferroso amoniacal. $\mathrm{O}$ estoque de carbono (Est $\mathrm{C}$ ) foi determinado em todas as áreas estudadas na profundidade de coleta de 0,00-0,05 e 0,05-0,10 e foi calculado pela expressão (Costa et al., 2009):

Est $\mathrm{C}=($ COT $\mathrm{x}$ Ds $\mathrm{x}$ e $) / 10$

em que:

Est $\mathrm{C}=$ estoque de carbono orgânico do solo $\left(\mathrm{Mg} \mathrm{ha}^{-1}\right)$;

COT $=$ teor de carbono orgânico total $\left(\mathrm{g} \mathrm{kg}^{-1}\right)$;

Ds $=$ densidade do solo $\left(\mathrm{kg} \mathrm{dm}^{-3}\right)$;

$\mathrm{e}=$ espessura da camada considerada $(\mathrm{cm})$.

Os dados foram submetidos à análise de variância (teste $\mathrm{F}$ ) e as médias foram comparadas pelo teste de Tukey, a 5\% de probabilidade, com auxílio do programa estatístico Statistica 7.0.

\section{RESULTADOS E DISCUSSÃO}

Os resultados dos atributos físicos e químicos sob mata nativa e nas áreas cultivadas com pastagem, mandioca, cana-de-açúcar e agrofloresta são apresentados na Tabela 1. Notaram-se 
variações nas frações granulométricas, com textura argilosa nas áreas de agrofloresta e pastagem, siltosa na área de mandioca e textura média nas demais áreas. Os elevados teores de silte nas áreas cultivada com cana-de-açúcar e mandioca pode ocasiona à obstrução dos poros do solo, o que poderá ocasionar baixa infiltração de água no perfil (Resende et al., 2002), além de dificultar o uso e manejo destes solos. Valores dominantes de silte nos solos da região foram observados também por Santos et al. (2012), trabalhando com caracterização de solos em uma topossequência sob terraços aluviais na região do médio rio Madeira, os autores encontraram valores de silte elevados chegando a valores de $600 \mathrm{~g} \mathrm{~kg}^{-1}$, mostrando assim que altos valores de silte são comuns nos solos da região.

Tabela 1. Caracterização física e química do solo sob diversos sistemas de usos (floresta nativa, agrofloresta, pastagem, cana-de-açúcar e mandioca) na profundidade 0,00-0,10 m de um Cambissolo Háplico Alítico plíntico na região Sul do Amazonas ( $(n=20)$.

\begin{tabular}{|c|c|c|c|c|c|}
\hline \multirow{2}{*}{$\begin{array}{l}\text { Atributos } \\
\text { do Solo }\end{array}$} & \multicolumn{5}{|c|}{ Sistemas de Uso } \\
\hline & Floresta & Agrofloresta & Pastagem & Cana-de-açúcar & Mandioca \\
\hline $\mathrm{pH}\left(\mathrm{H}_{2} \mathrm{O}\right)$ & 3,9 & 3,8 & 4,3 & 5,3 & 4,0 \\
\hline$P\left(\mathrm{mg} \mathrm{dm}^{-3}\right)$ & 0,10 & 0,60 & 0,40 & 0,70 & 0,50 \\
\hline $\mathrm{K}^{+}\left(\mathrm{cmol}_{\mathrm{c}} \mathrm{dm}^{-3}\right)$ & 0,18 & 0,08 & 0,16 & 0,03 & 0,16 \\
\hline $\mathrm{Ca}^{2+}\left(\mathrm{cmol}_{\mathrm{c}} \mathrm{dm}^{-3}\right)$ & 0,30 & 0,20 & 0,80 & 1,80 & 0,20 \\
\hline $\mathrm{Mg}^{2+}\left(\mathrm{cmol}_{\mathrm{c}} \mathrm{dm}^{-3}\right)$ & 0,02 & 0,01 & 0,04 & 0,20 & 0,01 \\
\hline $\mathrm{Al}^{+3}\left(\mathrm{cmol}_{\mathrm{c}} \mathrm{dm}^{-3}\right)$ & 5,40 & 4,80 & 5,10 & 4,80 & 5,10 \\
\hline Areia $\left(\mathrm{g} \mathrm{kg}^{-1}\right)$ & 379,36 & 220,79 & 336,80 & 259,43 & 138,71 \\
\hline Silte $\left(\mathrm{g} \mathrm{kg}^{-1}\right)$ & 293,84 & 230,11 & 223,20 & 452,21 & 518,50 \\
\hline Argila $\left(\mathrm{g} \mathrm{kg}^{-1}\right)$ & 326,80 & 549,10 & 440,00 & 288,36 & 342,80 \\
\hline
\end{tabular}

Quanto aos atributos químicos verificaram-se que os resultados são semelhantes entre as áreas estudadas, independente do manejo todos os solos apresentam uma baixa a moderada acidez e baixos teores de nutrientes (Tabela 1) de acordo com Raij et al. (1985). Os menores valores de $\mathrm{pH}$ foram observados para as áreas de agrofloresta e floresta nativa respectivamente, evidenciando assim, a natureza ácida e pobre dos solos estudados. Para Brandão et al. (2010), essas características refletem a pobreza do material de origem, os quais são submetidos a intenso intemperismo e lixiviação e nessas condições, as cargas negativas e a disponibilidade de nutrientes dependem da fração orgânica do solo.

Os teores de carbono orgânico total (COT), densidade do solo (DS) e estoque de carbono (ECOT) são expressos na Tabela 2. Verificou-se que os maiores teores de C orgânico total foram encontrados no sistema com cana-de-açúcar $\left(18,09 \mathrm{~g} \mathrm{~kg}^{-1}\right)$ diferindo estatisticamente dos demais sistemas de manejos, seguido do sistema de pastagem $\left(16,13 \mathrm{~g} \mathrm{~kg}^{-1}\right)$ e mandioca $\left(15,57 \mathrm{~g} \mathrm{~kg}^{-1}\right)$, enquanto que os menores teores foram encontrados na área de floresta nativa $\left(3,61 \mathrm{~g} \mathrm{~kg}^{-1}\right)$. De acordo com Carvalho et al. (2010), algumas pesquisas avaliando a conversão de áreas nativa em pastagens com manejo adequado têm demonstrado um aumento no teor de $\mathrm{C}$ no solo em função do tempo de implantação das forrageiras e do manejo adotado na região amazônica.

O maior teor de carbono orgânico observado na área de pastagem em relação a área nativa, pode ser explicado pelas as gramíneas forrageiras (Brachiaria decumbens), utilizadas em pastagem possui alta capacidade de aumentar o estoque e distribuir o $\mathrm{C}$ na subsuperfície do solo e o não sobrepastejo nas áreas (Paustian et al., 2000). Para Carvalho et al. (2010), tal 
efeito das gramíneas atuando no teor carbono orgânico, é referente a elevada entrada de biomassa e a ausência de revolvimento do solo contribuindo assim para um maior acumulo de carbono no solo. Além disso, o acúmulo de $\mathrm{CO}$ pode estar associado a extrema pobreza dos solos e presença de elementos tóxicos, a exemplo do Al trocável (Tabela 1), que de certa propiciam o maior acúmulo de $\mathrm{C}$ no solo.

A maior densidade de solo foi observada no sistema de manejo de pastagem e agrofloresta coincidente com os maiores teores de argila, seguidos pela floresta nativa, canade-açúcar e mandioca. A maior densidade na área de pastagem pode ser explicada pelo o efeito do pisoteio animal, já os animais pastejam a área de forma extensiva. O aumento da densidade do solo é um efeito comum em áreas de pastagens na região amazônica, resultados semelhantes ao encontrado neste trabalho para a DS, foi verificado em trabalho de Araújo et al. (2004), em uma área de Argissolo Amarelo sob pastagem na Amazônia

Tabela 2. Carbono orgânico total, densidade do solo e estoque de carbono orgânico em diferentes sistemas de usos (floresta nativa, agrofloresta, pastagem, cana-de-açúcar e mandioca) em um Cambissolo Háplico Alítico plíntico na região Sul do Amazonas.

\begin{tabular}{lccc}
\hline \multirow{2}{*}{ Sistemas de Usos } & Carbono orgânico total & Densidade do solo & Estoque de Carbono \\
\cline { 2 - 4 } & $\left(\mathrm{g} \mathrm{kg}^{-1}\right)$ & $\left(\mathrm{g} \mathrm{cm}^{-3}\right)$ & $\left(\mathrm{Mg} \mathrm{ha}^{-1}\right)$ \\
\hline Floresta Nativa & $3,61 \mathrm{~d}$ & $1,30 \mathrm{ab}$ & $4,72 \mathrm{~d}$ \\
Agrofloresta & $12,29 \mathrm{c}$ & $1,32 \mathrm{a}$ & $16,25 \mathrm{c}$ \\
Pastagem & $16,13 \mathrm{~b}$ & $1,35 \mathrm{a}$ & $21,72 \mathrm{a}$ \\
Cana-de-acúçar & $18,09 \mathrm{a}$ & $1,27 \mathrm{~b}$ & $22,83 \mathrm{a}$ \\
Mandioca & $15,57 \mathrm{~b}$ & $1,17 \mathrm{c}$ & $18,14 \mathrm{~b}$ \\
CV \% & 5,92 & 6,34 & 5,46 \\
\hline
\end{tabular}

Os estoques de carbono no solo variaram de 4,72 a 22,83 $\mathrm{Mg} \mathrm{ha}^{-1}$, houve diferenças estatísticas significativas entre os sistemas de manejo estudados, sendo que os maiores valores de estoque de carbono (ECOT) foram observados nas áreas de cana-de-açúcar e pastagem (22,83 e 21,72 $\mathrm{Mg} \mathrm{ha}^{-1}$ respectivamente), seguidos pelas áreas de mandioca $\left(18,14 \mathrm{Mg} \mathrm{ha}^{-1}\right)$, agrofloresta $\left(16,25 \mathrm{Mg} \mathrm{ha}^{-1}\right)$ e floresta nativa $\left(4,72 \mathrm{Mg} \mathrm{ha}^{-1}\right)$. Estes resultados assemelham-se aos encontrados por Araújo et al. (2011) no qual o maior estoque de carbono total foi verificado para o ambiente de pastagem quando comparado a área de floresta, este fato ocorre devido ao maior acúmulo de matéria orgânica à superfície devido ao sistema radicular das gramíneas.

Os altos valores de ECOT da área sob pastagem em relação aos demais sistemas pode ser explicado pela a presença das gramíneas que exibem efeito rizosférico intenso por causa do seu abundante sistema radicular, que mediante a sua decomposição libera nutrientes e também contribui para a formação da matéria orgânica do solo, favorecendo assim seu estado de agregação (Souza et al., 2012).

Em trabalho avaliando a dinâmica do carbono na conversão de florestas para pastagens em Argissolos da formação Geológica Solimões, no Sudoeste da Amazônia Salimon et al. (2007), encontraram maiores estoques de carbono sob áreas de pastagens em comparação com áreas de floresta, os quais foram devido a maior densidade e teor de carbono orgânico desta área. Os mesmos autores, ainda relata que com a introdução da pastagem os estoques de $\mathrm{C}$ no solo podem decrescer nos primeiros anos da implantação, no entanto os mesmos devem aumentar nos anos seguintes, até atingir valores próximos ou superiores aos existentes antes da conversão.

Várias pesquisas tem mostrado o comportamento do estoque de carbono em maior 
quantidade na área sob pastagem em relação à floresta nativa, bem como, Araújo et al. (2011) e Desjardins et al. (2004), que observaram o mesmo tipo de comportamento, dentre estes sistemas é possível observar dois processos simultâneos de evolução do carbono orgânico do solo:

a) a contínua mineralização do carbono derivado da vegetação nativa devido aos ciclos de umedecimento e secagem do solo e;

b) a progressiva incorporação do carbono derivado dos restos da cultura introduzida pela pastagem, principalmente pelas raízes das gramíneas.

O maior estoque de carbono na área de cana de açúcar, pode ser justificado pelo grande aporte de resíduo (palhadas) provenientes da própria cultura e que é depositada no solo, corroborando assim com Carvalho et al. (2010), que segundo os autores com a ausência da queima no processo de colheita, os resíduos vegetais são depositados na superfície do solo e com o passar do tempo parte desses resíduos é decomposto e parte é incorporada à matéria orgânica do solo, contribuindo assim para o aumento do estoque de C. Por outro lado Canellas et al. (2007), estudando um Cambissolo sob cana-de-açúcar queimada, encontraram valores ECOT superiores ao do presente estudo $\left(36,12 \mathrm{mg} \mathrm{ha}^{-1}\right)$.

Em ambientes de floresta nativa de ecossistemas Amazônicos a maior parte do carbono encontra-se contida na biomassa da vegetação conforme destaca Araújo et al. (2011). No entanto esperava-se encontrar maior conteúdo de $\mathrm{C}$ no solo, porém este foi o sistema que menos estocou carbono (4,72 $\mathrm{Mg} \mathrm{ha}^{-1}$ ) quando o comparado com os demais sistemas estudados. Além disso, Silva e Machado (2000) sugerem que os menores estoques de carbono de regiões tropicais, estão relacionados às condições de temperaturas elevadas, os altos índices pluviométricos, e a intensa atividade microbiana que propiciam a rápida decomposição dos materiais orgânicos depositados no solo, e como consequência ocorre um decréscimo do estoque de carbono no solo. Neste contexto Melo (2003) sugere que os ciclos de umedecimento e secagem do solo por favorecer a mineralização do C seja responsável pelo os menores estoques de carbono.

Estimativas do estoque de carbono na região amazônica tem sido feita em diferentes locais, e os resultados encontrados pelos os pesquisadores são variados (Novaes Filho et al., 2007). Para Costa et al. (2009), os trabalhos encontrados na literatura muitas vezes são contraditórios em relação às diferenças entre os teores de $\mathrm{C}$ encontrados em solos de mata nativa e pastagens. Alguns trabalhos como de Salimon et al. (2007), mostra que os solos sob pastagens apresentam teores iguais ou superiores aos encontrados em ambientes de mata primária, já trabalhos como o de Noordwijk et al. (1997), mostra um maior estoque de carbono em áreas nativas em comparação com áreas de pastagem.

A distribuição dos agregados estáveis em água na profundidade de $0,0-0,10 \mathrm{~m}$ dos cinco sistemas de uso encontra-se na Figura 2. Nota-se que ouve predominância de macroagregados da classe 4,0-2,0 mm na camada de 0,0 - 0,10 m dos cinco sistemas estudados. Hickmann \& Costa (2012) observaram comportamento semelhante da distribuição dos agregados estáveis em água em um Argissolo Vermelho Amarelo sob cinco diferentes manejos de longa duração, no município de Coimbra, MG. Da mesma maneira, a correlação positiva para as classes 4,02,0 $\mathrm{mm}$ indicou um aumento dos agregados com o aumento do COT.

Em ordem decrescente esta classe de tamanho (4,0-2,0) representou 92, 90, 86, 84 e 70\%, nos sistemas cana-de-açúcar, pastagem, mandioca, agrofloresta e floresta nativa respectivamente, na camada 0-10 m, Esse comportamento também foi observado por Longo et al. (1999), em um Latossolo Vermelho-Amarelo numa sequência pasto/floresta no município de Porto Velho, RO. De acordo com estes mesmos autores a maior parte dos agregados que ficou retido na peneira de $4,0 \mathrm{~mm}$ de malha, indica que, nestas condições, os 
agregados formados são bastante estáveis em água. Para Fabrizzi et al. (2009), a predominância de macro e mesoagregados é uma característica de solos tropicais e evidencia a elevada influência das interações eletrostáticas dos óxidos e minerais de argila do tipo 1:1 no processo de agregação.

Observando a Figura 2, é possível verificar que as maiores porcentagens de agregado da classe 4,0-2,0mm foram encontradas na área de cana-de-açúcar (CNA) 92\% e pastagem (PAT) 90\%. A pastagem foi favorecida pela maior distribuição relativa nos macroagregados devido ao sistema radicular de gramíneas que colaborou para um maior estoque de COT. Esses resultados estão de acordo com Vezzani (2001) que mostra o potencial do uso de pastagens para a recuperação de solos degradados.

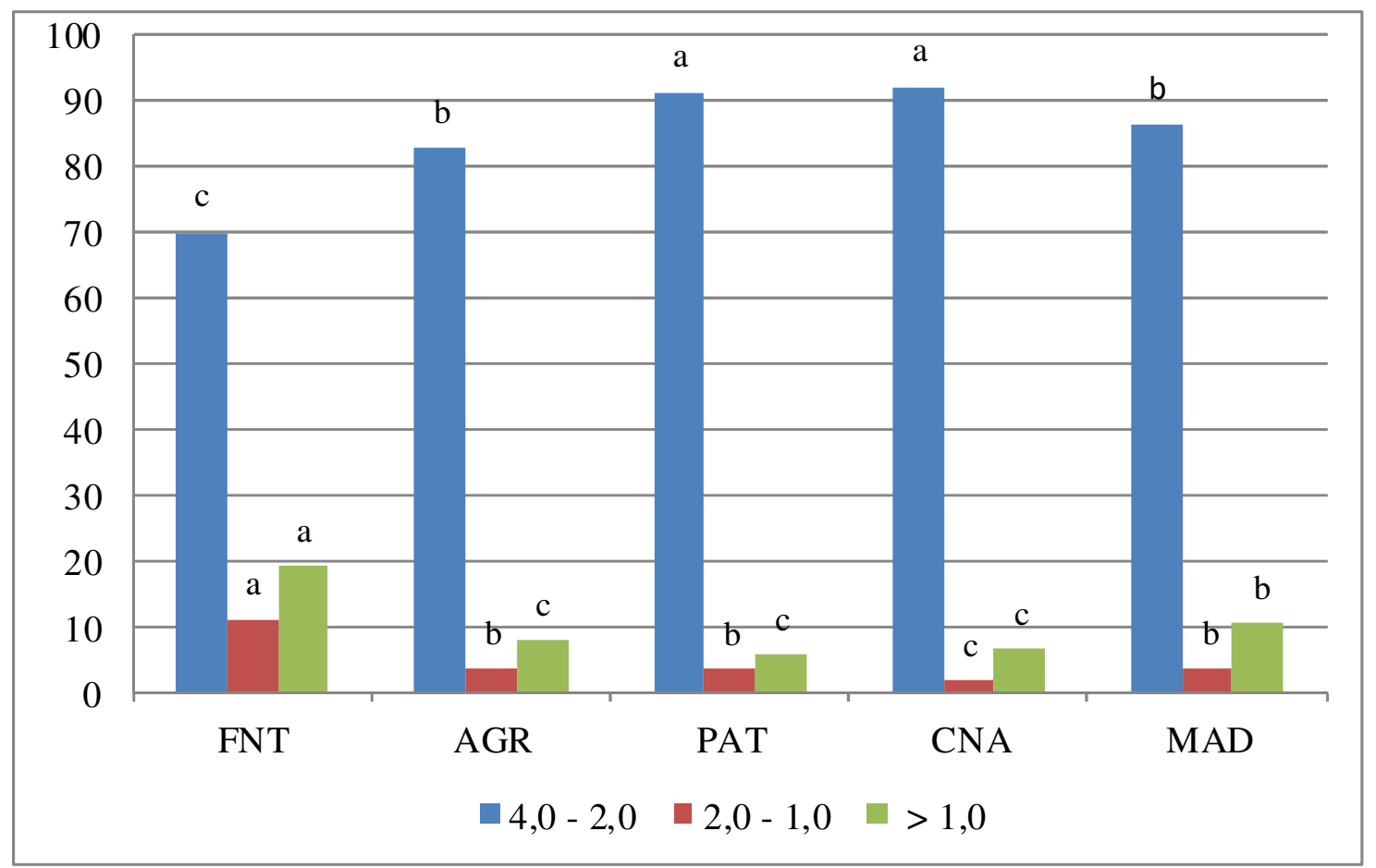

Figura 2. Distribuição dos agregados estáveis em água na profundidade de 0,0-0,10 m em um Cambissolo Háplico Alítico plíntico, sob diversos sistemas de usos, floresta nativa (FTN), agrofloresta (AGR), pastagem (PAT), cana-de-açúcar (CNA) e mandioca (MAD) na região Sul do Amazonas.

A maior porcentagem dos agregados da classe de 2,0-1,0 mm encontra-se no solo sob floresta nativa (11\%), seguidos pela pastagem, agrofloresta e mandioca que não diferiram estatisticamente entre si, o sistema sob cana-de-açúcar apresentou uma menor porcentagem dos agregados estáveis em água. Na classe $>1,0 \mathrm{~mm}$, a maior porcentagem dos agregados estáveis em água foi no solo sob floresta nativa, seguidos pelos sistemas sob mandioca e pastagem, o sistema sob cana-de-açúcar e agrofloresta não diferiram estatisticamente entre si.

\section{CONCLUSÕES}

O estoque de carbono foi afetado de modo significativo pelos sistemas de uso e manejo do solo nos cinco sistemas estudados, existiu uma correlação positiva entre a distribuição agregados com COT, em que a porcentagem dos agregados aumentou com os maiores teores de COT.

O sistema que mais estocou carbono foi o sistema sob cana-de-açúcar e pastagem, e nestes as maiores porcentagens de macroagregados e o sistema que menos estocou carbono 
foram os sistemas sob floresta nativa e agrofloresta.

Após a conversão de floresta para áreas de pastagem e de cana-de-açúcar, estas depois de anos de cultivo podem apresentar o mesmo estoque de carbono ou até mesmo superar as áreas nativas.

\section{REFERÊNCIAS}

AQUINO, R. E.; CAMPOS, M. C. C.; MARQUES JÚNIOR, J.; OLIVEIRA, I. A.; MANTOVANELLI, B. C.; SOARES, M. D. R. Geoestatística na avaliação dos atributos físicos em latossolo sob floresta nativa e pastagem na Região de Manicoré, Amazonas. Revista Brasileira de Ciência do Solo, v. 38, n. 2, p. 397-406, 2014. http://dx.doi.org/10.1590/S0100-06832014000200004

ARAÚJO, E. A.; KER, J. C.; MENDONÇA, E. S.; SILVA, I. R.; OLIVEIRA, E. K. Impacto da conversão floresta - pastagem nos estoques e na dinâmica do carbono e substâncias húmicas do solo no bioma amazônico. Acta Amazônica, v. 41, n. 1, p. 103-114, 2011. http://dx.doi.org/10.1590/S0044-59672011000100012

ARAÚJO, E. A.; LANI, J. L.; AMARAL, E. F.; GUERRA, A. Uso da Terra e propriedades físicas e químicas de Argissolo Amarelo distrófico na Amazônia Ocidental. Revista Brasileira Ciência do Solo, v. 28, n. 2, p. 307-315, 2004. http://dx.doi.org/10.1590/S0100-06832004000200009.

BRANDÃO, P. C.; SOARES, V. P.; SIMAS, F. N. B.; SCHAEFER, C. E. G. R.; SOUZA, A. L.; MENDONÇA, B. A. F. Caracterização de geoambientes da floresta nacional do Purus, Amazônia Ocidental: uma contribuição ao plano de manejo. Revista Árvore, v. 34, n. 1, p. 115-126, 2010. http://dx.doi.org/10.1590/S0100-67622010000100013

BRASIL. Ministério das Minas e Energia. Projeto Radam Brasil, folha SB. 20, Purus. Rio de Janeiro, 1978. $561 \mathrm{p}$.

CAMPOS, M. C. C.; RIBEIRO, M. R; SOUZA JÚNIOR, V. S.; RIBEIRO FILHO, M. R.; ALMEIDA, M. C. Topossequência de solos na transição campos naturais-floresta na região de Humaitá, Amazonas. Acta Amazonica, v. 42, n. 3, p. 387-398, 2012. http://dx.doi.org/10.1590/S0044-59672012000300011

CANEllaS, L. P.; ALTOÉ B. M.; GALBA B. J.; MARCIANO, C. R.; CABRAL, M.; MACHADO, S. N. et al. Estoque e qualidade da matéria orgânica de um solo cultivado com cana-de-açúcar por longo tempo. Revista Brasileira de Ciência do Solo, v. 31, n. 2, p. 331-340, 2007. http://dx.doi.org/10.1590/S0100-06832007000200015

CARVAlHO, J. L. N.; AVANZI, J. C.; SILVA, M. L. N.; MELlO, C. R.; CERRI, C. E. P. Potencial de sequestro de carbono em diferentes biomas do Brasil. Revista Brasileira de Ciência do Solo, v. 34, n. 2, p. 277-289, 2010. http://dx.doi.org/10.1590/S010006832010000200001

CASTRO FILHO, C.; LOGAN, T. J. Liming effects on the stability and erodibility of some Brazilian Oxisols. Soil Science Society of America Journal, v.55, n.1, p.1407-1413, 1991. http://dx.doi.org/10.2136/sssaj1991.03615995005500050034x

CHAVES, L. H. G.; FARIAS, C. H. A. Variabilidade espacial do estoque de carbono nos tabuleiros costeiros da Paraíba: solo cultivado com cana-de-açúcar. Revista Brasileira de Ciências Agrárias, v. 3, n. 1, p. 20-25, 2008. 
COSTA, O. V.; CANTARUTTI, R. B.; FONTES, L. E. F.; COSTA, L. M.; NACIF, P. G. S.; FARIA, J. C. Estoque de carbono do solo sob pastagem em área de tabuleiro costeiro no sul da Bahia. Revista Brasileira de Ciência do Solo, v. 33, n. 5, p. 1137-1145, 2009. http://dx.doi.org/10.1590/S0100-06832009000500007

D'ANDREA, A. F.; SILVA, M. L. N.; CURI, N.; GUILHERME, L. R. G. Estoque de carbono e nitrogênio e formas de nitrogênio mineral em um solo submetido a diferentes sistemas de manejo. Pesquisa agropecuária brasileira, v. 39, n. 2, p. 179-186, 2004. http://dx.doi.org/10.1590/S0100-204X2004000200012

DESJARDINS, T.; BARROS, E.; SARRAZIN, M.; GIRARDIN, C.; MARIOTTI, A. Effects of forest conversion to pasture on soil carbon content and dynamics in Brazilian Amazonia. Agriculture Ecosystms \& Environment, v. 103, n. 2, p. 365-373, 2004. http://dx.doi.org/10.1016/j.agee.2003.12.008

EMPRESA BRASILEIRA DE PESQUISA AGROPECUÁRIA - EMBRAPA. Centro Nacional de Pesquisa de Solos. Manual de métodos de análise de solo. Rio de Janeiro, 1997. 212p.

FABRIZZI, K. P.; RICE, C. W.; AMADO, T. J. C.; FIORIN, J.; BARBAGELATA, P.; MELCHIORI, R. Protection of soil organic $\mathrm{C}$ and $\mathrm{N}$ in temperate and tropical soils: effect of native and agroecosystems. Biogeochemistry, v. 92, n. 1, p. 129-143, 2009. http://dx.doi.org/10.1007/s10533-008-9261-0

HEID, D. M.; VITORINO, A. C. T.; TIRLONI, C.; HOFFMANN, N. T. K. Frações orgânicas e estabilidade dos agregados de um latossolo vermelho distroférrico sob diferentes usos. Revista de Ciências Agrárias, n. 51, p. 143-160, 2009.

HICKMANN, C.; COSTA, L. M. Estoque de carbono no solo e agregados em Argissolo sob diferentes manejos de longa duração. Revista Brasileira de Engenharia Agrícola e Ambiental, v. 16, n. 10, p. 1055-1061, 2012. http://dx.doi.org/10.1590/S141543662012001000004

KEMPER, W. D.; CHEPIL, W. S. Size distribution of aggregates. In: BLACK, C. A.; EVANS, D. D.; WHITE, J. L.; ENSMINGER, L. E.; CLARK, F. E. (Eds.). Methods of soil analysis: Physical and mineralogical properties, including statistics of measurement and sampling. Madison: American Society of Agronomy, 1965. Part 1. p.499-510.

LAVELLE, P.; GILOT, C.; FRAGOSO, C.; PASHANASI, B. Soil fauna and sustainable land use in the humid tropics. In: GREENLAND, G. A.; SZALBOLCS, I. (Ed.). Soil resilience and sustainable land use. Wallingford: CAB International, 1994. Cap.18, p.291-307.

LONGO, R. M.; ESPÍNDOLA, C. R.; RIBEIRO, A. I. Modificações na estabilidade de agregados no solo decorrentes da introdução de pastagens em áreas de cerrado e floresta amazônica. Revista Brasileira de Engenharia Agrícola e Ambiental, v. 3, n. 3, p. 276-280, 1999. http://dx.doi.org/10.1590/1807-1929/agriambi.v3n3p276-280

MAKEWITZ, D.; DAVIDSON, E.; MOUTINHO, P.; NEPSTAD, D. Nutrient loss and redistribution after forest clearing on a highly weathered soil in Amazonia. Ecological Applications, v. 14, n. 4, p. 177-199. 2004. http://dx.doi.org/10.1890/01-6016 
MELO, A. W. F. Avaliação do estoque e composição isotópica do carbono do solo do Acre. 2003. 74f. Dissertação (Mestrado em Ecologia de Agroecossistemas.) - Escola Superior de Agricultura "Luiz de Queiroz", Universidade de São Paulo, Piracicaba, 2003.

NOORDWIJK, M. V.; CERRI, C. C.; WOOMER, P. L.; NUGROHO, K.; BERNOUX, M. Soil carbon dynamics in the humid tropical forest zone. Geoderma, v. 79, p. 187-225, 1997. http://dx.doi.org/10.1016/S0016-7061(97)00042-6

NOVAES FILHO, J. P.; SELVA, E. C.; COUTO, E. G.; LEHMANN, J.; JOHNSON, M. S.; RIHA, S. J. Distribuição espacial de carbono em solo sob floresta primária na Amazônia Meridional. Revista Árvore, v. 31, n. 1, p. 83-92, 2007. http://dx.doi.org/10.1590/S0100-67622007000100010

PAUSTIAN, K.; SIX, J.; ELLIOTT, E.T.; HUNT, H.W. Management options for reducing CO2 emissions from agricultural soils. Biogeochemistry, v. 48, p. 147-163, 2000. http://dx.doi.org/10.1023/A:1006271331703

RAIJ, B. VAN; SILVA N. M.; BATAGLIA, O. C; QUAGGIO, J. A.; HIROCE, R.; CANTARELLA, H. et al. Recomendações de adubação e calagem para o Estado de São Paulo. Campinas: Instituto Agronômico de Campinas, 1985. 107p. (Instituto Agronômico. Boletim Técnico, 100).

RESENDE, M.; CURI, N.; REZENDE, S. B.; CORRÊA, G. F. Pedologia base para distinção de ambientes. 4. ed. Viçosa: NEPUT, 2002. 338 p.

SALIMON, C. I.; WADT, P. G. S.; MELO, A. W. F. Dinâmica do carbono na conversão de florestas para pastagens em Argissolos da Formação Geológica Solimões, no Sudoeste da Amazônia. Revista de Biologia e Ciências da Terra, v. 7, n. 1, p. 29-38, 2007.

SANTOS, L. A. C.; CAMPOS, M. C. C.; COSTA, H. S.; PEREIRA, A. R. Caracterização de solos em uma topossequência sob terraços aluviais na região do médio rio Madeira (AM). Ambiência, v. 8, n. 2, p. 319 - 331, 2012.

http://dx.doi.org/10.5777/ambiencia.2012.02.07

SILVA, C. A.; MACHADO, P. L. O. A. Sequestro e emissão de carbono em ecossistemas agrícolas: estratégias para o aumento dos estoques de matéria orgânica em solos tropicais. Rio de Janeiro: Embrapa Solos, 2000. 23p. (Documentos, 19)

SOUZA, H. A.; MARCELO, A. V; CENTURION, J. F. Carbono orgânico e agregação de um Latossolo Vermelho com colheita mecanizada de cana-de-açúcar. Revista Ciência Agronômica, v. 43, n. 4, p. 658-663, 2012. http://dx.doi.org/10.1590/S180666902012000400006

VEZZANI, F. M. Qualidade do sistema solo na produção agrícola. 2001. 184f. Tese (Doutorado em Ciência do Solo) - Universidade Federal do Rio Grande do Sul, Porto Alegre, 2001.

YEOMANS, J. C.; BREMNER, J. M. A rapid and precise method for routine determimation of organic carbon in soil. Communications in Soil Science and Plant Analysis, v. 19, n. 13, p. 467-1476, 1988. http://dx.doi.org/10.1080/00103628809368027

ZINN, Y. L.; LAL, R.; RESCK, D. V. S. Changes in soil organic carbon stocks under agriculture in Brazil. Soil Tillage Research, v. 84, n. 1, p. 28-40, 2005. http://dx.doi.org/10.1016/j.still.2004.08.007 


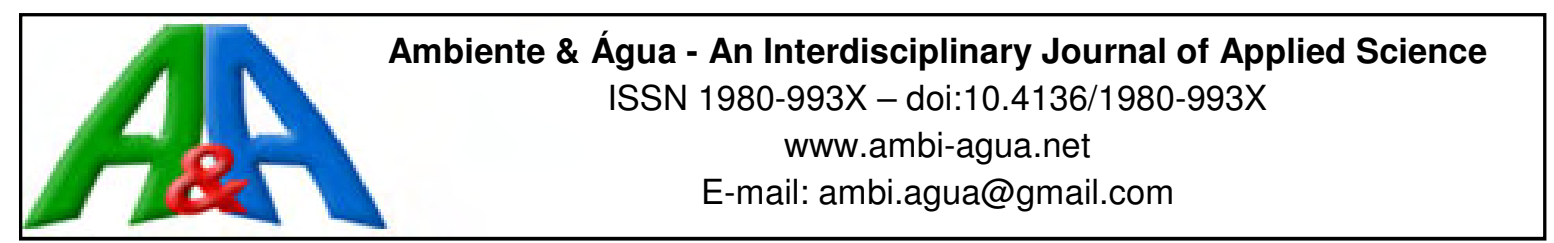

\title{
Impacto da alteração do uso do solo no saldo de radiação no Cerrado do sul de Mato Grosso
}

\author{
doi:10.4136/ambi-agua.1843
}

Received: 17 Jan. 2016; Accepted: 28 Mar. 2016

\author{
Marcos Alves Fausto' ${ }^{1}$ ' Lucas Peres Angelini' ${ }^{1}$; Heloisa Oliveira Marques ${ }^{1}$; \\ Armando Silva Filho ${ }^{2}$; Nadja Gomes Machado ${ }^{1,3}$; Marcelo Sacardi Biudes ${ }^{\text {* }}$ \\ ${ }^{1}$ Universidade Federal de Mato Grosso (UFMT), Cuiabá, MT, Brasil \\ Programa de Pós-Graduação em Física Ambiental (PPGFA) \\ ${ }^{2}$ Universidade do Estado de Mato Grosso (UNEMAT), Barra do Bugres, MT, Brasil \\ Departamento de Ciência da Computação \\ ${ }^{3}$ Instituto Federal de Mato Grosso (IFMT),Cuiabá, MT, Brasil \\ Laboratório de Biologia da Conservação \\ *Autor correspondente: e-mail: marcelo@ fisica.ufmt.br, \\ mffausto.fisica@gmail.com, peres.angelini52@gmail.com, heloisa@ fisica.ufmt.br, \\ armandosf2000@gmail.com,nadja.machado@blv.ifmt.edu.br
}

\section{RESUMO}

As transformações decorrentes do uso e ocupação do solo modifica o balanço radioativo à superfície. $\mathrm{O}$ objetivo do trabalho foi avaliar o impacto no saldo de radiação em função da alteração de uma área de Cerrado em área agrária no sul do Mato Grosso por meio de técnica de sensoriamento remoto. Imagens do sensor TM Landsat 5 adquiridas entre junho e outubro de 2011 foram utilizadas. As análises foram realizadas nos seguintes usos do solo: Cerrado, mata ciliar, cana-de-açúcar, soja, pastagem, solo exposto e água. A substituição da área de Cerrado por áreas agrícolas neste estudo alterou os índices biofísicos da superfície, devido à mudança na biomassa e nas propriedades óticas da superfície. O NDVI apresentou maiores valores na vegetação típica de Cerrado e Mata Ciliar e menores valores nas áreas agrícolas. A temperatura da superfície e o albedo da superfície apresentaram padrões inversos ao NDVI, com menores valores na vegetação típica de Cerrado e Mata Ciliar e maiores valores nas áreas agrícolas e solo exposto. A substituição do Cerrado por culturas agronômicas no sul do Mato Grosso diminuiu a energia disponível à superfície, indicado pelo saldo de radiação.

Palavras-chave: desmatamento, imagem de satélite, planejamento do uso do solo, troca de energia.

\section{Impact of land-use change in the net radiation of the Cerrado of the southern Mato Grosso}

\begin{abstract}
Changes resulting from land use and occupation modify the surface radioactive balance. This paper evaluated the impact on the net radiation caused by the conversion of a Cerrado area in an agricultural zone in the southern Mato Grosso using Landsat 5 TM sensor imagery acquired between June and October 2011. The analyses were performed of the following land use classes: Cerrado, riparian vegetation, sugarcane, soybean, pasture, bare soil and water. The replacement of Cerrado by agricultural areas changed the biophysical indices of the
\end{abstract}


surface due to the change in biomass and the optical properties of the surface as observed in this study. The NDVI values were higher in the typical Cerrado vegetation and Riparian Forest than in agricultural areas. The surface temperature and the surface albedo showed an inverse pattern of NDVI, with lower values in the typical Cerrado vegetation and Riparian Forest and higher values in agricultural areas and bare soil. The replacement of Cerrado by cultivated crops in the south of Mato Grosso decreased the available energy at the surface, as indicated by the radiation balance.

Keywords: deforestation, energy exchange, land use planning, satellite imagery.

\section{INTRODUÇÃO}

O estado de Mato Grosso é composto pelos biomas Amazônico, Cerrado e Pantanal, o qual tem elevadas taxas de desmatamentos nas últimas décadas, causando um mosaico de florestas naturais e manejadas, terras agrícolas e pastagens (Biudes et al., 2015). Esse mosaico, implica em transformações na cobertura do solo, desencadeando mudanças na distribuição de energia solar disponível ao ambiente (Silva et al., 2011).

A cobertura do solo pode ser monitorada por índices de vegetação como o Índice de Vegetação da Diferença Normalizada (NDVI), Índice de área foliar (LAI), Índice de vegetação ajustado ao solo (SAVI), dentre outros, que, estimado a partir de valores de refletâncias medidas por sensores orbitais. O NDVI é capaz de determinar a densidade de fitomassa foliar fotossinteticamente ativa por unidade de área, o qual varia de $-1 \mathrm{a}+1$ (Demarchi et al., 2011). Os valores de NDVI próximos de +1 indicam maior densidade de cobertura vegetal e valores negativos indicam superfície com água (Allen et al., 2007; Tasumi et al., 2008; Bezerra et al., 2011).

Alterações no NDVI em decorrência da substituição de vegetação densa, como florestas, por vegetação rasteira, como pastagens, modificam significativamente a temperatura e umidade relativa do ar e os balanços de radiação e energia da superfície em escala local e regional (Biudes et al., 2012). As áreas de floresta apresentam maior índice de vegetação decorrente de maior biomassa, o que influencia diretamente no balanço de radiação e, posteriormente no balanço de energia local, acarretando mudança no particionamento de energia destinada ao calor sensível, latente e aquecimento do solo (Biudes et al., 2015).

Estudos envolvendo o balanço de radiação são realizados por saldo radiômetros instalados em campo, mas essa metodologia apresenta limitação espacial devido ao alto custo para realização dessas medidas em escala regional (Gusmão et al., 2012). Diante disso, o sensoriamento remoto é uma importante ferramenta para estimar o saldo de radiação, pois permite obtenção de dados e suas variações espacial e temporal, com baixo custo e forte correlação com dados medidos em campo (Oliveira et al., 2012).

Diversos métodos foram propostos para estimativa do saldo de radiação da superfície a partir de imagens de sensores orbitais. Muitos deles apresentam limitações ao estimar o saldo de radiação diário devido à sua formulação. Dentre eles, destacam-se os de Bruin (1987) que propôs um modelo baseado no balanço de ondas curtas diário e uma compensação ao balanço de ondas longas diário em função da transmissividade atmosférica média diária e um coeficiente calibrado para a região que varia de 95 a 144; o de Bisht et al. (2005) que propuseram um modelo de balanço de radiação diário senoidal baseado em uso de produtos derivativos do sensor MODIS (Moderate Resolution Imaging Spectroradiometer); e o de Long et al. (2010) que combinaram produtos MODIS, imagens de modelo de elevação digital e dados meteorológicos de superfície para estimativa do saldo de radiação instantâneo e diário. Dentre os três apresentados, o modelo que apresenta menores erros na estimativa do saldo de radiação diário é o de Bruin (1987). Por essa razão, este modelo tem sido amplamente utilizado em modelos de estimativa do balanço de energia e evapotranspiração da 
superfície (Allen et al., 2007; Gusmão et al., 2012; Fausto et al., 2014).

Como há uma lacuna no conhecimento sobre a variação espacial do saldo de radiação diário em área agrícola, o objetivo do trabalho foi avaliar o impacto no saldo de radiação em função da alteração de uma área de Cerrado em área agrária no sul do Mato Grosso por meio de técnica de sensoriamento remoto.

\section{MATERIAL E MÉTODOS}

\section{1. Área de estudo}

A área de estudo composta por diferentes tipos de cobertura do solo está localizada no município de Barra do Bugres, Mato Grosso, Brasil (Figura 1). O município está localizado ao sul do Estado de Mato Grosso, a $160 \mathrm{~km}$ de Cuiabá, capital do Estado, tem uma população de 31.793 habitantes (IBGE, 2010). As principais atividades econômicas estão relacionadas ao agronegócio (Dubreuil et al., 2005), tais como a pecuária e o cultivo da cana-de-açúcar em larga escala. Os tipos de cobertura do solo selecionados para as análises foram: Cerrado (CE), mata ciliar (MC), cana-de-açúcar (CA), soja (SO), pastagem (PA), solo exposto (SE) e água (AG).
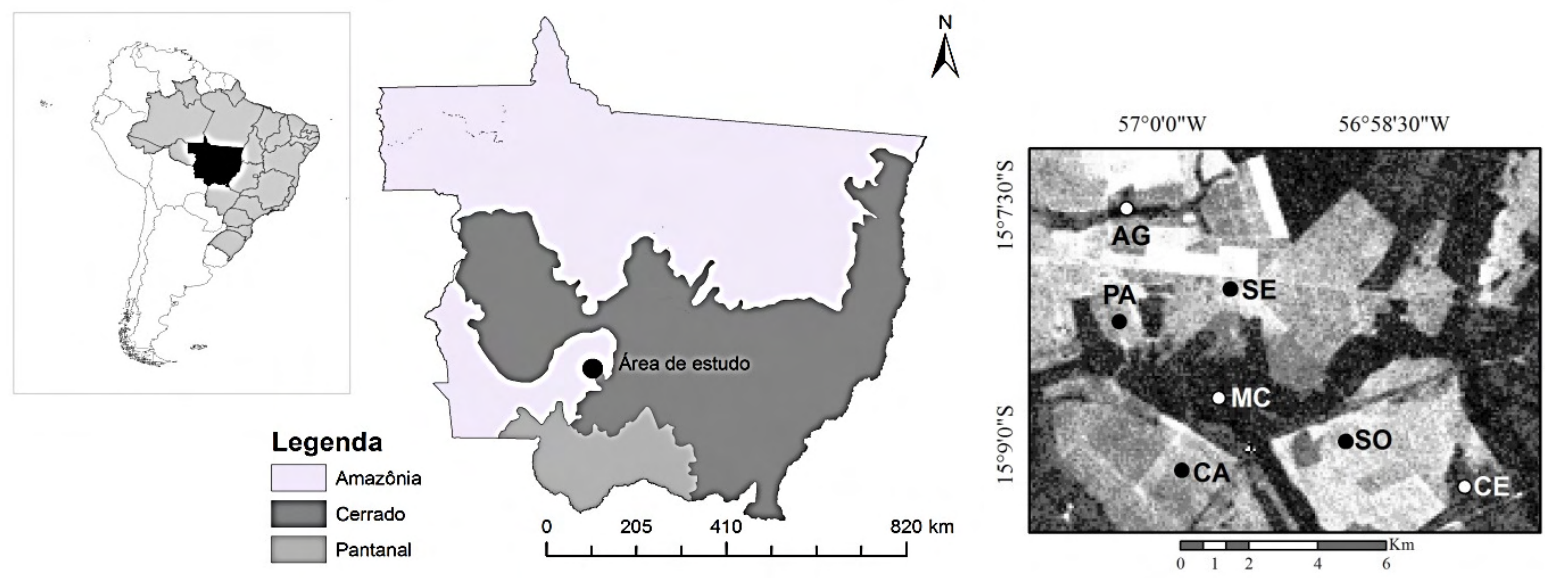

Figura 1. Localização da área de estudo em Barra do Bugres, Mato Grosso, Brasil.

De acordo com a classificação de Köppen, o clima regional é do tipo Aw, caracterizado como quente semiúmido (tropical), com precipitação média anual de $1.208 \mathrm{~mm}$, em que o período seco ocorre de junho a agosto, e o chuvoso de novembro a março (Martins et al., 2011). A vegetação predominante da região é de transição da Floresta Amazônica e Cerrado e o solo é composto principalmente pelo Latossolo Vermelho-Amarelo distrófico (Pessoa et al., 2011).

\subsection{Cálculo do saldo de radiação por sensoriamento remoto}

Foram usadas imagens do sensor TM do Landsat 5 (orbita 227 e ponto 70) durante o período seco e com ausência de nuvens e fumaça nos dias 16/06, 18/07, 04/09 e 06/10 do ano de 2011. Para avaliar o saldo de radiação diário, albedo e temperatura da superfície e NDVI considerou 6 pixels ao redor de cada ponto selecionado, na área de estudo.

O saldo de radiação diário $\left(R n_{\text {Diário }}\right)$ foi estimado pela Equação 1 definida por Bruin (1987) e avaliada por Fausto et al. (2014).

$$
R n_{\text {Diário }}=\left(1-\alpha_{\text {sup }}\right) R s_{24 h}-110 \tau_{24 h}
$$

em que: 


\section{$\alpha_{\text {sup }}$ é o albedo;}

$R s_{24 h}\left(\mathrm{~W} \mathrm{~m}^{-2}\right)$ é a radiação solar incidente média diária, e o valor numérico de 110 é um coeficiente de ajuste associado à transmissividade atmosférica média diária para compensar o balanço de onda longa diário. A transmissividade atmosférica média diária $\left(\tau_{24 h}\right)$ foi obtida através da Equação 2.

$$
\tau_{24 h}=\left(\frac{R s_{24 h}}{R s_{T O A 24 h}}\right)
$$

em que:

$R s_{24 h}\left(\mathrm{~W} \mathrm{~m}{ }^{-2}\right)$ é a radiação solar diária incidente a superfície, que foi obtida de estação meteorológica; e

$R s_{T O A 24 h}\left(\mathrm{~W} \mathrm{~m}^{-2}\right)$ é a radiação solar diária incidente no topo da atmosfera, calculada segundo procedimentos descritos em Iqbal (1984).

O albedo de superfície $\alpha_{\text {sup }}$ foi obtido pela Equação 3 .

$$
\alpha_{\text {sup }}=\left(\frac{\alpha_{t o a}-\alpha_{a t m}}{\tau_{w}^{2}}\right)
$$

em que:

$\alpha_{\text {toa }}$ é o albedo do topo da atmosfera; 2005); e

$\alpha_{\text {atm }}$ é refletância da atmosfera, considerada nesse trabalho igual a 0,03 (Pelgrum et al.,

$\tau_{w}$ é a transmissividade atmosférica no momento da passagem do satélite. $\mathrm{O}$ albedo no topo da atmosfera $\left(\alpha_{t o a}\right)$ foi obtido por meio da Equação 4, pela contabilização da radiação refletida de cada pixel resultante de uma combinação linear das refletâncias espectrais $\left(\rho_{\lambda i}\right)$ das seis bandas espectrais (Allen et al., 2007).

$$
\alpha_{\text {toa }}=w_{\lambda 1} \rho_{\lambda 1}+w_{\lambda 2} \rho_{\lambda 2}+w_{\lambda 3} \rho_{\lambda 3}+w_{\lambda 4} \rho_{\lambda 4}+w_{\lambda 5} \rho_{\lambda 5}+w_{\lambda 7} \rho_{\lambda 7}
$$

A transmissividade atmosférica $\left(\tau_{w}\right)$ à radiação de onda curta em condições de céu claro foi obtida pela Equação 5 (Allen et al., 2007).

$$
\tau_{w}=0.35+0.627 \exp \left[\frac{-0.00146 P a}{K t \operatorname{Cos} Z}-0.75\left(\frac{W}{\cos Z}\right)^{0.4}\right]
$$

em que:

$P a$ é a pressão atmosférica $(\mathrm{kPa})$;

$Z$ é o ângulo zenital do Sol;

$K t$ é o coeficiente de turbidez $(0<K t<1)$

em que:

$K t=1$ para $o$ ar limpo;

$K t=0,5$ para turbidez extrema e poeira; e

$W$ a água precipitável na atmosfera (mm) (Equação 6) em função a pressão de vapor atual (ea) e a $\mathrm{Pa}$ (Allen et al., 2007). 


$$
W=0.14 e a P_{\mathrm{a}}+2.1
$$

A refletância monocromática que representa o cômputo da refletância em cada banda $\left(\rho_{\lambda i}\right)$ foi calculada pela razão entre o fluxo da radiação solar refletida e o fluxo da radiação solar incidente em cada pixel considerando as bandas espectrais do TM Landsat-5, Equação 7.

$$
\rho_{\lambda i}=\frac{\pi \cdot L_{\lambda i}}{K_{\lambda i} \cdot \cos Z \cdot d_{r}}
$$

A radiância espectral $\left(L_{\lambda i}\right)$ foi obtida a partir da carta de radiância em número digital (valor inteiro de 0 a 255 correspondentes a 1 byte de informação) de cada pixel utilizando os coeficientes determinados por Chander et al. (2009). As radiâncias representam a energia solar refletida por cada pixel, por unidade de área, de tempo, de ângulo sólido e de comprimento de onda, medida ao nível do satélite TM Landsat 5 para as bandas de 1 a 7 , pela Equação 8.

$$
L_{\lambda i}=L_{\lambda \min }+\left(\frac{L_{\lambda \operatorname{máx}}-L_{\lambda \min }}{255}\right) \cdot N D
$$

em que:

$L_{\lambda \min }$ e $L_{\lambda \text { máx }}$ são os coeficientes de calibração mínimo e máximo; e

ND refere-se ao número digital. Essas constantes de calibração são correspondentes aos intervalos de comprimento de onda de cada banda espectral do TM Landsat 5.

O Índice de Vegetação por Diferença Normalizada (NDVI) foi obtido pela razão entre a diferença das refletâncias das bandas 3 e 4 do TM Landsat 5 e a soma das mesmas bandas (Equação 9). O NDVI é um indicador sensível da quantidade e da condição da vegetação verde. Seus valores variam de -1 a +1 . Para superfícies com alguma vegetação o NDVI é maior que zero e para superfície de água o NDVI geralmente é menor ou igual a zero (Allen et al., 2007; Tatsumi et al., 2008; Bezerra et al., 2011).

$$
\mathrm{NDVI}=\frac{\rho_{4}-\rho_{5}}{\rho_{4}+\rho_{5}}
$$

Para a obtenção da temperatura de superfície $\left(T_{S}\right)$, foi utilizada a equação de Planck invertida, válida para um corpo negro, pela Equação 10.

$$
T_{S}=\frac{K_{2}}{\ln \left(\frac{\varepsilon_{N B} K_{1}}{L_{\lambda, 6}}+1\right)}
$$

em que:

$K_{1}=607,76 \mathrm{~W} \mathrm{~m}^{-2} \mathrm{sr}^{-1} \mu \mathrm{m}^{-1}$ e $K_{2}=1260,76 \mathrm{~W} \mathrm{~m}^{-2} \mathrm{sr}^{-1} \mu \mathrm{m}^{-1}$ são constantes de calibração da banda termal do fornecida pelo sensor TM Landsat 5 (Silva et al., 2005).

Como cada pixel não emite radiação eletromagnética como um corpo negro, há a necessidade de introduzir a emissividade de cada pixel no domínio espectral da banda termal $\left(\varepsilon_{N B}\right)$ entre 10,4 a 12,5 $\mu \mathrm{m}$ (Equação 11$)$ e o cômputo da radiação de onda longa emitida por cada pixel deve considerar a emissividade no domínio da banda larga $\left(\varepsilon_{0}\right)$ entre 5 a $100 \mu \mathrm{m}$ (Equação 12). Segundo Allen et al. (2007), as emissividades $\varepsilon_{N B}$ e $\varepsilon_{0}$ podem ser obtidas, para $\mathrm{NDVI}>0$ e $\mathrm{IAF}<3$. 


$$
\begin{aligned}
& \varepsilon_{\mathrm{NB}}=0,97+0,0033 . \mathrm{IAF} \\
& \varepsilon_{0}=0,95+0,01 . \mathrm{IAF}
\end{aligned}
$$

Para pixels com IAF $\geq 3, \varepsilon_{N B}=\varepsilon_{0}=0,98$ e para corpos de água (NDVI $\left.<0\right) \varepsilon_{N B}=0,99 \mathrm{e}$ $\varepsilon_{0}=0,985$, segundo recomendações de Allen et al. (2007). Dessa forma, obtém-se a temperatura de superfície (K).

O Índice de Área Foliar (IAF), definido pela razão entre a área foliar de toda a vegetação por unidade de área utilizada por essa vegetação, constituindo um indicador da biomassa de cada pixel (Allen et al., 2007) dado pela Equação 13.

$$
\mathrm{IAF}=\frac{-\ln \left(\frac{0,69-S A V I}{0,59}\right)}{0,91}
$$

em que:

o valor máximo atingido pelo IAF é igual a 6,0, ocorrendo quando o SAVI vale 0,69.

O Índice de Vegetação Ajustado aos Efeitos do Solo (SAVI) proposto por Huerte (1988) usando a equação (14).

$$
\mathrm{SAVI}=\left(\frac{(1+\mathrm{L})\left(\rho_{4}-\rho_{3}\right)}{L+\rho_{4}+\rho_{3}}\right)
$$

em que:

L é a constante de ajuste ao solo cujo valor usado no estudo foi 0,1 (Allen et al., 2007 e Silva et al., 2011).

\section{RESULTADOS E DISCUSSÃO}

O albedo da superfície apresentou valores distintos entre os usos do solo, com maiores valores em área de solo exposto (23\%) aproximadamente e menores valores em superfície de corpos d'água (5\%). O albedo não variou significativamente entre as áreas agrícolas, mantendo o patamar de 21 a $22 \%$, em relação as áreas de vegetação nativa de Cerrado e a Mata ciliar (15\%). Na pastagem, os valores de albedo foram semelhantes aos encontrados em áreas agrícolas (Figura 2A).

$\mathrm{O}$ albedo da superfície do presente estudo foi semelhante aos valores encontrados na bacia do Alto Rio Paraguai de 14 a $18 \%$ na Mata Ciliar, de $22 \%$ a 24\% na Pastagem e de 14 a $20 \%$ no Cerrado (Fausto et al., 2014). Também foi semelhante à uma floresta densa localizada na região amazônica de 13 a 15\% (Querino et al., 2006) e em uma cultura de cana-de-açúcar em Petrolina/PE de 22\% (Silva et al., 2010). O albedo em áreas de Cerrado e Mata Ciliar foram menores devido a maior presença da biomassa nesses locais (Gomes et al., 2013), pois a biomassa tem alta capacidade de absorver a radiação solar e utilizá-la na evapotranspiração (Biudes et al., 2014). O aumento/diminuição da biomassa nas áreas de soja e cana-de-açúcar estão relacionados ao estádio de desenvolvimento da cultura. Em Paragominas/PA, foram encontrados albedos de $17 \%$ na fase vegetativa, $23,3 \%$ na frutificação e $14,8 \%$ na maturação (Souza et al., 2010). Por isso, nessas áreas ocorreram as maiores variações do albedo comparados as áreas de vegetação nativa.

No entanto, fatores como superfícies de cores claras, lisas e secas apresentam maiores albedos enquanto que superfícies ásperas e escuras os menores valores (Silva et al., 2011), além da composição estratificada das folhas, a presença de sub-bosque e a umidade do solo 
que também contribuem para a diminuição desse parâmetro (Leitão e Oliveira, 2000; Biudes et al., 2014).
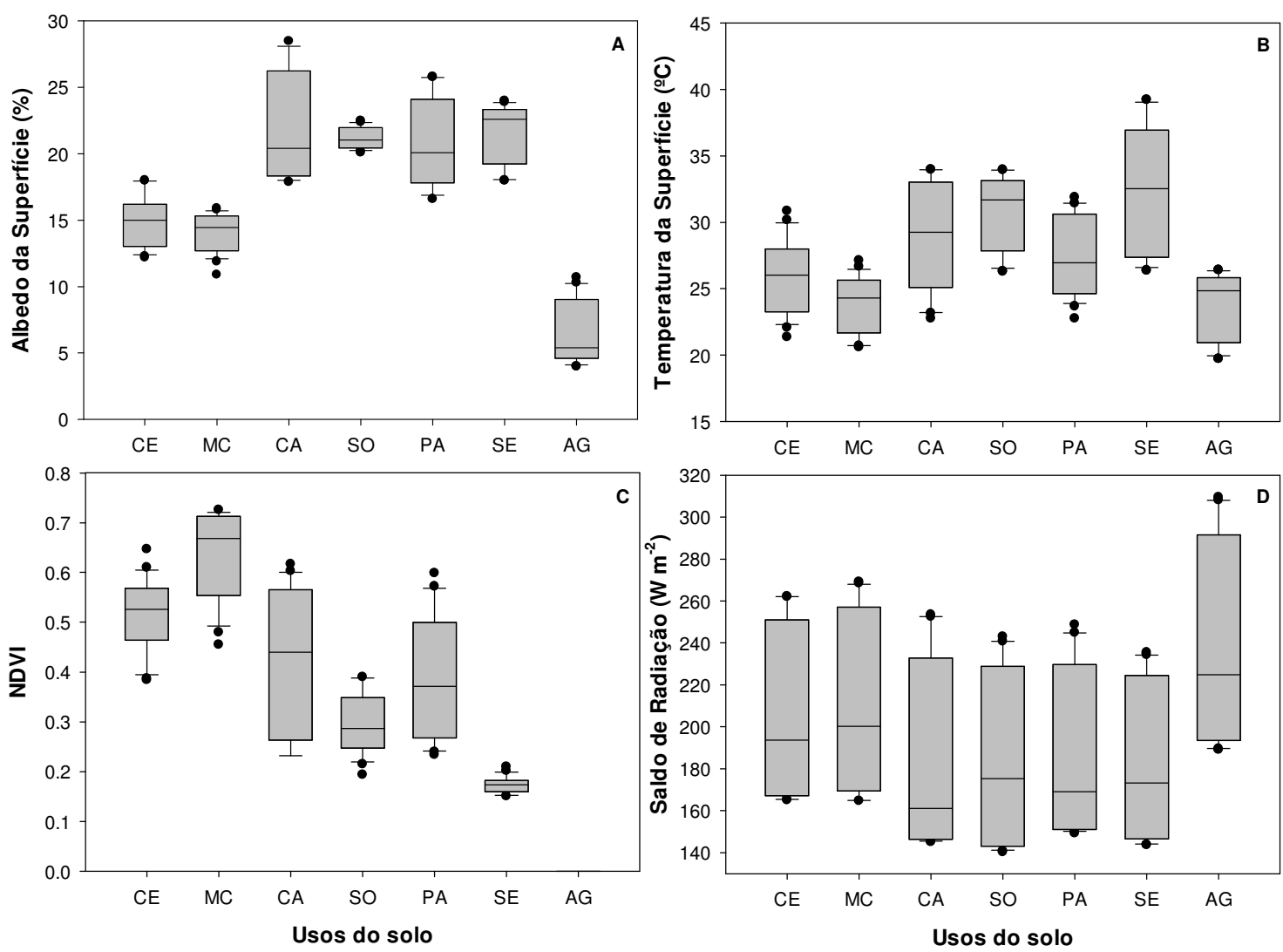

Figura 2. Variação espacial do albedo da superfície (A), da temperatura da superfície (B), do NDVI (C), e do saldo de radiação diários (D) na área de estudo na estação seca em 2011. $\mathrm{CE}=$ cerrado $; \mathrm{MC}=$ mata ciliar $; \mathrm{CA}=$ cana-de-açúcar $; \mathrm{SO}=$ soja $; \mathrm{PA}=$ pastagem; $\mathrm{SE}=$ solo exposto; $\mathrm{AG}=$ água.

A temperatura média da superfície no solo exposto foi de $32,5^{\circ} \mathrm{C}$ e na Mata Ciliar de $23,8^{\circ} \mathrm{C}$, o que corresponde a uma diferença de $8,7^{\circ} \mathrm{C}$. As áreas de cana-de-açúcar $\left(29^{\circ} \mathrm{C}\right)$, soja $\left(30,8^{\circ} \mathrm{C}\right)$ e pastagem $\left(27,7^{\circ} \mathrm{C}\right)$ apresentaram valores superiores às áreas de vegetação nativa de Cerrado $\left(25,8^{\circ} \mathrm{C}\right)$ e Mata Ciliar $\left(24,7^{\circ} \mathrm{C}\right)$ (Figura $\left.2 \mathrm{~B}\right)$. A presença da vegetação mantém menores temperaturas de superfície e conserva o microclima (Pavão et al., 2015). As áreas em estudo, apresentam baixa densidade de biomassa, que contribui com uma maior absorção da radiação solar pela vegetação, a qual é utilizada prioritariamente na forma de calor latente. Dessa forma, uma menor quantidade de energia é utilizada na forma de calor sensível, responsável pelo aquecimento do ar/superfície (Biudes et al., 2009; 2015).

A estimativa da temperatura da superfície em áreas naturais, agrícolas e pastagens corroboram com estudos realizados em outras regiões do Brasil. Em Santo Antônio de Leverger/MT, a diferença da temperatura da superfície entre Pastagem e Mata ciliar variou entre 5 e $15^{\circ} \mathrm{C}$ (Fausto et al., 2014). Num solo exposto no perímetro irrigado de Petrolina/PE, a temperatura da superfície foi acima de $33^{\circ} \mathrm{C}$ (Silva et al., 2011).

Houve diferença significativa nos valores de NDVI entre as áreas de vegetação nativa e agrícolas (Figura 2C). O NDVI da Mata ciliar foi $57 \%$ maior do que na soja, 35\% na cana-deaçúcar e $40 \%$ na Pastagem. Como esperado, o NDVI foi negativo em corpos d'água.

Os valores de NDVI na área de estudo foram semelhantes aos encontrados em áreas de Cerrado no estado de São Paulo, que variaram de 0,6 a 0,7 (Gomes et al., 2013). No entanto, os valores de NDVI do presente estudo foram inferiores, quando comparados à valores 
encontrados em uma área de transição Cerrado-Amazônia, cujos valores são aproximadamente de 0,80 (Risso et al., 2012). Isso porque a vegetação de floresta apresenta maior biomassa e maior atividade fotossintética, em função do potencial de absorver água em profundidade, mesmo em época de seca (Barbosa et al., 2012). Como o NDVI é capaz de determinar a densidade de fitomassa foliar fotossinteticamente ativa por unidade de área, a boa acurácia do NDVI na identificação de distintas áreas vegetadas indica sua eficiência quanto à condição da biomassa sobre a superfície (Esteves et al., 2012).

$\mathrm{O}$ saldo de radiação diário (Figura 2D) não foi significativamente diferente entre os usos do solo. Os valores encontrados foram de $230,0 \mathrm{~W} \mathrm{~m}^{-2}$ aproximadamente em corpos d'água, e entre 190,0 e 200,0 W m ${ }^{-2}$ em Mata Ciliar e Cerrado. Já em áreas agrícolas (culturas de soja, cana-de-açúcar e pastagem) e solo exposto, o saldo de radiação diário foi em média 175,0 e $160,0 \mathrm{~W} \mathrm{~m}^{-2}$, respectivamente.

A diferença do saldo de radiação diário entre as áreas analisadas foi devido ao albedo e à temperatura da superfície. Esses parâmetros contribuem para a reemissão de ondas longas. Portanto, o saldo de radiação diário em área de solo exposto foi menor, onde a maior reflexão de ondas curtas refletidas (albedo) diminui o balanço de onda curta e o aquecimento do solo aumenta a temperatura da superfície, elevando a radiação de onda longa emitida pela superfície (Frey et al., 2007).

Espacialmente, às áreas claras apresentaram os maiores valores de albedo (Figura 3A) e temperatura da superfície (Figura 3B), enquanto que as áreas mais escuras (menor albedo e temperatura de superfície) correspondente às áreas agrícolas e de vegetação nativa, respectivamente. Por outro lado, os maiores valores de NDVI (Figura 3C) e saldo de radiação diário (Figura 3D) ocorreram em áreas de vegetação nativa indicado em tonalidade claras e os menores (áreas mais escuras) ocorreram em áreas agrícolas.

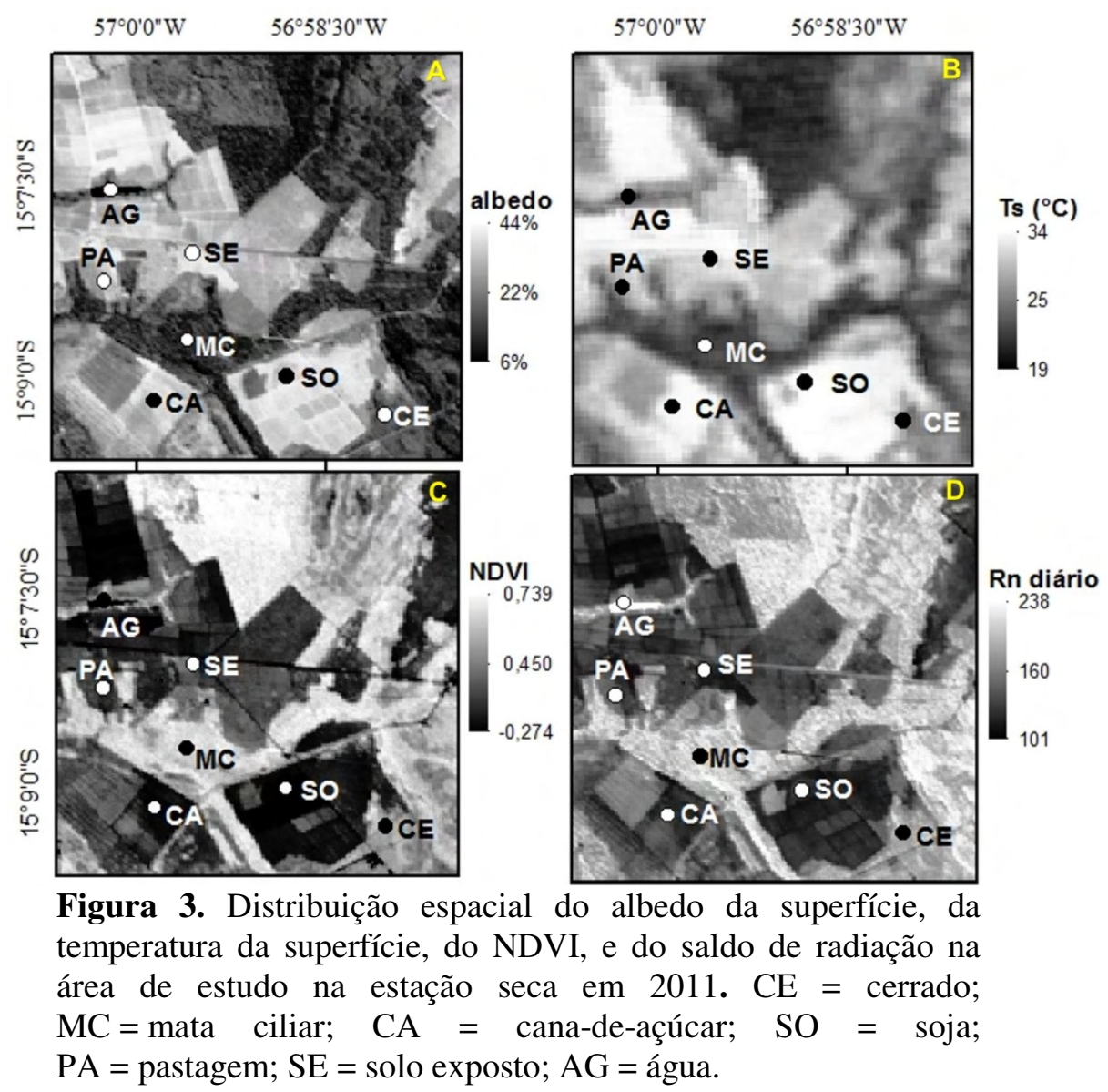




\section{CONCLUSÕES}

A substituição da área de Cerrado por áreas agrícolas nesse estudo impactou na alteração dos índices biofísicos da superfície, devido à mudança na biomassa e nas propriedades óticas da superfície. O NDVI apresentou maiores valores na vegetação típica de Cerrado e Mata Ciliar e menores valores nas áreas agrícolas. A temperatura da superfície e o albedo da superfície apresentaram padrões inversos ao NDVI, com menores valores na vegetação típica de Cerrado e Mata Ciliar e maiores valores nas áreas agrícolas e solo exposto. Dessa forma, a substituição do Cerrado por culturas agronômicas no sul do Mato Grosso impactou na diminuição da energia disponível à superfície, representada pelo saldo de radiação.

\section{AGRADECIMENTOS}

A pesquisa foi apoiada pela Universidade Federal de Mato Grosso (UFMT), Programa de Pós-Graduação em Física Ambiental (PPGFA/IF/UFMT), Conselho Nacional de Desenvolvimento Científico e Tecnológico (CNPq - Bolsa, Processo no 303625/2015-5) e Coordenação de Aperfeiçoamento de Pessoal do Ensino Superior (CAPES - Bolsas, Processo $n^{\circ}$ 9750/13-4 e no 9768/13-0), e financiada pela Fundação de Amparo à Pesquisa do Estado de Mato Grosso (FAPEMAT - PRONEM 2014, processo nº 561397/2014).

\section{REFERENCIAS}

ALLEN, R. G.; TASUMI, M.; MORSE, A.; TREZZA, R.; WRIGHT, J. L.; BASTIAANSSEN, W. et al. Satellite based Energy Balance for Mapping Evapotranspiration with Internalized Calibration, (METRIC) - Applications. Journal of Irrigation And Drainage Engineering, v. 133, p. 395-406, 2007. http://dx.doi.org/10.1061/(ASCE)0733-9437(2007)133:4(395), 395-406-406

BARbOSA, J. P. R. A. D.; MARTINS, G. A.; FERREIRA, R. T.; PENNACCHI, J. P.; SOUZA, V. F.; SOARES, A. M. Estimativa do IAF de cafeeiro a partir do volume de folhas e arquitetura da planta. Coffee Science, v. 7, n. 3, p. 267-274, 2012.

BEZERRA, M. V. C.; SILVA, B. B. da; BEZERRA, B. G. Avaliação dos efeitos atmosféricos no albedo e NDVI obtidos com imagens de satélite. Revista Brasileira de Engenharia Agrícola e Ambiental, v. 15, n. 7, p. 709-717, 2011. http://dx.doi.org/10.1590/S141543662011000700009

BISHT, G.; VENTURINI, V.; ISLAM, S.; JIANG, L. Estimation of the net radiation using MODIS (Moderate Resolution Imaging Spectroradiometer) data for clear-sky days. Remote Sensing of Environment, v. 97, p. 52-67, 2005. http://dx.doi.org/10.1016/j.rse.2005.03.014

BIUDES, M. S.; CAMPELO JUNIOR, J. H.; NOGUEIRA, J. S.; SANCHES, L. Estimativa do balanço de energia em Cambarazal e pastagem no Norte do Pantanal pelo Método da Razão de Bowen. Revista Brasileira de Meteorologia, v. 24, p. 135-143, 2009. http://dx.doi.org/10.1590/S0102-77862009000200003

BIUDES, M. S.; MACHADO, N. G.; DANELICHEN, V. H. M.; SOUZA, M. C.; VOURLITIS, G. L. NOGUEIRA, J. S. Ground and remote sensing-based measurements of leaf área index in a transitional forest and seasonal flooded forest in Brazil. International Journal of Biometeorology, v. 56, p. 1181-1193, 2014. http://dx.doi.org/10.1007/s00484-013-0713-4 
BIUDES, M. S.; NOGUEIRA, J. S.; DALMAGRO, H. J.; MACHADO, N. G.; DANELICHEN, V. H. M.; SOUZA, M. C. Mudança no microclima provocada pela conversão de uma floresta de cambará em pastagem no Norte do Pantanal. Revista de Ciências Agro-Ambientais, v. 10, p. 61-68, 2012.

BIUDES, M. S.; VOURLITIS, G. L.; MACHADO, N. G.; ARRUDA, P. H. Z.; NEVES, G. A. R.; LOBO, F. A. et al. Patterns of energy exchange for tropical ecosystems across a climate gradient in Mato Grosso, Brazil. Agricultural and Forest Meteorology, v. 202, p. 112-124, 2015. http://dx.doi.org/10.1016/j.agrformet.2014.12.008

BRUIN, H. A. R. From Penman to Makkink. In: HOOGHART, J. C. (Ed.). Proceedings and information: TNO Commitee on Hydrological, v. 39, p. 5-31, 1987.

CHANDER, G.; MARKHAM, B. L.; HELDER, D. L. Summary of current radiometric calibration coefficients for Landsat MSS, TM,ETM+, and EO-1 ALI sensors. Remote Sensing of Environment, v. 113, p. 893-903, 2009.

http://dx.doi.org/10.1016\%2Fj.rse.2009.01.007

DEMARCHI, J. C.; PIROLI, E. L.; ZIMBACK, C. R. L. Analise temporal do uso do solo e comparação entre os índices de vegetação NDVI e SAVI no município de Santa Cruz do Rio Pardo - SP usando imagens LANDSAT-5. RA'E GA, v. 21, p. 234-271, 2011.

DUBREUIL, V.; BARIOU, R.; PASSOS, M.; FERRAND, R.; NEDELEC, V. Evolução da fronteira agrícola no Centro-Oeste de Mato Grosso: municípios de Tangará da Serra, Campo Novo do Parecis e Diamantino. Cadernos de Ciência \& Tecnologia, v. 22, p. 463-478, 2005.

ESTEVES, B. S.; SOUSA, E. F.; LOUSADA, L. L.; MENDONÇA, J. C.; MUNIZ, R. A.; SILVA, R. M. Variações do albedo, NDVI e SAVI durante um ciclo da cana-de-açúcar no Norte Fluminense. Revista Brasileira de Ciências Agrárias, v. 7, p. 663-670, 2012. http://dx.doi.org/10.5039/agraria.v7i4a1597

FAUSTO, M. A.; MACHADO, N. G.; NOGUEIRA, J. S.; BIUDES, M. S. Net radiation estimated by remote sensing in Cerrado areas in the Upper Paraguay River Basin. Journal of Applied Remote Sensing, v. 8, p. 1-17, 2014.

FREY, C. M.; RIGO, G.; PARLOW, E. Urban radiation balance of two coastal cities in a hot and dry environment. International Journal of Remote Sensing, v. 28, p. 2695-2712, 2007. http://dx.doi.org/10.1080/01431160600993389

GOMES, L. C. F.; SANTOS, C. A. C.; ALMEIDA, H. A. Balanço de energia à superfície para a cidade de Patos-PB usando técnicas de sensoriamento remoto. Revista Brasileira de Geografia Física, v. 6, p. 15-28, 2013.

GUSMÃO, A. C. V. L.; SILVA, B. B.; MONTENEGRO, S. M. G. L.; GALVÍNCIO, D. Determinação do saldo radiativo na Ilha do Bananal, TO, com imagens orbitais. Revista Brasileira de Engenharia Agrícola e Ambiental, v. 16, p. 1107-1114, 2012.

HUERTE, A. R. Adjusting vegetation indices for soil influences. International Agrophysics, v. 3, p. 367-376, 1988.

IQBAL, M. An introduction to solar radiation. Ontario: Academic Press, 1983. 330 p. 
INSTITUTO BRASILEIRO DE GEOGRAFIA E ESTATÍSTICA - IBGE. Cidades. Censo 2010. Disponível em: http://www.cidades.ibge.gov.br/xtras/perfil.php?lang=\&codmun= 510340. Acesso em: 14 dez. 2014

LEITÃO, M. M. V. B. R.; OLIVEIRA, G. M. Influência da irrigação sobre o albedo. Revista Brasileira de Engenharia Agrícola e Ambiental, v. 4, p. 214-218, 2000. http://dx.doi.org/10.1590/S1415-43662000000200014

LONG, D.; GAO, Y.; SINGH, V. P. Estimation of daily average net radiation from MODIS data and DEM over the Baiyangdian watershed in North China for clear sky days. Journal of Hydrology, v. 388, p. 217-233, 2010. http://dx.doi.org/10.1016\%2Fj.jhydrol.2010.04.042

MARTINS, J. A.; DALLACORT, R.; INOUE, M. H.; GALVANIN, E. A. S.; MAGNANI, E. B. Z.; OLIVEIRA, K. C. Caracterização do regime pluviométrico no arco das nascentes do rio Paraguai. Revista Brasileira de Meteorologia, v. 26, p. 639-647, 2011. http://dx.doi.org/10.1590/S0102-77862011000400013

OLIVEIRA, L. M. M.; MONTENEGRO, S. M. G. L.; ANTONINO A. C. D.; SILVA, B. B.; MACHADO, C. C. C.; GALVÍNCIO, J. D. Análise quantitativa de parâmetros biofísicos de bacia hidrográfica obtidos por sensoriamento remoto. Pesquisa Agropecuária Brasileira, v. 47, p. 1209-1217, 2012.

PAVÃO, V. M.; QUERINO, C. A. S.; BENEDITTI, C. A.; PAVÃO, L. L.; QUERINO, J. K. A. S.; MACHADO, N. G. et al. Temperatura e albedo da superfície por imagens TM Landsat 5 em diferentes usos do solo no sudoeste da Amazônia brasileira. Revista Brasileira de Climatologia, v. 16, p. 169-183, 2015.

PELGRUM, H.; DAVIDS, G.; THORESON, B. P.; ALLEN, R. G.; BASTIAANSSEN, W. G. M.; NOORDMAN, E. J. M. SEBAL model with remotely sensed data to improve water-resources management under actual field conditions. Applications. Journal of Irrigation and Drainage Engineering, v. 131, N. 1, p. 85-93, 2005.

PESSOA, S. P. M.; GALVANIN, E. A. S.; NEVES, S. M. A. S.; KREITLOW, J. P. Análise espaço-temporal do uso e cobertura da terra na bacia hidrográfica do rio do Bugres Mato Grosso, Brasil. Enciclopédia Biosfera, v. 9, p. 162-174, 2011.

QUERINO, C. A. S.; MOURA, M. A. L.; LYRA, R. F. F.; MARIANO, G. L. Avaliação e comparação de radiação solar global e albedo com ângulo zenital na região Amazônica. Revista Brasileira de Meteorologia, v. 21, p. 42-49, 2006.

RISSO, J.; RIZZI, R.; RUDORFF, B. F. T.; ADAMI, M.; SHIMABUKURO, Y. E.; FORMAGGIO, A. R. et al. Índices de vegetação MODIS aplicados na discriminação de áreas de soja. Pesquisa Agropecuária Brasileira, v. 47, p. 1317-1326, 2012. http://dx.doi.org/10.1590/S0100-204X2012000900017

SILVA, B. B.; BRAGA, A. C.; BRAGA, C. C. Balanço de radiação no perímetro irrigado São Gonçalo - PB mediante imagens orbitais. Revista Caatinga, v. 24, p. 145-152, 2011.

SILVA, B. B.; LOPES, G. M.; AZEVEDO, P. V. Determinação do albedo de áreas irrigadas com base em imagens Landsat 5 TM. Revista Brasileira de Agrometeorologia, v. 13, p. 201-211, 2005. 
SILVA, B. B.; SILVA, S. T. A.; GOMES, H. B. Alterações climáticas decorrentes de mudanças no uso da terra mediante sensoriamento remoto. Mercator, v. 9, p. 91-106, 2010. http://dx.doi.org/10.4215/RM2010.0901.0006

SOUZA, P. J. O. P.; RIBEIRO, A.; DA ROCHA, E. J. P.; LOUREIRO, R.; BISPO, C. J. C.; SOUSA, A. M. L. Albedo da cultura da soja em área de avanço da fronteira agrícola na Amazônia. Revista Brasileira de Engenharia Agrícola e Ambiental, v. 14, p. 65-73, 2010. http://dx.doi.org/10.1590/S1415-43662010000100009

TASUMI, R. G. ALLEN, AND R. TREZZA. At-surface reflectance and albedo from satellite for operational calculation of land surface energy balance. Journal of Hydrologic Engineering, v. 13, n. 2, p. 51-63, 2008. http://dx.doi.org/10.1061/(ASCE)10840699(2008)13:2(51), 51-63 


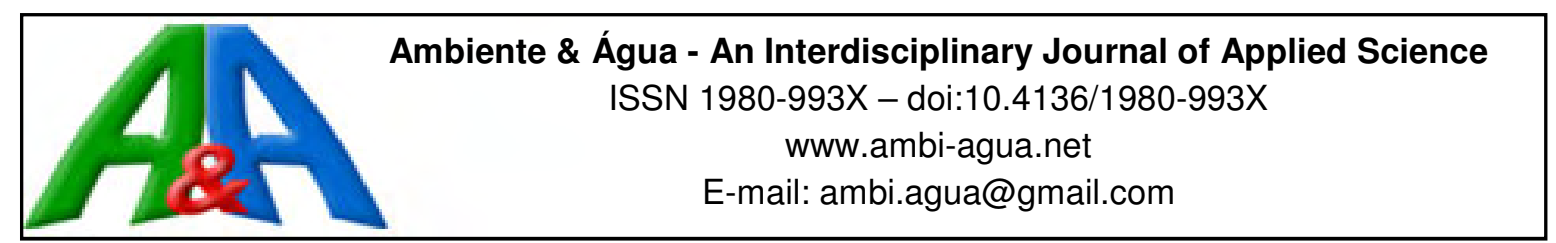

\title{
Gestão dos serviços públicos de água e esgoto operados por municípios em Goiás, GO, Brasil
}

\author{
doi:10.4136/ambi-agua.1739 \\ Received: 21 Aug. 2015; Accepted: 11 Feb. 2016
Poliana Nascimento Arruda; Aline Souza Carvalho Lima; Paulo Sérgio Scalize*

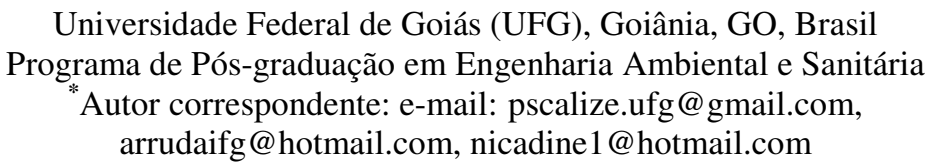

\section{RESUMO}

As características dos serviços prestados e a regulação da cobrança refletem na satisfação dos usuários e na definição da tarifa a ser cobrada em função da qualidade dos serviços ofertados. Dessa forma, o objetivo do estudo foi analisar o tipo de prestação dos serviços públicos de água e esgoto em 21 municípios por prefeituras no Estado de Goiás. Para isso, foram realizadas visitas in loco, aplicação de formulários e entrevistas para obter informações técnicas e verificar a satisfação. Observou-se que em dez municípios os sistemas são geridos por autarquias, quatro por departamentos e secretarias e sete não possuem órgão específico. Foi observado que em sete municípios não há tratamento de água, destes, seis não possuem órgão específico revelando a deficiência de gestão. No esgotamento sanitário, notou-se a presença de apenas fossas negras em $57,1 \%$ dos municípios. Neles não foi encontrado órgão regulador e os reajustes de cobrança são realizados de três formas: i) aprovação do projeto na câmara de vereadores, ii) aprovação do prefeito em forma de decreto e iii) análise pelo Conselho Municipal de Saneamento (CMS). A satisfação da população com os serviços públicos de água e esgoto está relacionada a fatores econômicos, culturais e políticos, este último é preponderante e a forma de gestão influencia a existência de melhores condições de infraestrutura.

Palavras-chave: gestão do saneamento, percepção dos usuários, qualidade, saneamento básico, tarifa.

\section{Management of public water and sewage services by municipalities in Goiás, GO, Brasil}

\begin{abstract}
The characteristics of services provided and the regulations governing their cost both contribute to the satisfaction of the consumer. Therefore, the aim of the study was to analyze the quality of public water and sewage services in 21 municipalities of Goiás, to include billing procedures and consumer satisfaction, and taking into account whether or not the operations were regulated. To accomplish this, we conducted on-site visits to complete questionnaires relating to our interviews with managers to obtain technical information and with consumers to determine their level of satisfaction. It was observed that systems are
\end{abstract}


managed by local authorities in ten municipalities, four by city hall departments or appointed officials, and seven did not have any specific regulatory oversight. Seven municipalities had no water treatment; of those, six had no specific regulatory oversight, revealing the lack of a planned management system. In $57.1 \%$ of the municipalities, there was no sewage treatment and sewage was dumped in soak pits. These had no governing body, and the price-charging adjustments were established in three ways: i) approval of the project by the Town Hall councilors; ii) decree by the mayor; and iii) analysis by the Municipal Sanitation Council (CMS). The satisfaction of the consumers was related to economic, cultural and, especially, political factors, and the existence of a management system improved infrastructure conditions.

Keywords: perceptions of users, price, quality, sanitation management, sewerage.

\section{INTRODUÇÃO}

A qualidade da água consumida pela população, a coleta e o tratamento do esgoto doméstico, a cobrança justa pelos serviços prestados e a satisfação dos usuários, são fatores fundamentais para um equilíbrio entre as questões ambientais e a qualidade de vida.

A prestação dos serviços públicos de saneamento básico, principalmente em municípios operados por instituições locais, ou seja, aqueles oferecidos por órgãos da administração direta, autarquias ou empresas multimunicipais, apresenta carência de estudos, necessitando maior atenção. As principais pesquisas que avaliam a satisfação dos usuários dos serviços públicos de abastecimento de água e esgotamento sanitário geralmente são aquelas contratadas pelas próprias empresas prestadoras dos serviços, e nelas são utilizados como ferramentas, formulários temáticos de satisfação para avaliarem os serviços, alimentando o banco de dados referente à qualidade, objetivando a melhoria contínua (ARSESP, 2013).

A Lei $n^{0} 11.445 / 2007$ (Brasil, 2007) tem como princípio a participação popular no processo de elaboração dos Planos Municiais de Saneamento Básico por meio de audiências ou consultas públicas, o que corrobora para a necessidade da verificação da satisfação e percepção dos usuários dos serviços por eles utilizados. Essa lei trata ainda, em um capítulo específico, sobre regulação dos serviços prestados, uma vez que não apresentam concorrência. Galvão Junior e Paganini (2009) esperam que a regulação, nos termos da referida lei, contribua diretamente para a introdução de mecanismos de eficiência, assegurando qualidade e preços mais acessíveis, além de maior eficácia das ações para a melhoria das condições de salubridade e bem-estar social. González-Gómez et al. (2014) relatam em seu trabalho que a alta concentração de participação privada no setor, a ausência de concorrência e deficiências regulatórias parecem ter colocado os interesses dos usuários dos serviços públicos de abastecimento de água em risco, sendo que a melhoria da governança não é garantida simplesmente mudando a gestão do sistema de água do público para o privado. Harutyunyan (2014), em estudo realizado na Armênia, constatou uma redução de consumo de $48 \%$ em longo prazo, que ocorreu após a privatização de tais serviços com a instalação de medidores de água nos imóveis e outras medidas. A definição de tarifas e reajustes a serem praticados pelas empresas privadas é feita por uma entidade independente, a Comissão Reguladora de Serviço Público, que atua na regulação de serviços públicos no país.

A cobrança pelos serviços prestados está instituída pela Lei $\mathrm{n}^{0} 11.445 / 2007$, que estabelece que caiba ao titular do serviço (município) determinar a forma que a cobrança ocorrerá, até mesmo quando e em quais condições poderá ser interrompida. Entretanto, no seu artigo 29, estabelece que essa cobrança deve ser preferencialmente sob a forma de tarifa e que deverá assumir um valor, de forma a garantir a sustentabilidade econômico-financeira do prestador com investimentos no setor, ampliação dos sistemas, continuidade e segurança dos 
serviços prestados (Brasil, 2007).

A cobrança por estes serviços ocorre também em diversos países como, por exemplo, em todos os constituintes do Reino Unido, onde é regulada pela Autoridade de Regulação de Serviços de Água (OFWAT - The Water Services Regulation Authority). Essa Autoridade, além de determinar, em função do tamanho da população atendida, aspectos qualitativos que os prestadores locais devem atender (municipais e privadas), estabelece o reajuste quinquenal que poderão praticar (Willis et al., 2005). No Brasil, segundo o levantamento realizado pela Associação Brasileira de Agências de Regulação (ABAR), em 2013 existiam 50 entes de regulação com competência para atuar no setor de saneamento básico, exercendo atividades em 2.716 municípios regulados para os componentes abastecimento de água e esgotamento sanitário, correspondendo a 48,8\% do total de municípios brasileiros. Esses dados representam um aumento de $18 \%$ em relação a 2012, consistindo em uma evolução da regulação no Brasil, mesmo que gradual (ABAR, 2013).

À medida que a demanda começa a crescer, torna-se necessária a utilização de meios para gerenciar o fornecimento da melhor forma possível. Yue e Tang (2011) relatam que, em Hong Kong, uma demanda crescente de consumo fez com que o governo implementasse medidas, dentre as quais estão a eficiência na medição e alterações nas faixas de cobrança, destacando que a participação do público é um elemento chave na gestão e, definitivamente, necessária para o sucesso dos programas.

Além da cobrança adequada, é necessário prezar pelo gerenciamento e controle da qualidade do serviço prestado. Holt (2005) ressalta a importância da relação de obter o máximo do serviço sobre a menor tarifa possível. $\mathrm{O}$ autor cita vários aspectos que devem ser atendidos pelas empresas concessionárias de água, energia e telefonia para integrar a qualidade aos serviços prestados, dentre os quais estão as medidas regulatórias, responsabilidades pelos serviços, padrões de qualidade e avaliação das informações obtidas e entendimento das tendências por meio do contexto geral.

A característica administrativa do prestador dos serviços de água e esgoto está relacionada com a infraestrutura e a abrangência dos serviços de água e esgoto. Isso pode ser observado em estudo realizado por Heller et al. (2006), em que se estabeleceu uma comparação entre 600 municípios do Estado de Minas Gerais, onde grupos foram formados de acordo com os diferentes gestores dos serviços. Observou-se, por meio de indicadores operacionais, epidemiológicos e sociais, que o grupo composto por autarquias obteve índices de cobertura de água superior aos outros grupos e se mostra semelhante aos da Companhia de Saneamento de Minas Gerais (Copasa) em outros aspectos analisados, evidenciando que esse tipo de administração utiliza-se de outras ações que compensou a ausência de investimentos em municípios com esse tipo de gestão devido à política implantada pelo Plano Nacional de Saneamento (Planasa).

Dessa forma, estabelecer um perfil de como as instituições municipais prestam seus serviços (nesse caso, saber se realizam a medição do consumo e como a fazem, além de analisar sua forma de cobrança) é fundamental para detectar falhas e possíveis aspectos para proposição de melhorias nos serviços. Nesse sentido, este estudo teve como objetivo verificar como é feita a gestão dos serviços públicos de abastecimento de água e de esgotamento sanitário em municípios do Estado de Goiás que são gerenciados por entidades de direito público, bem como a forma de cobrança pelos serviços prestados, sua regulação, a influência na qualidade da água distribuída à população e a percepção dos usuários.

\section{MATERIAL E MÉTODOS}

Este estudo foi realizado em 21 municípios, de um total de 246 localizados no Estado de Goiás, em que os serviços públicos de saneamento básico são prestados diretamente pelas 
prefeituras. Eles representam 6,67\% da população do Estado, totalizando 400.909 habitantes. De acordo com o Censo do IBGE (2010), Goiás possui em sua totalidade 6.003.788 habitantes e apresenta densidade demográfica de 17,65 hab. $\mathrm{km}^{-2}$, sendo o Estado mais populoso da Região Centro-Oeste. Na Figura 1 é mostrada a distribuição espacial dos 21 municípios e sua variação populacional segundo dados do Censo do IBGE (2010).

$\mathrm{O}$ estudo foi realizado durante as visitas técnicas por meio de levantamento de informações diretamente com os gestores de cada unidade gerenciadora dos serviços de água e esgoto, além da verificação da satisfação dos usuários dos serviços, ambos com a aplicação de formulários. Dessa forma, foram levantadas as principais características do saneamento básico referentes aos serviços públicos de água e esgoto em 21 municípios do Estado de Goiás prestados pelas próprias prefeituras.

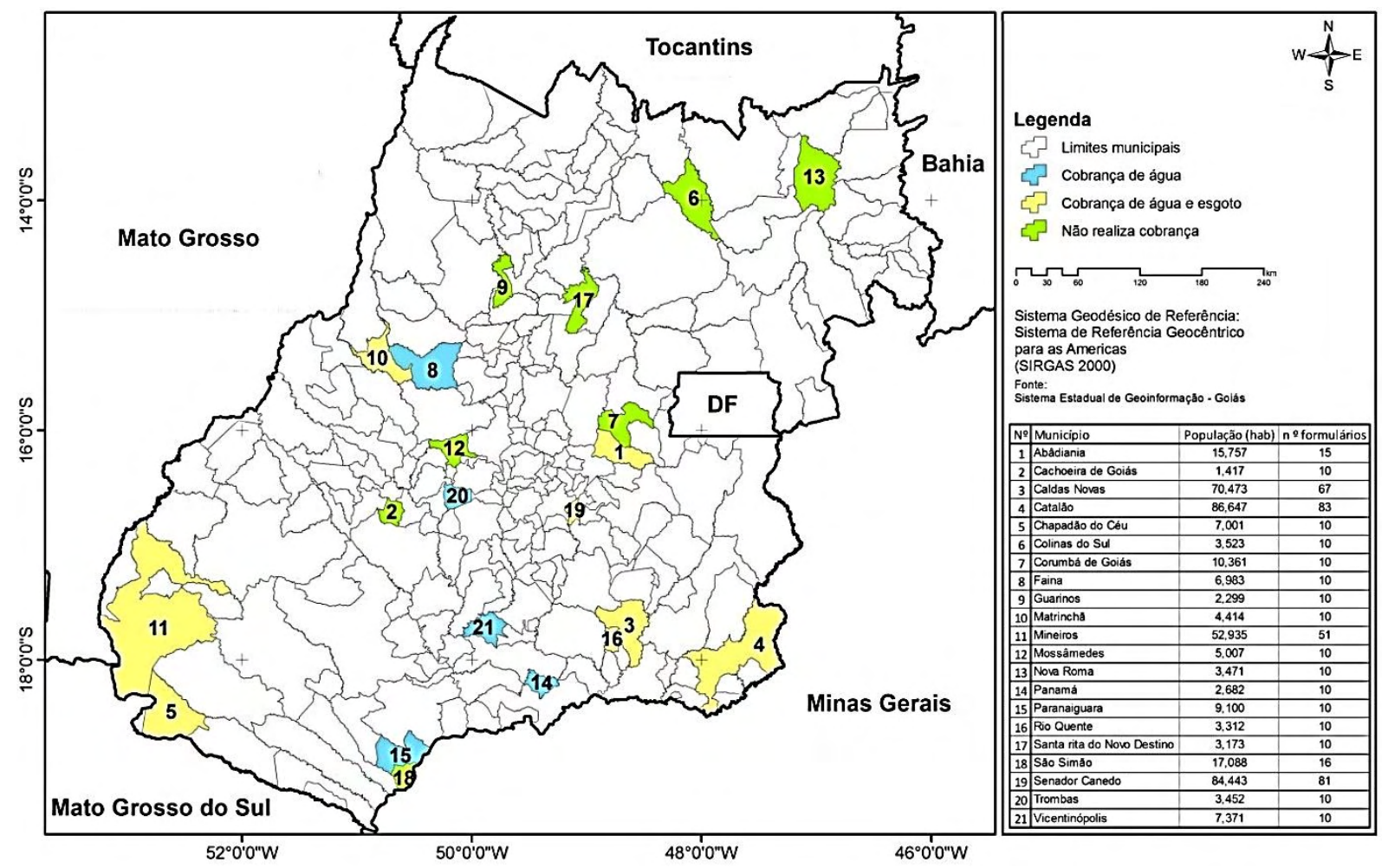

Figura 1. Distribuição espacial dos municípios da área de estudo, sua variação populacional e número de formulários aplicados aos usuários dos serviços de água e esgoto.

Incialmente verificou-se quais as formas de administração são empregadas pelas entidades responsáveis pelos serviços públicos de abastecimento de água e de esgotamento sanitário. Para isso, estipularam-se dois grupos de categorias: entidades de direito público e entidades de direito privado, sendo que nas entidades de direito público, os serviços municipais são operados por entidade da administração direta centralizada (secretaria, departamento ou outra entidade municipal) ou por entidade também da administração direta, mas descentralizada, organizada na modalidade de autarquia. As entidades de direito privado são as empresas públicas, as sociedades de economia mista, as empresas privadas e as organizações sociais (Brasil, 2013).

Foram levantadas as informações quanto à forma de regulação existente em cada entidade de saneamento básico, sendo que, no Estado de Goiás, existe a Agência Goiana de Regulação, Controle e Fiscalização de Serviços Públicos (AGR) que regula a empresa Saneamento de Goiás S/A (Saneago), responsável pelo abastecimento de água em 225 municípios, não atuando em 21 municípios restantes, onde a administração é publica direta. A 
aplicação de formulários foi realizada diretamente com os usuários dos serviços de água e esgoto durante as visitas aos municípios, que ocorria em horário comercial, abrangendo vários de seus bairros. A verificação da percepção dos usuários com relação à realidade encontrada foi feita comparando os resultados dos formulários com as condições constatadas in loco. $\mathrm{O}$ formulário (Apêndice 1), composto por seis questões, foi submetido e aprovado pelo Comitê de Ética em Pesquisa da Universidade Federal de Goiás sob o Parecer 391.907/2013.

A quantidade de pessoas entrevistadas foi determinada por meio de amostragem estratificada, recomendada para estudos nos quais as respostas terão comportamento homogêneo e heterogêneo dentro e entre os estratos, respectivamente. Considera-se que cada município representa um estrato e que dentro dos mesmos as características das respostas serão homogêneas, pois se tratam de pessoas submetidas a um mesmo prestador de serviço, refletindo em pequena variação nas respostas. No entanto, quando avaliada a relação entre os municípios, as amostras serão heterogêneas em função das características peculiares a cada serviço e entidade prestadora. Além disso, o objetivo principal da estratificação é garantir que todos os estratos sejam pesquisados, atingindo diferentes perfis de usuários (Rossi e Slongo, 1998).

O cálculo da amostragem em cada município foi realizado pela Equação 1, seguindo a regra da alocação de Neyman (1934), que leva em consideração a proporção entre a população total dos estratos e a população em cada estrato. Esse método também foi aplicado nos estudos de Netto e Sanquetta (1997) e Luiz et al. (2012). O trabalho foi realizado com erros amostrais de 5\% e nível de confiança de $95 \%$, sendo que dez foi o número mínimo de formulários aplicados em cada município.

$$
n^{*}=\frac{\sum_{h=1}^{L} N_{h}^{2} \widehat{\sigma}_{h}^{2} / W_{h}}{N^{2} E^{2} / t^{2}+\sum_{h=1}^{L} N_{h} \hat{\sigma}_{h}^{2}}
$$

em que:

$N_{h}=$ tamanho do estrato h (população de cada município);

$\mathrm{N}$ = somatório de $\mathrm{Nh}$ (soma das populações dos municípios objetos do estudo);

$\hat{\sigma}_{h}^{2}=$ é a variância amostral no estrato h;

$E=$ erro amostral;

$W_{h}=$ proporção de unidades amostrais no estrato $h$.

A partir da obtenção dos dados dos formulários, utilizou-se o programa Excel ${ }^{\circledR}$ juntamente com o XLSTAT com um intervalo de confiança de 95\% para tratamento dos resultados que foram expostos por meio de gráficos de boxplot, barras e tabelas.

\section{RESULTADOS E DISCUSSÃO}

Quanto ao tipo das entidades prestadoras aos serviços públicos de abastecimento de água (SAA) e de esgotamento sanitário (SES), em dez municípios eles são prestados por entidade da Administração Pública Direta Descentralizada por meio de autarquia e 11 por entidade da Administração Pública Direta Centralizada, sendo quatro por meio de departamentos ou secretarias municipais e sete por órgãos não especificos para os serviços prestados. $\mathrm{Na}$ Tabela 1 são apresentados os 21 municípios segundo a forma de administração, tipo de entidade prestadora, tipo de manancial de captação, serviços prestados e o que é cobrado.

Quanto ao abastecimento público de água tratada e cobrança, 14 municípios realizam algum tipo de tratamento, dos quais dez são gerenciados por autarquias, três por departamentos ou secretarias e um por entidade não específica. Os sete municípios restantes 
não realizam tratamento, bem como cobrança de tarifa, exceto o município de Paranaiguara, que distribui água sem tratamento e pratica a cobrança do serviço. Pode ser observado que as entidades da Administração Pública Direta Centralizada apresentam maiores carências quando comparadas à gestão descentralizada. Em quatro municípios, em que os serviços são prestados por departamentos e secretarias, foram observadas limitações em vários aspectos, porém as maiores deficiências estão naqueles em que não há entidades específicas para a prestação dos serviços. Entre os sete municípios que se enquadram nessa situação, seis não realizam o tratamento da água, estando em desacordo com a Portaria $n^{0}$ 2.914/2011 do Ministério da Saúde (Brasil, 2011), referente à potabilidade da água para consumo humano, no qual o processo de desinfecção é obrigatório para água oriunda de captação subterrânea e para captações em mananciais superficiais. Além da desinfecção, o processo de filtração também é exigido. Foram verificados problemas de planejamento, deficiência de estrutura organizacional, investimentos e manutenções (realizadas em caráter emergencial), quantitativo insuficiente de funcionário e falta de capacitação técnica.

Quanto à origem da água distribuída à população, foi observada que a captação de forma mista (manancial superficial e subterrâneo, simultaneamente) foi a mais comum, representando 52,4\% (Tabela 1). Nos municípios de Colinas do Sul e Nova Roma, os gestores afirmam que diante da dificuldade de disponibilidade de água nos mananciais superficiais, principalmente na época de seca, a opção foi perfurar poços profundos. Outro fator que propicia essa forma de utilização dos recursos hídricos é a construção de sistemas isolados, composto por captação subterrânea e reservatório, utilizados para abastecer novos bairros e os distritos mais afastados, não sendo necessário estender a rede de distribuição a esses locais.

Em se tratando de regulação, nota-se que há uma deficiência, uma vez que não foram encontrados órgãos reguladores municipais, intermunicipais ou estaduais atuantes nesses municípios. Segundo a Lei $\mathrm{n}^{\mathrm{o}} 11.445 / 2007$ (Brasil, 2007), um dos objetivos do órgão regulador é a definição de tarifas, em que o valor deve favorecer tanto a entidade prestadora do serviço nos aspectos financeiros e econômicos como a qualidade dos serviços prestados à população. Neste trabalho, a cobrança foi constatada em 14 dos 21 municípios estudados (Tabela 1), sendo que os reajustes são baseados em propostas elaboradas pelos próprios prestadores e são aprovados de três formas: i) aprovação do projeto de lei na Câmara de Vereadores $(64,3 \%)$; ii) aprovação do prefeito em forma de decreto $(28,6 \%)$; e iii) análise do Conselho Municipal de Saneamento (CMS) $(7,1 \%)$. Somente em Caldas Novas é praticada a fiscalização das revisões tarifárias, além do monitoramento dos serviços prestados com a participação da população nas decisões por meio de um CMS, proposto no Plano Municipal de Saneamento (PMS).

Vale ressaltar que a função de uma entidade reguladora não se restringe apenas aos reajustes das tarifas, como foi observado no município de Cachoeiro de Itapemirim que, após instituído o PMS, que propôs a criação do CMS e a Agência Reguladora dos Serviços de Água e Esgoto, percebeu que as pautas das reuniões focavam apenas em questões referentes à cobrança, não discutindo assuntos de interesse da população, como a qualidade dos serviços e a expansão da rede de distribuição de água para as áreas rurais. Além disso, a interferência política nas discussões era intensa, desmotivando a participação dos representantes da sociedade civil (Aguiar et al., 2012).

Galvão Junior (2009) afirma que a entidade reguladora tem papel fundamental na busca pela universalização do saneamento, em que ações podem ser realizadas por esse órgão no intuito de melhorar a eficiência das prestadoras e proporcionar uma visão mais estável e confiável às empresas reguladas, atraindo mais recursos para investimentos em infraestrutura e desenvolvimento para o setor. 
Tabela 1. Tipos de administração dos prestadores dos SAA e SES, serviço existente, forma de captação de água e serviço cobrado.

\begin{tabular}{|c|c|c|c|c|c|}
\hline Categoria & $\begin{array}{c}\text { Tipo de } \\
\text { administração }\end{array}$ & $\begin{array}{l}\text { Tipo de } \\
\text { entidade }\end{array}$ & Município & Serviço existente & $\begin{array}{l}\text { Serviço } \\
\text { cobrado }\end{array}$ \\
\hline \multirow{21}{*}{$\begin{array}{l}\text { Entidade } \\
\text { de Direito } \\
\text { Público }\end{array}$} & & & Abadiânia $^{(4)(a)}$ & Água e esgoto & Água e esgoto \\
\hline & & & Catalão $^{(4)(a)}$ & Água e esgoto & Água e esgoto \\
\hline & & & Chapadão do Céu ${ }^{(3)(a)}$ & Água e esgoto & Água e esgoto \\
\hline & & & Corumbá de Goiás ${ }^{(2)(b)}$ & Água & Água \\
\hline & Administração & A & Faina $^{(4)(b)}$ & Água & Água \\
\hline & Descentralizada & Autarquia & Matrinchã $\tilde{a}^{(2)(a)}$ & Água & Água \\
\hline & & & Mineiros $^{(2)(a)}$ & Água e esgoto & Água e esgoto \\
\hline & & & Senador Canedo ${ }^{(4)(a)}$ & Água e esgoto & Água e esgoto \\
\hline & & & $\operatorname{Trombas}^{(2)(a)}$ & Água & Água \\
\hline & & & Caldas Novas $^{(4)(c)}$ & Água e esgoto & Água e esgoto \\
\hline & \multirow{11}{*}{$\begin{array}{l}\text { Administração } \\
\text { Pública Direta } \\
\text { Centralizada }\end{array}$} & Departamento & Panamá(4)(a) & Água & Água \\
\hline & & ou secretaria & Rio Quente $^{(2)(b)}$ & Água e esgoto & Água e esgoto \\
\hline & & específica & São Simão ${ }^{(3)}$ & Água $^{(1)}$ e esgoto & Sem tarifa \\
\hline & & & Vicentinópolis ${ }^{(3)(a)}$ & Água & Água \\
\hline & & \multirow{7}{*}{$\begin{array}{l}\text { Departamento } \\
\text { ou secretaria } \\
\text { não específica } \\
\text { para o serviço }\end{array}$} & Paranaiguara $^{(3)(b)}$ & Água ${ }^{(1)}$ e esgoto & Água \\
\hline & & & $\begin{array}{l}\text { Santa Rita do Novo } \\
\text { Destino }^{(4)}\end{array}$ & Água & Sem tarifa \\
\hline & & & Cachoeira de Goiás ${ }^{(2)}$ & Água $^{(1)}$ & Sem tarifa \\
\hline & & & Colinas do Sul ${ }^{(4)}$ & Água $^{(1)}$ & Sem tarifa \\
\hline & & & Mossâmedes ${ }^{(4)}$ & Água $^{(1)}$ & Sem tarifa \\
\hline & & & Nova Roma ${ }^{(4)}$ & Água $^{(1)}$ & Sem tarifa \\
\hline & & & Guarinos ${ }^{(4)}$ & Água $^{(1)}$ & Sem tarifa \\
\hline
\end{tabular}

Nota: ${ }^{(1)}$ Água fornecida sem tratamento; ${ }^{(2)}$ captação superficial; ${ }^{(3)}$ captação subterrânea; ${ }^{(4)}$ misto (captação superficial e subterrânea); ${ }^{(a)}$ aprovação do projeto na Câmara de Vereadores; ${ }^{(b)}$ aprovação do projeto em forma de decreto; ${ }^{(c)}$ análise por meio do Conselho Municipal de Saneamento.

No intuito de verificar os valores cobrados nos municípios estudados e devido à inexistência da tarifa média praticada nos mesmos, foi realizada uma estimativa baseada em uma família composta por quatro pessoas, superior ao considerado pelo IBGE (2010), que estabelece 3,3 pessoas residência $^{-1}$, considerando o consumo per capita médio de 2010 a 2012 de 141,3 L hab $\mathrm{d}^{-1}$ para o Estado de Goiás (Brasil, 2013), o que gera $17 \mathrm{~m}^{3}$ mês ${ }^{-1}$. Para esse consumo foi calculado o valor pago mensalmente (Figura 2), sendo comparados com a tarifa cobrada pela Saneago. Pode ser observado que entre os seis menores valores praticados, quatro são realizados pelos únicos órgãos com Administração Pública Direta Centralizada que realizam a cobrança. Dos moradores desses quatro municípios, quando perguntados sobre a definição da tarifa cobrada entre "barato", "justo" e "caro", mais de 50\% respondeu como sendo "justa". Trombas, Chapadão e Rio Quente obtiveram valores acima de 70\%, considerando justo o preço que pagam, com destaque para Trombas, em que o valor está acima do praticado pela Saneago (Figura 2a).

Para o critério "cobrança" foi analisada a percepção do usuário obtida nos formulários aplicados a eles. Nos municípios que cobram pelos serviços públicos de abastecimento de 
água, 57,1\% consideram "justo" o preço que pagam (Figura 2c). Em Faina e Matrinchã, os usuários ficaram divididos quanto ao "justo" e "barato" e, em Catalão e Caldas Novas, mais de $65 \%$ deles consideram "caro" o que pagam pelo serviço de água. Observam-se ainda, na Figura 2b, os valores atípicos superiores quanto aos indicadores "barato" (Paranaiguara - 50\%) e "justo" (Trombas - 90\%). Paranaiguara é o único município que não possui hidrometração entre os que cobram pelos serviços, sendo que o valor da tarifa é calculado em função de determinadas condições, tais como área do imóvel e número de residentes, sendo que mais de $70 \%$ da população paga somente $\mathrm{R} \$ 6,20$, resultando na tarifa mais barata dos 14 municípios que cobram pelo uso (Figura 2a). Vale ressaltar que nesse município não há um departamento ou secretaria específica responsável pelos serviços de saneamento básico, bem como não há hidrometração, contribuindo ainda mais para as deficiências encontradas.

Uma situação intrigante foi encontrada no município de Trombas, onde é praticada a tarifa mais alta de todo o Estado para o consumo somente de água (Figura 2a), sendo que 90\% dos respondentes acham "justo" o valor cobrado (Figura 2c). No entanto, $70 \%$ dos entrevistados estão insatisfeitos (Figura 4a). Isso pode ser explicado pela falta de atenção dos entrevistados quando da entrevista, resultando em respostas incoerentes. Porém um fato marcante foi a indagação por parte dos entrevistados sobre o aumento da tarifa e, ainda, se a Saneago iria assumir os serviços públicos de água e esgoto no município.

Assim como em Trombas, durante a pesquisa, principalmente nos municípios com menor contingente populacional e que realizam a cobrança da água, houve questionamentos quanto à presença da Saneago no município, sendo observado receio da população quanto ao aumento da tarifa praticada, influenciando assim nas respostas quanto à qualidade dos serviços prestados pelas entidades municipais.

Sobre a satisfação quanto ao abastecimento de água, foi observado que 15 municípios $(61,9 \%)$ possuem mais de $50 \%$ dos usuários satisfeitos (Figura 4a). A insatisfação dos usuários prevalece em 28,6\% dos municípios onde é realizada a cobrança pelo uso da água. Em Santa Rita do Novo Destino a insatisfação alcançou 90\%. Esse município se diferencia dos demais por realizar o tratamento de água e não efetuar a cobrança, o que é justificado pelo fato de não haver a medição da água consumida nas residências. Além disso, a prestação dos serviços não possui entidade específica na estrutura organizacional da prefeitura, refletindo numa maior dificuldade na implantação de um sistema tarifário devido à carência de autonomia política e financeira. Observa-se que nos sete municípios onde não é realizado o tratamento da água (Figura 4a), a satisfação dos usuários quanto à água que consomem encontra-se igual ou superior a $70 \%$, valor acima da média e da mediana para a situação encontrada (Figura 4b).

Como citado anteriormente, a questão econômica está fortemente ligada às respostas dos usuários dos serviços de água, pois, apesar da água distribuída em sete municípios não ser tratada e haver o conhecimento por parte da população da situação existente, há o receio da inserção da cobrança mediante a pesquisa. A questão cultural em torno do tratamento da água, devido à adição de substâncias químicas, também motivou as respostas, induzindo a população a ser contrária às mudanças no sistema de abastecimento de água, devido à rejeição da população ao cloro que seria usado na desinfecção.

Dos 14 municípios que possuem entidades prestadoras específicas, com a presença de autarquias ou departamentos, a insatisfação superou a satisfação em cinco deles. Em Mineiros, um dos maiores municípios estudados, a insatisfação superou $40 \%$. Durante a aplicação dos formulários os entrevistados reclamavam sobre a coloração da água, que era rejeitada até para lavar roupas. Esse município conta com dois sistemas de captação de água e, no momento da pesquisa, a estação de tratamento de água (ETA) operava acima da sua capacidade, interferindo na qualidade da água tratada e, segundo os gestores, uma outra ETA (sistema compacto) estava sendo licitada para suprir a demanda. Em Catalão, a insatisfação 
superou os $60 \%$. O município também estava em processo de ampliação, uma vez que a estrutura existente na ETA estava alcançando sua capacidade limite. Nesse município, assim como em Abadiânia e Caldas Novas, mais de 60\% dos entrevistados consideraram "caro" o preço que pagam pela água, coincidindo com a insatisfação vivida pelos moradores.
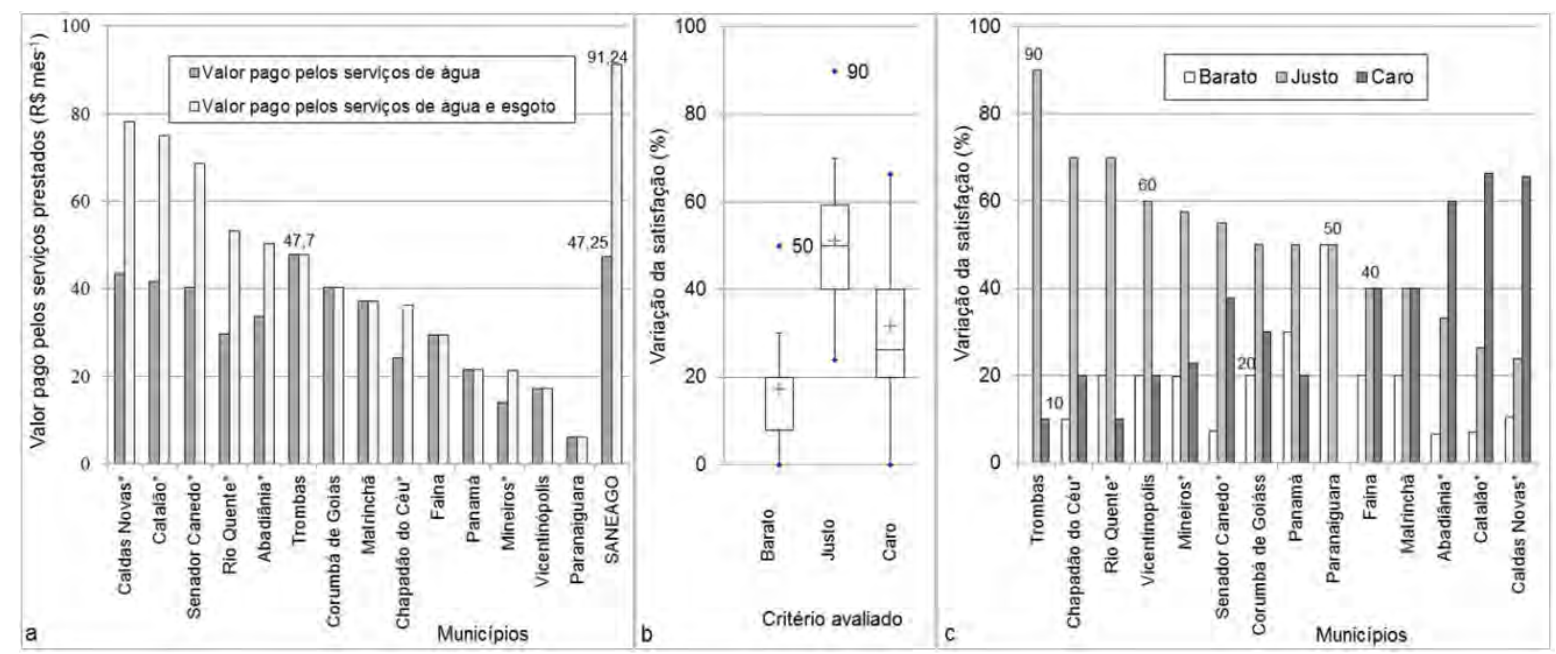

Figura 2. Valor pago mensalmente considerando um consumo de $17 \mathrm{~m}^{3}$, seja de água ou de água e esgoto (a); opinião dos entrevistados quanto ao preço que pagam pela qualidade da água recebida no seu imóvel (b, c).

Nota: (*) municípios que cobram pelo serviço de esgoto.

O crescimento das cidades, com o uso e ocupação de áreas próximas aos mananciais, contribui para a perda da qualidade da água, exigindo mais dos processos de tratamento. Além disso, a demanda pela água potável aumenta, sendo necessários investimentos para as adequações a fim de garantir a qualidade da água distribuída para a população.

Desse modo, relacionando a satisfação com a prestação dos serviços públicos de abastecimento de água, nos 21 municípios foi observado que a infraestrutura e a presença ou ausência de tratamento não é fator determinante para a satisfação da população, uma vez que aspectos culturais e econômicos estão fortemente relacionados a essas questões.

Avaliando a satisfação dos usuários quanto à qualidade da água consumida e relacionando com o tipo de prestador de serviço do município, foi possível observar que onde não há uma entidade específica para a prestação dos serviços de água e esgoto o nível de satisfação é superior a $70 \%$, notado em seis dos sete municípios que se encontram nessa situação, sendo que apenas um desse grupo, Santa Rita do Novo Destino, obteve um índice de satisfação baixo (10\%). Nos municípios com serviços prestados por autarquias houve uma significativa variação quanto às respostas dos usuários, variando entre $10 \%$ (Faina) a $80 \%$ (Corumbá de Goiás). Onde há presença de departamentos e secretarias, a satisfação se encontra acima de $70 \%$ e, entre os 21 municípios estudados, apenas Rio Quente, presente nesse grupo, obteve $100 \%$ de satisfação quanto à qualidade da água (Figuras $3 \mathrm{~b}$ e $4 \mathrm{a}$ ).

Vale salientar que no grupo de municípios onde não há uma entidade específica apenas em Santa Rita do Novo Destino é realizado o tratamento de água, apresentando um índice de insatisfação de 90\% (Figura 4a). Entretanto, nos municípios com serviços prestados por autarquias, apenas dois dos dez municípios incluídos nesse grupo obtiveram índices acima de $70 \%$, destacando que todos desse grupo possuem tratamento de água. Nota-se que a satisfação dos usuários não está ligada ao tipo de entidade prestadora, tampouco com a presença ou ausência de tratamento de água. Porém é preciso destacar que nos seis municípios que não possuem entidade específica para prestação dos serviços e que o nível de satisfação se 
encontra alto, a captação de água é realizada em nascentes ou em poços profundos localizados em áreas protegidas, característica que contribui para melhor qualidade físico-química e microbiológica da água. Esses municípios são Cachoeira de Goiás, Colinas do Sul, Guarinos, Nova Roma, Paranaiguara e Mossâmedes.

\subsection{Esgotamento Sanitário}

Com relação ao SES nos municípios estudados notou-se um descompasso quando comparado à preocupação com a distribuição de água. Esse cenário é vivenciado no Brasil desde Planasa de 1971, em que houve um grande investimento em abastecimento de água, deixando a coleta e tratamento de esgoto em segundo plano. Esse plano, fruto de uma política centralizada adotada na época, atendeu aos municípios que aderiram as Companhias Estaduais de Água e Esgoto quanto a investimentos, e excluiu aqueles cuja prestação permaneceu sendo realizada pela Administração Pública Direta do município (Britto et al., 2012).

Segundo dados do IBGE (2010), nove municípios dos 21 estudados possuem rede coletora de esgotamento sanitário e seis deles coletam esgotos de mais de $70 \%$ dos domicílios, sendo que São Simão, Paranaiguara e Mineiros não realizam tratamento do que é coletado, lançando os esgotos in natura no ambiente (Figura 3b).

Relacionando o tipo de entidade prestadora com o SES, nota-se que quatro dos municípios com serviços de esgoto prestados por autarquias realizam a coleta e o tratamento de esgoto de $45 \%$ a $60 \%$ dos domicílios, refletindo em um déficit que é suprido pela presença de fossas sépticas ou de fossas negras, além de outras formas, como lançamento de esgotos em lagos, rios e valas (IBGE, 2010). Nos municípios de Corumbá de Goiás, Faina, Matrinchã e Trombas, também com serviços prestados por autarquias, a presença de fossas negras abrange mais de $80 \%$ dos domicílios (Figura 3b).

No município de Faina, apesar de existir uma ETE, não há o sistema de coleta e afastamento. Segundo gestores, a estrutura foi implantada com verba que abrangia apenas a construção da ETE e, após o seu término, não havia verba para o sistema de coleta e afastamento, levando assim ao seu abandono.

Em Mineiros, um dos maiores municípios em população estudados, há presença de rede coletora de esgoto, com sistemas de bombeamento e gradeamento, porém não há ETE construída, levando ao lançamento do efluente no Córrego Mineiros, assim como em São Simão e Paranaiguara, municípios gerenciados por departamento e sem entidade específica, respectivamente. No caso de Paranaiguara, devido ao embargo da ETE, por ter sido construída em área de preservação ambiental, o esgoto coletado é encaminhado sem tratamento para o manancial. Em São Simão, quando da realização do trabalho de campo, a ETE ainda encontrava-se em processo de enchimento das lagoas.

Dos sete municípios que não possuem entidade específica, apenas Paranaiguara possui um sistema melhor estruturado, sendo que o restante, com exceção de Cachoeira de Goiás, apresentam fossas negras em mais de $70 \%$ dos domicílios. Apesar do município de Cachoeira de Goiás não possuir rede coletora de esgoto, constatou-se que 98,38\% dos domicílios do município possuem fossas sépticas instaladas por meio de programa da prefeitura. Essa unidade de tratamento de esgoto é normatizada pela NBR 13.969, que objetivou oferecer opções para tratamento e disposição final de efluentes domésticos em locais que não são servidos por rede de coleta e tratamento de esgoto. Ainda segundo a norma, quando esse dispositivo é dimensionado e operado de forma adequada, constitui uma alternativa viável e confiável quando comparado ao sistema de esgotamento sanitário tradicional (ABNT, 1997). Confirmando os benefícios dessa unidade, em Cachoeira de Goiás, quando perguntados sobre a ocorrência de inconveniente quanto ao SES, $100 \%$ dos entrevistados responderam não (Figura 3b). 
Em relação ao tipo de coleta e afastamento do esgoto existente, percebeu-se concordância entre as respostas dadas e a situação real do município, pois os mesmos não são cobertos por rede coletora, tendo como resposta dos usuários a presença de fossas sépticas ou negras. Nas cidades com rede coletora de esgoto, os inquiridos responderam que suas casas são ligadas à rede, sendo que em $75 \%$ dos casos essa resposta foi dada por mais de $50 \%$ dos pesquisados. Observa-se que é substancial o conhecimento dos entrevistados quanto ao tipo de coleta ou afastamento do esgoto presente no seu município, porém, em Caldas Novas, Catalão, Rio Quente, Senador Canedo, Trombas e Vicentinópolis, entre $4,5 \%$ e $20 \%$ dos usuários não responderam ou não souberam responder como é feita a coleta do esgoto de suas casas.

Com relação à ocorrência de inconvenientes com o SES, como a geração de odores, rompimento da rede coletora, explosão e vazamento de fossas, nota-se na Figura 3a que não há uniformidade nas respostas dos entrevistados nos municípios com os serviços prestados por autarquias em relação à insatisfação quanto ao SES, com resultados variando entre $20 \%$ a 90\%. Já naqueles em que a prestação é realizada por Administração Direta Centralizada, a insatisfação variou pouco, porém com valores iguais ou superiores a $60 \% \mathrm{em} 63 \%$ deles. Quanto aos inconvenientes nesse último grupo, os valores foram baixos, sendo o maior em Colinas do Sul (40\%).

Na Figura 3a é possível observar que a insatisfação prevalece naqueles municípios que não possuem entidade específica. Já nos municípios com presença de autarquias ocorrem índices altos de insatisfação, ressaltando que $60 \%$ deles possuem rede coletora de esgoto. Naqueles em que não há entidade específica os valores se concentram acima de $40 \%$ (Figura 3b).

Quando comparados os dez municípios com serviços prestados por entidade da Administração Direta Descentralizada com os 11 da Administração Direta Centralizada, 63\% respondentes do primeiro grupo e $70 \%$ do segundo apresentaram insatisfação acima de $60 \%$, ou seja, apesar das autarquias serem vistas como entidade com mais autonomia política, administrativa e financeira, e que poderia prestar melhores serviços, em relação aos SES deixa a desejar.

Comparando os municípios que possuem rede geral para coleta e afastamento de esgoto dos domicílios com aqueles que dispõem de fossas sépticas ou negras, nota-se que o nível de insatisfação é maior na segunda situação, com índices que chegam a 90\%, como os casos de Faina, Matrinchã e Santa Rita do Novo Destino.

Nos municípios em que estão presentes as fossas sépticas ou negras, os inconvenientes estiveram abaixo dos $40 \%$, havendo uma uniformidade nas respostas dos entrevistados nos 12 municípios desse grupo, com exceção do município de Faina, que alcançou $60 \%$ nesse quesito (Figura 3b). Apesar dos baixos índices de inconvenientes, nota-se que a insatisfação é presente na população, o que corrobora com os resultados de Neumann et al. (2013), que verificaram a percepção ambiental de moradores de um loteamento no município de Serra (ES), em que $99 \%$ dos domicílios possuíam fossas e $1 \%$ lançava o esgoto na rede de água pluvial. A fim de obter o nível de satisfação da população, foram aplicados formulários e $94 \%$ dos entrevistados se mostraram insatisfeitos com o SES e $96 \%$ desses, relataram que a ausência de rede coletora de esgoto é o principal motivo dessa insatisfação. A metodologia utilizada no estudo desses pesquisadores identificou setores com maiores carências e que o SES do loteamento necessita de maiores investimentos e atenção da entidade responsável pelo serviço. Em Cachoeira de Goiás, município que obteve nível de insatisfação elevado e $0 \%$ de inconvenientes, é notável a preocupação da população quanto à presença de rede coletora de esgoto, apesar de fossa séptica ser a solução sanitária identificada no local. 
Nota-se que, em se tratando de coleta e tratamento de esgoto, os municípios estudados se encontram em situação crítica, pois em apenas 28,5\% dos municípios eles ocorrem simultaneamente. A presença de fossas negras ainda é presente de forma integral em $57,1 \%$ dos municípios estudados.

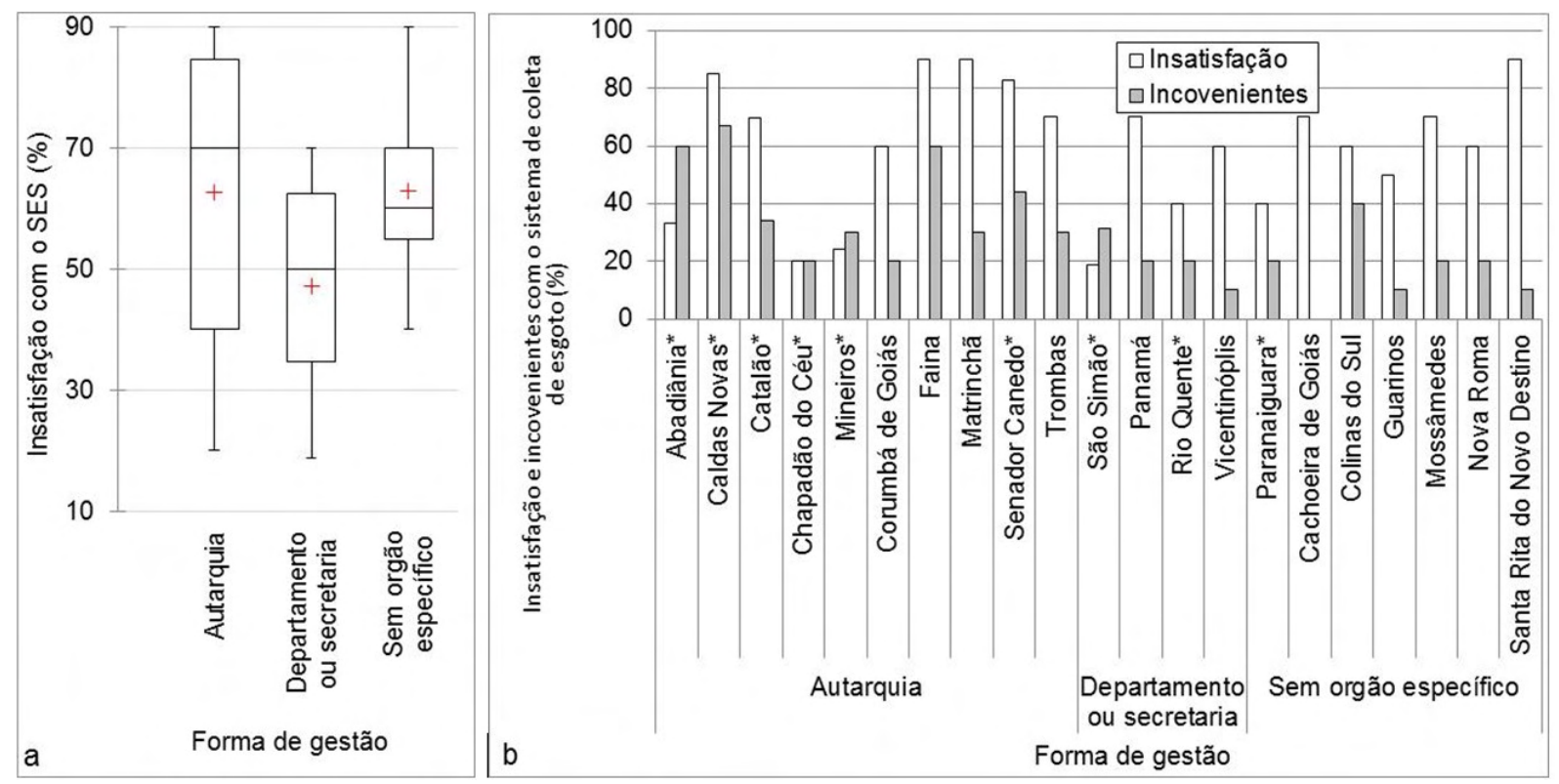

Figura 3. Insatisfação quanto ao SES por tipo de gestão (a) e sua relação com inconvenientes no SES (b).

Nota: $(*)$ municípios com presença de rede coletora de esgoto.

\subsection{Disposição a pagar}

Verificou-se que em 90,5\% dos municípios, 50 a 100\% dos entrevistados aceitariam pagar mais por um serviço melhor. Destacam-se os municípios de Vicentinópolis e Santa Rita do Novo Destino, onde $100 \%$ dos entrevistados estão dispostos a pagar mais pelos serviços públicos de água e esgoto e, na outra extremidade, estão Guarinos e Catalão, onde somente $30 \%$ e $31,3 \%$ aceitariam tal condição, onde a satisfação quanto ao SES não ultrapassou $30 \%$. Porém, em relação ao SAA em Catalão, o índice de satisfação foi de $40 \%$, ao contrário de Guarinos, que alcançou 90\%, ressaltando que nesse município não há tratamento de água.

Assim como em Guarinos, mais seis municípios não cobram pelo serviço de distribuição de água, sendo que a disposição em pagar mais pelos serviços ficou acima de $60 \%$ para os entrevistados. Destaca-se que o único que dispõe de tratamento de água é Santa Rita do Novo Destino, que ficou com a pior satisfação para o SAA (10\%).

Comparando a satisfação entre o SES e o SAA, nota-se que a satisfação com o SES não ultrapassou os $40 \%$ em seis municípios, sendo que em São Simão, onde há presença de rede coletora de esgoto, a satisfação foi de $80 \%$. Porém, mesmo sem a presença de tratamento de água (água de aquífero), o município ficou com satisfação acima de $70 \%$ para o SAA juntamente com mais cinco municípios. Constata-se que a disposição dos respondentes em pagar mais nesses municípios, no geral, se deve a deficiências no SES, ou seja, a ausência de rede coletora de esgoto, não incomodando o consumo de água não potável.

É possível verificar na Figura 4c que, naqueles municípios que realizam a cobrança pelos serviços públicos de água e esgoto ou apenas de água, a disposição em pagar ficou acima dos $50 \%$, mesmo para aqueles que praticam as maiores tarifas do Estado, com exceção de Catalão $(31,3 \%)$. Dessa forma, os resultados sugerem que a disposição em pagar mais independe do valor da tarifa cobrada pelos serviços prestados. 


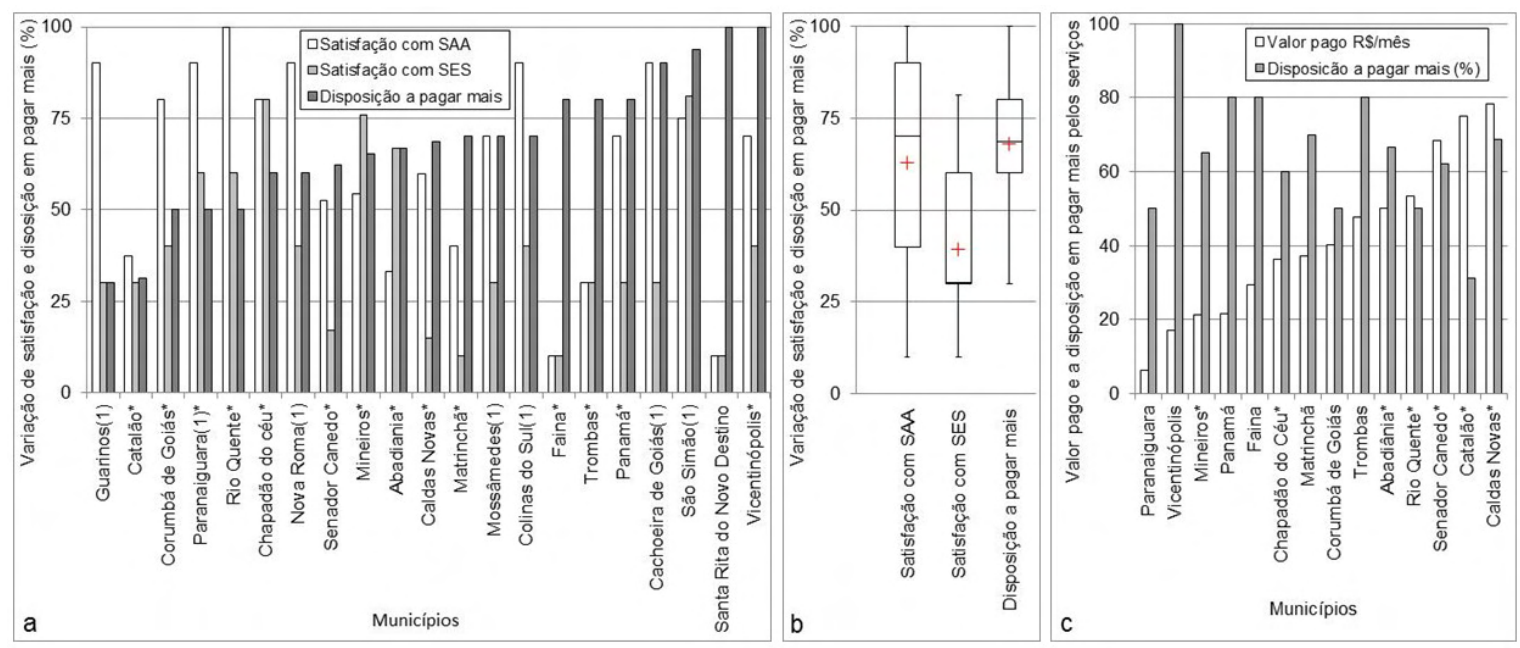

Figura 4. Satisfação dos usuários com relação à água e esgoto e disposição a pagar mais pelos serviços (a e b), e sua relação com o valor pago pelos serviços.

Nota: (1) municípios onde não é realizado o tratamento da água;

(*) municípios onde é cobrado pelo uso.

\section{CONCLUSÃO}

O presente estudo permite concluir que quando os serviços públicos de abastecimento de água e esgotamento sanitário são prestados por entidades da Administração Direta Descentralizada, ou seja, na forma de autarquias, a infraestrutura é mais ampla e apresenta maior qualidade, porém ainda com muitas deficiências, principalmente em relação ao Serviço de Esgotamento Sanitário. Contudo, essa maior disponibilidade de recursos não reduz a insatisfação da população, exigindo uma melhor gestão e aplicação dos recursos.

Naqueles municípios em que não há presença de uma entidade específica para os serviços de saneamento, a situação é crítica, pois não há o atendimento à obrigação básica de tratamento da água, sendo que sua ausência contribui efetivamente para a baixa qualidade de vida da população. Entretanto, devido a aspectos culturais e econômicos a inserção do tratamento não é discutida, pois não há reinvindicação da população, sendo em alguns casos até recusado. Entretanto, o estudo mostrou que a disposição a pagar mais pela melhoria dos serviços públicos de água e esgoto é aceita pela maioria da população.

Conclui-se ainda que a presença de uma entidade reguladora seria fundamental, uma vez que o equilíbrio entre o valor cobrado e a qualidade dos serviços é essencial para a satisfação do usuário. Apesar das práticas culturais relacionadas à água, como a rejeição a cloração, observadas em alguns municípios, a entidade prestadora do serviço deve garantir a saúde pública, que precisa ser desvinculada do âmbito político, havendo uma interação entre as entidades ligadas ao saneamento básico a fim de buscar um efetivo planejamento e aplicação de recursos favoráveis à salubridade ambiental.

A deficiência de capacidade técnica é outro fator que inviabiliza a manutenção e a inserção de melhorias nos serviços conforme a demanda de cada município, necessitando de contratação de novos técnicos e a capacitação dos existentes. É necessária uma maior atuação do poder público nesses municípios, por meio de fiscalizações e investimentos em ações e serviços de saneamento básico, buscando o cumprimento da legislação e o alcance da qualidade de vida da população, assim como a garantia da satisfação quanto aos serviços prestados. 


\section{AGRADECIMENTOS}

À Fundação de Amparo à Pesquisa do Estado de Goiás (Fapeg), pelo apoio financeiro concedido para a realização desse projeto. Processo $n^{\circ} 201010267000775$, relativo ao edital $003 / 2010$.

\section{REFERÊNCIAS}

ASSOCIAÇÃO BRASILEIRA DE AGÊNCIAS DE REGULAÇÃO - ABAR. Saneamento Básico - Regulação 2013. Fortaleza: Expressão Gráfica e Editora, 2013. 92p.

ASSOCIAÇÃO BRASILEIRA DE NORMAS TÉCNICAS - ABNT. NBR 13.969: 1997. Tanques sépticos - Unidades de tratamento complementar e disposição final dos efluentes líquidos - Projeto, construção e operação. Rio de Janeiro, 1997.

AGUIAR, M. M.; HELLER, L.; MELO, E. M. Ação comunicativa na gestão de um serviço privatizado de água e esgotos: uma avaliação em Cachoeiro de Itapemirim (ES). Revista de Administração Pública, v. 46, n. 6, p. 1505-1527, 2012. http://dx.doi.org/10.1590/S0034-76122012000600005

AGÊNCIA REGULADORA DE SANEAMENTO E ENERGIA DO ESTADO DE SÃO PAULO - ARSESP. Pesquisa de satisfação dos usuários residenciais dos serviços de água e esgoto de municípios do estado de São Paulo. 2013. Disponível em: http://www.arsesp.sp.gov.br/ResultadoPesquisaSatisfacaoArquivo/Jales.pdf. Acesso em: 17 out. 2014.

BRASIL. Lei $\mathrm{n}^{\circ} 11.445$, de 5 de janeiro de 2007. Estabelece diretrizes nacionais para o saneamento básico; altera as Leis nos 6.766, de 19 de dezembro de 1979, 8.036, de 11 de maio de 1990, 8.666, de 21 de junho de 1993, 8.987, de 13 de fevereiro de 1995; revoga a Lei no 6.528, de 11 de maio de 1978; e dá outras providências. Diário Oficial [da] União, Brasília, 08 jan. 2007.

BRASIL. Ministério da Saúde. Portaria no 2914, de 12 de dezembro de 2011. Dispõe sobre os procedimentos de controle e de vigilância da qualidade da água para consumo humano e seu padrão de potabilidade. Diário Oficial [da] União, Brasília, 14 dez. 2011.

BRASIL. Ministério das Cidades. Secretaria Nacional de Saneamento Ambiental. Sistema Nacional de Informações sobre Saneamento. 2013. Disponível em: http://www.snis.gov.br/PaginaCarrega.php?EWRErterterTERTer=4. Acesso em: 17 maio 2013.

BRITTO, A. L. N. P.; LIMA, S. C. R. B.; HELLER, L.; CORDEIRO, B. S. Da fragmentação à articulação: a política nacional de saneamento e seu legado histórico. Revista Brasileira de Estudos Urbanos e Regionais, v. 14, n. 1, p. 65-83, 2012.

GALVÃO JUNIOR, A. C. Desafios para a universalização dos serviços de água e esgoto no Brasil. Revista Panamericana Salud Publica, v. 25, n. 6, p. 548-56, 2009. http://dx.doi.org/10.1590/S1020-49892009000600012

GAlVÃO JUNIOR, A. C.; PAGANINI, W. S. Aspectos conceituais da regulação dos serviços de água e esgoto no Brasil. Engenharia Sanitária e Ambiental, v. 14, n. 1, p. 70-88, 2009. http://dx.doi.org/10.1590/S1413-41522009000100009 
GONZÁLEZ-GÓMEZ, F.; GARCÍA-RUBIO, M. A.; GONZÁLEZ, J. M. Beyond publicprivate controversy in urban water management in Spain. Utilities Policy, v. 31, p. 1-9, 2014. http://dx.doi.org/10.1016/j.jup.2014.07.004

HARUTYUNYAN, N. Metering drinking water in Armenia: the process and impacts. Sustainable Cities and Society, v. 14, n. 1, p. 352-358, 2014. http://dx.doi.org/10.1016/j.scs.2014.05.014

HELlER, L.; COUTINHO, M. L.; MINGOTI, S. A. Diferentes modelos de gestão de serviços de saneamento produzem os mesmos resultados? Um estudo comparativo em Minas Gerais com base em indicadores. Engenharia Sanitária e Ambiental, v. 11, n. 4, p. 325-336, out./dez. 2006. http://dx.doi.org/10.1590/S1413-41522006000400005

HOLT, L. Utility service quality - telecommunications, electricity, water. Utilities Policy, v. 13, n. 3, p. 189-200, 2005. http://dx.doi.org/10.1016/j.jup.2004.08.003

INSTITUTO BRASILEIRO DE GEOGRAFIA E ESTATÍSTICA - IBGE. Censo demográfico - características da população e dos domicílios. 2010. Disponível em: http://censo2010.ibge.gov.br/apps/atlas/. Acesso em: 24 set. 2014.

LUIZ, A. J. B.; FORMAGGIO, A. R.; EPIPHANIO, J. C. N.; ARENAS-TOLEDO, J. M.; GOLTZ, E.; BRANDÃO, D. Estimativa amostral objetiva de área plantada regional, apoiada em imagens de sensoriamento remoto. Pesquisa Agropecuária Brasileira, v. 47, n. 9, p. 1279-1287, 2012. http://dx.doi.org/10.1590/S0100-204X2012000900013

NETTO, S. P.; SANQUETTA, C. R. Ganhos de precisão na alocação ótima em estratificação volumétrica de florestas naturais e plantações florestais. Floresta, v. 27, n. 12, p. 71-82, 1997. http://dx.doi.org/10.5380/rf.v27i12.2302

NEUMANN, B.; CALMON, A. P. S.; AGUIAR, M. M. Aplicação do ISA e Diagrama de Pareto como ferramentas de gestão do loteamento Lagoa Carapebus. Latin American Journal of Business Management, v. 4, n. 1, p. 44-65, 2013.

NEYMAN, J. On the two different aspects of the representative method: the method of stratified sampling and the method of purposive selection. Journal of the Royal Statistical Society, v. 97, n. 4, p. 558-625, 1934.

ROSSI, C. A. V.; SLONGO, L. A. Pesquisa de satisfação de clientes: o estado-da-arte e proposição de um método brasileiro. RAC. Revista de Administração Contemporânea, v. 2, n. 1, p. 101-125, 1998. http://dx.doi.org/10.1590/S141565551998000100007

YUE, D.; TANG, S. L. Sustainable strategies on water supply management in Hong Kong. Water and Environment Journal, v. 25, n. 2, p. 192-199, 2011. http://dx.doi.org/10.1111/j.1747-6593.2009.00209.x

WILLIS, K. G.; SCARPA, R.; ACUTT, M. Assessing water company customer preferences and willingness to pay for service improvements: a stated choice analysis. Water Resources Research, v. 41, n. 2, p. 1-11, 2005. http://dx.doi.org/10.1029/2004WR003277 


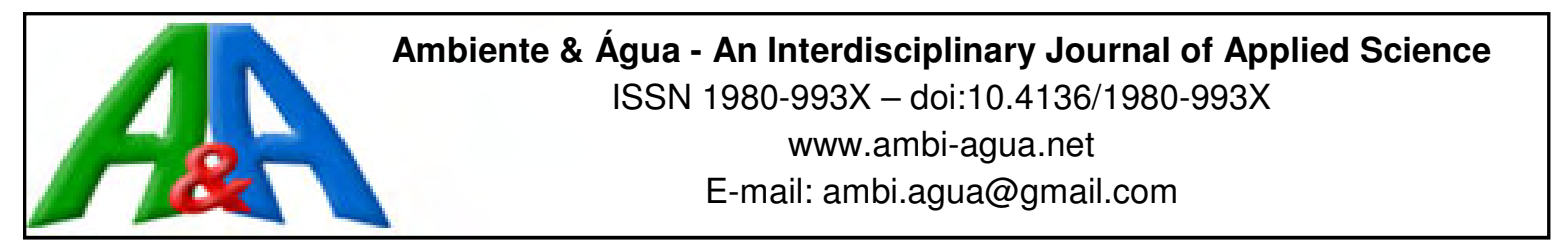

\title{
A Dinâmica entre as águas e terras na Amazônia e seus efeitos sobre as várzeas
}

\author{
doi:10.4136/ambi-agua.1805
}

Received: 16 Nov. 2015; Accepted: 29 Mar. 2016

\author{
Sandra Helena Silva*; Sandra Nascimento Noda \\ Universidade Federal do Amazonas(UFAM), Manaus, Amazonas, Brasil \\ Centro de Ciências do Ambiente \\ *Autor correspondente: e-mail: sandrahsf@gmail.com, \\ snoda@ufam.edu.br
}

\section{RESUMO}

As águas e terras na Amazônia, com destaque rio Solimões/Amazonas, apresentam uma dinâmica própria, re-criando as paisagens a cada movimento do rio em todo seu trajeto. São terras caídas, transportadas e deixadas pelas águas, desencadeando mudanças no modo de vida dos povos varzeanos. Soma-se a esse movimento as recentes mudanças climáticas, sob os efeitos do fenômeno El Niño, intensificando as transformações nas várzeas. Essa é uma pesquisa quanti e qualitativa, indicando o valor dos saberes, para a compreensão do ambiente vivenciado. Foi o entendimento do sistema ambiental das Ilhas e a percepção de dezessete mulheres cultivadoras das várzeas amazônicas, acoplados ao suporte teórico-metodológico que possibilitou a reflexão e concretização dessa pesquisa. As Ilhas abordadas foram a do Valha-me-Deus e Chaves, ambas situadas em Juruti, PA. Esse estudo teve por objetivo identificar a dinâmica entre as águas e as terras no rio Amazonas, a associação desses componentes para a re-criação de Ilhas fluviais e os efeitos das mudanças climáticas sobre as várzeas. Os dados indicaram transformações significativas nos sistemas ambientais pesquisados, com perdas irreversíveis nos cultivos de espécies alimentares como as espécies de mamão, mandioca, cacau e banana, especialmente após as intensas cheias do rio a partir do ano de 2009.

Palavras-chave: clima, El Niño, ilhas fluviais.

\section{The effects on Amazon floodplains of the dynamics between the water and land}

\begin{abstract}
Waters and lands in the Amazon, especially near the Solimões/Amazonas Rivers, are very dynamic, recreating the landscapes along the rivers' paths. The waters transport and deposit eroded materials, causing changes in the lifestyles of the meadow's residents. In addition to this, there are the recent climatic changes caused by the El Niño phenomenon, intensifying the meadows' transformations. This research explored the quantitative and qualitative values of knowledge of local people in order to understand the environment in which they live. With an understanding of the islands' environmental system and the perceptions of seventeen female farmers of the amazon meadow, coupled with appropriate
\end{abstract}


theory and methods, it was possible to explore and execute this research. Valha-me-Deus and Chaves, both in the county of Jurupis, PA, were the islands chosen for the study. The goal of the study was to characterize the dynamics of the waters and lands of the Amazon River together with the re-creation of the river islands and the effects of climate change over the floodplains. The data show meaningful changes in the studied environmental systems, resulting in irreversible losses in the cultivation of food crops such as papaya, cocoa, manioc and bananas, especially after the intense river flooding of 2009.

Keywords: El Niño, fluvial islands, weather.

\section{INTRODUÇÃO}

O objetivo dessa pesquisa foi caracterizar a dinâmica entre as águas e as terras no rio Amazonas na re-criaçao das ilhas fluviais do Valha-me-Deus e Chaves - Juruti, PA e os efeitos das mudanças climáticas sobre essas áreas de várzea para se compreender como se conserva a vida nesses ambientes.

As águas na Amazônia representam um dos mais importantes vetores de transformação da superfície terrestre, em seu regime fluvial altera física e quimicamente rochas, transportando, por meio da gravidade, partículas em suspensão e sais minerais para os fundos dos vales, lagos, mares e oceanos. Três por cento da água existente no planeta é água doce corrente e um quinto dessa água é resultante da descarga do rio Solimões/Amazonas no oceano Atlântico (Pacheco et al., 2012; Nobre, 2014).

As águas e as terras possuem uma relação de circularidade na Amazônia. As primeiras são responsáveis pelos transportes de sedimentos provenientes de processos de erosão marcantes para formação e transformação das paisagens por todo trajeto do rio Solimões/Amazonas. $\mathrm{O}$ valor das águas está na sua contribuição para manutenção na vida de diversas espécies vegetais, animais, humanas e pela produção de um solo fértil, rico em nutrientes como os encontrados nos agroecossistemas de várzeas. Os materiais e organismos componentes dos solos dependem do movimento e das propriedades das águas amazônicas conduzidas nos pulsos de inundação (Junk et al., 2010) e dependentes das características de seu escoamento.

O Rio em sua trajetória recebe diversas denominações. Em terras brasileiras é reconhecido como rio Solimões, seguindo com este nome até a confluência com o rio Negro nas proximidades da cidade de Manaus, capital do Amazonas. Em sua trajetória à jusante, em direção ao Baixo Amazonas, passa a ser chamado de rio Amazonas, percorrendo em território brasileiro um total de $2.921 \mathrm{~km}$, até desembocar no oceano Atlântico. O volume de água do rio Amazonas despejado neste oceano é pouco mais de 17 bilhões de toneladas métricas ao dia (Nobre, 2014, p. 12).

As várzeas sistemas ambientais dessa pesquisa são banhadas pelos rios de água branca (cor amarela ou turva), também, reconhecida como barrenta. São sujeitas às inundações e uma intensa atividade de sua tríade (erosão, transporte, deposição) (Pacheco et al., 2012). Nessa tríade estão imbricados os processos de erosão ao longo da bacia do rio Solimões/Amazonas, conhecidos como terras caídas - o transporte de sedimentos, materiais orgânicos e nutrientes, os quais são depositados ao longo de seu trajeto, ampliando as dimensões das terras.

As várzeas recriam-se periodicamente, em sua própria organização, pela manutenção da vida, possuem uma estrutura e organização próprias, as quais são resultantes do acoplamento estrutural (Maturana e Varela, 2001, p.115), entre as unidades das águas, terras, vegetações e ações antrópicas. Toda unidade organizacional no ambiente varzeano seja biótico ou abiótico desencadeiam transformações estruturais e profundas, numa dinâmica de re-organização permanente, para a conservação da vida, uma verdadeira ontogenia. 
Ao longo do trajeto do rio Solimões/Amazonas, segue-se a dinâmica de perdas (terras caídas) e ganhos (novas terras), em um movimento de circularidade, entre a água e a terra. Neste processo, cada ecossistema depende diretamente dos demais no sistema ambiental, não havendo um todo sozinho, mas um todo de diversas partes associadas e interdependentes.

Para Pacheco et al. (2012, p. 543) "[...]o rio Solimões/Amazonas é o principal canal coletor de águas da maior e mais volumosa bacia hidrográfica do mundo." Esse rio ao modelar o relevo fluvial durante seu percurso promove modificações frequentes nas paisagens das áreas de várzeas, ora erodindo-as ora sedimentando-as. Por meio dessa dinâmica o processo fluvial do rio vai deixando bancos dentríticos podendo formar ilhas fluviais, ecossistemas de várzeas, onde os seres humanos passam a interagir com seu sistema ambiental.

Águas, terras, vegetações e seres humanos em conexão contribuem para a formação das paisagens amazônicas. Os seres antrópicos com suas interferências no ambiente, como o desmatamento, as queimadas, criações de áreas de agricultura e pecuária, de moradias, tem transformado substancialmente a estrutura do sistema ambiental amazônico.

\section{MATERIAL E MÉTODOS}

Para responder aos objetivos propostos tem-se como aporte teórico o paradigma dialético da complexidade sistêmica (Morin, 2008), por este oportunizar uma melhor compreensão dos seres bióticos e abióticos com o sistema ambiental, por meio de um circuito recursivo. Os humanos como seres bio-sócio-culturais em total interação com o sistema ambiental, indicando o movimento de associação, complementariedade e antagonismos entre o todo e as partes.

A análise de conteúdo teve como fundamento os estudos de Bardin (2011, p.15) e Guerra (2010, p.62). Para Bardin (2011, p.15), a análise de conteúdo é um instrumento metodológico aplicado a discursos (conteúdos e continentes) diversificados, oscila entre os polos da objetividade, podendo os discursos serem transformados numericamente, e o polo da subjetividade, valorando os dísticos dos informantes da pesquisa como dados qualitativos fundamentais para a interpretação e compreensão do real. Para Guerra (2010, p.16-62), a análise de conteúdo possibilita o mergulho em universos sistêmicos e complexos, apresenta uma dimensão descritiva e interpretativa.

O delineamento deste estudo foi projetado por meio do estudo de caso múltiplo. Esse possibilitou uma investigação descritiva e analítica sobre as características holísticas das experiências vividas pelas cultivadoras (Yin, 2015). Essas foram sendo selecionados primeiro como tendo uma associação práxica com os agroecossistemas pesquisados; seguindo da aplicação da lógica da replicação das informações, até a saturação das mesmas, indicando o quanto quantitativa e qualitativamente os dados eram suficientes para uma análise robusta dos resultados, dando validade aos mesmos tanto teórica como metodologicamente. A etapa da saturação dos dados apresentou-se no processo de coleta de forma singular, indicando ao pesquisador que os dados e o tempo de coleta já foram suficientes para prosseguir para uma nova etapa, a análise dos dados.

Assim foram participantes dessa pesquisa dezessete mulheres, oito na Ilha do Valha-meDeus, e nove na Ilha do Chaves, cultivadoras de uma diversidade de espécies alimentares e não alimentares e criadoras de pequenos animais. A práxis produtiva nos agroecossistema foi o principal critério para inclusão das cultivadoras na pesquisa, nas Ilhas do Valha-me-Deus e Chaves. As mulheres nas Ilhas pesquisadas executam hoje uma série de atividades produtivas, para auferir renda monetária, costuram, comercializam produtos diversos, prestam serviços nas esferas públicas, mas associadas a agricultura somente algumas se destacam. E essa associação era um elemento fundamental para o alcance dos objetivos propostos. 
O estudo de casos múltiplos oportunizou uma liberdade na escolha e uso de técnicas e instrumentos diversos os quais foram compondo cada etapa da pesquisa de campo, tendo ocorrido no período de março de 2014 a junho de 2015. Desta forma, foram utilizadas entrevistas formais com roteiro de perguntas e entrevistas informais; observação sistemática e diário de campo. Os dados foram analisados quanti e qualitativamente, a partir dos resultados dos dísticos proferidos pelas cultivadoras. Na literatura referente ao clima na Amazônia foram coletados dados e fontes para corroborar ou refutar as percepções das cultivadoras quanto as recentes transformações no sistema ambiental.

As Ilhas do Valha-me-Deus e Chaves, são duas das duzentos e quatorze comunidades rurais pertencentes ao munícipio de Juruti, PA. Estão localizadas a jusante do rio Amazonas, leste do Estado do Amazonas e oeste do Estado do Pará, e são banhadas em todas as suas extremidades por esse rio (Figura 1). As ilhas são áreas lacustres, possuindo uma diversidade de lagos, fundamentais para garantir a sobrevivência das unidades familiares nessas ilhas. $\mathrm{Na}$ ilha do Valha-me-Deus residem 213 pessoas, distribuídas em 65 famílias. Na ilha do Chaves residem 182 pessoas organizadas em 37 famílias.

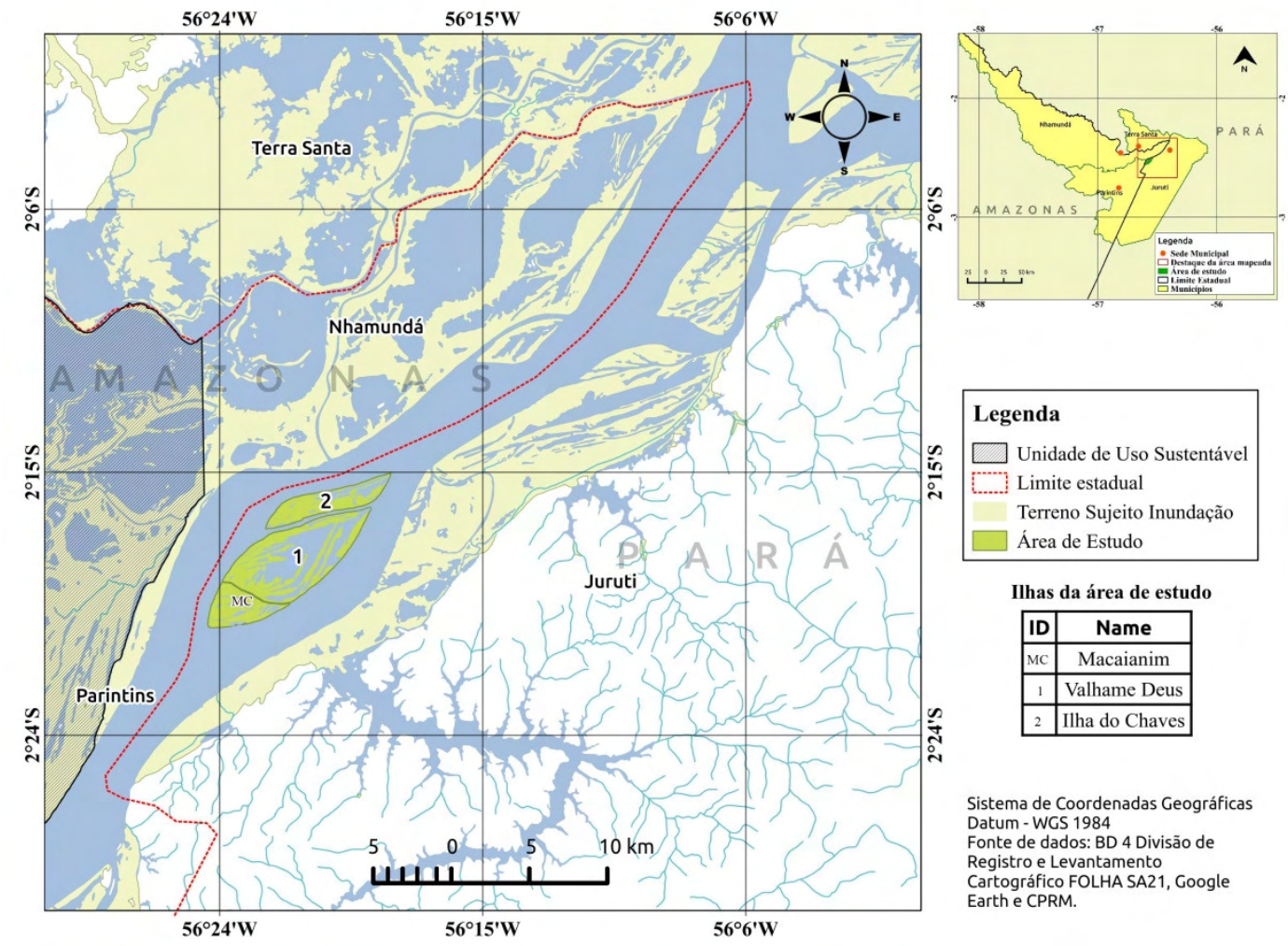

Figura 1. Área de estudo - ilhas 1) Valha-me-Deus e 2) Chaves, Juruti, PA.

Foram coletados dados relativos aos índices pluviométricos e fluviométricos no Estado do Amazonas. Optou-se por esse Estado visto as Ilhas pesquisadas se localizarem na divisa estadual entre o Amazonas e Pará, estando mais próximas ao primeiro. Em relação aos dados pluviométricos foram utilizados dados da estação meteorológica do município de Parintins, AM que se localiza próximo às ilhas (Figura 1). Quantos aos índices fluviométricos foram utilizados dados tanto dos Portos de Manaus, como Parintins, AM, sendo esses os municípios onde há um registro oficial dos índices de volume das águas do rio Negro e Amazonas.

Entendem-se as ilhas do Valha-me-Deus e Chaves como um sistema ambiental, constituído por uma diversidade de unidades agrícolas e criatórias fundamentais para garantir a sobrevivência das unidades familiares. Essas unidades estão em continua interação com o 
todo do sistema ambiental das ilhas, apresentando uma relação de associação, complementariedade e antagonismo entre as partes e o todo.

\section{RESULTADOS E DISCUSSÃO}

\subsection{A sazonalidade amazônica e o ambiente das Ilhas do Valha-me-Deus e Chaves}

Uma grande preocupação das mulheres nas ilhas pesquisadas é em relação ao clima amazônico, o volume das águas trazidas pelas chuvas e cheias do rio. Observam o clima, atentam aos índices meteorológicos pela rede midiática e utilizam suas próprias ferramentas para medir o nível das águas. Fazem suas marcas com o terçado nas bases de sustentação da casa e observam o movimento da natureza.

Não necessariamente o volume dos índices pluviométricos irá determinar os índices fluviométricos no baixo Amazonas, visto esta região sofrer influências das precipitações da bacia hidrográfica amazônica. Para Fraxe et al. (2007, p.15), a falta de sincronização entre o regime fluvial e pluvial contribui para a existência de um pulso de inundação das águas nos ecossistemas de várzea, as quais vão regular o calendário da produção agrícola.

A bacia amazônica é a mais extensa rede hidrográfica do globo terrestre; é limitada a oeste pela Cordilheira dos Andes, a norte pelo Planalto das Guianas, ao sul pelo Planalto Central e a leste pelo Oceano Atlântico (Fisch et al., 1998, p.101). A sazonalidade e abundância das precipitações na região dos Andes influencia o nível das águas nos rios Solimões/Amazonas, por produzir uma flutuação anual, regular e de grande amplitude.

A Região Amazônica apresenta, em relação ao clima, uma alta umidade relativa atmosférica, grande índice de nebulosidade, precipitações abundantes e temperaturas médias altas. A precipitação é uma das variáveis climáticas de maior importância quando se analisa a Região Amazônica, pois esta interfere nas demais características como: a temperatura, a umidade relativa e o vento. A precipitação na área de captação do rio Solimões/Amazonas é fundamental para a sua descarga (Junk, 1980, p.781).

Para Fisch et al. (1998, p.102), a Região Amazônica tem uma precipitação anual média de $2.300 \mathrm{~mm} / \mathrm{ano}$, embora tenha regiões na fronteira com o Brasil, como a Colômbia, Venezuela, onde o total anual pode atingir até $3.500 \mathrm{~mm}$. No noroeste do Estado do Amazonas, na região conhecida como "Cabeça do Cachorro", é onde ocorrem as maiores precipitações em torno de $3.600 \mathrm{~mm} / \mathrm{ano}$. No norte, até além do Médio e Baixo Amazonas, há uma faixa mais pobre em chuvas, ficando, em certos, anos abaixo de $2.000 \mathrm{~mm} / \mathrm{ano}$.

As mudanças climáticas mais recentes, resultantes dos desmatamentos, queimadas na floresta amazônica, além do aquecimento global, tem afetado diretamente o clima na Região. O clima ressalta Nobre (2014, p.26), interage com a vegetação, e ao alterar um, ao outro tende a sofrer mudanças em retroalimentação positiva (desestabilizando) ou negativa (estabilizando) até o surgimento de um novo equilíbrio.

A floresta e os rios amazônicos têm um valor central para a manutenção das precipitações por meio do oceano verde. Este seria como um rio aéreo, sendo alimentado pelo conjunto das árvores, as quais bombeiam do solo e transpiram diariamente mais de vinte bilhões de toneladas de água para a atmosfera (Nobre, 2014, p.12), contribuindo na formação das nuvens e precipitações a serem distribuídas para todo continente. Além de conectar regiões doadoras de umidade com outras receptoras de umidade, indicando o valor ambiental das florestas a montante.

Nos últimos quarenta anos, a floresta amazônica, a cabeceira das águas atmosféricas (Nobre, 2014, p. 10), foi refém de inúmeros ataques antrópicos como o desmatamento e as grandes queimadas para exploração madeireira, abertura de áreas de pastagens e agricultura, gerando desastres naturais ligados a anomalias tanto por excessos (de chuva, calor, ventos) como por falta (secas). 
Esse processo de degradação da natureza esteve associado a uma concepção de mundo pré-dado, em relação à experiência humana e promotora de uma mentalidade extrativista, hierárquica e separatista entre o ser humano e ambiente (Mariotti, 2001, p.7).

Destaca-se, ainda, no clima da bacia amazônica as influências dos fenômenos El Niño $e$ La Niña, repercutindo na região do Baixo Amazonas. Os episódios de El Niño mais recentes ocorreram em 2009, 2010; La Niña em 2008, de acordo com os dados do CPTEC-INPE (2015). Segundo as analises desse Centro os modelos de previsão climática sazonal afirmam a ocorrência desse fenômeno até o final do verão de 2015/2016.

Quando ocorre um El Niño há um aquecimento anômalo das águas superficiais do Pacífico Equatorial Oriental. O mesmo tem duração típica de doze a dezoito meses e reaparece em intervalos de dois a sete anos. Este fenômeno ocorre pela forte influência da alteração do regime dos ventos alísios sobre o Oceano Pacífico. As nuvens que normalmente produzem chuvas abundantes na parte oeste do Oceano Pacífico, próximo à Indonésia, movimentam-se para leste, para o Pacífico Central, e, em seguida, para a costa oeste da América do Sul, trazendo chuvas para toda região da bacia amazônica. As maiores precipitações ocorrem a oeste da Amazônia e maiores secas na parte leste da Região (Oliveira, 2001).

La Niña é um fenômeno contrário ao El Niño, resfriamento das águas superficiais no Pacífico Equatorial Central e Leste. Em sua dinâmica começa a se desenvolver no início do ano, atinge sua intensidade máxima no final desse e se dissipa em meados do ano seguinte. Entre seus efeitos há um maior volume de chuvas no nordeste brasileiro e no leste da Amazônia. (Oliveira, 2001).

Os dados organizados e apresentados na Figura 2 sobre os índices pluviométricos de 2013 e 2014 indicam este movimento.

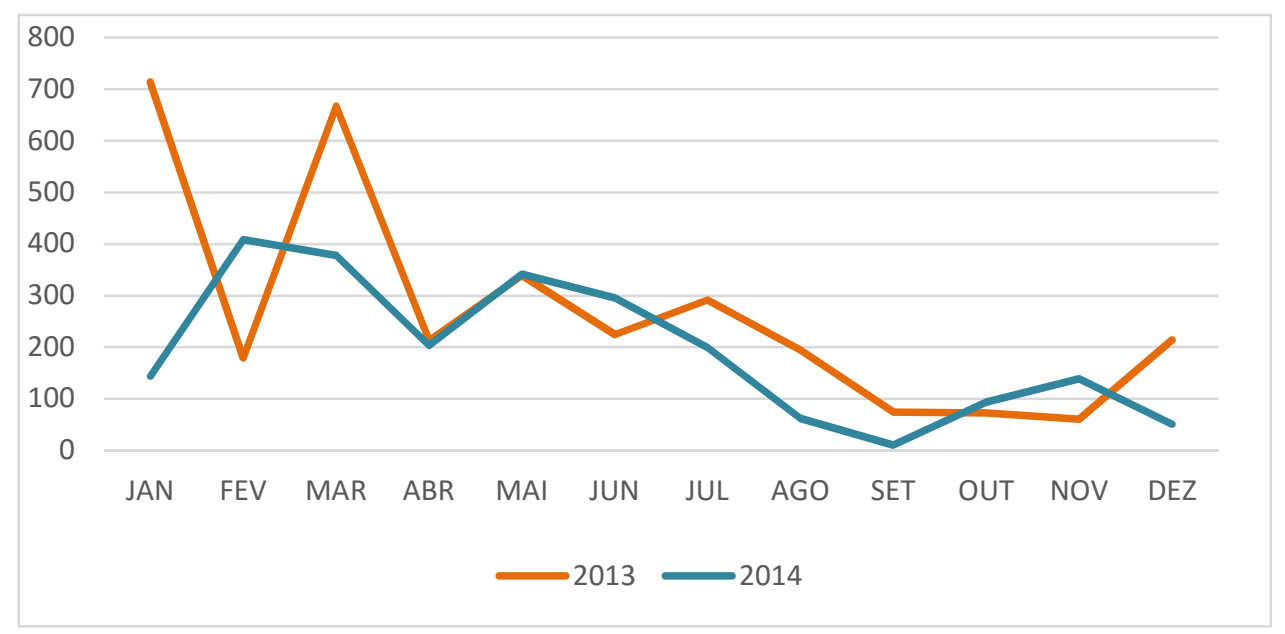

Figura 2. Índice Pluviométrico mensal (mm). Parintins, AM. 2013/2014.

Fonte: Estação Meteorológica de Parintins, AM, 2014.

No ano de 2013, a Bacia Amazônica estava sobre influência do fenômeno La Niña, trazendo chuvas intensas para esta região, registrando na Estação Meteorológica de Parintins, AM uma precipitação total de $3.244 \mathrm{~mm}$. A precipitação na bacia Amazônica pode variar entre 1.800 e $3.000 \mathrm{~mm} / \mathrm{ano}$, na cabeceira do rio Amazonas, chega a valores acima de $5.000 \mathrm{~mm} / \mathrm{ano}$, chegando a Manaus pode variar em torno de $2.100 \mathrm{~mm} / \mathrm{ano}$ (Junk, 1980).

Em 2014, o total de $2.328 \mathrm{~mm} /$ ano de precipitações indica uma substancial redução nesse índice quando comparado a 2013. Infere-se essa ocorrência devido à influência do fenômeno El Niño, como aponta os estudos de Nobre (2014) e Val et al.(2010), contribuindo para maiores precipitações nas cabeceiras dos rios amazônicos e um aumento no índice 
fluviométrico por todo trajeto do rio Solimões/Amazonas, alagando as várzeas, os beiradões, as ilhas e cidades.

Relacionando os dados da estação meteorológica de Parintins, AM (Figura 2), com o índice fluviométrico (Figura 3) e os dados do CPTEC/INPE, identifica-se, em 2009, um ano recorde nas cheias dos rios amazônicos, sendo um ano de influência do fenômeno El Niño. Os estudos de Val et al. (2010, p. 100) atestam o quanto as mudanças climáticas têm afetado a Amazônia, com a ampliação dos efeitos do fenômeno El Niño e La Niña e a previsão de diminuição significativas de chuvas na parte leste e nos bordos da bacia.

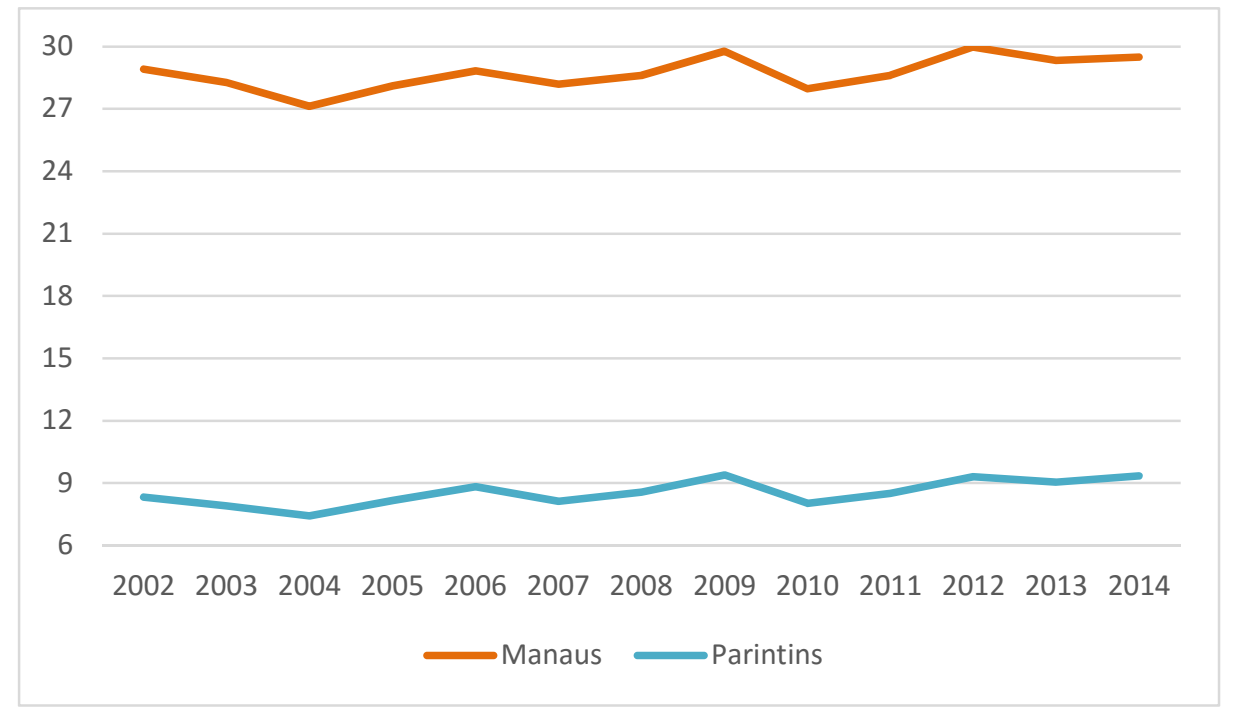

Figura 3. Índice Fluviométrico (m) no município de Manaus e Parintins, AM no período de 2002 a 2014.

Fonte: Dados coletados pelos autoresnos Portos de Manaus e Parintins, AM em 2014.

Os estudos de Junk et al. (2010, p.535), em relação as mudanças climáticas, indicam o quanto as áreas úmidas costeiras serão afetadas pela subida do nível do mar, além do aumento da incidência das queimadas; os pequenos igarapés e áreas alagáveis poderão sofrer excessivas secas, trazendo consequências drásticas para a fauna e a flora; e, por fim, que as áreas de cerrado poderão experimentar impactos significativos de amplitude, afetando negativamente a biodiversidade desses locais.

Os processos de ocupação nas férteis áreas de várzeas ocasionou uma crescente demanda por madeira, resultando em uma acelerada destruição das florestas de várzea. Hoje, as florestas inundáveis estão entre os tipos de florestas mais ameaçadas do mundo (Junk e Piedade, 2010, p.4-5). A pressão humana nessas áreas está aumentando, devido à contínua exploração da madeira, a agricultura, a formação de pastagem, habitações e a construção de infraestruturas, como as construções de reservatórios, diques, estação de captação de água.

As cultivadoras entendem a lentidão da vazante como reflexo da sazonalidade e das mudanças climáticas e essas como sendo consequência dos desmatamentos. Informam sobre os períodos antecedentes aos dos desmatamentos nas ilhas, nesses não havia problemas de enchente. Entretanto, com a implantação de pastagem, campos abertos os efeitos começaram a aparecer nas ilhas. A cultivadora Dona V.B.S., (79 anos, Ilha do Chaves, 2014), destacou a presença da espécie arbórea - cedro (Caducifólia), sendo essa extinta na Ilha. No período de sua infância, tem a lembrança de homens retirando as madeiras da floresta, na Ilha do Chaves, para comercialização.

Os episódios mencionados fazem-nos refletir sobre a complexidade do sistema ambiental. Há uma total e profunda interdependência entre os ventos, as águas dos oceanos, 
dos rios, das florestas, da atmosfera, determinando e ditando a dinâmica de todos os demais sistemas compostos no ambiente, como o humano. Como já afirmava o anatomista suíço em 1912, citado em Sioli (2006, p. 291), na Amazônia tudo está conectado, o vento, a planície, a floresta e a água agem todos juntos e sofrem influências um do outro.

Volumes de águas pluviométricas e/ou fluviométricas serão influenciados pelas mudanças climáticas de todo planeta, não podendo deixar de negar as fortes pressões antrópicas ocorridas no desenvolvimento da sociedade "civilizada" capitalista, influenciadoras dessas mudanças climáticas. Destacam-se os desmatamentos ocorridos na floresta amazônica, em 2004 contabilizou-se um total de $663 \mathrm{mil} / \mathrm{km}^{2}$, em anos mais recentes, o total de desmatamento acumulado até 2013 chegou a $762.979 \mathrm{~km}^{2}$. Nesse processo de destruição e degradação da floresta superior a $60 \%$ de sua cobertura, tem-se uma substancial mudança nas características estruturais, ecológicas e fisiológicas, repercutindo em inúmeras consequências ambientais para todo planeta (Nobre, 2014, p. 24).

Os discursos proferidos pelas cultivadoras indicam a associação dessas com o sistema ambiental das ilhas. Afirmam observar a direção dos ventos e das chuvas, para se prevenirem contra uma maior enchente. Quando estes vêm da região de Parintins significa a ocorrência de maiores chuvas e cheias do rio; ao vir da região de Juruti Velho, as chuvas rápidas acompanhadas de ventanias, com temperaturas mais baixas, indicam o início da vazante. Conhecer a complexidade do clima amazônico, no que tange ao saber herdado dos antepassados, é possuir maiores condições de adaptação e sobrevida neste sistema, onde o pulsar das águas fluviais e pluviais condiciona parte do viver.

Esse conhecer sobre o clima amazônico e as transformações pertinentes a cada estação do ano expressam o conhecer adquirido no fazer cotidiano, o qual está enraizado na própria maneira do ser humano em sua unidade autopoiética. Nas estruturas dessas unidades estão contidos saberes ancestrais e aqueles adquiridos por meio das condutas culturais, os quais compõem o ser e fazer dos seres humanos, possibilitando a sua organização e manutenção no sistema ambiental (Maturana e Varella, 2001, p. 40).

Para as cultivadoras as maiores cheias ocorreram a partir de 2009, seguidas de períodos de grandes secas. Os índices fluviométricos (Figura 3) indicam essa percepção. Desde esse período, observam-se mudanças significativas no clima, no pulso das inundações (Junk, 2010) do rio Amazonas, desencadeando inúmeras consequências para os cultivadores das várzeas Amazônicas.

As cultivadoras afirmam até 2009, haver bananais (Musa spp.), cacaueiros (Theobroma cacao), mangueiras (Mangifera), mamoeiros (Carica papaya), as frutas eram fartas nas ilhas, tinham o suficiente para sobrevivência e geração de renda. $\mathrm{Na}$ atualidade sobram-lhes poucos cultivos de bananas (Musa spp.) e mangueiras (Mangifera), os cultivos de cacau e de mamão não existem mais. Os dísticos a seguir evidenciam essas mudanças.

Antes de 2009 a ilha não ia para o fundo, alguns pedaços mais baixos, os furos enchiam, mas depois de 2009 mudou muito, nunca mais teve cheia pouca. Agora todo ano vai para o fundo. Hoje fica mais cheia que antigamente, o tempo de terra é menor. (I.B.S. 25 anos - Ilha do Chaves, 2014).

Quando a água não estava invadindo muito assim, todo ano seguido, tinha muita fruta. Tinha cacau que a gente ia lá apanhar, tirava a semente e fazia o vinho. Banana também era uma época de muita fartura. Hoje tudo tem que comprar por causa da água, quando a gente nem espera, ela chega e vai derrubando tudo. Depois da cheia de 2009 tudo mudou. (L.F.B., 56 anos - Ilha do Valha-me-Deus, 2014).

$\mathrm{Na}$ ilha do Chaves a preocupação dos moradores é maior cada ano, vão seguindo o movimento das águas e terras, quanto maiores estas, mais mudanças são percebidas, tanto na altura das casas como na alteração do próprio espaço geográfico, procurando áreas mais altas, 
garantindo uma maior segurança para a família.

$\mathrm{Na}$ ilha do Valha-me-Deus o movimento do pulso de inundação das águas influenciam na altura dos assoalhos das casas, não havendo, em contrapartida, mudanças na localização das mesmas. As cultivadoras vão buscando a cada ano estratégias para sobreviverem nesse sistema ambiental em constantes e excessivas transformações em suas paisagens.

Observa-se o processo de contínua adaptação dos moradores frente às adversidades colocadas a eles pelo pulso das águas. Pergunta-se o porquê esse povo ainda se mantém nesse sistema ambiental? Entende-se a resposta como o forte sentimento topofílico (Tuan, 2012) em relação às ilhas, as quais foram ocupadas pelos seus familiares a mais de um século. Há um sentimento de pertença, de identidade comunal. Morar na ilha percebida como lugar de segurança, de maior controle do tempo e espaço, lhes permite ainda sentir-se parte de um coletivo, num contexto social contemporâneo onde tende a prevalecer o individual.

\section{CONCLUSÃO}

Essa pesquisa não tem a pretensão de fazer uma análise totalitária sobre as influências das mudanças climáticas sobre as várzeas amazônicas, mas sim dar voz as cultivadoras das ilhas do Valha-me-Deus e Chaves - Juruti, PA, sobre suas percepções referentes às transformações ambientais vividas em anos recentes, mas precisamente pós 2009. Os dados dessa pesquisa, assim como os enunciados teóricos, indicaram a intrínseca associação entre os diversos componentes do sistema ambiental, a fauna, flora, os seres humanos e as influencias do clima não só na Amazônia, mas em todo planeta. Evidenciam recentes mudanças climáticas promovidas pelas ações antrópicas, desencadeando uma tendência no aumento do pulso das inundações do rio Solimões/Amazonas e significativas perdas para as unidades agrícolas e criatórias das unidades familiares das várzeas pesquisadas.

As cultivadoras apresentaram em seus discursos uma preocupação com a intensidade do pulso das inundações, exigindo novas estratégias para sobreviverem nesse ambiente tão incerto, desencadeado pelas mudanças climáticas no planeta. Entre as estratégias está a prática da agricultura na terra firme, a execução de atividades produtivas diversas, caracterizando a pluriatividade.

As casas nos sistemas ambientais pesquisados são invadidas pelas águas por três a quatro meses ao ano, o tempo para plantar está ficando mais curto, e as águas do rio durante as cheias eliminaram a possibilidade de uma série de cultivos alimentares, os quais não resistem ao pulso das inundações e o tempo de permanência da lamina da água. Os agricultores das várzeas têm passado por uma reconstrução cultural, o seu acervo imaterial e material adquirido ao longo das gerações já não lhe dão condições para se adaptar aos efeitos das mudanças climáticas, os quais têm degradado não só o sistema ambiental, mas toda e qualquer possibilidade para a realização de um viver mais sustentável.

\section{REFERÊNCIAS}

BARDIN, L. Análise de conteúdo. 70. ed. São Paulo: Martins Fontes, 2011.

CÁUPER, G. C. de B. (Org). Biodiversidade Amazônica. Manaus: CCPA, 2006.

FISCH, G.; MARENGO, J.; NOBRE, C. Clima da Amazônia. Acta Amazônica, v. 28, n. 2, p. 101-126, 1998. http://dx.doi.org/10.1590/1809-43921998282126

FRAXE, T. de J. P.; PEREIRA, H. dos S.; WITKOSKI, A. C.. Comunidades ribeirinhas amazônicas: modos de vida e uso dos recursos naturais. Manaus: EDUA, 2007. 224 p. 
GUERRA, I. C. Pesquisa qualitativa e análise de conteúdo: sentidos e formas de uso. Cascais: Princípia, 2010.

JUNK, J. W.; PIEDADE, M. T. F. Na. Introduction to South America wetland forests: distribution, definitions and general characterization. In: JUNK, W. J.; PIEDADE, M. T. F.; WITTMANN, F.; SCHÖNGART, J.; PAROLIN, P. (Eds.). Amazonian floodplain forests: ecophysiology, biodiversity and sustainable management. Dordrecht: Springer Science, 2010.

JUNK, J. W. et al. Ecophysiology, Biodiversity and Sustainable Management of Central Amazonian Floodplain Forests: A Synthesis. In: JUNK, W. J.; PIEDADE, M. T. F.; WITTMANN, F.; SCHÖNGART, J.; PAROLIN, P. (Eds.).. Amazonian floodplain forests: ecophysiology, biodiversity and sustainable management. Editors. Springer Science, 2010.

JUNK. J. W. Áreas inundáveis: um desafio para a limnologia. Acta Amazônica, v. 10, n. 4, p. 775-795, 1980.

INSTITUTO NACIONAL DE PESQUISAS ESPACIAIS. Centro de Previsão de Tempo e Estudos Climáticos - CPTEC/INPE. Website. Disponível em: http://enos.cptec.inpe.br/. Acesso em: nov. 2015.

MARIOTTI, H. Prefácio. In: MATURANA, H.; VARELA, F. J. A árvore do conhecimento: as bases biológicas da compreensão humana. São Paulo: Palas Athena, 2001.

MORIN, E. O método 1: a natureza da natureza. 2. ed. Porto Alegre: Sulina, 2008. 479 p.

Ciência com consciência. 13. ed. Rio de Janeiro: Bertrand, 2010.

MATURANA, H.; VARELA, F. J. A árvore do conhecimento: as bases biológicas da compreensão humana. São Paulo: Palas Athena, 2001.288 p.

NOBRE, A. D. O Futuro Climático da Amazônia: relatório de avaliação científica. Articulación Regional Amazônica - ARA. São José dos Campos: CPTEC/INPE, out. 2014. 42 p.

OLIVEIRA, G. S. O El Niño e você - o fenômeno climático. In: CPTEC/INPE. Website. 2001. Disponível em: http://enos.cptec.inpe.br/. Acesso em: jun. 2014.

PACHECO, J. B.; BRANDÃO, J. C. M.; CARVALHO, J. A. L. Geomorfologia fluvial do Rio Solimões/Amazonas: estratégias do povo varzeano do sudoeste do Careiro da Várzea. Revista Geonorte, v. 2, n. 4, p. 542-554, 2012.

SIOLI, H. 50 anos de pesquisa em limnologia na Amazônia. Palestra editada por Therezinha Soares. Acta Amazônica, v. 36, n. 03, 2006. http://dx.doi.org/10.1590/S004459672006000300001

TUAN, Yi-Fu. Topofilia: um estudo da percepção, atitudes e valores do meio ambiente. Londrina: Eduel, 2012.

VAL, A. L. et al. Amazônia: recursos hídricos e sustentabilidade. In: BICUDO, C. E. M.; TUNDISI, J. G.; SCHEUENSTUHL, M. C. B. (Org.). Águas do Brasil: análises estratégias. São Paulo: Instituto de Botânica, 2010, p. 95-109.

YIN, R. K. Estudo de caso: planejamento e métodos. 5. ed. Porto Alegre: Bookman, 2015. $290 \mathrm{p}$. 


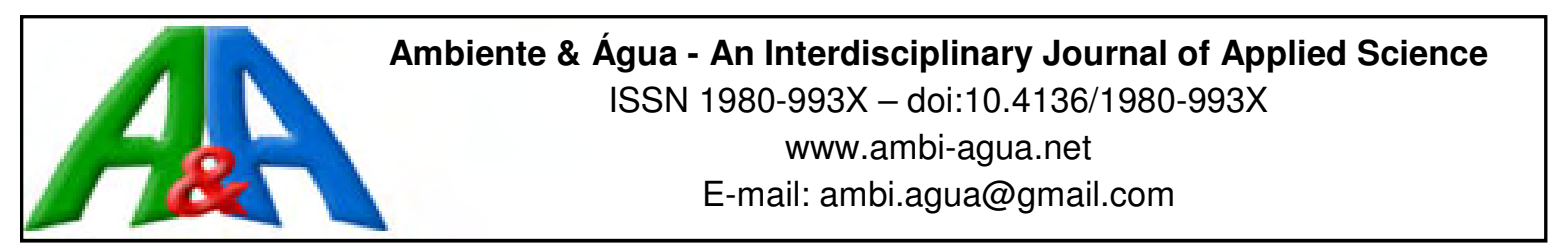

\title{
Processos oxidativos avançados: uma revisão de fundamentos e aplicações no tratamento de águas residuais urbanas e efluentes industriais
}

\author{
doi:10.4136/ambi-agua.1862
}

Received: 12 Feb. 2016; Accepted: 24 Mar. 2016

\author{
Karla Santos de Araújo ${ }^{1}$; Raissa Antonelli²; Beatriz Gaydeczka ${ }^{2}$; \\ Ana Claudia Granato ${ }^{2}$; Geoffroy Roger Pointer Malpass ${ }^{2 *}$ \\ Universidade Federal do Triângulo Mineiro (UFTM), Uberaba, MG, Brasil \\ ${ }^{1}$ Programa de Mestrado Profissional em Inovação Tecnológica \\ ${ }^{2}$ Departamento de Engenharia Química \\ *Autor correspondente: e-mail: geoffroy@icte.uftm.edu.br, \\ karla.s.araujo@gmail.com, raissaantonelli@hotmail.com, \\ biagaydeczka@gmail.com, acgmalpass.uftm@gmail.com
}

\section{RESUMO}

A contaminação de águas por espécies tóxicas ou recalcitrantes gera grandes impactos ambientais. Nesse contexto, os Processos Oxidativos Avançados (POAs), tecnologias que utilizam principalmente o radical hidroxila $\left(\mathrm{HO}^{\bullet}\right)$ para a oxidação dos poluentes, têm se destacado como métodos alternativos promissores no tratamento de águas residuais e efluentes industriais. Os POAs têm sido considerados uma estratégia eficaz do ponto de vista técnico, econômico e ambiental para a degradação de poluentes presentes em águas residuais e efluentes industriais, apesar de possuir limitações como alto custo das fontes de energia, desenvolvimento de novos materiais catalíticos de baixo custo e construção de reatores em escala real. Há uma grande relevância na aplicação desses processos em escala industrial mediante a otimização desses fatores de eficácia. Sendo assim, o objetivo deste trabalho foi realizar um levantamento bibliográfico sobre os POAs e apresentar dados a respeito da eficiência desses processos na degradação de poluentes, comparando os embasamentos teóricos e a sua aplicação industrial. Diante disso, os fundamentos e aplicações dos principais POAs (químicos, fotoquímicos, eletroquímicos, sonoquímicos, sonoeletroquímico e processos baseados em ozônio), bem como suas vantagens e desvantagens foram descritos nesta revisão da literatura.

Palavras-chave: degradação de poluentes, radical hidroxila, tratamento de efluentes.

\section{Advanced oxidation processes: a review of fundamentals and applications in the treatment of urban and industrial wastewaters}

\begin{abstract}
Contamination of water by toxic and/or recalcitrant species has great environmental impacts. In this context, Advanced Oxidation Processes (AOPs) - technologies that principally use the hydroxyl radical $\left(\mathrm{HO}^{\bullet}\right)$ for oxidation - have emerged as promising
\end{abstract}


alternatives in treating urban and industrial wastewaters. This study reviewed the literature on POAs and presented data regarding the efficiency of these processes in pollutant degradation, comparing the theoretical reasoning and its industrial applications. The fundamentals and major applications of AOPs (chemical, photochemical, electrochemical, sonochemical and ozone-based processes), as well as their advantages and disadvantages, are described in this review. AOPs have been considered an effective alternative from a technical, economic and environmental viewpoint for the degradation of pollutants in effluents and industrial wastewater, despite having limitations such as high cost of available energy sources, development of new low-cost catalytic materials and construction of full-scale reactors. It is greatly important to the industrial application of AOPs to optimize the effectiveness of these factors.

Keywords: degradation of pollutants, effluent treatment, hydroxyl radical.

\section{INTRODUÇÃO}

O descarte inapropriado de efluentes industriais e águas residuais no meio ambiente causa preocupação pública além de possíveis sanções legais, conforme legislação vigente. Adicionalmente, este problema configura um importante desafio técnico para a comunidade científica envolvida na resolução de problemas ambientais.

Os resíduos produzidos pela indústria em todos os setores são bastante diversificados na sua composição química, podem variar desde compostos inorgânicos a orgânicos, que contém poluentes tóxicos e resistentes (recalcitrantes) aos sistemas convencionais de tratamento. (Florêncio e Malpass, 2014). Tais problemas de poluição e de contaminação, provenientes especialmente da indústria química, geram um aumento das exigências ambientais, impondo a necessidade de otimização dos próprios processos industriais e o eventual descarte dos resíduos gerados.

Desde 1990, no Brasil, observou-se notável evolução e limitações legais quanto ao uso da água, e restrições para descarte de efluentes através de tratamentos até atingir os limites ideais para lançamento nos corpos d'água. Mais de 100 leis, decretos, portarias e resoluções brasileiras existem e se fazem aplicar normatizando as ações legais de estabelecimentos, indústrias e empresas perante o meio ambiente e os recursos naturais (Florêncio e Malpass, 2014).

Diversos órgãos de vários países e organizações transnacionais, têm se dedicado à recomendação de parâmetros para a utilização de esgotos sanitários e efluentes industriais. Por exemplo, a Organização Mundial da Saúde (OMS) em 2006 apresentou novas diretrizes sanitárias voltadas para o reuso de águas residuárias. As diretrizes apresentadas pela United States Environmetal Protection Agency (USEPA), e recomendadas pela OMS, têm servido de base para normas que regulam o reuso da água em outros países, tanto como cópias fieis, quanto como adaptações às situações locais. A agência de proteção ao Meio Ambiente da União Europeia (EPA) define o termo Best Available Techniques (BAT - Melhores Técnicas Disponíveis) para o tratamento de efluentes, entre os quais abre-se espaço para Emerging Techniques (Técnicas Emergentes), ou seja, técnicas inovadoras não convencionais.

Assim, diante da crescente preocupação com as questões ambientais, torna-se imprescindível o desenvolvimento de tecnologias ecologicamente corretas e economicamente viáveis para tratamento de efluentes industriais. O campo das Ciências Exatas e Engenharias dirige evidente interesse para os variados métodos de tratamento de águas residuais, tendo como alvos específicos a eficiência na remoção e na degradação dos compostos prejudiciais cumprindo os limites legais estabelecidos e a redução dos custos de instalação e operação para atrair os setores industriais. 
Nas últimas décadas os Processos Oxidativos Avançados $(P O A s)^{1}$ têm se destacado na pesquisa e desenvolvimento de tecnologias de tratamento de águas residuais, por se tratar de métodos eficientes que reduzem os impactos ambientais. A eficácia dos POAs depende da geração de radicais livres reativos, sendo o mais importante o radical hidroxila $\left(\mathrm{HO}^{\bullet}\right)$. Estes processos (por exemplo, a química de Fenton, fotólise e fotocatálise, sonólise, além das tecnologias de oxidação eletroquímica) têm sido aplicados com êxito para a remoção ou a degradação de poluentes recalcitrantes.

Nesse contexto, o estudo dos Processos Oxidativos Avançados, como tecnologias eficientes na degradação de poluentes presentes em efluentes e águas residuais, tem se tornado uma área de extensa investigação. Assim, torna-se interessante confrontar os fundamentos obtidos no âmbito laboratorial com a efetiva aplicação desses processos na Indústria Química.

Desta forma, este trabalho tem como objetivo a realização de um levantamento bibliográfico a respeito dos POAs. São apresentados dados, encontrados na literatura científica, relacionados à eficiência desses processos na degradação de poluentes para comparar os embasamentos teóricos e a aplicação industrial dos referidos processos.

\section{PROCESSOS OXIDATIVOS AVANÇADOS}

A aplicação dos POAs no tratamento de efluentes tem sido observada em uma série de estudos ao longo dos anos. Para estabelecer uma comparação, levantou-se o número de artigos científicos, artigos de revisão, bem como, de patentes publicados entre 2006-2015, visando observar o perfil de publicação no assunto. Para tanto, realizou-se uma busca direcionada com as palavras-chave "Advanced Oxidation Processes" na base de busca mundial Web of Science, buscando as publicações por ano dentro do período de 2006-2015. Com isso, observa-se através da Figura 1, que de maneira geral houve um crescimento nas publicações relacionadas ao tema POAs. Com relação ao número de artigos científicos, a busca revelou um crescimento mais expressivo quando comparado ao número de patentes. A publicação de patentes sobre o tema apresenta um crescimento constante até 2014, quando houve uma queda e elevou-se novamente em 2015. Com relação aos artigos de revisão, a busca não mostra constância no período analisado.

O número total de artigos científicos sobre POAs publicados em periódicos obtido nessa busca foi de 5411 ao longo dos 10 anos analisados e destes, 301 ( 6\%) envolveram pesquisadores brasileiros. Dos artigos encontrados, 260 foram publicados em 2006 e 918 em 2015, comprovando um evidente aumento nas publicações sobre o tema. Para artigos de revisão, nota-se que é crescente a quantidade de publicações representando um total de 449 ao longo dos dez anos e destes, 17 ( 4\%) envolveram pesquisadores brasileiros. Este aumento do número de publicações a respeito de POAs em artigos e revisões, consequentemente, implica de certa forma, na geração de propriedade intelectual e transferência de tecnologia. Assim, detecta-se uma evolução positiva visto que, em 2006, foram 21 patentes e, em 2016, esse número foi maior, atingindo um valor de 115 patentes. Ao consultar a base de dados do Instituto Nacional da Propriedade Industrial (INPI) - entidade Brasileira responsável pelo registro de patentes - foram encontrados 7 documentos depositados no período estudado. Isso demonstra, talvez, o pouco incentivo ou, talvez, o pouco conhecimento pelos pesquisadores brasileiros sobre a importância de se proteger o conhecimento, embora existam pesquisadores/inventores ativos na área.

\footnotetext{
${ }^{1}$ Daqui em diante será utilizada a abreviatura POAs para se referir a Processos Oxidativos Avançados.
} 


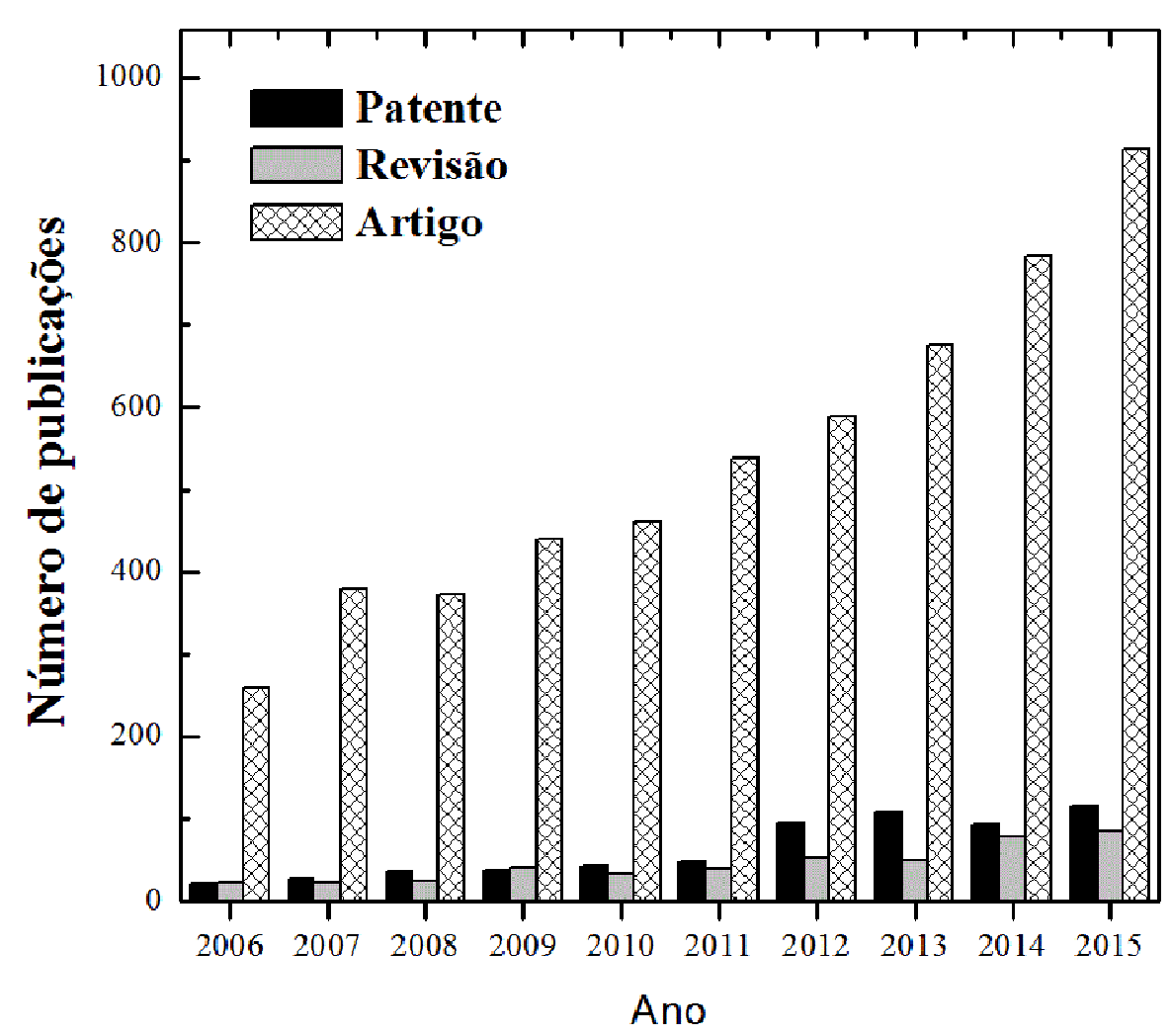

Figura 1. Publicações em periódicos e patentes sobre POAs nos últimos 10 anos.

Fonte: (Web of Science, 2016).

Visto o crescente interesse nos POAs, torna-se importante o conhecimento do princípio de funcionamento dos referidos processos na degradação de espécies tóxicas e/ou recalcitrantes.

Os POAs têm recebido destaque como processos de tratamento alternativos que atingem a degradação de espécies orgânicas pela ação do radical hidroxila $\left(\mathrm{HO}^{\bullet}\right)$. Segundo Pignatello et al. (2006), os POAs caracterizam-se por transformar, parcial ou totalmente, os poluentes em espécies mais simples como dióxido de carbono, água, ânions inorgânicos ou substâncias menos tóxicas e de fácil degradação por tecnologias comuns. No entanto, vale ressaltar que em alguns casos os produtos de degradação dos POAs podem ser mais tóxicos e menos biodegradáveis dos que os compostos originais. Um critério importante a ser levado em conta na avaliação de tecnologias de tratamento é a formação potencial de poluentes orgânicos persistentes (POPs) e outros subprodutos tóxicos. Vários métodos têm sido considerados no desenvolvimento de uma abordagem eficiente para destruir POPs, como fotólise, fotocatálise, ozonólise, oxidação Fenton, tratamento de água supercrítica, biodegradação, entre outros (Vallejo et al., 2015).

Todos os POAs apresentam em comum a participação do radical hidroxila $\left(\mathrm{HO}^{\bullet}\right)$ no mecanismo de reação, sendo este altamente reativo, não seletivo e capaz de oxidar e decompor várias espécies tóxicas e/ou recalcitrantes, o que configura um importante ponto no tratamento de resíduos (Pignatello et al., 2006). Além disso, este radical é responsável por iniciar reações em cadeia, sendo utilizado em tratamentos de águas contaminadas, uma vez que atua como iniciador dos processos de purificação.

$\mathrm{Na}$ degradação de uma espécie orgânica genérica $(\mathrm{EO})$, o radical hidroxila $\left(\mathrm{HO}^{\bullet}\right)$ oxida a espécie orgânica por abstração de hidrogênio, originando o radical orgânico (EO ${ }^{\bullet}$ ) que, em 
seguida, pela adição de oxigênio, forma o radical orgânico peróxido. Dessa maneira, as reações em cadeia são iniciadas por estes intermediários, gerando radicais secundários, intermediários mais oxidados. Após sucessivas etapas, na presença de oxigênio $\left(\mathrm{O}_{2}\right)$, são produzidos água, sais orgânicos e dióxido de carbono $\left(\mathrm{CO}_{2}\right)$ (Pignatello et al., 2006).

A produção do radical hidroxila pode ocorrer por aplicação da radiação UV ou utilização de agentes oxidantes fortes como ozônio $\left(\mathrm{O}_{3}\right)$ e peróxido de hidrogênio $\left(\mathrm{H}_{2} \mathrm{O}_{2}\right)$, bem como por diferentes possibilidades de combinações provenientes da radiação e desses agentes oxidantes. Além disso, esse radical pode ser gerado por oxidação eletroquímica e/ou ultrassom (Azbar et al., 2004). O radical hidroxila possui potencial padrão de redução $\left(\mathrm{E}^{0}\right)$ superior aos das demais espécies oxidantes, como pode ser visualizado na Tabela 1, podendo levar a mineralização de ampla faixa de espécies orgânicas em efluentes, dependendo das condições operacionais.

Tabela 1. Valores do potencial padrão de redução $\left(\mathrm{E}^{\mathrm{o}}\right)$ de espécies oxidantes.

\begin{tabular}{lc}
\hline \multicolumn{1}{c}{ Espécie } & $\mathrm{E}^{\mathrm{o}}(\mathrm{V})$ \\
\hline Radical Hidroxila, $\mathrm{HO}^{\bullet}$ & $+2,80$ \\
Ozônio, $\mathrm{O}_{3}$ & $+2,07$ \\
Peróxido de Hidrogênio, $\mathrm{H}_{2} \mathrm{O}_{2}$ & $+1,77$ \\
Hipoclorito, $\mathrm{ClO}^{-}$ & $+1,43$ \\
Radical Peridroxil, $\mathrm{HO}_{2}{ }^{\bullet}$ & $+1,42$ \\
Cloro, $\mathrm{Cl}_{2}$ & $+1,36$ \\
Oxigênio, $\mathrm{O}_{2}$ & $+1,23$ \\
\hline
\end{tabular}

Fonte: (Shin et al., 2008).

Dezotti (2008) explicitou diversas vantagens que os POAs apresentam, como: forte poder oxidante; mineralização total dos poluentes e oxidação total de espécies inorgânicas; versatilidade e eficiência; decomposição dos reagentes utilizados como oxidantes em produtos de menor impacto ao meio ambiente; e condições operacionais de temperatura e pressão ambiente.

Apesar de alguns estudos mostrarem que o consumo energético pode ser reduzido, estes processos têm como desvantagem a limitação econômica que está relacionada ao alto custo da fonte de radiação UV quando comparado, por exemplo, com o custo de implementação do sistema eletroquímico, implicando em consumo de energia elétrica e custo de manutenção, e ao alto custo do agente oxidante (Dezotti, 2008). Tal inconveniente pode ser solucionado mediante o uso de energia solar, catalisadores de baixo custo e combinação com outros processos de tratamento, desde que não haja interferência no desempenho do processo.

De acordo com a literatura (Pignatello et al., 2006), os principais POAs são Químicos (processo Fenton), Fotoquímicos (incluindo $\mathrm{H}_{2} \mathrm{O}_{2} / \mathrm{UV}, \mathrm{O}_{3} / \mathrm{UV}, \mathrm{O}_{3} / \mathrm{H}_{2} \mathrm{O}_{2} / \mathrm{UV}$, Foto-Fenton, Fotocatálise heterogênea), Sonoquímicos (incluindo US, $\mathrm{O}_{3} / \mathrm{US}, \mathrm{H}_{2} \mathrm{O}_{2} / \mathrm{US}$, Fotocatálise/US, Sono-Fenton), e Eletroquímicos (incluindo Oxidação Anódica, Eletro-Fenton, Fotoeletro-Fenton, Sonoeletroquímico, Sonoeletro-Fenton). Em muitas combinações de POAs existem efeitos de sinergia, ou seja, há uma melhora na eficiência que é maior que a simples soma das duas (ou mais) técnicas. Um exemplo disso é a degradação do pesticida Atrazina (Malpass et al., 2007), onde a combinação de técnicas Eletroquímicas e Fotoquímicas produziram um efeito além da simples soma das duas técnicas.

\subsection{POAs Químicos}

Dentre os POAs Químicos destaca-se o processo Fenton que envolve reações da espécie peróxido de hidrogênio $\left(\mathrm{H}_{2} \mathrm{O}_{2}\right)$ dissolvido na presença de íons de ferro a fim de gerar espécies fortemente oxidantes para degradar ou destruir uma variedade de poluentes orgânicos. $\mathrm{O}$ 
processo Fenton utiliza íons ferrosos $\left(\mathrm{Fe}^{2+}\right)$ ou férricos $\left(\mathrm{Fe}^{3+}\right)$ como catalisadores, em meio ácido, para promover a decomposição de $\mathrm{H}_{2} \mathrm{O}_{2}$ e, assim, gerar radicais hidroxila $\left(\mathrm{HO}^{\bullet}\right)$ (Equação 1) (Brillas et al., 2009).

$$
\mathrm{Fe}^{2+}+\mathrm{H}_{2} \mathrm{O}_{2} \rightarrow \mathrm{Fe}^{3+}+\mathrm{HO}^{\bullet}+\mathrm{OH}^{-}
$$

Bautista et al. (2008) descreveram as inúmeras vantagens do processo Fenton no tratamento de águas residuais, dentre as quais destacam-se operação simples e flexível, facilidade de manuseio, uso de produtos químicos de baixo custo e ausência de entrada de energia. E como desvantagem pode não alcançar a mineralização total dos poluentes orgânicos, pode apresentar riscos devido ao transporte e armazenamento de $\mathrm{H}_{2} \mathrm{O}_{2}$ e necessidade de grandes quantidades de produtos químicos para manter o $\mathrm{pH}$ ótimo da reação (próximo a 3) e para neutralizar as soluções tratadas antes do descarte, o que pode gerar custos relativamente elevados.

A fim de tentar solucionar estas limitações pode-se recorrer à redução da concentração do reagente, ou mesmo optar pelo uso de catalisadores de baixo custo. Outra possibilidade é associar este processo com outros métodos de tratamento como, por exemplo, o biológico ou aplicar o processo foto-Fenton.

Alguns trabalhos conseguiram alcançar resultados muito próximos à mineralização utilizando processos Fenton e Fenton-like. Os radicais hidroxila gerados a partir da reação dos íons ferrosos com peróxido de hidrogênio são altamente reativos e espécies podem atacar e mineralizar os poluentes orgânicos de forma não seletividade (Fan, 2011). Kulik et al. (2008) confirmaram que os efluentes farmacêuticos poderiam ser bem tratado com a reação Fenton-like. Elmolla e Chaudhuri (2009) investigaram a degradação da solução aquosa contendo antibióticos com processo Fenton, onde foi comprovado que a biodegradabilidade da solução foi aumentada.

\subsection{POAs Fotoquímicos}

Os POAs fotoquímicos consistem em tecnologias simples e mais eficientes que os POAs químicos, podendo desinfetar águas e destruir uma alta porcentagem das poluentes presentes. A associação da irradiação UV com agentes oxidantes fortes como, peróxido de hidrogênio $\left(\mathrm{H}_{2} \mathrm{O}_{2}\right)$, ozônio $\left(\mathrm{O}_{3}\right)$ e catálise com dióxido de titânio $\left(\mathrm{TiO}_{2}\right)$, origina diversos tipos de POAs fotoquímicos capazes de degradar ou destruir poluentes através de três reações: foto-decomposição (baseada na irradiação UV, excitação e degradação de moléculas de poluentes), oxidação por ação direta de $\mathrm{H}_{2} \mathrm{O}_{2}$ e $\mathrm{O}_{3}$, e oxidação por fotocatálise com $\mathrm{TiO}_{2}$ levando à formação de radicais hidroxila.

A fotólise do peróxido de hidrogênio por irradiação UV $\left(\mathrm{H}_{2} \mathrm{O}_{2} / \mathrm{UV}\right)$ é um processo que pode ocorrer naturalmente, constituindo em uma alternativa para degradar compostos orgânicos tóxicos. $\mathrm{O} \mathrm{H}_{2} \mathrm{O}_{2}$ pode ser fotolisado por irradiação $\mathrm{UV}$ em comprimentos de onda de 200 a $300 \mathrm{~nm}$ (representado como hv) ocasionando a quebra da ligação O-O da molécula de $\mathrm{H}_{2} \mathrm{O}_{2}$ gerando radicais hidroxila ( $\mathrm{HO}^{\bullet}$ ) (Equação 2) que age $\mathrm{m}$ na degradação de espécies orgânicas (Hernandez et al., 2002).

$$
\mathrm{H}_{2} \mathrm{O}_{2}+h v \rightarrow 2 \mathrm{HO}^{\bullet}
$$

No processo combinado de ozônio e irradiação UV $\left(\mathrm{O}_{3} / \mathrm{UV}\right)$ os radicais hidroxila $\left(\mathrm{HO}^{\bullet}\right)$ são produzidos direta e indiretamente, aumentando a degradação da matéria orgânica. Em solução aquosa, o $\mathrm{O}_{3}$ absorve irradiações UV entre 200 e $360 \mathrm{~nm}$, gerando radicais hidroxila (Equações 3, 4 e 5) (Hernandez et al., 2002). 


$$
\begin{aligned}
& \mathrm{O}_{3}+\mathrm{H}_{2} \mathrm{O}+h v \rightarrow \mathrm{O}_{2}+\mathrm{H}_{2} \mathrm{O}_{2} \\
& \mathrm{O}_{2}+\mathrm{H}_{2} \mathrm{O}_{2}+h v \rightarrow 2 \mathrm{HO}^{\bullet} \\
& \mathrm{O}_{3}+\mathrm{H}_{2} \mathrm{O} \rightarrow \mathrm{O}_{3}+\mathrm{HO}_{2}^{-} \rightarrow 2 \mathrm{HO}^{\bullet}
\end{aligned}
$$

Conforme Azbar et al. (2004), a adição de $\mathrm{H}_{2} \mathrm{O}_{2}$ ao processo $\mathrm{O}_{3} / \mathrm{UV}$ ocasiona um aumento da taxa de geração de radicais hidroxila, podendo acelerar a degradação de poluentes. $\mathrm{O}$ processo $\mathrm{O}_{3} / \mathrm{H}_{2} \mathrm{O}_{2} / \mathrm{UV}$, comparado aos processos $\mathrm{UV}, \mathrm{H}_{2} \mathrm{O}_{2} / \mathrm{UV}$ e $\mathrm{O}_{3} / \mathrm{UV}$, apresenta grau de mineralização mais elevado.

Da mesma maneira, o processo foto-Fenton $\left(\mathrm{H}_{2} \mathrm{O}_{2} / \mathrm{Fe}^{2+} / \mathrm{UV}\right)$ aumenta a formação de radicais hidroxila $\left(\mathrm{HO}^{\bullet}\right)$. Trata-se do processo Fenton assistido por irradiação UV que induz a redução catalítica em soluções aquosas de $\mathrm{H}_{2} \mathrm{O}_{2}$ e de $\mathrm{Fe}^{3+}$ (íons férricos) a $\mathrm{Fe}^{2+}$ (íons ferrosos) (Equação 6). No processo foto-Fenton também ocorre a decomposição direta de moléculas de $\mathrm{H}_{2} \mathrm{O}_{2}$ em radicais hidroxila como no processo $\mathrm{H}_{2} \mathrm{O}_{2} / \mathrm{UV}$ (Equação 1). Uma alternativa para reduzir os custos econômicos do processo foto-Fenton é pelo processo foto-Fenton solar que utiliza todo o espectro eletromagnético (Silva et al., 2007).

Sirtori et al. (2009a) descontaminaram um efluente industrial farmacêutico real com energia solar foto-Fenton combinado com tratamento biológico. Eles mostraram que o processo foto-Fenton aumentou a biodegradabilidade e reduziu o carbono orgânico dissolvido (DOC) da solução inicial.

$$
\mathrm{Fe}^{3+}+\mathrm{H}_{2} \mathrm{O}_{2}+\mathrm{hv} \rightarrow \mathrm{Fe}^{2+}+\mathrm{H}^{+}+\mathrm{HO}^{\bullet}
$$

Outro tipo de POA Fotoquímico é a fotocatálise heterogênea, uma tecnologia de foto-indução que atua sobre o catalisador sólido (superfície e suspensão) semicondutor, geralmente o dióxido de titânio $\left(\mathrm{TiO}_{2}\right)$, sob irradiação UV ou luz visível, cujo processo pode ser visto na Figura 2.

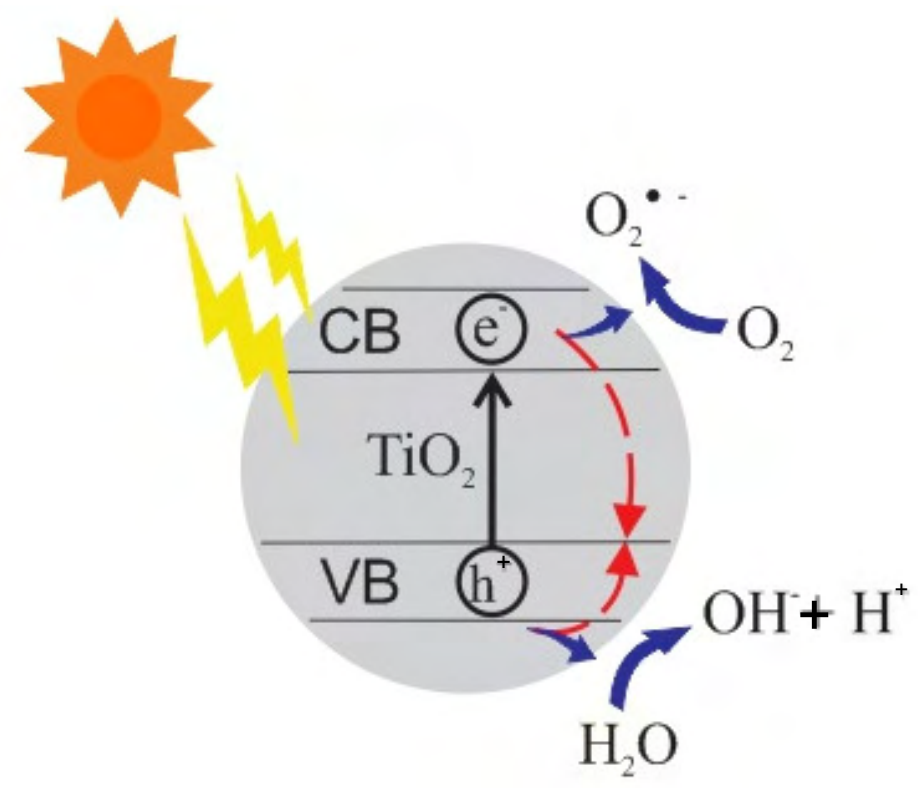

Figura 2. Esquema do processo fotocatalítico atuando no fotocatalisador semicondutor.

No catalisador semicondutor existe uma descontinuidade de energia entre a banda de valência (BV - região de energia mais baixa) e a banda de condução (BC - região de energia mais alta). Quando a energia de irradiação $(h v)$ é igual ou ultrapassa a energia de band-gap 
(diferença de energia entre as bandas BV e BC) os elétrons são promovidos da BV para a BC e deixam buracos $\left(\mathrm{h}_{\mathrm{bv}}{ }^{+}\right)$originando um par elétron/lacuna $\left(\mathrm{e}_{\mathrm{bc}}{ }^{-} / \mathrm{h}_{\mathrm{bv}}{ }^{+}\right)$que podem recombinar-se diretamente ou migrar para a superfície do semicondutor, induzindo reações de oxidação-redução. As reações de oxidação podem acontecer entre a lacuna da BV e os grupos hidroxila ou água formando radicais hidroxila. Enquanto isso, as reações de redução podem ocorrer entre $\mathrm{o} \mathrm{e}_{\mathrm{bc}}{ }^{-}$e o oxigênio, desencadeando reações que ocasionam a geração de radicais hidroxila (Angelo et al., 2013).

\subsection{POAs Sonoquímicos}

As técnicas de oxidação sonoquímicas são baseadas na utilização de radiação ultrassônica (US) a fim de criar um ambiente oxidativo (Sathishkumar et al., 2016). Sob radiação ultrassônica os radicais hidroxila são formados na presença de diferentes gases e também em combinação com outros processos $\left(\mathrm{O}_{3} / \mathrm{US}, \mathrm{H}_{2} \mathrm{O}_{2} / \mathrm{US}\right.$ e fotocatálise/US) (Adewuyi, 2001). A sonólise é um processo fundamentado especialmente na cavitação acústica, abrangendo a formação, o crescimento e o colapso implosivo de bolhas em um líquido, como ilustrado na Figura 3.

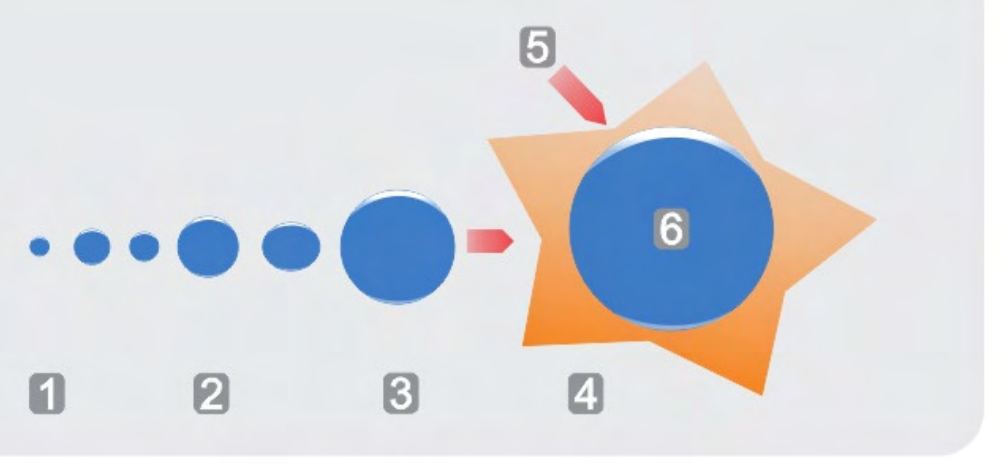

Figura 3. Esquema da sonólise, abrangendo a formação, o crescimento e o colapso implosivo de bolhas em um líquido.

De acordo com a Figura 3, quando as ondas ultrassônicas incidem na solução a ser tratada, cavidades de bolhas são formadas (1), crescem (2), alcançam um tamanho instável (3) e entram em colapso (4). Na interface entre o gás da bolha e o líquido da solução (5) pode-se alcançar temperaturas de aproximadamente $2000 \mathrm{~K} \mathrm{e} \mathrm{(6)} \mathrm{na} \mathrm{parte} \mathrm{interna} \mathrm{da} \mathrm{bolha} \mathrm{pressões}$ próximas a $500 \mathrm{~atm}$ e temperaturas de até $5000 \mathrm{~K}$ podem ser atingidas. Nessas condições extremas, ocorre a sonólise de moléculas de água, gerando radicais muito reativos capazes de reagir com espécies químicas orgânicas presentes no meio aquoso (Equação 7), degradando-as (Adewuyi, 2001).

$$
\mathrm{H}_{2} \mathrm{O} \stackrel{\mathrm{US}}{\rightarrow} \mathrm{HO}^{\bullet}+\mathrm{H}^{\bullet}
$$

Os processos combinados de ozônio com ultrassom $\left(\mathrm{O}_{3} / \mathrm{US}\right)$, peróxido de hidrogênio com ultrassom $\left(\mathrm{H}_{2} \mathrm{O}_{2} / \mathrm{US}\right)$ ou ultrassom com fotocatálise (fotocatálise/US) ocasionam um aumento expressivo da taxa de geração de radicais livres. Outro tipo de associação de POAs é o processo Sono-Fenton. Trata-se do acoplamento da radiação ultrassônica com o processo Fenton, em que a decomposição de $\mathrm{H}_{2} \mathrm{O}_{2}$ sob radiação ultrassônica resulta em uma maior concentração de $\mathrm{HO}^{\bullet}$, promovendo a aceleração da degradação dos contaminantes (Chakinala et al., 2009). 


\subsection{POAs Eletroquímicos}

Os POAs eletroquímicos (POAEs) consistem em técnicas baseadas na transferência de elétrons, sendo uma forma limpa de energia e eficiente na degradação de poluentes orgânicos. Neste processo ocorre a produção in situ do radical hidroxila $\left(\mathrm{HO}^{\bullet}\right)$ o qual degrada uma grande variedade de compostos. No processo eletroquímico a degradação de um poluente pode ocorrer diretamente (processo de oxidação anódica) ou indiretamente (processo eletro-Fenton).

Na oxidação anódica (OA) a destruição do poluente ocorre pela transferência de elétrons na superfície do eletrodo. Neste método, os radicais hidroxilas são diretamente formados na superfície do ânodo, por oxidação das moléculas de água (Marselli et al., 2003).

No processo eletro-Fenton (EF) a degradação do poluente ocorre por meio da formação de um agente oxidante in-situ que pode migrar da superfície do eletrodo e reagir no seio da solução. Neste método de eletro-oxidação indireta, os radicais hidroxila $\left(\mathrm{HO}^{\bullet}\right)$ são gerados na reação Fenton eletroquimicamente assistida através do reagente de Fenton (mistura de $\mathrm{H}_{2} \mathrm{O}_{2} \mathrm{e}$ íons ferrosos) em meio homogêneo, conforme a Equação 1 (Brillas et al., 2009).

Comumente a eficácia de remoção é maior em um processo indireto pelo fato de evitar problemas, tais como limitações de transferência de massa e envenenamento da superfície do eletrodo. A eficiência do processo pode ser aumentada por meio da combinação de ambos os processos eletroquímicos e seus acoplamentos com outros métodos de tratamento, tais como fotoquímico (fotoeletro-Fenton) e sonoquímico (sonoeletro-Fenton e sonoeletroquímico) (Brillas et al., 2009).

$\mathrm{O}$ processo fotoeletro-Fenton (PFE) envolve o tratamento de soluções sob condições de eletro-Fenton (processo EF) com utilização simultânea de irradiação UV ou luz visível, durante ou após a eletrólise, para acelerar a taxa de mineralização dos poluentes. No processo sonoeletro-Fenton, as soluções a serem tratadas são submetidas ao processo EF e radiação ultrassônica concomitantemente, aumentando a taxa de transferência de massa na solução (Sires e Brillas, 2012). Já no processo sonoeletroquímico, a solução a ser tratada é submetida ao processo eletroquímico simultaneamente com radiação ultrassônica, o qual promove aumento no transporte de massa, auxilia na interface eletrodo-solução e apresenta efeitos benéficos quanto à limpeza da superfície eletródica (Compton et al., 1997).

No entanto, os POAEs apresentam algumas desvantagens, dentre elas: o alto consumo energético; podem necessitar de grande tempo de retenção; custo elevado quando comparado, por exemplo, aos processos biológicos; formação de subprodutos de reação e outros. Contudo, segundo Sires e Brillas (2012) os POAEs tem como principais vantagens para desintoxicação/descontaminação de água a produção in situ de $\mathrm{H}_{2} \mathrm{O}_{2}$ (evitando os riscos com manuseio, armazenamento e transporte), a regeneração contínua de $\mathrm{Fe}^{2+}$ no cátodo (promovendo maior taxa de remoção de poluentes orgânicos), possibilidade de mineralização total a um custo relativamente baixo (otimizando os parâmetros de operação), rápida degradação dos poluentes orgânicos (evitando a formação de novas espécies tóxicas), e não possui necessidade de adição de reagentes químicos ou de grandes quantidades de catalisador no suporte (permitindo a descarga direta dos efluentes tratados em águas naturais). Tais pontos positivos evidenciam quesitos como compatibilidade ambiental, segurança e eficiência desses processos no tratamento de águas residuais e efluentes industriais.

\subsection{POAs Sonoeletroquímicos}

Steter et al. (2016) realizaram um estudo comparativo de sonoquímica, eletroquímica e sonoeletroquímica para a degradação do fungicida tirame em solução aquosa diluída. Os resultados mostraram que a taxa de degradação de tirame e a quantidade de energia consumida foi diretamente proporcional à densidade de corrente aplicada, enquanto que a eficiência de corrente foi inversamente proporcional à densidade de corrente. A degradação de 
tirame foi alcançada pelos processos eletroquímico e sonoeletroquímico com densidade de corrente de $35 \mathrm{~mA} \mathrm{~cm}^{-2}$ e $5 \mathrm{~h}$ de tratamento.

A pesquisa de Steter et al. (2014a) descreve a degradação do metilparabeno por meio dos processos eletroquímico e sonoeletroquímico. A mineralização parcial do metilparabeno foi atingida depois de 120 minutos de eletrólise por ambos os processos com uma remoção máxima de COT de aproximadamente $50 \%$.

A degradação do corante amaranto mediante aplicação de ultrassom associado a um sistema eletroquímico foi investigada por Steter et al. (2014b). Mediante 90 min de eletrólise a $35 \mathrm{~mA} \mathrm{~cm}^{-2}$ obteve-se uma remoção de COT de $92,1 \%$ e $95,1 \%$ para os processos eletroquímico e sonoeletroquímico, com eficiência de $18,2 \%$ e $23,6 \%$, respectivamente.

\subsection{Aplicações}

$\mathrm{Na}$ literatura não faltam estudos da aplicação de POAs em escala piloto, uma etapa imprescindível para futuro uso comercial/industrial de qualquer processo. Em exemplos recentes disponíveis na literatura podem ser citados vários trabalhos. Wang et al. (2015b) estudaram a remoção de poluentes orgânicos por POAs a base de $\mathrm{O}_{3}$ em uma estação de tratamento de água e observaram um grande eficiência na remoção de substâncias de interesse. Papoutsakis et al. (2015) investigaram o acoplamento de radiação ultrassônica de alta frequência com o processo solar Foto-Fenton em escala piloto. Foi constatada a necessidade de estudar cada sistema (poluente) individualmente para otimizar o processo, mas com limitação cuidadosa do tempo de sonificação é possível tornar o processo economicamente viável. O POA de UV/Cloro foi investigado por Wang et al. (2015a) com o intuito de remover odores e gosto de água para uso doméstico. Constatou-se que o processo $\mathrm{UV} /$ Cloro compete economicamente com o processo $\mathrm{UV} / \mathrm{H}_{2} \mathrm{O}_{2}$. Adicionalmente, Kong et al. (2016) estudaram a degradação do pesticida atrazina pelo processo UV/Cloro e foi observado que a remoção foi mais eficiente que o processo $\mathrm{UV} / \mathrm{H}_{2} \mathrm{O}_{2}$.

Quando se trata de aplicações industriais, a literatura científica é escassa e se encontra, basicamente, na mesma situação observada por Vogelpohl (2007). Existe uma falta de dados publicados que fornecem comparações com dados obtidos em escala de bancada ou piloto. $\mathrm{Na}$ experiência dos autores, muitas vezes estudos desenvolvidos por empresas são somente divulgados internamente. Como observado por Vogelpohl, existem poucos dados sobre custos, tanto de instalação quanto de operação, sem os quais existirá uma lacuna considerável entre a academia e indústria. Apesar das últimas observações, o crescente número de patentes na área (Figura 1) é um fator positivo que indica que a aceitação dos POAs pelo setor produtivo ganha mais espaço a cada ano.

Em termos de custo, a principal restrição da aplicação industrial dos POAs baseia-se no alto custo das fontes de energia como, irradiação UV e reagente (peróxido de hidrogênio e ozônio). Em relação ao processo Fenton, a utilização de catalisador com ferro sólido promove a reação com o oxigênio dissolvido, ao invés de reagir com o peróxido de hidrogênio, resultando em um tratamento mais acessível economicamente. Para os POAs fotoquímicos, a solução deste problema consiste em desenvolver fotocatalisadores usando como fonte de energia a luz solar a fim de reduzir os custos. Quanto aos POAs eletroquímicos, a demanda de energia pode ser reduzida por meio da geração de reagentes eletroquímicos in situ. Assim, a aplicação dos POAs pode ser otimizada mediante o desenvolvimento de novos materiais catalíticos de baixo custo (Bandala et al., 2008; Brillas et al., 2009; Sirtori et al., 2009b).

Diversas questões relacionadas à qualidade da água vêm sendo extensivamente estudadas e discutidas, pois é fato que se trata de um recurso natural substancial a um amplo espectro de atividades humanas, dentre elas, o abastecimento público e industrial, a irrigação agrícola, as atividades de lazer, a produção de energia e a preservação da vida aquática. Diante dessa conjuntura, temas como reuso, minimização e tratamento de resíduos vêm ganhando cada vez 
mais importância (Melo et al., 2009).

Outro ponto considerável está relacionado com a escassez de água doce, a qual está diminuindo a um ritmo alarmante, tanto em países de alta como de baixa renda. Também há uma crescente presença de subprodutos da desinfecção em água potável devido ao uso generalizado de cloração e ozonização. Além disso, muitos países e comunidades são incapazes de assumir os custos econômicos e energéticos de alguns dos tratamentos de desinfecção atuais. Ademais, a eficácia de alguns tratamentos de desinfecção utilizada é limitada no que diz respeito à remoção de agentes patogênicos resistentes. Fatos que tornam ainda mais necessário o estudo de mais pesquisas sobre novas tecnologias de desinfecção da água (Agulló-Barceló et al., 2013).

Os processos oxidativos avançados (POAs) têm sido extensivamente estudados, devido ao seu potencial como alternativas ou complementos aos processos convencionais de tratamento de efluentes (Melo et al., 2009). Os POAs têm demonstrado ser confiável para tratamento de águas residuais, uma vez que têm uma elevada capacidade para oxidar quase todos os poluentes orgânicos. Esta capacidade resulta da geração de $\mathrm{HO}^{\bullet}$, a segunda espécie mais oxidante depois de flúor (Agulló-Barceló et al., 2013)".

$\mathrm{Na}$ atual situação econômica, é crucial para o desenvolvimento de técnicas eficientes, que sejam economicamente viáveis e capazes de atenuar os perigos destes contaminantes. Em geral, os POAs se tornam mais atraentes quando a irradiação UV é usada porque melhora a eficiência de remoção em diferentes matrizes dos contaminantes. No entanto, a avaliação econômica do sistema de tratamento, muitas vezes é comprometida em termos de custos de energia, o que justifica a necessidade de encontrar fontes alternativas. Portanto, não só incluiu a redução do uso de energia, mas também a substituição de irradiação UV artificial por uma obtida a partir de fontes naturais e limpas, o que origina uma redução das perdas de transporte de eletricidade (Marcelino et al., 2015). Diversos pesquisadores estão trabalhando em políticas públicas para promover a geração de energia solar no sistema elétrico brasileiro, que está atualmente baseado em usinas hidrelétricas e termelétricas. Portanto, a energia solar tem o potencial de atender as demandas para o desenvolvimento de POAs irradiados e as perspectivas são atraentes para os países com altas taxas de insolação como o Brasil (Marcelino et al., 2015).

No entanto, apesar do potencial de energia solar no Brasil e as informações já publicadas dos POAs solares em todo o mundo, a utilização da energia solar ainda está caminhando em um nível embrionário no Brasil, destacando a importância da aplicação de irradiação UV natural como um mecanismo para mitigar os danos ambientais. Assim, as pesquisas brasileiras referentes aos processos fotoquímicos solares e suas aplicações são de suma importância e relevância (Marcelino et al., 2015).

\section{CONCLUSÕES}

De acordo com os dados apresentados na literatura, os POAs Fotoquímicos demonstraram ser tecnologias mais eficazes que os POAs químicos, devido à associação da irradiação UV com agentes oxidantes fortes o que aumenta a capacidade de degradar ou destruir uma alta porcentagem de poluentes presentes. Quanto aos POAs Sonoquímicos, apesar da combinação da radiação ultrassônica com reações Fenton resultarem em efeitos promissores na descontaminação de efluentes, torna-se necessário comprovar a viabilidade econômica da aplicação deste processo industrialmente. Dentre os POAs pesquisados, os eletroquímicos (POAEs) mostraram ser vantajosos devido à capacidade de minimizar ou eliminar o uso de reagentes químicos.

Ressalta-se que a combinação de vários POAs torna-se mais adequada para a degradação/destruição de espécies tóxicas e/ou recalcitrantes visto que resulta em uma maior 
geração de radicais hidroxila e/ou outras espécies reativas. Com base nos dados encontrados na literatura científica, conclui-se que os POAs tornam-se aplicáveis para aumento de escala mediante a otimização dos fatores de eficácia como, custo das fontes de energia (irradiação UV e reagente) e desenvolvimento de novos materiais catalíticos que possibilitem a utilização de luz solar, além da combinação desses diferentes processos para eliminar as desvantagens das técnicas individuais. Além disso, a ampliação de escala de reatores utilizados no tratamento de águas residuais e/ou efluentes industriais é complexa, estando relacionada com materiais, volume, carregamento de catalisador, turbidez e penetração da irradiação UV. Portanto, para aplicações industriais, os fotoreatores enfrentam o desafio de capacidade, robustez, confiabilidade e facilidade de uso.

Dessa maneira, torna-se necessário realizar mais pesquisas a respeito dos pontos negativos dos POAs e dos fotoreatores em nível industrial a fim de solucionar as limitações e restrições existentes, promovendo a efetivação do emprego dessas tecnologias no tratamento de águas residuais e efluentes industriais.

\section{AGRADECIMENTOS}

Os autores agradecem a Universidade Federal do Triângulo Mineiro (UFTM), ao CNPq e à FAPEMIG pelo apoio financeiro. Este trabalho foi feito em colaboração entre pesquisadores da Rede Mineira de Química - RQMG (Projeto: CEX - RED-00010-14).

\section{REFERÊNCIAS}

ADEWUYI, Y. G. Sonochemistry: Environmental science and engineering applications. Industrial \& Engineering Chemistry Research, v. 40, p. 4681-4715, 2001. http://dx.doi.org/10.1021/ie0100961

AGULLÓ-BARCELÓ, M.; POLO-LOPEZ, M. I.; LUCENA, F., JOFRE, J.; FERNÁNDEZIBÁÑEZ, P. Solar advanced oxidation processes as disinfection tertiary treatments for real wastewater: implications for water reclamation. Applied Catalysis B: Environmental, v. 136-137, p. 341-350, 2013. http://dx.doi.org/10.1016/j.apcatb.2013.01.069

ANGELO, J.; ANDRADE, L.; MADEIRA, L. M.; MENDES, A. An overview of photocatalysis phenomena applied to NOx abatement. Journal of Environmental Management, v. 129, p. 522-539, 2013. http://dx.doi.org/10.1016/j.jenvman.2013.08.006

AZBAR, N.; YONAR, T.; KESTIOGLU, K. Comparison of various advanced oxidation processes and chemical treatment methods for COD and color removal from polyester and acetate fiber dyeing effluent. Chemosphere, v. 55, n. 1, p. 35-43, 2004. http://dx.doi.org/10.1016/j.chemosphere.2003.10.046

BANDALA, E. R.; PELÁEZ, M. A.; GARCÍA-LÓPEZ, A. J.; SALGADO, M. D.; MOELLER, G. Photocatalytic decolourisation of synthetic and real textile wastewater containing benzidine-based azo dyes. Chemistry Engineering and Processing, v. 47, p. 169-176, 2008. http://dx.doi.org/10.1016/j.cep.2007.02.010

BAUTISTA, P.; MOHEDANO, A. F.; CASAS, J. A.; RODRIGUEZ, J. J. An overview of the application of Fenton oxidation to industrial wastewaters treatment. Journal Chemical Technology Biotechnology, v. 83, p. 1323-1338, 2008. http://dx.doi.org/10.1002/jctb.1988 
BRILLAS, E.; SIRES, I.; OTURAN, M. A. Electro-Fenton process and related electrochemical technologies based on Fenton's reaction chemistry. Chemical Reviews, v. 109, p. 6570-6631, 2009. http://dx.doi.org/10.1021/cr900136g

CHAKINALA, A. G.; GOGATE, P. R.; BURGESS, A. E.; BREMNER, D. H. Industrial wastewater treatment using hydrodynamic cavitation and heterogeneous advanced Fenton processing. Chemical Engineering Journal, p. 498-502, 2009. http://dx.doi.org/10.1016/j.cej.2009.05.018

COMPTON, R. G.; EKLUND J. C.; MARKEN, F.; AKKERMANS, T. R. P.; WALLER, D. N. Dual activation: coupling ultrasound electrochemistry-an overview. Electrochimica Acta, v. 42, p. 2919-2927, 1997. http://dx.doi.org/10.1016/S0013-4686(97)00113-8

DEZOTTI, M. (Coord.). Processos e técnicas para o controle ambiental de efluentes líquidos. Rio de Janeiro: E-papers, 2008.

ELMOLLA, E.; CHAUDHURI, M. Optimization of Fenton process for treatment of amoxicillin, ampicillin and cloxacillin antibiotics in aqueous solution. Journal Hazardous Materials. v. 170, p. 666-672, 2009. http://dx.doi.org/10.1016/j.jhazmat.2009.05.013

FAN, X.; HAO, H.; SHEN, X.; CHEN, F.; ZHANG, J. Removal and degradation pathway study of sulfasalazine with Fenton-like reaction. Journal of Hazardous Materials, v. 190, p. 493-500, 2011. http://dx.doi.org/10.1016/j.jhazmat.2011.03.069

FLORÊNCIO, T. M.; MALPASS, G. R. P. A brief explanation about environmental licenses in Brazil. The Nexus - American Chemical Society, 2014.

HERNANDEZ, R.; ZAPPI, M.; COLLUCI, F.; JONES, R. Comparing the performance of various advanced oxidation process for treatment of acetone contaminated water. Journal Hazardous Materials, v. 92, p. 33-50, 2002. http://dx.doi.org/10.1016/S03043894(01)00371-5

KONG, X.; JIANG, J.; MA, J.; YANG, Y., LIU, W.; LIU, Y. Degradation of atrazine by UV/chlorine: Efficiency, influencing factors, and products. Water Research, v. 90, p. 15-23, 2016. http://dx.doi.org/10.1016/j.watres.2015.11.068

KULIK, N.; TRAPIDO, M.; GOI, A.; VERESSININA, Y.; MUNTER, R. Combined chemical treatment of pharmaceutical effluents from medical ointment production. Chemosphere, v. 70, p. 1525-1531, 2008.

http://dx.doi.org/10.1016/j.chemosphere.2007.08.026

MALPASS, G. R. P.; MIWA, D. W.; MIWA, A.C.P.; MACHADO, S. A. S.; MOTHEO, A. J. Photo-assisted electrochemical oxidation of Atrazine on a commercial Ti/Ru0.3Ti0.7O2 DSA electrode. Environmental Science and Technology, v. 41, p. 7120-7125, 2007. http://dx.doi.org/10.1021/es070798n

MARCELINO, R. B. P.; QUEIROZ, M. T. A.; AMORIM, C. C. Solar energy for wastewater treatment: review of international technologies and their applicability in Brazil. Environmental Science and Pollution Research, v. 22, p. 762-773, 2015. http://dx.doi.org/10.1007/s11356-014-3033-2 
MARSELLI, B.; GARCIA-GOMEZ, J.; MICHAUD, P. A.; RODRIGO, M. A.; COMNINELLIS, C. Electrogeneration of hydroxyl radicals on boron-doped diamond electrodes. Journal of the Electrochemical Society, v. 150, p. 79-83, 2003. http://dx.doi.org/10.1149/1.1553790

MELO, S. A. S.; TROVÓ, A. G.; BAUTITZ, I. R.; NOGUEIRA, R. F. P. Degradação de fármacos residuais por processos oxidativos avançados. Química Nova, v. 32, p.188197, 2009. http://dx.doi.org/10.1590/S0100-40422009000100034

PAPOUTSAKIS, S.; MIRALLES-CUEVAS, S.; GONDREXON, N.; BAUP, S.; MALATO, S.; PULGARIN, C. Coupling between high-frequency ultrasound and solar photoFenton at pilot scale for the treatment of organic contaminants: An initial approach. Ultrasonics Sonochemistry, v. 22, p. 527-534, 2015.

http://dx.doi.org/10.1016/j.ultsonch.2014.05.003

PIGNATELLO, J. J.; OLIVEROS, S. E.; MACKAY, A. Advanced oxidation processes of organic contaminant destruction based of the Fenton reaction and related chemistry. Critical Reviews in Environmental Science and Technology, v. 36, p. 1-84, 2006. http://dx.doi.org/10.1080/10643380500326564

SATHISHKUMAR, P.; MANGALARAJA, R.V.; ANANDAN, S. Review on the recent improvements in sonochemical and combined sonochemical oxidation processes - A powerful tool for destruction of environmental contaminants. Renewable and Sustainable Energy Reviews, v. 55, p. 426-454, 2016.

http://dx.doi.org/10.1016/j.rser.2015.10.139

SHIN, S.; YOON, H.; JANG, J. Polymer-encapsulated iron oxide nanoparticles as highly efficient Fenton catalysts. Catalysis Communications, v. 10, p. 178-182, 2008. http://dx.doi.org/10.1016/j.catcom.2008.08.027

SILVA, M. R. A.; TROVÓ, A. G.; NOGUEIRA, R. F. P. Degradation of the herbicide tebuthiuron using solar photo-Fenton process and ferric citrate complex at circumneutral pH. Journal of Photochemistry and Photobiology A: Chemistry, v. 191, p. 187-192, 2007. http://dx.doi.org/10.1016/j.jphotochem.2007.04.022

SIRES, I.; BRILLAS, E. Remediation of water pollution caused by pharmaceutical residues based on electrochemical separation and degradation technologies: A review. Environmental International, v. 40, p. 212-229, 2012.

http://dx.doi.org/10.1016\%2Fj.envint.2011.07.012

SIRTORI, C.; ZAPATA, A.; OLLER, I.; GERNJAK, W.; AGÜERA, A.; MALATO, S. Decontamination industrial pharmaceutical wastewater by combining solar photoFenton and biological treatment. Water Research, v. 43, p. 661-668, 2009a. http://dx.doi.org/10.1016\%2Fj.watres.2008.11.013

SIRTORI, C.; ZAPATA, A.; OLLER, I.; GERNJAK, W.; AGÜERA, A.; MALATO, S. Solar photo-Fenton as finishing step for biological treatment of a pharmaceutical wastewater. Environmental Science \& Technology, v. 43, p. 1185-1191, 2009b. http://dx.doi.org/10.1021/es802550y 
STETER, J. R.; DIONISIO, D.; LANZA, M. R. V.; MOTHEO, A. J. Electrochemical and sonoelectrochemical processes applied to the degradation of the endocrine disruptor methyl paraben. Journal of Applied Electrochemistry, v. 44, n. 12, p. 1317-1325, 2014a. http://dx.doi.org/10.1007/s10800-014-0742-7

STETER, J. R.; Barros, W. R. P.; LANZA, M. R. V.; MOTHEO, A. J. Electrochemical and sonoelectrochemical processes applied to amaranth dye degradation. Chemosphere, v. 117, p. 200-207, 2014b. http://dx.doi.org/10.1016/j.chemosphere.2014.06.085

STETER, J. R.; KOSSUGA, M. H.; MOTHEO, A. J. Mechanistic proposal for the electrochemical and sonoelectrochemical oxidation of thiram on a boron-doped diamond anode. Ultrasonics Sonochemistry, v. 28, p. 21-30, 2016. http://dx.doi.org/10.1016/j.ultsonch.2015.06.022

VALLEJO, M.; ROMÁN, M. F. S. R.; ORTIZ, I.; IRABIEN, A. Overview of the PCDD/Fs degradation potential and formation risk in the application of advanced oxidation processes (AOPs) to wastewater treatment. Chemosphere, v. 118, p. 44-56, 2015. http://dx.doi.org/10.1016\%2Fj.chemosphere.2014.05.077

VOGELPOHL, A. Applications of AOPs in wastewater treatment. Water Science \& Technology, v. 55, n. 12, p. 207-2011, 2007. http://dx.doi.org/10.2166/wst.2007.408

WANG, D.; BOLTON, J. R.; ANDREWS, S. A.; HOFMAN, R. UV/chlorine control of drinking water taste and odour at pilot and full-scale. Chemosphere, v. 136, p. 239-244, 2015a. http://dx.doi.org/10.1016/j.chemosphere.2015.05.049

WANG, J.; RIED, A.; STAPEL, H.; ZHANG, Y.; CHEN, M.; ANG, W.S. et al. A pilot-scale investigation of ozonation and advanced oxidation processes at Choa Chu Kang Waterworks. Water Practice \& Technology, v. 10, n. 1, p. 43-49, 2015b. http://dx.doi.org/10.2166/wpt.2015.006

WEB OF SCIENCE. WoS. 2016. Disponível em: http://www.isiknowledge.com. Acesso em: fev. 2016. 


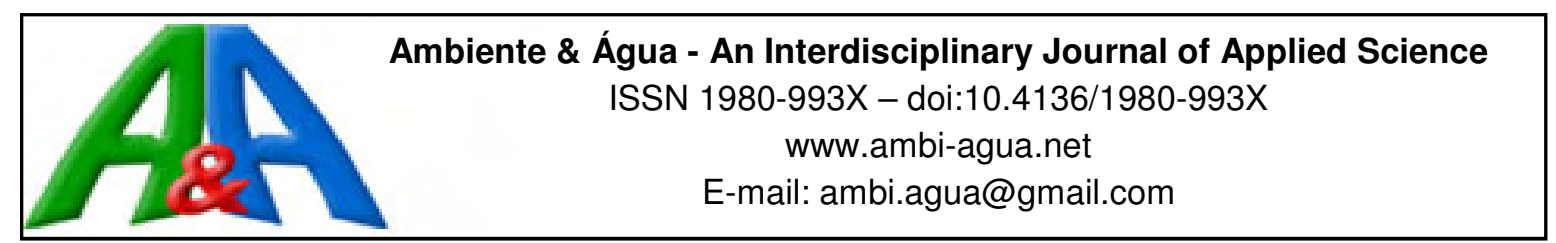

\title{
Vulnerabilidade à contaminação das águas subterrâneas no município de Humaitá, Amazonas, Brasil
}

doi:10.4136/ambi-agua.1797

Received: 04 Nov. 2015; Accepted: 25 Jan. 2016

\author{
Miqueias Lima Duarte ${ }^{1 *}$; Fabrício Berton Zanchi ${ }^{2}$; Juliana Rocha Duarte Neves ${ }^{1}$; \\ Heron Salazar Costa ${ }^{1}$; Walleson Higor Corrêa Jordão ${ }^{1}$ \\ ${ }^{1}$ Universidade Federal do Amazonas (UFAM), Humaitá, AM, Brasil \\ Instituto de Educação Agricultura e Ambiente - IEAA \\ ${ }^{2}$ Universidade Federal do Sul da Bahia (UFSB), Porto Seguro, BA, Brasil \\ *Autor correspondente: e-mail: miqueiaseng@ hotmail.com, \\ faberzanchi@gmail.com,julianaengamb@outlook.com, \\ hescosta@ufam.edu.br,wallesonjordao@gmail.com
}

\section{RESUMO}

Os recursos hídricos subterrâneos têm sido utilizados em grande escala em todo o território brasileiro. No sul do estado do Amazonas, sua utilização é exclusiva em vários municípios, porém esta região é caracterizada pelo precário quadro de saneamento básico. Considerando-se tal importância das águas subterrâneas, foi realizado um estudo com o objetivo de classificar e mapear a vulnerabilidade à contaminação da água subterrânea sob área urbana e adjacências do município de Humaitá, sul do Estado do Amazonas. A aplicação do método GOD (Groundwater occurrence; Overall lithology of the unsaturated zone; and Depth of the water table), permitiu identificar as classes de vulnerabilidade na área. Os resultados obtidos revelaram a existência de média e alta vulnerabilidade à contaminação do aquífero na área, indicando a fragilidade do sistema aquífero que abastece o município, e a necessidade da adoção de políticas públicas que visem à proteção dos recursos hídricos subterrâneos da região.

Palavras-chave: aquífero aluvionar, método GOD, recursos hídricos.

\section{Vulnerability of groundwater to contamination in the municipality of Humaitá, Amazonas}

\begin{abstract}
Groundwater has been used intensively throughout Brazil. In southern Amazonas state, the water supplies of some municipalities are derived exclusively from wells. Yet this region generally has no wastewater treatment, leading to potential contamination of the underground water. We classified and mapped the vulnerability of groundwater supplies to contamination in the urban and peri-urban area of Humaitá in southern Amazonas State. We used the GOD method (Groundwater occurrence; Overall Lithology of the unsaturated zone; Depth of the water table) to score vulnerability classes. The results revealed the existence of average and
\end{abstract}


high vulnerability of aquifer contamination in the area, indicating the fragility of the aquifer system that supplies the municipality, and showing the need for public policies aimed at the protection of the region's groundwater resources.

Keywords: alluvial aquifer, GOD method, water resources.

\section{INTRODUÇÃO}

Os sistemas de águas subterrâneas são fontes naturais bem mais resistentes à poluição do que os de águas superficiais, pois a camada de solo sobrejacente atua como filtro impedindo o deslocamento de poluentes para a camada saturada (Foster et al., 2006). E por serem fontes de água mais limpas, e geralmente possuindo boa qualidade, vêm sendo utilizados em grande escala para abastecimento de cidades e núcleos urbanos em todo Brasil (ANA, 2010).

No estado do Amazonas, a maioria das comunidades e aglomerados urbanos está situada na margem dos rios da região. No entanto, a despeito da grande disponibilidade hídrica superficial, a maioria dos municípios amazonenses possui captação de água para abastecimento urbano efetuado por poços rasos (ANA, 2010).

Os principais aquíferos explorados para abastecimento público no estado do Amazonas são: Içá, Alter do Chão e os demais relacionados às Coberturas Aluvionares. Os classificados como de Cobertura Aluvionares recentes e antigas se constituem como o terceiro sistema aquífero mais importante do estado do Amazonas, sendo fonte de abastecimento de vários núcleos urbanos (Maia, 2010).

O município de Humaitá, localizado ao sul do estado, é um exemplo onde o abastecimento de água consiste exclusivamente de fontes subterrâneas. Os sistemas de abastecimento de água desse município e de outras 18 sedes municipais são bastante precários, uma vez que é captada e distribuída sem tratamento (ANA, 2010). Segundo Maia (2010), os sistemas aquíferos relacionados à Cobertura Aluvionares que abastece a região são mais susceptíveis à contaminação por serem geralmente mais raso e facilmente alcançado por poluentes. Além disso, a região é marcada pelo precário quadro de saneamento básico, que segundo Foster et al. (2006), o tratamento inadequado desses resíduos é uma das principais fontes de contaminantes das águas subterrâneas.

Vários métodos de avaliação de vulnerabilidade à contaminação de aquíferos têm sido utilizados no Brasil e em diversas partes do mundo. Tais metodologias apresentam grande aplicabilidade no planejamento do uso do solo, no monitoramento da qualidade das águas subterrâneas e em investigação de risco de contaminação dos aquíferos (Tavares et al., 2009; Cutrim e Campos, 2010; Barbosa et al., 2011; Meira et al., 2014; Caniani et al., 2015; Eke et al., 2015; Löbler e Silvério da Silva, 2015; Miranda et al., 2015; Muhammad, et al,. 2015). Dentre eles, destaca-se o Método GOD (Groundwater Overall Depth) proposto por Foster e Hirata (1988), que pela simplicidade de aplicação e praticidade nas análises dos resultados, tem sido amplamente utilizado na avaliação de aquíferos e como auxílio no gerenciamento dos recursos hídricos subterrâneos e no planejamento de políticas públicas.

Os métodos de avaliação de vulnerabilidade à contaminação de aquíferos aliados às técnicas de cartografia em ambiente SIG (Sistema de Informação Geográfica) têm sido amplamente utilizados no estudo de vulnerabilidade de aquíferos, e sua aplicação tem sido bem descrita em vários trabalhos (Miranda et al., 2015; Linhares et al., 2014; Tavares et al., 2009; Nobre et al., 2008). Segundo Foster et al. (2006), a utilização da plataforma SIG adequada facilita a interação, a atualização e a apresentação dos resultados.

O preocupante quadro de saneamento básico apresentado no município de Humaitá/AM juntamente com insuficiência de informação do sistema aquífero da região, estimulou o desenvolvimento deste estudo que tem como objetivo avaliar a vulnerabilidade à contaminação das águas subterrâneas na área urbana e adjacências do município, com o 
emprego do método GOD.

\subsection{Caracterização da área de estudo}

A área de estudo compreende o meio urbano e parte da zona rural do munícipio de Humaitá, sul do estado do Amazonas (Figura 1). Situada à margem esquerda do rio Madeira,

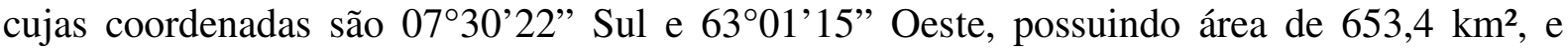
distante $591,1 \mathrm{~km}$ da capital amazonense.

O município de Humaitá limita-se com os municípios de Canutama, Tapauá, Manicoré e com o estado de Rondônia (Jordão et al., 2015). Sua população, segundo IBGE (2011), é de 44.116 habitantes, sendo que o meio urbano possui uma população de 34.501 habitantes. Segundo a ANA (2010), o abastecimento de água no município é realizado por meio de poços pouco profundos, ou tipo amazonas.

Segundo informações obtidas junto à companhia de saneamento do município, o sistema de abastecimento municipal é constituído por 25 poços tubulares e seis reservatórios (COHASB, 2015). Com base nas informações disponíveis na décima nona edição do Diagnóstico dos Serviços de Água e Esgotos - 2013 elaborado pela Secretaria Nacional de Saneamento Ambiental do Ministério das Cidades, e com base em dados do Sistema Nacional de Informações sobre Saneamento - SNIS, o sistema pode ser considerado precário, pois não conta com procedimentos e infraestrutura para o tratamento, consistindo apenas da captação e distribuição. Ainda segundo a mesma fonte, o município de Humaitá não possui sistema de tratamento de esgoto.

\subsubsection{Clima}

Segundo a classificação de Köppen, o clima da região é do tipo Am (tropical úmido), caracterizado por temperatura média anual de $25^{\circ} \mathrm{C}$ e uma estação seca de pequena duração, entre os meses de junho e agosto. A elevada pluviosidade é um dos aspectos mais característicos da região, com valores entre 2.050 a $2.650 \mathrm{~mm}$ por ano e elevada umidade do ar, variando entre 85 e $90 \%$ (Martins et al., 2006).

\subsubsection{Geologia}

A região sul do Amazonas que inclui o município de Humaitá é caracterizada por planícies de grande extensão, constituídas por depósitos sedimentares, em que, a Formações Terraços Fluviais, Depósitos Aluvionares e Formação Içá são os principais que afloram na área (Figura 1).

Segundo Maia (2010), os sedimentos depositados nas margens dos grandes rios amazônicos correspondem aos terrenos geologicamente mais novos do estado, os quais se apresentam como produto inconsolidados ou pouco consolidados da sedimentação dos rios, e em bacias de deposição fluviolacustre ao longo de todo o período Quaternário. Reis (2006) afirma que os Terraços Fluviais correspondem a amplos depósitos sedimentares constituídos por argila, areia e cascalho, via-de-regra, inconsolidados a semiconsolidados. Já os Depósitos Aluvionares são descritos e representados por sedimentos arenosos e argilosos que são classificados como inconsolidados a semiconsolidados, associando-lhes níveis de cascalho e matéria orgânica.

A unidade geológica denominada Formação Içá que aflora em grande extensão no município, no geral, é constituída por siltitos, arenitos finos a médio (Sarges et al., 2010). Encontra-se acamada de maneira descontinua sobre a formação médio-Mioceno Solimões (Maia et al., 1977; Latrubesse et al., 1994).

A Figura 2 mostra uma seção geológica esquemática, elaborada dos dados sobre os poços tubulares da região disponibilizados pelo Sistema de Informações de Águas Subterrâneas/SIAGAS (2015) da Companhia de Pesquisas e Recursos Minerais/CPRM (2015) 
e pela Companhia de Abastecimento e Saneamento de Humaitá (COHASB, 2015).

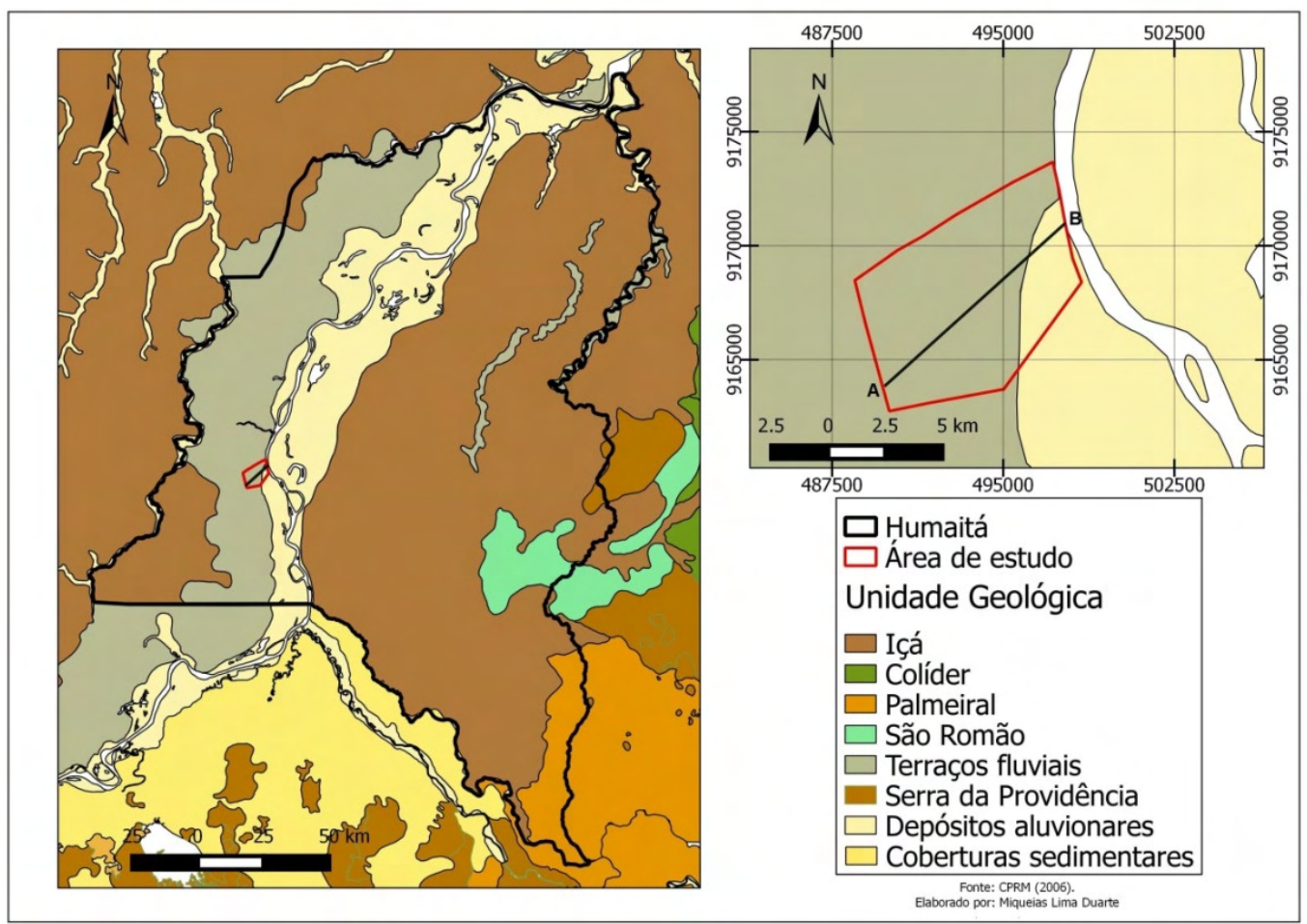

Figura 1. Mapa da geologia da área de estudo.

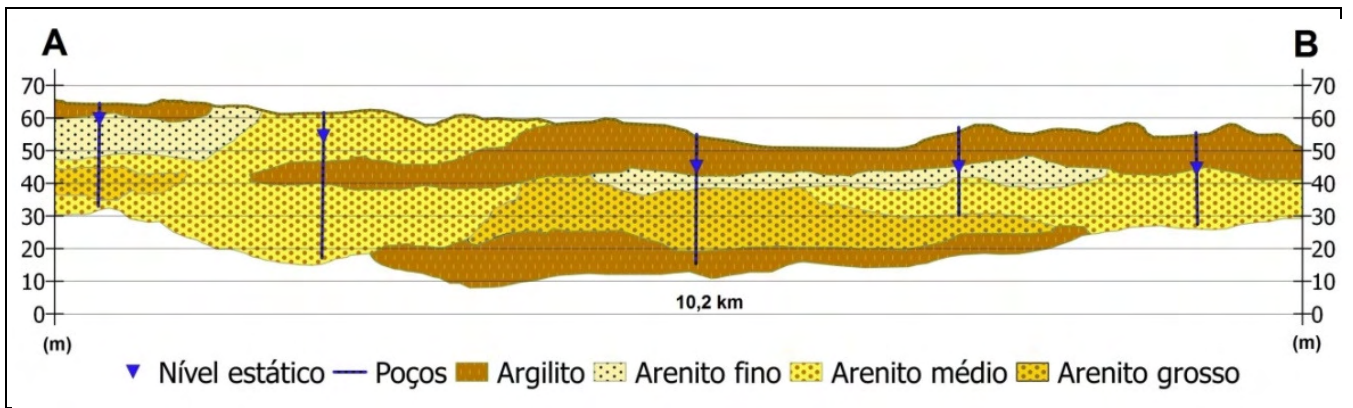

Figura 2. Seção geológica esquemática da área de estudo.

De modo geral, há primeiramente a ocorrência de argilitos ou argilitos arenosos, com espessura média de $8,7 \mathrm{~m}$, e em alguns casos a ocorrência de afloramento arenoso. Essa camada argilosa recobre arenitos finos a médios e grossos, apresentando, em alguns locais, intercalados a argilito. A seção de arenito fino, médio e grosso pode alcançar profundidades de até $35 \mathrm{~m}$ (espessura média de $20 \mathrm{~m}$ ). É nessa camada que está localizada grande parte das seções de filtros da maioria dos poços tubulares utilizados para o abastecimento de água na região.

\subsubsection{Hidrogeologia}

Conforme o mapa geológico (Figura 1) disponibilizado pela CPRM, a área de estudo apresenta dois afloramentos geológicos: Depósito Aluvionar e Terraço Fluvial. No entanto, os dados dos perfis de poços tubulares disponibilizados pela SIAGAS indicam apenas a Formação Depósito Aluvionar na área de estudo.

Nesse trabalho, adotou-se a definição de sistema aquífero Aluvionar em acordo com 
Maia (2010), a qual relaciona os aquíferos da região com as diversas coberturas aluvionares formadas ao longo dos grandes rios amazônicos. Pereira e Cajazeiras (2012) caracterizam esses aquíferos como sendo livres, com porosidade intergranular; sendo compreendidos pelos sedimentos arenosos da Formação Depósito Aluvionar formada às margens do rio Madeira.

Esses sistemas aquíferos são responsáveis por abastecimento de vários núcleos urbanos e comunidades em boa parte do estado do Amazonas, apresentam vazão de 10 a $15 \mathrm{~m}^{3} \mathrm{~h}^{-1}$, e boa qualidade química (Maia, 2010). Normalmente apresentando espessura máxima de $40 \mathrm{~m}$, e transmissividade variando de $6,6 \times 10^{-6} \mathrm{~m}^{2} \mathrm{~s}^{-1}$ a $4,27 \times 10^{-3} \mathrm{~m}^{2} \mathrm{~s}^{-1}$, com valor médio de $6,03 \times 10^{-4} \mathrm{~m}^{2} \mathrm{~s}^{-1}$. E normalmente, encontram-se presente nos depósitos sedimentares constituídos por areia, silte, argila e cascalho (Maia, 2010; Pereira e Cajazeiras, 2012).

\section{MATERIAL E MÉTODOS}

\subsection{Obtenção dos Dados}

Para aplicação do método GOD, foram extraídos informações de poços tubulares da área de estudo no banco de dados do Sistema de Informações de Águas Subterrâneas/SIAGAS da Companhia de Pesquisas e Recursos Minerais/CPRM.

No banco de dados do SIAGAS, existem registros de 162 poços tubulares para a área de estudo, no entanto, apenas 16 poços contêm os requisitos necessários para a aplicação do método GOD. Nesse caso, foram extraídas informações sobre a identificação dos poços (ID), coordenadas UTM, nível estático, formação geológica e perfil litológico. Também foi realizada uma inspeção de campo para identificação e verificação da situação dos poços de captura, sendo utilizado um GPS (Global Position System), modelo Garmim 60CSx para validação dos dados.

\subsection{Método GOD}

O método GOD proposto por Foster e Hirata (1988) e modificado por Foster et al. (2006) para avaliar a vulnerabilidade à contaminação de aquíferos é baseado na análise de três parâmetros representados por "G" (Groundwater hydraulic confinement) que é o grau de confinamento do aquífero, variado de 0 a 1, "O" (Overlaying strata) que corresponde ao tipo de litologia encontrada na zona não saturada, variando de 0,4 a 1 , e " $\mathrm{D}$ " (Depth to groundwater table) que corresponde à profundidade do nível d'água, variando de 0,6 a 1 (Foster et al. 2006).

O índice de vulnerabilidade (IV) constitui-se a partir do produto dos três parâmetros (Equação 1), onde valores mais próximos de 0 corresponde a menores índices de vulnerabilidade, já valores mais próximos de 1 corresponde a maiores índices de vulnerabilidade (Foster et al. 2006).

$$
I V=G \times O \times D
$$

\subsection{Obtenção dos parâmetros GOD}

Com os dados do perfil dos poços tubulares da área de estudo obtidos no SIAGAS, e de acordo com Maia (2010), é possível caracterizar o sistema aquífero que abrange a área como sendo livre com porosidade intergranular, compreendidos pelos sedimentos arenosos da Formação Depósito Aluvionar na parte superior, e na parte inferior pela Formação Içá, formado à margem do rio Madeira.

O método GOD atribui índice 0,6 a 1,0 para aquíferos livres, onde 0,6 é atribuído para aquíferos livres que apresentam cobertura, e 1,0 para aquíferos sem cobertura. Nesse trabalho, atribui-se índice 0,6 para pontos que apresentaram, na seção superior, camadas de sedimentos argilosos, já os locais que apresentaram cobertura por sedimentos arenosos, o índice empregado para tal parâmetro foi igual a 1,0. 
No que diz respeito ao índice "O", o método GOD atribui valores a esse parâmetro com base na litologia da camada insaturada, ou seja, a camada acima do nível estático. Desse modo, foram avaliadas as seções geológicas presente, sendo observadas as seções de argilito, arenito fino, arenito médio e arenito grosso. Nesse caso, o parâmetro "O" deu-se com base na presença dessas seções, sendo atribuído índice 0,5 (argilito), 0,66 (arenito sobreposto a argilito) e 0,8 (arenito médio e grosso).

O parâmetro " $D$ " deu-se conforme os registros do nível estático dos poços, sendo verificado que o mesmo variou entre 4,0 e 18,2 metros (média de 9,95 m), onde os índices empregados foram 0,8 para profundidades de 20 a 5 metros e 0,9 para profundidades menores que 5 metros.

O índice de vulnerabilidade à contaminação do aquífero foi obtido pela multiplicação dos três parâmetros GOD, conforme descrito por Foster et al. (2006).

\subsection{Interpolação e Confecção Cartográfica}

O processamento dos dados foi realizado com auxílio do Sistema de Informação Geográfica (SIG) QGIS 2.8, onde foi realizada uma interpolação dos índices "G" "O" e "D" aplicando o método Inverso Ponderado da Distância (Inverse Distance Weighting - IDW) conforme descrito por Marcuzzo et al. (2011).

O mapa de vulnerabilidade à contaminação foi obtido por meio da ferramenta Calculadora Raster do QGIS, sendo realizada uma multiplicação entre os parâmetros "G" "O" e "D" interpolados. A multiplicação pixel a pixel de cada parâmetro GOD permitiu obter um novo Raster resultante dos valores das imagens originais interpoladas (Medeiros et al., 2011).

Foi realizado o estudo da tendência de direção do fluxo das águas subterrâneas do local, utilizando-se as cotas altimétricas extraídas da base de dados do SIAGAS. A superfície potenciometrica foi obtida com base na diferença entre a cota da "boca" do poço e o nível da água de cada poço avaliado. A espacialização dos dados foi realizada no ambiente QGIS 2.8.

$\mathrm{Na}$ confecção cartográfica do mapa dos parâmetros GOD, IV e tendência de fluxo, utilizou-se a malha do setor censitário disponibilizado pelo IBGE, o sistema de coordenadas Universal Transversal de Mercator (UTM), e base de referência SIRGAS 2000, Zona 20S.

\section{RESULTADOS E DISCUSSÃO}

Com base nos dados apresentados, o sistema aquífero livre, intergranular que abastece o município é constituído pela Formação Depósito Aluvionar, ocorrendo sobreposto a Formação Içá (Tabela 1), com espessura média de 23,75 metros. Esse sistema de aquífero apresenta nível estático pouco profundo, o que o caracteriza como mais vulnerável à contaminação, por ser mais raso, e apresentar na camada instaurada, constituintes de predominância arenosa.

A Tabela 1 apresenta algumas características gerais dos poços tubulares analisados nesse estudo, e a Figura 3 apresenta o mapa do nível estático da área bem como a distribuição dos parâmetros GOD.

Com a multiplicação dos parâmetros GOD obteve-se o índice de vulnerabilidade à contaminação do aquífero. Foram identificados 3 classes de vulnerabilidade (Figura 4), sendo elas: baixa, média e alta. A vulnerabilidade predominante foi baixa, cobrindo $49 \%$ da região, seguida de vulnerabilidade alta com $38,3 \%$ de área e por último, a vulnerabilidade média, correspondendo a $12,7 \%$ da área.

A predominância da baixa vulnerabilidade observada em $49 \%$ da área de estudo deve-se a ocorrência em predominância da camada superficial argilosa, como apresentado na Figura 2. Essas camadas constituídas de argila servem como proteção natural ao aquífero, 
agregando menores índices de vulnerabilidade pelo método empregado.

Tabela 1. Identificação dos poços (ID) e informações das respectivas profundidades dos poços e Formação Geológica, Nível Estático (NE) e índice de vulnerabilidade (IV).

\begin{tabular}{|c|c|c|c|}
\hline ID & Profundidade dos Poços/Formação Geológica & $\mathrm{NE}$ & IV \\
\hline 1300000910 & 0 a 23m Depósito Aluvionar & 11,5 & Baixa \\
\hline 1300000912 & 0 a 30m Depósito Aluvionar, 30 a 36m Formação Içá & 18,2 & Baixa \\
\hline 1300000913 & 0 a 30m Depósito Aluvionar, 30 a 36m Formação Içá & - & Baixa \\
\hline 1300000914 & 0 a 26m Depósito Aluvionar & 10 & Média \\
\hline 1300000916 & 0 a 30m Depósito Aluvionar, 30 a 34m Formação Içá & 7,4 & Média \\
\hline 1300000917 & 0 a 23m Depósito Aluvionar & 12,3 & Baixa \\
\hline 1300004807 & 0 a 30m Depósito Aluvionar & 6 & Alta \\
\hline 1300004809 & 0 a 30m Depósito Aluvionar & - & Alta \\
\hline 1300004986 & 0 a 30m Depósito Aluvionar, 30 a 36m Formação Içá & 12 & Baixa \\
\hline 1300004991 & 0 a 30m Depósito Aluvionar, 30 a 36m Formação Içá & 12 & Baixa \\
\hline 1300004992 & 0 a 30m Depósito Aluvionar, 30 a 36m Formação Içá & 12 & Baixa \\
\hline 1300005007 & 0 a 23m Depósito Aluvionar & 11 & Baixa \\
\hline 1300005034 & 0 a $18 \mathrm{~m}$ Depósito Aluvionar & 6 & Alta \\
\hline 1300005055 & 0 a 30m Depósito Aluvionar, 30 a 40m Formação Içá & 8 & Média \\
\hline 1300005064 & 0 a 20m Depósito Aluvionar & 4 & Alta \\
\hline 1300007151 & 0 a 30m Depósito Aluvionar, 30 a 43m Formação Içá & 9 & Alta \\
\hline
\end{tabular}

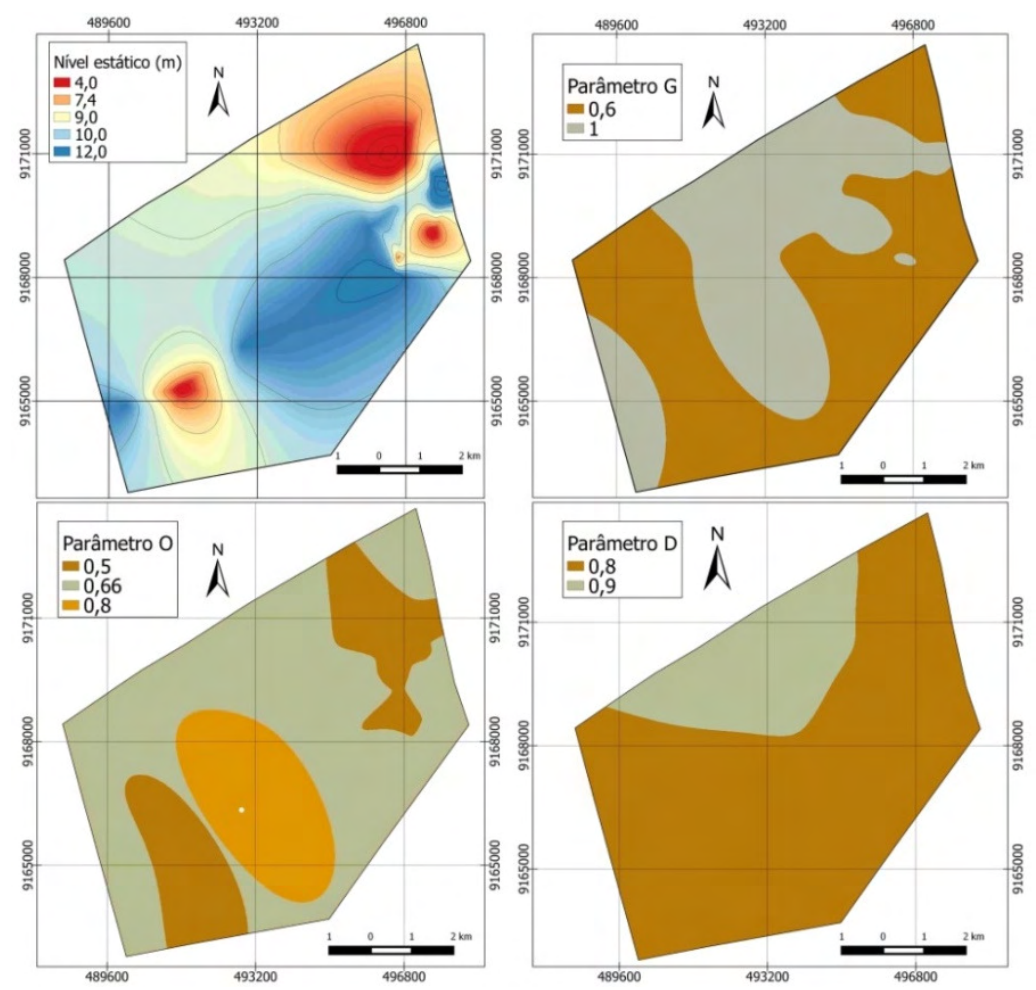

Figura 3. Mapa de nível estático e distribuição dos parâmetros GOD. 


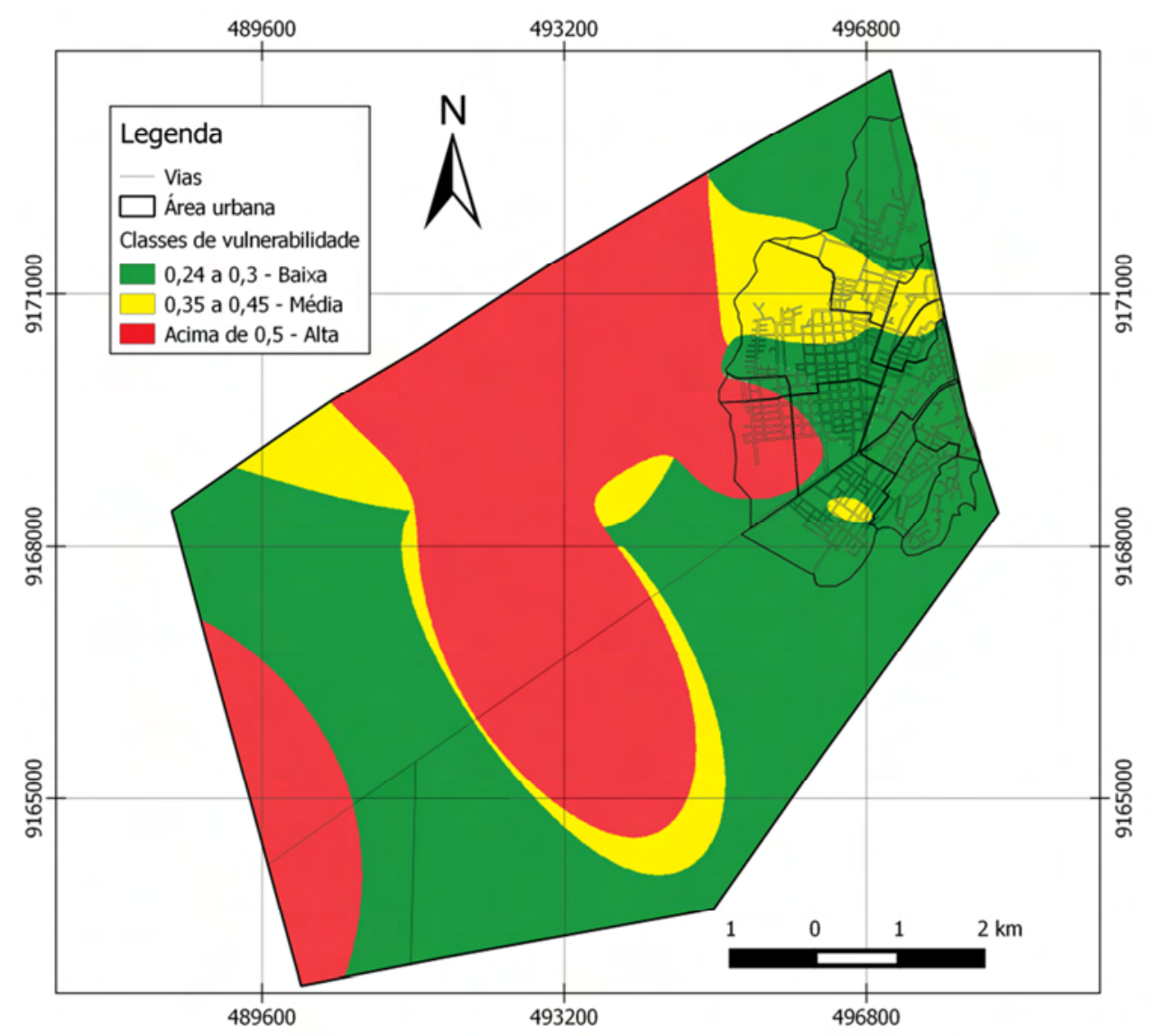

Figura 4. Mapa de vulnerabilidade à contaminação do aquífero.

Por outro lado, a somatória da vulnerabilidade média e alta apresenta-se em $51 \%$ da área de estudo, o que é explicado pelo fato de se tratar de um aquífero livre, com nível estático pouco profundo, juntamente com a camada vadosa constituída por sedimentos arenosos. Essas áreas apresentam um maior potencial à contaminação, pois a acessibilidade hidráulica é maior em função das características geológicas e hidrogeológicas do local.

Vale ressaltar que, as áreas de alta e média vulnerabilidade à contaminação ocorreram em predominância no meio rural, enquanto que, no meio urbano apenas uma pequena parte a oeste apresentou alta vulnerabilidade, enquanto a parte sul apresentou média e baixa vulnerabilidade à contaminação do aquífero. É importante destacar que $25 \%$ dos poços localizam-se em área de alta vulnerabilidade e 18,7\% em áreas de média vulnerabilidade, o restante, cerca de 56,3\% encontra-se em áreas de baixa vulnerabilidade à contaminação. Esses últimos são os que apresentam maior taxa de bombeamento para abastecimento residencial (COHASB, 2015).

Nesse caso, uma informação importante seria a provável direção de fluxo do aquífero, uma vez que a alta vulnerabilidade à contaminação encontra-se em predominância, fora da zona de captura do meio urbano. O estudo da tendência de fluxo local é ilustrado na Figura 5, onde é possível observar a predominância de fluxo de área de alta vulnerabilidade para áreas de média e baixa vulnerabilidade à contaminação (do extremo Norte para a parte Sul e Leste da área).

A predominância desse comportamento de fluxo é preocupante, pois caso ocorra uma contaminação do aquífero nesses locais, o mesmo pode comprometer a qualidade da água captada no meio urbano do município (Leste). Deste modo, é de suma importância o planejamento do uso e ocupação da área pelos órgãos gestores, bem como análises mais especifica de avaliação e proteção de zonas de captação. 


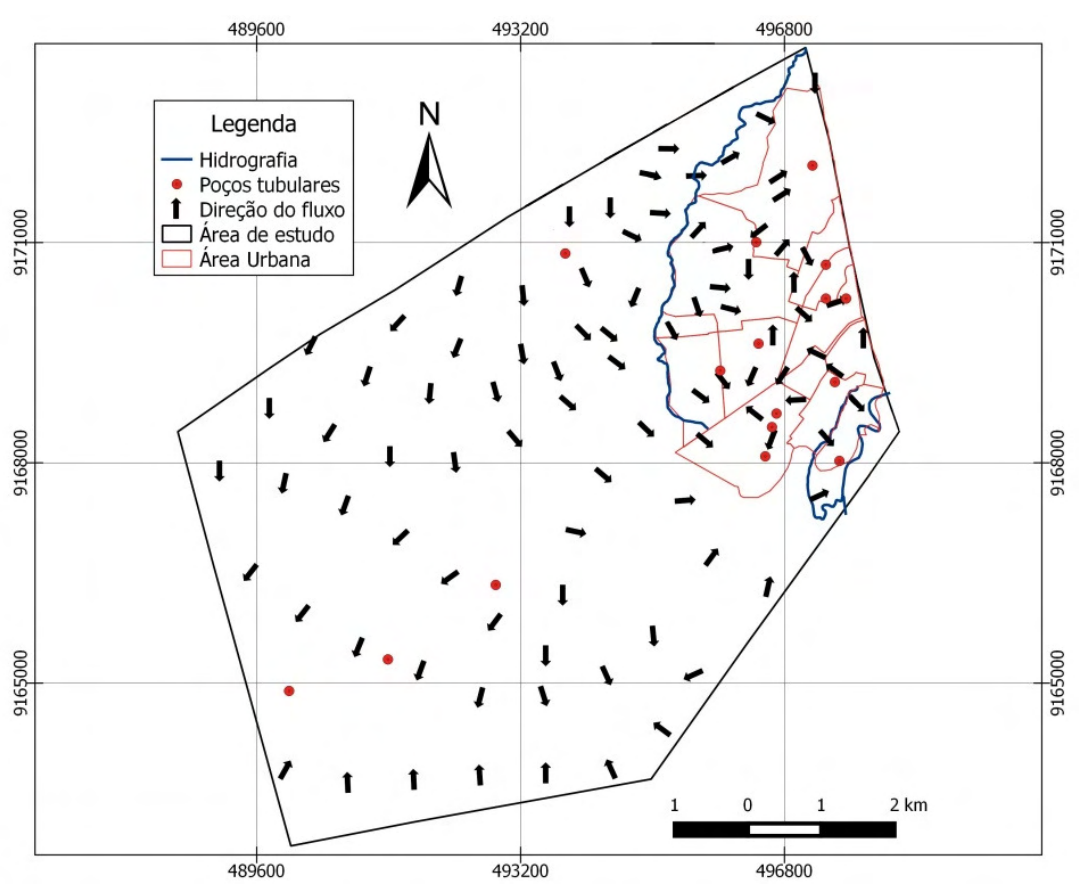

Figura 5. Mapa de direção de fluxo da água subterrânea na área de estudo.

\section{CONSIDERAÇÕES FINAIS}

A Formação geológica Depósito Aluvionar que compreende o sistema aquífero avaliado, constituído por material arenoso, foi um fator que contribuiu para a ocorrência de altos índices de vulnerabilidade à contaminação.

A elaboração do mapa de vulnerabilidade à contaminação, com base no método GOD possibilitou observar que $49 \%$ da área possui baixa vulnerabilidade à contaminação, no entanto, a média e alta vulnerabilidade perfazem $51 \%$ da área, o que decorre das características geológicas e hidrogeológicas do local. Isso não caracteriza com sendo uma situação de risco à contaminação do sistema aquífero por se tratar de uma área que, atualmente apresenta pouca ação antrópica.

Mesmo ocorrendo predominância da baixa vulnerabilidade à contaminação na área de estudo, é motivo de preocupação a ocorrência das áreas de média e alta vulnerabilidade à contaminação, pois a deficiência na infraestrutura de coleta de esgoto do município poderá acarretar em contaminação do recurso hídrico subterrâneo. Deste modo, é de suma importância o delineamento de áreas de proteção, bem como o mapeamento das fontes potenciais de geração de carga contaminante na área. Também é recomendável o monitoramento físico-químico e microbiológico da qualidade da água distribuída pelos poços na área de estudo.

Espera-se que o resultado apresentado no presente trabalho possa auxiliar os órgãos gestores em um melhor planejamento do uso e ocupação da área, bem como contribuir na difusão do conhecimento dos sistemas de aquíferos da região.

\section{AGRADECIMENTOS}

À Universidade Federal do Amazonas - UFAM/IEAA, à Fundação de Amparo e Pesquisa do Estado do Amazonas/FAPEAM e ao Programa de Apoio à Iniciação em Desenvolvimento Tecnológico/PAITI pelo auxílio financeiro concedido (Processo $\mathrm{N}^{\circ}$ 062.00455/2015). 


\section{REFERÊNCIAS}

AGÊNCIA NACIONAL DE ÁGUAS - ANA (Brasil). Atlas Brasil. Abastecimento Urbano de Água: panorama nacional. Brasília: Agência Nacional de Águas; Engecorps/Cobrape, 2010.

BARBOSA, C. M.; CARVALHO, A. M.; IKEMATSU, P.; ALBUQUERQUE FILHO, J. L.; CAVANI, A. C. M. Avaliação do perigo de contaminação do Sistema Aquífero Guarani em sua área de afloramento do estado de São Paulo decorrente das atividades agrícolas. Águas subterrâneas, v. 25, n, 1, p. 1-14, 2011.

http://dx.doi.org/10.14295/ras.v25i1.21296

CANIANI, D.; LIOI, D. S.; IGNAZIO M.; MANCINI, I. M.; MAIS, S. Hierarchical classification of groundwater pollution risk of contaminated sites using Fuzzy Logic: A Case study in the Basilicata Region (Italy). Water, v. 7, p. 2013-2036, 2015. http://dx.doi.org/10.3390/w7052013

COMPANHIA HUMAITAENSE DE ÁGUAS E SANEAMENTO BÁSICO - COHASB. Relatório técnico dos poços. Humaitá, 2015. p. 2. (Relatório não publicado).

CUTRIM, A. O.; CAMPOS, J. E. G. Avaliação da vulnerabilidade e perigo à contaminação do Aquífero Furnas na cidade de Rondonópolis (MT) com aplicação dos métodos GOD e POSH. Revista Geociências, v.29, n. 3. 2010.

EKE, D. R.; OPARA, A. I.; INYANG, G. E.; EMBERGA, T. T.; ECHETAMA, H. N.; UGWUEGBU, C. A. et al. Hydrogeophysical evaluation and vulnerability assessment of Shallow Aquifers of the Upper Imo River Basin, Southeastern Nigeria. American Journal of Environmental Protection, v. 3, n. 4, p. 125-136, 2015. http://dx.doi.org/10.12691/env-3-4-3

FOSTER, S.; HIRATA, R. Groundwater pollution risk assessment: a methodology using available data. Lima: WHO/PAHO/HPECEPIS, 1988. p. 81.

FOSTER, S.; HIRATA, R.; GOMES, D.; D’ELIA, M.; PARIS, M. Proteção da qualidade da água subterrânea: um guia para empresas de abastecimento de água, órgãos municipais e agências ambientais. São Paulo: Servemar, 2006. p.15-81.

INSTITUTO BRASILEIRO DE GEOGRAFIA E ESTATÍSTICA - IBGE. Censo Demográfico 2010. Indicadores de bairros - região norte. Rio de Janeiro, 2011. Disponível em: http://www.ibge.gov.br. Acesso em: 20 mar. 2014.

JORDÃO, W. H. C.; ZANCHI, F. B.; FERREIRA, D. M. M.; PAGANI, C. H. P.; LUIZÃO, F. J.; NEVES, J. R. D. et al. Variabilidade do índice de área foliar em campos naturais e floresta de transição na região Sul do Amazonas. Revista Ambiente \& Água, v. 10, n. 2, p. 363-375, 2015. http://dx.doi.org/10.4136/ambi-agua. 1490

LATRUBESSE, E.; RANCY, A.; RAMONELL, C. G.; SOUZA FILHO, J. P. A formação Solimões: uma formação do Mio-Plioceno da Amazônia sul-ocidental. In: SIMPÓSIO DE GEOLOGIA DA AMAZÔNIA, 4., 1994, Belém. Boletim de Resumos Expandidos... Belém: Sociedade Brasileira de Geologia. Núcleo Norte, 1994. p. 204205 
LINHARES, F. M.; ALMEIDA, C. N.; SILANS, A. M. B. P.; COELHO, V. H. R. Avaliação da vulnerabilidade e do risco à contaminação das águas subterrâneas da bacia hidrográfica do Rio Gramame (PB). Sociedade \& Natureza, v. 26, n. 1, p. 139-157, 2014. http://dx.doi.org/10.1590/1982-451320140110

LÖBLER, C. A.; SILVERIO DA SILVA, J. L. Vulnerabilidade à contaminação das águas subterrâneas do munícipio de Nova Palma, Rio Grande do Sul, Brasil. Revista

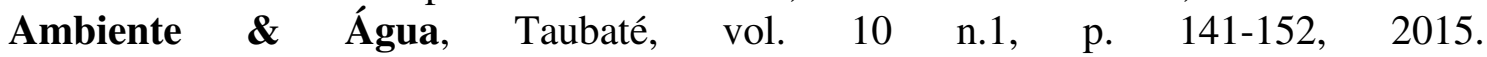
http://dx.doi.org/10.4136/ambi-agua.1390

MAIA, M. A. M. Geodiversidade do estado do Amazonas. Manaus: CPRM, 2010. p. 59-71.

MAIA, R. G.; GODOY, H. K.; YAMAGUTI, H. S.; MOURA, P. A.; COSTA, F. S. Projeto carvão no Alto Amazonas. Relatório Final. Rio de Janeiro: CPRM, 1977.

MARCUZZO, F. F. N.; DE ANDRADE, L. R.; MELO, D. C. R. Métodos de interpolação matemática no mapeamento de chuvas do estado do Mato Grosso. Revista Brasileira de Geografia Física, n. 04, p. 193-804, 2011.

MARTINS, G. C.; FERREIRA, M. M.; CURI, N.; VITORINO, A. C. T.; SILVA. M. L. N. Campos nativos e matas adjacentes da região de Humaitá (AM): atributos diferenciais dos solos. Ciência e Agrotecnologia, v. 30, n. 2, 2006. http://dx.doi.org/10.1590/S1413-70542006000200005

MEDEIROS, C. M.; RIBEIRO, M. A. DE F. M.; RUFINO, I. A. A.; BARBOSA, D. L. Mapeamento da vulnerabilidade de parte da bacia sedimentar do baixo curso do Rio Paraíba utilizando o método GOD. In: SIMPÓSIO BRASILEIRO DE SENSORIAMENTO REMOTO - SBSR, 15., Curitiba. Anais... São José dos Campos: INPE, 2011. p. 3819-3826.

MEIRA, J. R.; DE-CAMPOS, A. B.; PEREIRA, L. C. Vulnerabilidade natural e perigo à contaminação de zona de recarga do Aquífero Guarani. Águas Subterrâneas, v. 28, n. 1, p. 31-46, 2014.

MIRANDA, C. DE S.; MIOTO, C. L.; LASTORIA, G.; GABAS, S. G.; PARANHOS FILHO, A. C. Uso de Sistemas de Informação Geográfica (SIG) na modelagem da vulnerabilidade de aquífero livre: comparação entre os métodos GOD e Ekv na bacia do Rio Coxim, São Gabriel do Oeste, MS, Brasil. Geociências, v. 34, n. 2, p. 312-322, 2015.

MUHAMMAD, A. M.; ZHONGHUA, T.; DAWOOD, A. S.; EARL, B. Evaluation of local groundwater vulnerability based on DRASTIC index method in Lahore, Pakistan. Geofísica Internacional, v. 54 -1, p. 67-81, 2015. http://dx.doi.org/10.1016/j.gi.2015.04.003

NOBRE, R. C. M.; NOBRE, M. M. M.; ROTUNNO FILHO, O. C.; MANSUR, W. J. Mapeamento do índice de perigo ao consumo de águas subterrâneas vulneráveis à contaminação. Revista Brasileira de Recursos Hídricos. v. 13, n. 2, p. 101-111, 2008.

PEREIRA, L. A. C.; CAJAZEIRAS, C. C. A. Caracterização dos principais aquíferos da região sudoeste da Amazônia Ocidental. In: CONGRESSO BRASILEIRO DE ÁGUAS SUBTERRÂNEAS, 17. E ENCONTRO NACIONAL DE PERFURADORES DE POÇOS, 18., 2012, Bonito. Anais... São Paulo: ABAS, 2012.p. 1-4. 
REIS, N. J. Geologia e recursos minerais do Estado do Amazonas. Manaus: CPRM, 2006. p. 35-96.

SARGES, R. R.; NOGUEIRA, A. C. R.; FROTA, C. A.; LOPES DA SILVA, C. Depósitos argilosos Cenozóicos do estado do Amazonas: utilização como agregados de argilas calcinadas para pavimentações na região Amazônica. Brazilian Geographical Journal: Geosciences and Humanities research médium, v. 1, n. 1, p. 33-49, 2010.

SERVIÇO GEOLÓGICO DO BRASIL - CPRM. Mapas estaduais de Geodiversidade. Rio de Janeiro: GEOBANK, 2015. Disponível em: http://geobank.cprm.gov.br/ . Acesso em: 31 ago. 2015.

SISTEMA DE INFORMAÇÃO DE ÁGUAS SUBTERRÂNEAS - SIAGAS. Website. 2015. Disponível em: http://siagasweb.cprm.gov.br. Acesso em: 23 mar. 2015.

TAVARES, P. R. L.; DE CASTRO, M. A. H.; DA COSTA, C.T. F.; DA SILVEIRA, J. G. P.; ALMEIDA JÚNIOR, F. J. B. Mapeamento da vulnerabilidade à contaminação das águas subterrâneas localizadas na Bacia Sedimentar do Araripe, Estado do Ceará, Brasil. Rem: Revista Escola de Minas, v. 62, n. 2, p. 227-236, 2009. http://dx.doi.org/10.1590/S0370-44672009000200015 


Ambiente \& Água - An Interdisciplinary Journal of Applied Science
ISSN 1980-993X - doi:10.4136/1980-993X
www.ambi-agua.net
E-mail: ambi.agua@gmail.com

\title{
Contaminação da água de reservatórios do semiárido potiguar por bactérias de importância médica
}

\author{
doi:10.4136/ambi-agua.1801 \\ Received: 08 Nov. 2015; Accepted: 01 Mar. 2016

\begin{abstract}
Ermeton Duarte do Nascimento ${ }^{1 *}$; Claudio Marcio de Medeiros Maia ${ }^{2}$; Magnólia Fernandes Florêncio de Araújo ${ }^{1}$
\end{abstract} \\ ${ }^{1}$ Universidade Federal do Rio Grande do Norte (UFRN), Natal, RN, Brasil \\ Departamento de Microbiologia e Parasitologia \\ ${ }^{2}$ Laboratorio Central Dr. Almino Fernandes (LACEN/RN), Natal, RN, Brasil \\ Departamento de Análise de Produto \\ *Autor correspondente: e-mail: ermeton_duarte@yahoo.com.br, \\ cmaia2004@yahoo.com.br, magffaraujo@gmail.com
}

\section{RESUMO}

A contaminação da água do semiárido brasileiro se tornou uma preocupação constante para os pesquisadores no país, principalmente porque essa região é considerada uma das mais carentes no Brasil e a água nessas localidades representa um importante veículo para a transmissão de doenças associadas aos recursos hídricos. Nessa pesquisa foram coletados dados físicos e químicos, bem como uma amostra da água de quatro reservatórios do semiárido potiguar durante o período seco e chuvoso de 2013 e 2014. Na Universidade Federal do Rio Grande do Norte (UFRN) essas amostras foram processadas e avaliadas, em laboratório, quanto às características físico-químicas e microbiológicas. Os procedimentos de isolamento e identificação microbiana seguiram as normas do Standard Methods for Examinations of Water and Wastewater. Em seguida foi usado o sistema Vitek II (Bio-Merieux ®) para a identificação dos espécimes e calculada a frequência de ocorrência dos isolados. Ao todo foram isoladas e identificadas 168 bactérias, sendo $97 \%$ delas Gram-negativas e apenas 3\% Gram-positivas. Dentre os isolados, 73,2\% foram identificados como da família Enterobacteriaceae e de um modo geral, os gêneros mais constantes na água dos reservatórios foram Vibrio e Aeromonas. Entre as enterobactérias, as espécies Escherichia coli, Enterobacter complexo cloacae e Klebsiella pneumoniae foram as mais frequentes. Não houve diferença estatistica entre o número ou grupo morfotintorial encontrados nos períodos, $p=0,255$ e $p=0,237$ respectivamente. Os dados analisados indicaram uma possível contaminação da água dos reservatórios estudados por uma fonte de material fecal humano e/ou animal.

Palavras-chave: contaminação hídrica, enterobactérias, região semiárida.

\section{Contamination of semiarid potiguar reservoirs by harmful bacteria}

\section{ABSTRACT}

Water contamination in the semi-arid section of Northeast Brazil is a current concern for the country's researchers, since this region is considered one of the poorest in Brazil and the 
water in these locations is a primary vehicle for disease transmission. We collected physical and chemical data as well as water samples from four semiarid potiguar reservoirs during the dry and rainy seasons of 2013 and 2014. These samples were prepared in a laboratory at the Federal University of Rio Grande do Norte (UFRN) and their physical, chemical and microbiological characteristics were evaluated. The procedures of microbial isolation and identification followed the Standard Methods for Examinations of Water and Wastewater. Then Vitek II system (Bio-Merieux ${ }^{\circledR}$ ) was used to identify the microbial specimens and we calculated the frequency of specimens' occurrence. Altogether, 168 bacteria were isolated and identified; $97 \%$ were Gram-negative and only 3\% were Gram-positive. Within the Gram-negatives, $73.2 \%$ were identified as belonging to the Enterobacteriaceae family and, in general terms, the most constant genera in the water reservoirs were Vibrio and Aeromonas. Among the Enterobacteriaceae family, the species Escherichia coli, Enterobacter cloacae complex and Klebsiella pneumoniae were the most frequent. There was no statistical difference between the number or morphotype groups found in the periods, $p=0.255$ and $p=0.237$, respectively. The analyzed data indicate possible contamination of these water reservoirs by human and/or animal fecal material.

Keywords: Brazilian semiarid, enterobacteria, hydric contamination.

\section{INTRODUÇÃO}

A baixa qualidade das águas naturais é hoje um dos mais graves problemas mundiais. No Brasil, cerca de $87 \%$ dos municípios tem acesso à água canalizada e de qualidade para consumo, porém apenas $55 \%$ dispõem de rede de esgotamento sanitário, e naqueles onde existe rede de esgoto, somente $28 \%$ possuem um sistema de tratamento (IBGE, 2010). Na região semiárida do Brasil, pela pouca disponibilidade de água durante o ano, é comum a construção de reservatórios como uma solução adotada para a garantia de água nos períodos de seca. Porém, o grande problema observado é que parte da água armazenada perde a qualidade para consumo (Nascimento et al., 2013) por causa das ações antrópicas ou por questões naturais.

O semiárido brasileiro é uma região seca que abrange oito Estados Nordestinos e o Norte do Estado de Minas Gerais, possuindo uma área total de $980.133,079 \mathrm{~km}^{2}$ onde vivem 22.5 milhões de pessoas distribuídas entre 1.135 municípios (INSA, 2014), e é considerada a região árida mais habitada do mundo. Esta região é caracterizada por um clima seco com precipitações médias anuais entre 250 e 500 mm (Cirilo, 2008), e apesar de 1.122 municípios disporem de rede de distribuição de água, $16 \%$ deles apresentam poluição ou contaminação da sua fonte de abastecimento (INSA, 2015). Como consequência, pela pouca disponibilidade, a água é considerada um fator crítico para as populações locais (GEO BRASIL, 2007).

Nessas áreas, devido ao crescimento populacional e ao mau uso dos recursos hídricos, a pouca disponibilidade da água acarreta a perda da sua qualidade devido à contaminação. Essa contaminação é uma consequência direta da ação antrópica, principalmente pela descarga de fezes humanas e animais ou esgoto doméstico nesses mananciais. Segundo a Organização Mundial de Saúde - OMS, a taxa de mortalidade por doenças associadas a água afeta mais de 5 milhões de pessoas por ano em todo o mundo (Cabral, 2010).

Entre outros fatores, a qualidade da água está diretamente ligada à presença microbiana, e o monitoramento de microrganismos torna-se essencial na busca de alternativas para questões ambientais relacionadas à água (Araújo e Costa, 2007; do Nascimento e Araújo, 2014). Nesse sentido, a identificação e quantificação de microrganismos, como bactérias, por exemplo nesses ambientes, podem ser fundamentais para a manutenção de uma boa qualidade hídrica e também alertar a favor da saúde das comunidades locais, principalmente, porque no caso de águas contaminadas, tratadas precariamente ou sem nenhum tratamento, as consequências são 
a poluição, a destruição da biodiversidade e as doenças de veiculação hídrica (Cirilo, 2008).

Sendo assim, o objetivo deste trabalho foi o isolamento e a identificação de bactérias de importância médica e a análise físico-química da água de reservatórios do semiárido potiguar que integram a Bacia hidrográfica Piancó-Piranhas-Assú.

\section{MATERIAL E MÉTODOS}

\subsection{Delimitação e caracterização da área de estudo}

Este estudo foi desenvolvido utilizando amostras de água coletadas nos períodos de estiagem e chuvoso em quatro reservatórios da bacia Hidrográfica Piancó-Piranhas-Assú no semiárido norte-rio-grandense, sendo eles: Engenheiro Armando Ribeiro Gonçalves (nas cidades de Itajá (IJ) e São Rafael (SR)) (0548`00,0"S; 036 55 14,1"W e 05`40`08,9"S; $036^{\circ} 52^{`} 35,3^{\prime \prime} \mathrm{W}$, respectivamente), Itans (IT) $\left(05^{\circ} 40^{`} 08,9^{\prime \prime} \mathrm{S}\right.$; $036^{\circ} 52^{`} 35,3$, $\left.\mathrm{W}\right)$, na cidade de Caicó (06²9`39,0”S; 03704`01,8”W), Marechal Dutra (Gargalheiras (GA)), na cidade de Acari $\left(06^{\circ} 25^{` 20}, 0^{\prime \prime} \mathrm{S}\right.$; $036^{\circ} 36$ 24,0”W), e Passagem das Traíras (PT), na cidade de Jardim do Seridó (06³0`90,0”'S; 03656`41,4”W) (Figura 1).

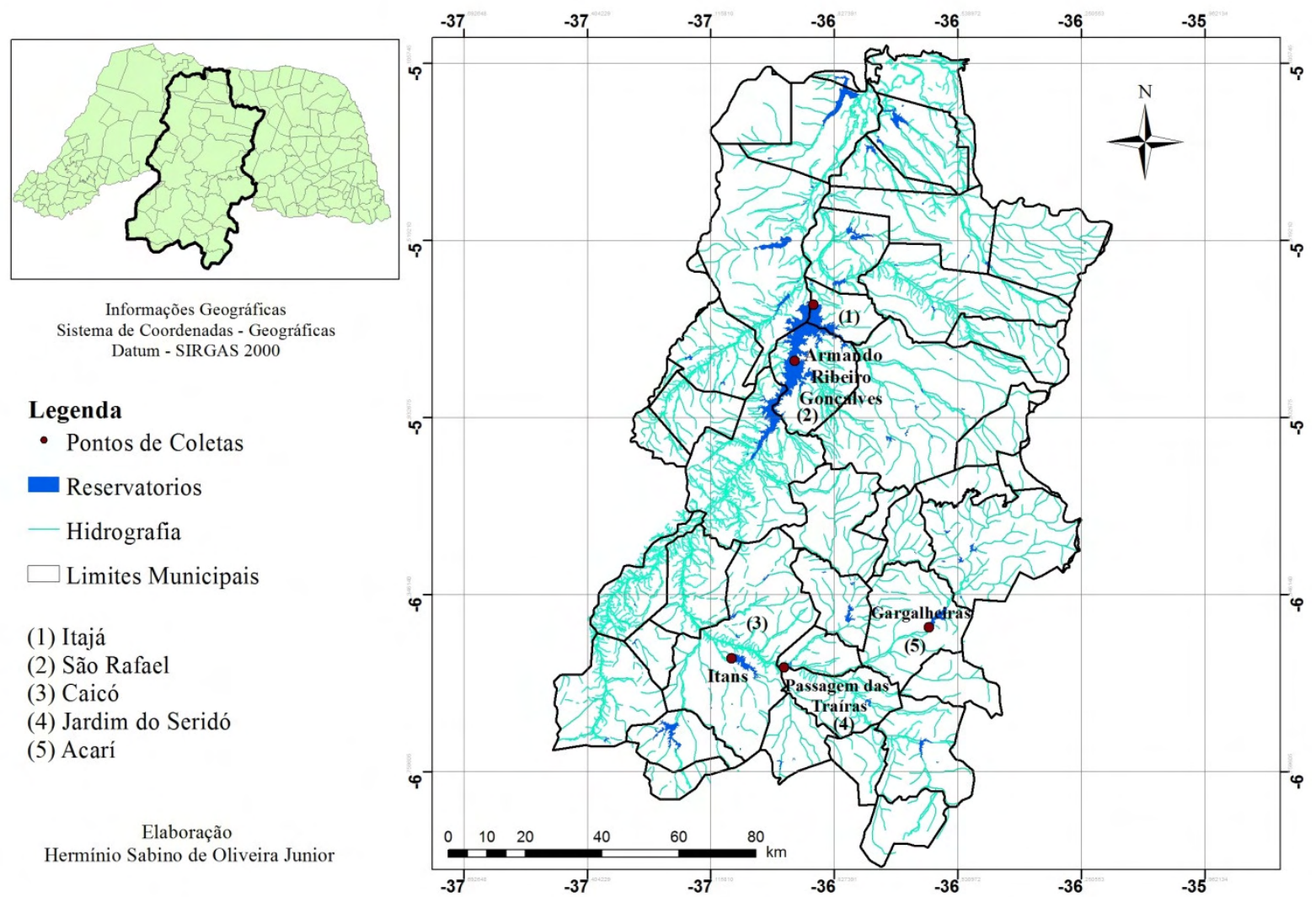

Figura 1. Mapa do Rio Grande do Norte com a localização dos reservatórios alimentados pela Bacia Hidrográfica Piancó-Piranhas-Assu onde foram realizadas as coletas.

\subsection{Procedimentos metodológicos}

Foram coletadas duas amostras de água, uma no período seco e outra no período chuvoso, de cada reservatório em cada cidade, totalizando 10 amostras. As coletas ocorreram de agosto de 2013 a meados de janeiro de 2014 (período seco) e de fevereiro a junho de 2014 (período chuvoso). As amostras foram coletadas na sub-superfície da água às margens dos reservatórios, a uma profundidade mínima de $20 \mathrm{~cm}$ em frascos estéreis de $5000 \mathrm{~mL}$. Em seguida, os frascos foram armazenados e transportados sob refrigeração, até o processamento no Laboratório de Microbiologia Aquática - LAMAq/UFRN. Foram coletados dados físicos e 
químicos (Temperatura, $\mathrm{pH}$, cloreto e turbidez) da água por meio da Sonda Multiparâmetro YSI $650 \mathrm{MDS} \circledast$. Em cada reservatório, o ponto de coleta escolhido encontra-se próximo a uma região com grande atividade antrópica.

No laboratório, toda a amostra foi processada seguindo normas do Standard Methods for Examinations of Water and Wastewater (APHA et al., 2012), adaptadas pelo Laboratório Central de Saúde Pública do Rio Grande do Norte Dr. Almino Fernandes (LACEN-RN) e avaliada quanto a turbidez, em turbidímetro DLM ${ }^{\circledR}$ para em seguida ser fracionada em cinco partes e submetida a análise microbiológica para isolamento e identificação de: $1^{\circ}$ ) Escherichia coli; $2^{\circ}$ ) Salmonella spp.; $3^{\circ}$ ) Shigella spp.; $4^{\circ}$ ) Vibrio spp. e Aeromonas spp. e $5^{\circ}$ ) Chromobacterium violaceum, Gram-positivos, Gram-negativos não fermentadores de glicose e outras enterobactérias.

Todas as amostras foram submetidas a filtração preconizada pelo Standard Methods for Examinations of Water and Wastewater (APHA et al., 2012). Durante a filtração foi utilizada uma membrana de éster de celulose com uma malha de $0,45 \mu \mathrm{m}$ e $47 \mathrm{~mm}$ de diâmetro (Millipore®). Após a filtração, o semeio primário também seguiu normas da APHA et al. (2012) e o isolamento e a técnica de Gram seguiram as orientações de Koneman e Winn (2008). Para identificação das espécies bacteriana foi usado o sistema automatizado Vitek II (Bio-Merieux(®), que usa a combinação de reações bioquímicas e leitura em espectrofotometria para a identificação dos isolados bacterianos.

Foi calculada a frequência de ocorrência (F), expressa em porcentagem, sendo esta a relação entre a ocorrência das diferentes espécies e o número total de amostras $(\mathrm{F}=(\mathrm{Pa} \times 100) / \mathrm{P})$, em que Pa é o número de amostras em que a espécie "a" está presente e $\mathrm{P}$ é o número total de amostras analisadas (Lobo e Leighton, 1986). As espécies foram consideradas:

constantes: quando $\mathrm{F}>50 \%$

comuns: quando $10 \%<\mathrm{F}<50 \%$

raras: quando $\mathrm{F}<10 \%$

Além da análise estatística descritiva, foi utilizado o test $t$ de student do Programa SPSS ${ }^{\circledR}$ Statistics 17.0, considerando um $\alpha=0,05$, para avaliar os grupos morfotintoriais e os gêneros bacterianos encontrados entre os períodos e os reservatórios.

\section{RESULTADOS E DISCUSSÃO}

Durante o período avaliado foram mensurados os valores de temperatura, $\mathrm{pH}, \mathrm{Cl}^{-} \mathrm{e}$ NTU+ e calculado o $p$ para cada dado coletado (Tabela 1).

Tabela 1. Dados físicos e químicos da água dos reservatórios Gargalheiras (GA), Itans (IT), Passagem das traíras (PT) e Armando Ribeiro Gonçalves nas cidades de Itajá (IJ) e São Rafael (SR), avaliados durante o período seco (S) e chuvoso (C), bem como o resultado da estatística $(p)$.

\begin{tabular}{|c|c|c|c|c|c|c|c|c|c|c|c|}
\hline & \multicolumn{2}{|c|}{ GA } & \multicolumn{2}{|c|}{ IT } & \multicolumn{2}{|c|}{ PT } & \multicolumn{2}{|c|}{ IJ } & \multicolumn{2}{|c|}{ SR } & \multirow[b]{2}{*}{$p$} \\
\hline & $\mathrm{S}$ & $\mathrm{C}$ & $\mathrm{S}$ & $\mathrm{C}$ & $\mathrm{S}$ & $\mathrm{C}$ & $\mathrm{S}$ & $\mathrm{C}$ & $\mathrm{S}$ & $\mathrm{C}$ & \\
\hline Temp & 27,04 & 28,15 & 29,43 & 30,18 & 28,85 & 30,47 & 28,35 & 30,21 & 28,55 & 29,54 & 0,00 \\
\hline $\mathrm{pH}$ & 8,79 & 7,81 & 8,34 & 6,81 & 8,55 & 6,99 & 6,9 & 6,97 & 7,7 & 6,4 & 0,02 \\
\hline $\mathrm{Cl}^{-}$ & 230,7 & 66,53 & 152,5 & 22,64 & 260,8 & 10,60 & 12,86 & 7,15 & 16,5 & 22,95 & 0,08 \\
\hline NTU+ & 43,4 & 21,1 & 1,90 & 5,7 & 58,7 & 18,1 & 18,8 & 12,6 & 20,8 & 23,5 & 0,21 \\
\hline
\end{tabular}


Nesse mesmo período foram coletados e identificados nos cinco reservatórios 168 isolados bacterianos, tendo sido $74(44,0 \%)$ no período seco e $94(56,0 \%)$ no período chuvoso. Durante a estiagem, nove bactérias $(12,1 \%)$ foram isoladas no Gargalheiras, 12 $(16,2 \%)$ no Passagem das Traíras, 15 (20,3\%) no Itans, 19 (25,7\%) no Armando Ribeiro Gonçalves, na cidade de Itajá e 19 (25,7\%) no Armando Ribeiro Gonçalves, na cidade de São Rafael. No período chuvoso, $23(24,5 \%)$ foram isoladas no Gargalheiras, 19 (20,2\%) no Passagem das Traíras, $18(19,1 \%)$ no Itans, $17(18,1 \%)$ no Armando Ribeiro Gonçalves, na cidade de Itajá e $17(18,1 \%)$ no Armando Ribeiro Gonçalves, na cidade de São Rafael (Figura 2). Não houve diferença estatística do número de bactérias isoladas entre o período seco e o chuvoso e nem entre os reservatórios $(p=0,255)$.

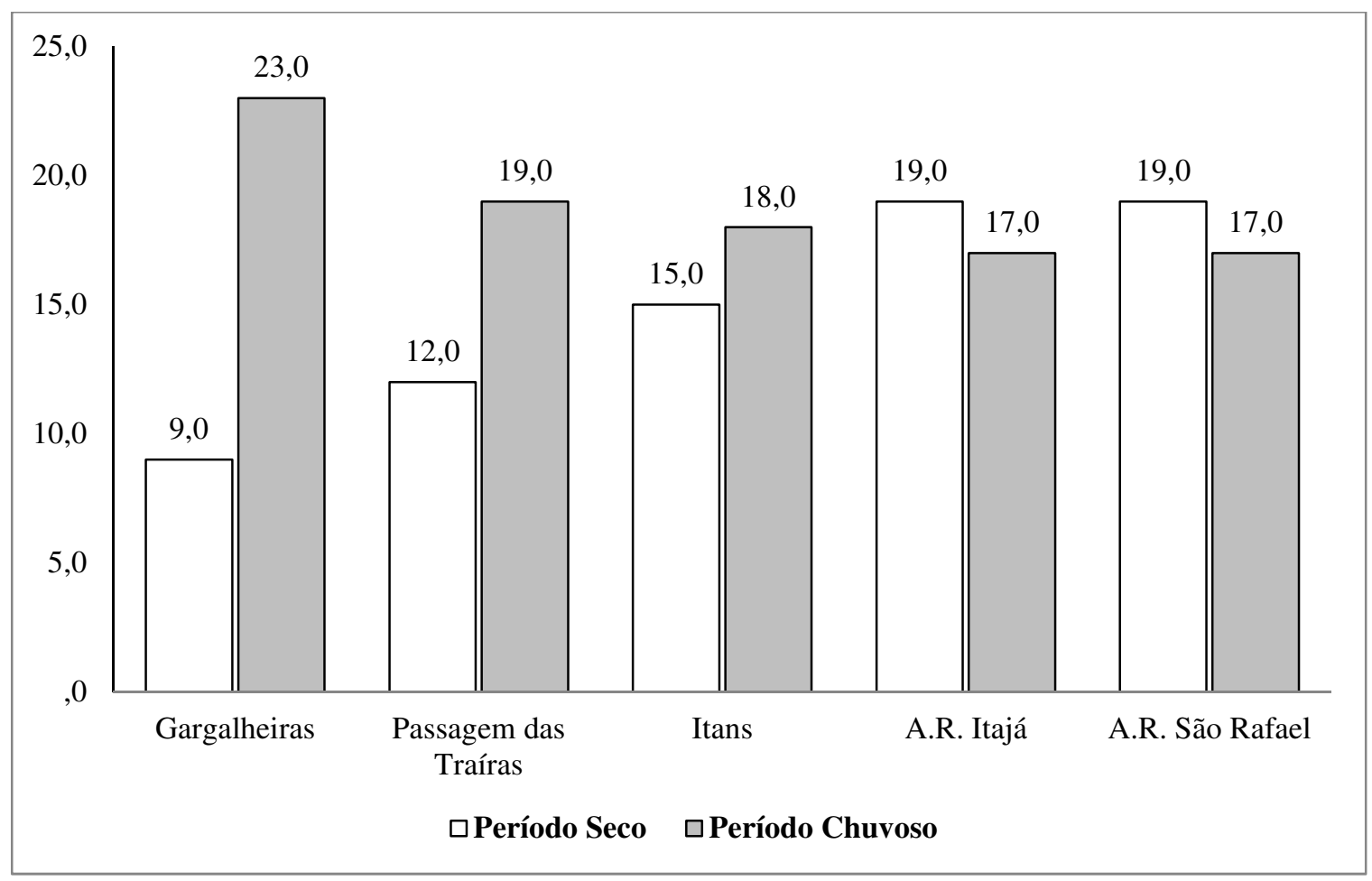

Figura 2. Número de isolados bacterianos dos reservatórios estudados durante o período seco e chuvoso (A.R. = Reservatório Armando Ribeiro Gonçalves).

Após o isolamento, as bactérias foram identificadas e entre os grupos morfotintoriais isolados, 97\% pertencem ao grupo das bactérias Gram-negativas e 3\% ao grupo das Gram-positivas. Entretanto, não há diferença estatística da prevalência dos grupos morfotintoriais entre os períodos seco e chuvoso e nem entre os reservatórios $(p=0,237)$.

Dentre as Gram-negativas, as enterobactérias apresentaram uma prevalência de 73,2\%. De um modo geral, a análise da frequência de ocorrência mostrou que 57,2\% das bactérias identificadas são comuns na água desses reservatórios e $42,8 \%$ são consideradas constantes naqueles ambientes. Os Gram-positivos, com apenas 20\%, foram menos frequentes que os Gram-negativos. Os gêneros mais constantes na água desses reservatórios foram Vibrio e Aeromonas com $100 \%$ de frequência de ocorrência cada, o primeiro no período seco e o segundo no chuvoso. Na família Enterobacteriacae, os gêneros mais constantes foram Enterobacter, Escherichia, Citrobacter. Klebsiella e Proteus com 80\% cada. (Tabela 2).

As espécies mais constantes na água dos reservatórios foram aquelas do grupo Enterobacter complexo cloacae, E. coli e $K$. pneumoniae com $80 \%$ de frequência de ocorrência cada. Foram identificadas dois espécimes de $V$. cholerae sorotipo não-O1 e nãoO139, uma no reservatório Gargalheiras e outra no Itans (Tabela 3). 
Tabela 2. Frequência de ocorrência $(F)$ de gêneros bacterianos identificados nos reservatórios Gargalheiras (GA), Passagem das Traíras (PT), Itans (IT) e Armando Ribeiro Gonçalves, nas cidades de Itajá (IJ) e São Rafael (SR) no semiárido potiguar, coletados nos períodos seco (S) e chuvoso (C), divididos por enterobactérias, Bacilos Gram-negativos não fermentadores de glicose $(\mathrm{NF})$, outros Gram-negativos (GN) e Gram-positivos. • $\leq 2$ ind./ por amostra • 3-5 ind./por amostra $\circ \geq 6$ ind./por amostra.

\begin{tabular}{|c|c|c|c|c|c|c|c|c|c|c|c|c|c|c|c|c|c|c|}
\hline \multirow{3}{*}{ 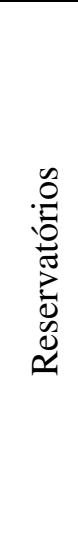 } & \multirow{3}{*}{$\begin{array}{l}\frac{0}{8} \\
\stackrel{0}{0} \\
2\end{array}$} & \multicolumn{16}{|c|}{ Gram-negativos } & \multirow{3}{*}{ 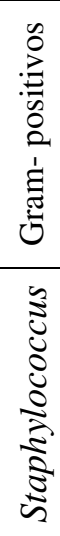 } \\
\hline & & \multicolumn{13}{|c|}{ Enterobactérias } & \multirow{2}{*}{ 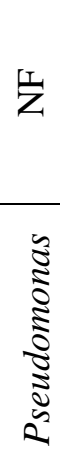 } & \multicolumn{2}{|c|}{$\begin{array}{c}\text { Outros } \\
\text { GN }\end{array}$} & \\
\hline & & 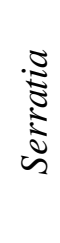 & 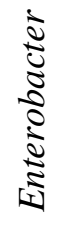 & 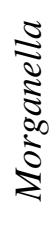 & $\begin{array}{l}\frac{3}{0} \\
\frac{5}{2} \\
2\end{array}$ & 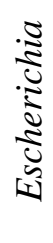 & $\begin{array}{l}\cdot \widetilde{J} \\
\mathbb{Z} \\
\mathbb{Z} \\
0 \\
0 \\
0\end{array}$ & 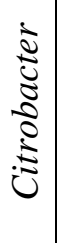 & 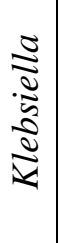 & 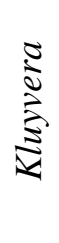 & 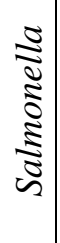 & 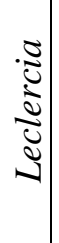 & 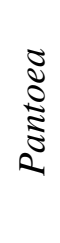 & 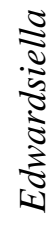 & & 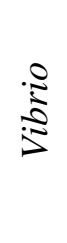 & 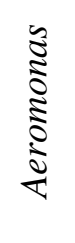 & \\
\hline GA & $\begin{array}{l}\mathrm{S} \\
\mathrm{C}\end{array}$ & • & • & • & • & • & $\bullet$ & & $\bullet$ & & $\bullet$ & & & & & • & • & \\
\hline PT & $\begin{array}{l}\mathrm{S} \\
\mathrm{C}\end{array}$ & & • & • & • & • & $\bullet$ & • & • & & & $\bullet$ & & & & • & • & $\dot{\bullet}$ \\
\hline IT & $\begin{array}{l}\mathrm{S} \\
\mathrm{C}\end{array}$ & & • & • & & • & & • & $\begin{array}{l}\circ \\
0\end{array}$ & & & & • & & - & • & $\bullet$ & • \\
\hline IJ & $\begin{array}{l}\mathrm{S} \\
\mathrm{C}\end{array}$ & & • & • & • & $\bullet$ & • & 0 & • & • & & & & • & & • & $\begin{array}{l}0 \\
\bullet\end{array}$ & \\
\hline SR & $\begin{array}{l}\mathrm{S} \\
\mathrm{C}\end{array}$ & & • & • & • & • & & • & $\bullet$ & & & & & & $\bullet$ & $\bullet$ & $\bullet$ & \\
\hline \multirow{2}{*}{$\mathrm{F}$} & $\begin{array}{c}\mathrm{S} \\
(\%)\end{array}$ & 20 & 80 & 40 & 80 & 80 & 20 & 80 & 60 & 20 & 0 & 0 & 0 & 0 & 40 & 100 & 40 & 40 \\
\hline & $\begin{array}{c}\mathrm{C} \\
(\%)\end{array}$ & 0 & 80 & 80 & 80 & 60 & 40 & 60 & 100 & 0 & 20 & 20 & 20 & 20 & 0 & 40 & 100 & 20 \\
\hline
\end{tabular}

A maior parte da contaminação dos ambientes aquáticos acontece por meio do despejo de dejetos industriais e urbanos. Esses dejetos são caracterizados não apenas pela presença de numerosas substâncias químicas tóxicas e carcinogênicas, como os metais pesados por exemplo, mas também por matéria orgânica que inclui uma microbiota típica, a qual pode contaminar a água e entrar na cadeia alimentar, causando um perigo considerável à saúde da população (Páll et al., 2013). Embora vários trabalhos sobre a contaminação desses ambientes já tenham sido desenvolvidos no Brasil (Alves et al., 2002; Buzelli e Cunha-Santino, 2013; Nascimento e Araújo, 2013), o isolamento de patógenos, em fontes de água se torna mais difícil devido a algumas limitações metodológicas, como por exemplo, a baixa concentração bacteriana na superfície da água (Páll et al., 2013). Neste trabalho, essa limitação foi amenizada pelo aumento da quantidade de água filtrada analizada, seguindo metodologia da APHA et al. (2012). 
Tabela 3. Frequência de ocorrência $(F)$ de espécies bacterianas identificadas nos reservatórios Gargalheiras (GA), Passagem das Traíras (PT), Itans (IT) e Armando Ribeiro Gonçalves, nas cidades de Itajá (IJ) e São Rafael (SR) no semiárido potiguar, coletados nos períodos seco (S) e chuvoso (C). $\bullet \leq 2$ ind./ por amostra $\bullet 3-5$ ind./por amostra $\circ \geq 6$ ind./por amostra.

\begin{tabular}{|c|c|c|c|c|c|c|c|}
\hline \multirow[b]{2}{*}{ Gênero } & \multirow[b]{2}{*}{ Espécie } & \multicolumn{5}{|c|}{ Reservatórios } & \multirow{2}{*}{$\begin{array}{c}\mathrm{F} \\
\mathrm{S} / \mathrm{C} \\
(\% / \%)\end{array}$} \\
\hline & & $\begin{array}{l}\text { GA } \\
\text { S/C }\end{array}$ & $\begin{array}{l}\mathrm{PT} \\
\mathrm{S} / \mathrm{C}\end{array}$ & $\begin{array}{l}\text { IT } \\
\text { S/C }\end{array}$ & $\begin{array}{c}\mathrm{IJ} \\
\mathrm{S} / \mathrm{C} \\
\end{array}$ & $\begin{array}{l}\mathrm{SR} \\
\mathrm{S} / \mathrm{C} \\
\end{array}$ & \\
\hline Serratia & $\begin{array}{l}\text { S. marcescens } \\
\text { S. fonticola }\end{array}$ & & & & & & $\begin{array}{l}20 / 00 \\
20 / 20\end{array}$ \\
\hline Enterobacter & $\begin{array}{l}\text { E. cloacae } \\
\text { E. aerogenes }\end{array}$ & • & - & $\bullet \bullet$ & $\bullet \bullet$ & $\bullet \bullet$ & $\begin{array}{l}80 / 80 \\
20 / 20\end{array}$ \\
\hline Morganella & M. morganii ssp. Morganii & $\bullet$ & $\bullet$ & $\bullet$ & $\bullet$ & $\bullet$ & $40 / 80$ \\
\hline Proteus & $\begin{array}{l}\text { P. vulgaris } \\
\text { P. mirabilis } \\
\text { P. penneri } \\
\text { P. vulgaris/penneri }\end{array}$ & • & $\bullet$ & & $\bullet \bullet$ & $\cdot$ & $\begin{array}{l}20 / 00 \\
40 / 40 \\
40 / 00 \\
00 / 20\end{array}$ \\
\hline Escherichia & E. coli & $\bullet \bullet$ & $\bullet$ & $\bullet$ & $\bullet$ & $\bullet$ & $80 / 60$ \\
\hline Providencia & $\begin{array}{l}\text { P. alcalifaciens } \\
\text { P. stuartii } \\
\text { P.rettgeri }\end{array}$ & - & - & & $\bullet$ & & $\begin{array}{l}20 / 00 \\
20 / 20 \\
00 / 40\end{array}$ \\
\hline Citrobacter & $\begin{array}{l}\text { C. youngae } \\
\text { C. amalonaticus } \\
\text { C. freundii }\end{array}$ & & $\bullet$ & • & $\bullet$ & $\bullet \bullet$ & $\begin{array}{l}20 / 20 \\
20 / 00 \\
40 / 40\end{array}$ \\
\hline Klebsiella & $\begin{array}{l}\text { K. pneumoniae } \\
\text { K. oxytoca }\end{array}$ & $\bullet$ & $\bullet \bullet$ & $\bullet \bullet$ & $\bullet$ & $\bullet \bullet$ & $\begin{array}{l}60 / 10 \\
00 / 20\end{array}$ \\
\hline Salmonella & Salmonella spp. & $\bullet$ & & & & & $00 / 20$ \\
\hline Kluyvera & K. ascorbata/cryocrescens & & & & $\bullet$ & & $20 / 00$ \\
\hline Pseudomonas & P. aeruginosa & & & $\bullet$ & & $\bullet$ & $40 / 00$ \\
\hline Vibrio & $\begin{array}{l}V . \text { cholerae } \\
V . \text { vulnificus } \\
\text { V. fluvialis }\end{array}$ & $\bullet$ & $\bullet$ & $\begin{array}{l}\bullet \\
\bullet \\
\bullet\end{array}$ & $\bullet$ & $\bullet$ & $\begin{array}{l}40 / 20 \\
60 / 00 \\
40 / 00\end{array}$ \\
\hline Aeromonas & $\begin{array}{l}\text { A. sóbria } \\
\text { A. caviae } \\
\text { A.hydrophila }\end{array}$ & $\bullet$ & $\bullet$ & $\bullet$ & $\begin{array}{l}\bullet \bullet \\
\bullet \\
\bullet\end{array}$ & $\bullet$ & $\begin{array}{l}40 / 10 \\
40 / 00 \\
00 / 40 \\
\end{array}$ \\
\hline Staphylococcus & $\begin{array}{l}\text { S. aureus } \\
\text { S. intermedius }\end{array}$ & & $\cdot \bullet$ & $\bullet$ & & & $\begin{array}{l}20 / 00 \\
20 / 20\end{array}$ \\
\hline
\end{tabular}

Dados físicos e químicos dos diversos trabalhos realizados anteriormente a esta pesquisa em vários reservatórios, rios e lagos potiguares corroboram com os resultados encontrados neste trabalho (Eskinazi-Sant'Anna et al., 2007; da Costa et al., 2009; Nascimento e Araújo, 2013), e mostraram que estes ambientes estão eutrofizados. Neste estudo, as temperaturas e o $\mathrm{pH}$ foram os únicos dados físico e químico que variaram entre os períodos seco e chuvoso e as análises estatísticas mostram isso, com $p=0,00$ e $p=0,02$, respectivamente. Mas apesar dessa 
diferença estatística, as temperaturas permaneceram elevadas (temperaturas médias superiores a $24^{\circ} \mathrm{C}$ ) praticamente durante todo o período de coleta. Resultados semelhantes foram encontrados por Eskinazi-Sant'Anna et al. (2007), quando analisaram os mesmos reservatórios.

Segundo Silva et al. (2011), a temperatura da água dos reservatórios no semiárido potiguar e a abundância de nutrientes praticamente constantes durante todo o ano favorecem a eutrofização. Em estudo anterior Eskinazi-Sant'Anna et al. (2007) mostraram que a alta concentração de nutrientes, e especificamente de fósforo total nesses reservatórios, bem como a elevada concentração da comunidade zooplanctônica na biomassa total, não apresentaram flutuações sazonais durante o ano. E ainda, a análise de regressão utilizando a densidade dessas comunidades zooplanctônicas como variável dependente mostrou uma correlação positiva entre o zooplâncton e o bacterioplâncton nesses ambientes. Araújo e Costa (2007), em estudo realizado com a água de reservatórios do semiárido potiguar, também encontraram uma elevada densidade bacteriana e assumem que a eutrofização nesses ambientes deve exercer uma forte influência na composição e na biomassa da comunidade microbiana desses locais.

Nesse contexto, é importante considerarmos que as bactérias, devido a sua enorme diversidade metabólica, são capazes de utilizar compostos orgânicos e sintéticos, com consequente relevância na assimilação e degradação dos detritos (Pomeroy, 1974), provavelmente isso explicaria o porquê do isolamento de bactérias heterotróficas em todos os locais de coleta, em todos os reservatórios, durante todo o período estudado nesta pesquisa.

Neste trabalho foi encontrada uma maior prevalência para as bactérias Gram-negativas $(97,0 \%)$ e apenas 3,0\% de prevalência de Gram-positivas. Esse resultado corrobora com aquele encontrado em um trabalho realizado anteriormente na Barragem Armando Ribeiro Gonçalves, nos anos de 2009 e 2010, nas cidades de Itajá, São Rafael e Assú, quando os autores apenas identificaram bactérias Gram-negativas na água do reservatório, e aceitaram que poderia está intimamente associado a contaminação por material fecal humano ou animal (Nascimento e Araújo, 2013).

Vários outros trabalhos relatam uma maior frequência de bactérias Gram-negativas nos ambientes aquáticos estudados. Em Pernambuco, num estudo realizado em 1993, os maiores índices de contaminação foram de bactérias Gram negativas $(90,3 \%)$ e apenas $9,7 \%$ de bactérias Gram-positivas (Alves et al., 2002). Numa pesquisa realizada no Estado de São Paulo, Rodrigues et al. (2009), acharam resultados semelhantes de prevalência de Gramnegativos para o Rio Piracuama e apenas identificaram uma espécie de Gram-positiva.

Segundo Sigee (2004), nos ambientes aquáticos, a frequência entre as bactérias Gram-negativas e Gram-positivas é bem diferente. Nesses ambientes, a maior parte das bactérias pertence ao grupo das Gram-negativas enquanto são relatados poucos representantes do grupo das Gram-positivas. Ainda segundo esse autor, o predomínio de determinados grupos bacterianos em determinados ambientes acontece devido a uma maior adaptação individual em decorrência a uma maior ou menor variação genética e expressão gênica entre os diferentes grupos ou entre diferentes indivíduos do mesmo grupo.

A prevalência de enterobactérias nesse estudo $(76,0 \%)$ foi corroborada com os resultados de Nascimento e Araújo (2013), que encontraram 78,0\% em um trabalho realizado no semiárido potiguar. Enquanto que no Rio Piracuama/SP, os autores identificaram uma prevalência maior da família Enterobacteriacea (90,0\%) (Rodrigues et al., 2009). A justificativa para a prevalência da família Enterobacteriaceae nos ambientes aquáticos neste estudo pode estar intimamente associada à contaminação desses ambientes por material fecal humano ou animal, considerando que essa família é normalmente identificada como parte integrante da microbiota intestinal humana e animal, e que são descritas inumeras atividades antrópicas que levam a contaminação desses ambientes por esse grupo de bactérias (Silva et 
al., 2007). Porém, alguns gêneros dessa família também são encontrados nos ambientes aquáticos como parte integrante da sua microbiota (Rodrigues et al., 2009; Nascimento e Araújo, 2013).

Neste trabalho foi observada uma maior frequência de isolamento e identificação de enterobacteriácias durante o período chuvoso. Segundo Rodrigues et al. (2009), há uma relação direta do aumento do número da frequência de usuários e de animais próximos as margens de corpos d'água durante os meses mais quentes e o aumento do número de coliformes totais, fecais e a identificação de cepas da família Enterobacteriaceae na água desses corpos d’água nos meses das estações chuvosas. Provavelmente por que os usuários desses reservatórios liberam suas excretas no solo durante os meses mais quentes e há o carreamento desses contaminantes para a água, pela água das chuvas, durante as estações chuvosas. Apesar de ter sido relatada a contaminação desses ambientes por meio da liberação de dejetos de excretas animais e humanos nos corpos d’água da Bacia Hidrográfica Piancó-Piranhas-Assú durante todo o ano (Silva et al., 2007).

A família Enterobacteriaceae está dividida em três grupos que se apresentam diferentemente no meio ambiente. O grupo I que é composto apenas pela Escherichia coli, considerada um excelente indicador de contaminação fecal, porque resiste no ambiente por pouco tempo, e demonstra uma contaminação recente nesses locais. O grupo II, considerado ubíquo, porque pode ser encontrado tanto no intestino do homem e dos animais como também no meio ambiente. E a sua presença no ambiente aquático não indica necessariamente contaminação fecal, sendo seus representantes algumas espécies de Klebsiella, Enterobacter e Citrobacter. E o grupo III, composto por bactérias que vivem no ambiente aquático, plantas e pequenos animais, formado por Raoultella planticola, $R$. terrigena, Enterobacter amnigenus e Kluyvera intermedia (Enterobacter intermedius), Serratia fonticola, e os gêneros Budvicia, Buttiauxella, Leclercia, Rahnella, Yersinia, e a maioria das espécies de Erwinia e Pantoea (Cabral, 2010).

Um fator que deve ser observado com mais atenção nesta pesquisa, é que a frequência de ocorrência das bactérias de um modo geral, foi considerada comum ou constante para a água dos reservatórios avaliados. Esse achado se torna preocupante uma vez que todas as bactérias identificadas neste trabalho são consideradas potencialmente patogênicas para o ser humano e sua frequência nesses locais expõe os usuários a maiores riscos de saúde pública.

A maior constância (100\%) dos gêneros Vibrio e Aeromonas na água desses reservatórios neste estudo é facilmente justificada. O gênero Vibrio está naturalmente presente na microbiota aquática (Páll et al., 2013) e tem uma alta capacidade adaptativa aos mais diversos nichos ambientais, provavelmente porque evolutivamente teve que se adaptar a diversos estressores ambientais, como escassez de nutrientes, flutuações na salinidade e temperatura, e resistir a predação por protistas heterotróficos e bacteriófagos (Lutz et al., 2013).

Esse gênero também foi identificado por outros pesquisadores em diversos ambientes aquáticos no Brasil (Costa et al., 2008; Rebouças et al., 2011; Ramos et al., 2014). Na Baía do Sul, perto da Ilha de Santa Catarina, no Sul do Brasil, as espécies patogênicas de víbrio mais frequentes foram $V$. parahaemolyticus e $V$. vulnificus. Segundo os autores da pesquisa, houve uma correlação direta entre a temperatura elevada da água e o isolamento de $V$. vulnificus nesse ambiente (Ramos et al., 2014). Segundo Rebouças et al. (2011), num trabalho realizado com água de cultivo de camarão no Ceará, o grande risco do isolamento de espécies de Vibrio está no fato desse gênero poder ser um reservatório para genes de patogenicidade, inclusive de resistência às drogas antimicrobianas, e nesse trabalho os autores perceberam que o padrão de resistência a essas drogas não estava relacionado a uma espécie apenas, mas ao gênero como um todo. Costa et al. (2008), também alertam para o aumento do número de isolamento de especimes de Vibrio nos ambientes aquáticos cada vez mais resistentes aos antibióticos.

Além disso, o risco que representa o isolamento de espécies de Vibrio reside no fato da 
possibilidade da identificação de $V$. Cholerae sorotipo $\mathrm{O} 1$, agente etiológico da cólera, ou o sototipo $\mathrm{O139}$, um sorotipo asiático raro, ambos extremamente patogênicos. Entretanto, os únicos dois espécimes de $V$. Cholerae isolados neste estudo não são do tipo $\mathrm{O} 1$ e nem do tipo O139. Porém, mesmo isolados de V.cholerae não O1 ou não O139 podem causar episódios diarreicos brandos em indivíduos saudáveis ou imunocomprometidos, quando ingeridos (Cabral, 2010). Em condições de estresse ambiental, $V$. cholerae pode entrar em um "estado-viável-mas-não-cultivável", em que normalmente não crescem nos meios de cultura utilizados para cultivo, reduzem em tamanho, mas continuam viáveis, resistindo aos mais diversos ambientes por longos períodos de tempo. A capacidade de V.cholerae resistir nos mais diversos ambientes está diretamente associada à produção de biofilme e de um polissacarídeo próprio do gênero (Vibrio PolySaccharide - VPS), que permitem a captação de nutrientes disponíveis na superfície à qual podem aderir (Lutz et al., 2013).

Já o gênero Aeromonas, considerado ubíquo no meio ambiente, é composto por bacilos Gram-negativos amplamente distribuídos no ambiente aquático, podendo ser encontrados tanto em água doce como em salobras, e até mesmo em águas residuais, e são considerados um importante patógeno associado à contaminação alimentar (Cabral, 2010), e responsável por vários surtos alimentares (Beaz-Hidalgo e Figueras, 2013). Indivíduos desse gênero podem causar principalmente gastroenterite em crianças, idosos e pacientes imunocomprometidos, mas também septicemia e óbito (Gowda et al., 2015).

Como muitas outras bactérias, o gênero Aeromonas é conhecido por possuir uma variedade de fatores de virulência que podem mediar a adesão e a invasão dos tecidos do hospedeiro, desde componentes estruturais mais comuns, como flagelo, fímbria e LPS (lipopolissacrídeo), até mecanismos mais sofisticados, como a produção de produtos de secreção extracelular, como hemolisinas, por exemplo, sistemas de secreção de toxinas, sistemas de aquisição de ferro e até mecanismos de comunicação por Quorum sensing (Beaz-Hidalgo e Figueras, 2013).

Neste trabalho, o gênero Staphylococcus foi o único representante entre as bactérias Gram-positivas, apresentando 3,0\% do total de bactérias isoladas e identificadas. Resultado semelhante foi encontrado por Rodrigues et al. (2009), no rio Piracuama/SP, para quem a explicação da presença dessa bactéria na água é o fato de que o gênero Staphylococcus é membro da microbiota normal da pele humana e no contato primário com águas superficiais, podem passar da pele para o corpo d'água.

No que se refere à família Enterobacteriacae, os gêneros mais frequentes neste estudo foram Enterobacter, Escherichia, Citrobacter, Klebsiella e Proteus, com $80 \%$ de frequência de ocorrência cada. Esses resultados são corroborados por vários estudos anteriores, como em um trabalho realizado com a água do Rio Arga, no norte da Espanha, em que os autores encontraram os mesmos gêneros da família Enterobacteriaceae e associaram essa contaminação com a descarga de esgoto doméstico ao longo do rio (Goñi-Urriza et al., 2000). $\mathrm{Na}$ cidade de Nyala, no Sudão, também foram isolados os mesmos gêneros na água de abastecimento, fazendo-se a mesma associação com a contaminação por águas residuais (Abdelrahman e Eltahir, 2011).

No Brasil, Nascimento e Araújo (2013), identificaram praticamente os mesmos organismos em um trabalho realizado em um reservatório do semiárido potiguar, possivelmente em decorrência do escoamento da água da bacia. Em águas do parque Nacional da Serra do Cipó e do Rio do Peixe em Minas Gerais, os autores identificaram esses gêneros da família Enterobacteriaceae em 111 isolados bacterianos, indicando uma possível contaminação externa desses ambientes aquáticos (Lima-Bittencourt et al., 2007).

É importante ressaltar que entre esses cinco gêneros mais constantes na água dos reservatórios estudados nesta pesquisa, três deles (Enterobacter, Citrobacter e Klebsiella) fazem parte do grupo dos coliformes não fecais, conhecidos também como coliformes totais. 
Entretanto, todos os gêneros participantes do grupo dos coliformes foram isolados e identificados neste trabalho, inclusive Escherichia coli, o único realmente considerado indicativo de contaminação fecal nos ambientes aquáticos (Cabral, 2010). Esses achados levam a uma maior preocupação e necessidade de cuidados quanto ao uso da água desses reservatórios. Considerando que essas bactérias foram isoladas na maioria deles, tanto no período seco como no chuvoso, pode-se concluir que esses ambientes estão sendo frequentemente contaminados por material fecal.

Ainda no contexto deste trabalho, as espécies mais constantes na água dos reservatórios foram aquelas do grupo Enterobacter complexo cloacae, Klebsiella pneumoniae e Escherichia coli, com $80 \%$ de frequência de ocorrência cada. Como essas três espécies fazem parte do grupo dos coliformes, esses achados dão mais força à afirmação de contaminação dos ambientes estudados por constante descarga de material fecal.

\section{CONCLUSÕES}

A utilização dos rios e reservatórios da bacia do rio Piancó-Piranhas-Assu para abastecimento público, recreação e pesca no semiárido brasileiro faz com que a qualidade da água seja um fator preocupante, já que muitos efluentes de atividades industriais e domésticas são lançados nestes ambientes.

Neste trabalho evidencia-se a contaminação dos ambientes aquáticos estudados por bactérias de importância médica e a indicação de uma contaminação constante desses reservatórios por material orgânico de origem fecal. Além da temperatura e do $\mathrm{pH}$, os únicos dados físico e químicos que apresentaram diferença estatística entre os períodos seco e chuvoso, nenhum outro dado parece variar ao longo do ano. Apesar disso, a temperatura, um fator de grande importância nos ambientes aquáticos, se mostra elevada durante todo o período de coleta e pode estar influenciando o desenvolvimento bacteriano.

Todas as bactérias isoladas neste estudo são consideradas patogênicas para o ser humano e considerando que no meio rural, o risco de ocorrência de surtos de doenças de veiculação hídrica é mais alto que nas áreas urbanas, principalmente em função da possibilidade de contaminação bacteriana de águas que muitas vezes são captadas inadequadamente e situadas próximas a fontes de contaminação, estudos detalhados sobre os possíveis mecanismos de patogenicidade nesses microrganismos são extremamente necessários.

Praticamente todos os gêneros de enterobactérias mais frequentemente isolados nas principais infecções hospitalares foram isolados e identificados neste estudo. Este fato faz com que estudos desta natureza se tornem indispensáveis à microbiologia porque contribuem para esclarecer e explicar o surgimento de novos casos de doenças associadas aos ambientes aquáticos e possibilitam a identificação de agentes contaminantes nesses ambientes.

\section{REFERENCIAS}

ABDELRAHMAN, A. A.; ELTAHIR, Y. M. Bacteriological quality of drinking water in Nyala, South Darfur, Sudan. Environmental monitoring and assessment, v. 175, n. 14, p. 37-43, abr. 2011. http://dx.doi.org/10.1007/s10661-010-1491-7

ALVES, N. C.; ODORIZZI, A. C.; GOULART, F. C. Microbiological analysis of mineral water and drinking water of reservoir supplies, Brazil. Revista saúde pública, v. 36, n. 6, p. 749-751, 2002. http://dx.doi.org/10.1590/S0034-89102002000700014 
AMERICAN PUBLIC HEALTH ASSOCIATION - APHA; AMERICAN WATER WORKS ASSOCIATION - AWWA; WATER ENVIRONMENT FEDERATON - WEF. Standard methods of examination of water and wastewater. 22. ed. Washington, 2012. p. 1360

ARAÚJO, M. F. F. DE; COSTA, I. A. S. Comunidades microbianas (bacterioplâncton e protozooplâncton) em reservatórios do semi-árido brasileiro. Oecologia Brasiliensis, v. 11, n. 3, p. 422-432, 2007.

BEAZ-HIDALGO, R.; FIGUERAS, M. J. Aeromonas spp. whole genomes and virulence factors implicated in fish disease. Journal of Fish Diseases, v. 36, n. 4, p. 371-388, 2013. http://dx.doi.org/10.1111/jfd.12025

BUZELLI, G. M.; CUNHA-SANTINO, M. B. DA. diagnóstico da qualidade da água e estado reservatório de Barra Análise e trófico do Diagnosis and analysis of water quality and trophic state of Barra Bonita reservoir, SP. Revista Ambiente e Água, v. 8, n. 1, p. 186-205, 2013. http://dx.doi.org/10.4136/1980-993X

CABRAL, J. P. S. Water microbiology. Bacterial pathogens and water. International Journal of Environmental Research and Public Health, v. 7, n. 10, p. 3657-703, 2010. http://dx.doi.org.10.3390/ijerph7103657

CIRILO, J. A. Políticas públicas de recursos hídricos para o semi-árido. Estudos Avançados, v. 22, n. 63, 2008. http://dx.doi.org/10.1590/S0103-40142008000200005

COSTA, R. A.; FERNANDES VIEIRA, G. H. F.; SILVA, G. C.; FERNANDES VIEIRA, R. H. S. DOS; SAMPAIO, S. S. Susceptibilidade " in vitro" a antimicrobianos de estirpes de Vibrio spp. isoladas de camarões (Litopenaeus vannamei) e de água de criação destes animais provenientes de uma fazenda de camarões no Ceará - Nota prévia. Brazilian Journal of Veterinary Research and Animal Science, v. 45, n. 6, p. 458-462, 2008. http://dx.doi.org/10.1590/S1413-95962008000600007

DA COSTA, I. A. S.; CUNHA, S. R. DE S.; DE FÁTIMA PANOSSO, R.; ARAÚJO, M. F. F.; SOUZA MELO, J. L. DE; ESKINAZI-SANT'ANNA, E. M. Dinâmica de cianobactérias em reservatórios eutróficos do semi-árido do Rio Grande Do Norte. Oecologia Brasiliensis, v. 13, n. 02, p. 382-401, 2009.

http://dx.doi.org/10.4257/oeco.2009.1302.11

DO NASCIMENTO, E. D.; ARAUJO, M. F. F. Antimicrobial resistance in bacteria isolated from aquatic environments in Brazil : a systematic review. Revista Ambiente e Água, v. 9, n. 2, p. 239-249, 2014. http://dx.doi.org/10.4136/1980-993X

ESKINAZI-SANT'ANNA, E. M.; MENEZES, R.; COSTA, I. S.; DE FÁTIMA PANOSSO, R.; ARAÚJO, M. F.; DE ATTAYDE, J. L. Composição da comunidade zooplanctônica em reservatórios eutróficos do semi-árido do rio grande do norte. Oecologia Brasiliensis, v. 11, n. 3, p. 410-421, 2007. http://dx.doi.org/10.4257/oeco.2007.1103.10.

GEO-BRASIL. GEO Brasil - Recursos Hídricos: resumo executivo. Brasília: Brasil GEO, 2007. (Temática) 
GOÑI-URRIZA, M.; CAPDEPUY, M.; ARPIN, C.; RAYMOND, N.; CAUMETTE,†P.; QUENTIN, C. Impact of an urban effluent on antibiotic resistance of riverine Enterobacteriaceae and Aeromonas spp. Applied and environmental Microbiology, v. 66, n. 1, p. 125-32, 2000. http://dx.doi.org/10.1128/AEM.66.1.125-132.2000

GOWDA TANUJA, K. G. M.; REDDY VISHWANATHA, R. A. P.; DEVLEESSCHAUWER BRECHT, Z. N. N.; CHAUDHARI SANDEEP, P.; KHAN WAQAR, A.; SHINDE SHILPA, V. et al. Isolation and Seroprevalence of Aeromonas spp. among common food animals slaughtered in Nagpur, Central India. Foodborne Pathogens and Disease, v. 12, n. 7, p. 1-5, 2015. http://dx.doi.org/10.1089/fpd.2014.1922

INSTITUTO BRASILEIRO DE GEOGRAFIA E ESTATISTICA - IBGE. Pesquisa nacional do saneamento básico. Rio de Janeiro, 2010.

INSTITUTO NACIONAL DO SEMIÁRIDO - INSA. Website. 2014. Disponível em: http://www.insa.gov.br. Acesso em: 05 abril 2015.

KONEMAN, E. W.; WINN, W. C. Diagnóstico microbiológico: texto e atlas colorido. 6. ed. Rio de Janeiro: Guanabara Koogan, 2008.

LIMA-BITTENCOURT, C. I.; CURSINO, L.; GONÇALVES-DORNELAS, H.; PONTES, D. S.; NARDI, R. M. D.; CALLISTO, M. et al. Multiple antimicrobial resistance in Enterobacteriaceae isolates from pristine freshwater. GMR Genetics and molecular research , v. 6, n. 3, p. 510-21, 2007.

LOBO, E.; LEIGHTON, G. Estructuras comunitarias de las fitocenosis planctonicas de los sistemas de desembocaduras de rios y esteros de la zona central de chile. Revista de Biología Marina y Oceanografía, v. 22, n. 1, p. 1-29, 1986.

LUTZ, C.; ERKEN, M.; NOORIAN, P.; SUN, S.; MCDOUGALD, D. Environmental reservoirs and mechanisms of persistence of Vibrio cholerae. Frontiers in microbiology, v. 4, , p. 375, 2013. http://dx.doi.org/10.3389/fmicb. 2013.00375

NASCIMENTO, V. S. F.; ARAÚJO, M. F. F.; NASCIMENTO, E. D. DO; SODRÉ NETO, L. Epidemiologia de doenças diarreicas de veiculação hídrica em uma região semiárida brasileira. ConScientiae e Saúde, v. 12, n. 3, p. 353-361, 2013. http://dx.doi.org/10.5585/ConsSaude.v12n3.4241

NASCIMENTO, V. S. F.; ARAÚJO, M. F. F. DE. Ocorrência de bactérias patogênicas oportunistas em um reservatório do semiárido do Rio Grande do Norte , Brasil. Revista de Ciências Ambientais, v. 7, n. 1, p. 91-104, 2013.

PÁLL, E.; NICULAE1, M.; KISS, Y.; ŞANDRU1, C. D.; SPÎNU1, M. Human impact on the microbiological water quality of the rivers. Journal of medical microbiology, v. 62, p. 1635-40, 2013. http://dx.doi.org/10.1099/jmm.0.055749-0.

POMEROY, L. R. The Ocean's food web, a changing paradigm. BioScience, v. 24, n. 9, p. 499-504, 1974. http://dx.doi.org/10.2307/1296885

RAMOS, R. J.; MIOTTO, L. A.; MIOTTO, M.; SILVEIRA JUNIOR, N.; CIROLINI, A.; SILVA, H. S. DA; et al. Occurrence of potentially pathogenic Vibrio in oysters (Crassostrea gigas) and waters from bivalve mollusk cultivations in the South Bay of Santa Catarina. Revista da Sociedade Brasileira de Medicina Tropical, v. 47, n. 3, p. 327-333, 2014. http://dx.doi.org/10.1590/0037-8682-0069-2014 
REBOUÇAS, R. H.; DE SOUSA, O. V.; LIMA, A. S.; VASCONCELOS, F. R.; DE CARVALHO, P. B.; DOS FERNANDES VIEIRA, R. H. S. Antimicrobial resistance profile of Vibrio species isolated from marine shrimp farming environments (Litopenaeus vannamei) at Ceará, Brazil. Environmental research, v. 111, n. 1, p. 214, jan. 2011. http://dx.doi.org/10.1016/j.envres.2010.09.012

RODRIGUES, J. R. D. D.; JORGE, A. O.; UENO, M. Evaluation of the quality of waters of two areas used for recreation of the River Piracuama-SP. Revista Biociências, v. 15, n. 2, p. 88-94, 2009.

SIGEE, D. C. Freshwater microbiology. 1st. ed. Manchester: John Wiley and Sons, 2004.

SILVA, S. M. DA et al. Levantamento ambiental do Rio Piranhas- Açu / Atividades poluidoras ou potencialmente poluidoras. Natal/RN e João Pessoa/PB: [s.n.] 2007.

SIlVA, L. A. P. DA; ARAÚJO, F.; PANOSSO, R.; CAMACHO, F.; COSTA, I. A. S. As águas verdes dos Reservatórios do Rio Grande do Norte: o problema das cianobactérias e cianotoxinas.Boletim ABLimno, v. 1, n. 36, 2011. 


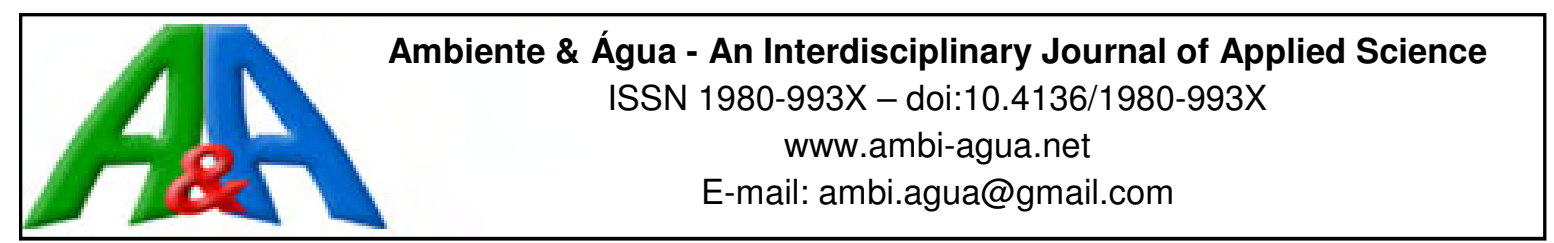

\title{
Análise bacteriológica das águas de irrigação de horticulturas
}

\author{
doi:10.4136/ambi-agua.1798 \\ Received: 06 Nov. 2015; Accepted: 11 Mar. 2016

\begin{abstract}
Ákylla Fernanda Souza Silva ${ }^{1 *}$; Camila Ananias de Lima ${ }^{2}$; José Jeyvson Florencio Queiroz ${ }^{2}$; Paula Regina Luna de Araújo Jácome ${ }^{3}$; Agenor Tavares Jácome Júnior ${ }^{2}$
\end{abstract}

\footnotetext{
${ }^{1}$ Associação Caruaruense de Ensino Superior e Técnico (ASCES), Caruaru, PE, Brasil

${ }^{2}$ Associação Caruaruense de Ensino Superior e Técnico (ASCES), Caruaru, PE, Brasil

${ }^{3}$ Universidade Federal de Pernambuco(UFPe), Caruaru, PE, Brasil

*Autor correspondente: e-mail: akyllafernanda@yahoo.com, camila1.0@hotmail.com, jeyvson.q@gmail.com,

paulajacome@ibest.com.br, agenorjacome@asces.edu.br
}

\section{RESUMO}

Este estudo envolveu a análise da qualidade das águas utilizadas na irrigação de cinco horticulturas por meio de microrganismos indicadores de contaminação fecal (Grupo coliformes) e de contaminação por material orgânico (Pseudomonas aeruginosa) tanto na água como nos alimentos irrigados. Foi verificada também a atividade de três sanitizantes na diminuição desses microrganismos por meio da contagem de bactérias heterotróficas antes e após o tratamento. Observou-se a presença do grupo coliformes (NMP > 1600) e da bactéria Pseudomonas aeruginosa tanto na água de irrigação como nos alimentos irrigados, de acordo com a análise dos coeficientes de variação $\left(\mathrm{R}^{2}\right)$, pode-se perceber uma forte correlação entre o índice de contaminação da água e dos alimentos. Todos os sanitizantes testados foram capazes de reduzir a carga bacteriana dos alimentos, com destaque a sanitização com Vinagre a 200 ppm, que além de ter reduzido consideralmente o índice de contaminação dos alimentos, pode ser indicado para este fim, haja vista ser considerado um produto de baixo custo e seguro, do ponto de vista toxicológico. Desse modo, o uso de uma água de má qualidade na irrigação de hortaliças pode influenciar diretamente a contaminação dos alimentos podendo trazer sérias implicações à saúde dos consumidores.

Palavras-chave: agricultura, coliformes, hortaliças, Pseudomonas aeruginosa, sanitizantes.

\section{Bacteriological analysis of horticultural irrigation water}

\section{ABSTRACT}

This study analyzed the quality of water used for the irrigation of five crops based upon microorganism indicators of fecal contamination (group coliforms) and contamination by organic material (Pseudomonas aeruginosa) in both the water and in the irrigated food. The study also verified the decrease in the activity of these microorganisms by heterotrophic bacterial count before and after treatment with three different sanitizers. The presence of coliform (NMP > 1600) and Pseudomonas aeruginosa was observed in both the irrigation water and in the irrigated food, and the coefficient of variation $\left(\mathrm{R}^{2}\right)$ revealed a strong correlation between the rates of contamination of the water and food. All of the sanitizers 
evaluated reduced the bacterial load of the food, especially sanitization with vinegar at 200 ppm, which, in addition to greatly reducing food contamination, is also considered a low-cost and toxicologically safe product, and therefore may be indicated for this purpose. Thus, the use of poor quality water in the irrigation of vegetables may directly contribute to food contamination, with serious implications for the health of consumers.

Keywords: agriculture, coliforms, Pseudomonas aeruginosa, sanitizers, vegetables.

\section{INTRODUÇÃO}

A água é um recurso natural fundamental para a agricultura por ser um nutriente essencial ao desenvolvimento de frutas e hortaliças. Sendo assim, a sua disponibilidade está diretamente relacionada com o aumento da produtividade nas áreas agrícolas (Falloon e Betts, 2010). Sabe-se que, a nível mundial, a irrigação é a maior consumidora de água derivada das fontes como rios, lagos e aquíferos subterrâneos (Dantas et al., 2014). Entretanto, uma das principais dificuldades do setor agrícola tem sido a disponibilidade desse recurso (Falloon e Betts, 2010).

Entre as atividades agrícolas desenvolvidas na cidade de Caruaru-PE, destacam-se a produção de frutas e hortaliças nas áreas de brejos de altitude. No entanto, tratando-se de uma região de clima semiárido, o município possui severos regimes pluviométricos que vem apresentando um forte entrave no desenvolvimento dessas atividades (Oliveira et al., 2014). O que pode ser explicado através de dados descritos pela Agência Pernambucana de Águas e Clima que afirmam que a precipitação pluviométrica média no período 2013-2014 em Caruaru foi de apenas 45,9 $\mathrm{mm} \mathrm{ano}^{-1}$ (Pernambuco, 2015).

O impacto de possíveis mudanças climáticas pode interferir negativamente em processos produtivos, na saúde e na qualidade de vida da região. Com a baixa pluviosidade, o agricultor de pequenas propriedades rurais fica à mercê de um curto período de chuvas para plantar a sua cultura de subsistência (Sadiq et al., 2014). Desse modo, ele se vê compelido a utilizar águas de poços artesianos, açudes e barragens para suprir as necessidades dos cultivos. No entanto, a prática da irrigação deve respeitar os critérios sanitários que garantam o uso de água de boa qualidade e em quantidade adequada (Andrade, 2009).

A qualidade microbiológica da água e dos alimentos pode ser estabelecida, utilizando-se, como parâmetro, microrganismos indicadores de contaminação fecal, como o grupo Coliforme, tendo como principal representante a Escherichia coli, que avalia suas condições higiênicas evidenciando sua relação com o histórico da amostra. Além do grupo coliforme, a pesquisa quanto a presença de Pseudomonas aeruginosa na água e nos alimentos tem se mostrado de grande importância, tendo em vista que é classificado como um dos microrganismos mais versáteis e oportunistas, e sua presença encontra-se cada vez mais difundida no meio ambiente (Almeida et al., 2009; Allydice-Francis e Brown, 2012).

Os alimentos irrigados, de modo especial as hortaliças, são caracterizadas por sua importância na alimentação e na saúde humana e o seu consumo tem crescido não só pelo aumento da população, mas sobretudo pela tendência de mudança no hábito alimentar do consumidor (Allydice-Francis e Brown, 2012). As mais consumidas são o coentro (Coriandrum sativum L.), que é rico em vitaminas A, B1 e B2 (Fiorotti et al., 2011) e a alface (Lactuca sativa L.) que se destaca como fonte de vitaminas e sais minerais, sendo assim constituída na mais popular hortaliça folhosa (Silva et al., 2011). De acordo com os dados de produção e valor de produção do coentro e alface, segundo as variáveis selecionadas no Brasil, a quantidade vendida para o consumo humano foi de 18.056 toneladas de coentro, resultando em um valor de produção de $\mathrm{R} \$ 24.742 .000$ e de 41.156 toneladas de alface, com valor de produção de $\mathrm{R} \$ 56.466 .000$, sendo, por exemplo, o consumo desses alimentos ainda 
maior que hortaliças como a couve (IBGE, 2006).

Entretanto, diversos estudos tem comprovado uma relação clara entre o aumento dos surtos de doenças ligadas à alimentação, com o maior consumo de produtos frescos como frutas e hortaliças (Allydice-Francis e Brown, 2012; Olaimat e Holley, 2012). Nesse sentido, Assis e Uchida (2014) caracterizam as hortaliças como sendo, muitas vezes, inseguras para o consumo humano, tratando-se de alimentos consumidos in natura e passíveis de contaminação microbiológica, sobretudo nas fases de pré-preparo. Logo, é imprescindível que a etapa de lavagem desses vegetais seja realizada com água de boa qualidade adicionada de soluções sanitizantes, obtendo-se produtos microbiologicamente mais seguros (Adami e Dutra, 2011).

Tendo em vista que o consumo da água e alimentos contaminados traz severas implicações para a saúde humana, o presente estudo tem por objetivo analisar a qualidade bacteriológica das águas utilizadas para irrigação, assim como dos alimentos por ela irrigados, destacando o coentro e a alface, além de avaliar a atividade de três sanitizantes (Água Sanitária, Vinagre e Ácido Peracético) na diminuição da carga bacteriana desses alimentos.

\section{MATERIAL E MÉTODOS}

Tratou-se de um estudo laboratorial (experimental) que ocorreu de Janeiro de 2014 a Junho de 2015, sendo a coleta realizada na zona rural, em uma área de brejo de altitude, do município de Caruaru, situado no Agreste Pernambucano. A escolha das propriedades se deu pelos seguintes critérios: serem fornecedores de grandes redes de supermercados e feiras livres, utilização de água para irrigação de açudes ou poços artesianos, e produção dos dois tipos de cultura (alface e coentro). Dentro desses critérios de elegibilidade, foram selecionadas cinco propriedades da zona rural de Caruaru. A obtenção das amostras de água foi realizada tanto nos períodos de estiagem (geralmente no mês de Abril e Maio, e de Agosto a Dezembro) quanto nos períodos chuvosos (de Janeiro a Março, e nos meses de Junho e Julho). A coleta das culturas irrigadas foi realizada em períodos próximos à colheita, o que podia variar entre cada propriedade.

\subsection{Amostras}

\subsection{1. Água de irrigação}

Em cada uma das cinco propriedades foram coletadas duas amostras da principal fonte hídrica utilizada pelos agricultores nos períodos de estiagem, sejam elas açudes ou poços artesianos. As propriedades rurais utilizavam açudes de médio e grande porte como fonte alternativa de captação de água para as práticas agrícolas. A água era drenada até as plantações e, assim, utilizada na irrigação das horticulturas. As amostras de água foram coletadas em sacos estéreis com capacidade para $150 \mathrm{~mL}$, contendo $0,2 \mathrm{~mL}$ de solução de tiossulfato de sódio a $10 \%$.

Foram coletados $200 \mathrm{~mL}$ (100 mL em cada saco de coleta) nos pontos de captação de cada uma das cinco propriedades agrícolas que estavam dentro dos critérios de inclusão. Os sacos de coleta foram identificados quanto ao tipo de amostra, origem, data e hora e, em seguida, transportadas sob condições de refrigeração utilizando-se uma caixa isotérmica contendo gelo a temperatura de $4^{\circ} \mathrm{C}$, estando todo o procedimento de acordo com plano de amostragem descrito no Standard Methods for the Examination of Water and Wastewater (APHA et al., 2005).

As amostras foram encaminhadas para o laboratório de Controle de Qualidade Microbiológico de Alimentos da Faculdade Asces. Foi preenchida uma ficha de registro de coleta contendo informações de procedência, número da amostra, data e horário da coleta. 


\subsubsection{Hortaliças}

Além das amostras de água, foram coletadas amostras de alface e coentro de acordo com o plano de amostragem descrito no Codex Alimentárius (Jay, 2005). Desse modo, o universo da amostra foi constituído de acordo com a quantidade de hortaliças produzidas em cada propriedade (200 unidades/dia) e, deste, foram coletadas de 5-10\% (10 a 20 unidades) da quantidade total produzida para a obtenção da amostra bruta. Essas unidades foram selecionadas das parcelas cultivadas, de preferência as mais irrigadas (centrais), independente do tamanho ou peso.

O transporte das hortaliças para o Laboratório de Controle de Qualidade de Alimentos da Faculdade Asces se deu acondicionando as mesmas em sacos plásticos estéreis devidamente fechados e etiquetados (tipo de análise, procedência, data e hora da coleta) e preservadas em caixa isotérmica contendo baterias de gelo a temperatura de $4^{\circ} \mathrm{C}$.

A redução da amostra bruta se deu pelo processamento em liquidificador industrial (METVISA LOL6) com copo esterilizado. As amostras foram trituradas e quarteadas desprezando-se $2 / 4$ do peso total, gerando com isso a amostra de laboratório. Todos os procedimentos foram feitos em condições estéreis dentro de uma capela de fluxo laminar. A partir da amostra de laboratório, foram retiradas alíquotas para as análises bacteriológicas.

Quanto ao processamento, uma parte da amostra de laboratório foi destinada a análise do alimento sem tratamento sanitizante, e três partes foram submetidas a tratamentos com três tipos de soluções, sendo elas: Água Sanitária 40 ppm, Vinagre 200 ppm e Ácido Peracético $120 \mathrm{ppm}$. Cada alimento ficou em solução durante 15 minutos. Após à sanitização, $50 \mathrm{~g}$ de cada parcela dos alimentos foram liquefeitas em $200 \mathrm{~mL}$ de soro fisiológico estéril obtendo-se um caldo para posterior análise bacteriológica.

\subsection{Análise bacteriológica}

As amostras da água foram homogeneizadas antes da retirada da unidade analítica. As análises seguiram os critérios estipulados pela portaria n. 2914 de 2011 do Ministério da Saúde (Brasil, 2011) e a RDC n.12 de 2001 da ANVISA (Brasil, 2001). Para as amostras de água e de alimentos processados pesquisou-se a presença de coliformes totais, termotolerantes e Pseudomonas aeruginosa utilizando-se a técnica dos tubos múltiplos recomendada pelo "Standard Methods for the Examination of Water and Wastewater" (APHA et al., 2005), onde os tubos foram incubados em temperatura de 35 a $37^{\circ} \mathrm{C}$, sendo na pesquisa de termotolerantes os tubos incubados em temperatura de $44,5^{\circ} \mathrm{C}$ em banho-maria.

\subsection{Bactérias Heterotróficas}

A quantificação de colônias de bactérias heterotróficas foi feita por meio da técnica de pour-plate como recomendado pelo "Standards Methods for the examination of water and wastewater" (APHA et al., 2005). Foram realizadas diluições de 10³. Os resultados foram expressos em UFC $\mathrm{mL}^{-1}$ (Unidades Formadoras de Colônias por mililitro) de água.

\subsection{Análises estatísticas}

As análises estatísticas foram conduzidas utilizando o software excel (v. 14.07). Os percentuais médios de redução microbiana após o uso dos sanitizantes foram feitos por meios de média com intervalo de confiança de $95 \%$ (IC95\%) e a pesquisa de correlação entre o nível de contaminação da água de irrigação e o nível de contaminação da alface e do coentro foi realizada por meio de regressão linear e cálculo do coeficiente de determinação $\left(\mathrm{R}^{2}\right)$.

\section{RESULTADOS E DISCUSSÃO}

Todas as amostras das águas de irrigação (10 amostras) e de hortaliças coletadas (50 amostras) nas cinco propriedades rurais revelaram a presença do grupo coliforme. A 
legislação brasileira (Brasil, 2001) por meio da RDC $\mathrm{n}^{\mathrm{o}}$ 12, de 2 de janeiro de 2001, estabelece limites microbiológicos para coliformes fecais (termotolerantes) em hortaliças in

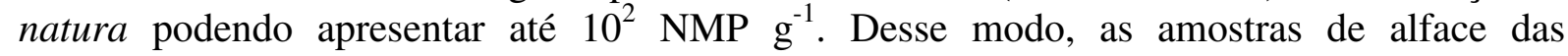
propriedades $\mathrm{C}$ e $\mathrm{E}$, e as amostras de coentro das propriedades $\mathrm{C}$ e $\mathrm{D}$, apresentaram contagens de coliformes de origem fecal acima do que é permitido pela legislação brasileira (Tabela 1).

Tabela 1. Resultados de análises de amostras de água de irrigação, alface e coentro de cinco propriedades rurais, em relação ao número de coliforme totais e termotolerantes (fecais).

\begin{tabular}{clcc}
\hline Propriedades & Amostras & Coliformes Totais* & Coliformes Termotolerantes* \\
\hline \multirow{2}{*}{ A } & Água & $\geq 1600$ & 2 \\
& Alface & $\geq 1600$ & 12 \\
& Coentro & $\geq 1600$ & 26 \\
B & Água & $\geq 1600$ & 21 \\
& Alface & $\geq 1600$ & 27 \\
& Coentro & $\geq 1600$ & 33 \\
C & Água & $\geq 1600$ & 26 \\
& Alface & $\geq 1600$ & 110 \\
& Coentro & $\geq 1600$ & 280 \\
D & Água & $\geq 1600$ & 12 \\
& Alface & $\geq 1600$ & 26 \\
& Coentro & $\geq 1600$ & 170 \\
& Água & $\geq 1600$ & 17 \\
E & Alface & $\geq 1600$ & 900 \\
& Coentro & 500 & 4 \\
\hline
\end{tabular}

* Nas amostras de água, o resultado é expresso em NPM $100 \mathrm{~mL}^{-1}$ (Número mais provável por 100 mililitro de amostra). Já nas amostras de alimentos (alface e coentro), o resultado é expresso em NMP $\mathrm{g}^{-1}$.

Em um estudo realizado por Santos et al. (2010) também foram encontrados índices elevados de contaminação por coliformes a $45^{\circ} \mathrm{C}$; dentre as hortaliças analisadas, a alface e o coentro foram os que apresentaram maior incidência de contaminação; e nas amostras de água de irrigação, $89 \%$ foram positivas para coliformes totais e $87 \%$ apresentaram coliformes termotolerantes. Assis e Uchida (2014) afirmam que contagens elevadas de coliformes podem indicar condições higiênico-sanitárias insatisfatórias no processamento ou pós-processamento dos alimentos.

A contagem de coliformes totais revelou um NMP altamente elevado (de $500 \mathrm{a} \geq 1600$ ). Apesar da legislação brasileira não possuir um padrão para coliformes totais em hortaliças, o monitoramento desses microrganismos faz-se necessário, tendo em vista que são deteriorantes potenciais pertencendo ao grupo dos bioindicadores de higiene dos alimentos (Srebernich, 2007; Arbos et al., 2010). Além disso, Cabral (2010) afirma que, de acordo com a legislação norte-americana, os coliformes totais são um parâmetro de rotina a ser determinado e que embora não sejam necessariamente bactérias fecais, a lógica por trás desse sistema é correta, uma vez que um teste positivo em coliformes fecais é necessariamente positivo no processo de coliformes totais.

A presença da espécie P.aeruginosa foi encontrada nas amostras de água de irrigação e hortaliças das cinco propriedades apresentando valores elevados de NMP (Tabela 2). Quando comparado o uso das três soluções sanitizantes foi observado que o percentual médio de redução microbiana, relativo à espécie, variou entre $-91,8 \%$ e $-99,5 \%$, no entanto, a 
comparação do intervalo de confiança de $95 \%$ revelou que não há diferença estatisticamente significativa dos percentuais médios de redução microbiana entre os sanitizantes (Tabela 2).

A contaminação de hortaliças por P.aeruginosa tem sido prevalente em diversos locais, sobretudo em alimentos folhosos como a alface (Allydice-Francis e Brown, 2012). Na falta de uma legislação que estabeleça limites à presença de P.aeruginosa nesse tipo de amostra, o presente estudo considerou a água de irrigação e os alimentos irrigados, como sendo impróprios para o consumo, tendo em vista que, além de se tratar de um patógeno oportunista, a presença deste microrganismo é indicativo da poluição da água por material orgânico (Almeida et al., 2009).

Tabela 2: Resultado da análise do número mais provável (NMP) de Pseudomonas aeruginosa nas amostras de água de irrigação, alface e coentro, com e sem tratamento sanitizante, e percentual de redução microbiana após o uso dos sanitizantes. O resultados do NMP nas amostras de água estão expressos em NPM $100 \mathrm{~mL}^{-1}$ e o das amostras de alface e coentro, expressos em NMP g ${ }^{-1}$.

\begin{tabular}{|c|c|c|c|c|c|c|c|c|c|c|c|c|}
\hline \multirow[b]{3}{*}{ Amostra } & \multicolumn{10}{|c|}{ Propriedades Rurais } & & \\
\hline & \multicolumn{2}{|c|}{ A } & \multicolumn{2}{|c|}{ B } & \multicolumn{2}{|c|}{$\mathrm{C}$} & \multicolumn{2}{|c|}{$\mathrm{D}$} & \multicolumn{2}{|c|}{$\mathrm{E}$} & \multicolumn{2}{|c|}{ Total } \\
\hline & NMP & $\% \mathrm{R} *$ & NMP & $\% \mathrm{R} *$ & NMP & $\% \mathrm{R}^{*}$ & NMP & $\% \mathrm{R}^{*}$ & NMP & $\% \mathrm{R} *$ & $\% \mathrm{MRB} * *$ & $\mathrm{IC}_{95 \%} * * *$ \\
\hline Água de Irrigação & $\geq 1600$ & - & 500 & - & 1600 & - & 500 & - & 900 & - & & \\
\hline $\begin{array}{l}\text { Alface sem } \\
\text { Tratamento }\end{array}$ & $\geq 1600$ & - & 900 & - & $\geq 1600$ & - & 110 & - & 1600 & - & & \\
\hline $\begin{array}{l}\text { Alface com Água } \\
\text { Sanitária }\end{array}$ & 50 & $-96,9$ & 2 & $-99,8$ & 11 & $-99,3$ & 4 & $-96,4$ & 13 & $-99,2$ & $-98,3$ & $(-96,7 \%)-(-99,9 \%)$ \\
\hline $\begin{array}{l}\text { Alface com } \\
\text { Vinagre }\end{array}$ & 34 & $-97,9$ & 2 & $-99,8$ & 4 & $-99,8$ & 2 & $-98,2$ & 14 & $-99,1$ & $-98,9$ & $(-98,1 \%)-(-99,8 \%)$ \\
\hline $\begin{array}{l}\text { Coentro sem } \\
\text { Tratamento }\end{array}$ & $\geq 1600$ & - & 110 & - & 900 & - & $\geq 1600$ & - & $\geq 1600$ & - & & \\
\hline $\begin{array}{l}\text { Coentro com Água } \\
\text { Sanitária }\end{array}$ & 90 & $-94,4$ & 33 & $-70,0$ & 26 & $-97,1$ & 11 & $-99,3$ & 30 & $-98,1$ & $-91,8$ & $(-79,5 \%)-(-104,1 \%)$ \\
\hline $\begin{array}{l}\text { Coentro com } \\
\text { Vinagre }\end{array}$ & 33 & $-97,9$ & 14 & $-87,3$ & 14 & $-98,4$ & 4 & $-99,8$ & 17 & $-98,9$ & $-96,5$ & $(-91,3 \%)-(-101,7 \%)$ \\
\hline $\begin{array}{l}\text { Coentro com Ácido } \\
\text { Peracético }\end{array}$ & 2 & $-99,9$ & 2 & $-98,2$ & 4 & $-99,6$ & 2 & $-99,9$ & $<2$ & $-99,9$ & $-99,5$ & $(-98,7 \%)-(-100,2 \%)$ \\
\hline
\end{tabular}

* \% $\mathbf{R}=$ Percentual de redução microbiana após o uso dos sanitizantes.

** \%MRB = Percentual médio de redução microbiana após o uso dos sanitizantes.

*** $\mathbf{I C}_{\mathbf{9 5} \%}=$ Intervalo de confiança de $95 \%$.

Quanto à contagem de bactérias heterotróficas, essas apresentaram números elevados tanto nas amostras de água quanto nas amostras de alimentos, variando principalmente entre $1,0 \times 10^{3}$ e $1,75 \times 10^{6}$ UFC $\mathrm{mL}^{-1}$ para as amostras de água e variação de $2,4 \times 10^{4}$ a $2,19 \times 10^{6} \mathrm{UFC} \mathrm{g}^{-1}$ nas amostras de hortaliças (Tabela 3). Essas contagens foram ainda maiores quando comparadas as de um estudo realizado por Coutinho et al. (2015), onde a enumeração das bactérias heterotróficas mesófilas tiveram variação de $4,5 \times 10^{4}$ a $7,7 \times 10^{5} \mathrm{UFC} \mathrm{g}^{-1} \mathrm{em}$ amostras de alface, demonstrando o alto grau de contaminação desse alimento.

Assim como no percentual médio de redução microbiana relativo à Pseudomonas aeruginosa, também não houve diferença estatisticamente significativa dos percentuais médios de redução microbiana entre os sanitizantes pela contagem de bactérias heterotróficas ( $\mathrm{IC}_{95 \%}$ ), tendo ocorrido variação de redução entre $-91,9 \%$ e $-98,4 \%$ (Tabela 3). 
De acordo com Abreu et al. (2010), a lavagem das hortaliças é a prática mais comum para se obter um produto mais seguro. No entanto, a seleção dos sanitizantes a serem empregados deve ser realizada cuidadosamente, baseando-se não apenas na eficácia do produto, mas também na sua segurança do ponto de vista toxicológico, uma vez que, para evitar riscos de contaminação, é recomendável que os alimentos sejam mantidos e consumidos sem enxágue subsequente (Adami e Dutra, 2011).

Tabela 3. Resultado da análise da contagem de bactérias heterotróficas (UFC $\left.\mathrm{mL}^{-1} \times 10^{3}\right)$ nas amostras de água de irrigação, alface e coentro, com e sem tratamento sanitizante, e percentual de redução microbiana após o uso dos sanitizantes.

\begin{tabular}{|c|c|c|c|c|c|c|c|c|c|c|c|c|}
\hline \multicolumn{13}{|c|}{ Propriedades Rurais } \\
\hline \multirow[b]{2}{*}{ Amostra } & \multicolumn{2}{|c|}{$\mathrm{A}$} & \multicolumn{2}{|c|}{$\mathrm{B}$} & \multicolumn{2}{|c|}{$\mathrm{C}$} & \multicolumn{2}{|c|}{$\mathrm{D}$} & \multicolumn{2}{|c|}{$\mathrm{E}$} & \multicolumn{2}{|c|}{ Total } \\
\hline & $\mathrm{n}^{*}$ & $\% \mathrm{R} * *$ & $\mathrm{n}^{*}$ & $\% \mathrm{R} * *$ & $\mathrm{n}^{*}$ & $\% \mathrm{R} * *$ & $\mathrm{n}^{*}$ & $\% \mathrm{R} * *$ & $\mathrm{n}^{*}$ & $\% \mathrm{R} * *$ & $\% \mathrm{MRB} * *$ & $\mathrm{IC}_{95 \%} * * * *$ \\
\hline $\begin{array}{l}\text { Alface sem } \\
\text { Tratamento }\end{array}$ & 801 & & 679 & & 740 & & 1730 & & 4940 & & & \\
\hline $\begin{array}{l}\text { Alface com Água } \\
\text { Sanitária }\end{array}$ & 14,6 & $-98,2$ & 156 & $-77,0$ & 26,5 & $-96,4$ & 7,5 & $-99,6$ & 480 & $-90,3$ & $-92,3$ & $(-83,1 \%)-(-101,5 \%)$ \\
\hline Alface com Vinagre & 241 & $-69,9$ & 45,3 & $-93,3$ & 10,5 & $-98,6$ & 3,5 & $-99,8$ & 117 & $-97,6$ & $-91,9$ & $(-79,3 \%)(-104,4 \%)$ \\
\hline $\begin{array}{l}\text { Alface com Ácido } \\
\text { Peracético }\end{array}$ & 4,15 & $-99,5$ & 31,5 & $-95,4$ & 1,5 & $-99,8$ & 10,6 & $-99,4$ & 104 & $-97,9$ & $-98,4$ & $(-96,5 \%)-(-100,2 \%)$ \\
\hline $\begin{array}{l}\text { Coentro sem } \\
\text { Tratamento }\end{array}$ & 680 & & 2190 & & 1210 & & 2400 & & 9040 & & & \\
\hline $\begin{array}{l}\text { Coentro com Água } \\
\text { Sanitária }\end{array}$ & 52 & $-92,4$ & 114 & $-94,8$ & 160 & $-86,8$ & 6 & $-99,8$ & 134 & $-98,5$ & $-94,4$ & $(-89,2 \%)-(-99,6 \%)$ \\
\hline Coentro com Vinagre & 197 & $-71,0$ & 29,5 & $-98,7$ & 52 & $-95,7$ & 8,66 & $-99,6$ & 232 & $-97,4$ & $-92,5$ & $(-80,4 \%)-(-104,6 \%)$ \\
\hline $\begin{array}{l}\text { Coentro com Ácido } \\
\text { Peracético }\end{array}$ & 58 & $-91,5$ & 176 & $-92,0$ & 33,5 & $-97,2$ & 0 & $-100,0$ & 55 & $-99,4$ & $-96,0$ & $(-92,0 \%)-(-100,1 \%)$ \\
\hline
\end{tabular}

UFC $\mathrm{mL}^{-1} \times \mathbf{1 0}^{3}$ = Unidade formadora de colônias por mililitro vezes dez ao cubo.

$* \mathbf{n}=$ número de batérias heterotróficas.

** $\% \mathbf{R}=$ Percentual de redução microbiana após o uso dos sanitizantes.

*** \% MRB = Percentual médio de redução microbiana após o uso dos sanitizantes.

***** $\mathbf{I C}_{\mathbf{9 5} \%}=$ Intervalo de confiança de $95 \%$.

Nesse sentido, observando a semelhante redução da carga microbiana dos alimentos, nas análises estatísticas, quanto ao uso da Água Sanitária 40ppm, Vinagre 200ppm e Ácido Peracético 120ppm, o Vinagre foi considerado o produto de melhor escolha, pois, sendo ele comumente utilizado como condimento, além de ser um produto facilmente encontrado, torna-se acessível à população por ter um baixo custo, podendo ser utilizado como sanitizante sem produção de resíduo tóxico.

Quanto a análise da água e sua relação com os vegetais, observou-se que o nível de contaminação da água de irrigação e o nível de contaminação da alface e do coentro apresentam forte correlação. Isto é, segundo análise dos coeficientes de determinação $\left(\mathrm{R}^{2}\right)$, 95,6\% do nível de contaminação da alface e 97,5\% do nível de contaminação do coentro podem ser explicados pelo nível de contaminação da água (Figura 1). 

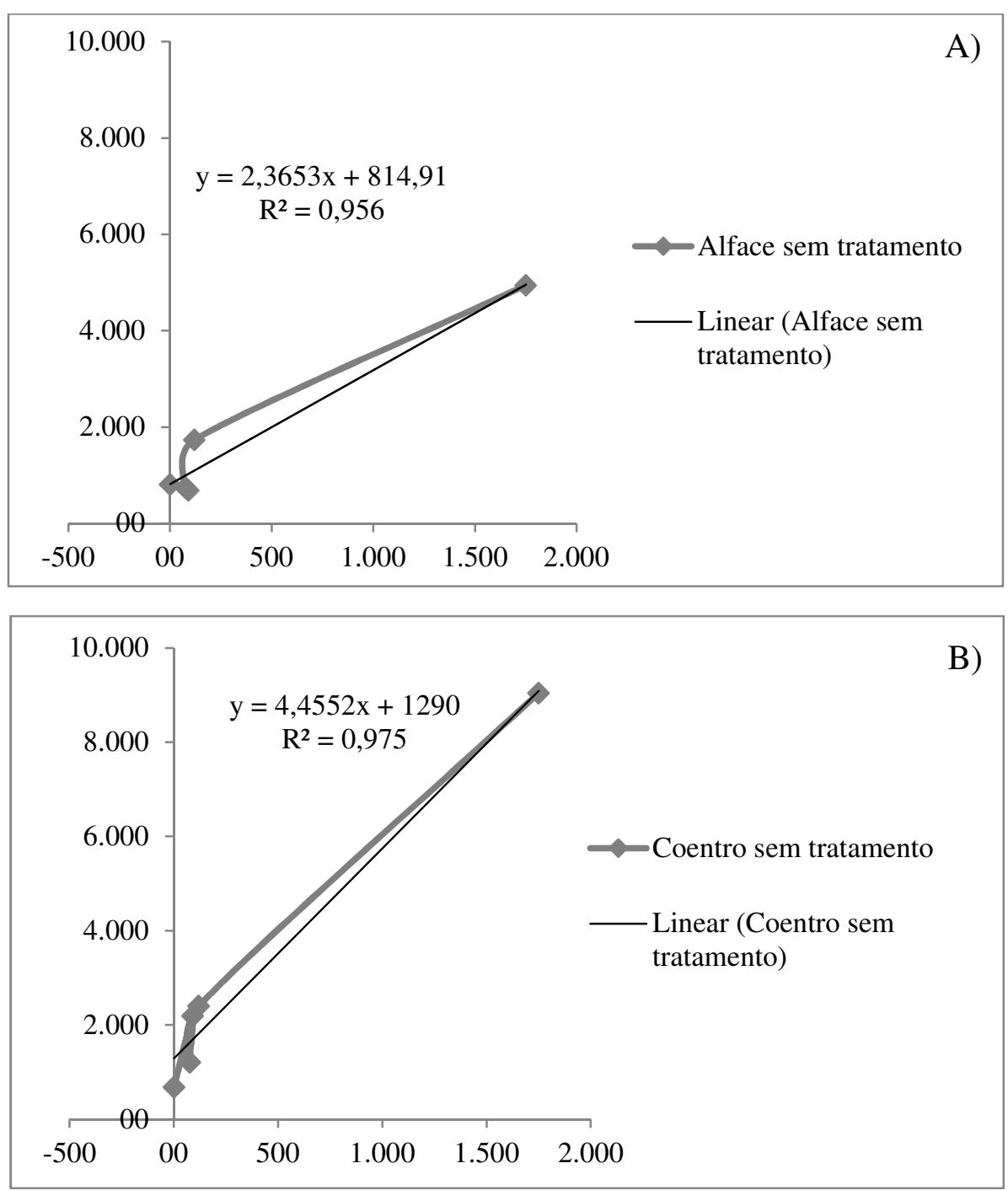

Figura 1. Correlação entre o nível de contaminação da água de irrigação e o nível de contaminação da alface (A) e do coentro (B).

Em um estudo realizado no Reino Unido sobre a qualidade microbiológica da água utilizada para irrigação de saladas, também demonstrou uma relação clara entre o uso de uma água de má qualidade com a contaminação dos alimentos irrigados, representando um sério risco de doenças (Tyrrel et al., 2006). De acordo com Cavalcante (2014) na região semiárida, os problemas relacionados à qualidade das fontes de água são ainda maiores devido à necessidade de fontes alternativas que complementem o abastecimento nos períodos de seca.

\section{CONCLUSÃO}

Como base neste estudo, pôde-se perceber que as águas destinadas à irrigação das hortaliças não possuíam qualidade do ponto de vista microbiológico e o índice de contaminação da água e dos vegetais apresentou uma forte correlação, segundo a análise dos coeficientes de determinação $\left(\mathrm{R}^{2}\right)$.

Com relação ao uso dos sanitizantes, foi observado que, apesar dos índices de contaminação das hortaliças terem sido elevados, as sanitizações com a Água Sanitária, Vinagre e Ácido Peracético, reduziram significativamente a carga bacteriana presente nos alimentos. No entanto, entre os três sanitizantes, o Vinagre foi considerado como sendo ideal para realização de etapas de sanitização das hortaliças, haja vista ser um produto com um baixo custo e considerado seguro, do ponto de vista toxicológico. 
Assim, torna-se indispensável um monitoramento adequado das águas destinadas à irrigação, sobretudo quando a mesma é aspergida sobre as partes comestíveis dos produtos cosnsumidos in natura, a fim de se evitar a contaminação potencial desses alimentos além das doenças por eles causadas.

\section{REFERÊNCIAS}

ABREU, I. M. O.; JUNQUEIRA, A. M. R.; PEIXOTO, J. R.; OLIVEIRA, S. A. Qualidade microbiológica e produtividade de alface sob adubação química e orgânica. Ciência e Tecnologia de Alimentos, v. 30, supl. 1, p. 108-118, 2010.

ADAMI, A. A. V.; DUTRA, M. B. L. Análise da eficácia do vinagre como sanitizante na alface (Lactuta sativa, L.). REAS, Revista Eletrônica Acervo Saúde, v. 3, p. 134-144, 2011.

ALLYDICE-FRANCIS, K.; BROWN, P. D. Diversity of antimicrobial resistance and virulence determinants in pseudomonas aeruginosa associated with fresh vegetables. $\begin{array}{lllll}\text { International Journal of Microbiology, v. 2012, } 2012 . & \end{array}$ http://dx.doi.org/10.1155/2012/426241

ALMEIDA, V. F. S.; OLIVEIRA, S. R.; JÁCOME, P. R. L. A.; JÁCOME-JÚNIOR, A. T. Avaliação de indicadores higiênico-sanitários e das características físico-químicas em águas utilizadas em escolas públicas de nível fundamental. Revista do Instituto Adolfo Lutz, v. 68, n. 3, p. 334-40, 2009.

AMERICAN PUBLIC HEALTH ASSOCIATION - APHA; AMERICAN WATER WORKS ASSOCIATON - AWWA; WATER ENVIRONMENT ASSOCIATION- WEF. Standard methods for the examination of water \& wastewater. 21st edition. Washington, 2005. $1496 \mathrm{p}$.

ANDRADE, E. M. A irrigação e suas implicações sobre o capital natural em regiões áridas e semi-áridas: uma revisão. Revista Ceres, v. 56, p. 390-398, 2009.

ARBOS, K. A.; FREITAS, R. J. S.; STERTZ, S. C.; CARVALHO, L. A. Segurança alimentar de hortaliças orgânicas: aspectos sanitários e nutricionais. Ciência e Tecnologia de Alimentos, v. 30, supl. 1, p. 215-220, 2010.

ASSIS, L. L. R.; UCHIDA, N. S. Análise da qualidade microbiológica de Hortaliças minimamente processadas comercializadas em campo mourão, PR. Brazilian Journal of Surgery and Clinical Research - BJSCR, v. 5, n. 3, p. 17-22, 2014.

BRASIL. Ministério da Saúde. Portaria n ${ }^{\circ} 2914$ de 12 de dezembro de 2011. Dispõe sobre os procedimentos de controle e de vigilância da qualidade da água para consumo humano e seu padrão de potabilidade. Diário Oficial [da] República Federativa do Brasil, Poder Executivo, Brasília, DF, 12 mar. 2011.

BRASIL. Ministério da Saúde. Agência Nacional de Vigilância Sanitária (ANVISA). Resolução RDC $n^{\circ}$ 12, de 2 de janeiro de 2001. Aprova Regulamento Técnico sobre Padrões Microbiológicos para Alimentos e seus anexos I e II. Diário Oficial [da] República Federativa do Brasil. Brasília, DF, 10 jan. 2001, Seção 1, n. 7-E, p. 45.

CABRAL, J. P. S. Water microbiology. Bacterial pathogens and water. International Journal of Environmental Research and Public Health, v. 7, n. 10, p. 3657-3703, 2010. http://dx.doi.org/10.3390/ijerph7103657 
CAVAlCANTE, R. B. L. Ocorrência de Escherichia coli em fontes de água e pontos de consumo em uma comunidade rural. Revista Ambiente \& Água, v. 9, n. 3, 2014. http://dx.doi.org/10.4136/ambi-agua.1301

COUTINHO, M. G. S.; FERREIRA, C. S.; NEVES, A. M.; ALVES, F. R. L.; SOUZA, F. F. P.; FONTENELLE, R. O. S. Avaliação microbiológica e parasitológica de alfaces (lactuca sativa L) comercializadas em feiras livres no município de sobral - CE. Revista da Universidade do Vale do Rio Verde, v. 13, n. 2, p. 388-397, 2015. http://dx.doi.org/10.5892/ruvrd.v13i2.2322

DANTAS, I. L. A.; FACCIOLI, G. G.; MENDONÇA, L. C.; NUNES, T. P.; VIEGAS, P. R. A.; SANTANA, L. O. G. Viabilidade do uso de água residuária tratada na irrigação da cultura do rabanete (Raphanus sativus L.). Revista Ambiente \& Água, v. 9, n. 1, 2014. http://dx.doi.org/10.4136/ambi-agua.1220

FALLOON, P.; BETTS, R. Climate impacts on European agriculture and water management in the context of adaptation and mitigation-The importance of an integrated approach. Science of the Total Environment, v. 408, n. 23, p. 5667-5687, 2010. http://dx.doi.org/10.1016/j.scitotenv.2009.05.002

FIOROTTI, J. L.; CARVALHO, E. D. S. S.; PIMENTEL, A. F.; SILVA, K. R. D. Horta: a importância no desenvolvimento escolar. In: ENCONTRO LATINO-AMERICANO DE INICIAÇÃO CIENTÍfICA, 14., 2011, São José dos Campos. Anais... São José dos campos: Universidade Vale do Paraíba, 2011.

INSTITUTO BRASILEIRO DE GEOGRAFIA E ESTATÍSTICA - IBGE. Brasil, grandes regiões e unidades da Federação. Censo Agropecuário, p. 1-777, 2006. Disponível em: http://www.ibge.gov.br/home/estatistica/economia/agropecuaria/ censoagro/brasil_2006/Brasil_censoagro2006.pdf. Acesso em: 26 fev. 2016.

JAY, J. M. Microbiologia de alimentos. 6. ed. Porto Alegre: Artmed, 2005. 712 p.

OLAIMAT, A. N.; HOLLEY, R. A. Factors influencing the microbial safety of fresh produce: a review. Food Microbiology, v. 32, n. 1, p. 1-19, 2012.

OLIVEIRA, A. F. M.; FERNANDES, F. G. B. C.; BATISTA, R. O.; SOUZA, L.; GURGEL, M. T. Teores de metais pesados em cambissolo irrigado com água residuária doméstica e água de poço. Revista Ambiente \& Água, v. 9, n. 2, 2014. http://dx.doi.org/10.4136/ambi-agua.1309

PERNAMBUCO. Agência Pernambucana de Águas e Clima. Monitoramento pluviométrico. Disponível em: http://www.apac.pe.gov.br/meteorologia/monitoramento -pluvio.php. Acesso: 12 fev. 2015.

SADIQ, A. A.; AMIN, S. A.; AHMAD, D.; UMARA, B. G. Characteristics of irrigation tube wells on major river flood plains in Bauchi State, Nigeria. Revista Ambiente \& Água, v. 9, n. 4, 2014. http://dx.doi.org/10.4136/ambi-agua.1314

SANTOS, Y. O.; AlMEIDA, R. C. de C.; GUIMARÃES, A. G.; AlMEIDA, P. F. Hygienicsanitary quality of vegetables and evaluation of treatments for the elimination of indigenous E. coli and E. coli O157:H7 from the surface of leaves of lettuce (Lactuca sativa L.). Revista Ciência e Tecnologia de Alimentos, v. 30, n. 4, p. 1083-1098, 2010 . 
SILVA, E. M. N. C. P.; FERREIRA, R. L. F.; ARAÚJO-NETO, S. E.; TAVELLA, L. B.; SOLINO, A. J. S. Qualidade de alface crespa cultivada em sistema orgânico, convencional e hidropônico. Horticultura Brasileira, v. 29, n. 2, p. 242-245, 2011. http://dx.doi.org/10.1590/S0102-05362011000200019

SREBERNICH, S. M. Utilização do dióxido de cloro e do ácido peracético como substitutos do hipoclorito de sódio na sanitização do cheiro-verde minimamente processado. Ciência e Tecnologia de Alimentos, v. 27, n. 4, p. 744-750, 2007.

TYRREL, S. F.; KNOX, J. W.; WEATHERHEAD, E. K. Microbiological water quality requirements for salad irrigation in the United Kingdom. Journal of food protection, $v$. 69, n. 8, p. 2029-35, 2006. 


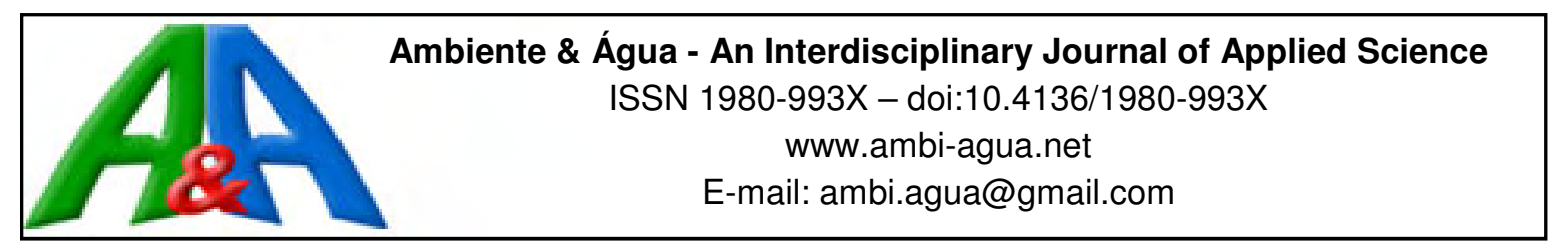

\title{
Eficácia de velas filtrantes na retenção de cistos de Giardia duodenalis em água experimentalmente contaminada
}

\author{
doi:10.4136/ambi-agua.1821
}

Received: 09 Dec. 2015; Accepted: 28 Mar. 2016

\author{
Larissa Imaculada da Costa Sobrinho ${ }^{{ }^{*}}$; Francine Alves da Silva Coelho ${ }^{1}$; \\ Matheus Diniz Gonçalves Coelho ${ }^{2}$ \\ ${ }^{1}$ Universidade de Taubaté (UNITAU), Taubaté, SP, Brasil \\ Departamento de Biologia- Instituto Básico de Biociências \\ ${ }^{2}$ Fundação Universitária Vida Cristã (FUNVIC), Pindamonhangaba, SP, Brasil \\ Laboratório de Parasitologia \\ *Autor correspondente: e-mail: larissaicsobrinho94@gmail.com, \\ francine.ascoelho@gmail.com, profmatheuscoelho@gmail.com
}

\section{RESUMO}

Giardia duodenalis é o principal protozoário de veiculação hídrica em países em desenvolvimento. No presente trabalho objetivou-se avaliar a eficácia de velas filtrantes na retenção de cistos de $G$. duodenalis, bem como verificar a porosidade mais adequada para remoção desses cistos em água contaminada. O estudo foi realizado no Laboratório de Parasitologia da Universidade de Taubaté, onde cada unidade filtrante foi confeccionada a partir da união de dois galões de Pet, mangueira de látex e vela filtrante. As porosidades das velas selecionadas foram de $0,5-1,0 \mu \mathrm{m}$ e de $5-15 \mu \mathrm{m}$, com e sem carvão ativado, e os ensaios realizados em triplicatas. Aproximadamente $60 \mu \mathrm{L}$ (cerca de 53cistos) de uma solução contendo cistos de G. duodenalis foram colocados em 2 litros de água destilada. A suspensão obtida foi colocada na parte superior do filtro onde permaneceu até total filtração. O material filtrado foi processado de acordo com a metodologia descrita por De Faria (2006), para concentrar os elementos parasitários. Os resultados obtidos foram avaliados estatisticamente, utilizando análise de variância e o teste de Tukey, demonstrando que as velas filtrantes (com e sem carvão ativado) com porosidades de $0,5-1,0 \mu \mathrm{m}$ foram capazes de reter $100 \%$ dos cistos de $G$. duodenalis, sendo este resultado significativamente superior ao observado no grupo controle $(\mathrm{p}<0,05)$. Na porosidade de 5-15 $\mu \mathrm{m}$ a retenção total ocorreu somente nas velas com carvão ativado. Frente aos resultados obtidos, pode-se concluir que todas as velas avaliadas, independente da porosidade com carvão ativado, apresentaram uma eficácia satisfatória para filtração de cistos de G. duodenalis.

Palavras-chave: água de consumo humano, protozoário, purificação da água.

\section{Effectiveness of ceramic filters in capturing Giardia duodenalis cysts in experimentally contaminated water}

\section{ABSTRACT}

Giardia duodenalis is the main water-transmitted protozoan in developing countries. This study evaluated the effectiveness of ceramic filters in capturing $G$. duodenalis cysts and 
verified the porosity size needed to remove cysts from contaminated water. The study was conducted in the Laboratory of Parasitology at the University of Taubaté, where each filter unit was made by joining two Pet gallons, latex hose and a ceramic filter. Two porosity sizes were selected: $0.5-1.0 \mu \mathrm{m}$ and 5-15 $\mu \mathrm{m}$ with or without activated carbon, and the assays were run in triplicate. Approximately $60 \mu \mathrm{L}$ (53 cysts) of $G$. duodenalis cysts were placed in 2 liters of distilled water. After the preparation of the contaminated water, this solution was run through the filter until the completely filtered. Afterwards, the filtrate was processed according to the methodology described by De Faria (2006), in order to concentrate parasitic elements. The results were statistically evaluated using ANOVA and Tukey tests, showing that the $0.5-1,0 \mu \mathrm{m}$ porosity filter candles (with and without activated carbon) were able to retain $100 \%$ of cysts of $G$. duodenalis. This is a result significantly superior to the results obtained in the control group $(\mathrm{p}<0.05)$. On the other hand, for the candles with porosity of 5-15 $\mu \mathrm{m}$, total retention occurred only in candles with activated carbon. Based upon our results, it can be concluded that, in candles with both porosity sizes with activated carbon, all filters showed a satisfactory efficacy for filtration of G. duodenalis cysts.

Keywords: consumption of water, protozoan, water purification.

\section{INTRODUÇÃO}

A água potável é um recurso finito, e está repartida de maneira desigual na superfície da Terra. Segundo dados da Organização Mundial da Saúde (OMS), 768 milhões de pessoas no mundo em 2011 não possuíam acesso a água potável. Esse número aumentou, em 2013 onde cerca de 783 milhões de pessoas em todo o mundo não possuíam acesso a água potável (UNICEF, 2013). A água é essencial para manutenção da vida, no entanto serve em alguns casos como veículo de transmissão de alguns patógenos. Embora a água não forneça as condições favoráveis à multiplicação de microrganismos, estes encontram na mesma, condições ideais de sobrevivência por tempo suficiente para permitir sua transmissão hídrica (D’Aguila et al., 2000).

Patógenos pertencentes a diversos grupos podem ser encontrados na água, dentre os quais se destaca os protozoários Giardia duodenalis e Cryptosporidium spp. Entre os helmintos pode-se citar o Ascaris lumbricoides e o Trichuris trichiura que apesar de terem como principal fonte de contaminação o solo, podem ser carreados pela chuva e atingir a água destinada ao consumo humano ou irrigação (Fundação Fiocruz, 2010). Além das doenças parasitárias, a água contaminada é capaz de transmitir uma série de outros patógenos de origem viral e bacteriana, sendo que a detecção e a remoção destes da água destinada principalmente ao consumo humano é de vital importância (Alabi e Adesiyun, 1986).

A ausência ou ineficácia de saneamento básico vem sendo uma problemática para a saúde pública. A contaminação do solo e das águas decorrente do descarte inadequado de dejetos humanos e animais em leitos de rios está intimamente relacionada ao crescimento populacional desordenado e a atividades antrópicas em torno dos corpos hídricos (Brasil, 2014; Mendonça e Motta, 2007; Iritani e Ezaki, 2012).

Giardia duodenalis é um protozoário cosmopolita, frequentemente encontrado parasitando crianças residentes em países em desenvolvimento. Além da ingestão de água contaminada, esse protozoário pode ser adquirido por meio da ingestão de alimentos in natura que sofreram contaminação durante a irrigação ou manipulação. Uma parcela dos indivíduos parasitados é assintomática; entretanto crianças, idosos e indivíduos imunodeprimidos podem apresentar quadros frequentes de diarreia com presença de muco, fortes dores abdominais, flatulência, anorexia e a Síndrome da Má Absorção Intestinal (Franco, 2007; Pasupuleti et al., 2014; Carvalho, 2009). 
No inicio do século XX diversos elementos filtrantes surgiram com o intuito de oferecer a população uma água de consumo com melhor qualidade. Dentre esses, os filtros caseiros de cerâmica que utilizam velas como elementos filtrantes teve elevada aceitação entre a população de diferentes classes sociais por tratar-se de um produto eficaz e de custo reduzido. O hábito de filtrar a água antes de beber auxilia na sua potabilidade, eliminando $99 \%$ dos patógenos, frente a isso, durante muitos anos essa prática vem sendo adotada tanto nas residências, quanto em escolas, hospitais e diversos outros estabelecimentos (Opryszko et al., 2013).

As velas filtrantes apresentam uma superfície com diferentes níveis de porosidade. Para a retenção de cistos de protozoários e ovos de helmintos a porosidade indicada para garantir a retenção desses patógenos é a de 0,5-1,0 micras. A troca da vela filtrante deve incidir a cada 1.400 litros de água filtrada ou a cada seis meses a mesma deve ser substituída por uma peça nova. Atualmente é possível encontrar no comércio diversos tipos e marcas de velas como elementos filtrantes, mas é importante verificar se a marca escolhida foi testada e aprovada pelo Instituto Nacional de Metrologia (Inmetro, 2005). Todas as informações que garantem a qualidade do produtos devem estar descritas na embalagem do produto (Alves et al., 2013; Clasen et al., 2004).

Assim sendo, o objetivo do presente estudo foi avaliar a eficácia de velas filtrantes, em diferentes porosidades, na retenção de cistos de $G$. duodenalis, bem como verificar a porosidade mais adequada para remoção desses cistos em água experimentalmente contaminada.

\section{MATERIAL E METODOS}

\subsection{Local de estudo, confecção dos filtros e escolha das velas filtrantes}

Os experimentos foram realizados no Laboratório de Parasitologia da Universidade de Taubaté durante o período de dezembro de 2014 à agosto de 2015. Para confecção de cada unidade filtrante foram utilizados dois galões plásticos acoplados pelas tampas, com capacidade de 05 litros cada. $\mathrm{O}$ galão superior teve o fundo retirado para colocação de um saco plástico antes de receber a água contaminada. A vela filtrante foi inserida no galão superior, e em sua base, foi colocada uma mangueira de látex usada para transferir a água filtrada para o galão inferior.

Todas as velas filtrantes (total 12 exemplares) utilizadas no experimento foram aprovadas pelo INMETRO. As mesmas apresentavam porosidades de 0,5 a $1,0 \mu \mathrm{m}$ e 05 à $15 \mu \mathrm{m}$ e traziam ou não em sua composição carvão ativado. Em acréscimo, utilizou-se um grupo controle, composto por três unidades não filtrantes, desprovidas de vela. O esquema completo do filtro confeccionado para a realização do experimento está apresentado na Figura 1.

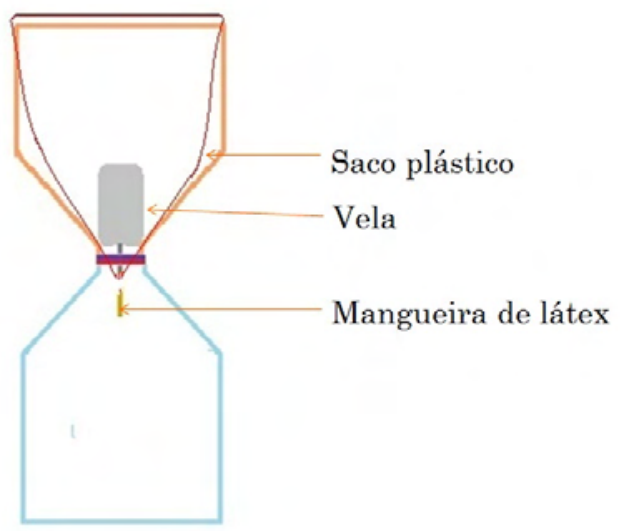

Figura 1. Esquema do filtro plástico com vela filtrante confeccionado no Laboratório de Parasitologia da Universidade de Taubaté. 


\subsection{Contaminação experimental da água e início da filtragem}

Para contaminação experimental da água foi necessário realizar a quantificação dos cistos de Giardia duodenalis presentes em um pool previamente preparado por meio do processamento e purificação de cistos do protozoário. Para tal, amostras fecais positivas para este parasito foram processadas pela técnica de Centrifugo Sedimentação em Formalina Acetato de Etila (Ritchie modificado) e posteriormente procedeu-se a quantificação dos cistos por meio da confecção de 03 lâminas contendo $20 \mu \mathrm{L}$ desse pool acrescido de uma gota de lugol e coberto por lamínula. Imediatamente após a montagem as mesmas foram lidas com auxílio de microscópio óptico para obtenção da média do número de cistos por lâmina. $\mathrm{O}$ número médio de cistos utilizado para cada experimento de filtragem foi de 115 , para filtros de $0,5-1,0 \mu \mathrm{m}$ e 97 cistos para filtros de $5-15 \mu \mathrm{m}$.

Ao total foram realizados 12 testes sendo que as unidades filtrantes foram agrupadas da seguinte maneira:

a) unidades filtrantes 1,2 e 3: velas filtrantes com porosidade $0,5-1,0 \mu \mathrm{m}$ e com carvão ativado;

b) unidades filtrantes 4,5 e 6 : velas filtrantes com porosidade $0,5-1,0 \mu \mathrm{m}$ sem carvão ativado;

c) unidades filtrantes 7,8 e 9: velas filtrantes com porosidade 5 - $15 \mu \mathrm{m}$ com carvão ativado;

d) unidades filtrantes 10,11 e 12 : velas filtrantes com porosidade $5-15 \mu \mathrm{m}$ sem carvão ativado.

e) unidades não filtrantes 13, 14 e 15: desprovidas de vela filtrante.

\subsection{Processamento da água experimentalmente contaminada e leitura das lâminas}

Para início do processo de filtragem foram colocados $60 \mu \mathrm{L}$ do pool de cistos de $G$. duodenalis, contendo aproximadamente 115 e 97 cistos para os filtros 0,5-1,0 e 5- 15 respectivamente, em 02 litros de água destilada. A água contaminada foi colocada na parte superior do filtro plástico previamente montado, e permaneceu lá até a filtragem completa da água. O material filtrado permaneceu em repouso por 48 horas, para sedimentação espontânea dos cistos de $G$. duodenalis, após esse período, o sobrenadante foi aspirado restando para processamento $200 \mathrm{~mL}$ do sedimento. Ao sedimento $(200 \mathrm{~mL})$ foi acrescentado $20 \mu \mathrm{L}$ de detergente Tween 20, posteriormente esse volume foi dividido em quatro tubos de centrífuga com Capacidade para $50 \mathrm{~mL}$ cada e os mesmos foram centrifugados a 100 giros durante 10 minutos. Depois de centrifugados o sobrenadante de cada tubo foi aspirado até que restassem $3 \mathrm{~mL}$ em cada tubo, estes foram unidos em um tubo com capacidade para $15 \mathrm{~mL}$. Esse material foi centrifugado na mesma programação anterior, e o sobrenadante foi aspirado, restando ao final do processo $1 \mathrm{~mL}$ do material a ser analisado (Adaptado De Faria et al., 2008).

Para o material processado foi colocado em lâminas de vidro com uma gota de lugol e coberta por lamínula. A leitura das lâminas foi realizada até o esgotamento total do sedimento final $(1 \mathrm{~mL})$ com auxílio de microscópio óptico, perfazendo um total de aproximadamente 25 lâminas por ensaio.

\subsection{Análise estatística dos resultados}

Para verificar a eficácia dos filtros determinou-se a quantidade de cistos no filtrado e os resultados das diferentes unidades filtrantes foram submetidos a análises estatísticas para determinação de variância, utilizando-se o método ANOVA, e, para verificar diferenças entre as médias, o teste de Tukey. 


\section{RESULTADOS E DISCUSSÃO}

No presente trabalho, foi determinada a eficiência de velas filtrantes para descontaminação de água artificialmente contaminada com cistos de Giardia duodenalis. Observou-se que a maioria das velas avaliadas apresentou uma eficiência significativa, já que induziram um percentual de eliminação de cistos superior a 95\%, conforme Tabela 1.

Tais resultados demonstraram que as velas filtrantes (com e sem carvão ativado) com porosidades de 0,5 - 1,0 $\mu \mathrm{m}$ foram capazes de reter $100 \%$ dos cistos de $G$. duodenalis, sendo este resultado significativamente superior $(\mathrm{p}<0,05)$ ao observado no grupo controle, onde não houve redução da quantidade de cistos. Na porosidade de $5-15 \mu \mathrm{m}$ a retenção total ocorreu somente nas velas com carvão ativado como mostra a Tabela 2.

A não retenção total dos cistos de $G$. duodenalis com porosidade de 5-15 $\mu \mathrm{m}$ na categoria sem carvão pode ser explicada devido a ausência de carvão ativado e que os cistos de $G$. duodenalis possuem um tamanho que pode variar de 8 a $12 \mu \mathrm{m}$ de comprimento por 7 a 10 $\mu \mathrm{m}$ de largura, sendo menor que o poros da vela cerâmica. Esses resultados destacam que velas cerâmicas dotadas de carvão ativado são mais indicadas para uma retenção de $100 \%$ na remoção de cistos desse protozoário, pois o carvão ativado é uma segunda barreira para retenção dos cistos. Entretanto os resultados obtidos nas velas sem carvão foram satisfatórios.

Tabela 1. Percentual de retenção de cistos de Giardia duodenalis, de acordo com o numero de cistos recuperados após a filtragem dos filtros.

\begin{tabular}{|c|c|c|c|c|}
\hline Teste & $\begin{array}{l}\text { Porosidade }(\mu \mathrm{m}) \mathrm{e} \\
\text { tipo da vela filtrante }\end{array}$ & $\begin{array}{l}\text { Número inicial } \\
\text { de cistos }\end{array}$ & $\begin{array}{l}\text { Número de cistos } \\
\text { recuperados }\end{array}$ & $\begin{array}{l}\text { Percentual } \\
\text { de remoção }\end{array}$ \\
\hline 01 & 0,5 - 1,0 com carvão & 115 & 0 & 100 \\
\hline 02 & 0,5 - 1,0 com carvão & 115 & 0 & 100 \\
\hline 03 & 0,5 - 1,0 com carvão & 115 & 0 & 100 \\
\hline 04 & 0,5 - 1,0 sem carvão & 115 & 0 & 100 \\
\hline 05 & 0,5 - 1,0 sem carvão & 115 & 0 & 100 \\
\hline 06 & 0,5 - 1,0 sem carvão & 115 & 0 & 100 \\
\hline 07 & 5 - 15 com carvão & 97 & 0 & 100 \\
\hline 08 & 5 - 15 com carvão & 97 & 0 & 100 \\
\hline 09 & 5 - 15 com carvão & 97 & 0 & 100 \\
\hline 10 & 5 - 15 sem carvão & 97 & 0 & 100 \\
\hline 11 & 5 - 15 sem carvão & 97 & 3 & 97 \\
\hline 12 & 5 - 15 sem carvão & 97 & 0 & 100 \\
\hline 13 & Controle & 115 & 115 & 0 \\
\hline
\end{tabular}


Apenas recentemente a legislação brasileira, por meio da portaria 2914 de 12 de Dezembro 2011 (Brasil, 2012), passou a exigir a análise periódica de cistos de Giardia e oocistos de Cryptosporidium nos pontos de captação dos mananciais de água superficial, porém apenas quando a média geométrica anual for igual ou superior a 1.000 UFC de Escherichia coli/100 mL. Cabe ressaltar, entretanto, que as bactérias comumente não são resistentes ao tratamento com cloro, procedimento este que já é rotineiro na maioria das estações de tratamento de água, porém os cistos de Giardia e oocistos de Cryptosporidium costumam resistir a esse procedimento, sendo necessárias outras estratégias para minimizar os riscos de infecção humana por estes protozoários (Brasil, 2010; Fragonesi et al., 2012).

A portaria 2914 estabelece que quando a média aritmética da concentração de oocistos de Cryptosporidium spp. for maior ou igual a 3,0 oocistos/L no(s) pontos(s) de captação de água, fica recomendada a obtenção de efluente em filtração rápida com valor de turbidez menor ou igual a 0,3 uT em $95 \%$ (noventa e cinco por cento) das amostras mensais ou uso de processo de desinfecção que comprovadamente alcance a mesma eficiência de remoção de oocistos desse protozoário

Cabe ressaltar, entretanto, que não existem valores claramente estipulados para a quantidade de cistos de Giardia, e, além disso, devido à resistência dos protozoários ao tratamento químico de água convencional, a ausência de $E$. coli não necessariamente anula a possibilidade de presença de Cryptosporidium, assim como a ausência deste não anula a possibilidade de encontro de Giardia duodenalis, inclusive porque Giardia apresenta uma maior ocorrência quando comparada ao Cryptosporidium, tornando mais provável a contaminação de água (Fragonesi et al., 2012).

No presente trabalho observou-se que algumas velas avaliadas permitiram a passagem de pequenas quantidades de cistos de $G$. duodenalis, chegando a quantidade máxima de 3 cistos. Essa quantidade não seria preocupante se for levado em consideração resultados de diversos estudos que avaliaram a presença de protozoários em amostras de água obtidas nas ETAs, após terem sido submetidas a tratamento convencional (Robertson et al., 2006; Marques et al., 2005; Lechevallier e Norton, 1995). Normalmente tais estudos expõem resultados de avaliação com ausência ou baixas quantidades de cistos, que possivelmente seriam completamente eliminadas após filtração utilizando qualquer das velas avaliadas, independente de porosidade ou uso de carvão ativado, porém acreditamos que populações carentes ou que não têm acesso ao tratamento convencional estão mais susceptíveis a infecção, mormente por necessitarem de outras fontes de aquisição de água para consumo humano, como, por exemplo, poços artesianos e minas (Yao et al., 2015; Amaral et al., 2003).

Diversos trabalhos já avaliaram a contaminação de águas de poço artesiano e minas, e demonstraram presença quantidade apreciáveis de cistos de G. duodenalis. Sabe-se que a quantidade mínima de $G$. duodenalis necessária para causar infecção é de 10 a 100 cistos (dose infectante) e, sendo assim, em altos níveis de contaminação de água, dependendo do tipo de vela avaliada, esta quantidade pode chegar a ser ingerida por um indivíduo, vindo a se tornar infectado (Rendtorff, 1954; Neves 2000).

Tabela 2. Média de retenção (\%) de cisto de G. duodenalis para todos os filtros de acordo com a porosidade e categoria.

\begin{tabular}{ccc}
\hline Porosidade & $\begin{array}{c}\text { Categoria com } \\
\text { carvão }\end{array}$ & $\begin{array}{c}\text { Categoria } \\
\text { sem carvão }\end{array}$ \\
\hline $0,5-1,0 \mu \mathrm{m}$ & 100,0 & 100,0 \\
$5-15 \mu \mathrm{m}$ & 100,0 & 98,9 \\
\hline
\end{tabular}


Por fim, conforme mencionado anteriormente, o tempo de vida útil de uma vela é de seis meses, mas a população, de um modo geral, pode vir a não efetuar a substituição da vela no tempo preconizado e, além disso, muitos indivíduos costumam desenvolver hábitos inadequados ao manipularem velas, substituindo o procedimento correto, que é a troca por vela nova, pela higienização manual da vela antiga, aumentando a dimensão dos poros e prejudicando ou inativando o processo de filtração.

Os resultados obtidos no presente estudo e as evidências supracitadas permitem inferir a necessidade do delineamento de novas pesquisas, que avaliem a eficácia das velas partindo de amostras de água contaminadas com uma quantidade maior de cistos de G. duodenalis e traz a tona a necessidade do desenvolvimento de campanhas para orientar a população, particularmente aquelas desprovidas de acesso ao tratamento convencional de água, no sentido de primarem pelo uso correto dos filtros de vela, prezando pela substituição periódica da mesma em detrimento a procedimentos inadequados de limpeza.

\section{CONCLUSÃO}

A partir dos resultados obtidos pode-se concluir que todas as marcas de vela filtrante que foram avaliadas no presente trabalho demonstraram-se satisfatórias para a remoção de cistos de Giardia duodenalis.

\section{REFERENCIAS}

ALABI, D. A.; ADESIYUN, A. A. Studies on microbial quality of filtered water in households of a university community in Nigeria. Journal of Hygiene, v. 96, n. 2, p. 239-248, 1986. http://dx.doi.org/10.1017/S0022172400066018

ALVES, C. R.; ASSIS, O. B. G. Alteração da superfície de velas cerâmicas porosas comerciais, por processo sol-gel, visando o aumento da organofilicidade. Revista Cerâmica, v. 59, p. 225-230, 2013. http://dx.doi.org/10.1590/S036669132013000200005

AMARAL, L. A.; NADER FILHO, A.; ROSSI JUNIOR, O. D.; FERREIRA, F. L. A; BARROS, L. S. S. Água de consumo humano como fator de risco à saúde em propriedades rurais. Revista de Saúde Pública, v. 37, n. 4, p. 510-4, 2003. http://dx.doi.org/10.1590/S0034-89102003000400017

BRASIL. Ministério da Saúde. Fundação Nacional de Saúde. Manual de controle da qualidade da água para técnicos que trabalham em ETAS. Brasília: Funasa, 2014. $112 \mathrm{p}$.

BRASIL. Ministério da Saúde. Portaria № 2.914 de 12 de dezembro de 2011. Diário Oficial [da] União, Seção 1, 03 jan. 2012, p. 43.

BRASIL. Ministério da Saúde. Departamento de Vigilância Epidemiológica. Doenças infecciosas e parasitárias: guia de bolso. 8. ed. rev. Brasília, 2010.

CARVALHO, T. T. R. Estado atual do conhecimento de Cryptosporidium e Giardia. Revista de Patologia Tropical, v. 38, n.1, p. 1-16. jan.-mar. 2009.

CLASEN, T. F.; BROWN, J.; COLLIN, S.; SUNTURA, O.; CAIRNCROSS, S. Reducing diarrhea through the use of household-based ceramic water filters: a randomized, controlled trial in rural Bolivia. The American journal of tropical medicine and hygiene, v. 70, n. 6, p. 651-657, 2004. 
D’AGUILA, P. S.; DA CRUZ ROQUE, O. C.; MIRANDA, C. A. S.; FERREIRA, A. P. Avaliação da qualidade de água para abastecimento público do Município de Nova Iguaçu Quality assessment of the public water supply in Nova Iguaçu, Rio de Janeiro. Cadernos de Saúde Pública, v.16, n. 3, p. 791-798, 2000. http://dx.doi.org/10.1590/S0102-311X2000000300027

DE FARIA, A. L.; LACAVA, P. M., ARAÚJO, A. J. U. S., SANTOS, S. I. S.; VILELLA, F. R. D. M. A. Condições ambientais e características de potabilidade da agua de bicas de uso publico da cidade de Taubaté-SP. Revista Biociências, v. 13, n. 3, 2008.

FRANCO, R. M. B. Protozoários de veiculação hídrica: relevância em saúde pública. Revista Panamericana de Infectologia, v. 9, n. 1, p. 36-43, 2007.

FRAGONESI, B. M.; SAMPAIO, C. de F.; RAGAZZI, M. F; TONANI, K. A. de A.; SEGURA-MUÑOZ, S. I. Cryptosporidium e Giardia: desafios em água de abastecimento público. O Mundo da Saúde, v. 36, p. 602-609, 2012.

FUNDAÇÃO FIOCRUZ. Glossário de doença relacionadas à água. 2010. Disponível em: http://www.aguabrasil.icict.fiocruz.br/index.php?pag=doe. Acesso em: 30 jan. 2015.

FUNDO DAS NAÇÕES UNIDAS PARA A INFÂNCIA - UNICEF. Uma criança morre a cada 15 segundos devido a problemas relacionados à falta de água potável. 2013. Disponível em: http://www6.ensp.fiocruz.br/visa/?q=node/4788. Acesso em: 12 nov. 2014.

INSTITUTO NACIONAL DE METROLOGIA, QUALIDADE E TECNOLOGIA INMETRO. Aparelho para melhoria da qualidade da água para uso doméstico aparelho por pressão. 2005. Disponível em: http://www.inmetro.gov.br/consumidor/ produtos/filtro2.asp. Acesso em 12 maio 2015.

IRITANI, M. A.; EZAKI, S. As águas subterrâneas do Estado de São Paulo. 3. ed. São Paulo: SMA, 2012. 104 p.

LECHEVALLIER, M. W.; NORTON, W. D. Giardia and Cryptosporidium in raw and finished water. Journal AWWA - American Water Works Association, v. 87, n. 9, p. 54-68, 1995.

MARQUES, A. D.; PEREIRA, D. S. C. D. A.; COVRE, M. A.; GONÇALVEZ, R. F.; KELLER, R. D. P. Remoção de Cryptosporidium sp e Giardia lamblia em águas de abastecimento. In: ASSOCIAÇÃO BRASILEIRA DE ENGENHARIA SANITÁRIA. Saneamento ambiental Brasileiro: utopia ou realidade? São Paulo: ABES, 2005. p. 15.

MENDONÇA, M. J. C.; MOTTA, R. S. Saúde e saneamento no Brasil. Planejamento e Políticas Públicas - PPP, v. 30, 2007.

NEVES, D. P. Parasitologia humana. 10 ed. São Paulo: Atheneu, 2000.

OPRYSZKO, M. C.; GUO, Y.; MACDONALD, L.; MACDONALD, L.; KIILH, S, SCHWAB K. J. Impact of water vending kiosks and hygiene education on households drinking water quality in rural Ghana. American Journal of tropical Medicine and Hygiene. v. 88, n. 4, p. 651-660, 2013. http://dx.doi.org/10.4269/ajtmh.12-0065 
PASUPUlETI, V.; ESCOBEDO, A. A.; DESHPANDE, A. THOTA, P.; ROMAN, Y.; HERNANDEZ, A.V. Efficacy of 5-Nitroimidazoles for the Treatment of Giardiasis: A Systematic Review of Randomized Controlled Trials. Plos Neglected Tropical Diseases, v. 8, n. 3, p. 1-11, 2014.

RENDTORFF, R. C. The experimental transmission of human intestinal protozoan parasites ii. Giardia lamblia cysts gwen in capsules. American Journal of Epidemiology, v. 59, n. 2, p. 209-222, 1954.

ROBERTSON, L. J.; HERMANSEN, L.; GLERDE, B. K. Occurrence of Cryptosopridium oocists and Giardia cysts in Sewage in Norway. Applied environmental Microbiology, v. 72, n. 8, p. 5297-5303, 2006. http://dx.doi.org/10.1128/AEM.0046406

YAO, H.; LI, W.; QIAN, X. Identification of Major risk sources for surface water pollution by risk indexes (IR) in the multi-provincial boundary region of of the Taihu Basin, China. International Journal of Environmental Research and Public Health, v. 12, n. 8, p. 10150-10170, 2015. 


Ambiente \& Água - An Interdisciplinary Journal of Applied Science
ISSN 1980-993X - doi:10.4136/1980-993X
www.ambi-agua.net
E-mail: ambi.agua@gmail.com

\title{
Eleição de áreas prioritárias para pagamento por serviços ambientais: uma análise em nível de microbacia
}

\author{
doi:10.4136/ambi-agua.1809
}

Received: 26 Nov. 2015; Accepted: 24 Feb. 2016

\author{
Fernando Salles Rosa ${ }^{1}$; Kelly Cristina Tonello ${ }^{1 *}$; Roberto Wagner Lourenço ${ }^{2}$ \\ ${ }^{1}$ Universidade Federal de São Carlos (UFSCar), Sorocaba, SP, Brasil \\ Departamento de Ciências Ambientais \\ ${ }^{2}$ Universidade Estadual Paulista "Júlio de Mesquita Filho" (UNESP), Sorocaba, SP, Brasil \\ "Autor correspondente: e-mail: kellytonello@ufscar.br, \\ fesrosa@yahoo.com.br, robertow@sorocaba.unesp.br
}

\section{RESUMO}

Esse trabalho objetivou a eleição de áreas prioritárias para conservação dos recursos hídricos para subsidiar programas de pagamentos por serviços ambientais (PSA). A proposta apresentada será utilizada para a implementação do projeto piloto de PSA na microbacia do Murundu, Ibiúna-SP, vislumbrando a contribuição para políticas públicas de PSA em busca da sustentabilidade. Para tanto, planos de informação de uso do solo e cobertura vegetal, e de declividade foram organizados em ambiente SIG que permitem por meio da tabulação cruzada a seleção de prioridades para a geração de um mapa temático, a partir do qual foram executadas análises qualitativas e quantitativas, assim como a determinação de faixas de prioridades. As ferramentas utilizadas demonstraram-se aplicáveis no suporte à tomada de decisão e no desenvolvimento de pesquisas e políticas públicas em PSA, com foco no incremento da governança dos recursos hídricos. Fica evidente que a remuneração pela "floresta em pé" definitivamente se apresenta como perspectiva principal na microbacia do ribeirão do Murundu, assim como a possibilidade de reversão dos valores monetários em outras formas de apoio aos provedores, sobretudo, para atendimento de suas prioridades.

Palavras-chave: nascentes, políticas públicas, provedor-recebedor.

\section{Selection of priority areas for payment of environmental services: an analysis at the watershed level}

\begin{abstract}
In this study, we selected priority areas for conservation of water resources to support programs for environmental services (PSA) payment. The proposal will be used for the implementation of the PSA pilot project in the watershed of the Murundu, Ibiúna-SP, to support PSA public policy to foster sustainability. To do so, land use information layers, vegetative cover and slope were organized in a GIS environment in order to allow through cross tabulation the selection of priorities to generate a thematic map. From this map, we performed qualitative and a quantitative analysis, as well as priority setting ranges. The tools used have shown to be useful in supporting decision-making and research and public policy in PSA, focusing on increasing the governance of water resources. It is clear that remuneration
\end{abstract}


for "standing forest" definitely represents the major prospect in the watershed of the river's Murundu, as well as the possibility of converting monetary values of the payment into other forms of support to providers of the service according to their priorities.

Keywords: public policy, recipient-provider, springs.

\section{INTRODUÇÃO}

O conceito de Pagamento por Serviços Ambientais - PSA e as inúmeras experiências de implantação em desenvolvimento pelo mundo estão em permanente debate e construção nas mais diversas áreas do conhecimento.

Os Pagamentos por Serviços Ambientais - PSA podem ser definidos como um acordo voluntário entre pelo menos um "vendedor" (provedor) e um "comprador" (beneficiário) de um serviço ambiental claramente definido, ou de um tipo de uso do solo que, presumidamente, assegure tal serviço, sob a condição (condicionalidade) de garantia de provimento do mesmo por parte do provedor (Wunder, 2005). Wunder (2015) em seu último trabalho traz ainda uma abordagem mais estreita dessa relação. No entanto, de modo geral, trata-se de um instrumento econômico que procura atribuir valores às externalidades positivas geradas pelos sistemas manejados ativamente pelo homem, de modo a garantir estímulos suficientes aos provedores, financeiros ou não, como forma de internalizá-las, induzindo a oferta de serviços ambientais em detrimento de atividades potencialmente degradantes. Ou seja, deve compensar o custo de oportunidade do proprietário (Pagiola e Platais, 2007; Sommerville et al., 2009; Muradian et al., 2009; Shiki e Shiki, 2011).

Sendo assim, a difusão de sistemas de PSA constitui-se uma promissora estratégia na estruturação de políticas públicas ambientais voltadas ao aprimoramento das relações entre as atividades humanas e a natureza, fundamentadas nos princípios do direito ambiental, como o poluidor-pagador, o usuário-pagador e o protetor-recebedor. Os potenciais benefícios do PSA são amplos, e, dependendo da regulamentação a ser estabelecida para sua aplicação, tendem a atingir todos os segmentos da sociedade perante o desafio de equacionar pagamentos com maior ganho ambiental e social possível (Nusdeo, 2012).

Sabe-se que uma série de serviços ambientais ocorre nos territórios dos entes federativos como, por exemplo, aqueles associados a práticas de conservação do solo e de conservação e restauração florestal para a proteção de recursos hídricos nas propriedades rurais, permitindo o abatimento da erosão e a infiltração de água. Neste caso, observando-se a bacia hidrográfica como unidade de planejamento, o aumento ou a manutenção de tais serviços, por meio da implantação de um esquema de PSA-Água, demanda que este esteja adaptado à realidade local em seus diversos aspectos e ao arranjo institucional e financeiro relacionado à gestão dos recursos ambientais em ecossistemas naturais, notadamente florestais.

No Brasil, com relação aos sistemas de PSA voltados à proteção de recursos hídricos, destacam-se o Programa Produtor de Água da Agência Nacional das Águas (ANA), seguido das políticas de caráter estadual e outras iniciativas. Predominam arranjos institucionais de no mínimo duas partes, com fonte de recursos dos orçamentos públicos, dos Comitês de Bacia Hidrográfica, de pessoas jurídicas relacionadas aos serviços de saneamento básico e de fundações e institutos. (Guedes e Seehusen, 2011). Tal cenário demonstra que o instrumento PSA vem sendo reconhecido como uma importante ferramenta de gestão ambiental compartilhada em áreas estratégicas para a produção de água (Vatn, 2010). Em projetos de PSA, a priorização de áreas é fundamental para garantir a viabilidade econômica e, por consequência, a melhor aplicação dos recursos financeiros e humanos, potencializando os ganhos socioambientais. Para tanto, as geotecnologias se mostram de grande relevância, uma vez que permitem uma série de análises úteis para o conhecimento das características importantes de uma dada região. 
O município de Ibiúna, localizado no estado de São Paulo, devido as suas características socioambientais, foi selecionado como o único participante da Bacia Hidrográfica do Rio Sorocaba e Médio Tietê para a implantação do projeto piloto de PSA no estado de São Paulo, denominado "Mina d' Água", e a microbacia do ribeirão do Murundu é o território em que o projeto está sendo desenvolvido. Sua economia é baseada na agricultura e no turismo. Hoje com uma população de mais de 74 mil habitantes, é uma das 20 cidades de São Paulo que levam o título de "Estância Turística". Dos 1.093 km² de Ibiúna, apenas $10 \%$ é considerado zona urbana. Os outros $90 \%$ correspondem às áreas rurais de agricultura e pecuária de pequenos produtores e a áreas de preservação ambiental (Rosa et al., 2014).

Nesse sentido, esse trabalho tem por objetivo a eleição de áreas prioritárias à conservação dos recursos hídricos para subsidiar programas de pagamentos por serviços ambientais. A proposta apresentada será utilizada no caso da implementação do projeto piloto de PSA na microbacia do Murundú, Ibiúna-SP, vislumbrando a contribuição para políticas públicas de PSA em busca da sustentabilidade.

\section{MATERIAL E MÉTODOS}

A microbacia do Murundu está localizada na zona rural do município de Ibiúna-SP, entre as coordenadas $23^{\circ} 47^{\prime} 28^{\prime \prime}$ e $23^{\circ} 48^{\prime} 53^{\prime \prime S}$ e $47^{\circ} 16^{\prime} 47^{\prime \prime}$ e $47^{\circ} 15^{\prime} 55^{\prime \prime O}$. Com aproximadamente 4.321 ha, a microbacia contribui para o Alto-Sorocaba onde se destacam os rios Sorocabuçu, Sorocamirim e Una. Estes rios são formadores do rio Sorocaba e do reservatório Itupararanga, responsável pela geração de hidroeletricidade e abastecimento de cerca de 1,5 milhões de pessoas em Sorocaba, Votorantim, Mairinque, Alumínio, Ibiúna e São Roque. Para além da densa rede hidrográfica e do relevo montanhoso (Rosa et al., 2014), a microbacia possui cerca de 250 nascentes e apresenta suscetibilidade alta a erosão (Marques e Kusano, 2009). De acordo com Koeppen, o clima é tropical de altitude ( $\mathrm{Cwa}$ ), com chuvas no verão e seca no inverno, com precipitações médias anuais em torno de $1.309 \mathrm{~mm}$ (Cepagri, 2015). A vegetação predominante é a Floresta Ombrófila Densa Montana.

$\mathrm{O}$ produto cartográfico digital foi obtido pela manipulação de cartas do Instituto Geográfico e Cartográfico de São Paulo (IGC) em AutoCAD Land Development Desktop 2i de modo a extrair informações sobre o limite da área de estudo, rede hidrográfica, cabeceiras de drenagem (nascentes) e declividade. Nas operações de análise espacial e processamento digital de imagens foi empregado o software IDRISI 32 - Release 2. Para as verificações de campo, foi empregado um receptor GPS com exatidão nominal de $15 \mathrm{~m}$.

A metodologia empregada foi subdividida nas seguintes etapas: a) processamento digital das imagens, b) georeferenciamento, c) classificação temática, d) obtenção da declividade da microbacia e) eleição de áreas prioritárias, f) quantificação do uso da terra.

No processamento digital das imagens orbitais, o mapa de uso do solo e cobertura vegetal foi obtido pela análise de imagens orbitais digitais de sete bandas espectrais ( 1 a 7 ) do satélite Landsat-5, sensor TM, de órbita/ponto 219/077 de 24/08/2010, com resolução geométrica de $30 \mathrm{~m}$, exceto para a banda $6-120 \mathrm{~m}$. As imagens possuíam $0 \%$ de nuvens e foram gratuitamente disponibilizadas pelo Instituto Nacional de Pesquisas Espaciais (INPE). Todos os planos de informação foram padronizados para a resolução espacial igual a da imagem de satélite (1:30.000), no sistema de coordenadas Universal Transverso de Mercator (UTM) e Datum SAD 69 Z22S. A correção atmosférica foi realizada pelo Princípio da Reflectância Zero. Para correção geométrica foi utilizado o modelo de transformação polinomial de primeiro grau e o método de interpolação do vizinho mais próximo, tendo por base uma amostragem de pontos reais e as imagens digitais.

$\mathrm{Na}$ etapa de definição das classes de uso e cobertura do solo foi aplicada a classificação digital supervisionada, desenvolvida em função do conhecimento prévio de áreas amostrais 
obtidas no trabalho de campo, o que permitiu a seleção de áreas de treinamento confiáveis, definindo-se que o algoritmo classificador pelo método de máxima verossimilhança operasse com base na distribuição de probabilidade de cada classe. Foi realizada a partir de missões de campo e análise de imagens de satélite, tendo em vista o mapeamento voltado à verificação das aptidões da microbacia para a implantação de um sistema de PSA-Água. A definição das classes de uso do solo e de cobertura vegetal para a área de estudo seguiu a metodologia de Rosa et al. (2014).

As faixas de declividade foram definidas a partir de critérios técnicos de fragilidade, conforme estudos de capacidade de uso e de aptidão agrícola desenvolvidos por Ross (1994), assim sendo: até $6 \%$ grau de declividade (muito baixa); 6 a $12 \%$ (fraca); 12 a $20 \%$ (média); 20 a $30 \%$ (forte); e acima de $30 \%$ (muito forte).

O mapa temático de prioridades foi obtido a partir da classificação cruzada entre informações de declividade, uso do solo e cobertura vegetal da microbacia do Murundu. Com relação ao ordenamento das classes temáticas prioritárias, as prioridades foram divididas em:

\section{Conservação; e}

2. Restauração ecológica.

Consideraram-se prioritárias à conservação as classes relacionadas à cobertura vegetal, ranqueadas como: floresta em estágio avançado/médio > mata ciliar > vegetação em estágio inicial > vegetação de várzea > zona mista. Para a restauração, as classes de uso do solo foram assim ranqueadas: agricultura $>$ campos rurais $>$ silvicultura $>$ instalações urbanas $>$ zona mista.

Com relação à declividade, em função da fragilidade, foram denominadas como prioritárias:

- Áreas com declividade acima de $30 \%$ (muito forte): referente à suscetibilidade a erosão de tais áreas com relação a aptidão ao uso agrícola (Ross, 1994), assim como a determinação da Lei Federal $n^{\circ} 6.766 / 1979$ no artigo $3^{\circ}$, inciso III, que impede o parcelamento do solo para fins urbanos, salvo o atendimento de exigências técnicas;

- Áreas com declividade entre 0 - $6 \%$ (muito fraca): ocorrência de Áreas de Preservação Permanente, zonas ripárias e planícies fluviais, e a relevância hidrológica e ecológica de tais ambientes (Metzger, 2010). Além disso, a Lei Federal no 6.766/1979 também disciplina que em terrenos alagadiços e sujeitos a inundações, antes de tomadas as providências para assegurar o escoamento das águas, não será permitido o parcelamento do solo para fins urbanos. Pode-se destacar, inclusive, que por serem planas, tais áreas acabam sendo objeto de especulação imobiliária e crescimento desordenado, acarretando em inúmeros problemas relacionados à impermeabilização e ao saneamento básico. Tal faixa de declividade ainda pode estar associada a áreas altas de recarga de nascentes.

As demais faixas de declividade foram cruzadas com cada classe de cobertura vegetal e com cada classe de uso do solo, sendo consideradas como zonas mistas. Tais áreas demonstram-se relevantes no sentido de, por meio das Áreas de Preservação Permanente às margens dos corpos d'água, executar a conexão entre as declividades e as classes temáticas consideradas prioritárias.

A partir das definições apresentadas, as categorias foram ordenadas em ordem decrescente, das áreas mais prioritárias para a conservação da vegetação até as áreas mais prioritárias para a restauração, conforme apresentado na Tabela 1.

Após a obtenção das áreas e conferência com os dados da tabela de classificação cruzada, para melhor visualização, o mapa foi submetido a um filtro da mediana, com aplicação de uma janela de tamanho 5 × $5 \mathrm{~m}$. 
A quantificação de cada classe de prioridade constituiu em determinar as áreas das diferentes classes obtidas por meio da função de cálculo de áreas, sendo este efetuado a partir da contagem do número de pixels classificados em cada uma das prioridades.

O mesmo procedimento de priorização de áreas foi realizado para as Áreas de Preservação Permanente (APPs), de modo a detalhar a cobertura vegetal, uso do solo e declividade associadas aos recursos hídricos e propor prioridades à conservação e restauração nesses locais. Para tanto, aplicou-se um "buffer" com base nas determinações do Código Florestal, Lei Federal no 12651 de 2012 (Brasil, 2012), e respectivo cálculo das APPs associadas a cursos d'água.

Com objetivo de integrar os mapas de prioridades e relacionar a área de cada classe de prioridade, foram instituídas 4 faixas de localidades prioritárias para a conservação e restauração florestal:

- Máxima: Áreas definidas como prioritárias com relação à declividade, cobertura vegetal e uso do solo, localizadas em APP;

- Alta: APP fora das áreas definidas como prioritárias com relação a declividade, cobertura vegetal e uso do solo;

- Média: Áreas definidas como prioritárias com relação a declividade, cobertura vegetal e uso do solo, fora de APP;

- Baixa: Áreas com cobertura vegetal ou sem cobertura vegetal em área comum, ou seja, fora de APP e das áreas definidas como prioritárias com relação à declividade.

Tabela 1. Prioridades de conservação e restauração em função da declividade.

\begin{tabular}{|c|c|c|c|c|c|c|c|}
\hline \multirow{2}{*}{ Prioridade } & \multirow{2}{*}{$\begin{array}{l}\text { Categoria de Uso do Solo } \\
\text { e Cobertura Vegetal }\end{array}$} & \multirow{2}{*}{$\begin{array}{l}\text { Classes de } \\
\text { Prioridades }\end{array}$} & \multicolumn{5}{|c|}{ Faixas de Declividade } \\
\hline & & & $0-6 \%$ & $6-12 \%$ & $12-20 \%$ & $20-30 \%$ & $>30 \%$ \\
\hline \multirow{5}{*}{ 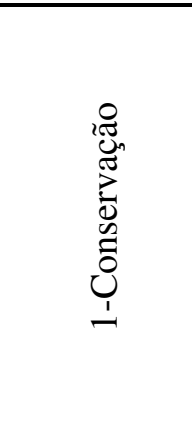 } & $\begin{array}{l}\text { Floresta em estágio } \\
\text { avançado/médio }\end{array}$ & 1.1 & $\mathrm{X}$ & - & - & $\mathrm{X}$ & $\mathrm{X}$ \\
\hline & Mata ciliar & 1.2 & $\mathrm{X}$ & - & - & - & $\mathrm{X}$ \\
\hline & $\begin{array}{l}\text { Vegetação em estágio } \\
\text { inicial }\end{array}$ & 1.3 & $\mathrm{X}$ & - & - & - & $\mathrm{X}$ \\
\hline & Vegetação de várzea & 1.4 & $\mathrm{X}$ & - & - & - & - \\
\hline & Zona mista* & 1.5 & - & $\mathrm{X}$ & $\mathrm{X}$ & $\mathrm{X}$ & - \\
\hline \multirow{5}{*}{ 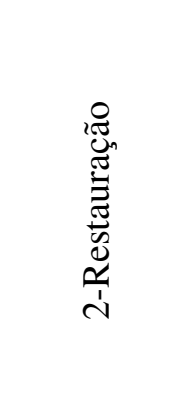 } & Agricultura & 2.1 & $\mathrm{X}$ & - & - & $\mathrm{X}$ & $\mathrm{X}$ \\
\hline & Campo rural & 2.2 & $\mathrm{X}$ & - & - & - & $\mathrm{X}$ \\
\hline & Silvicultura & 2.3 & $\mathrm{X}$ & - & - & - & $\mathrm{X}$ \\
\hline & Instalações urbanas & 2.4 & $\mathrm{X}$ & - & - & - & $\mathrm{X}$ \\
\hline & Zona Mista** & 2.5 & - & $\mathrm{X}$ & $\mathrm{X}$ & $\mathrm{X}$ & - \\
\hline
\end{tabular}

* Corresponde a todas as categorias de cobertura vegetal ocorrentes nas declividades intermediárias.

** Corresponde a todas as categorias de uso do solo ocorrentes nas declividades intermediárias 
A quantificação de áreas em cada faixa prioritária irá permitir a criação de uma matriz de prioridades, tanto para conservação como para restauração. Tal quantificação irá facilitar a criação de cenários em potencial para a implantação gradativa do PSA-Água, inclusive possibilitando o estabelecimento de critérios de valoração diferenciados, tanto entre as classes de prioridade como entre as faixas prioritárias, o que auxiliaria na estimativa do montante de recursos a serem disponibilizados para o projeto de PSA-Água.

\section{RESULTADOS E DISCUSSÃO}

As áreas prioritárias para conservação representam 67,7 \% das categorias de cobertura vegetal (incluindo a rede hidrográfica, 3,2 \%), assim como 41,1 \% da área total da microbacia, indicando, portanto, que $1.776,3$ ha são prioritários para incentivos ambientais. As áreas prioritárias para restauração ecológica representam 57,2 \% das categorias de uso do solo, assim como 22,5\% da área do território, resultando em 971,2 ha (Tabela 2, Figura1).

Tabela 2. Quantificação das áreas com relação a cada classe de prioridade.

\begin{tabular}{|c|c|c|c|c|c|}
\hline Prioridade & $\begin{array}{l}\text { Classes de } \\
\text { prioridades }\end{array}$ & $\begin{array}{l}\text { Área total } \\
\text { (ha) }\end{array}$ & $\begin{array}{l}\text { Área total da } \\
\text { categoria } \\
\text { relacionada } \\
\text { (ha) }\end{array}$ & $\begin{array}{l}\text { \% com relação à } \\
\text { categoria } \\
\text { correspondente }\end{array}$ & $\begin{array}{l}\text { \% com relação } \\
\text { à área da } \\
\text { microbacia } \\
(4320 \text { ha })\end{array}$ \\
\hline \multirow{8}{*}{ 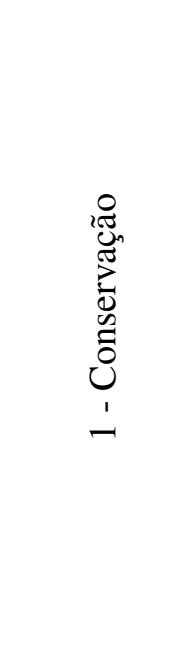 } & Prioridade 1.1 & 1060,6 & 1298,8 & 81,6 & 24,5 \\
\hline & Prioridade 1.2 & 222,4 & 364,4 & 61,0 & 5,1 \\
\hline & Prioridade 1.3 & 183,4 & 339,1 & 54,1 & 4,2 \\
\hline & Prioridade 1.4 & 169,4 & 479,6 & 35,3 & 3,9 \\
\hline & Hidrografia & 140,4 & 140,4 & 100,0 & 3,2 \\
\hline & Subtotal & 1776,3 & 2622,5 & 67,7 & 41,1 \\
\hline & Prioridade 1.5 & 846,2 & 2622,5 & 32,3 & 19,6 \\
\hline & Total & 2622,5 & & 100,0 & 60,7 \\
\hline \multirow{8}{*}{ 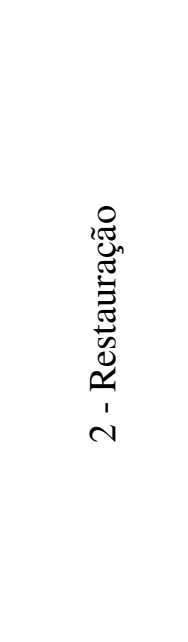 } & Prioridade 2.1 & 487,1 & 879,6 & 55,4 & 11,3 \\
\hline & Prioridade 2.2 & 302,5 & 596,4 & 50,7 & 7,0 \\
\hline & Prioridade 2.3 & 20,9 & 50,2 & 41,6 & 0,5 \\
\hline & Prioridade 2.4 & 23,9 & 36,4 & 65,8 & 0,5 \\
\hline & Estradas & 136,7 & 136,7 & 100,0 & 3,2 \\
\hline & Subtotal & 971,2 & 1699,3 & 57,2 & 22,5 \\
\hline & Prioridade 2.5 & 728,0 & 1699,3 & 42,8 & 16,9 \\
\hline & Total & 1699,3 & & 100,0 & 39,3 \\
\hline
\end{tabular}


Diante disso, para um cenário de planejamento e implantação de projeto de PSA-Água, 2.747,5 ha são considerados prioritários em termos de conservação e restauração, o que perfaz um total de 63,6\% da área da microbacia do Murundu.

Nesse contexto, de acordo com a hierarquização de graus de proteção aos solos pela cobertura vegetal, determinada por Ross (1994), e conforme outras experiências de programas por PSA-Água (Pagiola et al., 2013), o enquadramento de cada prioridade estabelecida, assim como as perspectivas inerentes à prestação de serviços ambientais são:

Grau de proteção "muito alto": relacionado com a presença de 81,6 \% da cobertura florestal (Prioridade 1.1) e de 61,0\% da mata ciliar (Prioridade 1.2) localizados nas áreas prioritárias, perfazendo $29,7 \%$ da área total da microbacia. Tal cenário converge para a possibilidade da manutenção da "floresta em pé" como serviço ambiental prioritário, visando ao monitoramento e à vigilância para fins de regeneração florestal, assim como possibilitando a exploração não madeireira sustentável (coleta de sementes, por exemplo), entre outros incentivos ambientais (Cotas de Reserva Ambiental, créditos de carbono etc.).

Grau de proteção “alto": relacionado com a presença de $54,1 \%$ de vegetação inicial (Prioridade 1.3) e de 35,3\% da vegetação de várzea (Prioridade 1.4) localizados nas áreas prioritárias, totalizando $8,1 \%$ da área da microbacia. Esta condição ensejaria como garantia da prestação dos serviços ambientais a regeneração assistida, ou até mesmo o enriquecimento da vegetação inicial (por exemplo, a conservação produtiva), visando, inclusive, à conexão entre fragmentos da cobertura florestal e da mata ciliar, conforme se pode observar na Figura 1. Especialmente com relação à vegetação de várzea, a manutenção da permeabilidade do solo e o manejo de espécies exóticas/invasoras são importantes.

Grau de proteção "médio": relacionado com a presença de 50,7 \% dos campos rurais (Prioridade 2.2) e de 41,6\% da silvicultura (Prioridade 2.3) localizados nas áreas prioritárias, totalizando 7,5\% da área da microbacia. Com relação aos campos rurais, presume-se a adoção de práticas de conservação do solo (por exemplo, a construção de barraginhas de contenção do escoamento superficial), a manutenção de pastagens cultivadas, o isolamento de APP's, a restauração com espécies produtivas (sistemas agroflorestais), nucleação, chuva de sementes etc. No caso da silvicultura, as atividades relacionadas com o preparo do solo, o corte e a retirada da madeira, constituem as causas principais de alteração da infiltração. Sendo assim, a preocupação de manutenção de condições ótimas de infiltração durante estas atividades deve estar centrada na manutenção da integridade do piso florestal (Lima, 2008).

Grau de proteção "baixo" e "muito baixo a nulo": relacionada com a presença de $55,4 \%$ da agricultura (Prioridade 2.1) e de 36,4 \% das instalações urbanas (Prioridade 2.4 ha) localizadas nas áreas prioritárias, totalizando, juntamente com as estradas, 15,0\% da área da microbacia. A agricultura pode ser considerada um serviço ambiental porque ela é uma atividade antrópica que resulta na oferta de um serviço ecossistêmico que é a provisão de alimentos. Todavia, a agricultura também pode resultar na diminuição de outros serviços ambientais se alguns princípios de boas práticas agrícolas não forem observados. Conforme Antoniazzi (2008) pode ocorrer a redução do uso de insumos, principalmente agroquímicos; o controle da erosão e do escoamento superficial (plantio em nível, terraços e barraginhas); e a proteção e/ou restauração de zonas de vegetação para a proteção dos recursos hídricos (em especial as matas ciliares). Tais práticas implicam na diminuição de custos na produção, inclusive devido à otimização na irrigação.

Com relação ao controle da erosão, este também se relaciona com a manutenção das estradas, ensejando a adoção de sistemas de contenção no interior das propriedades rurais, inclusive nas margens das vias utilizadas para a mecanização. 


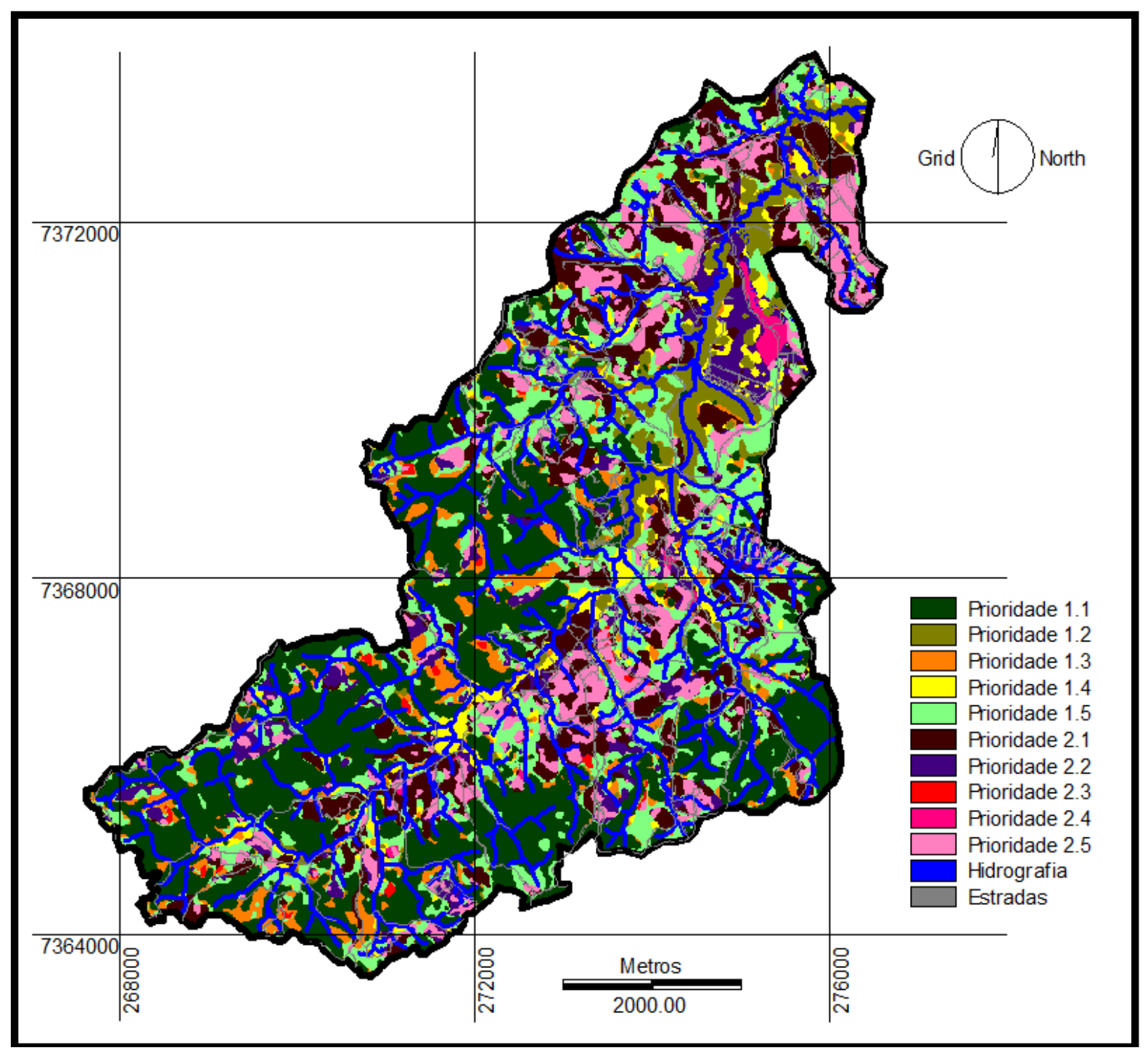

Figura 1. Mapa de prioridades da microbacia do ribeirão do Murundu, Ibiúna-SP.

No caso das instalações urbanas, além dos impactos ambientais já mencionados, as atividades de terraplanagem representam ameaça à proteção dos solos e potencial interferência sobre os recursos hídricos. Como possibilidade de manutenção de serviços ambientais, o controle da expansão via determinações de uso e parcelamento do solo, assim como o saneamento rural e o controle do descarte das águas captadas pelos telhados, apresentam-se como práticas a serem integradas a um projeto de PSA-Água.

Conforme com relação a Antoniazzi (2008), a predominância de áreas com grau de proteção do solo "baixo" e "muito baixo a nulo", são prioritárias à conservação do solo, tendo em vista que os impactos da erosão do solo incidem tanto fora dos corpos d'água (obstrução dos poros do solo) como dentro (eutrofização). Dessa forma, tendo em vista que a adoção de boas práticas resultaria em maior adicionalidade de serviços ambientais, os incentivos ambientais para restauração devem ser maiores em tais localidades.

Diante do exposto, a criação das zonas mistas, resultantes dos critérios de priorização propostos, não descarta a relevância de cada uso do solo ou cobertura vegetal no que diz respeito à proteção do solo e, por consequência, aos serviços ambientais hidrológicos prestados. Porém, no âmbito de um projeto de PSA-Água, estas localidades, caso contempladas, resultariam em pagamentos menores. Além de menores, tais pagamentos poderiam variar de acordo com o tipo de uso do solo e de cobertura vegetal, 
independentemente da declividade, respeitando os mesmos critérios já estabelecidos. Dessa forma, a análise das zonas mistas deve ser efetuada em conjunto com o mapa temático de uso do solo e cobertura vegetal.

No caso das zonas mistas de conservação, que cobrem 19,6 \% da área da microbacia (Prioridade 1.5), estas são áreas de extrema importância não somente para a conectividade entre os remanescentes de vegetação nas faixas de declividades prioritárias, assim como para o amortecimento dos impactos negativos oriundos dos usos do solo.

Com relação às zonas mistas de restauração, que cobrem $16,7 \%$ da área da microbacia (Prioridade 2.5), estas são consideradas relevantes, principalmente, para a instalação dos sistemas de contenção do escoamento superficial e infiltração de água no âmbito do planejamento hidroambiental das propriedades rurais. Além disso, seriam as áreas mais propícias para a instalação dos usos do solo, como alternativa à ocupação das faixas de declividades prioritárias.

Considerando que as zonas mistas encontram-se na transição entre as áreas de declividade acentuada e as áreas planas, entende-se que no âmbito de um projeto de PSA-Água, tais zonas teriam o papel principal de conectar as localidades prioritárias, sobretudo, por meio das Áreas de Preservação Permanente, as quais, independentemente da classe de prioridade, imputariam valores maiores aos pagamentos.

\subsection{Quantificação das Áreas de Preservação Permanente (APPs) associadas a cursos d’água}

As APPs totalizam 1.014,3 ha, sendo 182,8 ha para as nascentes e 831,5 ha para as faixas ciliares, correspondendo a 4,2 \% e 19,2 \% da área da microbacia, respectivamente. Especificamente com relação às nascentes, 67,4 \% da APP, incluindo a hidrografia, encontram-se protegidos pela cobertura vegetal, enquanto $32,6 \%$ estão associados a algum tipo de uso do solo.

Diante do exposto, verifica-se que as nascentes, por estarem proporcionalmente menos protegidas, apesar do predomínio da cobertura florestal, demandariam maior prioridade, principalmente para a restauração, com relação às APP's das faixas ciliares dos corpos d'água.

Comparando-se os valores apresentados com os valores totais de cobertura vegetal e de uso do solo na microbacia, respectivamente, $60,68 \%$ e $39,32 \%$, verifica-se que as APP's estão mais protegidas do que a área total. Tal cenário indica que mesmo em localidades em que predominam os usos do solo, as APP's foram conservadas. Tal condição possibilita que, no âmbito de um projeto de PSA-Água, sejam efetuados maiores pagamentos aos proprietários que detêm tais áreas protegidas em suas propriedades. Além disso, os esforços de restauração da vegetação seriam menores, possibilitando maiores investimentos nas práticas de conservação do solo.

Quando avaliados os valores das APP's consideradas prioritárias (Tabela 3), as áreas sujeitas à conservação, incluindo a rede hidrográfica, totalizam 58,1 \% da APP total, ao passo que $14,9 \%$ das APP's necessitam de restauração.

Especificamente com relação às nascentes, 54,1 \% da APP, incluindo a hidrografia, encontra-se em localidades prioritárias à conservação, enquanto $21,5 \%$ estão associados a algum tipo de uso do solo em local prioritário à restauração. De acordo com tais valores, reforça-se a demanda de esforços para a restauração das APP's prioritárias de nascentes com relação às APP's prioritárias das faixas ciliares dos corpos d'água.

Diante do contexto apresentado, 73,1 \% da APP total estão em áreas prioritárias, o quê reforça a importância da interação entre estas localidades determinadas por lei e as faixas de declividade determinadas como prioritárias no presente estudo, o quê destaca a promoção de maiores incentivos ambientais para essas áreas do que para as áreas comuns. 
Para complementar tal análise, os dados de porcentagem de APP prioritária com relação à área total de preservação permanente para cada classe de prioridade correspondente, são de extrema importância para a execução dos esforços principais de conservação e restauração com os maiores ganhos ambientais e sociais. Em outras palavras, tais valores indicam quais seriam as prioridades dentro das próprias prioridades, tendo em vista a necessidade de diminuição dos custos de transação em um projeto de PSA-Água.

Tabela 3. Dados da ocorrência de prioridades em APP.

\begin{tabular}{|c|c|c|c|c|c|}
\hline Prioridade & $\begin{array}{l}\text { Classes de } \\
\text { prioridades }\end{array}$ & $\begin{array}{c}\text { APP prioritária } \\
\text { nascentes (ha) }\end{array}$ & $\begin{array}{l}\% \text { na APP } \\
\text { nascentes }\end{array}$ & $\begin{array}{l}\text { APP prioritária } \\
\text { total (ha) }\end{array}$ & $\begin{array}{c}\% \text { na APP } \\
\text { total }\end{array}$ \\
\hline \multirow{8}{*}{ 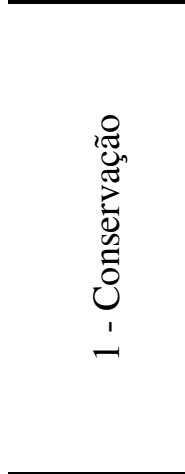 } & Prioridade 1.1 & 75,0 & 41,0 & 251,0 & 24,7 \\
\hline & Prioridade 1.2 & 2,8 & 1,5 & 86,9 & 8,6 \\
\hline & Prioridade 1.3 & 8,3 & 4,5 & 37,9 & 3,7 \\
\hline & Prioridade 1.4 & 2,6 & 1,4 & 73,4 & 7,2 \\
\hline & Hidrografia & 10,2 & 5,6 & 140,4 & 13,8 \\
\hline & Subtotal & 98,9 & 54,1 & 589,7 & 58,1 \\
\hline & Prioridade 1.5 & 35,3 & 19,3 & 186,5 & 18,4 \\
\hline & Total & 134,2 & 73,4 & 776,1 & 76,5 \\
\hline \multirow{8}{*}{ 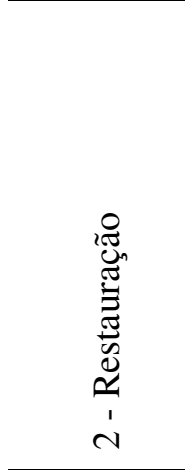 } & Prioridade 2.1 & 22,8 & 12,5 & 63,3 & 6,2 \\
\hline & Prioridade 2.2 & 10,9 & 5,9 & 56,4 & 5,6 \\
\hline & Prioridade 2.3 & 0,7 & $0,4 \%$ & 1,5 & 0,1 \\
\hline & Prioridade 2.4 & 0,0 & $0,0 \%$ & 2,4 & 0,2 \\
\hline & Estradas & 4,9 & 2,7 & 27,9 & 2,7 \\
\hline & Subtotal & 39,3 & 21,5 & 151,5 & 14,9 \\
\hline & Prioridade 2.5 & 9,2 & 5,0 & 86,6 & 8,5 \\
\hline & Total & 48,5 & 26,6 & 188,6 & 23,5 \\
\hline
\end{tabular}

Sendo assim, com relação à cobertura vegetal, os maiores impactos resultantes da proteção das zonas ripárias correspondem à conservação da floresta (Prioridade 1.1), à mata ciliar (Prioridade 1.2), à vegetação de várzea (Prioridade 1.4) e à vegetação em estágio inicial (Prioridade 1.3).

No caso dos usos do solo prioritários à restauração em APP, destacam-se a agricultura (Prioridade 2.1) e posteriormente os campos rurais (Prioridade 2.2). Em seguida, demandando maiores esforços de conservação do solo, as estradas $(2,75 \%)$, e posteriormente as instalações urbanas (Prioridade 2.4) e a silvicultura (Prioridade 2.3).

Com relação às zonas mistas, as APP's voltadas à conservação cobrem 18,4\% da área total (Prioridade 1.5), ao passo que as áreas para restauração, cobrem 8,5 \% da área da microbacia (Prioridade 2.5). Estas últimas, apesar de induzirem a valores menores de remuneração aos proprietários, devem obrigatoriamente ser restauradas, conforme a recente obrigatoriedade na recuperação de APPs imposta pelo Código Florestal.

Nesse sentido, no quesito de restauração, os valores de APP prioritárias associadas aos usos do solo (151,5 ha) quando acrescidos aos valores de APP em zonas mistas de restauração (86,6 ha), resultam em 238,1 ha passíveis de serem recuperados ou compensados na microbacia.

Ainda com relação às zonas mistas em APP, mesmo sendo consideradas mais prioritárias do que as áreas comuns, faz-se necessária a diferenciação dos valores a serem 
pagos de acordo com a categoria de uso do solo e cobertura vegetal, independentemente da declividade, por serem protegidas por lei. Logo, aqueles proprietários a montante e nas áreas de planície de inundação seriam mais beneficiados. Sendo assim, espera-se que o proprietário intermediário busque o aprimoramento da proteção do recurso hídrico, podendo destinar mais áreas protegidas à contratação ou até mesmo restaurar áreas maiores do que a legislação obriga, visando aumentar a sua remuneração, gerando uma competição saudável entre os provedores.

\subsection{Determinação e quantificação das localidades prioritárias ao PSA-Água}

A síntese dos resultados relacionados com as áreas prioritárias para a conservação indica que 589,7 ha representam a faixa de prioridade "máxima", 186 ha estão relacionados com a prioridade "alta", 1.186,6 ha estão na faixa de prioridade "média" e 659,7 ha se encontram na faixa de prioridade "baixa" (Tabela 4).

Tabela 4. Quantificação das classes prioritárias à conservação e restauração.

\begin{tabular}{|c|c|c|c|c|c|}
\hline \multirow[b]{2}{*}{ Prioridade } & \multirow[b]{2}{*}{$\begin{array}{l}\text { Classes de } \\
\text { Prioridades }\end{array}$} & Máxima & Alta & Média & Baixa \\
\hline & & $\begin{array}{l}\text { Prioridade em } \\
\text { APP (ha) }\end{array}$ & $\begin{array}{l}\text { APP fora de } \\
\text { prioridade (ha) }\end{array}$ & $\begin{array}{l}\text { Prioridade fora } \\
\text { de APP (ha) }\end{array}$ & $\begin{array}{l}\text { Cobertura vegetal } \\
\text { em área comum } \\
\text { (ha) }\end{array}$ \\
\hline \multirow{7}{*}{ 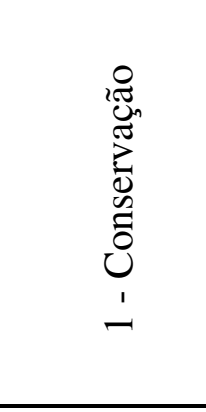 } & Prioridade 1.1 & 251,0 & 55,5 & 809,6 & 182,7 \\
\hline & Prioridade 1.2 & 86,9 & 30,4 & 135,5 & 111,6 \\
\hline & Prioridade 1.3 & 37,9 & 28,4 & 145,5 & 127,3 \\
\hline & Prioridade 1.4 & 73,4 & 72,2 & 96,1 & 238,0 \\
\hline & Hidrografia & 140,4 & 0,0 & 0,0 & 0,0 \\
\hline & Subtotal & 589,7 & 186,5 & 1186,6 & 659,7 \\
\hline & Total & \multicolumn{4}{|c|}{2622,5} \\
\hline \multirow[b]{2}{*}{ Prioridade } & & Máxima & Alta & Média & Baixa \\
\hline & $\begin{array}{l}\text { Classes de } \\
\text { Prioridades }\end{array}$ & $\begin{array}{l}\text { Prioridade em } \\
\text { APP (ha) }\end{array}$ & $\begin{array}{c}\text { APP fora de } \\
\text { prioridade (ha) }\end{array}$ & $\begin{array}{l}\text { Prioridade fora } \\
\text { de APP (ha) }\end{array}$ & $\begin{array}{l}\text { Sem cobertura } \\
\text { vegetal em área } \\
\text { comum (ha) }\end{array}$ \\
\hline \multirow{7}{*}{ 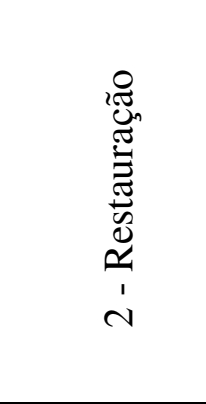 } & Prioridade 2.1 & 63,3 & 34,2 & 423,9 & 358,3 \\
\hline & Prioridade 2.2 & 56,4 & 49,9 & 246,1 & 244,0 \\
\hline & Prioridade 2.3 & 1,5 & 2,3 & 19,4 & 26,9 \\
\hline & Prioridade 2.4 & 2,4 & 0,3 & 21,5 & 12,2 \\
\hline & Estradas & 27,9 & 0,0 & 108,8 & 0,0 \\
\hline & Subtotal & 151,5 & 86,6 & 819,7 & 641,4 \\
\hline & Total & \multicolumn{4}{|c|}{1699,3} \\
\hline
\end{tabular}

Em 2.622,5 ha da microbacia (60,7 \%), a contratação de áreas prioritárias à conservação seria o ponto de partida para estimular a participação dos provedores. Sendo assim, uma vez inseridos no projeto de PSA-Água, os proprietários poderiam estar mais convencidos a, gradativamente, adequarem ambientalmente as suas propriedades $\mathrm{e}$ suas atividades produtivas, de preferência com os próprios incentivos recebidos por suas áreas conservadas.

Convém reforçar que do ponto de vista ecológico e de geração de serviços ecossistêmicos, florestas já estabelecidas, e até mesmo as vegetações em estágio inicial, geram mais benefícios e serviços ecossistêmicos de que as florestas implantadas, em processo 
de restauração (Pagiola et al., 2013). Dessa forma, o ideal seria um maior pagamento para a conservação das florestas do que para a restauração e implantação delas. Entretanto, a partir das ferramentas e dos critérios utilizados pelo presente capítulo, foram quantificadas e analisadas as áreas prioritárias para restauração, incluindo as práticas de conservação do solo, que por sua vez, pode ser uma prática imediata ao invés da implantação de plantios, nucleação etc.

Para as áreas prioritárias à restauração, 151,5 ha representam a faixa de prioridade "máxima", 86,6 ha estão relacionados com a prioridade "alta", 819,7 ha estão na faixa de prioridade "média" e 641,4 ha se encontram na faixa de prioridade "baixa".

Em 1.699,3 ha da microbacia (39,3\%), entende-se que a contratação de áreas prioritárias à restauração seja introduzida gradativamente no projeto de PSA-Água. O ideal seria iniciar um processo de convencimento de cada provedor, primeiramente, por meio da remuneração das áreas prioritárias à conservação na propriedade, passando pela execução das práticas de conservação do solo, inclusive para preparo do solo para o plantio e outras práticas atreladas à restauração ecológica, que seriam as últimas medidas a serem executadas.

Nesse formato, a priorização fatalmente tornaria um projeto de PSA-Água menos custoso, mais completo e com mais participantes, proporcionando a conexão entre fragmentos florestais e a propagação de práticas de conservação do solo e de restauração ecológica como oportunidades aos proprietários rurais.

De maneira geral, a consideração das APP's como as localidades mais prioritárias demonstra-se como alternativa para a implantação piloto de um PSA-Água, sobretudo visando conectar as localidades mais declivosas com as áreas planas. Por se tratarem de áreas menores, resultariam em menores investimentos iniciais, e ao mesmo tempo viabilizaria o processo de adequação ambiental da propriedade com relação à legislação. Tal processo de adequação, por sua vez, facilitaria o acesso dos provedores a outros incentivos ambientais.

Apesar de possíveis contrariedades, já que se discute que a conservação e a restauração de APP's são práticas obrigatórias imputadas ao proprietário e, portanto, não geram adicionalidades, entende-se que a remuneração consiste em uma recompensa àqueles que cumpriram a legislação e uma "chance" de promover a restauração, com a aceitação do proprietário. Nesse sentido, a restauração pode ocorrer, inclusive, com a inserção de espécies produtivas, visando, por exemplo, implantar sistemas agroflorestais.

Vale destacar que na microbacia as APP's estão intimamente relacionadas com as planícies aluvionares e, estas, com as áreas de declividades prioritárias, o que favorece a proteção dos recursos hídricos, sobretudo em razão da conectividade entre as áreas prioritárias, proporcionando a recarga hídrica e o melhor desenvolvimento do ciclo hidrológico.

Em relação às áreas prioritárias identificadas fora de APPs, a utilização das faixas de declividade e da hierarquização de graus de proteção aos solos, ambas determinadas por Ross (1994), apresentam-se condizentes para a priorização proposta, apesar do reconhecimento de que a definição de áreas prioritárias está geralmente atrelada com análises multicriteriais.

Nesse sentido, são necessários maiores estudos, inclusive de campo, para a obtenção de outros fatores que compõem a paisagem, como, por exemplo, a morfologia da bacia hidrográfica, a vulnerabilidade à erosão e as características de fragmentos florestais, visando à geração de novos planos de informação que possam ser incorporados. Essa perspectiva de enriquecimento aplicada a um sistema de PSA-Água se mostra importante para criar outros níveis de prioridade, visando até mesmo reduzir as áreas a serem remuneradas e os custos de transação, garantindo, assim, melhores resultados para a provisão de serviços ecossistêmicos e ambientais.

Diferentemente da remuneração exclusiva para as nascentes, a priorização de áreas proposta enseja também a participação dos proprietários que não têm nascentes. Além disso, 
possibilita uma maior proteção dos recursos hídricos, com destaque para a conservação e a restauração das zonas ripárias e a possibilidade de sua conexão com as localidades de declividades acentuadas, por meio das APP's. Contudo, em termos de priorização, a presença de nascentes nas propriedades poderia imputar maiores valores de remuneração para as APP's.

É importante ressaltar que o PSA tem utilidade transversal, ou seja, é um mecanismo em potencial para auxiliar na regularização de propriedades rurais, no processo de mapeamento do território, na aplicação do Código Florestal, na conservação dos solos e melhor aproveitamento dos recursos ambientais, e, em alguns casos, na execução de medidas sanitárias em regiões de mananciais (como a instalação de fossas sépticas).

Sendo assim, a sua implementação depende da governança da água, ou seja, da criação de alternativas de arranjos institucionais para o gerenciamento dos recursos hídricos, de forma a contribuir para o desenvolvimento econômico e o bem-estar das populações das áreas rurais e a jusante. Isso inclui o envolvimento de pessoal técnico capacitado, a criação de instâncias decisórias que envolvam diferentes níveis de governo e organizações da sociedade, e instâncias de articulação com as localidades prioritárias ao PSA-Água.

Portanto, a articulação entre os diversos atores responsáveis pela gestão dos recursos hídricos, assim como a ampliação do conhecimento técnico e científico sobre o PSA-Água, são fundamentais para o desenvolvimento de políticas públicas de incentivos ambientais, favorecendo o manejo de bacias hidrográficas.

\section{CONCLUSÃO}

Com o intuito de traduzir um cenário possível para o planejamento de um projeto de PSA-Água na microbacia do ribeirão do Murundu, a proposta de priorização demonstrou-se viável para a tomada de decisão, podendo ser aplicada para a seleção de áreas entre bacias hidrográficas, no interior de microbacias hidrográficas e até mesmo dentro de propriedades.

Fica evidente, entretanto, que a remuneração pela "floresta em pé" definitivamente se apresenta como perspectiva principal na microbacia do ribeirão do Murundu, assim como a possibilidade de reversão dos valores monetários em outras formas de apoio aos provedores, sobretudo, correspondendo ao atendimento das suas prioridades.

\section{REFERÊNCIAS}

ANTONIAZZI, B. L. Agricultura como provedora de serviços ambientais para proteção de bacias hidrográficas. Revista Tecnologia \& Inovação Agropecuária, p. 52-63, junho 2008.

BRASIL. Lei Federal no 12.651, de 25 de maio de 2012. Dispõe sobre a proteção da vegetação nativa; altera as Leis $n^{\circ} 6.938$, de 31 de agosto de 1981, 9.393, de 19 de dezembro de 1996, e 11.428, de 22 de dezembro de 2006; revoga as Leis $\mathrm{n}^{\circ} 4.771$, de 15 de setembro de 1965, e 7.754, de 14 de abril de 1989, e a Medida Provisória ${ }^{\circ} 2.166-$ 67, de 24 de agosto de 2001; e dá outras providências. Diário Oficial [da] União, Brasília, 28 maio 2012.

CENTRO DE PESQUISAS METEOROLÓGICAS E CLIMÁTICAS APLICADAS A AGRICULTURA - CEPAGRI. Clima dos municípios paulistas. 2015. Disponível em: http://www.cpa.unicamp.br/outrasinformacoes/clima_muni_228.html. Acesso em: 10 mar. 2015. 
GUEDES, F. B.; SEEHUSEN, S. E. Pagamentos por serviços ambientais na Mata Atlântica: lições aprendidas e desafios. Brasília: MMA, 2011. 272p.

LIMA, W. P. Hidrologia florestal aplicada ao manejo de bacias hidrográficas. Piracicaba: USALQ/USP, 2008. 245 p.

MARQUES, V. K. G. P.; KUSANO, H. R. Estudo de caracterização morfométrica e análise de disponibilidade hídrica do Rio Murundu. 2009. 42f. Trabalho de Conclusão de Curso (Graduação em Engenharia Ambiental) - Universidade Estadual Paulista, Sorocaba, 2009.

METZGER, J. P. O Código Florestal tem base científica? Natureza \& Conservação, v. 8, p. 92-99, 2010.

MURADIAN, R.; CORBERA, E.; PASCUAL, U.; KOSOY N.; MAY. P. H. Reconciling theory and practice: an alternative conceptual framework for understanding payments for environmental services. Ecological Economics, v. 69, n. 6, p. 1202-1208, 2009. http://dx.doi.org/10.1016/j.ecolecon.2009.11.006

NUSDEO, A. M. O. Pagamento por serviços ambientais: sustentabilidade e disciplina jurídica. São Paulo: Atlas, 2012. 179p.

PAGIOLA, S.; GLEHN, H. C.; TAFARELLO, D. Experiências de pagamentos por serviços ambientais no Brasil. São Paulo: SMA/CBRN, 2013. 336p.

PAGIOLA, S.; PLATAIS, G. Payments for environmental services: from theory to practice. Washington D.C.: World Bank, 2007.

ROSA, F. S.; TONELLO, K. C.; VALENTE, R. O. A.; LOURENÇO, R. W. Estrutura da paisagem, relevo e hidrografia de uma microbacia como suporte a um programa de pagamento por serviços ambientais relacionados à água. Revista Ambiente e Água, v. 9, n. 3, p. 526-539, 2014. http://dx.doi.org/10.4136/ambi-agua.1326

ROSS, J. L. S. Análise empírica da fragilidade dos ambientes naturais e antropizados. Revista do Departamento de Geografia, n. 8, 1994.

SHIKI, S., SHIKI, S.F.N. Os Desafios de uma política nacional de pagamentos por serviços ambientais: lições a partir do caso do Proambiente. Sustentabilidade em Debate, v. 2, n. 1, p. 99-118, 2011.

SOMMERVILLE, M. M.; JONES, J. P. G.; MILNER-GULLAND, E, J. A. Revised conceptual framework for payments for environmental services. Ecology and Society, v. 14, n. 02, 2009.

VATN, A. An institutional analysis of payments for environmental services. Ecological Economics, v. 69, n. 6, p. 1245-1252, 2010. http://dx.doi.org/10.1016/j.ecolecon.2009.11.018

WUNDER, S. Payments for environmental services: some nuts and bolts. Jakarta: Center for International Forestry Research, 2005. 24p. (CIFOR Occasional Paper, n. 42)

WUNDER, S. Revisiting the concept of payments for environmental services. Ecological Economics, n. 117, p. 234-243, 2015. http://dx.doi.org/10.1016/j.ecolecon.2014.08.016 


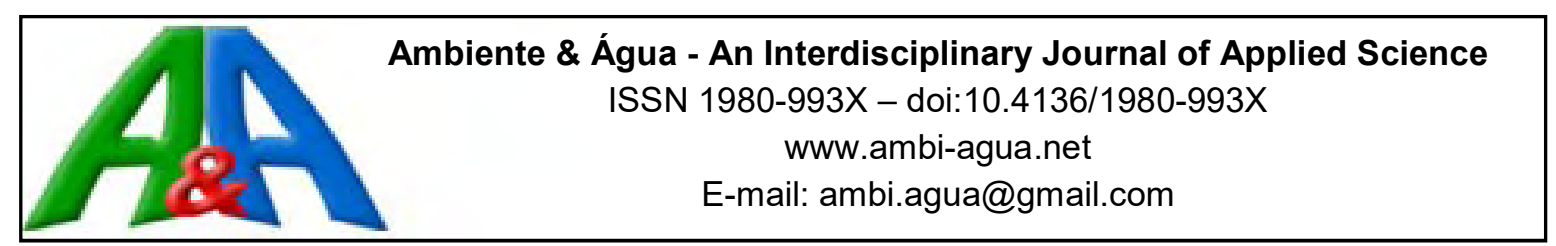

\title{
Crescimento inicial e tolerância de cultivares de meloeiro à salinidade da água
}

\author{
doi:10.4136/ambi-agua.1726
}

Received: 14 Aug. 2015; Accepted: 11 Feb. 2016

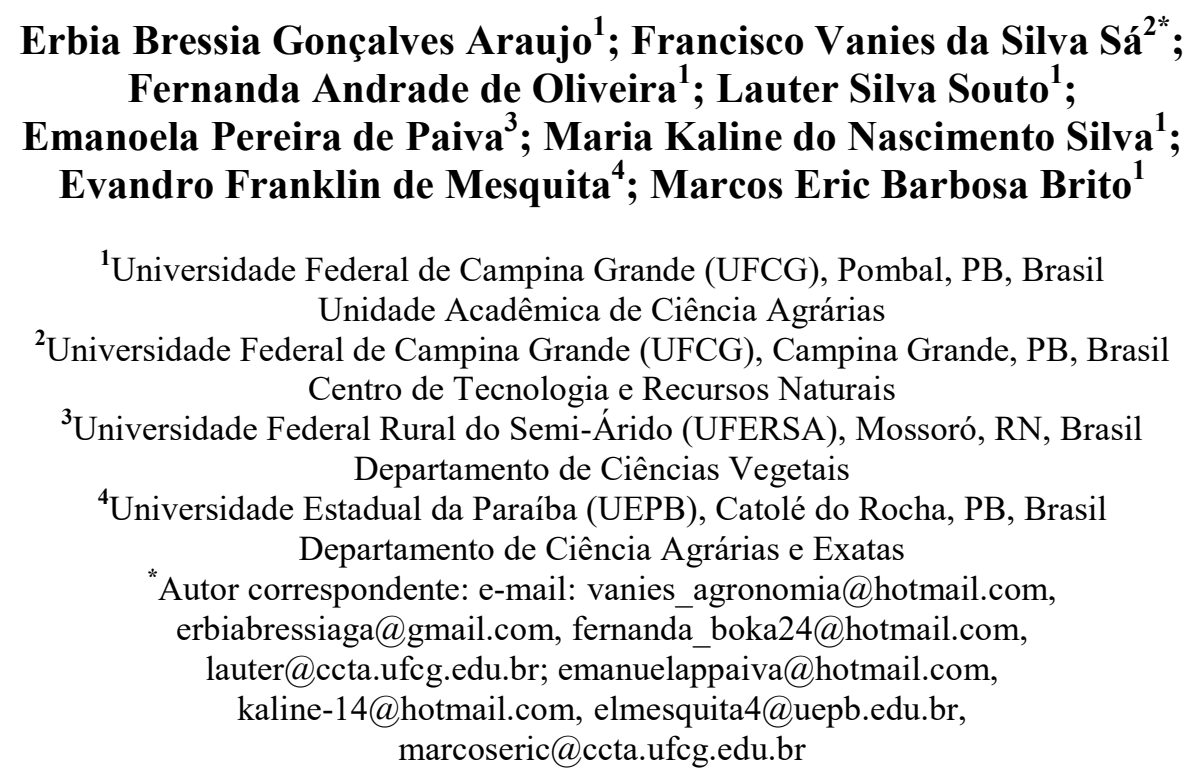

\section{RESUMO}

O cultivo do meloeiro é desenvolvido, principalmente, em áreas de clima semiárido, onde a limitação hídrica é o principal fator de estresse, sendo necessária a utilização de águas de qualidade inferior, principalmente as salinas para o aumento da água disponível, o que pode prejudicar o crescimento e a produção das plantas, contudo, o uso de genótipos tolerantes pode amenizar este problema. Com isso, objetivou-se estudar a emergência, o crescimento inicial e a tolerância de cultivares de meloeiro irrigado com águas de diferentes salinidades. $\mathrm{O}$ experimento foi desenvolvido em ambiente protegido da Universidade Federal de Campina Grande - UFCG, Campus de Pombal, Paraíba. Estudaram-se três cultivares de meloeiro (Gaúcho Redondo, Gaúcho Casca de Carvalho e Halles Best Jumbo) sob irrigação com águas com cinco níveis diferentes de salinidade $\left(0,6 ; 1,2 ; 1,8,2,4\right.$ e $\left.3,0 \mathrm{dS} \mathrm{m}^{-1}\right)$, perfazendo um esquema fatorial, $3 \times 5$, sendo os tratamentos resultantes distribuídos em um delineamento experimental de blocos ao acaso, com quatro repetições. As plantas foram monitoradas por 30 dias após a semeadura, e aos 30 dias, avaliou-se o crescimento e o índice de tolerância à salinidade. A cultivar Halles Best Jumbo é a mais tolerante à salinidade da água na fase inicial de crescimento, enquanto que a cultivar Gaúcho redondo é mais sensível à salinidade da água. Águas salinas de até $1,8 \mathrm{dS} \mathrm{m}^{-1}$ são indicadas para irrigação da plantas de meloeiro Gaúcho redondo e águas de até $2,4 \mathrm{dS} \mathrm{m}^{-1}$ podem ser utilizadas para irrigação das cultivares Gaúcho Casca de Carvalho e Halles Best Jumbo durante a fase inicial de crescimento.

Palavras-chave: Cucumis melo L., irrigação, salinidade. 


\section{Initial growth and tolerance of melon cultivars under salt stress}

\section{ABSTRACT}

The melon crop is normally developed in semiarid regions, where water resources are limited. This scarcity of water is a strong stressor on the crops, and requires the supplementation of existing water supplies with poor quality water, especially saline water. This can impede the growth and production of plants; however, the use of tolerant genotypes may minimize this problem. Thus, a greenhouse experiment was developed at the Federal University of Campina Grande - UFCG, Pombal Campus, Paraiba State, Brazil, in order to study the emergence, initial growth, and tolerance of melon cultivars irrigated with waters of different salt content. We studied three melon cultivars (Gaúcho Redondo, Gaúcho Casca de Carvalho and Halles Best Jumbo) irrigated with five levels of saline water $(0.6 ; 1.2 ; 1.8 ; 2.4$; and $\left.3.0 \mathrm{dS} \mathrm{m}^{-1}\right)$, arranged in a $3 \times 5$ factorial scheme, with the treatments distributed in a randomized block design with four replications. The plants seeds were monitored for 30 days after sowing, and at 30 days the growth and salinity tolerance index was evaluated. Cultivar Halles Best Jumbo was the most tolerant to saline water during initial stage of growth, while the Gaucho Redondo was more sensitive to salinity. It was found that saline waters up to $1.8 \mathrm{dS} \mathrm{m}^{-1}$ were suitable for irrigation of melon plants round Gaucho and waters up to $2.4 \mathrm{dS} \mathrm{m}^{-1}$ could be used for irrigation of Gaucho Casca de Carvalho and Halles Best Jumbo crops during the initial growth phase.

Keywords: Cucumis melo L., irrigation, salinity.

\section{INTRODUÇÃO}

O meloeiro (Cucumis melo L.) é uma planta olerícola pertencente à família cucurbitaceae, cultivado em várias regiões do mundo, devido a sua adaptabilidade há diversos tipos de clima e solo, além de sua elevada expressão econômica. O Brasil é o maior produtor de melão do mundo, com uma produção de 565.900 t em 2013. Sendo a região Nordeste a principal produtora, responsável por $95 \%$ da produção nacional, concentrada principalmente nos estados do Rio Grande do Norte e Ceará (IBGE, 2015).

Apesar da ampla adaptabilidade do meloeiro à região Nordeste, o seu cultivo nas áreas semiáridas do mundo apresenta risco, principalmente devido à escassez de recursos hídricos, relacionada à baixa intensidade pluviométrica, além da irregularidade das chuvas e elevada evaporação, sendo necessária a utilização de águas de qualidade inferior, em geral ricas em sais, principalmente de sódio (Medeiros et al., 2010). Desse modo, a alta demanda atmosférica exige o uso da irrigação para garantia de sobrevivência e manutenção da produtividade da cultura, todavia, deve-se usar de águas salinas (água de poços rasos), visando o aumento da água disponível, o que pode ocasionar distúrbios no crescimento e desenvolvimento das plantas, já que o uso de água com condutividade elétrica superior ao limiar das culturas tende a reduzir o potencial hídrico de água no solo e exercer efeitos negativos por íons específicos, isto é, efeitos de ordem iônica, limitando o desenvolvimento e produtividade das plantas, como tem sido observado por vários autores (Shannon, 1978; Queiroga et al., 2006; Medeiros et al., 2007; Neves et al., 2009; Porto Filho et al., 2011; Dias et al., 2011; Sá et al., 2013).

A salinidade afeta o crescimento das plantas em todos os estádios de desenvolvimento, todavia, a germinação, a emergência e o crescimento inicial são as fases mais afetadas pela salinidade, na maioria das culturas agrícolas. Em regiões semiáridas, o acúmulo de sais, especialmente $\mathrm{Na}^{+}$e $\mathrm{Cl}^{-}$, tem afetado o funcionamento da raiz pela redução do potencial osmótico devido a um maior desequilíbrio iônico no solo, o que reduz a absorção de alguns 
nutrientes minerais, principalmente $\mathrm{K}^{+}$e $\mathrm{Ca}^{+}$. Sendo estas alterações variáveis entre espécies e entre cultivares de uma mesma espécie (Ayers e Westcot, 1999; Flowers e Flowers, 2005; Queiroga et al., 2006; Medeiros et al., 2007; Munns e Tester, 2008; Al-Karakiet al., 2009; Sá et al., 2013; Brito et al., 2014).

Desse modo, a seleção de cultivares com tolerância à salinidade é uma alternativa viável para o desenvolvimento da agricultura em regiões áridas e semiáridas (Queiroga et al., 2006; Medeiros et al., 2007; Secco et al., 2010). Sendo de grande importância aumentar o rol de genótipos com potencial tolerância à salinidade, e com capacidade de oferecer produtividades elevadas, mesmo com uso de águas de qualidade inferior, como a salina.

Com isso, objetivou-se estudar a emergência, o crescimento inicial e a tolerância de cultivares de meloeiro à salinidade da água de irrigação.

\section{MATERIAL E MÉTODOS}

O experimento foi desenvolvido em ambiente protegido (casa de vegetação) do Centro de Ciências e Tecnologia Agroalimentar - CCTA da Universidade Federal de Campina Grande - UFCG, localizado no município de Pombal, Paraíba, PB, sobre coordenadas geográficas $6^{\circ} 47^{\prime} 20^{\prime \prime}$ ' de latitude S e $37^{\circ} 48^{\prime} 01^{\prime \prime}$ ' de longitude W, a uma altitude de $194 \mathrm{~m}$, no período de agosto a setembro de 2014.

Três cultivares de meloeiro foram estudadas (C1 - Gaúcho Redondo e C2- Gaúcho Casca de Carvalho e C3- Halles Best Jumbo) irrigadas com águas de cinco níveis de salinidade ( 0,6 (controle); 1,$2 ; 1,8 ; 2,4$ e $\left.3,0 \mathrm{dS} \mathrm{m}^{-1}\right)$, sendo três abaixo da salinidade limiar da cultura $\left(2,0 \mathrm{dS} \mathrm{m}^{-1}\right)$ (Shannon, 1978) e dois níveis acima, de modo a identificar genótipos com maior tolerância ou sensibilidade à salinidade da água. Os tratamentos foram arranjados em esquema fatorial, 3 x 5, em um delineamento experimental de blocos ao acaso, com quatro repetições e cinco plantas por parcela, totalizando 300 plantas experimentais.

As plantas de meloeiro foram cultivadas em bandejas de 30 cédulas com capacidade de $0,1 \mathrm{dm}^{3}$ de substrato, até os 30 dias após a semeadura (DAS). O substrato para a produção de mudas foi composto por solo (Neossolo Flúvico Tb Eutrófico típico) (Embrapa, 2013) e substrato comercial, misturados na proporção 1:1, respectivamente, cuja caracterização química encontra-se na Tabela 1 (Embrapa, 2011). Para o semeio, foram distribuídas cinco cédulas por tratamento, de modo que cada cédula recebesse duas sementes, totalizando 10 sementes por tratamento, após o final do processo de emergência das plântulas, realizou-se o desbaste, deixando-se apenas uma planta, a mais vigorosa, por célula. As sementes de ambas as cultivares foram adquiridas em casa comercial, apresentando $99 \%$ de pureza e $95 \%$ de germinação.

Tabela 1. Características químicas dos componentes dos substratos usados no cultivo do meloeiro.

\begin{tabular}{cccccccccccc}
\hline & $\mathrm{CE}$ & $\mathrm{pH}$ & $\mathrm{P}$ & $\mathrm{K}^{+}$ & $\mathrm{Ca}^{+2}$ & $\mathrm{Mg}^{+2}$ & $\mathrm{Na}^{+}$ & $\mathrm{Al}^{3+}$ & $\mathrm{H}^{+}+\mathrm{Al}^{3+}$ & $\mathrm{T}$ & $\mathrm{MO}$ \\
\hline \multirow{2}{*}{ Substrato } & $\begin{array}{c}\mathrm{dS} \mathrm{m}^{-1} \\
(1: 2,5)\end{array}$ & $\mathrm{H}_{2} 0$ & \multicolumn{1}{c}{$\mathrm{mg}$} & & & & & & & & \\
& & & & & & & & & & & \\
\hline A & 0,09 & 8,07 & 3,00 & 0,32 & 6,40 & 3,20 & 0,18 & 0,00 & 0,00 & 10,49 & 16,0 \\
B & 1,65 & 5,75 & 86,00 & 1,67 & 11,60 & 28,50 & 17,84 & 0,00 & 11,88 & 71,49 & 570,0 \\
\hline
\end{tabular}

Nota: $\mathrm{SB}=$ soma de bases; $\mathrm{CE}=$ condutividade elétrica; $\mathrm{T}$ = capacidade de troca de cátions total; $\mathrm{M} . \mathrm{O}=$ matéria orgânica; $\mathrm{A}=\mathrm{Solo} ; \mathrm{B}=$ substrato comercial.

As irrigações foram realizadas diariamente, de modo a manter o solo com umidade próxima à máxima capacidade de retenção, com base no método da lisimétria de drenagem, 
sendo a lâmina aplicada acrescida de uma fração de lixiviação de $20 \%$. O volume aplicado $\left(\mathrm{V}_{\mathrm{a}}\right)$ por recipiente foi obtido pela diferença entre o volume anterior $\left(\mathrm{V}_{\text {ant }}\right)$ aplicado e o volume drenado (d), dividido pelo número de recipientes (n), como indicado na Equação 1.

$$
V_{a}=\frac{V_{a n t}-D}{n(1-F L)}
$$

No preparo das águas de irrigação referentes aos respectivos níveis de salinidade, foi considerada a relação entre $\mathrm{CE}_{\mathrm{a}}$ e concentração de sais $\left(10 *\right.$ meq $\mathrm{L}^{-1}=1 \mathrm{dS} \mathrm{m}^{-1}$ de $\left.\mathrm{CE}_{\mathrm{a}}\right)$ extraída de Rhoades et al. (1992), válida para $\mathrm{CE}_{\mathrm{a}}$ de 0,1 a 5,0 $\mathrm{dS} \mathrm{m}^{-1}$ em que se enquadram os níveis testados. Foi utilizada água de abastecimento existente no local $\left(\mathrm{CE}_{\mathrm{a}}=0,3 \mathrm{dS} \mathrm{m} \mathrm{m}^{-1}\right)$, cujas características estão dispostas na Tabela 2, para o preparo das demais águas de irrigação após se acrescentar o $\mathrm{NaCl}$, conforme necessário, aferindo-se a condutividade desejada com uso de um condutivímetro portátil microprocessado que possuía ajuste automático de temperatura.

Após preparadas, cada tipo de água foi armazenada em recipiente plástico de $30 \mathrm{~L}$, que foram cobertos para evitar a evaporação, a entrada de água de chuva e a contaminação com materiais que pudessem comprometer sua qualidade.

Tabela 2. Análise química da água de abastecimento, utilizada no preparo das soluções.

\begin{tabular}{cccccccccccc}
\hline \multirow{2}{*}{ Água } & $\mathrm{CE}_{\mathrm{a}}$ & $\mathrm{pH}$ & $\mathrm{K}$ & $\mathrm{Ca}$ & $\mathrm{Mg}$ & $\mathrm{Na}$ & $\mathrm{SO}_{4}^{-2}$ & $\mathrm{CO}_{3}^{-2}$ & $\mathrm{HCO}_{3}^{-}$ & $\mathrm{Cl}^{-}$ & $\mathrm{RAS}^{1}$ \\
\cline { 2 - 10 } & $\mathrm{dSm}^{-1}$ & & $\ldots \ldots \ldots \ldots \ldots \ldots \ldots \ldots \ldots \ldots \ldots .\left(\mathrm{mmol}_{\mathrm{c}} \mathrm{L}^{-1}\right) \ldots \ldots \ldots \ldots \ldots \ldots \ldots \ldots \ldots \ldots$ & $\left(\mathrm{mmol} \mathrm{L}^{-1}\right)^{0,5}$ \\
\cline { 2 - 10 } & 0,3 & 7,0 & 0,3 & 0,2 & 0,6 & 1,4 & 0,2 & 0,0 & 0,8 & 1,3 & 2,21 \\
\hline
\end{tabular}

Nota ${ }^{1}$ RAS $=$ Razão de adsorção de sódio.

Durante a condução do experimento as plantas foram monitoradas em relação à emergência, pela contagem diária de plântulas emergidas, ou seja, com os cotilédones acima do nível do solo, obtendo-se um valor cumulativo. Dessa maneira, o número de plântulas emergidas referentes a cada contagem foi obtido pela subtração do valor lido, com o valor referente à leitura do dia anterior e o número de plântulas emergidas referentes a cada leitura foi calculada a velocidade de emergência (VE) (dias), empregando-se a Equação 2, descrita em Schuab et al. (2006).

$$
V E=\frac{\left(N_{1} G_{1}\right)+\left(N_{2} G_{2}\right)+\ldots+\left(N_{n} G_{n}\right)}{G_{1}+G_{2}+\ldots+G_{n}}
$$

em que:

$\mathrm{VE}=$ velocidade de emergência (dias);

$\mathrm{G}$ = número de plântulas emergidas observadas em cada contagem; e

$\mathrm{N}=$ número de dias da semeadura a cada contagem.

Após a estabilização da emergência, foi determinada a percentagem de emergência (PE) (\%), obtida pela relação entre o número de plantas emergidas e o número de sementes plantadas.

A avaliação morfológica do crescimento das plântulas, aos 30 dias após a semeadura (DAS), foi feita com a determinação da altura de planta (AP) $(\mathrm{cm})$, medida com uso de uma régua graduada pela distância entre o solo e o ápice da planta, do diâmetro do caule (DC), medido com paquímetro digital, a um centímetro da superfície do solo e pela contagem do número de folhas (NF), a partir da contagem das folhas maduras. Ao fim das análises 
morfológicas, as plantas foram coletadas, separando-se a parte aérea das raízes e acondicionadas em estufa com circulação de ar na temperatura de $65^{\circ} \mathrm{C}$, até atingir massa constante para obtenção, da massa seca da parte aérea (MSPA) (g), e das raízes (MSR) (g) em balança analítica; a massa seca total (MST) (g) correspondeu à soma da MSPA e MSR respectivamente.

Com os dados de produção de matéria seca total, foram calculadas as percentagens particionadas entre os órgãos vegetativos e o índice de tolerância à salinidade, comparando-se os dados dos tratamentos salinos com os do controle $\left(\mathrm{CEa}=0,6 \mathrm{dS} \cdot \mathrm{m}^{-1}\right)$, usando-se da Equação 3.

$$
I T(\%)=\frac{\text { Produção de MST no tratamento salino }}{\text { Produção de MST no tratament o controle }} \times 100
$$

Nos cálculos dos índices utilizaram-se a produção de matéria seca total dos genótipos como parâmetro principal para determinação da tolerância dos materiais ao estresse salino.

Os dados obtidos foram submetidos à análise de variância, teste ' $F$ ', nos casos de significância, foram realizadas análises de regressão para o fator níveis de salinidade da água de irrigação e teste de média, Tukey, para o fator cultivares, ambos ao nível de 5\% de probabilidade, com auxilio do software estatístico SISVAR ${ }^{\circledR}$ (Ferreira, 2011).

\section{RESULTADOS E DISCUSSÃO}

A cultitvar Halles Best Jumbo com 91,11\% de emergência de plântulas normais superou, significativamente, as cultivares Gaúcho Casca de Carvalho $(74,44 \%)$ e Gaúcho redondo $(61,11 \%)$, que não diferiram entre si, caracterizando-se como a mais tolerante à salinidade durante o processo de germinação das sementes (Tabela 3). Ao considerar que todos os genótipos são da mesma espécie, constata-se variabilidade na tolerância aos sais durante o processo de germinação, como identificado também por Queiroga et al. (2006) e Secco et al. (2009), ambos estudando a germinação de genótipos de meloeiro.

Tabela 3. Teste de médias para as variáveis percentagem de emergência (PE), altura de plantas (AP) e massa seca da parte aérea (MSPA) de cultivares de melão.

\begin{tabular}{lccc}
\hline \multicolumn{1}{c}{ Cultivares } & PE $(\%)$ & AP $(\mathrm{cm})$ & MSPA (g) \\
\hline Gaúcho redondo & $61,11 \mathrm{~b}$ & $4,08 \mathrm{a}$ & $0,0307 \mathrm{a}$ \\
Gaúcho Casca de carvalho & $74,44 \mathrm{~b}$ & $4,67 \mathrm{a}$ & $0,0302 \mathrm{a}$ \\
Halles Best Jumbo & $91,11 \mathrm{a}$ & $3,45 \mathrm{~b}$ & $0,0249 \mathrm{~b}$ \\
\hline
\end{tabular}

Nota: Letras minúsculas iguais não diferem perante o teste de Tukey ao nível de $5 \%$ de probabilidade.

A salinidade da água, além de elevar linearmente o tempo para a emergência das plântulas de meloeiro, independentemente da cultivar, na ordem de 6,25\% por aumento unitário da salinidade da água (Figura 1A), inibiu em 11,4\% o percentual de germinação (Figura 1B). Em termos efetivos, o incremento da salinidade da água de 0,6 para $1,6 \mathrm{dS} \mathrm{m}^{-1}$ ocasionou aumento de 6,6 para 7,0 dias na velocidade de emergência e reduziu de $88,5 \%$ para $77,7 \%$ o percentual de germinação. Ao considerar que o processo de germinação depende da absorção de água e energia, por meio de calor (Taiz e Zeiger, 2013), percebe-se que o aumento da concentração de sais na água de irrigação ocasionou redução no potencial osmótico, diminuindo a disponibilidade de água para embebição das sementes, conforme 
observado também por Freitas et al. (2006), Porto Filho et al. (2006) e Queiroga et al. (2006).

A

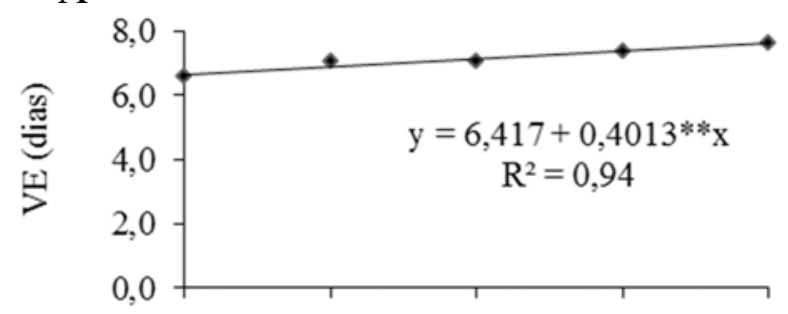

$\mathrm{C}$

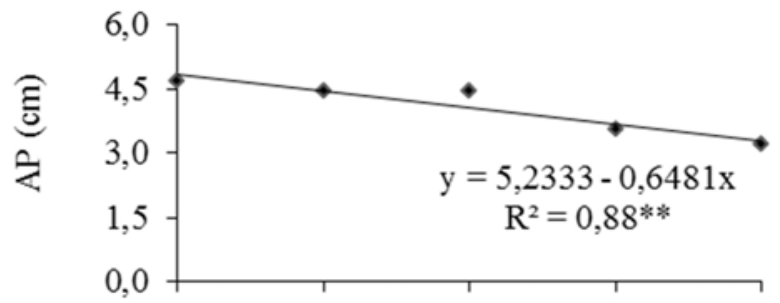

$\mathrm{E}$

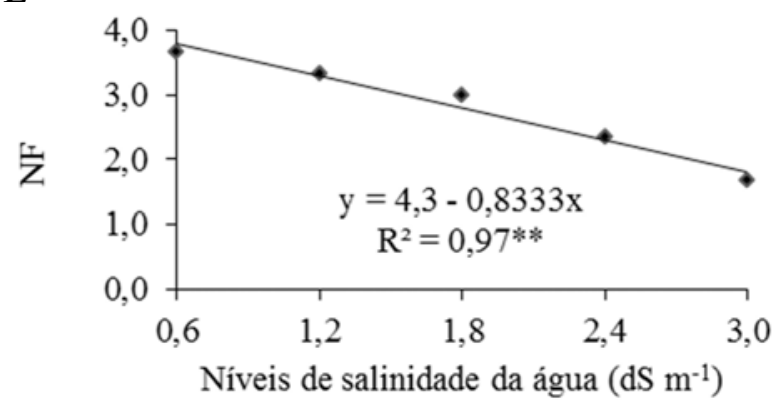

B

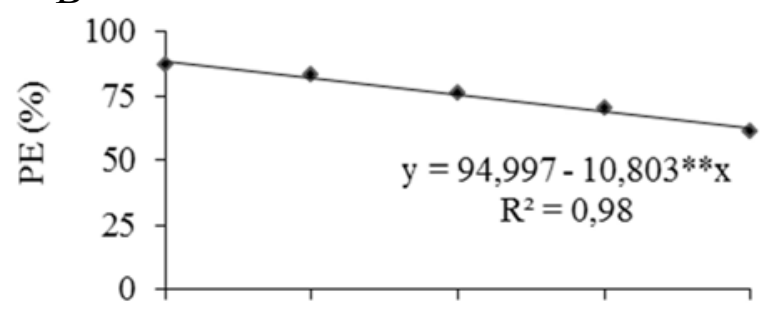

$\mathrm{D}$

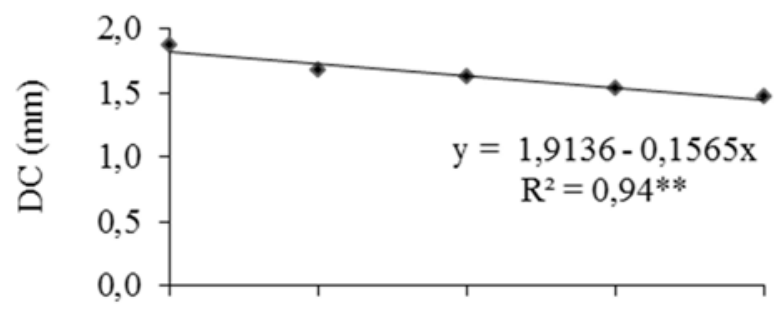

$\mathrm{F}$

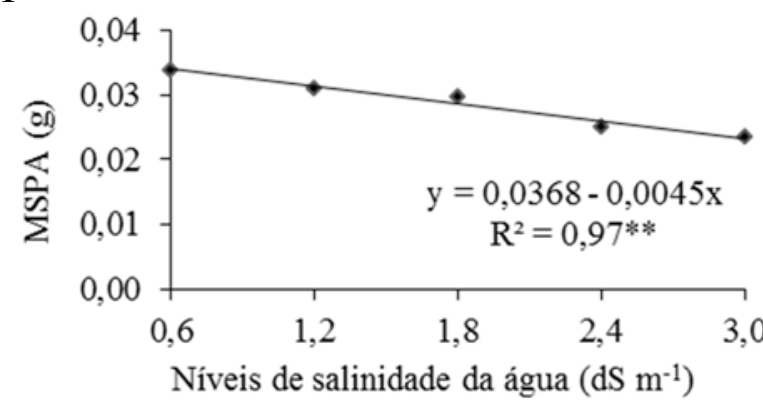

G

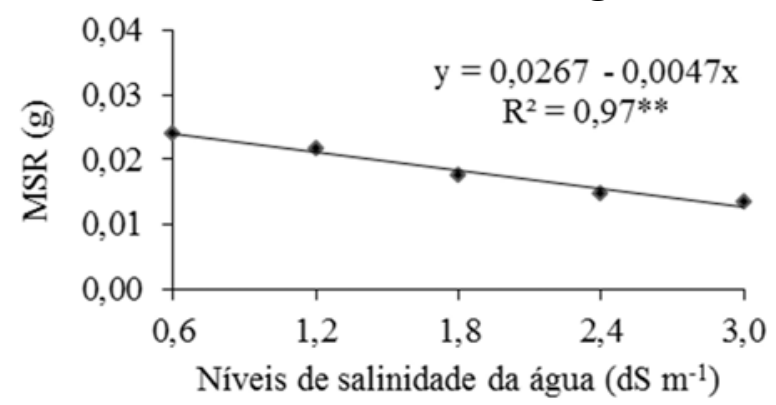

Figura 1. Velocidade de emergência (VE) (A), percentagem de emergência (PE)(B), Altura de planta $(\mathrm{AP})(\mathrm{C})$, diâmetro do caule (DC)(D), número de folhas $(\mathrm{NF})(\mathrm{E})$, massa seca da parte aérea (MSPA)(F), massa seca da raiz (MSR) (G)de cultivares de meloeiro sob diferentes níveis de salinidade da água de irrigação.

Os resultados estão em acordo com os obtidos por Secco et al. (2010), ao observarem que a elevação do nível salino comprometeu a germinação das sementes independente do genótipo estudado. Entretanto, neste trabalho não foi registrado efeito da interação salinidade $\mathrm{x}$ genótipo na fase de germinação, diferente do observado por aqueles autores.

O melhor crescimento em altura foi observado na cultivar Gaúcho Casca de Carvalho $(4,67 \mathrm{~cm})$, mas sem diferir do Gaúcho redondo para massa seca da parte aérea. Acredita-se que as variações no crescimento e acúmulo de massa seca podem estar relacionadas ao potencial de crescimento das cultivares, haja vista que os meloeiros Gaúchos possuem maior crescimento quando comparados à Halles Best Jumbo.

Quanto ao crescimento em altura, diâmetro do caule e número de folhas, verificaram-se declínios lineares e decrescentes com o aumento da condutividade elétrica da água, com 
decréscimos unitários na ordem de $12,38 \%, 8,17 \%$ e 19,37\%, respectivamente, com o aumento da salinidade da água de irrigação (Figura $1 \mathrm{C}, \mathrm{D}$ e E), respectivamente. De acordo com Taiz e Zeiger (2013), a inibição do crescimento ocasionada pela salinidade se deve ao efeito osmótico, pois promove à seca fisiológica, assim como pode ocorrer o efeito tóxico, resultante da concentração de íons no protoplasma. Em trabalho similares, Queiroga et al. (2006) verificaram nos híbridos de meloeiro Hy Mark; Honey Dew Red Fresh e Daimiel, redução no crescimento das plantas com aumento da salinidade, assim como observado neste trabalho e confirmando o efeito depressivo da salinidade da água.

As concentrações de sais de $\mathrm{NaCl}$ na água de irrigação interferiram no crescimento das plântulas de meloeiro, o que corrobora com Aragão et al. (2009), os quais afirmam que o aumento da salinidade prejudica diretamente o crescimento de plantas em todas as fases do crescimento e de forma diferenciada, sendo a maioria das cultivares mais sensíveis durante a fase de plântulas.

O aumento da salinidade da água de irrigação, independentemente da cultivar, promoveu efeitos negativos no acúmulo de massa seca da parte aérea (MSPA) e das raízes (MSR), com perdas de $12,2 \%$ e 17,6\%, com aumento unitário na condutividade elétrica da água, ocasionando uma redução de $31,7 \%$ e 47,2\%, respectivamente, entre o menor e maior nível de salinidade da água (Figuras $1 \mathrm{~F}$ e G). Os resultados estão coerentes com Ferreira et al. (2007) que, estudando os híbridos de meloeiro 'Vereda' e 'Mandacaru', submetidos a diferentes níveis de salinidade, também constataram reduções lineares no acúmulo de massa seca das plantas, fato que pode estar relacionado à redução da capacidade fotossintética das plantas, por meio de interações iônicas promovidas pelo excesso de sais de sódio, assim como observado em outros trabalhos (Silva et al., 2014; Soares et al., 2015). Provendo, com isso, redução no acúmulo de fotoassimilados pela menor produção do mesmo, além de que há aumento do gasto de energia na planta, devido, principalmente, a redução do potencial osmótico, que promove a redução da disponibilidade de água para o crescimento vegetal (Taiz e Zeiger, 2013).

As reduções na massa seca da parte aérea e raízes são transferidas ao acúmulo de fitomassa seca total das cultivares de meloeiro, verificando-se nas cultivares gaúcho redondo a maior redução unitária do acúmulo de fitomassa $(0,0144 \mathrm{~g})$ em função do aumento da salinidade. Seguida do meloeiro Gaúcho Casca de Carvalho, com reduções de 0,0089g para cada aumento unitário da salinidade da água de irrigação (Figura 2A). Situação também observada por Costa et al. (2008), ao avaliarem plântulas de meloeiro, híbridos Goldex e Vereda, constatarem reduções lineares da massa seca dos híbridos com o aumento da salinidade de 0,45 para $4,70 \mathrm{dS} \mathrm{m}^{-1}$. Esta redução pode estar relacionada ao desequilíbrio nutricional causado pela interação entre íons na solução do solo, notadamente o sódio, que pode ter reduzido à absorção de outros elementos, ocasionando efeito tóxico às plantas (Flowers e Flowers, 2005; Munns e Tester, 2008).

O menor acúmulo de massa seca total foi registrado nas plantas da cultivar Halles Best Jumbo, todavia, esta cultivar sofreu as menores reduções unitárias em função do aumento da salinidade, o que implica em maior tolerância à salinidade.

Quanto ao caráter tolerância, verificou-se na cultivar Halles Best Jumbo o maior índices, mantendo o rendimento relativo em acúmulo de biomassa na ordem de $80,3 \%$, entre os valores das plantas irrigadas com água de 3,0 e $0,6 \mathrm{dS} \mathrm{m}^{-1}$. Essa situação evidencia o potencial de maior tolerância desse genótipo na fase inicial de crescimento (Figura 2). Na cultivar

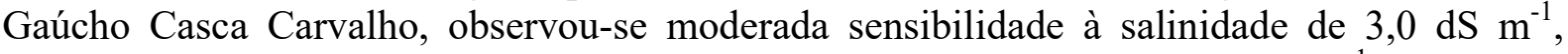
todavia, esse material foi moderadamente tolerante à salinidade de $2,0 \mathrm{dS} \mathrm{m}^{-1}$, sendo um material interessante a ser usado quando se tem águas com condutividade elétrica igual ou inferior a este nível, já que possui bom potencial de crescimento, mesmo sob salinidade da 
água.

A

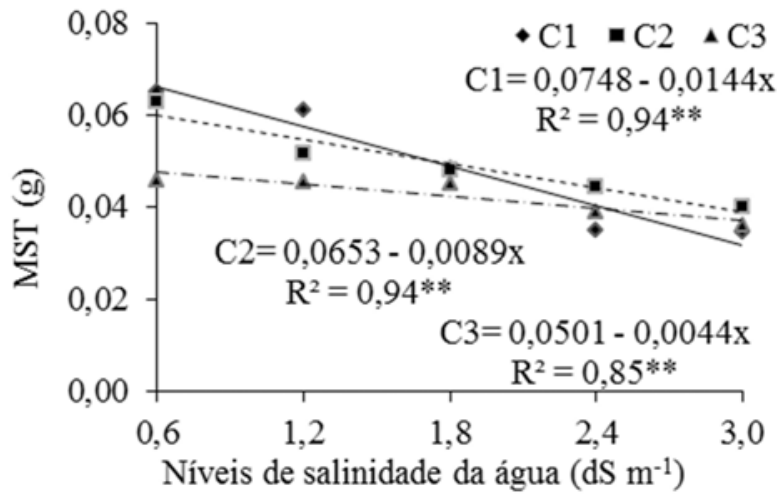

B

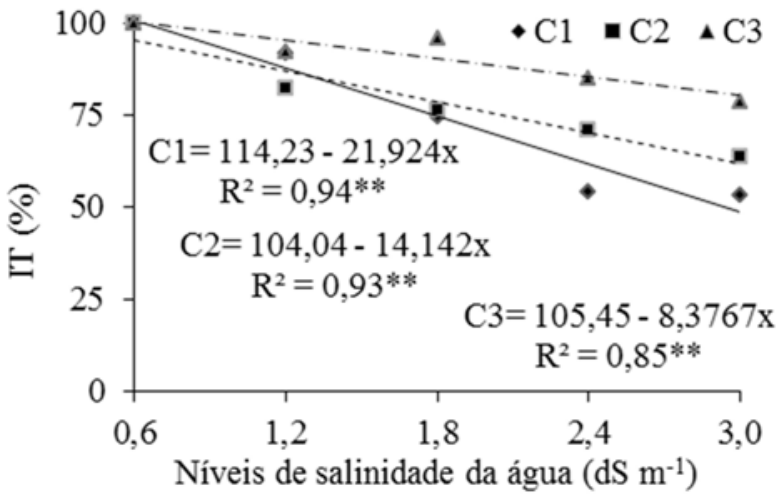

Figura 2. Massa seca total (MST) (g), índice de tolerância (IT) (\%) de cultivares de meloeiro (C1 - Gaúcho redondo; C2- Gaúcho Casca de carvalho e C3- Halles Best Jumbo) sob diferentes níveis de bsalinidade da água de irrigação.

Dentre os genótipos, o Gaúcho Redondo caracterizou-se como o mais sensível, com rendimento relativo de $75 \%$ quando irrigado com água de salinidade $1,8 \mathrm{dS} \mathrm{m}^{-1}$, chegando atingir o nível de 48,46\% quando submetido ao maior nível de salinidade $\left(3,0 \mathrm{dS} \mathrm{m}^{-1}\right)$, podendo ser considerado um genótipo moderadamente sensível à este nível de salinidade da água na fase inicial de crescimento (Figura 2B).

\section{CONCLUSÕES}

O aumento da salinidade da água de irrigação inibiu o crescimento e acúmulo de massa seca das cultivares de meloeiro.

A cultivar Halles Best Jumbo revelou - se a mais tolerante e a Gaúcho redondo mais sensível à salinidade da água na fase inicial de crescimento.

Águas salinas de até $1,8 \mathrm{dS} \mathrm{m}^{-1}$ são indicadas para irrigação da plantas de melão Gaúcho e águas de até $2,4 \mathrm{dS} \mathrm{m}^{-1}$ podem ser utilizadas para irrigação das cultivares Gaúcho Casca de Carvalho e Halles Best Jumbo durante a fase inicial de crescimento.

\section{REFERENCIAS}

AL-KARAKI, G.; AL-AJMI, A.; OTHMAN. Y. Response of soilless grown bell pepper cultivars to salinity. Acta Horticulturae, v. 807, n. 2, p. 227-232, 2009. http://dx.doi.org/10.17660/ActaHortic.2009.807.29

ARAGÃO, C. A.; SANTOS, J. S.; QUEIROZ, S. O. P.; FRANÇA, B. Avaliação de cultivares de melão sob condições de estresse salino. Revista Caatinga, v. 22, n. 2, p. 161-169, 2009.

AYRES, R. S.; WESCOT, D. W. A qualidade da água na agricultura. Tradução de GHEYI, H. R.; MEDEIROS, J. F.; DAMASCENO, E F. A. V. Campina Grande, UFPB, 1999. $153 \mathrm{p}$.

BRITO, M. E. B.; FERNANDES, P. D.; GHEYI, H. R.; MELO, A. S.; SOARES FILHO, W. S.; SANTOS, R. T. Sensibilidade à salinidade de híbridos trifoliados e outros portaenxertos de citros. Revista Caatinga, v. 27, p. 17-27, 2014. 
COSTA, A. R. F. C.; TORRES, S. B.; OLIVEIRA, F. N.; FERREIRA, G. S. Emergência de plântulas de melão em diferentes níveis de salinidade da água de irrigação. Revista Caatinga, v. 21, n. 3, p. 89-93, 2008.

DIAS, N. S.; OLIVEIRA, A. M.; SOUSA NETO, O. N.; BLANCO, F. F.; REBOLÇAS, J. R. L. Concentração salina e fases de exposição à salinidade do meloeiro cultivado em substrato de fibra de coco. Revista Brasileira de Fruticultura, v. 33, n. 3, p. 915-921, 2011. http://dx.doi.org/10.1590/S0100-29452011005000084

EMPRESA BRASILEIRA DE PESQUISA AGROPECUÁRIA - EMBRAPA. Centro Nacional de Pesquisa de Solos. Manual de métodos de análise do solo. 3. ed. Rio de Janeiro, 2011. 230 p. (Documentos, 132).

EMPRESA BRASILEIRA DE PESQUISA AGROPECUÁRIA - EMBRAPA. Centro Nacional de Pesquisa de Solos. Sistema Brasileiro de Classificação de Solos. 3. ed. Brasília, DF: Embrapa Solos, 2013. 353p.

FERREIRA, D. F. Sisvar: a computer statistical analysis system. Ciência e Agrotecnologia, v. 35, p. 1039-1042, 2011. http://dx.doi.org/10.1590/S1413-70542011000600001

FERREIRA, G. S.; TORRES, S. B.; COSTA, A. R. F. C. Germinação e desenvolvimento inicial de plântulas de meloeiro em diferentes níveis de salinidade da água de irrigação. Revista Caatinga, v. 20, n. 3, p. 181-185, 2007.

FLOWERS, T. J.; FLOWERS, S. A. Why does salinity pose such a difficult problem for plant breeders? Agricultural Water Management, v. 78, n. 1, p. 15-24, 2005.

FREITAS R. S.; AMARO FILHO J.; MOURA FILHO, E. R. Efeito da salinidade na germinação e desenvolvimento de plantas de meloeiro. Revista Verde de Agroecologia e Desenvolvimento Sustentável, v. 1, n. 2, p. 113-121, 2006.

INSTITUTO BRASILEIRO DE GEOGRAFIA E ESTATÍSTICA - IBGE. Indicadores IBGE. Produção Agricola Municipal. Disponível em: http://www.sidra.ibge. gov.br/bda/eQUAC/protabl.asp?c=1612\&z=t\&o=1\&i=P. Acesso em: 16 maio 2015.

MEDEIROS, A. M. A.; BARBOSA, J. E. L.; MEDEIROS, P. R.; ROCHA, R. M.; SILVA, L. F. Salinityandfreshwaterdischarge determine rotiferdistributionatthe Mossoró River Estuary (Semiarid Region of Brazil). Brazilian Journal of Biology, v. 70, n. 3, p. 551557, 2010. http://dx.doi.org/10.1590/S1519-69842010000300011

MEDEIROS, J. F.; SILVA, M. C. C.; SARMENTO, D. H. A.; BARROS, A. D. Crescimento do meloeiro cultivado sob diferentes níveis de salinidade, com e sem cobertura do solo. Revista Brasileira de Engenharia Agrícola e Ambiental, v. 11, n. 3, p. 248-255, 2007. http://dx.doi.org/10.1590/S1415-43662007000300002

MUNNS, R.; TESTER, M. Mechanisms of salinity tolerance. Annual Review of Plant Biology, v. 59, n. 6, p. 651-681, 2008. http://dx.doi.org/10.1146/annurev.arplant.59.032607.092911

NEVES, A. L. R.; LACERDA, C. F.; GUIMARÃES, F. V. A.; HERNANDEZ, F. F. F.; SILVA, F. B.; PRISCO, J. T. et al. Acumulação de biomassa e extração de nutrientes por plantas de feijão-de-corda irrigadas com água salina em diferentes estádios de desenvolvimento. Ciência Rural, v. 39, n. 3, p. 758-765, 2009. http://dx.doi.org/10.1590/S0103-84782009005000014 
PORTO FILHO, F. Q.; MEDEIROS, J. F.; GHEYI, H. R.; DIAS, N. S.; SOUSA, P. S.; DANTAS, D. C. Evolução da salinidade e pH de solo sob cultivo de melão irrigado com água salina. Revista Brasileira de Engenharia Agrícola e Ambiental, v. 15, n. 11, p. 1130-1137, 2011. http://dx.doi.org/10.1590/S1415-43662011001100004

PORTO FILHO, F. Q.; MEDEIROS, J. F.; GHEYI, H. R.; MATOS, J. A.; SOUZA, E. R.; SOUSA NETO, E. R. Crescimento do meloeiro irrigado com aguas de diferentes salinidades. Horticultura Brasileira, v. 24, n. 3, p. 334-341, 2006. http://dx.doi.org/10.1590/S0102-05362006000300013

QUEIROGA, R. C. F.; ANDRADE NETO, R. C.; NUNES, G. H. S.; MEDEIROS, J. F.; ARAÚJO, W. B. M. Germinação e crescimento inicial de híbridos de meloeiro em função da salinidade. Horticultura Brasileira, v. 24, n. 3, p. 315-319, 2006. http://dx.doi.org/10.1590/S0102-05362006000300009

RHOADES, J. D.; KANDIAH, A.; MASHALI, A. M. The use of saline waters for crop production. Rome: FAO, 1992. 133 p. (Irrigation and Drainage Paper, 48).

SÁ, F. V. S.; BRITO, M. E. B.; MELO, A. S.; ANTÔNIO NETO, P.; FERNANDES, P. D.; FERREIRA, I. B. Produção de mudas de mamoeiro irrigadas com água salina. Revista Brasileira de Engenharia Agrícola e Ambiental, v. 17, n. 10, p. 1047-1054, 2013. http://dx.doi.org/10.1590/S1415-43662013001000004

SCHUAB, S. R. P.; BRACCINI, A. L.; FRANÇA NETO, J. B.; SCAPIM, C. A.; MESCHEDE, D. K. Potencial fisiológico de sementes de soja e sua relação com a emergência das plântulas em campo. Acta Scientiarum Agronomy, v. 28, n. 4, p. 553 561, 2006. http://dx.doi.org/10.4025/actasciagron.v28i4.928

SECCO, L. B.; QUEIROZ, S. O. P.; DANTAS, B. F.; SILVA, Y. A.; SILVA, P. P.; SILVA, P. S.; NUNES, L. A. Germinação de sementes de melão (Cucumis melo L.) em condições de estresse salino. Revista Brasileira de Sementes, v. 26, n. 2, p. 144-149, 2009 .

SECCO, L. B.; QUEIROZ, S. O.; DANTAS, B. F.; SOUZA, Y. A.; SILVA, P. P. Qualidade de sementes de acessos de melão (cucumis melo L.) em condições de estresse salino. Revista Verde de Agroecologia e Desenvolvimento Sustentável, v. 5, n. 2, p. 01-11, 2010 .

SHANNON, M.; FRANCOIS, L. Salt tolerance of three muskmelon cultivars. Journal of the American Societyfor Horticultural Science, v. 103, p. 127-30, 1978.

SILVA, L. A.; BRITO, M. E. B.; SÁ, F. V. S.; MOREIRA, R. C. L.; SOARES FILHO, W. S.; FERNANDES, P. D. Mecanismos físiológicos de percepção do estresse salino de híbridos de porta-enxertos citros em cultivo hidropônico. Revista Brasileira de Engenharia Agrícola, v. 18, suplementar, p. S1-S7, 2014.

http://dx.doi.org/10.12702/ii.inovagri.2014-a533

SOARES, L. A. A.; BRITO, M. E. B.; FERNADES, P. D.; LIMA, G. S.; SOARES FILHO, W. S.; OLIVEIRA, E. S. Crescimento de combinações copa-porta-enxerto de citros sob estresse hídrico em casa de vegetação. Revista Brasileira de Engenharia Agrícola e Ambiental, v. 19, n.3, p. 211-217, 2015. http://dx.doi.org/10.1590/18071929/agriambi.v19n3p211-217

TAIZ, L.; ZEIGER, E. Fisiologia vegetal. 5. ed. Porto Alegre: Artmed, 2013. 918p. 


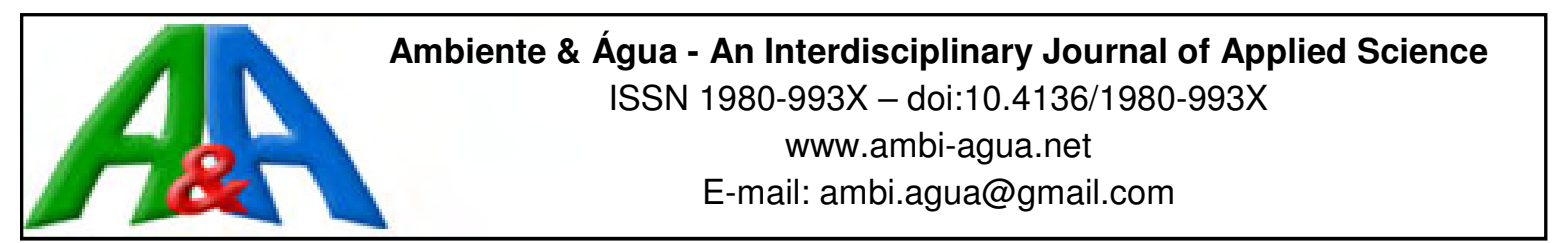

\title{
Uso da terra e degradação na qualidade da água na bacia hidrográfica do rio Peixe-Boi, PA, Brasil
}

\author{
doi:10.4136/ambi-agua.1802
}

Received: 11 Nov. 2015; Accepted: 16 Feb. 2016

\author{
Bruno Wendell de Freitas Pereira ${ }^{1}$; Maria de Nazaré Martins Maciel ${ }^{1}$; \\ Francisco de Assis Oliveira ${ }^{2}$; Marcelo Augusto Moreno da Silva Alves ${ }^{3}$; \\ Adriana Melo Ribeiro ${ }^{3}$; Bruno Monteiro Ferreira ${ }^{1}$; \\ Ellen Gabriele Pinto Ribeiro ${ }^{1 *}$ \\ Universidade Federal Rural da Amazônia (UFRA), Belém, PA, Brasil \\ ${ }^{1}$ Instituto Ciber Espacial (ICIBE) \\ ${ }^{2}$ Instituto de Ciências Agrárias (ICA) \\ ${ }^{3}$ Instituto Socioambiental e dos Recursos Hídricos (ISARH) \\ *Autor correspondente: e-mail: ellengpr@gmail.com, \\ brunowendell@yahoo.com.br,nazamaciel@yahoo.com.br,fdeassis@gmail.com, \\ marcelo.moreno@ufra.edu.br, anamellory@hotmail.com, \\ brunoferreiramont@gmail.com
}

\section{RESUMO}

O trabalho objetivou mapear a cobertura e uso do solo na área da bacia hidrográfica do rio Peixe-Boi, nordeste paraense, identificar conflitos de uso nas áreas de preservação permanente e investigar a relação deles com a qualidade da água. Utilizou-se imagem do sensor LISS-3 do satélite Resourcesat com resolução espacial de 23,5 m para classificação supervisionada e obtenção de classes de uso e cobertura da terra com base em 22 amostras de treinamento. Para se determinar a qualidade da água foram coletados 28 pontos amostrais nas redes de drenagem. A relação entre antropização e qualidade da água foi analisada a partir das observações das mudanças de uso da terra, por meio de imagens de satélite e coletas in loco das amostras de água. Os resultados obtidos revelam que $46 \%$ das APPs encontra-se em conflito de uso, sobretudo pela ocupação indevida das classes área urbana, solo exposto e especialmente pastagem com mais de $84 \%$ da área em conflito de uso. Em alguns pontos amostrais, foram observados níveis críticos de oxigênio dissolvido chegando a $2,14 \mathrm{mg} \mathrm{L}^{-1} \mathrm{e}$ pH de 5,12, valores abaixo do estabelecido pela resolução 357/05 do CONAMA para água doce. Constatou-se que as piores condições de qualidade da água podem estar relacionadas às áreas de uso e ocupação irregulares dentro das APPs. Diante do exposto, verifica-se a necessidade, emergencial, de planejamento do uso e ocupação das terras na área da bacia hidrográfica do rio Peixe-Boi para a recuperação ambiental e da qualidade da água.

Palavras-chave: cobertura do solo, desmatamento, recursos hídricos.

\section{Land use and water quality degradation in the Peixe-Boi River watershed}

\section{ABSTRACT}

This study mapped the land use and land cover of the catchment area of the Peixe-Boi 
River watershed, in northeast Pará, in order to identify conflicts of land use in the permanent preservation areas, and to relate them to water quality. We used LISS-3 sensor imagery from the Resourcesat satellite with a spatial resolution of $23.5 \mathrm{~m}$ for supervised classification of land use and land cover based on 22 training samples. Water quality was determined based on 28 sampling points in drainage network. The relationship between human disturbance and water quality was analyzed based on observations of land use changes using satellite imagery and in situ collection of water samples. The results show that $46 \%$ of the permanent preservation areas have conflicted uses, especially with respect to urban squatters, exposed soil and, most notably, pasture, with over $84 \%$ of the area in conflict. Critical levels of dissolved oxygen reaching $2.14 \mathrm{mg} \mathrm{L}^{-1}$ and $\mathrm{pH}$ of 5.12 were observed in some sampling points. These values are below the fresh water standards set by Resolution 357/05 of CONAMA. The poorest water quality may be related to irregular use and occupation of areas within the permanent preservation areas. There is therefore an urgent need to develop a plan for the sustainable use and occupation of catchment area land in the Peixe-Boi River watershed in order to restore the environment and improve water quality.

Keywords: deforestation, land cover, water resources.

\section{INTRODUÇÃO}

O processo de ocupação do território brasileiro é marcado, historicamente, pela intensa exploração de seus recursos naturais e supressão da vegetação nativa, voltadas para diversas atividades antrópicas, com destaque para a agropecuária e expansão da urbanização. $\mathrm{Na}$ região Amazônica, ausência de práticas conservacionistas, voltadas à sustentabilidade ambiental e econômica desencadeou severos problemas e impactos negativos, com destaque a erosão hídrica, perda de qualidade dos solos, redução de oferta hídrica e drástica alteração da cobertura vegetal (Ferreira e Coelho, 2015).

No Estado do Pará, a diminuição foi de $8870 \mathrm{~km}^{2}$ ano $^{-1}$ em 2004, para $1887 \mathrm{~km}^{2} /$ ano em 2014, o que representa uma redução de 79\%, conforme dados mapeamento consolidado pelo Projeto de Monitoramento do Desmatamento na Amazônia Legal (PRODES) ainda em 2014. Contudo, embora os resultados indiquem eficácia no combate ao desmatamento, ainda há muito que ser feito para se atingir níveis aceitáveis de sustentabilidade ambiental para a região (Schmitt e Paiva, 2015).

Para que haja um processo sustentável que possibilite o desenvolvimento da produção agrícola, paralelo à preservação do meio ambiente, faz-se necessárias ações de políticas públicas, que viabilizem o desenvolvimento econômico e a manutenção dos ecossistemas naturais. Assim, com o intuito de disciplinar e limitar as alterações antrópicas negativas ao meio ambiente, o Código Florestal Brasileiro - Lei n. ${ }^{\circ}$ 4.771, de 15 de setembro de 1965, instituiu a criação das Áreas de Preservação Permanente - APPs (Brasil, 1965), posteriormente modificado pela Lei 12.727/2012.

É importante ressaltar que além do Código Florestal, a Constituição Federal determina no artigo 186 toda propriedade rural deverá cumprir sua função social, promovendo, a "utilização adequada dos recursos naturais disponíveis e preservação do meio ambiente" (Brasil, 1988). Dessa forma, os proprietários de imóveis rurais têm por obrigação adotar as normas de proteção do meio ambiente legalmente instituídas, uma vez que, os benefícios socioambientais de proveito coletivo, prevalecem sobre as garantias individuais de uso do proprietário.

Araújo et al. (2013) reiteram que monitorar as alterações na paisagem da região Amazônica é um fator de primordial importância no controle e planejamento racional de utilização do uso da terra, em função do avanço da ocupação do espaço físico. Nesse sentido, 
Pires (2013) complementa e discute a necessidade do mapeamento eficaz das APPs, para manutenção das bacias hidrográficas, para o planejamento territorial, e monitoramento do uso sustentável e legal dos recursos naturais.

Para Pires et al. (2012) e Santos et al. (2015), o estudo de bacias hidrográficas mostra-se cada vez mais necessário na correlação com as Áreas de Preservação Permanente (APPs), pois, a existência de conflitos entre uso e ocupação e o descumprimento da legislação nessas áreas, põem em risco a integridade dos recursos hídricos, afetando a qualidade da água, devido à dinâmica fluvial e ao escoamento superficial da água ao longo da bacia de drenagem.

Desta forma, a análise da qualidade de água dentro das APPs na bacia hidrográfica do rio Peixe-Boi vem como instrumento norteador de políticas públicas para qualificar e quantificar a realidade existente na região da bacia hidrográfica. Com isto será possível estabelecer metas de planejamento dos recursos hídricos nos municípios abrangidos pela bacia hidrográfica, equalizando a problemática e evitando a contaminação de seus mananciais.

Neste sentido, o presente trabalho teve por objetivo mapear a cobertura e uso do solo na área de abrangência da bacia do rio Peixe-Boi, identificar conflitos de uso nas áreas de preservação permanente, de acordo com o Código Florestal (Lei 12.727/2012) e, relacioná-los com a qualidade da água na bacia hidrográfica, com base na resolução $\mathrm{n}^{\circ} 357$ de 17 de março de 2005 do Conselho Nacional do Meio Ambiente-CONAMA, no uso integrado de produtos e técnicas de sensoriamento remoto e geoprocessamento, para subsidiar ações de gestão para minimizar a degradação da qualidade da água nesta bacia.

\section{MATERIAL E MÉTODOS}

\subsection{Caracterização da área de estudo}

A bacia hidrográfica do rio Peixe-Boi está localizada na mesorregião do Nordeste Paraense, mais precisamente na microrregião denominada Bragantina (Figura 1). Ela estende-se entre as coordenadas $0^{\circ} 53^{\prime} 57^{\prime \prime} \mathrm{S}$ e $1^{\circ} 26^{\prime} 10^{\prime \prime} \mathrm{S}$ de Latitude e $47^{\circ} 24^{\prime} 29^{\prime \prime} \mathrm{W}$ e $47^{\circ} 7^{\prime}$ 4" W de Longitude. Esta bacia tem como rio principal o rio Peixe-Boi, com cerca de $60 \mathrm{~km}$ de extensão, sendo sua nascente está situada próxima município de Bonito e caminha no sentido norte, até sua foz na confluência com o rio Maracanã. Possui uma área de 103400,42ha, abrangendo um total de seis municípios, sendo que, 43,6\% de sua área pertencem ao município de Peixe-Boi, 24,3\%, ao município de Bonito, 15,4\% Nova Timboteua, 7,4\% Capanema, 5,6\% Santarém Novo e 3,6\% ao município de Primavera (Pereira et al., 2015a).

A região apresenta o clima do tipo Am, segundo a classificação de Köppen. A precipitação pluviométrica média está em torno de $2.200 \mathrm{~mm}$ anuais. A temperatura varia entre 29 e $31^{\circ} \mathrm{C}$.

$\mathrm{O}$ relevo apresenta formas suaves de tabuleiros e elevações ligeiramente colinoformes, além de planaltos e planícies fluviais. (IBGE, 2008). Os solos que abrangem a área da bacia hidrográfica do rio Peixe Boi são representados pelo tipo Latossolo Vermelho Amarelo Distrófico Típico (IBGE, 2012).

A cobertura vegetal da área da bacia hidrográfica é característica de vegetação secundária em vários estágios de sucessão, por motivo da ação dos desmatamentos demandados para a implantação dos sistemas produtivos locais, representado em geral pelo plantio de espécies agrícolas de subsistência e principalmente por pastagens cultivadas, destinados à pecuária de leite e de corte.

\subsection{Coleta e avaliação da qualidade da água}

As coletas foram realizadas em 28 pontos, no ano de 2013, nos meses de maio (período chuvoso, onde a precipitação pode chegar a $400 \mathrm{~mm}$ ) e outubro (período seco, onde tem 
precipitação não ultrapassa $50 \mathrm{~mm}$ ), e distribuídos ao longo dos municípios que fazem parte da bacia hidrográfica do rio Peixe Boi (Figura 1). E os pontos foram distribuídos ao longo dos municípios que fazem parte da bacia hidrográfica do rio Peixe Boi, a fim de se traçar o background local dos padrões de qualidade das águas da área de estudo dentro das APPs, desde suas nascentes, no município de Bonito, passando pelo seu curso principal, onde a ele contribuem os igarapés que nele deságuam, até sua desembocadura no Rio Maracanã.
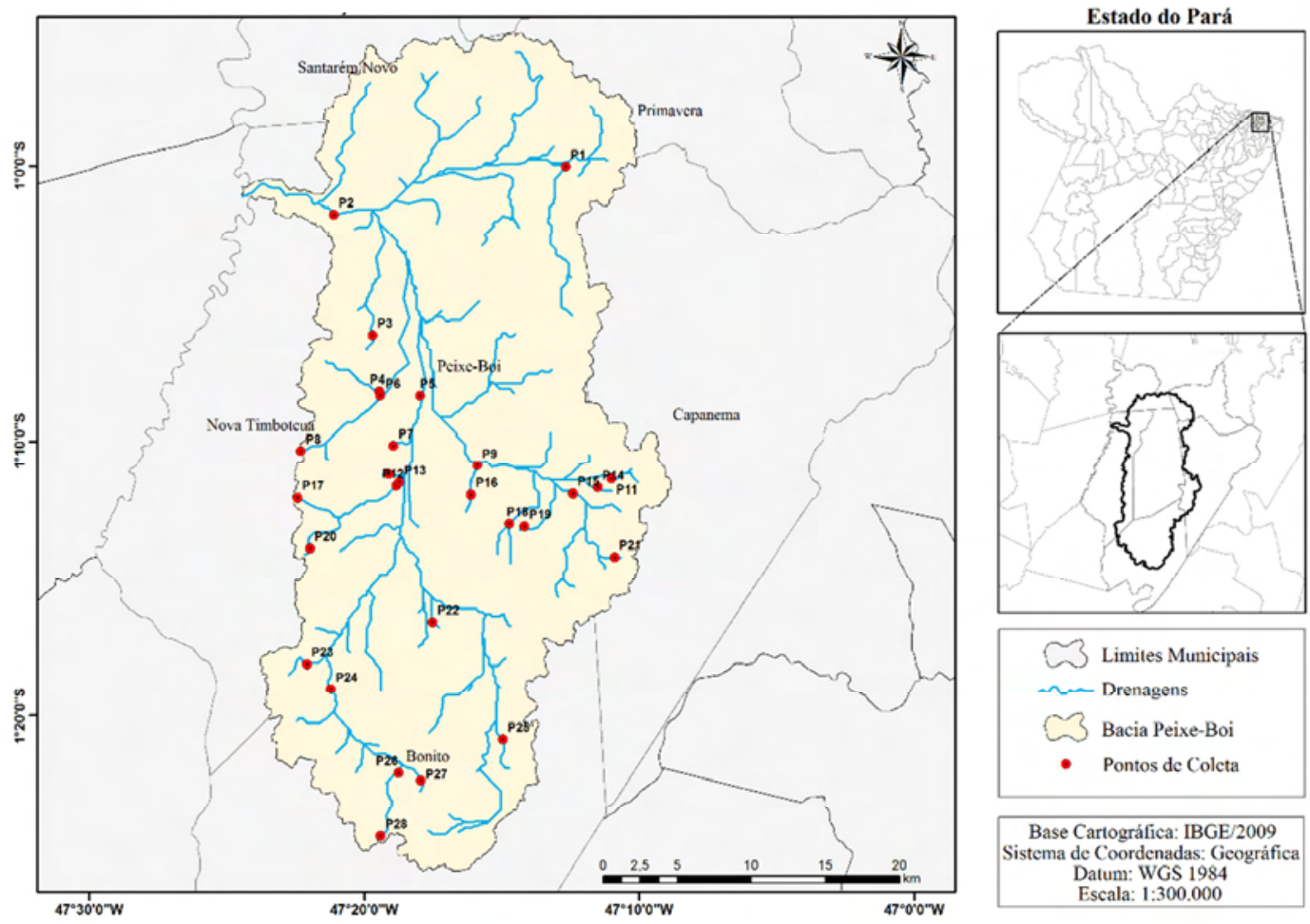

Figura 1. Localização da bacia hidrográfica do rio Peixe-Boi e dos pontos de coleta de água. Base cartográfica (IBGE, 2009).

No ponto exato de cada estação de amostragem foram registradas as coordenadas geográficas, utilizando-se um GPS de navegação modelo Garmin $76 \mathrm{Cx}$, configurado de acordo com o sistema métrico de coordenadas planas e ajustado para precisão média de $3 \mathrm{~m}$.

As amostragens foram baseadas nas recomendações do guia de coleta e preservação de amostras de água Companhia de Tecnologia e Saneamento Ambiental (CETESB, 1988). Para análise dos padrões ambientais mínimos de qualidade de água foram seguidas a recomendações da Resolução CONAMA 357/2005 (CONAMA, 2005), que classifica as águas doces segundo seu uso, em:

Classe especial: Águas destinadas ao abastecimento para consumo humano, com desinfecção. Essa classe não está presente na área de estudo.

Classe 1 - Abastecimento para consumo humano, após tratamento simplificado, proteção das comunidades aquáticas, recreação, irrigação de hortaliças e frutas consumidas cruas.

Classe 2 - Abastecimento para consumo humano, após tratamento convencional, proteção das comunidades aquáticas, recreação, irrigação, aquicultura e a atividade de pesca.

Classe 3 - Abastecimento para consumo humano, após tratamento convencional ou avançado, irrigação de culturas arbóreas, cerealíferas e forrageiras, pesca amadora, recreação de contato secundário, dessedentação de animais. 
Classe 4 - Navegação, harmonia paisagística.

Os equipamentos utilizados para as coletas dos parâmetros de qualidade de água foram as sondas multiparâmetros HANNA HI9828 e YSI 6600, onde foram utilizados para avaliar as seguintes variáveis físicas e químicas: temperatura $\left({ }^{\circ} \mathrm{C}\right)$, turbidez (MTU), sólidos totais dissolvidos (ppm), oxigênio dissolvido - OD $\left(\mathrm{mg} \mathrm{L} \mathrm{L}^{-1}\right), \mathrm{pH}$, condutividade $\left(\mu \mathrm{S} \mathrm{cm}^{-1}\right)$, Salinidade (ppt), nitrato $\left(\mathrm{mg} \mathrm{L}^{-1}\right)$, cloretos $\left(\mathrm{mg} \mathrm{L}^{-1}\right)$, e clorofila-a $\left(\mathrm{mg} \mathrm{L}^{-1}\right)$. Os dados coletados ficam armazenados no sistema integrado dos equipamentos, que gravam as informações específicas de registro.

No Laboratório de Geologia de Ambientes Aquáticos (LGAA/UFRA), as amostras de água foram manipuladas para a medição de outros parâmetros, como por exemplo, a determinação da concentração de nitrato $\left(\mathrm{mg} \mathrm{L}^{-1}\right)$, por meio de uma subamostra.

\subsection{Processamento digital dos dados espaciais}

$\mathrm{Na}$ classificação da cobertura vegetal e uso da terra utilizou-se o software ENVI 4.5, e uma imagem multiespectral de 2013 do satélite Resourcesat-1, sensor LISS III, no Sistema de Coordenadas Universal Transversa de Mercator (UTM), datum WGS84, com 7 bits de resolução radiométrica e $23,5 \mathrm{~m}$ de resolução espacial das bandas espectrais (vermelho, infravermelho próximo, infravermelho médio). Utilizou-se a metodologia adotada para a classificação supervisionada, por meio do algoritmo de máxima verossimilhança, em oito classes de uso e cobertura da bacia hidrográfica foram consideradas: área urbana, solo exposto, agricultura, pastagens, campos naturais, vegetação arbórea, água e nuvens/sombra, para cada classe obtiveram-se vinte e duas amostras de treinamento. Então, após a coleta de amostras das classes de interesse, foi efetuada a análise do desempenho das mesmas gerando classificação final para obter o maior índice Kappa. Diante disso, a relação entre qualidade da água e a antropização da bacia foi elaborada a partir das observações das mudanças de uso da terra, por meio de imagens de satélite, e coletas in loco das amostras de água, permitindo que o ambiente de sistema de informação geográfica - SIG determine as alterações presentes.

\subsection{Delimitação das Áreas de Preservação Permanente}

Para as análises envolvendo os dados espaciais e tabulares referentes à área de estudo, na confecção do buffer das APPs e para a confecção dos mapas, utilizou-se o software ArcGIS 10.1 e suas extensões. Foram consideradas neste trabalho, somente, as APPs ao longo dos cursos d'água e de nascentes, sendo extraídas da rede hidrográfica do IBGE (2010). As delimitações das APPs foram criadas por meio da geração de buffer's partindo do leito dos cursos d'água da bacia hidrográfica, seguindo a legislação do Código Florestal Brasileiro (Lei 12.727/2012). A delimitação foi baseada na digitalização dos dados vetoriais dos cursos d'água, com larguras de 10, 50, 100, 200 e maior que 600 metros. Enquanto as APPs das nascentes foram traçadas a partir $50 \mathrm{~m}$, tendo a nascente como ponto central, como determinado pelo Código Florestal.

\subsection{Estudo do conflito de uso da terra}

Com o intuito de identificar as áreas de incidência de conflitos de uso da terra, nas áreas de preservação permanente, foi realizada uma sobreposição, ou overlay, do mapa de uso e cobertura vegetal sob os polígonos de delimitação das APPs, de acordo com o Código Florestal Brasileiro de 2012. Então, realizou-se um recorte para determinar a localização das áreas consolidadas, e os polígonos obtidos, corresponderam às áreas de usos conflitantes inseridos nas APPs, ou seja, áreas que deveriam estar preservadas, mas que estão sendo utilizado para outros fins de ocupação. 


\section{RESULTADOS E DISCUSSÃO}

Na classificação do uso e cobertura do solo na área da bacia hidrográfica, foram identificadas oito classes: área urbana, solo exposto, agricultura, pastagens, campos naturais, vegetação arbórea, água e nuvens/sombra (Figura 2). A classe de maior incidência foi a pastagem, ocupando mais de $54 \%$ da área total da bacia hidrográfica, seguida pela vegetação arbórea, com $28,47 \%$, indicando uma intensa degradação ambiental e alteração da paisagem. Pereira et al. (2015b), estudando a mesma bacia hidrográfica, obteve uma cobertura de $43 \%$ de vegetação arbórea, e 35\% de pastagem, utilizando imagem TM-Landsat 5 do ano de 2008, o que revela a acelerada transição da cobertura natura da bacia hidrográfica do rio Peixe-Boi, para pastos, em função do crescimento da pecuária extensiva e a baixa sustentabilidade do sistema de agricultura tradicional praticado na região.

É possível constatar que os maiores fragmentos de tipologia florestal encontram-se diretamente relacionas às margens dos recursos hídricos, principalmente no quadrante oeste, formando uma rede de corredores denominados de mata ciliar.

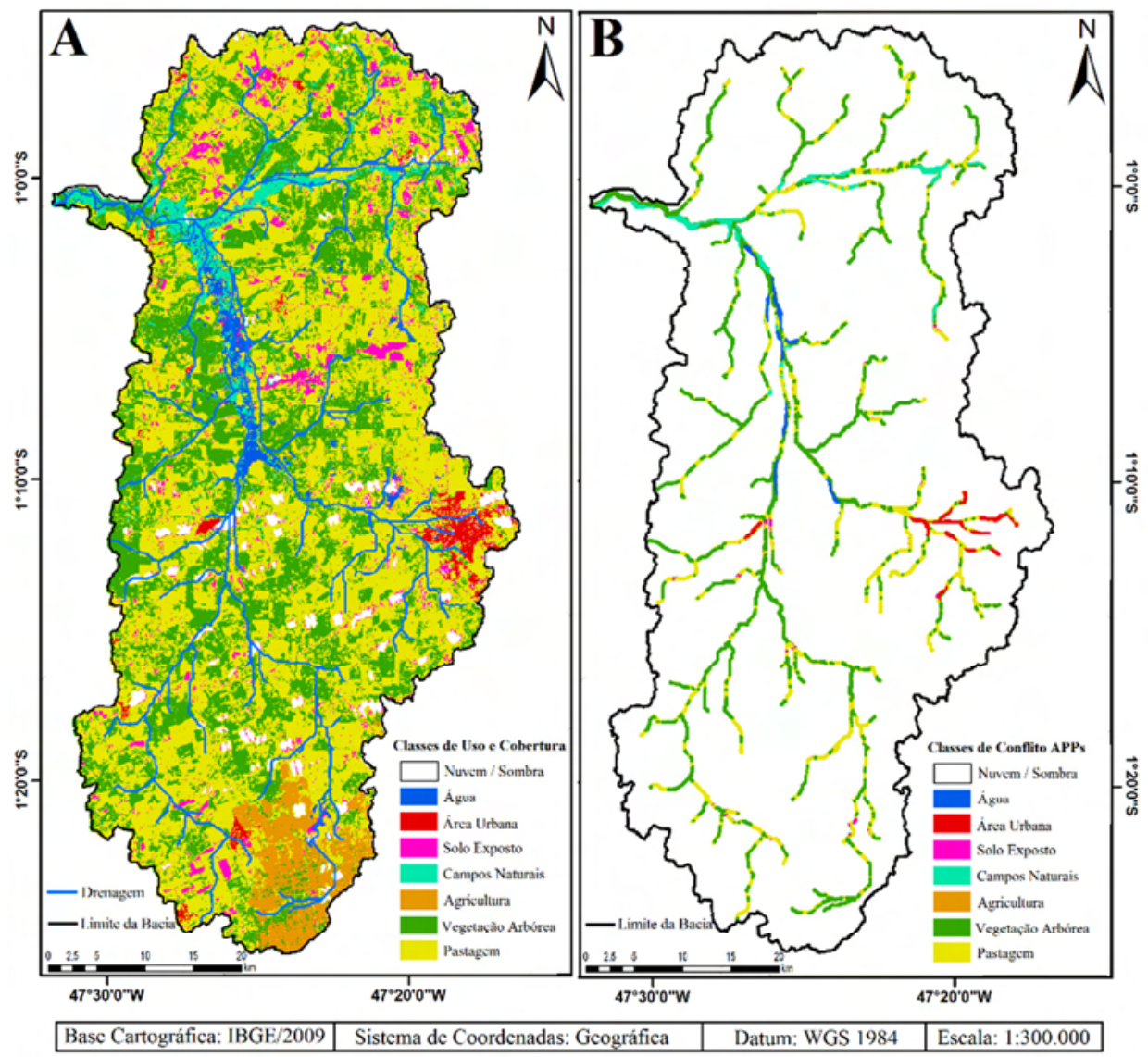

Figura 2. A) Classificação de uso e ocupação do solo e; B) áreas de conflito de uso nas APPs. Base cartográfica (IBGE, 2009).

De acordo com a legislação, a área mínima de preservação permanente ao longo dos cursos d'água e das nascentes, na bacia hidrográfica do rio Peixe-Boi, deveria ser de $2.873,5$ ha, o que equivale a 2,8\% da área total. Contudo, temos que $46 \%$ da área total das APPs encontra-se em conflito de uso, o que representa 1.321,9 ha, como pode ser constatado na Tabela 1 e observado na Figura 2. Souza et al. (2012), em seus estudos, corroboram a situação alarmante com relação aos conflitos de uso do solo, em que se encontram as APPs no Nordeste Paraense. 
Tabela 1. Distribuição das áreas e porcentagens de conflitos de uso do solo em APPs.

\begin{tabular}{|c|c|c|c|c|c|c|}
\hline \multirow[b]{2}{*}{ Classes } & \multicolumn{2}{|c|}{ Bacia hidrográfica } & \multicolumn{2}{|c|}{ APP } & \multicolumn{2}{|c|}{ Conflito } \\
\hline & (ha) & $\%$ & (ha) & $\%$ & (ha) & $\%$ \\
\hline Área Urbana & $1.494,2$ & 1,5 & 32,4 & 1,1 & 32,4 & 2,5 \\
\hline Solo Exposto & $5.608,9$ & 5,4 & 124,7 & 4,4 & 124,7 & 9,4 \\
\hline Agricultura & $3.733,7$ & 3,6 & 53,0 & 1,9 & 53,0 & 4,0 \\
\hline Pastagem & $55.971,7$ & 54,1 & $1.111,7$ & 38,7 & $1.111,7$ & 84,1 \\
\hline Campos Naturais & $3.207,9$ & 3,1 & 323,3 & 11,3 & - & - \\
\hline Vegetação Arbórea & $29.446,8$ & 28,5 & 990,3 & 34,5 & - & - \\
\hline Água & $1.888,2$ & 1,8 & 165,3 & 5,8 & - & - \\
\hline Nuvem/Sombra & $2.049,1$ & 2,0 & 72,8 & 2,5 & - & - \\
\hline Total & $103.400,5$ & 100,0 & $2.873,5$ & 100,0 & $1.321,9$ & 100,0 \\
\hline
\end{tabular}

As classes campos naturais, vegetação arbórea, e água, compuseram o montante de aproximadamente $54 \%$ do total das APPs. Foi observado que, do total das áreas em conflito de uso, a classe pastagem é responsável pela maior área conflitante, ocupando 38,7\% desse conflito. Estudando a mesma bacia hidrográfica, no ano de 2009, Pereira et al. (2015b) verificaram que a pastagem correspondeu a $35,6 \%$ da área da bacia hidrográfica, constatando uma forte atividade pecuária próxima aos rios da região.

A classe solo exposto, também se apresentou em conflito dentro das áreas de proteção permanente, concentrando-se com maior evidência em dois pontos das APPs, na área central da bacia, próximo a cidade de Peixe-Boi, e na porção extremo Leste da bacia, nas imediações da cidade de Capanema, como pode ser visto na Figura 1.

As classes área urbana e agricultura, juntas, correspondem a menos de 7\% das áreas em conflito de uso, porém, não são menos relevantes em sua contribuição para a degradação ambiental das APPs, sendo essencialmente grandes fontes poluidoras, produtoras de resíduos industriais, domésticos, e de agentes agrotóxicos (Cordeiro et al., 2014).

\subsection{Classificação e mapeamento da qualidade da água}

A figura abaixo (Figura 3), revela que mais de 35\% dos pontos coletados, para ambos os períodos, apresentaram-se como sendo de classe 4 , ou seja, com uso restrito a navegação, sem condições para o consumo humano, mesmo em áreas próximas as nascentes. As estações amostrais P6, P15 e P25, localizadas respectivamente, no Igarapé Abaeté, rio Capanema e na Nascente do rio das Pedras, mantiveram-se enquadradas na classe 4 para ambos os períodos de coleta, devido as baixas concentrações de oxigênio dissolvido. Silva e Ferrari (2012) apontam a deficiência de oxigênio dissolvido, em função do seu consumo pelos microrganismos, decorrentes do lançamento de matéria orgânica e efluentes nos rios.

Constatou-se que a porção norte da bacia, expressa os melhores valores para qualidade da água, variando de $1^{\mathrm{a}}$ a $3^{\mathrm{a}}$ classe, onde os parâmetros que resultaram no enquadramento para $3^{\mathrm{a}}$ classe foram o oxigênio e o $\mathrm{pH}$, por estarem abaixo dos limites permitidos, a Tabela 2 expressa as classes de qualidade da água nos períodos seco e chuvoso conforme cada classe de uso do solo. 


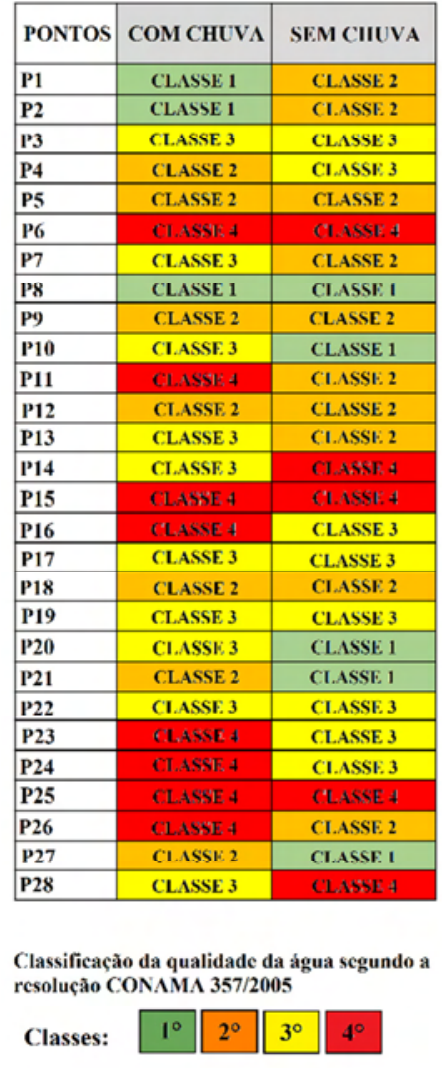

Classificacãa da qualidade da água scgundo
resoluçâ CON $\mathrm{AMA} \quad 357 / 2005$
Classes: \begin{tabular}{|l|l|l|l|l|}
$1^{\circ}$ & $2^{\circ}$ & $3^{\circ}$ & $4^{\circ}$ \\
\hline
\end{tabular}

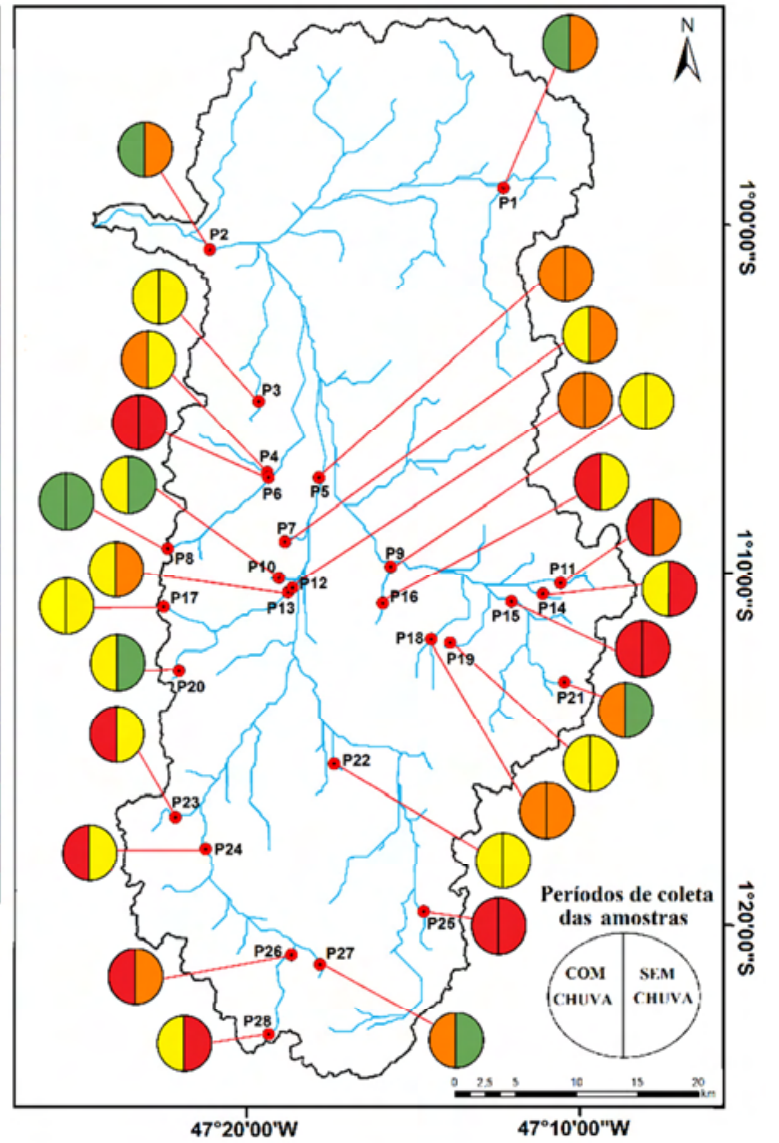

$47^{\circ} 20^{\prime} 00^{\prime} \mathrm{W}$

Figura 3. Localização e classificação dos pontos de coleta de água na bacia hidrográfica.

Verificou-se, ainda, que para todos os pontos amostrais, a qualidade da água coletada nos dois períodos, foi inversamente proporcional à sua proximidade em relação às áreas antropizadas. Constatou-se que as variáveis que mais influenciaram na deterioração da qualidade da água foram o oxigênio, a condutividade e o $\mathrm{pH}$, o que também foi constatado por Souza e Gastaldini (2014) em seus estudos sobre qualidade da água do rio Almada no sul da Bahia. Barros et al. (2014) fizeram um levantamento sobre a dinâmica de infiltração da agua em uma bacia hidrográfica no Rio Grande do Sul e Anelli (2015) avaliou a urbanização em favor da renaturalização da bacia hidrográfica do Córrego Lajeado em São Paulo.

Com relação ao oxigênio dissolvido (OD), mais de 69\% dos pontos amostrais, para ambos os períodos, apresentaram valores inferiores ao estabelecido como mínimo pelo CONAMA. O OD é um dos principais parâmetros de caracterização dos efeitos da poluição das águas decorrentes de despejos orgânicos. Segundo a resolução CONAMA 357/2005, não são aceitos valores de oxigênio dissolvido inferiores a $6 \mathrm{mg} \mathrm{L}^{-1}$. Esses dados expressam a delicada situação que se encontram determinadas áreas da bacia hidrográfica, em que valores críticos de níveis de oxigênio dissolvido são encontrados, como é o caso do ponto amostral P26, no período chuvoso, apresentando $2,14 \mathrm{mg} \mathrm{L}^{-1}$, o que corresponde a um terço da concentração mínima aceitável.

Em trabalho semelhante, Souza e Gastaldini (2014) constataram em suas coletas que valores inferiores a $6 \mathrm{mg} \mathrm{L}^{-1}$ eram normalmente encontrados em coletas mais próximas a áreas antropizadas às margens dos rios, e onde havia lançamento direto de matéria orgânica e outras substancias, o que também foi constatado no rio Peixe-Boi.

$\mathrm{O}$ pH teve importante participação para o desequilíbrio da qualidade da água na bacia hidrográfica, sobretudo no período chuvoso. No geral houve pouca variação nos pontos com 
relação aos dois períodos, exceto no ponto P17, localizado na área urbana periférica do município de Capanema. A pequena variação no $\mathrm{pH}$, revelou uma boa capacidade de tamponamento pelo ecossistema, principalmente no período sem chuva, uma vez que, os valores determinados do $\mathrm{pH}$ variaram em uma faixa de baixa acidez, devido principalmente à contribuição da bacia hidrográfica e decomposição da matéria orgânica, até uma relativa alcalinidade, provavelmente devido à contribuição geológica da região (Lima et al., 2015; Vasco et al., 2011).

A condutividade apresentou valores bastante elevados, especial no período chuvoso, chegando a $336 \mu \mathrm{Scm}^{-1}$, no rio Capanema (P15), próximo a uma área desmatada de uma fazenda. Souza et al. (2014), explicam que a condutividade é originada da presença de sais dissolvidos na água na forma de íons dissociados eletrolíticamente. Estes íons, quando de origem antropogênica, são resultantes de descargas industriais, esgotos domésticos entre outros. Quanto às variáveis sólidos dissolvidos, salinidade, nitrato, cloreto, turbidez e clorofila, em ambos os períodos amostrais apresentaram concentrações dentro dos padrões exigidos pela CONAMA 3572005.

\subsection{Relação da cobertura vegetal e do uso do solo nas APPs com a qualidade da água na bacia do rio Peixe-Boi}

Foram caracterizadas oito tipologias de uso e cobertura na bacia hidrográfica do rio Peixe-Boi, e constatou-se que os 28 pontos de coleta de água estavam inseridos em cinco destas tipologias; vegetação arbórea, pastagem, água, solo exposto e área urbana. As classes campos naturais e agricultura, se fazem presentes dentro das áreas de APPs, assim, também entram nas análises no que tange a alteração da qualidade da água.

Ao relacionar os resultados obtidos pelo mapeamento da cobertura vegetal e uso do solo nas áreas de APPs, com a classificação da qualidade da água nos diversos pontos de análise, obteve-se como resultado, considerável relação entre a preservação da vegetação natural nas APPs e a manutenção de uma boa qualidade da água na bacia hidrográfica, nos períodos amostrais com e sem chuva conforme a Tabela 2.

A tipologia referente a vegetação arbórea, responde por 34,5\% do total das APPs da bacia hidrográfica em questão (Tabela 1), sendo a segunda maior classe na área da bacia, e presente em 9 pontos de coleta de água. Apresentou uma elevada amplitude de variação para as classes de qualidade de água, permeando pelas quatro classes propostas pela resolução 357 de 2005, do CONAMA.

Os pontos com melhores avaliações da qualidade da água, na classe vegetação arbórea, e para ambos os períodos (com/sem chuva), foram o P2 e P8, no rio Peixe-Boi e em uma nascente dentro do batalhão de infantaria, respectivamente, ambos localizados em Nova Timboteua (Figura 1). Ressalta-se que nas áreas da classe vegetação arbórea, naturalmente, ocorre pouco escoamento superficial, em decorrência da maior cobertura do solo, o que irá refletir positivamente sobre a qualidade da água, uma vez da diminuição do processo erosivo, e da lixiviação do solo para os cursos d'água (Dechen et al., 2015).

Os pontos com as piores avaliações da qualidade da água (classe 4), em ambos os períodos amostrais, foram o P6, P15 e P24, todos localizados em áreas próximas a zonas antropizadas, onde a população usa as margens para lavar roupas, depositar entulhos, e despejar efluentes. O enquadramento na classe 4, para os três pontos, se deu fundamentalmente, pela baixa concentração de oxigênio dissolvido. Freitas et al. (2013) explicam que as florestas protegem a zona ribeirinha funcionando como área tampão, porém, a depreciação da qualidade da água, pode se dar, mesmo em ambientes de cobertura arbórea preservada, desde que hajam pressões poluentes nas proximidades, o que justificaria os resultados obtidos para os pontos amostrais em questão. 
Tabela 2. Relação da qualidade da água com as tipologias encontradas nos pontos de coleta.

\begin{tabular}{|c|c|c|c|}
\hline & \multirow{2}{*}{$\begin{array}{c}\text { Classes de coberturas } \\
\text { nas APPs }\end{array}$} & \multicolumn{2}{|c|}{ Classes segundo CONAMA (357/2005) } \\
\hline & & Período Chuvoso & Período Seco \\
\hline $\mathrm{P} 1$ & Pastagem & Classe 1 & Classe 2 \\
\hline $\mathrm{P} 2$ & Vegetação Arbórea & Classe 1 & Classe 2 \\
\hline $\mathrm{P} 3$ & Vegetação Arbórea & Classe 3 & Classe 3 \\
\hline $\mathrm{P} 4$ & Pastagem & Classe 2 & Classe 3 \\
\hline P5 & Água & Classe 2 & Classe 2 \\
\hline P6 & Vegetação Arbórea & Classe 4 & Classe 4 \\
\hline P7 & Pastagem & Classe 3 & Classe 2 \\
\hline P8 & Vegetação Arbórea & Classe 1 & Classe 1 \\
\hline P9 & Pastagem & Classe 2 & Classe 2 \\
\hline $\mathrm{P} 10$ & Vegetação Arbórea & Classe 3 & Classe 1 \\
\hline P11 & Área Urbana & Classe 4 & Classe 2 \\
\hline $\mathrm{P} 12$ & Solo Exposto & Classe 2 & Classe 2 \\
\hline $\mathrm{P} 13$ & Solo Exposto & Classe 3 & Classe 2 \\
\hline P14 & Pastagem & Classe 3 & Classe 4 \\
\hline $\mathrm{P} 15$ & Vegetação Arbórea & Classe 4 & Classe 4 \\
\hline P16 & Pastagem & Classe 4 & Classe 3 \\
\hline P17 & Vegetação Arbórea & Classe 3 & Classe 3 \\
\hline P18 & Pastagem & Classe 2 & Classe 2 \\
\hline P19 & Pastagem & Classe 3 & Classe 3 \\
\hline $\mathrm{P} 20$ & Vegetação Arbórea & Classe 3 & Classe 1 \\
\hline $\mathrm{P} 21$ & Pastagem & Classe 2 & Classe 1 \\
\hline $\mathrm{P} 22$ & Pastagem & Classe 3 & Classe 3 \\
\hline $\mathrm{P} 23$ & Pastagem & Classe 4 & Classe 3 \\
\hline P24 & Vegetação Arbórea & Classe 4 & Classe 3 \\
\hline P25 & Pastagem & Classe 4 & Classe 4 \\
\hline P26 & Pastagem & Classe 4 & Classe 2 \\
\hline P27 & Pastagem & Classe 2 & Classe 1 \\
\hline P28 & Pastagem & Classe 3 & Classe 4 \\
\hline
\end{tabular}

A pastagem representa a tipologia de maior abundancia na bacia hidrográfica do rio Peixe-Boi, e também é a classe mais presente nas áreas de preservação permanente da bacia, correspondendo a 38,7\% do total das APPs (Tabela 1). E apresentou uma grande amplitude de variação para as classes de qualidade de água, variando pelas quatro classes propostas pelo CONAMA.

Ainda para a classe pastagem, os pontos com as piores avaliações da qualidade da água (classe 4), foram o P14, P16, P23, P25, e o P26, nesta categoria sobressaiu-se o período chuvoso, apresentando os piores índices para a qualidade da água. Lima et al. (2015), constataram que ao redor das nascentes, principalmente no período chuvoso, deságuam produtos químicos e fertilizantes utilizados na pastagem, contribuindo fortemente para a 
degradação da qualidade da água.

As tipologias referentes a solo exposto e agricultura, correspondem a apenas 6,20\% do total das APPs da bacia (Tabela 1), ficando entre as classes menos presentes na bacia, contudo, contribuem direta e indiretamente para a depreciação da qualidade da água, de forma pontual, e ao logo da bacia de drenagem. Os pontos P12 e P13, localizados no igarapé Apuí e no rio Peixe Boi, ambos no município de Peixe-Boi, são representativos dessas tipologias, e especificamente, para esses pontos amostrais, expressaram valores que enquadraram a qualidade da água em um patamar que varia de intermediário a ruim, quanto à qualidade (Classes 2 e 3).

Para Souza et al. (2012), a retirada total da cobertura natural do solo nas APPs, e as áreas recém-plantadas, expõem o solo às intempéries, e imprime aos recursos hídricos uma carga de defensivos e corretivos agrícolas, propiciando um desequilíbrio na qualidade dos recursos hídricos, especialmente nos períodos chuvosos, como pode ser observado para os pontos P12 e P13 (Tabela 2). A condutividade elétrica apresentou-se bem elevada para ambos os pontos, especialmente para o P13 $\left(113 \mu \mathrm{Scm}^{-1}\right)$, devido a sua localização às margens da rodovia estadual PA-282, e ao lado de um balneário, injetando diariamente partículas e substratos no igarapé.

No que tange a tipologia área urbana, esta corresponde a 32,44 ha, ocupando apenas $1,13 \%$ do total das APPs da bacia hidrográfica (Tabela 1), sendo a classe menos presente na área da bacia hidrográfica, e apresentando apenas 1 ponto representativo (P11), de coleta de água. Ele localiza-se na área urbana central do município de Capanema, e recebe diretamente todos os efluentes domésticos locais, despejados por meio de tubulações.

Souza et al. (2015) explicam que o lançamento de lixo, entulhos, e de despejos domésticos do município, sem tratamento, é conduzido pelas chuvas até os mananciais, alterando o pH natural, a concentração de nitrogênio e oxigênio, aumentando a turbidez das águas através da incorporação de carga orgânica, e injetando substancias químicas diversas, o que afeta os padrões estabelecidos pelo CONAMA para qualidade das aguas doces destinadas ao consumo humano.

A classe campos naturais, ocupa 11,3\% da área total das APPs, e assim como a classe vegetação arbórea, representam as áreas de cobertura original das zonas ripárias da bacia hidrográfica, sendo responsáveis pela proteção e manutenção da qualidade dos recursos hídricos da bacia do rio Peixe-Boi. Segundo Oliver e Ribeiro (2014), o ambiente de campos naturais é uma zona fundamental para a preservação da qualidade da água e diversificação de habitats, constituindo uma interface entre o ambiente terrestre e o aquático. Esta lógica de preservação da qualidade da água é observada na porção Norte e Centro-Norte onde está localizada a maior concentração da classe de campos naturais na bacia do rio Peixe-Boi.

\section{CONCLUSÃO}

Por meio do uso de geotecnologias, foi possível mapear as APPs existentes na bacia, e constatou-se que $46 \%$ delas encontra-se em conflito de uso, frente ao que determina a legislação vigente. Assim como, identificar que as classes área urbana, solo exposto e pastagem são as principais responsáveis pelo uso indevido do solo nas APPs.

Os piores índices de qualidade da água podem estar associados às áreas de uso e ocupação irregulares das APPs, onde a cobertura vegetal original foi substituída por outras classes. Desta forma, verifica-se a necessidade emergencial de planejamento do uso e ocupação das terras e a adoção de práticas de manejo do solo e da água mais sustentáveis na bacia em questão.

Há necessidade da implementação de medidas de planejamento estratégico de gestão dos recursos hídricos na bacia hidrográfica do rio Peixe-Boi para a recuperação e melhoria da 
qualidade da água.

\section{REFERÊNCIAS}

ARAÚJO, E.; MARTINS, H.; BARRETO, P.; LIMA, A. C. Áreas protegidas da Amazônia legal com mais alertas de desmatamento em 2012-2013. Belém: IMAZON, 2013. p. 32 .

ANELLI, R. L. S. Uma nova cidade para as águas urbanas. Estudos avançados, v. 29, n. 84, p. 69-84, 2015. http://dx.doi.org/10.1590/S0103-40142015000200005

BARROS, C. A. P.; SIQUEIRA, P. T.; CORLONE, A. A. Estimativa da infiltração de água no solo na escala de bacia hidrográfica. Revista Brasileira de Ciência do Solo, v. 38, n. 2, p. 557-564, 2014. http://dx.doi.org/10.1590/S0100-06832014000200020

BRASIL. Constituição da República Federativa do Brasil de 1988: promulgada em 5 de outubro de 1988. Disponível em: http://www.planalto.gov.br/ccivil_03/Constituicao/ Constituicao.htm. Acesso em: 13 maio 2014.

BRASIL. Ministério do Meio Ambiente. Lei $\mathrm{n}^{\circ}$ 4.771, de 15 de setembro de 1965. Institui o Código Florestal Brasileiro. Diário Oficial [da] República Federativa do Brasil, 16 set. 1965.

COMPANHIA DE TECNOLOGIA DE SANEAMENTO AMBIENTAL - CETESB. Guia de coleta e preservação de amostras de água. São Paulo, 1988. p. 50.

CONSELHO NACIONAL DE MEIO AMBIENTE - CONAMA. Resolução n. 357 de 17 de marco de 2005. Classificação de corpos d'água e diretrizes ambientais. Conselho Nacional do Meio. Ministério do Meio Ambiente. Disponível em: http://www.mma.gov.br/port/conama/res/res05/res35705.pdf. Acesso em: 16 jun. 2014.

CORDEIRO, T. T. S.; FERREIRA, E. M.; RODRIGUES, V. J. O. Contenção de erosão em área de preservação permanente (APP). Enciclopédia Biosfera, v. 10, n. 18, p. 1032 1041, 2014.

DECHEN, S. C. F.; TELlES, T. S.; GUIMARAES, M. F.; MARIA, I. C. Perdas e custos associados à erosão hídrica em função de taxas de cobertura do solo. Bragantia, v. 74, n. 2, p. 224-233, 2015. http://dx.doi.org/10.1590/1678-4499.0363

FERREIRA, M. D. P.; COELHO, A. B. Desmatamento recente nos Estados da Amazônia Legal: uma análise da contribuição dos preços agrícolas e das políticas governamentais.

Revista Economia Sociologia Rural, v. 53, n. 1, p. 91-108, 2015.

FREITAS. E. P.; MORAES, J. F. L.; PECHE FILHO, A. Indicadores ambientais para áreas de preservação permanente. Revista Brasileira de Engenharia Agrícola e Ambiental. v. 17, n. 4, p. 443-449, 2013. http://dx.doi.org/10.1590/S1415-43662013000400013

INSTITUTO BRASILEIRO DE GEOGRAFIA E ESTATÍSTICA - IBGE. Bases Cartográficas. 2009. Disponível em: http://mapas.ibge.gov.br/bases-ereferenciais/bases-cartograficas/mapas-municipais.html. Acesso em: 10 fev. 2014.

INSTITUTO BRASILEIRO DE GEOGRAFIA E ESTATÍSTICA - IBGE. Banco de dados georeferenciado sobre recursos naturais. 2010. Disponível em: http://mapas.ibge.gov.br/bases-e-referenciais/bases-cartograficas/cartas.html. Acesso em: 24 maio 2014. 
INSTITUTO BRASILEIRO DE GEOGRAFIA E ESTATÍSTICA - IBGE. Diretoria de geociências. Mapas temáticos: solos. 2012. Disponível em: ftp://geoftp.ibge.gov.br/mapas_tematicos/pedologia/unidades_federacao/pa_pedologia.p df. Acesso em: 24 maio 2014.

INSTITUTO BRASILEIRO DE GEOGRAFIA E ESTATÍSTICA - IBGE. País evolui mais nos indicadores econômicos e sociais do que nos ambientais. . 04. jun. 2008. Disponível em: http://www.ibge.gov.br/home/presidencia/noticias/noticia_visualiza. php?id_noticia=1246\&id_pagina=1. Acesso em: 24 maio 2014.

LIMA, C. R. N.; ZEILHOFER, P.; DORES, E.; CRUZ, I. F. Variabilidade espacial da qualidade de água em escala de bacias - Rio Cuiabá e São Lourenço, Mato Grosso. Revista Brasileira de Recursos Hídricos, v. 20 n. 1, p. 169 -178, 2015.

OLIVER, S. L.; RIBEIRO, H. Variabilidade climática e qualidade da água do Reservatório Guarapiranga. Estudos avançados, v. 28, n. 82, p. 95-128, 2014. http://dx.doi.org/10.1590/S0103-40142014000300007

PEREIRA, B. W. F.; MACIEL, M. N. M.; OLIVEIRA, F. A.; SILVA, H. A. S.; BRAGA, T. G. M.; FIGUEIREDO, D. B. Estrutura da paisagem da bacia hidrográfica do rio PeixeBoi com base na fragmentação da vegetação. Revista de Ciências Agrárias, v. 58, n. 2, p. $159-167,2015 b$.

PEREIRA, B. W. F.; MACIEL, M. N. M.; OLIVEIRA, F. A. O.; FERREIRA, B. M.; RIBEIRO, E. G. P. Geotecnologias com apoio de índices morfométricos para a caracterização da bacia hidrográfica do rio Peixe-Boi, Nordeste Paraense. Enciclopédia Biosfera, v. 12, n. 22, p. 2960-2974, 2015a.

PIRES, M. O. O cadastro ambiental rural: das origens às perspectivas para a política ambiental. Brasília: Conservação Internacional do Brasil, 2013. p. 44.

PIRES, E. V. R.; SILVA, R. A.; IZIPPATO, F. J.; MIRANDOLA, P. H. Geoprocessamento Aplicado a análise do uso e ocupação da terra para fins de planejamento ambiental na bacia hidrográfica do Córrego Prata - Três Lagoas (MS). Revista Geonorte, v. 2, n. 4, p. $1528-1538,2012$.

SANTOS, E. C. A.; ARAUJO, L. E.; MARCELINO, A. S. Análise climática da Bacia Hidrográfica do Rio Mamanguape. Revista Brasileira de Engenharia Agrícola e Ambiental, v. 19, n. 1, p. 9-14, 2015. http://dx.doi.org/10.1590/18071929/agriambi.v19n1p9-14

SILVA, S. F.; FERRARI, J. L. Análise espacial de atributos físico-químicos da água em viveiros de piscicultura com geometrias diferentes. Enciclopédia Biosfera, v. 8, n. 14, p. 51-63, 2012.

SCHMITT, J. S.; PAIVA, F. A descentralização das competências ambientais e a fiscalização do desmatamento na Amazônia. Revista de Administração Pública, v. 49, n. 5, p. 1121-1142, 2015.

SOUZA, M. M.; GASTALDINI, M. C. C. Water quality assessment in watersheds with different anthropogenic impacts. Engenharia Sanitária Ambiental, v. 19, n. 3 p. 263 274, 2014. http://dx.doi.org/10.1590/S1413-41522014019000001097 
SOUZA, J. R.; MORAES, M. E. B.; SONODA, S. L.; SANTOS, H. C. R. A importância da qualidade da água e os seus múltiplos usos: caso Rio Almada, sul da Bahia, Brasil. REDE -Revista Eletrônica do Prodema, v. 8, n. 1, p. 26-45, 2014.

SOUZA, S. R.; MACIEL, M. N. M.; OLIVEIRA, F. A.; JESUÍNO, S. A. Caracterização do conflito de uso e ocupação do solo nas áreas de preservação permanente do rio Apeú, Nordeste do Pará. Floresta, v. 42, p. 701, 2012. http://dx.doi.org/10.5380/rf.v42i4.19508

SOUZA, J. A. R.; MOREIRA, D. A.; CONDÉ, N. M.; CARVALHO, W. B. Análise das condições de potabilidade das águas de surgências em Ubá, MG. Rev. Revista Ambiente \& Água, v. 10, n. 3, p. 614-622, 2015. http://dx.doi.org/10.4136/ambiagua. 1630

VASCO, A. N.; BRITTO, F. B.; PEREIRA, A. P. S.; JÚNIOR, A. V. M.; GARCIA, C. A. B.; NOGUEIRA, L. C. Avaliação espacial e temporal da qualidade da água na sub-bacia do rio Poxim, Sergipe, Brasil. Revista Ambiente \& Água, v. 6, n. 1, p. 118-130, 2011. http://dx.doi.org/10.4136/ambi-agua.178 